UNIVERSIDAD POLITÉCNICA DE MADRID

ESCUELA TÉCNICA SUPERIOR DE ARQUITECTURA DE MADRID

\title{
EL JARDÍN MODERNO EN ESPAÑA (1926-1980)
}

\section{TESIS DOCTORAL}

AUTORA: PATRICIA HERNÁNDEZ LAMAS. ARQUITECTA, MÁSTER EN JARDINERÍA Y PAISAJISMO UPM 
DEPARTAMENTO DE COMPOSICIÓN ARQUITECTÓNICA ESCUELA TÉCNICA SUPERIOR DE ARQUITECTURA DE MADRID

\section{EL JARDÍN MODERNO EN ESPAÑA (1926-1980)}

\section{TESIS DOCTORAL}

AUTORA: PATRICIA HERNÁNDEZ LAMAS. ARQUITECTA, MÁSTER EN JARDINERÍA Y PAISAJISMO UPM

DIRECTORES: D. MIGUEL ÁNGEL ANÍBARRO RODRÍGUEZ Doctor Arquitecto

D. ALBERTO SANZ HERNANDO Doctor Arquitecto 
Tribunal nombrado por el Mgfco. y Excmo. Sr. Rector de la

Universidad Politecnica de Madrid, el dia $\cdots \cdots$ de $\cdots$ de 2017

Presidente D.

Vocal D.

Vocal D.

Vocal D.

Secretario D.

Realizado el acto de defensa y lectura de la Tesis el día de de 2017

En

Calificación

EL PRESIDENTE LOS VOCALES

EL SECRETARIO 


\section{AGRADECIMIENTOS}

Durante el largo camino de la realización de esta tesis doctoral, han sido varias las personas que de algún modo $u$ otro han colaborado para que pudiera llevarse a cabo y a las que quiero reconocer mi especial agradecimiento:

Al personal de la Biblioteca de Caminos -Conchita García Viñuela, Marisol Martínez, Carmen Delgado e Isidro Fernández- y de la Biblioteca de Arquitectura -especialmente a Blanca Ruilope y Margarita Suárez-, quienes tan amablemente me han guiado y ayudado en mis búsquedas y consultas.

A los responsables de la Fundación DOCOMOMO Ibérico, especialmente a Susana Landrove y Celestino García Braña, con quienes he tenido el placer de trabajar y quienes me han facilitado documentación y material para esta investigación.

Al personal de la biblioteca y del Servicio Histórico del COAM -Miguel Lasso de la Vega, Alberto Sanz, y Pilar Rivas-, con quien tuve la suerte de poder colaborar en las guías de Madrid y quienes me facilitaron el acceso a los fondos documentales.

A las personas del Departamento de Parques y Jardines del Ayuntamiento de Madrid; especialmente a Santiago Soria, Director de Parques y jardines de Patrimonio Nacional y antiguo profesor mío, por facilitarme el acceso a los archivos; y a Sonia, quien pacientemente me atendió en mis semanas de investigación en el archivo del Retiro.

A Antonio Martín y el resto de viveristas que de forma desinteresada han compartido su tiempo, experiencias y material conmigo para este trabajo; especialmente a Javier Spalla quien puso a mi disposición todo el legado de su padre Javier Spalla y toda su colección de fotografías y planos antiguos. También a Nacho Turc quien me facilitó los planos y el material recopilado sobre su bisabuelo, el viverista Luciano Turc.

A los profesores de Montes, Santiago González, Rafael Escribano y Pedro Cifuentes, quienes me han facilitado documentación y han apoyado y seguido de cerca el desarrollo de esta tesis.

A los profesores con quienes comparto la docencia en la ETSI Caminos -Jorge Bernabeu, José Antonio Martín-Caro, Roberto Revilla y Mercedes López-, y quienes me han animado y ayudado a compaginar las tareas docentes con el desarrollo de la tesis.

A Miguel Aguiló por darme la oportunidad de trabajar en la Fundación, ampliar nuevos horizontes, emprender aventuras nacionales e internacionales, alentarme continuamente para terminar lo que parecía imposible y darme el tiempo para ello. 
A todos mis compañeros de la Fundación, especialmente a Antonio Sarabia por sus sabios consejos, todas sus correcciones y su gran cariño; a Óscar de Castro por su ayuda con la maquetación y a Beatriz Cabau por su colaboración con los planos antiguos. También al resto de compañeros que siempre han estado a mi lado y me han animado: Ana Rubio, Julián Ortega, Roberto Turégano, Ma Luisa Ruiz-Bedia, Almudena Herrera, José de la Paz, Jesús Fernández, Mạ José Ramiro, Carlos Álvarez, Verónica Hernández y Alicia López.

A profesores como Milla Hernández Pezzi, Ángela Souto, Carmen de Andrés y Llanos Masiá de las que tanto aprendí en la ETSAM y cuyo apoyo y consejos han sido fundamentales en mi carrera profesional, docente e investigadora.

A mis directores de tesis, Miguel Ángel Aníbarro y Alberto Sanz, por su orientación, sus apreciados aportes, críticas, comentarios y sugerencias durante el desarrollo de esta investigación, junto con su paciente seguimiento y dedicación.

A Lalo Relinque quien me transmitió su amor por la pintura y el dibujo de la naturaleza.

Al paisajista y escultor Álvaro de la Rosa con el que me adentré en el mundo profesional de la jardinería y quien me contagió su pasión. A grandes profesionales y amigos como Antonio Hernando y Juan Carlos Sánchez con los que tanto he disfrutado realizando jardines.

A mis compañeros del máster de Jardinería, especialmente a Miguel Aguilar y Sara Marjanizadeh, con los que compartí tantos buenos ratos paseando entre jardines.

A mi familia y amigos, que han sabido disculpar mis ausencias y siempre han tenido una palabra de ánimo; especialmente a Sara Cano, Leonor Hernández, Carlos Lamas, Camino Díaz, Pilar Hernández-Márquez, Eduardo Navas, Fátima Megia, Salus Asencio, Sara Picazo y Rocío Cejudo, siempre dispuestos en sus viajes a hacerme las fotos que me faltaban.

A Paloma y toda mi familia política por su apoyo y cuidar de mis hijos para que pudiese sacar horas y cerrar este trabajo.

A mi tía Montse Dou, quien tan cariñosamente desde Barcelona me ha ayudado con el tema de los archivos.

A mi abuela Carmen, quien me transmitió su amor por las plantas y los jardines, con quien pude compartir muchos de estos maravillosos lugares aunque fuese a través de fotografías- $y$ que por poco no ha podido ver terminado este trabajo.

A mi hermano Eduardo por estar siempre junto a mí y ser mi fiel carabina en muchas de mis excursiones.

A mis padres, Carmen y Jose $\mathrm{M}^{\mathrm{a}}$, por ser mi gran ejemplo en la vida, enseñarme el camino del trabajo y la superación, y brindarme siempre su 
apoyo incondicional.

A Sofía, Marcos y Juan, cuya llegada me obligó a aplazar algunas cosas al convertirse en lo prioritario en mi vida; por todas las horas robadas y vuestra compañía recorriendo tantos jardines, a pesar de vuestras quejas por no tener columpios.

A Diego, por su infinita paciencia y amor, estar siempre a mi lado y compartirlo todo.

A las personas que, aunque no aparecen aquí con nombre y apellidos, han estado presentes de alguna forma durante el desarrollo de este trabajo y han hecho posible que hoy sea una realidad.

A todos mi más sincero agradecimiento. 


\section{RESUMEN}

El jardín moderno en España (1926-1980)

Hasta hace algunos años en el estudio de la historia y evolución del jardín, el siglo XX se presentaba como un gran vacío, a excepción de algunas figuras como Barragán y Burle Marx, y negando la existencia de un jardín vinculado a la arquitectura moderna. Tanto más ocurría en el jardín español del siglo XX que no había sido estudiado desde una perspectiva analítica, ni tampoco agrupado geográfica, estilística o cronológicamente. Aunque algunos ejemplos particulares, especialmente los del primer tercio de siglo, poseen una amplia bibliografía, en un gran número de ellos (jardines de paisajistas, de jardineros, de viveristas y de arquitectos como García Mercadal, Zuazo, Sert, Moreno Barberá, Fisac, etc.) y en su tratamiento conjunto era a día de hoy prácticamente inexistente.

Si se entiende el jardín como género arquitectónico, es posible afirmar que el jardín español del siglo XX, considerado en su conjunto o en cualquiera de sus ejemplos más notorios, no había sido aún analizado desde el punto de vista de la arquitectura por considerarse como algo secundario respecto a la edificación. Un trabajo tal, que supone un estudio de los trazados, de la organización espacial y sólida, de la correspondencia entre forma y función, de la relación entre el jardín y su entorno, y de las elaboraciones teóricas y su influencia sobre las distintas realizaciones, todavía no ha sido llevado a cabo de un modo sistemático, aplicado a los ejemplos de nuestro país.

Con este estudio se obtienen una serie de conclusiones acerca de las líneas de desarrollo evolutivo del jardín español a lo largo del siglo, sus tendencias formales, sus períodos evolutivos y la variación de los usos, realizando una comparación del panorama español con el europeo e internacional. Se centra en el período del Movimiento Moderno, en cuyo estudio siempre se ha dado importancia a los edificios, sin profundizar en el jardín; se pretende, de esta manera, completar el panorama de la arquitectura del siglo $\mathrm{XX}$. 


\section{ABSTRACT}

The modern garden in Spain (1926-1980)

Until recently, the $20^{\text {th }}$ Century was shown in gardening historiography mainly as a void, with the odd exception made for icons such as Barragán and Burle Marx, and the very existence of a garden linked to Modern architecture was mostly negated. This situation was especially harsh regarding 20th Century Spanish gardening, which has neither ever been studied from an analytical point of view, nor geographically, stylistically or culturally classified. Although some specific cases, especially those of the first third of the century, boast an ample bibliography, for a large number of them (including works by landscapers, gardeners, nurserymen and architects as significant as García Mercadal, Zuazo, Sert, Moreno Barberá, Fisac, etc.) and for a collective understanding of them there is a marked lack thereof.

If the garden is to be understood as an architectural type, one may justly assert that Spanish gardens of the 20th Century, whether as a whole or specifically regarding any of their foremost examples, have not as yet been assessed form an architectural point of view, maybe due to their being perceived as secondary to the building itself. A work such as the one being undertaken here, that is, one which comprehends a study of layouts, of spatial and volumetric organizations, of the correspondence between form and function, of the relationship between the garden and its surroundings, and of theoretical constructs and their influence on actual works, is yet to be undertaken systematically regarding the Spanish case.

With this study some conclusions are obtained about the evolutionary lines of the Spanish garden throughout the century, its formal trends, its evolutionary periods and the variation of the uses, comparing the Spanish panorama with the European and international one. It focuses on the period of the Modern Movement, which study has always been given importance to buildings, without deepening the garden; In this way it is intended to complete the panorama of the $20^{\text {th }}$ century architecture. 


\section{ANTECEDENTES}

El tema del paisajismo y todo lo relacionado con el jardín y el mundo vegetal siempre me ha atraído, por eso mis investigaciones han profundizado en este campo. Con los trabajos tutelados del doctorado: "Dimensiones de la vegetación en la arquitectura contemporánea", "Teoría del paisaje del siglo XX desde el paisajismo" y "Jean Claude Nicolas Forestier", comencé a investigar el jardín del siglo XX. Actualmente mi trabajo de investigación se dirige a la reflexión crítica sobre éste con las herramientas propias de la composición arquitectónica. Por esta razón propuse como tema de tesis el jardín moderno en España entre 1926 y 1980.

Si se entiende el jardín como género arquitectónico, es posible afirmar que el jardín español del siglo XX, considerado en su conjunto o en cualquiera de sus ejemplos más notorios, no ha sido aún analizado desde el punto de vista de la arquitectura por considerarse como algo secundario respecto a la edificación. Un trabajo tal, que supone un estudio de los trazados, de la organización espacial y sólida, de la correspondencia entre forma y función, de la relación entre el jardín y su entorno, y de las elaboraciones teóricas y su influencia sobre las distintas realizaciones, todavía no ha sido llevado a cabo de un modo sistemático, aplicado a los ejemplos de nuestro país.

\section{OBJETIVOS E HIPÓTESIS}

La evidencia de la naturaleza arquitectónica del jardín suscita la necesidad de un estudio de esta índole, cuyos principales objetivos son los siguientes: 1) la formación de un cuerpo teórico que permita abordar el análisis de los proyectos, el establecimiento de las clases de jardín y la determinación de sus directrices compositivas; 2 ) la identificación de los elementos o rasgos y de las estructuras formales básicas, que, como unidades independientes o como módulos repetibles, conformen la organización del jardín; 3) la evolución de acuerdo con las tendencias formales del siglo XX y con la variación de los usos, así como las líneas de desarrollo de dichas estructuras formales básicas, organización espacial, relación con el edificio, relación con el entorno (ciudad o campo), percepción y relaciones generales de jardín y arquitectura; 4) el establecimiento de la posición relativa de los jardines de nuestro país en la historia europea y occidental de la arquitectura de jardines, al precisar su propia originalidad y su integración en la sucesión de las grandes corrientes internacionales; y 5) la recuperación de la cartografía y demás documentación gráfica. 
La hipótesis de partida es que el jardín español del siglo XX forma parte activa de la historia de la jardinería contemporánea, es decir, sus ejemplos tienen una calidad semejante a los de las obras coetáneas y vecinas, aquéllas que por cercanía geográfica, histórica y cultural, han definido la jardinería del siglo XX francesa, inglesa, italiana, norteamericana, brasileña, etc.- y a la que pertenecemos por razones obvias. El trabajo de esta tesis ha consistido en analizar estos ejemplos españoles, equipararlos y valorarlos frente a las jardinerías que han definido la evolución de la disciplina. Este hecho no ha sido analizado en absoluto, a pesar de que nuestro país ha disfrutado de una rica tradición histórica de jardinería hispana, una de las más interesantes y diversas al integrar la tradición occidental y la musulmana, y la arquitectura española se ha encontrado a la altura de las grandes movimientos arquitectónicos del siglo XX. Al existir varios casos similares en los países de su entorno, existe la posibilidad lógica que suceda lo mismo en España, y es lo que se pretende comprobar con esta investigación. Por tanto, se plantean una serie de cuestiones para ir resolviendo a lo largo de la investigación: ¿existe un jardín moderno en España?, ¿tiene interés?, ¿alcanza la calidad de los jardines contemporáneos europeos?, ¿está ligado a la tradición o son dos tendencias paralelas?, ¿cómo ha podido entrar este jardín moderno en España?

\section{ESTADO DE LA CUESTIÓN}

Hasta hace algunos años en el estudio de la historia y evolución del jardín, el siglo XX se presentaba como un gran vacío, a excepción de figuras como Luis Barragán y Roberto Burle Marx, y negando la existencia de un jardín vinculado a la arquitectura moderna. Tanto más ocurría en el jardín español del siglo XX que no ha sido estudiado desde una perspectiva analítica, ni tampoco agrupado geográfica, estilística o cronológicamente. Aunque algunos ejemplos particulares poseen una amplia bibliografía (Parque Güell, Parque María Luisa, Montjuïc, jardines de Rubió, etc.), en un gran número de ellos (jardines domésticos de arquitectos como García Mercadal, Zuazo, Sert, Moreno Barberá, Fisac, etc.) y en su tratamiento conjunto es a día de hoy prácticamente inexistente. En general, son abundantes los estudios que poseen un carácter histórico, principalmente en el primer tercio de siglo $\mathrm{XX}$, tendente al establecimiento, muy necesario, de una base documental, tanto gráfica como escrita, que proporcione la inserción del jardín en su marco temporal. Estos trabajos, normalmente, carecen de un rigor analítico que sistematice los datos aportados, que permitan una elaboración de los mismos 
para establecer líneas de desarrollo y conexiones estilísticas. Además, la composición no ha sido tratada más que en contados casos, no existen análisis formales del jardín español; los trazados son descritos, en el mejor de los casos, pero no analizados, ni siquiera comparados.

Profundizando más en la investigación teórica he constatado que existen varias lagunas sobre todo en la recopilación de una base teórica al respecto. Hay algunos artículos relacionados pero poca bibliografía sistemática del tema. Para poder fundamentar teóricamente los jardines, se tiene que investigar acerca de sus autores, sus pensamientos e inquietudes respecto a la arquitectura y concretamente en su relación con el jardín y la naturaleza. Prácticamente en ningún libro se ha encontrado un pronunciamiento sobre las posibles características comunes, tendencias formales y variación de usos, del jardín español en este período. Los principales textos existentes muestran que hay estudios sobre el jardín del primer cuarto de siglo pero no sobre el resto. Es el caso de los libros Jean Claude Nicolas Forestier 1861-1930. Du jardin au puisage urbain, Javier de Winthuysen Jardinero Andalucía, Los jardines de Gaudi, Del paraíso al jardín latino: origen y formación del moderno jardín latino, El jardín meridional: estudio de su trazado y plantación, y otros.

\section{MÉTODO}

El método de investigación ha comprendido los siguientes pasos: 1.recopilación de documentación gráfica y bibliográfica, 2.clasificación de los jardines, descripción y el análisis de los ejemplos, 3.establecimiento de la influencia de las obras foráneas y de las teorías de la Arquitectura y del Jardín, y 4 .el estudio de las relaciones del jardín con el edificio, la ciudad y el paisaje.

1. La fase de recopilación de documentación de los jardines de este periodo, tanto teórica como de los proyectos, ha partido de un barrido de la bibliografía general sobre jardines, específica de jardines españoles, publicaciones al respecto en revistas de la época, catálogos, actas de congresos y recopilaciones.

Además, se han consultado una serie de fuentes, en lo referente a cartografía y documentación, y para la bibliografía especializada se han visitado varios organismos. 
Se ha realizado un trabajo de campo importante visitando la mayoría de jardines estudiados, realizando fotografías y obteniendo datos sobre el terreno.

Aunque se han estudiado diferentes ejemplos repartidos en el territorio nacional, se ha prestado especial atención a Madrid y a Barcelona, como capitales administrativas y económicas del país así como los focos donde se realizan las principales operaciones arquitectónicas y urbanísticas que han servido de modelo y ejemplo para el resto de las ciudades. Este estudio no pretende ser un catálogo de los jardines y parques madrileños o barceloneses, sino entresacar los ejemplos más relevantes para poder estudiar su evolución histórica y compositiva a lo largo de los diferentes capítulos que tratan la jardinería urbana.

2. Posteriormente se ha procedido a la realización de una serie de fichas donde se han analizado los diferentes aspectos del jardín: el estudio histórico, el clima del lugar, la orientación, la topografía donde se asienta, los cursos de agua, la zonificación, los elementos arquitectónicos, la vegetación, los accesos, los flujos, las relaciones espaciales, los cerramientos, los usos originales y actuales, las instalaciones, el equipamiento y mobiliario, la imagen y su relación visual con el entorno, etc. ; factores, todos ellos, que pueden condicionar la organización del jardín. Las fichas se han acompañado de planos, fotos actuales, vistas antiguas, etc.

A continuación se han abordado la descripción de los ejemplos más interesantes o significativos y el análisis de su estructura formal, basados en el examen de la cartografía existente en cada caso, lo que ha supuesto un acercamiento a la evolución en el tiempo del trazado del mismo. Estos esquemas formales, dentro de cada grupo, permiten la comparación de los trazados de diferentes jardines, lo que posibilita el rastreo de los elementos o características constantes. Con ello se ha realizado primero una clasificación de los distintos jardines estudiados por géneros: propiedad (privado, público, para edificios públicos, en viviendas sociales, exposiciones internacionales y efímeras, etc.), tendencias formales (modernistas, biomórficos, clásicos, paisajistas, neoandaluces, mediterráneos, etc.), cronológico (antes de la guerra, posguerra, desarrollismo, etc.), para luego, cuando ya se ha encontrado la clasificación o clasificaciones más pertinentes, considerar cada ejemplo cronológicamente, para así posibilitar el estudio de la línea evolutiva del jardín moderno en España. 
También se han realizado unas fichas de los textos teóricos que se han ido encontrando, que han permitido estudiar cómo se introduce el concepto de jardín moderno y la teoría del jardín en España a través de congresos, jornadas y exposiciones, cómo influye en el pensamiento español. Se han recopilado diferentes libros y escritos, la mayoría de los cuales se encuentran dispersos en varias revistas y publicaciones. Una gran fuente de información son las entrevistas realizadas a varios de los arquitectos, los cuales expresaban ideas al hablar sobre el tema en introducciones de libros, artículos, comentarios de algunos proyectos, etc. De esta forma se intenta crear una cuerpo teórico, o al menos de un conjunto de ideas, que explique y dé fundamento a las obras estudiadas e intente llevar un hilo conductor a lo largo del proceso evolutivo seguido por los jardines españoles del siglo XX.

3. El establecimiento del contexto teórico e histórico internacional: la influencia del jardín coetáneo y de las teorías de la Arquitectura y del Jardín del siglo XX, a partir de la confrontación del jardín español con las obras europeas y americanas, pero también con el jardín musulmán y el japonés, cuyas respectivas estructuras formales y la codificación y el desarrollo de las mismas pueden haber servido de pautas para el establecimiento y evolución de los objetivos propuestos para el primero, gracias a mecanismos de transmisión desde los países más avanzados al nuestro. Según lo antedicho, se establecerá una comparación compositiva del jardín foráneo -en especial, franceses, italianos, alemanes, americanos- con el español, estableciendo las similitudes y las diferencias.

4. El estudio del entorno, esto es, de la relación del jardín con el edificio, la ciudad y el paisaje, pues la investigación, aunque centrada en los jardines, se ha extendido, cuando se ha considerado necesario, a la casa u otros edificios a los que acompañen, cuyo análisis puede dar luz a la composición del jardín. En cuanto al jardín privado o al institucional, incluye la determinación del grado de correlación entre ambos, es decir, la importancia del jardín en la concepción de la vivienda -donde el jardín no es un mero complemento, sino parte primordial en la composición del conjunto-, o la trascendencia del edificio como componente básico del jardín, y un estudio formal comparativo entre ambas arquitecturas, la del jardín y la del edificio, que permite determinar la idea de proyecto global, si la hubiera; la continuidad entre ambos; la influencia del trazado del jardín en el edificio, y viceversa; focalidad de la planta del jardín debido a otros elementos construidos, etc., y, además, un análisis funcional del jardín, a partir de los elementos puntuales (pérgolas, miradores, pabellones, fuentes,...). 
Respecto al jardín público y al parque, el estudio ha analizado la forma de conexión de cada ejemplo con los trazados y los espacios urbanos, intentando establecer la influencia de éstos en la configuración de la planta del jardín, o viceversa, como parece ocurrir en muchos de los jardines públicos, sobre todo del siglo XX.

Se ha buscado con todo ello el estudio de las directrices compositivas, la sistematización de las mismas y el reconocimiento de unas constantes, si las hubiese, en la estructura formal del jardín moderno español. Para ello se han estudiado los antecedentes de estos jardines en nuestro país en el primer tercio del siglo XX, con figuras modernistas como Gaudí y Otamendi -este último utiliza el jardín modernista como telón de fondo decorativo de sus villas sin proponer trazados, en principio- , y otras más clásicas, como Forestier. Éste tuvo gran repercusión en los jardines españoles posteriores, pues su vertiente mediterránea será el punto de partida de Nicolás María Rubió i Tudurí en sus obras de los decenios siguientes, que continúan la tradición de lo que él llamó el "jardín latino"; mientras que su reconsideración del jardín andaluz servirá de referencia a Javier de Winthuysen, que con sus escritos y realizaciones intentará recuperar el jardín clásico en España; la vida de Winthuysen giró siempre alrededor del jardín, pues durante los primeros años lo convirtió en el tema central de su pintura, y desde 1919 se dedicó al arte de la jardinería, rescatando del abandono muchos de los jardines españoles. Otro caso en el que se presenta la relación de los jardines con la pintura es el jardín de la casa del pintor Sorolla, actualmente sede del Museo Sorolla, donde el pintor presenta una interpretación del jardín hispanomusulmán destacando su interioridad en convivencia con lo vegetal y el agua.

Como casos particulares pueden citarse el jardín como integración de las artes en las Exposiciones Internacionales: Exposición Iberoamericana de Sevilla de 1929 (Parque de María Luisa) y Exposición Internacional de Barcelona de 1929 (jardines de Montjuïc). En estos primeros años también empiezan a aparecer jardines en las primeras colonias del ensanche madrileño y en los últimos años de esta etapa se empieza a gestar el proyecto singular de la Ciudad Universitaria de Madrid. Sin embargo, el objeto de esta tesis no es centrarse sólo en el primer período del siglo XX, en el que predomina la recuperación de la tradición mediterránea, sino avanzar en los posteriores, en los que se plantea la introducción del jardín moderno en España y su desarrollo. 


\section{MARCO TEMPORAL}

Se propone para el estudio un límite inicial positivo y un límite final negativo, siendo las fechas entre las que se comprenden los jardines objeto de este trabajo las siguientes: 1926, comienzo de la arquitectura del Movimiento Moderno en España con el proyecto del Rincón de Goya de García Mercadal primer edificio de arquitectura Racionalista que se construye en España-, y 1980, ya que a partir de entonces se manifiesta en España la crisis del Movimiento Moderno al tiempo que, con los ayuntamientos democráticos, aparecen los primeros parques públicos contemporáneos, especialmente en Barcelona (Parque Joan Miró, 1981, el primero en el que se dio un nuevo uso a espacios urbanos con equipamientos obsoletos, Parque de la España Industrial de Luis Peña Ganchegui construido en 1983-1985, etc.) iniciándose otra etapa del desarrollo del jardín a una escala urbana, ya de parque, que continúa en el presente e implicaría otro estudio independiente.

Dentro de estos límites cronológicos y estilísticos se estudian, no sólo los jardines que se han conservado, sino aquellos en los que, habiendo desaparecido, existe la posibilidad, por medio de planos, dibujos, croquis, o en su caso de la interpretación de sus restos y con el apoyo de las descripciones escritas o fotografías, de conocer su organización en el momento en que fueron construidos, permitiendo llevar a cabo un análisis arquitectónico. También se analizan los proyectos que no se hayan construido -hay muchos en revistas, legados, etc.- que a veces son tanto o más interesantes que los que se han llegado a materializar. Por lo tanto, dentro del campo de trabajo, se incluyen todos aquellos escritos sobre el jardín que nos ayuden a un acercamiento al estado inicial del mismo, como las referencias en libros y artículos, noticias en la prensa, etc.

\section{PERIODIZACIÓN}


1a etapa: La llegada del Movimiento Moderno (1926-1936): entre la tradición española y el jardín racionalista

Dentro del jardín moderno español (1926-1980) es posible distinguir varias etapas: los primeros años (1926-1936) corresponden a la introducción del período del Movimiento Moderno. Esta etapa comienza con el proyecto del Rincón de Goya -diseñado por Fernando García Mercadal en 1926 y terminado de construir en 1928 para conmemorar el primer centenario de la muerte del pintor Francisco de Goya-, que se considera el primer ejemplo de arquitectura racionalista diseñado en España. Este edificio, situado en el parque de Buenavista de Zaragoza y destinado inicialmente a servir de museo del pintor, se abría a un jardín formando un conjunto arquitectónico y paisajístico unitario en el que ambos, espacio ajardinado y espacio edificado, guardaban estrecha relación y semejanza formal y distributiva en su composición. García Mercadal fue el arquitecto que introdujo el Racionalismo en España y representó el enlace de la cultura arquitectónica racionalista española con la europea de los años veinte y treinta, realizando varios viajes por Berlín, París y Viena, donde conoció a Walter Gropius, Mies van der Rohe, Le Corbusier, Peter Behrens o Adolf Loos.

En este período empiezan a destacar un grupo de arquitectos interesados en el tema del jardín, como los miembros del grupo GATEPAC (Grupo de Arquitectos y Técnicos Españoles para el Progreso de la Arquitectura Contemporánea) -fundado en 1930 en Zaragoza-, con García Mercadal a la cabeza, y el grupo catalán GATCPAC, además de otros profesionales, como Zuazo o Gutiérrez Soto, Bergamín, Blanco Soler que realizan jardines en las colonias. También destacan grandes operaciones urbanas como la Ciudad Universitaria de Madrid. La etapa termina con el comienzo de la Guerra Civil.

2a etapa: Los años de posguerra (1940-1965): la apuesta por el jardín moderno

Tras el vacío de la guerra, la siguiente etapa corresponde al jardín español de posguerra (1940-1965) en el que se empiezan a realizar las nuevas colonias y barrios; en Madrid destacan: Manzanares, Niño Jesús, Virgen del Pilar, Cruz del Rayo, la Elipa, la Estrella, etc.

También aparecen jardines privados y jardines urbanos en las grandes ciudades como Madrid y Barcelona, destacando figuras como Rubió en su segunda etapa y la finalización de los jardines de Mercadal que fue 
arquitecto de parques y jardines de Madrid durante la República y profundizará en la historia del jardín europeo. En esta etapa hay una vuelta a los principios del Movimiento Moderno o del Estilo Internacional, aparecen arquitectos como Fisac u Oiza que comenzarán a trabajar en estas décadas por la recuperación de la arquitectura española a la modernidad tras la arquitectura nacionalista de los primeros años de la posguerra. En esta etapa cobran gran importancia los jardines de los distintos equipamientos reforzando la idea de la vida comunitaria. Se analizan los jardines de los viveristas, como personajes clave que colaboraron estrechamente con los arquitectos.

\section{3a etapa: Los años de apertura (1965-1980): la inclusión del paisaje y las nuevas escalas}

Poco estudiada con anterioridad es la contribución de los arquitectos más avanzados de la segunda mitad del siglo; entre los arquitectos españoles con prestigio internacional hicieron jardines Corrales y Vazquez Molezún, Moreno Barberá, Cano Lasso, Fisac, Carvajal, Fernández Alba, Higueras, Cabrero, Oiza, etc. En sus obras habrá que diferenciar las contribuciones propias de las influencias foráneas de esta época y señalar las contribuciones teóricas.

Se estudian los jardines privados y los jardines y espacios públicos ajardinados, analizando las actuaciones en los nuevos conjuntos residenciales y barrios, pero sin profundizar en los poblados de vivienda social. En ellos la ordenación es más precisa y variada, la distribución de edificios altos e hileras de viviendas unifamiliares configura un paisaje más equilibrado, pues son poblados más estructurados, con espacios y recorridos públicos donde aparecen jardines entre bloques.

También se presta atención a los jardines a gran escala, destacando los de los complejos turísticos, dada la importancia que cobra el turismo en esta época. En esta etapa el gran protagonista va a ser el paisaje y se va a incluir en las composiciones. La escultura es otro de los aspectos que se analiza en este periodo y no solo en el interior de las viviendas, sino que va a dar el paso a la calle introduciéndose en el paisaje urbano.

Aparecen jardines efímeros con ejemplos como los Festivales florales del Retiro, Feria del Campo (Casa de Campo, Fisac, de la Sota...), y a las actuaciones españolas en América, como es el caso del arquitecto español José Luis Sert que planteó un desarrollo del patio jardín, donde se aprecian visiblemente las influencias de las casas patio de Mies de los años 1930, etc. 
La mayoría de figuras destacadas son arquitectos que han diseñado jardines en consonancia con su propia arquitectura, pero también aparecen paisajistas y otros artistas que no se ciñen únicamente a una mera plantación sino que buscan una calidad espacial en sus jardines. Entre ellos destaca la figura de Leandro Silva, uruguayo que se estableció en Madrid desde 1969, introduciendo las principales corrientes del paisajismo del siglo XX en nuestro país, en especial de la tendencia biomórfica, que logró conjugar con los principios estructurantes del jardín español. También se analizan otras realizaciones de autores menos relevantes como las de la Marquesa de Casa Valdés.

\section{BIBLIOGRAFÍA}

Respecto a la bibliografía sobre el tema de investigación, existen algunas monografías particulares dirigidas a muy pocos autores destacados como es el caso de Gaudí, Rubió i Tudurí o Winthuysen, a quienes habrá que referirse como antecedentes, pero que no constituyen el objeto del estudio que se propone. Sin embargo no se observa un estudio global y sistematizado que permita conocer las obras de paisajistas y arquitectos españoles que hacen jardines, estudiando a partir de la evolución de la obra arquitectónica la evolución del jardín, y relacionándolo con ejemplos contemporáneos de otros países.

\section{Bibliografía general sobre la Historia del Jardín}

Hay diversos libros dentro de la bibliografía general sobre la Historia del Jardín que nos permiten un acercamiento a la arquitectura de jardines española, pero en la mayoría de ellos éste ocupa un único capítulo, prestando especial atención a los jardines antiguos y prácticamente sin ninguna referencia a los jardines del siglo XX; además casi todas las descripciones de los jardines que se realizan son desde el punto de vista histórico, como es el caso de Historia de la Arquitectura de Jardines (Madrid, 1855), Histoire des Jardins Anciens et Modernes (Tours, 1887), L'Art des Jardins (Paris, 1934), A History of Garden Art (Thacker, 1943), L'art des jardins (Paris, 1962), etc.

Un libro interesante, al menos por la originalidad del planteamiento, es Los jardines. Historia, trazado y arte... (Madrid, 1970. 1ạ edic. inglesa: 1962), de Derek Clifford. El autor intenta estudiar los jardines a partir del carácter de los pueblos que los han creado, dedicando un capítulo a los españoles. 
Una publicación española de interés es la realizada por Francisco Páez de la Cadena, que se titula Historia de los Estilos en Jardinería (Madrid, 1982). El autor diferencia los estilos jardineros "en estado puro" de las jardinerías no autóctonas, es decir, aquellas que provienen de la reelaboración de estilos o los ejemplos aislados del momento formal que fueron concebidos. Entre los estilos se encontraría la jardinería hispano-musulmana, y el resto de las obras españolas, en el grupo de las jardinerías autóctonas. El libro inicia un estudio básico de los trazados, el espacio, las influencias estilísticas, las similitudes con otras jardinerías, así como intenta encontrar las estructuras básicas de la jardinería española, que el autor cree descubrir en el patio.

Entre las numerosas historias generales del jardín que han sido publicadas destaca, por el tratamiento arquitectónico de los ejemplos estudiados, la obra La arquitectura de los jardines: de la Antigüedad al siglo XX (Barcelona, 2004; 1a edición en italiano: Roma, 1985), de Francesco Fariello. Presenta también suficiente planimetría, aunque proviene de otras publicaciones.

La arquitectura de los jardines de Occidente de Mosser y Teyssot (Milán, 1990) presenta una visión internacional del diseño de jardines desde el Renacimiento hasta el siglo XX, mediante la recopilación muy interesante de más de setenta artículos de académicos de Europa y América. Organizados cronológicamente, los artículos e ilustraciones forman un mosaico del jardín en el mundo occidental, tratando temas como: el jardín humanista en la Italia renacentista, los conceptos de "Sublime" y el pintoresco "," laberintos, grutas, y otras curiosidades, parques de la ciudad, el land art americano, etc. Las discusiones sobre aspectos característicos de la historia y la teoría son seguidos por los análisis de los jardines individuales como: el Hortus Palatinus en Heidelberg, el Parc Monceau de París, el Park Güell en Barcelona, Stowe en Inglaterra, etc. Se incluyen una gran cantidad de planos, dibujos, reconstrucciones, pinturas y fotografías, todo ello procedente de los proyectos originales. 


\section{Bibliografía general sobre la Historia del Jardín Español}

La bibliografía general sobre la historia del Jardín Español es más escasa, la mayoría de los textos son de carácter global, entre ellos destacan varios títulos. Arthur y Mildred Byne publican Spanish Gardens and Patios (Philadelphia \& London, 1924), donde estudian el modelo del patio. En Jardinería general y española (Madrid, 1925), J. M. Priego, realiza una historia global de los estilos de jardinería, centrándose en los españoles. Mientras, Georges Gromort, en su magnífico libro, titulado Jardins d'Espagne (Paris, 1926), reúne un interesante conjunto de levantamientos de gran calidad, además de una documentación fotográfica de primer orden, describe el trazado y la composición.

Un paso importante fue Jardines Clásicos de España (Madrid, 1930), escrito por Javier de Winthuysen, donde resalta la importancia del jardín español, expone las primeras noticias históricas sobre muchos de los ejemplos estudiados, presenta el interés de publicar levantamientos de los jardines, así como detalles de elementos y fotos de gran valor, todos realizados por el autor.

Louis Bertrand estructura su obra Jardins d'Espagne (Avignon, 1940) como un libro de viajes, donde se describen los lugares visitados, con una fuerte intención literaria.

El arquitecto Fernando García Mercadal escribe Parques y jardines (su historia y sus trazados) (Madrid, 1949), obra que, aunque general, recoge con mayor énfasis los ejemplos españoles. Profundiza en el estudio de tipologías de jardines, sobre todo en el hispano-musulmán, ofreciendo un análisis más arquitectónico de los mismos. El interés de este libro es que presenta obras suyas del siglo XX junto a otras extranjeras contemporáneas.

El Marqués de Lozoya publica Los jardines españoles (Madrid, 1951), donde hace un breve y superficial recorrido descriptivo por varias obras de arquitectura de jardines. Similares, tanto en contenido como en formato, a la obra del Marqués de Lozoya, son las obras de Arturo Rigol y de Felipe Torroba Bernaldo de Quirós, que, se titulan, respectivamente, Los Viejos Jardines (Barcelona, s.d.) y Palacios y jardines (Madrid, 1959); en todos ellos apenas se hace referencia al siglo XX. 
Otra publicación que ya recoge ejemplos del siglo XX es Jardines de España (Madrid, 1987, 2ª edic.), de la Marquesa de Casa Valdés, que es importante por la exhaustividad de datos históricos y literarios, y la prolijidad de ejemplos presentados, aunque faltos de una sistematización que clarifique el desarrollo de los mismos. Realiza un acercamiento estilístico, a veces no acertado, de los jardines recogidos. Además publica una cartografía básica, pero insuficiente, que incluye planos históricos.

La obra de Ana Luengo y Coro Millares, Parámetro del Jardín Español (Madrid, 2007) se presenta en tres tomos -Naturaleza, Paisaje, Territorio-, que establece los principios básicos que rigen los estilos del arte del paisaje en España, permitiendo definir claramente las influencias estilísticas que el paso del tiempo ha podido imprimir en un jardín. En el Tomo I se estudia la evolución desde los orígenes hasta los monasterios, destacando el jardín hispanomusulmán. En el Tomo II se recogen principalmente todos los jardines reales, las fincas de recreo nobiliarias y los jardines ingleses a la española del siglo XVIII. El Tomo III aborda: el nacimiento de la jardinería urbana con la función higienista del verde en los parques, plazas y paseos españoles del siglo XIX, la globalización y vernaculismo: la definición del estilo nacional. Al final de este último tomo es donde se adentra en el siglo XX estudiando aspectos como: el modernismo vernáculo, la Exposición Internacional: Barcelona 1929, la personalización de estilos, etc., pero no presenta un panorama completo del jardín del siglo XX, tan solo un esbozo de los inicios de siglo. La publicación se acompaña de planimetría, fotografías y esquemas de análisis de algunos de los ejemplos.

Alberto Sanz Hernando con su tesis Un jardín clásico en España: un análisis arquitectónico (Madrid, ETSAM-UPM, 2006), en parte publicada en su libro, El jardín clásico madrileño y los reales sitios (Madrid, 2009), reivindica y estudia la jardinería clásica en nuestro país, donde se funden dos tradiciones opuestas: la musulmana y la occidental clásica -flamenca e italiana-. El jardín hispanomusulmán proporciona los rasgos distintivos de la jardinería española posterior, derivados de la necesaria adaptación compositiva a un medio físico, que soluciona tradicionalmente con el patio y el apoyo de una serie de elementos arquitectónicos de carácter ligero articulados aleatoriamente con la vivienda para organizar su entorno, con una ordenación quebrada y una fragmentación espacial. Analiza la doble vertiente del jardín renacentista español dependiendo del medio físico donde se asiente: en entornos poco propicios a la creación de jardines, se recuperará la ordenación espacial medieval musulmana como respuesta compositiva a dicho ambiente; mientras que en territorios propicios - 
generalmente, riberas de ríos-, se podrá desarrollar el espacio perspectivo unitario italiano, produciendo ejemplos de gran calidad. Las ideas de Sanz sobre la adaptación compositiva al medio físico, debido a las dificultades de estructurar el espacio del jardín en España con las componentes naturales topografía, vegetación y agua-, realizadas con éxito en la jardinería hispanomusulmana y reutilizadas en siglos posteriores, e incluso alcanzando el momento actual, son de especial interés y aplicación para la jardinería moderna española.

\section{Monografías de jardines históricos españoles}

Dentro del grupo de monografías de jardines históricos españoles, el número de publicaciones referentes a diferentes momentos históricos o distintas localizaciones geográficas de los jardines españoles y a ejemplos aislados es muy amplio y se señalan en la bibliografía. Destaca la obra muy completa del arquitecto Francisco Prieto-Moreno sobre Granada, titulada, precisamente, Los jardines de Granada (Madrid, 1973), donde se recogen un importante número de levantamientos de cármenes y de los jardines de La Alhambra y del Generalife. A partir de unos planteamientos espaciales y compositivos, estudia el jardín y lo relaciona con el medio, con el territorio que le circunda, analizando las referencias formales, los elementos del jardín y la relación jardín-casa.

\section{Jardines españoles del siglo XX}

La bibliografía específica sobre los jardines españoles del siglo XX se ha clasificado en tres grupos: monografías de jardines del siglo $X X$, generales de arquitectura y monografías de arquitectos.

\section{a) Monografías de jardines del siglo XX}

Dentro de las monografías de jardines del siglo XX aparecen escritos de los propios autores de los jardines (Forestier, Winthuysen, Rubió i Tudurí, etc.) y otros estudios o recopilaciones realizados por otros autores, principalmente del primer tercio del siglo XX.

Forestier escribió dos libros: su obra original titulada Jardins, Carnet de plans et de dessins (Jardines. Cuaderno de dibujos y planos. Barcelona, 1985) contribuyó a hacer de los dibujos de Forestier el arquetipo del nuevo jardín francés. Según el autor, "Estos planos son una lección de aplicación universal ya que poseen las cualidades que todos los jardines deberían 
tener", por lo que da ejemplos de pequeños jardines y hace especial hincapié en los jardines que él llama del "clima del naranjo". Dentro de sus obras en España destacan: el Parque de María Luisa (Sevilla, 1911) con motivo de la Exposición Ibero-Americana de Sevilla de 1929, y el parque de Montjuïc (Barcelona, 1915-23).

Su otra gran obra fue Grandes Villes et systèmes de parcs, título que es una traducción casi literal del ensayo de Frederick Law Olmsted Public Parks and the Enlargement of Towns. Plantea su pensamiento sobre el crecimiento urbano y metropolitano y reúne a un pequeño grupo de paisajistas que están interesados directamente en el futuro de las ciudades. Describe los principios y las ventajas de un sistema de parques siguiendo de cerca la línea teórica e ideológica de F.L. Olmsted y de sus seguidores, como su hijo F.L. Olmsted Junior, George Kessler y en menor medida John Nolen. En ella Forestier a través de diversos ejemplos de proyectos urbanos en Europa meridional o en América central o latina defiende la buena distribución de parques y jardines, la protección de paisajes, la constitución de grandes reservas para futuras extensiones urbanas, todo ello necesario para el estudio de un programa de conjunto de planificación urbana a una escala que reúne "varias ciudades, municipios, departamentos o provincias". Existe un libro que recopila una serie de artículos sobre este personaje: Jean Claude Nicolas Forestier 1861-1930. Du jardin au paisaje urbain (Paris, 1994).

Existe una tesis doctoral, Los jardines de Jean Claude Nicolas Forestier en España (Sevilla, 1986), de Cristina Domínguez Peláez, que tiene por objeto dar a conocer la obra que Forestier desarrolla en España durante las tres primeras décadas del siglo XX mediante el estudio minucioso exhaustivo y analítico de cada una de las realizaciones que la integran. Previamente se efectúa una aproximación al concepto e historia del jardín a través de los tiempos. Se revelan algunos datos biográficos del artista para pasar a descubrir los fundamentos teóricos que sustentan la producción y que dan lugar a que su estilo este definido por el eclecticismo como consecuencia de una heterogeneidad de influencias y la adaptación al medio desde un punto de vista climatológico e histórico, respetando siempre gustos y tradiciones. A continuación se analizan una a una sus distintas obras, destacando las realizadas a fin de realzar las exposiciones Iberoamericana de Sevilla y Universal de Industrias Eléctricas y General Española de Barcelona, ambas celebradas en 1929; además de una serie de jardines diseminados por la geografía española tanto públicos como privados. Esta tesis se realiza desde el punto de vista histórico, no habiendo un análisis arquitectónico. 
Nicolau María Rubió i Tudurí es arquitecto, urbanista, diseñador de jardines y escritor, discípulo de Forestier con el que colaboró en el parque de Montjuïc. Realiza varios jardines públicos y privados y escribe varios ensayos sobre arquitectura y urbanismo; entre sus publicaciones sobre jardines destaca El jardín meridional: estudio de su trazado y plantación (Barcelona, 1934) y Del paraíso al jardín latino: origen y formación del moderno jardín latino (Barcelona, 1981), en las que propugna un jardín entroncado a la vez la tradición árabe y latina.

En el caso de Gaudí existe un libro específico de Juan Basegoda Nonell que analiza los conceptos y las formas de los jardines en los que intervino Gaudí como proyectista o consejero: Los jardines de Gaudí (Barcelona, 2001). También describe aquellos edificios del arquitecto en los que el concepto de formas propias de la naturaleza influye en la idea compositiva. Analiza las ideas concretas que Gaudí mantuvo sobre las formas naturales y su incorporación a la arquitectura. Estudia el tratamiento metafórico de su arquitectura basada en la naturaleza, la espiritualidad y la trascendencia, especialmente en los jardines, a los que incorporó el pensamiento franciscano de la relación fraternal entre seres humanos, plantas y animales. El texto se acompaña de fotos de la época, pero la planimetría es muy escasa. También sobre el Park Güell Conrad Kent escribe: Hacia la arquitectura de un paraíso: Park Güell (Madrid, 1992), con fotografías e imágenes de la época como telón de fondo, los autores muestra el proyecto del parque Güell tal como Gaudí y sus colaboradores lo concibieron; asimismo se realiza un profundo y serio análisis de la sociedad de la época.

El libro escrito por Javier de Winthuysen, pintor y diseñador de jardines, Jardines clásicos de España (Madrid, 1930) contiene planos y fotografías de estudios que realiza sobre jardines históricos españoles. A parte de él, se han editado varias publicaciones sobre su figura, entre ellas las de Carmen Añón Feliu y José Luis Sancho Notas sobre la vida y escritos de Xavier de Winthuysen (Madrid, 1990); Maseda García publica en 2004, Javier de Winthuysen. Crónicas y proyectos (1874-1956). Otros de los catálogos de las exposiciones sobre Winthuysen son: Javier de Winthuysen: giardini di Sapagna: (mostra) (Madrid, 1986), Javier de Winthuysen: jardinero (Madrid, 1986) y Javier de Winthuysen: jardinero. Andalucía (Sevilla, 1989).

Destacan también otras monografías como la del paisajista Leandro Silva, de José Antonio Gómez Municio, Leandro Silva: El universo en el Jardín. Paisaje y arte en la obra de Leandro Silva (Valladolid, 2002), donde recoge 
su sabiduría y experiencia en el mundo de la jardinería y paisaje; se complementa con una amplia documentación de planos, escritos, acuarelas y fotografías. Silva, amigo personal de Roberto Burle Marx desde mediados de los años cincuenta, con el que colaboró esporádicamente, constituyó la principal conexión europea con el gran maestro del paisajismo y fue uno de sus continuadores más representativos, convirtiéndose en el paisajista más importante de la segunda mitad del siglo XX en nuestro país. Sus mejores obras las realiza en su primera etapa, destacando: la plaza de Pérez Galdós en Las Palmas de Gran Canaria, el parque de Logroño en Burgos, el Romeral de San Marcos en Segovia y, en Madrid, la restauración del Real Jardín Botánico, los jardines de la Torre Picasso, el parque de Palomeras, los jardines del Banco de España en Canillejas y el monumento a Gregorio Marañón en la Ciudad Universitaria, también realiza varios jardines privados diseminados por España. Además de paisajista, trabajó como arquitecto y artista plástico, siendo seleccionado como este último para representar a Uruguay en la Bienal de Sao Paulo y en la Bienal Hispanoamericana de Barcelona, y exponiendo repetidas veces en diversas galerías y museos. Colaboró, también, con importantes arquitectos del momento, como Corrales y Molezún o Antonio Fernández Alba, y con diversos artistas plásticos, como Pablo Serrano. El archivo profesional de Leandro Silva ha sido donado a la ETSAM y está depositado en su biblioteca, por lo que es fácil el acceso a su consulta. El legado está compuesto por material gráfico y escrito de naturaleza diversa: planos y dibujos, memorias, pliegos de condiciones, mediciones y presupuestos, material fotográfico, cartas, postales y correspondencia varia, recortes de prensa e información sobre acontecimientos relacionados con la actividad del paisajista (exposiciones, congresos, etc.) y documentos relativos a viajes y visitas de obra.

Se han publicado algunas monografías sobre jardines específicos (El Parque de la Ciudadela, Jardines del Palacio de Pedralbes, El jardín de Monforte, el Parque de María Luisa, los cármenes, el Romeral de San Marcos,...) que se recogen en la bibliografía. Destaca el catálogo de la exposición Jardines de España (1870-1936), donde se presenta el jardín como imagen esencial de la pintura española de esa época, formando la pintura de jardín un género particular. Se ve el jardín a partir de varios temas: sus elementos y habitantes, el viejo parque abandonado, el legado hispanoárabe, el jardín en la pintura catalana y el parque público urbano. Se destacan tres pintores en cuya obra el jardín fue fundamental: Santiago Rusiñol, Joaquín Sorolla y Javier de Winthuysen. Es un enfoque muy interesante que permite el estudio de los jardines a través de la pintura, mediante la cual se observa el momento 
decisivo del renacimiento del jardín español, que se plasma en plantaciones de nuevos parques y la rehabilitación de jardines en diversas partes de España. El catálogo aporta una recopilación de textos literarios de la época sobre el jardín es un complemento fundamental.

Existen pocas tesis doctorales que guardan alguna relación con el tema del jardín español del siglo XX; además de las ya comentadas, destaca la de Marta Marco Mallent: Del jardín construido al jardín pintado. Aproximación a la temática del jardín en la pintura de Pinazo, Sorolla y Benlliure (Politécnica de Valencia, 2004), donde recoge que el jardín es la Naturaleza reconstruida por el hombre para expresar en ella su espíritu, un lugar que induce a la contemplación, a la meditación y al sosiego. Se analiza la relación que se establece entre el artista pintor y el entorno ajardinado, más concretamente entre dicho artista y su jardín privado. Desde aquellos que diseñan su propio espacio, haciendo de sus jardines una prolongación de sí mismos, hasta esos otros que, sin haber intervenido en el diseño, establecen un vínculo tan intenso con la naturaleza que les rodea, que gran parte de su producción pictórica hace referencia a estos espacios, por diminutos e insignificantes que puedan ser, analizando los diferentes modelos de conexión entre el artista y su jardín a través de las obras surgidas de esta relación. El trabajo se compone de una primera parte introductoria donde se analizan los conceptos de paisaje y jardín, y se hace un breve apunte histórico de la imagen pintada de la Naturaleza. Una segunda parte está orientada al estudio pormenorizado de tres casos concretos de pintores que han creado un vínculo especial con su jardín privado: Ignacio Pinazo, Joaquín Sorolla y José Benlliure. A lo largo del trabajo se compara constantemente el hecho físico, es decir, lo construido, el jardín real, material y tangible, con lo pintado, ya que esta tesis se aborda desde el campo de la pintura principalmente.

\section{b) Generales sobre arquitectura y monografías de arquitectos}

Los libros generales sobre arquitectura y las monografías de los arquitectos de este periodo son muy numerosos, por lo que se toma como referencia para la tesis las publicaciones en las que se han realizado previamente una selección de las principales obras, recopilaciones realizadas por expertos como la Fundación del Colegio de Arquitectos de Madrid (FCOAM) y la Fundación DOCOMOMO Ibérico, organización internacional dedicada a la documentación y conservación de la arquitectura del Movimiento Moderno en España y Portugal, ha llevado a cabo numerosas iniciativas de 
documentación y estudio del patrimonio moderno sobre las principales temáticas de la arquitectura de dicho movimiento: la vivienda, la industria, los equipamientos, etc., que se han concretado en publicaciones y seminarios de gran interés. Todas estas publicaciones son de gran utilidad para la tesis porque además de la selección de las principales obras, se acompañan de documentación gráfica y planimétrica.

La primera labor a la que se enfrentó DOCOMOMO Ibérico fue la de seleccionar y documentar un conjunto de 166 obras que constituyen el Registro DOCOMOMO Ibérico, publicado en noviembre de 1996 bajo el título Arquitectura del Movimiento Moderno. Registro DOCOMOMO Ibérico, 1925-1965 (Barcelona, 1996). Este trabajo culmina la labor realizada durante dos años por especialistas del ámbito territorial que nos ocupa. La publicación del registro no es sólo una labor historiográfica y de estudio del patrimonio arquitectónico sino que dirige una mirada renovadora a la arquitectura y a la ciudad del siglo XX desde una perspectiva compleja $\mathrm{y}$ contrastada, acometiendo la doble tarea de presentar un amplio y detallado material gráfico y documental y a la vez ofrecer una reflexión crítica sobre dicha documentación.

Similar es la publicación La arquitectura de la industria. Registro DOCOMOMO Ibérico, 1925-1965 (Barcelona, 2005), donde el DOCOMOMO dirige sus estudios al campo la industria, llevando a cabo una labor de investigación y documentación de la arquitectura ligada a las estructuras industriales. Partiendo del análisis de las obras seleccionadas, se propone articular una visión global y pormenorizada de lo que la industria ha supuesto para el desarrollo del Movimiento Moderno en los territorios ibéricos, revelándose la industria como un campo en el que el ensayo de nuevos materiales y la búsqueda de la eficacia constructiva permiten el pleno desarrollo de la nueva arquitectura, en la que los condicionantes representativos y simbólicos pasan a un segundo plano. Con ese fin, un cuerpo de ensayos abordan diversos aspectos sobre la manera a encuadrar la temática; exponen los criterios metodológicos de la selección; contextualizan las obras en el periodo histórico así como en la realidad económica y geográfica; analizan el peso de la arquitectura de la industria en el desarrollo del Movimiento Moderno; estudian la implantación de la industria en el territorio y en el entorno urbano $y$, finalmente, examinan el devenir de la industria y las estrategias de preservación del patrimonio industrial. En una mirada más pormenorizada se documentan las obras seleccionadas, por áreas geográficas según un orden cronológico, resaltándose aquellas obras que se estimen de mayor interés. 
La vivienda moderna, 1925-1965: registro DOCOMOMO Ibérico (Madrid, 2009), está dedicado a una de las temáticas principales de la arquitectura del Movimiento Moderno, que constituyó uno de los campos de investigación más fructífero de la arquitectura moderna, no sólo desde el punto de vista del desarrollo y aplicación de las nuevas tecnologías, sino también desde el punto de vista de los tipos arquitectónicos y del papel social de la arquitectura, temas hoy de gran actualidad. Aborda tanto la vivienda colectiva como la unifamiliar, así como los conjuntos de viviendas, ya sean en medios urbanos o rurales, descartándose aquellos tipos residenciales que puedan ser entendidos como equipamientos.

Paralelamente a la tarea de registro de la Fundación, algunos de los miembros de DOCOMOMO Ibérico han realizado ampliaciones del Registro en los territorios que representan. Es el caso del Collegi d'Arquitectes de Catalunya que publicó, en 1996, junto al Departament de Cultura y al Departament de Política Territorial i Obres Públiques de la Generalitat de Catalunya el Registro de arquitectura moderna en Catalunya: 1925-1965. También es el caso del Colegio Oficial de Arquitectos de la Comunidad Valenciana y de la Conselleria d'Obres Públiques, Urbanisme i Transports de la Generalitat Valenciana que publicaron en 1997, bajo el título 20×20, Siglo $X X$, Veinte obras de arquitectura moderna, una selección de veinte obras del Movimiento Moderno en la Comunidad Valenciana. En 1998, el Colegio Oficial de Arquitectos de Galicia, junto a los Colegios Oficiales de Arquitectos de Asturias, Castilla y León Este y León publicaron Arquitectura Moderna en Asturias, Galicia, Castilla y León, ortodoxia, márgenes y transgresiones. En 1999, La Junta de Andalucía, a través de las Consejerías de Obras Públicas y Transportes y de Cultura, publicó el libro MoMo Andalucía, Arquitectura del Movimiento Moderno en Andalucía, 1925-1965. Asimismo, en 2002, el Colegio Oficial de Arquitectos de las Islas Canarias publicó Arquitectura Moderna en Canarias, 1925-1965.

La Fundación COAM a través del Servicio Histórico realiza una serie de publicaciones de interés entre las que destacan: Arquitectura de Madrid, volumen del Ensanche (Madrid, 2003), Arquitectura y desarrollo urbano de la Comunidad de Madrid (Madrid, 2009), y publica sobre otros temas como son la vivienda social, el racionalismo madrileño, etc. Además el Archivo del Servicio Histórico cuenta con algunos legados de los arquitectos más importantes del siglo XX como el de Ramón Vázquez Molezún, Francisco Asís Cabrero, Luis Cubillo de Arteaga, Fernando García Mercadal, Antonio Fernández de Alba, Antonio Perpiñá, Luis García de la Rasilla, Fernando Higueras, Alas y Casariego, Julián Otamendi, etc.; de los tres primeros además se han publicado una monografía y un DVD, en el que se recoge 
una parte representativa de la documentación legada. En todas estas publicaciones del COAM se han seleccionado las obras más representativas y de mayor interés por lo que son de gran utilidad para la tesis por haber realizado un filtro previo por especialistas; se acompañan de gran cantidad de documentación fotográfica y planimétrica. Esta bibliografía de carácter general de la arquitectura del siglo XX se completa con otras guías de arquitectura y urbanismo que se especifican en la bibliografía.

\section{Recopilaciones generales del Jardín del siglo XX en otros países}

Entre las recopilaciones generales del Jardín del siglo XX en otros países se encuentra Gardens in the Modern Landscape, de Christopher Tunnard (Londres, 1938), quien vincula la historia del jardín del siglo XX a la tradición inglesa. También hay algunas recopilaciones de artículos y textos clave como en Denatured Visions: Landscape and Culture in the Twentieth Century (Nueva York-Londres, 1991), de Stuart Wrede y William H. Adams, y Modern Landscape Architecture: A Critical Review (Massachussets, 1993) de Marc Treib. En el libro de Panzini, Per i piaceri del popolo (Bolonia, 1993) se estudia la evolución del jardín público en Europa desde sus orígenes al siglo XX. Jane Brown en El jardín moderno (Barcelona, 2000) pone de relieve las visiones inglesas y, en Open to the Sky (Copenhagen, 2003), Malene Hauxner hace hincapié en las contribuciones de los países nórdicos.

Mientras que en El jardín en la arquitectura del siglo XX. Naturaleza artificial en la cultura moderna (Reverté, 2007) de Darío Álvarez, basado en la tesis doctoral del mismo autor El Jardín de la Arquitectura Moderna (Valladolid, 1992) presenta una visión panorámica completa del jardín del siglo XX sin desviarse hacia ningún país ni momento en especial. Investiga la relación del jardín según los principios teóricos de la arquitectura moderna, y siguiendo sus mismas pauta y criterios formales. En las últimas décadas del siglo XX el jardín ha sido asumido de nuevo como disciplina arquitectónica, permitiendo la experimentación de nuevos conceptos y sistemas, lo que no siempre es posible en el ámbito de una construcción convencional. Esta recuperación no se basa únicamente, como algunos han podido pensar, en la revisión directa de los grandes modelos históricos, sino que utiliza otras referencias. La tesis doctoral analiza la existencia de una cierta, aunque irregular, tradición moderna en la proyectación del jardín, que puede ser considerada como el antecedente de las nuevas reinterpretaciones. El trabajo no se construye desde un proceso sistemáticamente histórico, sino que aborda el tema desde diferentes 
puntos de vista, teniendo especialmente en cuenta la relación intrínseca entre edificio y jardín, en todas las escalas, desde la villa o residencia privada hasta la ciudad, buscando introducir análisis compositivos y espaciales de los jardines y de su relación con la arquitectura. Con este estudio se presenta un panorama en la arquitectura moderna del siglo XX a nivel internacional, pero el caso español no lo estudia salvo excepciones como Sert en la recuperación del patio jardín, o Forestier con su nuevo jardín francés y como supervisor de la sección de jardines de la Exposición de Artes Decorativas de París de 1925.

Una visión también panorámica se ofrece en "Los jardines del siglo XX", de Miguel Ángel Aníbarro, epílogo que completa la parte relativa al siglo XX de la obra de Francesco Fariello, La Arquitectura de los jardines.

Este panorama de carácter general se completa con monografías de diferentes autores y obras, ya sea en artículos o libros. Ahora bien, ni en aquellos ni en éstos se profundiza en el jardín español de este periodo, analizándolo desde el punto de vista arquitectónico y dando una visión de conjunto. Sin embargo todos estos textos servirán de apoyo para la tesis: modelos para el análisis, la constatación de tipos o etapas, etc.

\section{Revistas y catálogos}

La aportación bibliográfica ofrecida por las revistas es mucho más numerosa; se hace especial hincapié a las revistas publicadas es la época de estudio, algunas de las que han desarrollado una especial atención al jardín son: $A C$ (Revista del GATEPAC 1931-1937); Academia (1951-); Administración y progreso: revista de derecho administrativo y servicios públicos (1932-1936); Anales del Instituto de Estudios Madrileños (1966-); Archivo Español de Arte (1925-); Arquitectura (1912-); Arquitectura COAM (1959-); Arte Español; Boletín de la Dirección General de Arquitectura (1946-1957); Casa de Campo; Ciudad y Territorio-Revista de Ciencia Urbana (Antigua Ciencia Urbana 19691983); Cointra-Press: revista de historia del arte (1947-); Cortijos y Rascacielos (1930-1954); Cuadernos de Arquitectura (1944-1974); Cuadernos de Arquitectura y Urbanismo (1971-1980); Fragmentos: revista de arte (1984-); Goya: revista de arte (1957-); Gran Madrid: boletín informativo de la Comisaría General para la Ordenación Urbana de Madrid y sus alrededores (1948-1956); Hogar y Arquitectura (1955-1977); Informes de la Construcción (1948-); La Esfera (1914-1915); Nueva Forma/Formas Nuevas (1934-1936)/El Inmueble (1966-1975); Revista Nacional de Arquitectura (1918-); Revista de Obras Públicas (1899-); Estudios Pro Arte 
(1975-1979); Reales Sitios (1964-); Revista de la Biblioteca, Archivo y Museo del Ayuntamiento de Madrid (1924-1982); Traza y Baza (1969-1978); Urbanistica (1949-); Villa de Madrid (1957-1992); Zona Verde: Boletín de la Asociación Española de Parques y Jardines (1983-1996), etc.

Dentro de las publicaciones aparecidas en los últimos años, destacan los catálogos de exposiciones, actas de congresos y jornadas, además de las recopilaciones de artículos, pues en ellos se han planteado y estudiado muchas cuestiones que no se recogen en los libros comentados. Aunque prácticamente no existe ninguno dedicado a un solo jardín, en muchos de ellos se estudia la arquitectura de jardines en algunas de sus facetas.

\section{FUENTES}

Cartografía y documentación: Biblioteca Nacional, Archivo General de la Administración, Cartoteca de la Consejería de Política Territorial de la Comunidad de Madrid, Gerencia de Urbanismo, Instituto Geográfico Nacional, Archivo de Palacio, Archivo de la Villa, Archivo del Real Jardín Botánico, Archivo de Parques y Jardines de Madrid, Archivo del Servicio Histórico del COAM, Archivo Histórico de la Ciudad de Barcelona, Archivo del Patronato de la Alhambra y Generalife, Archivo de la biblioteca de la ETSAM, Archivo de la Fundación Miguel Aguiló, archivos nobiliarios, archivos provinciales, archivos fotográficos, diferentes legados de los arquitectos, colección Javier Spalla y otros legados de viveristas, etc.

Bibliografía especializada: Biblioteca Nacional, Biblioteca COAM, Biblioteca ETSAM, Biblioteca Jardín Botánico, Biblioteca CSIC, Biblioteca del Instituto Torroja, Biblioteca de la Consejería de Política Territorial de la Comunidad de Madrid, Biblioteca de Palacio, Fundación APE (Portal de Archivos Europeos), biblioteca de la Fundación Miguel Aguiló, Hemeroteca Municipal, Hemeroteca Nacional, etc. 


0. ANTECEDENTES: DEL MODERNISMO A LA RECUPERACIÓN DE LA TRADICIÓN (19001926)

1. AFIANZAMIENTO DE LOS PARQUES PÚBLICOS

El modelo inglés

El jardín español

2. EL JARDÍN MODERNISTA

Los jardines de Antonio Gaudí i Cornet (1852-1926)

Otros jardines modernistas

3. EL JARDÍN TRADICIONAL MEDITERRÁNEO

Jean-Claude Nicolas Forestier (1861-1930)

Los seguidores de Forestier

4. LOS NUEVOS CÁRMENES

5. LA RECUPERACIÓN DEL JARDÍN CLÁSICO EN ESPAÑA: PINTORES JARDINEROS Santiago Rusiñol y Prats (1861-1931)

Joaquín Sorolla y Bastida (1863-1923)

Javier de Winthuysen Losada (1874-1956)

I. LA LLEGADA DEL MOVIMIENTO MODERNO (1926-1936): ENTRE LA TRADICIÓN ESPAÑOLA Y EL JARDÍN RACIONALISTA

6. WINTHUYSEN Y LA RECUPERACIÓN DEL JARDÍN CLÁSICO EN ESPAÑA

La recuperación de la tradición española

El estilo Winthuysen, un estilo propio

Jardines domésticos

Jardines urbanos

Jardines de instituciones y servicios públicos

Salvar y proteger los jardines

Los parajes naturales y pintorescos

La jardinería como disciplina docente

7. EL JARDÍN DOMÉSTICO

Las colonias jardín

Antecedentes

Ejemplos madrileños

Ciudad Lineal, Madrid, 1882-1906

Jardín de la residencia del Sr. Dantín Cereceda, Madrid 1911

Jardín del Sr. Ribera Pastor, Madrid, 1925

Jardín de la residencia del Sr. Casares, Madrid, 1926

Jardín de José Pérez Stella, Madrid, h. 1930

Colonia Residencial Cruz del Rayo, Madrid, 1927-1929

Jardín de la residencia de los Sres. de Monfort, Madrid, 1931

Colonia Parque Residencia, Madrid, 1931-1934

Jardín de la residencia del Sr. D. Julio Blanco, Madrid, 1934

Jardín de la casa de García Mercadal, Madrid, 1932

Vivienda del arquitecto José Luis Picardo, Madrid, casa h. 1934, jardín h.1958

Colonia Residencial El Viso, Madrid, 1933-1936

Jardín de la residencia del Sr. Madariaga, Madrid, 1934

Jardín de la residencia del Sr. Olarra, Madrid, 1934 


\section{Grandes fincas privadas}

Fincas de Madrid y sus alrededores

Jardines de Cecilio Rodríguez: Villa Ángeles en San Rafael, Segovia, Jardín del Cerro, Cuenca, 1860-1950, La Puebla de Mendoza, Guadalajara, 1929

Quinta de los Molinos, Madrid, 1922

Otros ejemplos del resto de España

\section{Fragmentos de modernidad}

Modernidad doméstica

¿El primer jardín moderno español?

Rincón de Goya, Zaragoza, 1926-1928

Jardines domésticos de Mercadal

Proyectos no construidos: casa mediterránea, casa al lado del mar, casa para un ingeniero

Jardín de los Sres. de Cantó, Málaga, 1941

Jardín de los Sres. de García Vicente, Valle de los Galanes, Málaga

Otros jardines de arquitectos

Casa del Marqués de Villora, Madrid, 1927-1929

Casa del Sr. Bergua Oliván, Zaragoza, 1930-1933

Casa del Marqués de Murrieta en Sierra de Córdoba, h. 1930

Jardines de arquitectos catalanes

Casa Duclós, Sevilla, 1929-1930

Casa Galobart, Barcelona, 1930

Casa Barangé, Barcelona, 1932-1933

Casa Cervigón, Oleiros, 1938

\section{ACTUACIONES URBANAS}

Jardines urbanos y espacios públicos madrileños: Mercadal clasicista

Fundamentos teóricos en jardinería urbana

Jardines urbanos realizados bajo su mandato

Jardines de Sabatini, Madrid, 1933-1934

Jardines de la Cuesta de la Vega, Madrid, 1932

Reforma de la Plaza Mayor, Madrid, 1934-1935

Reforma de los jardines del Paseo del Prado, Madrid, 1935

Reforma del jardín del Museo del Prado, Madrid, 1935

Jardines de plazas urbanas

\section{Los parques de Rubió i Tudurí en Cataluña}

El personaje y su pensamiento

Los inicios como discípulo de Forestier

Los parques públicos en Barcelona

Parque de Montjuic, Barcelona, 1916-1928

Parque de la Font del Racó, 1922-28

Parque del Palacio Real de Pedralbes, Barcelona, 1925-27

Plaza Comte d'Urgell, Barcelona, 1926

Turó Park, Barcelona, 1934

El jardín latino

Jardines Bertrán i Güell, Barcelona, 1962

Jardín pabellón Eduard Rosa, Calella de Palafrugell, 1961

Su última obra y sus sucesores

Plaza Gaudí, Barcelona, 1978

\section{Jardines reinventados}

Arqueología y jardín: Torres Balbás como jardinero en La Alhambra

El Partal, La Alhambra, Granada, h.1924-1936

Jardín de Secano, La Alhambra, Granada, h.1930

Prieto-Moreno y los nuevos jardines granadinos

Jardines Bajos o Jardines Nuevos del Generalife, Granada, 1921-1951 


\section{Las nuevas ciudades verdes}

Las ciudades futuras funcionales: el plan Macià de Barcelona

La Casa Bloc, Barcelona, 1932-1936

La Casa de las Flores, Madrid, 1930-1932

El ocio y reposo de las masas

"La Ciutat de Repòs i de Vacances"

La Playa de Madrid y otras propuestas madrileñas

La playa de Madrid, 1932

R. S. H. E. Club de Campo de Madrid, 1930

Parque Sindical, Madrid, 1954

Ciudad Verde del Jarama

Una universidad parque: la Ciudad Universitaria

Una universidad al estilo americano

De la utopía a la realidad: primeros trazados

Los nuevos Campus

Otras actuaciones

Vivir en el Campus: residencias de estudiantes

Expansión y recreo: campos deportivos

Recuperación de la cubierta vegetal: un gran parque forestal

La recuperación de la idea original: planes de reforma y protección

Un modelo a seguir

\section{LOS AÑOS DE POSGUERRA (1940-1965): LA APUESTA POR EL JARDÍN MODERNO}

\section{LOS JARDINES DE LOS ARQUITECTOS MODERNOS}

\section{Aportaciones teóricas}

El Manifiesto de la Alhambra: los jardines hispanoárabes como modelo para los jardines modernos

\section{Jardines domésticos}

Precedentes

Viviendas de Zuazo: Sebastián Miranda, Madrid, 1928-1929 y Zuazo-Enea, Zarauz, 1963

Ocupación libre del entorno

Casa Gomis - La Ricarda, Barcelona, 1949-1963

Casa Felipe Huarte, Pamplona, 1959

Casa Ugalde, Barcelona, 1951-1953

Casa de Fernando Gómez, Álava, 1959-1960

Casa Rubió, Tarragona, 1959-1962

Grupo de cuatro apartamentos, Tarragona, 1954-1957

Jardines organicistas

Fisac: sus viviendas

Corrales + Vázquez-Molezún: apertura al paisaje

Centro de segunda enseñanza y formación profesional, Palencia, 1954-1956

Residencia Infantil en Miraflores, Madrid,

Laboratorios Profidén en Fuencarral, Madrid, 1960

Laboratorios Ibys en Alcobendas, Madrid, 1976

Casa Pastor Botí, Madrid, 1955

Casa Álvarez Mon en Cercedilla, Madrid, 1957

Nuevas propuestas para manzanas

Grupo residencial Escorial, Barcelona, 1952-1962

Grupo de viviendas Milans del Bosch, Barcelona, 1962-1964

Grupo de viviendas para la Cooperativa de Agentes Comerciales, Valencia, 1958-1961

Nuevos barrios

Unidades Vecinales de Absorción 


\section{JARDINES DE EQUIPAMIENTOS}

\section{Jardines de recreo \\ Antecedentes}

Grupo escolar de Atarfe, Granada, 1933

Escuela graduada en Cantillana, Sevilla, 1931

Grupo Escolar Blanquerna, Barcelona, 1933

Concurso para escuela maternal, 1931

\section{Colegios-jardín}

Colegio del Pilar de Reyes Magos, Madrid, 1956-1973

Colegio Guadalaviar, Valencia, 1957-1960

Escuelas tipo para los suburbios 1956: poblados de Villaverde y Fuencarral B, Madrid, 1958

Escuelas de Tarrasa, Barcelona, 1960

Guardería infantil San José, Zaragoza, 1956

Instituto Laboral de Betanzos, La Coruña, 1952

Instituto Laboral La Carolina, Jaén, 1958

\section{Patios-jardín}

Escuela Nacional de Hostelería, Madrid, 1956-1957

Facultad de Derecho de Valencia, 1959-1968

Escuela de agrónomos de Valencia,1962-1967

Escuela de Maestría Industrial de San Blas, Madrid,1964-1968

\section{Modernas complejos y residencias universitarias}

Universidades Laborales: Zamora, 1949-1953; Córdoba, 1952-1956; Cheste, 1967-1968, etc.

Colegio Mayor Santo Tomás de Aquino, Madrid, 1953-1957

Colegio Mayor Jorge Juan, Madrid, 1958

Casa de Brasil, Madrid, 1959

Colegio Mayor Nuestra Señora de Luján, Madrid, 1964

Colegio Mayor César Carlos, Madrid, 1967

Colegios mayores en Aravaca: Lasalle, 1963 y Blanca de Castilla, 1965, Madrid

Tendencias posteriores

Guardería infantil en Manoteras, Madrid, 1972-1973

Concurso Facultad de Ciencias de Córdoba, 1974

\section{Jardines institucionales}

Jardines del poder

Ministerio del Aire, Madrid, 1940-1951

Nuevos Ministerios, Madrid, 1932-1936,1940-1953

\section{Patios-jardín}

Fundación Miró, Barcelona, 1972-1975

Monasterio de Las Salesas, Córdoba, 1959-1962

Parroquia San Nicolás, Gandía, 1958-1962

Jardín del Instituto Torroja, Madrid,

Fábrica SEAT de Barcelona, 1954-1956

Concurso para la Delegación de Hacienda en Valencia, 1953

\section{Nuevos jardines para el deporte y el ocio}

Las propuestas de los arquitectos

Hipódromo de la Zarzuela, Madrid, 1934

Stadium Casablanca, Zaragoza, 1947-1992

Piscina Villa Rosa, Madrid,1953

Club de Tenis Mallorca, 1961-1964

Club Náutico Dos Mares, Murcia 1964-1966

Club de Campo de la Sociedad Bilbaína, Bilbao 1971-1975

Snack y vestuarios en Cala Crancs, 1961

Paisajes latinos Hoteles de Rubió

\section{Jardines industriales modernos}

\section{Precedentes}

Central Eléctrica de Alcalá del Río, Sevilla, 1931

La Yutera palentina, Palencia, 1936

Jardines de poblados industriales

Central Nuclear de Zorita, Guadalajara, 1965

Poblado HIFRENSA, Tarragona

Poblados de colonización 


\section{AZOTEAS URBANAS: PAISAJES SOBRE LA CIUDAD}

\section{Una tradición arraigada}

\section{Azoteas modernas}

Casa Duclós, Sevilla, 1929-1930

Casa Moratiel, Barcelona, 1955-1958

Casa Broner, Ibiza, 1960

Casa Wütrich en Papagayo, Lanzarote, 1962

Casa Higueras, Madrid, 1972-1973

Casa Cela en Puerto Pi, Palma de Mallorca, 1961

\section{Terrazas escalonadas}

Ciudad Blanca en Puerto de Alcudia, Mallorca, 1961-1963

Apartamentos Las Terrazas de Almuñécar, Granada, 1964-1965

Viviendas jardín en el Soto de la Moraleja, Madrid, 1965-1969

\section{Tapices urbanos}

Casal Sant Jordi, Barcelona, 1929-1931

Casa Cambó, Barcelona, 1921-1925

Palacio March, Palma de Mallorca, 1940-1943

Torres Blancas, Madrid, 1961-1968

AZCA, Madrid, 1957-1964

\section{Nuevos espacios cívicos}

Centro comercial de La Vaguada, Madrid, 1980-1983

\section{Terrazas de juego}

Terraza del Colegio Maravillas, Madrid, 1962

Azotea de las Escuelas "Sant Jordi" Pineda, Barcelona, 1969

\section{ACTUACIONES URBANAS}

\section{Jardines botánicos}

Jardines científicos y de aclimatación

Jardín de la Universidad de Barcelona, 1889-1933

Jardín Botánico Histórico de Barcelona, 1930

Jardín de Aclimatación de Barcelona, 1930

Vistas al mediterráneo

Jardín Botánico Mar i Murtra, Blanes, 1920-1952

Jardín Botánico de Cap Roig, Calella de Palafrugel, 1927-1974

Jardín Botánico Tropical Pinya de Rosa, Blanes, 1945

Jardines cientificos interiores

Arboreto de la Escuela de Ingenieros de Montes de Madrid, 1946-1947

Botánicos insulares

Jardín Botánico Viera y Clavijo, Las Palmas de Gran Canaria, 1952-1973 Jardín de Cactus en Guatiza, Lanzarote, 196x-1991

\section{Jardines y parques madrileños}

Parque de Eva Duarte de Perón, Madrid, 1945-1954

Jardines de las Vistillas, Madrid, 1913-1945

La rosaleda Ramón Ortiz del Parque del Oeste, Madrid, 1955-1956

Jardines de Cecilio Rodríguez, Madrid, 1941

Puerta del Sol, Madrid, 1959

\section{Otros jardines y parques fuera de la capital}

Parque de Monterols, Barcelona, 1947

Vuelta a la Naturaleza

Jardín de los Derechos Humanos, Barcelona, 1960

Mirador del Alcalde, Barcelona, 1962-1969

\section{Exposiciones y viveristas}

Exposiciones de planta y flor

Familias de viveristas

Los jardines de los viveristas

Contribuciones teóricas 


\section{LOS AÑOS DE APERTURA (1965-1980): LA INCLUSIÓN DEL PAISAJE Y LAS NUEVAS ESCALAS}

\section{ESCALA DOMÉSTICA: JARDINES PRIVADOS}

\section{Jardines unifamiliares}

Búsqueda de un paisaje interior

Casa Huarte, Madrid, 1965-1967

Casa Arche, Madrid, 1966

Casa Andrés Múñoz, Valladolid, 1969

Casa Arturo Echevarría, Madrid, 1972

Patios excavados

Viviendas de Carvajal: Casa Carvajal y Casa García Valdecasas en Somosaguas, 1965-1966 y Casa Sobrino en Aravaca, Madrid, 1965-1968

Aperturas al paisaje

Casa de Juan Huarte en Formentor, 1968

Casa Felipe Huarte en la Manga del Mar Menor, Murcia, 1969

Casa Port D’Esclanya en Aigua Blava, Gerona, 1967-1968

Jardín-casa Rudofsky en Frigiliana, Nerja, 1970-1972

Casa Guzmán, Madrid, 1972-1975

Belvedere Georgina, Gerona, 1970-1972

Casa de fin de semana en Guadarrama, Madrid, 1967

\section{Nuevos conjuntos residenciales}

Les Escales Park, Barcelona, 1966-1973

Las Cocheras, Barcelona, 1968

Viviendas calle Jerez, Madrid, 1970

Edificio Tiuna, Madrid, 1971

Viviendas experimentales en Torrejón de Ardoz, Madrid, 1973-1977

Viviendas en Paseo de la Habana, Madrid, 1970

Viviendas de la calle Bonetero, Madrid, h.1969

\section{Naturalezas recreadas}

Vivienda Taro de Tahíche, Lanzarote, 1968

Últimas realizaciones: jardines clasicistas postmodernos

Jardín de Olivares, Sevilla, 1976

Ikastola de Fuenterrabía, Guipúzcoa, 1974

Asador Erreleku, Pamplona, 1978-1980

\section{ESCALA TERRITORIAL: GRAN ESCALA}

\section{Jardines de complejos turísticos}

Paisajes artísticos recreados/ jardines "publicos" territoriales

Jameos del Agua, Lanzarote, 1964-1967

Mirador del Río, Lanzarote, 1971-1973

Lago de la Costa Martiánez, Tenerife, 1969-1971

Terrazas sobre el mar

Plan Parcial Urbanización de Playa Blanca, Lanzarote, 1963

Centro Turístico en Punta de La Mona de La Herradura, Granada, 1964

Jardines y piscinas del complejo Hotel Meliá Las Salinas, Lanzarote 1973-1977

Urbanización Na Blanca en Formentor, Mallorca, 1963

Apartamentos Playa en San Roque, Cádiz, 1978

Urbanización Jardines colgantes Hill Club, Málaga, 1981

Nuevos espacios recreativos interiores

Umbráculo en Cercedilla, Madrid, 1976

\section{JARDÍN Y ESCULTURA}

\section{Jardines de esculturas}

Antecedentes

Monumentos conmemorativos: Monumento a Pablo Iglesias, Madrid, 1932

Concurso para el Museo de Arte Moderno, Madrid, 1933

Nuevos museos al aire libre

Sa Torre Cega, Mallorca, 1960 
Museo de Bellas Artes de Bilbao, 1963-1970

Fundación Joan Miró: azotea y Jardín de cipreses, Barcelona, 1972-1975

Museo de Escultura Abstracta al aire libre bajo el puente de Juan Bravo, Madrid, 1971-1972

\section{Jardines monumentales: jardines simbólicos}

Arco de la Victoria, Madrid, 1946

Monumento a los Caídos, Madrid,

Cementerio Vergara, Guipúzcoa, 1974

La Pirámide-Marca Hispánica, La Junquera, Gerona, 1976

\section{Figuras en el horizonte}

Pabellón de Alemania para la Exposición Internacional de Barcelona,1929

Museo de Bellas Artes de Bilbao y parque Doña Casilda, Bilbao

Fundación Miró, Barcelona

Plaza del Tenis con el Peine del Viento, San Sebastián, 1975-1977

\section{ARQUITECTURA URBANA DE JARDINES}

\section{Jardinería urbana madrileña}

Plazas, calles, paseos y bulevares arbolados

Plaza de las Salesas, Madrid, 1974

Plaza de Cantoria, Madrid, 1976

Bulevares de Alcalde Sainz de Baranda e Ibiza, Madrid, 1976

Avenida del Generalísimo, Madrid, 1977

Calle Antonio Pirala, Madrid, 1977

Jardines urbanos madrileños

Jardines de Vallehermoso, Madrid, 1976

Jardines del Descubrimiento de la plaza de Colón, Madrid, 1972-1977

Parques urbanos madrileños

Parque de Berlín, Madrid, 1967-1970

Parque de La Arganzuela, Madrid, 1968-1969

Parque Norte, Madrid, 1978

Parque de La Vaguada, Madrid, h.1976

Barrios II, III y VI de Moratalaz, Madrid, 1971-1975

Pozo del Tío Raimundo, Madrid, 1977

Ampliación de la Casa de Campo, Madrid, 1968-1973

Parque zoológico, Madrid, 1968-1972

\section{Otras actuaciones urbanas fuera de la capital}

Jardines de Montjuic: Joan Maragall, Mossen Costa i Llobera y Mossen Jacinto Verdaguer, Barcelona, 1970 Parque de la Guineueta, Barcelona, 1970-1971

Parque de Santa Margarita, La Coruña, 1977

Jardines de la Cuarentena, Palma de Mallorca, 1965-1966

Parque del Mar, Palma de Mallorca, 1976-1994

\section{Tendencias paralelas}

Plaza Benito Pérez Galdós, Gran Canaria, 1968-1969

Parque de los Sitios a Gibraltar, San Roque, Cádiz, 1969

\section{Tendencias posteriores}

Madrid: Parque Lineal del Manzanares, parque Juan Carlos I...

Valencia: Parque del Turia, Valencia, 1986

Sevilla: Exposición Universal, 1992

Barcelona: Olimpiadas, 1992

\section{Acrónimos empleados:}

APAG - Archivo del Patronato de la Alhambra y Generalife

APJM - Archivo Parques y Jardines de Madrid

ARJB - Archivo del Real Jardín Botánico

ASH COAM - Archivo del Servicio Histórico del Colegio Oficial de Arquitectos de Madrid

FMA - Fundación Miguel Aguiló

PHL - Patricia Hernández Lamas 

ANTECEDENTES:

DEL MODERNISMO A LA RECUPERACIÓN DE LA TRADICIÓN (1900-1926) 
Mejor que toda obra de arte, los jardines se deben a la colaboración de la Naturaleza y el hombre. Reflejan los sentimientos y los gustos de una raza, expresan la manera cómo interpreta la Naturaleza; resumen, después de siglos de experiencia en que sus tradiciones se establecen, los resultados de su perfecta adaptación al suelo.

FORESTIER, J.C.N.: "Jardines andaluces". Arquitectura, no 39. Madrid: Sociedad Central de Arquitectura, 1922, p. 298. 


\section{AFIANZAMIENTO DE LOS PARQUES PÚBLICOS}

\section{El modelo inglés}

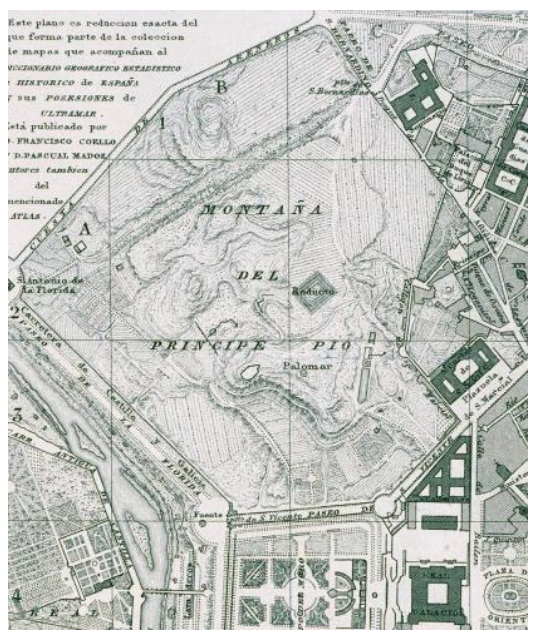

1.1 Fragmento del plano de Madrid de Francisco Coello, 1848, donde se la antigua montaña de Príncipe Pío La Planimetría de Madrid del siglo XIX. Levantamiento topográfico del Instituto Geográfico y Catastral.
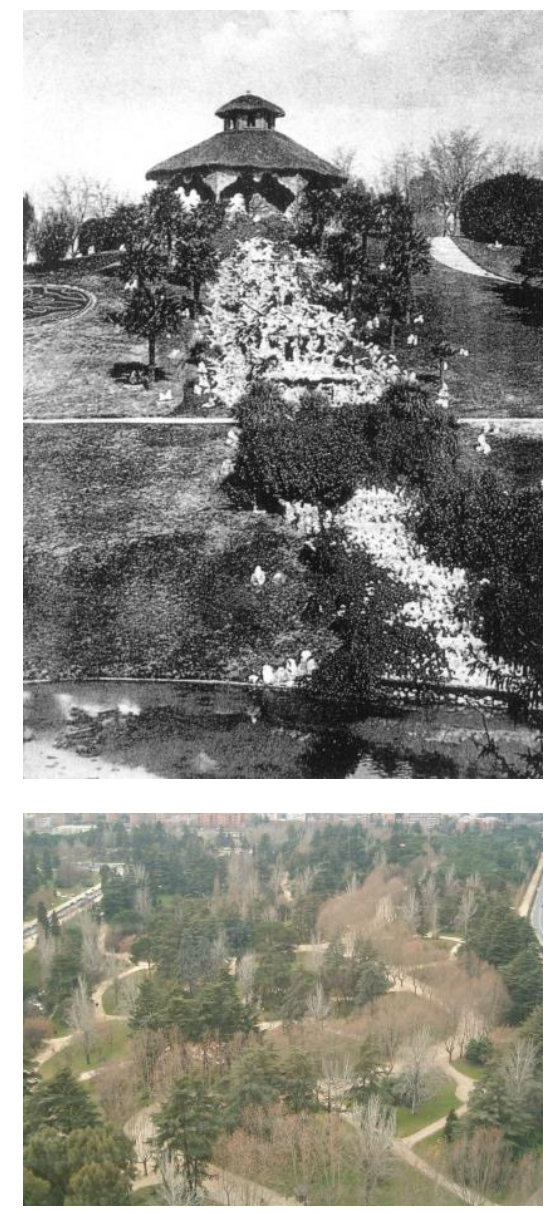

1.2 Vista del parque del Oeste de 1906 y actual desde el faro de Moncloa. ASH COAM. PHL, enero 2004.
En España hasta el siglo XVIII solo se hacían jardines renacentistas y barrocos, y a lo largo de esa centuria empezaron a surgir ejemplos neoclásicos. El jardín inglés o romántico se desarrolló en España desde finales del siglo XVIII y a finales del mismo predominaban los jardines y parques de trazado paisajista que se extendían por toda Europa y América; estos lugares se entendían como instrumentos de socialización donde la población participaba en actividades deportivas y recreativas; también en ellos se evocaban tiempos y lugares remotos (ruinas de templos clásicos, góticas, cuevas prehistóricas...). Las ciudades del siglo XIX cada vez más masificadas por el desarrollo industrial necesitaban espacios libres y parques públicos necesarios para la higiene y la salud, lugares donde la población pudiese salir a respirar y a pasear: los parques y jardines ya no son sólo para ser observados sino que responden a unas necesidades higiénicas $y$ sociológicas. Primero en Inglaterra y luego en Estados Unidos aparecen movimientos a favor de la creación de nuevas zonas verdes públicas que fueran un desahogo para las clases obreras.

En España se produjo un fenómeno similar y como respuesta se procedió a la apertura de los antiguos Reales Sitios; en Madrid EI Retiro se abrió completamente en 1868 con la expulsión de Isabel II del trono cambiando de titularidad muchas posesiones reales. Poco a poco también se fueron haciendo parques públicos de nueva creación; el primero de este tipo que se realizó en Madrid fue el Parque del Oeste. En 1893 el ingeniero agrónomo Celedonio Rodrigáñez y Vallejo, director de Parques y Jardines del Ayuntamiento de Madrid, diseñó este parque paisajista para dignificar los barrancos y taludes abandonados donde se asentó. Tiene caminos de trazado sinuoso que se adaptan a la marcada y modulada topografía con fuertes desniveles; se alternan extensas praderas verdes con zonas más densas de arbolado formando bosquecillos. Rodrigáñez realizó un estanque que actualmente no se conserva y en la zona norte convirtió el arroyo de San Bernardino en una pequeña ría con lagos en sus extremos, numerosas cascadas y puentes rústicos. Una de estas cascadas caía a lo largo de una colina, flanqueada por rocallas y en cuya cima se levantaba una construcción de planta octogonal, conocida como la Sombrilla; realizada con troncos de madera y cubierta de paja, era uno de los 
miradores del parque por su elevada situación. También proyectó un paseo de coches, siguiendo el ejemplo del parque de El Retiro ${ }^{1}$.

En Barcelona se hizo el parque de la Ciudadela ${ }^{2}$, el primero de los actualmente existentes que se diseñó específicamente como parque público; su trazado original (Josep Fontserè i Mestre 1872) incluía los elementos típicos de este tipo de jardines: una cascada, imitación de la de Longchamps en Marsella; un lago; avenidas bordeadas de tilos, castaños y palmeras; plataforma para la banda municipal; umbráculo; invernáculo; y caminos curvos con pavimento de gravilla y plantaciones dispuestas de forma irregular, siguiendo los criterios románticos del jardinero Oliver con enormes extensiones de hiedra y grandes árboles. En 1888 fue modificado para albergar la primera Exposición Universal de Barcelona, posteriormente para instalar el zoológico en 1892 -proveniente de una colección particular-, y durante el novecentismo J.C.N. Forestier diseñó la Plaza de Armas (1916) delante del arsenal ${ }^{3}$.

Este modelo paisajista del siglo XIX no sólo afectó a los parques públicos, se extendió también por las plazas y los jardines privados de las residencias burguesas de la época. Un claro ejemplo es el jardín del castillo de los condes de Peralada en Gerona.
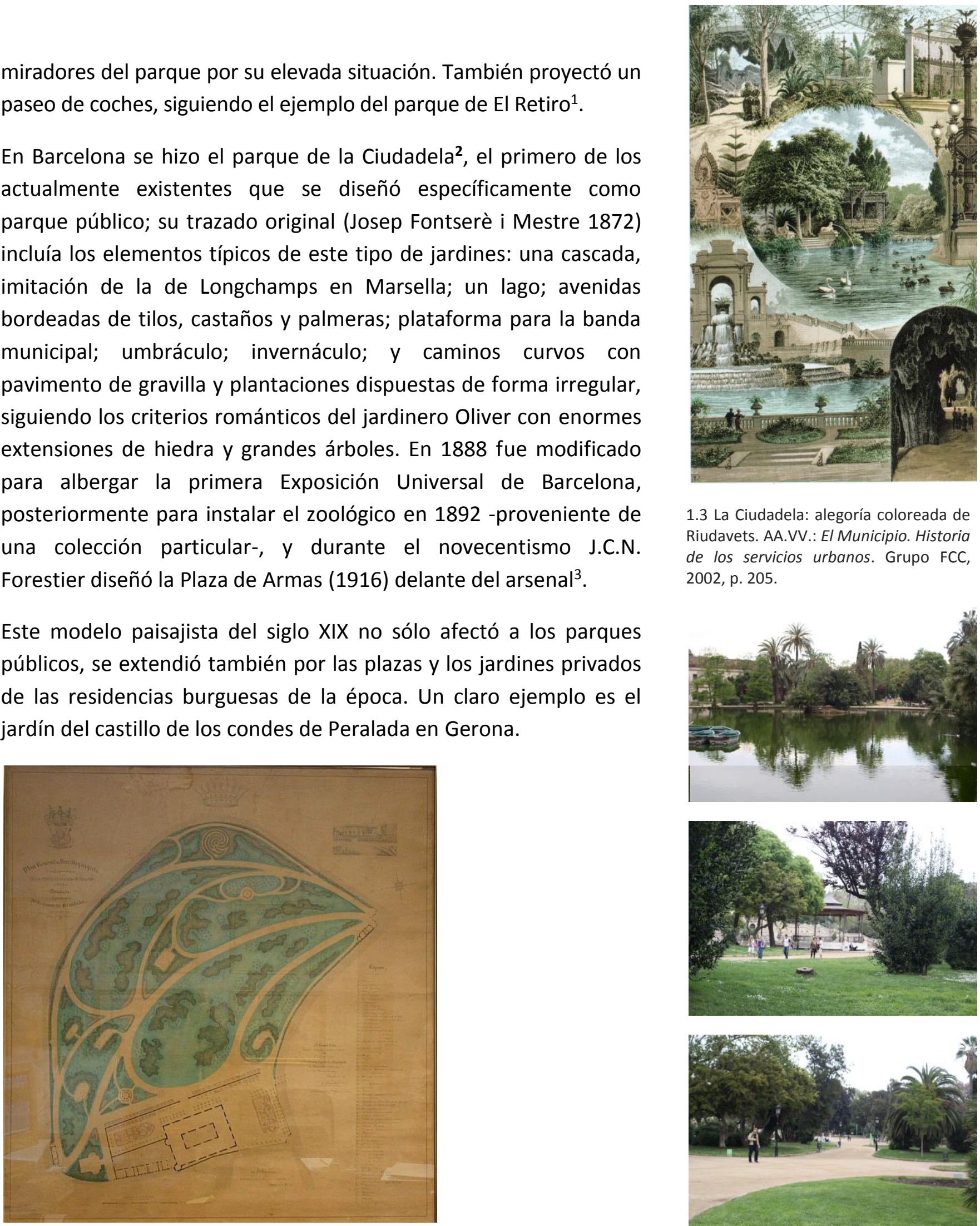

1.3 La Ciudadela: alegoría coloreada de Riudavets. AA.VV.: El Municipio. Historia de los servicios urbanos. Grupo FCC, 2002, p. 205.
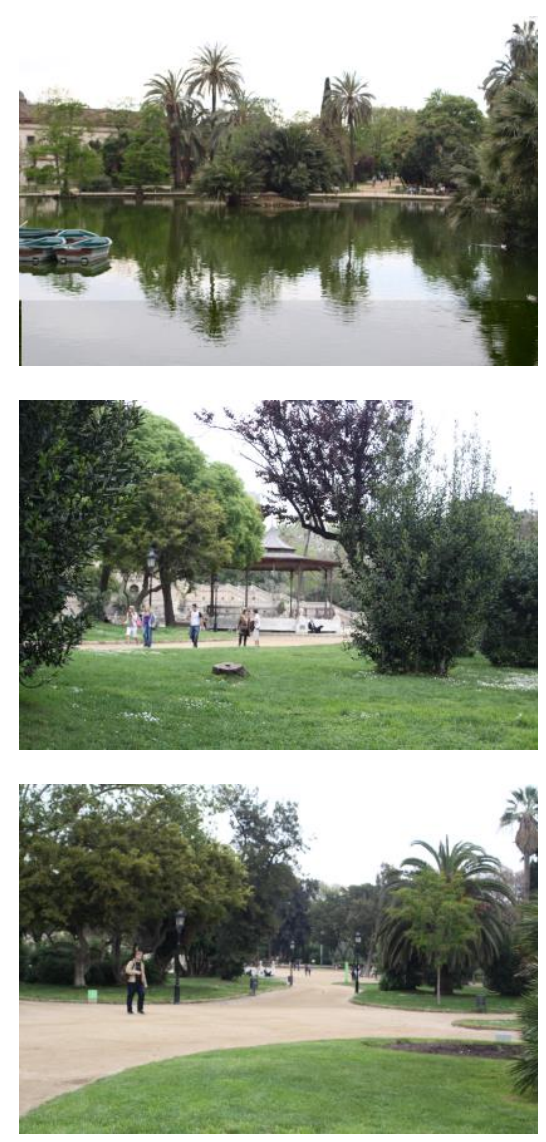

1 ARIZA, C.; MASATS, O.: Jardines de Madrid. Paseos arbolados, Plazas y Parques. Ayuntamiento de Madrid, Lunwerg, 2001, p. 165.

${ }^{2}$ Su nombre proviene de la antigua Ciudadela de la ciudad, demolida en 1862 y en cuyos terrenos cedidos por el general Juan Prim Prats se proyectó el nuevo parque. BASSEGODA NONELL, J.: "Del Eclecticismo a la actualidad en los jardines de Cataluña". Historia de los parques y jardines de España. Grupo FCC, 2001, p. 312.

${ }^{3}$ Ver capítulo de Los parques de Rubió i Tudurí en Cataluña.

1.4 Parque de la Ciudadela: lago, quiosco de música y caminos sinuosos. PHL, abril 2010.

1.5 "Plan Général du Parc Paysagiste. Et de ces dependences de la terre et Palais de Peralada. Situé à Peralada. Appartenant à Mr. Le Comte de Peralada", François Duvillers, 1877. BAPP, Fondo de los Condes de Peralada, jardinsijardiners.espais.iec.cat. 

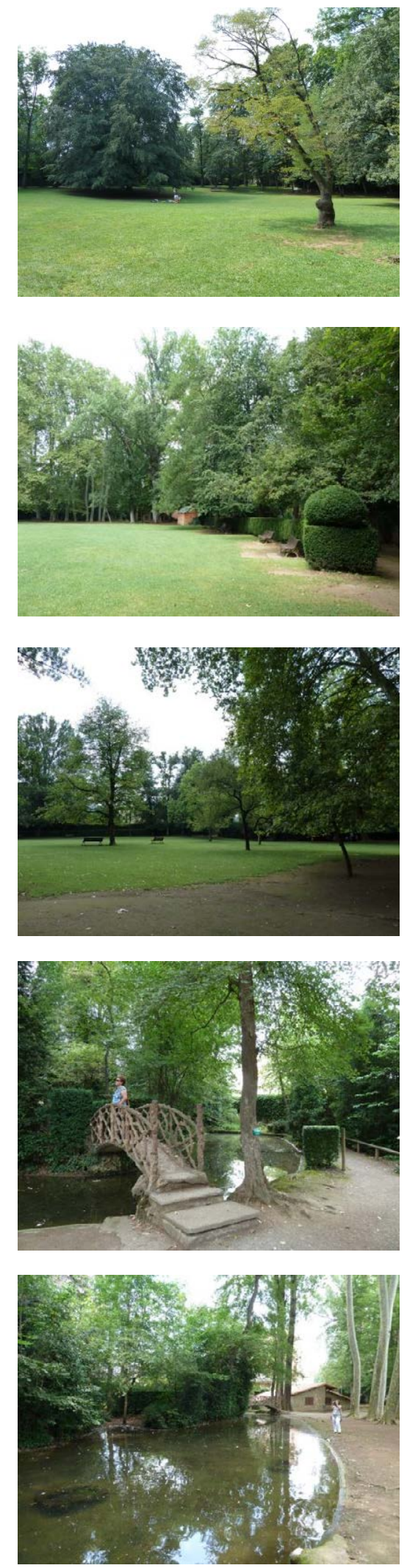

1.6 Parc Nou de Olot: lago y praderas paisajistas. PHL, agosto 2013.
En estos grandes parques paisajistas se van a intercalar los trazados regulares e irregulares e incluso la mezcla de ambos o estilo mixto, siendo este último el más abundante"; así lo explica Rubió i Tudurí en su libro: "La ofensiva paisajista no triunfó del todo. En la mayoría de los casos, en Alemania incluso, en todas partes, y en el Mediterráneo sin duda, el paisajismo llegó a composición con el jardín regular. Se inventó el estilo mixto -si puede llamarse invento al hallazgo de una solución de yuxtaposición-. Junto a la casa, o palacio, el jardín adopta las líneas de la geometría tradicional; más lejos de la vivienda, el espectáculo cambia y se entra en el paisaje convencional del estilo de Kent y Girardin" 5 .

En el inicio del capítulo sobre jardinería contemporánea del libro de Fernando García Mercadal, Parques y Jardines, se describe la situación de esta época: "Ni durante el pasado siglo XIX ni en el actual se ha creado ningún nuevo estilo de jardines $y$, al igual que en las artes plásticas, o en la literatura, no se hizo otra cosa que continuar y a veces perfeccionar lo existente, legado del pasado./ El arte de los jardines de esta época es ecléctico, y en sus creaciones se manifiesta, por lo general, la fusión, o más bien la mezcla, de los dos grandes estilos jardineros.../.../ no se puede deducir ninguna nueva teoría de jardinería, un estilo propio característico, pero sí observarse que los jardines han dejado de ser el lujo de unos pocos para irse transformando en las ciudades en la necesidad de todos, y pasar a formar parte de las nuevas exigencias de la colectividad, de la salud pública en una palabra"6. Señala que en los jardines del siglo XIX se había abusado de los quioscos, pasarelas y pabellones de estilos exóticos y que generalmente se había adoptado el estilo mixto rodeando la casa de un jardín regular que a su vez se circundaba de un parque a la inglesa, muchas veces separados por una verja; mientras que en los jardines del siglo XX se adopta el espíritu práctico del momento y se realizan generalmente diseños paisajistas, más económicos de establecer que los clásicos, inspirados en ejemplos franceses e italianos.

\footnotetext{
${ }^{4}$ ARIZA, C.; MASATS, O.: Jardines de Madrid. Ayuntamiento de Madrid, Lunwerg, 2001, p. 20.

${ }^{5}$ RUBIÓ Y TUDURÍ, N.: Del Paraíso al jardín latino: origen y formación del moderno jardín latino (Barcelona, 1953). Publicado en Barcelona: Tusquets Editores, Colección Los 5 Sentidos, 1981, p. 148.

${ }^{6}$ GARCÍA MERCADAL, F.: Parques y Jardines. Su historia y sus trazados. Zaragoza: Éntasis, CSIC, Diputación de Zaragoza, 2003, p. 245-246.
} 
Hoy en día todavía se conservan ejemplos eclécticos de finales del siglo XIX donde se mezclan jardines más clásicos predominando la geometría, acompañados de terrazas y parterres, como los jardines del Palau de les Heures de Barcelona (August Font i Carreras, 18931895); con otros de carácter más paisajista con praderas a la inglesa, lagos con bordes naturales y vegetación de crecimiento natural, como el Parc Nou de Olot, con un palacete de estilo italiano en su interior (Josep Fontserè i Mestre, 1854).

Otro ejemplo es el parque Samá (1881) en Vinyols, cerca de Tarragona, antigua propiedad del marqués de Marianao, Salvador Samá i Torrens (1861-1933), realizado por Josep Fontserè i Mestres, autor también del parque de la Ciutadella en Barcelona y con colaboración de Antonio Gaudí. Todavía conserva las islas románticas en el centro del lago artificial enlazadas con sus puentes-mirador de cemento imitando troncos de madera, y su acueducto elevado que da a una cascada artificial -realizada por Gaudí-, que abastece todo el lago proveniente de una mina subterránea; la Torre-Angulo, un magnífico mirador sobre la montaña artificial; el pabellón de los loros; la cueva del pirata; plantaciones exóticas de palmáceas en recuerdo de Cuba ${ }^{7}$-ciudad natal del antiguo propietario-, entre otros elementos. Todo estaba lleno de jaulas que albergaban el pequeño zoo particular del marqués, desaparecido durante la Guerra Civil. Una vecina que vivía cerca, recuerda cómo era la finca: "Eran famosas las fiestas que daba el marqués. Se accedía en coche de caballos por la gran avenida y en cada árbol había un ave exótica"8. Una serie de ejes acompañados de alineaciones estructuran el espacio dejando espacios más libres alrededor de las principales construcciones.

\footnotetext{
${ }^{7}$ En el Levante español en el siglo XIX aparecen los jardines de las casas de los indianos o americanos, de emigrantes catalanes y valencianos, que venían principalmente de Cuba y Puerto Rico -entonces posesiones españolas-, o de República Dominicana, El Salvador, Argentina, Paraguay o Chile. BASSEGODA NONELL, J.: "Del Eclecticismo a la actualidad en los jardines de Cataluña". Historia de los parques y jardines de España. Grupo FCC, 2001, p. 316.

8 Testimonio oral de Carmen Peris Corominas (Tarragona, agosto 2015) que recuerda cómo su madre, Carmen Corominas Gotarra, asistía a dichas fiestas.
}
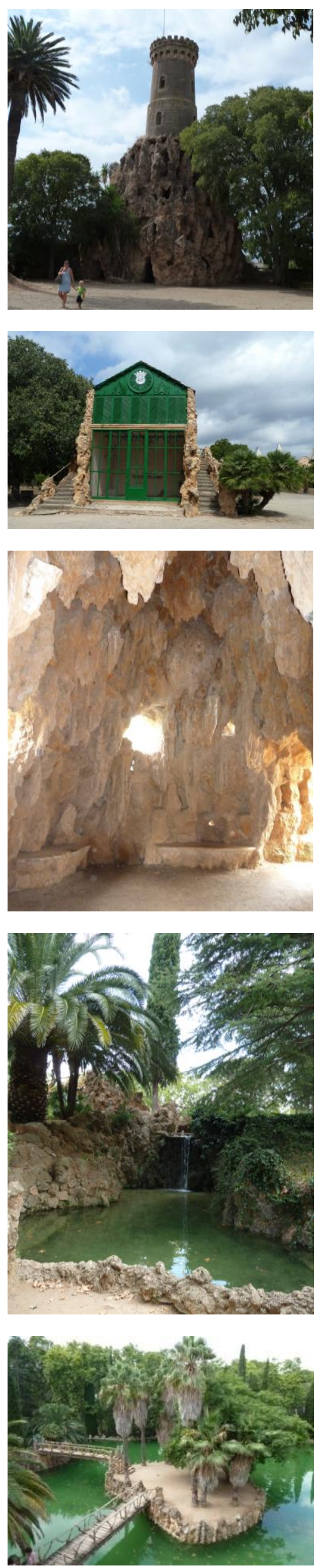

1.7 Parque Samá en Vinyols: isla del lago artificial con puente-mirador, torre sobre montaña artificial, pabellón de los loros, cueva del pirata y cascada artificial. PHL, agosto 2011. 


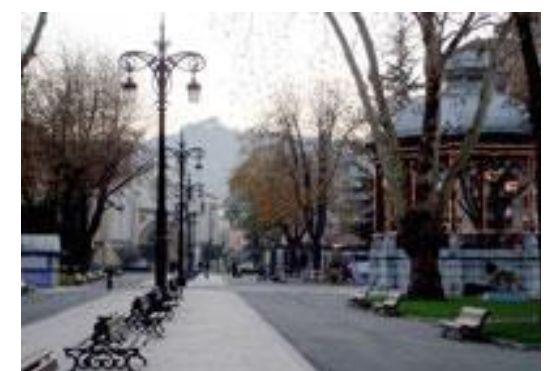

1.8 Parque Dolores Fernández Duro: quiosco. Elhogarnatural.com
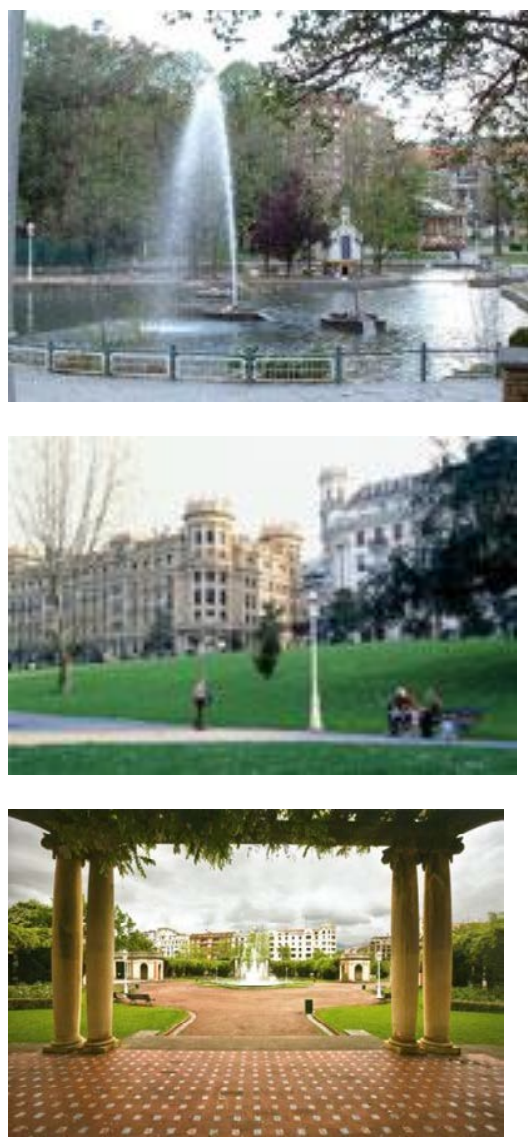

1.9 Parque Doña Casilda: estanque, praderas y pérgola. Ayuntamiento de Bilbao. RAMíREZ J.L.: Bilbao. Retrato de mi ciudad. Bilbao: José Luis Ramírez, 2012, p. 303.
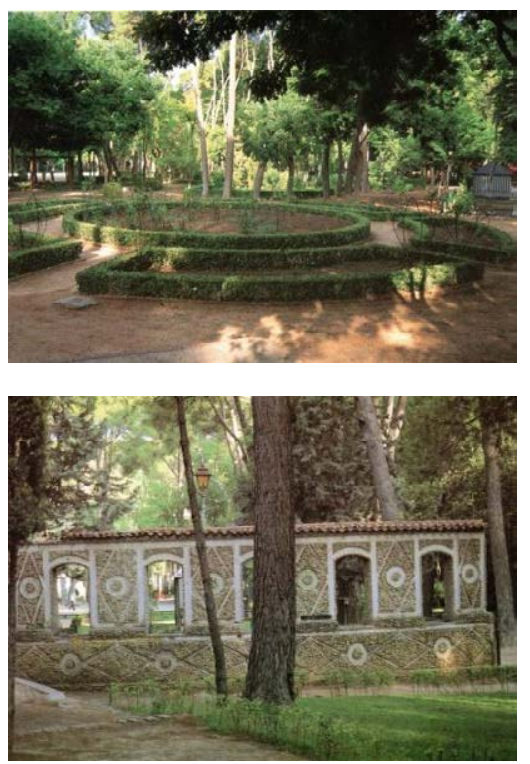

1.10 Jardinillos de la Feria y parque de los Mártires, Albacete. JIMÉNEZ, A., 1993 , p. 140 y 134.
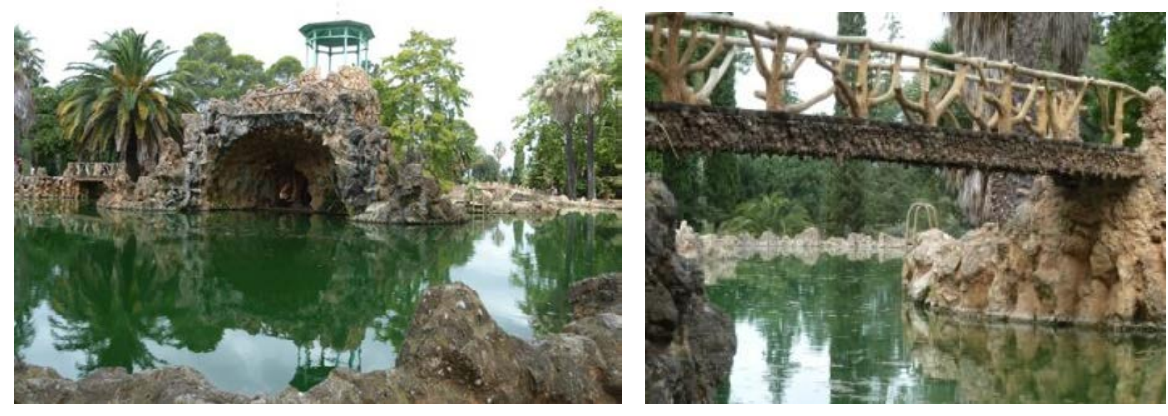

Relacionado con estos jardines indianos, Antonio Gaudí y su ayudante Francisco Berenguer Mestres realizaron el proyecto de la Cuadra de Garraf (1895-1897): una casa encima de las bodegas enterradas para Eusebio Güell, hijo del indiano Juan Güell Ferrer, que en 1870 había comprado una extensa finca en el macizo de Garraf, utilizando piedra del lugar y rodeado de viñedos.

Fue en el primer tercio del siglo XX cuando se afianzó la idea de parque público en España, constituyéndose dentro de un sistema urbanístico integrado; los gobiernos fueron los responsables de su creación y adecuada administración al alcance de todos ${ }^{9}$. Paralelamente en el campo legal estos parques, jardines, terrenos para juego y ejercicio físico también fueron reforzando su importancia. En 1924 el Reglamento de Obras, Servicios y Bienes municipales los transformó en una obligación legal, dedicando para dicho uso un mínimo del $10 \%$ de la superficie de ordenación en las ciudades. Posteriormente esta exigencia fue recogida por la Ley del suelo de 1956 y el Reglamento de Planeamiento de 1978 lo amplió, alcanzando una superficie aproximada de $11 \mathrm{~m}^{2}$ por habitante. Esto convirtió a las zonas verdes en el uso de mayor extensión superficial de la ciudad que siguió ampliándose mediante las leyes autonómicas ${ }^{10}$.

Poco a poco la presencia de los espacios verdes fueron adquiriendo mayor protagonismo en la ciudad y las necesidades funcionales fueron ganado terreno, convirtiéndose en la base del posterior Movimiento Moderno. Todavía se conservan algunos parques públicos de principios del siglo XX, la mayoría de estilo romántico o paisajista, aunque también hay ejemplos con partes regulares. Generalmente están muy modificados debido a las diversas restauraciones y ampliaciones, pero aún mantienen varios

\footnotetext{
${ }^{9}$ AÑóN, C.: "El s. XX". Historia de los parques y jardines de España. Grupo FCC, 2001, p. 356.

${ }^{10}$ El Municipio. Historia de los servicios urbanos. Grupo FCC, 2002, p. 310.
} 
elementos originales como quioscos, carruseles, fuentes, pequeños estanques, alamedas, arboledas primitivas, entre otros. Algunos de ellos son: el parque Dorado (1902) y el antiguo parque Viejo (1917) -actual parque Dolores Fernández Duro-, ambos en Langreo, Asturias; antiguos jardines del Real (1903) -actual jardín de Viveros en Valencia-; jardines de Pereda (1902-1905) y jardines de Piquio (Ramiro Sainz Martínez, 1925), ambos en Santander; parque de Doña Casilda Iturrízar (1907) en Bilbao; Jardinillos de la Feria (1910) y antiguo parque de Canalejas o de los Mártires (1910-1911) -actual parque de Abelardo Sánchez-, ambos en Albacete; parque de San Julián (h. 1910) en Cuenca; parque de Gasset (1915) en Ciudad Real; parque Primo de Rivera (1913-1927) -actual parque Grande o José Antonio Labordeta- y parque Pignatelli (1920), ambos en Zaragoza; etc.
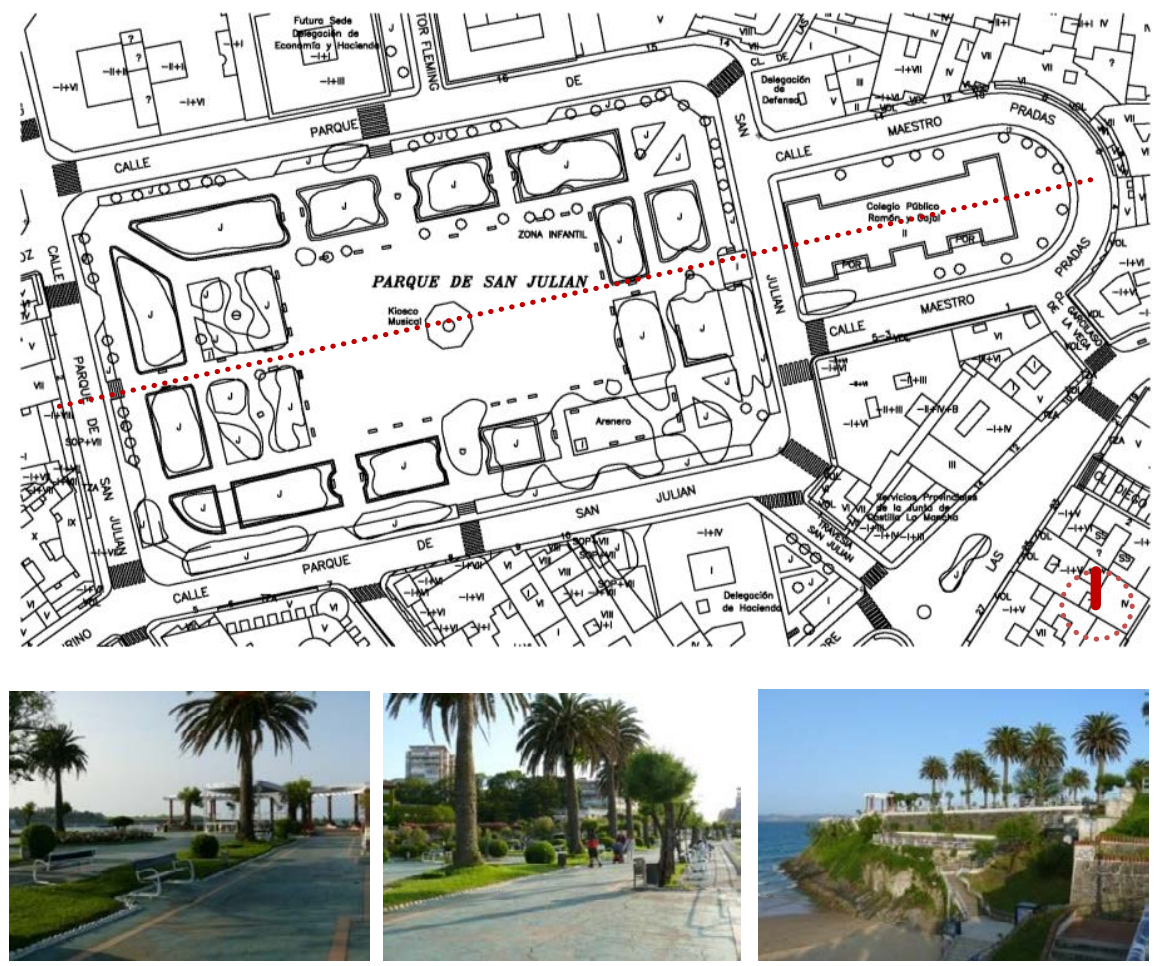

En algunas provincias la escasez de agua impidió la implantación y difusión de estos parques, llegando muchos a desaparecer, como el parque del Milagro de Tarragona (Josep M. Pujol, 1920) ${ }^{11}$; situado a las afueras del fuerte de Cervantes, integraba los restos del anfiteatro acompañados de caminos sinuosos y pequeñas plazas estanciales.

11 ORTUETA de, Elena: Tarragona, el camino hacia la modernidad. Urbanismo y arquitectura. Barcelona: Lunwerg, 2006, p. 146-147.
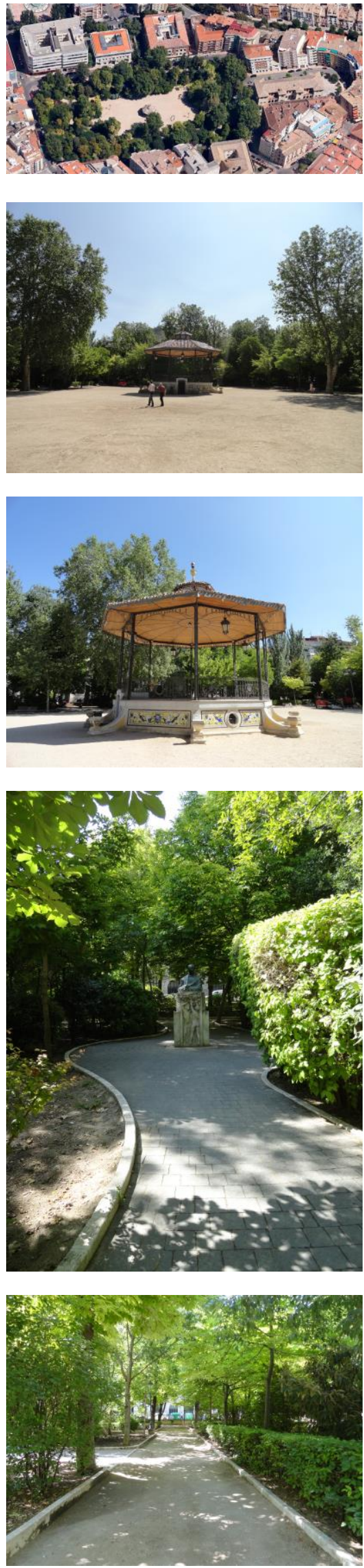

1.11 Parque de San Julián en Cuenca: vista aérea y actuales. Googlemaps y PHL, junio 2013.

Planta del parcelario de Cuenca, Ayuntamiento de Cuenca.

1.12 Jardines de Piquio, Santander: vistas actuales. PHL, julio 2013. 
1.13 Proyecto del Parque del Milagro, h.1920. Archivo Histórico Municipal de Tarragona.

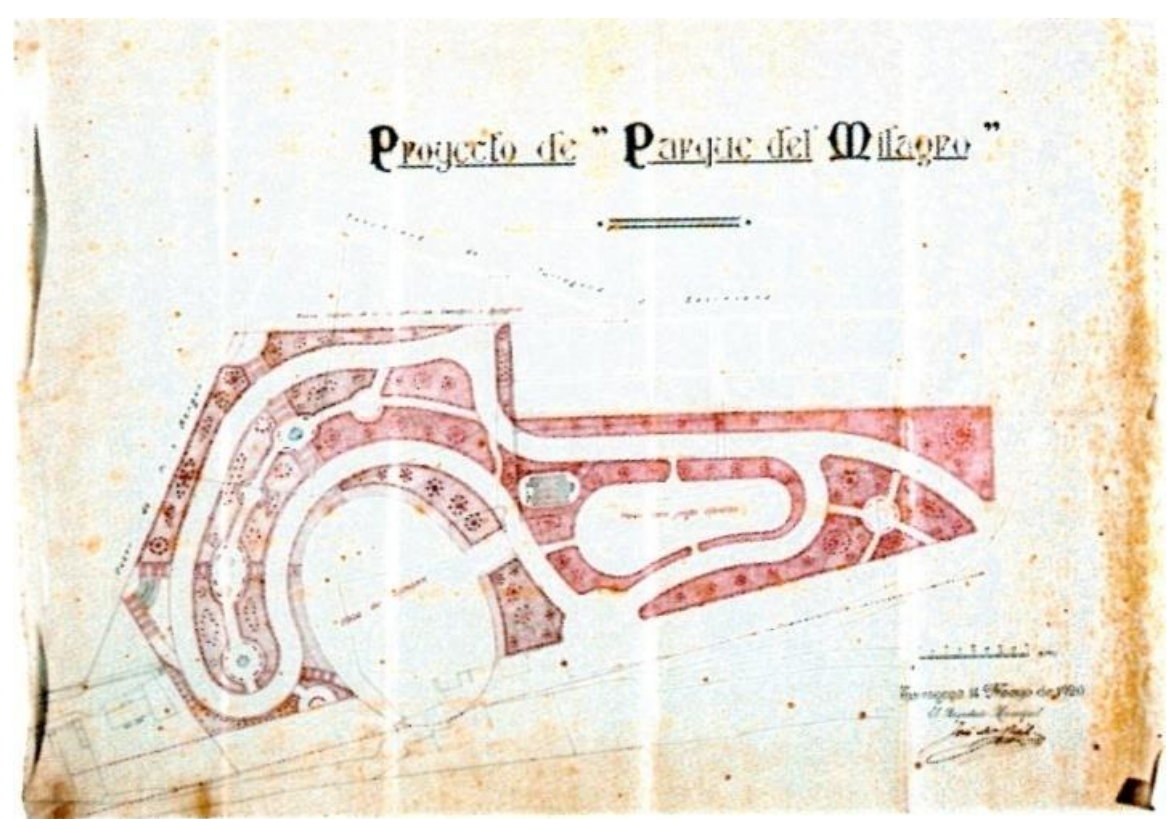

\section{El jardín español}

Sin embargo a partir de mediados de 1920 van a comenzar las críticas de este modelo de parque "a la inglesa"; así pues existen documentos como el Catálogo de los Establecimientos Hortícolas "La Quinta» de Granada que juzgan: "En España, ha habido una época (no muy lejana) de la cual aún quedan reminiscencias, en que se han transformado la mayoría de los jardines públicos y particulares por un estilo indefinido que se ha llamado inglés, sin que de inglés tenga absolutamente nada. Nuestra afición por lo exótico por una parte, el deseo de imitar siempre lo extranjero y la confianza extremadamente puesta en todo aquel que se dice es jardinero han hecho abandonar nuestro estilo para aceptar aquel." ${ }^{12}$ Critica los trazados caprichosos, la ausencia de arte, de valor decorativo, de perspectivas y de continuaciones florales 0 forestales de este modelo inglés; y contrapone un nuevo tipo de jardín: "el jardín español", el cual define como "una transición o modificación del jardín árabe, acomodado a nuestros gustos". Un estilo "árabe modernizado" y es "el español moderno o andaluz", donde todo son ventajas: belleza, fantasía, de acuerdo con nuestro gusto, variados recursos, menor riego, etc. Finalmente aconseja: "por todas las razones expuestas, debemos tender siempre a construir este jardín con preferencia a ningún otro"13.

\footnotetext{
12 Juan Leyva (ca. 1924). Grandes Establecimientos Hortícolas "La Quinta», Juan Leyva, sucesor de Pedro Giraud. Granada, p.180. TITO ROJO, J.: El "jardín hispanomusulmán": la construcción histórica de una idea. Awraq: Estudios sobre el mundo árabe e islámico contemporáneo, № 11, 2015, p.35.

13 Ibíd., p.182-184.
} 
Personajes como Javier de Winthuysen se van a unir a estas críticas, como las que realiza sobre el parque del Oeste: “...donde, sustituyendo a la Naturaleza, se forman agrupaciones de árboles, contrastes de luz y color, serpenteo de calles, hermosos tapices de verdor perenne; obra exótica norteña sostenida artificialmente por riegos constantes con una humedad excesiva del suelo, en desequilibrio con el ambiente natural seco. / Evaporación molesta, praderas impracticables, gérmenes perniciosos, etc. Obra pudiéramos decir decorativa $y$, prescindiendo de detalles ridículos que encierra (cascadas, obeliscos, etc., de gusto depravado, composición paisajista de indudables bellezas,..." ${ }^{14}$.

Siguiendo estas indicaciones poco a poco van a ir apareciendo parques y jardines que adopten estas ideas, produciéndose un cambio de tendencia en la jardinería española. Se va a empezar a adoptar el modelo regular y geométrico frente al irregular. Este es el caso del parque Pignatelli de Zaragoza (1920), concebido para albergar la estatua de Ramón Pignatelli ${ }^{15}$ y condicionado por el paseo Cuéllar y los antiguos depósitos de agua potable de Zaragoza; se vuelve a un trazado clásico con dos partes: una doble avenida recta arbolada que une las entradas de Sagasta y Maestro Estremiana y otra zona más verde con grandes cuadros todavía de pradera, rodeados de arbolado, y que se ven interrumpidos por un paseo central que conecta dos grandes plazas circulares, ubicándose la estatua en una de ellas, introduciendo ejes transversales en el cruce de las mismas. Destaca la utilización de especies autóctonas adaptadas al clima español: pinos piñoneros, acacias, olivos, aligustres, etc.

\footnotetext{
14 Winthuysen: "El Parque de la Moncloa". La Voz, 13 de febrero de 1929. En Javier de

Winthuysen Jardinero, Madrid: Real jardín Botánico, CSIC, 1986, p. 167.

${ }^{15}$ Realizado por Antonio Palao en conmemoración del 150 aniversario de la construcción del Canal Imperial para cuya finalización fue fundamental Pignatelli.
}
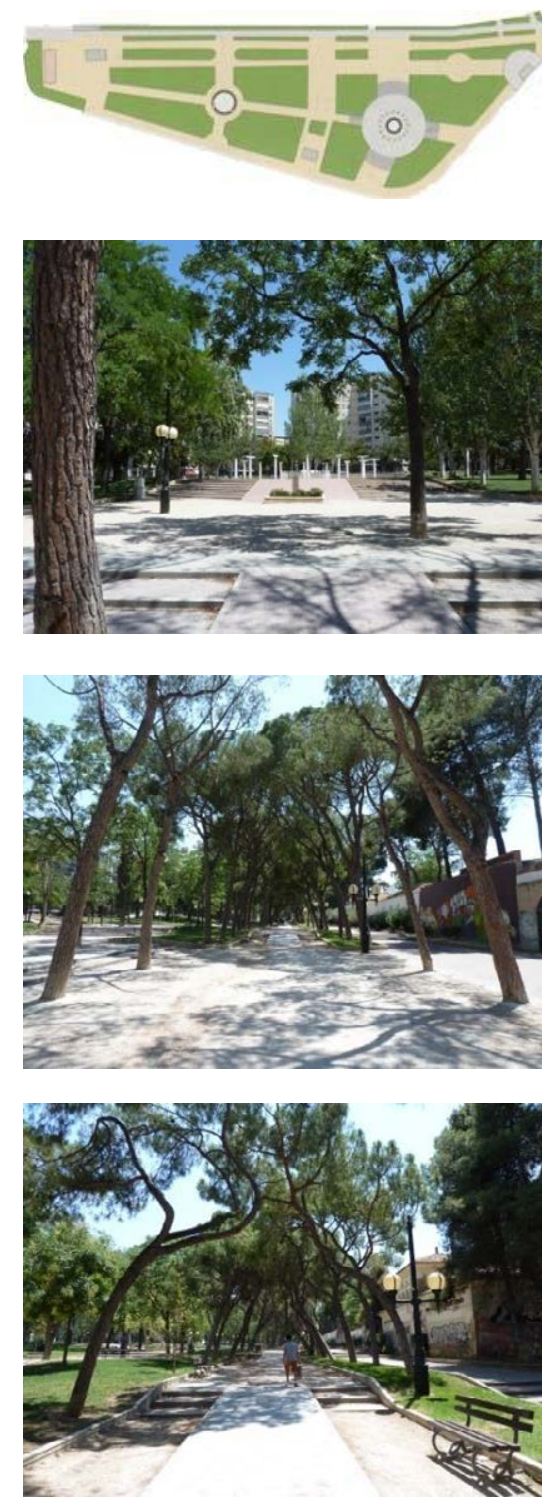

1.14 Parque de Pignatelli, Zaragoza: planta y vistas actuales. Ayuntamiento de Zaragoza y PHL, julio 2012. 


\section{EL JARDÍN MODERNISTA}

El fenómeno artístico del Modernismo surgió en las décadas finales del siglo XIX y primeras del XX, época de cierto confusionismo artístico en la que la arquitectura ochocentista entró en crisis por la repetición de movimientos artísticos neoclásicos y neorrománticos ${ }^{16}$. Se adscribió fundamentalmente al área de Cataluña y especialmente en Barcelona, respondiendo al nuevo ambiente social y cultural, consecuencia de la evolución política y económica. También tuvo su representación en la jardinería, al igual que en el resto de manifestaciones del movimiento aparecen actitudes independientes aunque con rasgos comunes entre ellos.

En el campo de la jardinería, destacó la figura de Antonio Gaudí i Cornet. Este personaje pretendió imprimir un carácter nuevo a la arquitectura del momento en búsqueda de una "modernidad" y participando del sentimiento común a toda la vanguardia europea de crear un arte nuevo capaz de expresar las inquietudes, anhelos y características de una época distinta ${ }^{17}$. Esta actitud renovadora de las ideas estéticas también se reflejó en sus jardines, rompiendo con el lenguaje historicista o ecléctico. No copió modelos anteriores sino que buscó originalidad, aunque a veces mezclada con elementos tradicionales reflejando una voluntad nacionalista; las soluciones espaciales alcanzadas son ricas, personales y libres de planteamientos academicistas. Su obra tiene una componente surrealista y muestra especial interés en la inclusión de las artes aplicadas (vidrio, cerámica, rejería, pintura, etc.) en sus proyectos, buscando llegar a la expresión de un tiempo nuevo mediante un arte total que integre la arquitectura y todas las artes plásticas ${ }^{18}$. La burguesía enriquecida, pretendiendo mostrar su posición económica privilegiada y las posibilidades de este nuevo movimiento, contribuyó al desarrollo de nuevos jardines en Barcelona, aprovechando la existencia de grandes parcelas sin edificar en lugares privilegiados del ensanche de la ciudad.

\section{Los jardines de Gaudí}

Antonio Gaudí i Cornet (1852-1926), hijo de un artesano calderero, recibió una educación artístico-racionalista, que recuerda a Viollet-

\footnotetext{
16 GÚELL, Xavier: Antoni Gaudí. Colección Obras y Proyectos. Barcelona: Gustavo Gili, 1990, p. 6.

${ }^{17}$ BENÉVOLO, L.: Historia de la Arquitectura moderna. Barcelona: Gustavo Gili, 1999, p. 330.

18 Ibid., p. 336.
} 
le-Duc y sus seguidores. Aficionado a observar la naturaleza y sus formas, en su época universitaria adquirió conocimientos botánicos. Trabajó para el capataz de obra Josep Fontseré i Mestres en la construcción del parque de la Ciudadela (1872-1892), el primer parque público de Barcelona con un estilo ecléctico, donde se conjuga romanticismo y naturalismo mediterráneo, inspirado en el parque de Longchamps de Marsella ${ }^{19}$ y en el Central Park de Nueva York (F.L. Olmsted, 1856); a Gaudí se le atribuye la rocalla de la cascada monumental (1875-1881) y algunos elementos decorativos ${ }^{20}$.

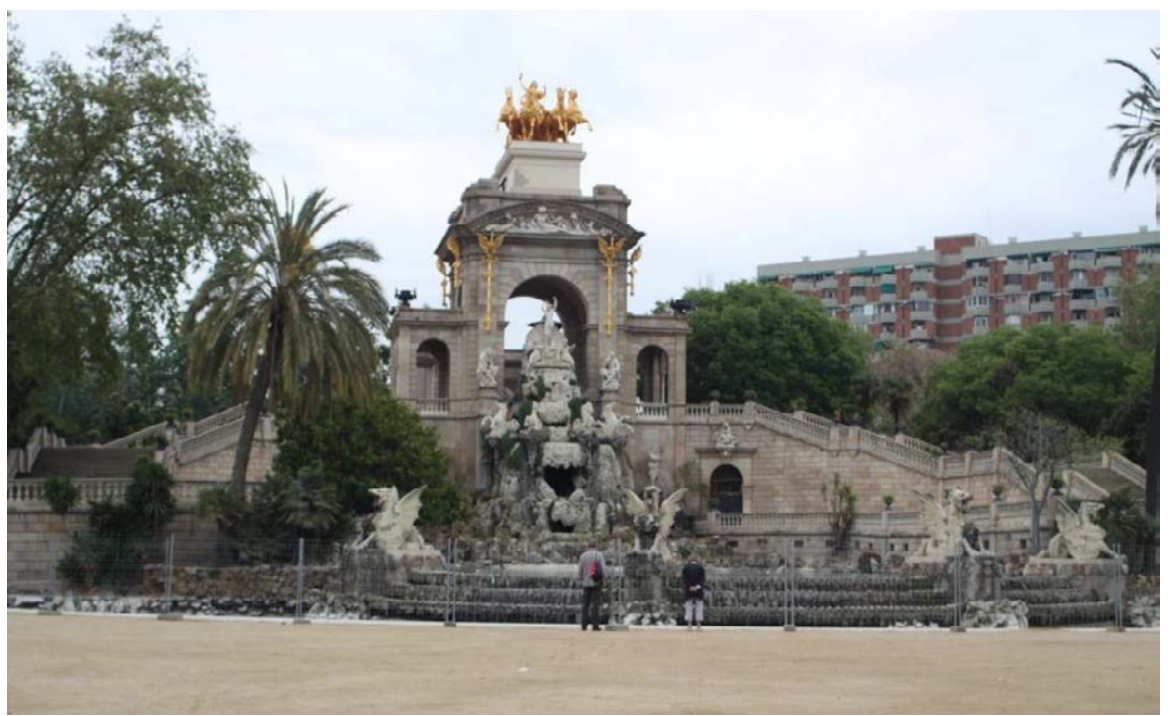

En los proyectos de este arquitecto hay un derroche de personalidad y fantasía que hacen sus obras únicas con una concepción singular y rompedora respecto de la jardinería romántica y del panorama europeo del momento, consiguiendo integrar arquitectura, urbanismo y paisaje. Aplicó un dominio absoluto sobre los materiales constructivos, ya sean pétreos o vegetales, utilizando formas zoomórficas o fitomórficas $y$ trabajando directamente con la naturaleza mediante un lenguaje orgánico. Como personaje polifacético trabajó como arquitecto, escultor, artesano y paisajista, procurando integrar todas las artes y

\footnotetext{
19 BASSEgOdA NONELL, J.: Gaudí. Temas Españoles o 517. Madrid: Publicaciones Españolas, 1971, p. 11

${ }^{20}$ Gaudí resolvió el problema del depósito elevado de la gran cascada e imprimió su sello en los elementos decorativos (candelabros, dragones, medallones, etc.). Fue ornamentada por muchos elementos escultóricos de artistas catalanes de finales del siglo XIX, colocados tras su inauguración. El elemento central es el Nacimiento de Venus (Venanci Vallmitjana), y en la parte superior, culminando el conjunto, La cuadriga de la Aurora, de Rossend Nobas, autor también de cuatro grupos de genios, dos faunos y de la figura de Eros. Abajo, cuatro grifos (Rafael Atché) protegen a Venus. Página de parques y jardines del Ayuntamiento de Barcelona.
}

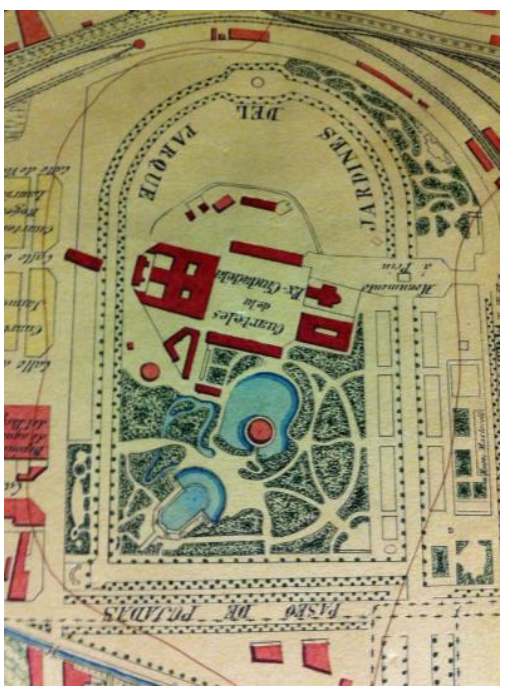

2.1 Parque de la Ciudadela: fragmento del Plano de Barcelona. Cuerpo de Estado Mayor del Ejército, 1885. Museo Cartográfico del Ejército de Madrid.

2.2 Parque de la Ciudadela: gran cascada monumental de Gaudí. PHL, abril 2010. 

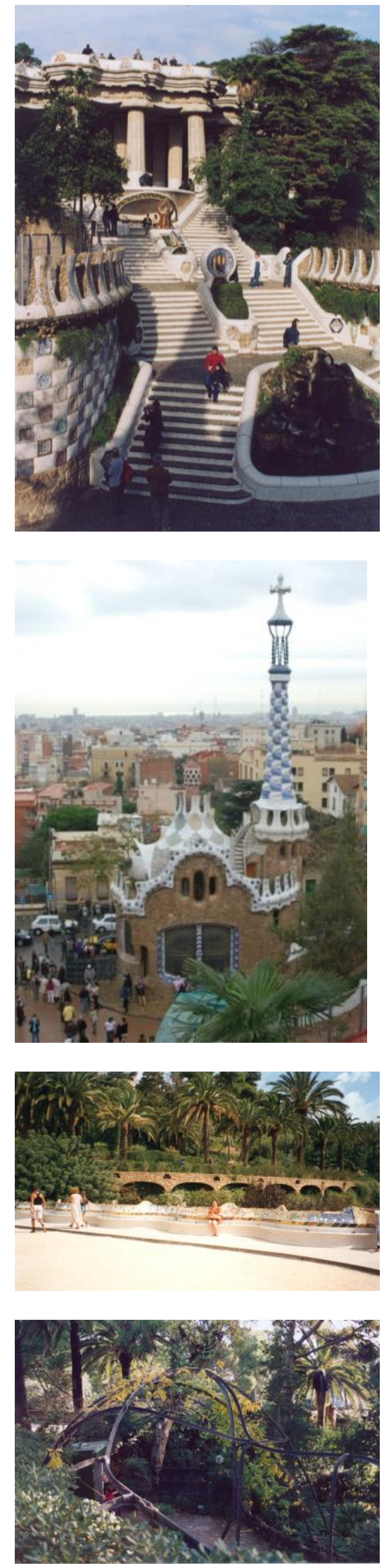

2.3 Park Güell: escalinata de acceso, pabellón de entrada, gran plaza y viaductos. PHL, agosto 1998, diciembre 2006. colaborando con otros arquitectos y artistas ${ }^{21}$. Su proceso fue casi artesanal y sufrió continuos cambios durante las obras haciendo que sus creaciones sean únicas y originales. Esto queda reflejado en su pensamiento: "Todo sale del gran libro de la Naturaleza. /.../ El auténtico arquitecto debe huir de toda imitación y engaño, debe ser sincero hasta la última consecuencia, debe hallar la expresión verdadera, no solamente de los materiales que emplee y de las formas de los elementos que adopte, sino hasta en la recta coordinación de los oficios que intervienen"22.

Una de las pocas manifestaciones modernistas en la creación de jardines es el peculiar Park Güell (1900-1914) de Gaudí en Barcelona. El proyecto se planteó como un suburbio jardín; comprendía una urbanización para 60 viviendas que no llegaron a realizarse ${ }^{23}$, en medio de un parque de 20 ha en la ladera este de la Montaña Pelada con una topografía difícil y vistas excelentes sobre la ciudad y el mar al estar elevada. Esta frustrada ciudad jardín aristocrática del conde Güell, influenciada por los movimientos ingleses de la ciudad jardín ${ }^{24}$ tras un viaje a Inglaterra ${ }^{25}$, pero en muchos casos opuesta a sus principios ya que no se dirigía a la clase obrera ni se abría al exterior; surgió en contraposición a la rigidez del Ensanche de Cerdá. Se concibió como una ciudad dentro de otra con todo su perímetro cerrado mediante un muro de mampostería concertada de casi $4 \mathrm{~m}$ y vigilado. No buscó fundirse con el paisaje de alrededor sino que creó un paisaje propio y singular. Interpretó el paisaje que lo rodea, no sólo el físico sino también el paisaje subjetivo construido desde sus vivencias propias a las referencias

\footnotetext{
${ }^{21}$ Colaboradores en el Park Güell: Joan Rubió, Francesc Berenguer y Josep Maria Jujol (arquitectos); Llorenç Matamala (escultor); Ricard Opisso (dibujante); Hermanos Badia (forjadores); Peris de Onda, Hijo de Jaume Pujol y Bausis, Sebastià Ribó (ceramistas); Agustí Masip, Josep Pardo y Juliano Barder (constructores). CIRLOT, J-E.; VIVAS, P.; PLA, R.: Gaudí. Menorca: Ayuntamiento de Barcelona, Triangle Postals, 2002, p. 400.

22 A. Gaudí. En: RAMíREZ DE LUCAS, J.: Jardín de Cactus. Madrid: Fundación César Manrique, 2000, p. 37. Estas ideas fueron recogidas por artistas que las plasmaron en sus jardines posteriores como es el caso de César Manrique en su Jardín de Cactus en Guatiza, (Lanzarote, 196x-1991). Ver capítulo de Jardines botánicos en Actuaciones urbanas de Posguerra.

${ }^{23}$ La mitad del terreno estaba destinada a zona verde y el resto se parceló en fincas triangulares de entre 1.000 y $2.000 \mathrm{~m}^{2}$. Las condiciones para cada parcela fueron muy exigentes, pudiendo edificar sólo un tercio y el resto tenía que destinarse a jardín privado, la altura y situación de las viviendas estaban limitadas para no obstaculizar la luz del sol y las vistas al mar. Se cree que fracasó por las estrictas condiciones de las construcciones y la vida en la urbanización, no pudiendo competir con los suntuosos palacios burqueses del ensanche.

${ }^{24}$ Su propio nombre Park pasa a establecer una referencia directa a los suburbios ingleses. Ver capítulo de Ciudades jardín.

25 CRIPPA, Mạ A.: Gaudí. Colección Descubrir el Arte. Madrid: Taschen, 2007, p. 61.
} 
místicas y religiosas ${ }^{26}$; estas diversas fuentes de inspiración (su fe religiosa católica, su interés por la cultura clásica helénica y la mitología, y su patriotismo catalán) conformaron su nueva creación.
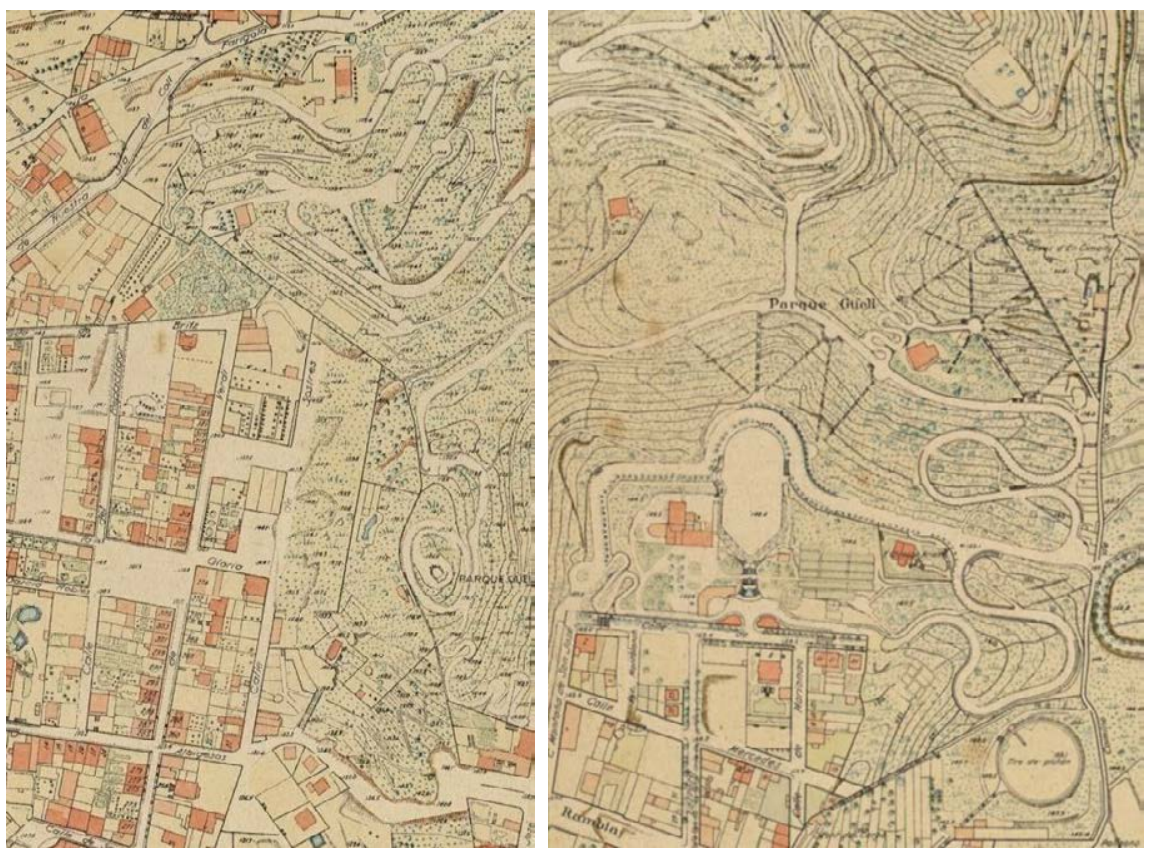

Se adaptó a la topografía fuerte y pedregosa de la montaña mediante una serie de terrazas escalonadas, donde construyó cerca de la entrada algunos equipamientos necesarios para una zona residencial autosuficiente: un acceso principal señorial con pabellones de recepción y portería con sus llamativas torres,actualmente convertidos en librería y centro de interpretación del parque respectivamente- $y$ el eje se bifurca en la doble escalinata curva con fuente; el irrealizado santuario, compensado con un calvario -un montículo de piedra rematado por tres cruces- con vistas sobre la ciudad y el mar; y una gran plaza cívica de tierra a modo de ágora -destinada a actos cívicos y reuniones populares-, sobre la sala hipóstila -destinada a mercado para proveer a las viviendas-, que hace de gran mirador delimitado con un bancobarandilla perimetral ondulado de trencadís ${ }^{27}$. Esta gran plataforma hace de transición entre el frente urbano y la agreste montaña; es permeable al agua y se sustenta por una potente estructura inferior

\footnotetext{
${ }^{26}$ VIDAL PLA, M.: Jardins de Barcelona. Barcelona: Ayuntamiento de Barcelona, Àmbit, 2003, p. 62.

${ }^{27}$ Este sistema decorativo realizado a partir de trozos de desechos de porcelana, cerámica y vidrios de colores, aparece por todo el parque. Aplica la decoración basada en el empleo de la cerámica y los azulejos siguiendo la tradición del jardín español y logrando un efecto de cromatismo plástico.
}

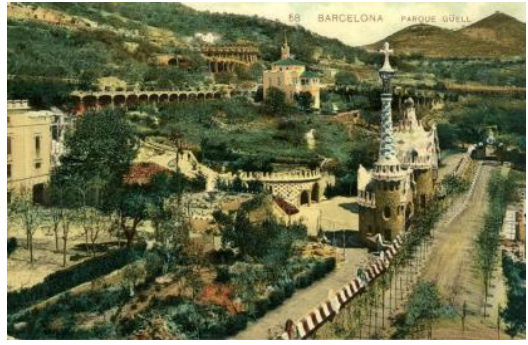

2.4 Park Güellel parque en 1906. wikipedia.org.

2.5 Park Güell. Plano de Martorell, 1931. Archivo Histórico Ciudad de Barcelona.

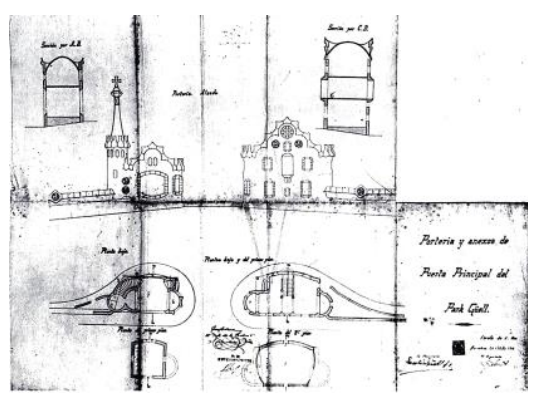

2.6 Park Güell: portería y anexos puerta principal. Gaudí. GÜELL, X.: Antoni Gaudí. Colección obras y proyectos. Barcelona: GG, 1990, p.109.

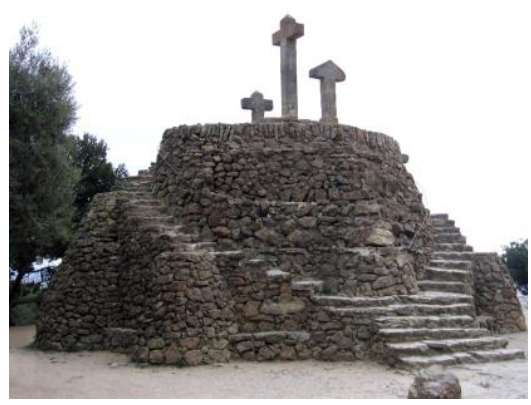

2.7 Park Güell: calvario. Foto: Canaan, trabajo propio, GFDL,https://commons. wikimedia.org/w/index. php?curid=3756 123. 


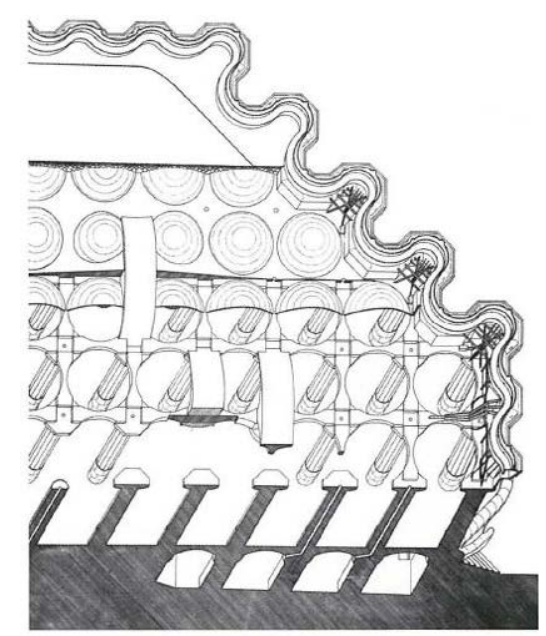

2.8 Park Güell: sala Hipóstila: axonometría y sección escalinata. Tectónica 30: Espacios exteriores, 2009, p. 45. HERRERO MATEY, S.; MARTINELLI, C.; GÜELL, X.: Antoni Gaudí. Colección obras y proyectos. Barcelona: GG, 1990, p.109.
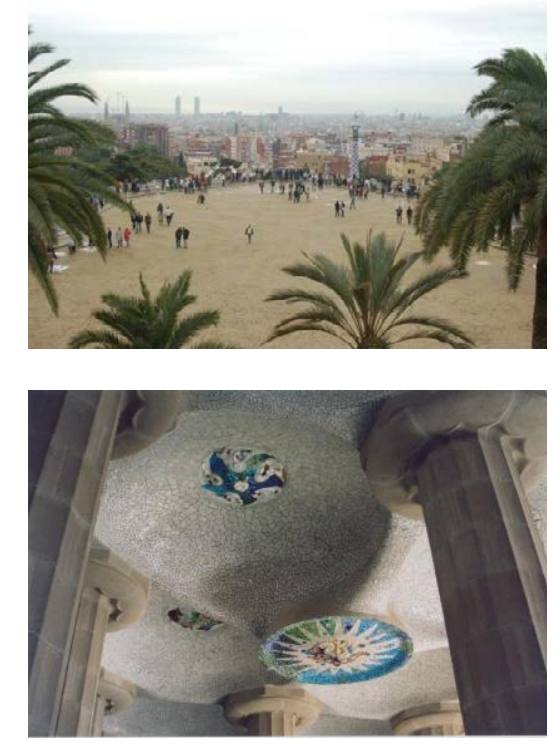

2.9 Park Güell: banco serpenteante que hace de friso de la gran sala columnada inferior, plaza superior y decoración de las bóvedas con trencadís. PHL, agosto 1998, diciembre 2006. de 86 pilares seudodóricos haciendo alusión al mundo clásico ${ }^{28}$, y cúpulas semiesféricas cóncavas, también decoradas con escudos de cerámica, que permiten la evacuación de pluviales por unos desagües que conectan con las bajantes introducidas en los huecos centrales de las columnas y que desembocan en un aljibe inferior de $12.000 \mathrm{~m}^{3}$ situado bajo la sala hipóstila. Las columnas se inclinan siguiendo el funicular de cargas de Gaudí y el entablamento va cambiando el perfil quebrado (dórico) al ondulado (modernista); combina lo recto de la columna clásica y la línea curva de los jardines ingleses. De esta forma consigue crear un frente escenográfico de cara a la ciudad.
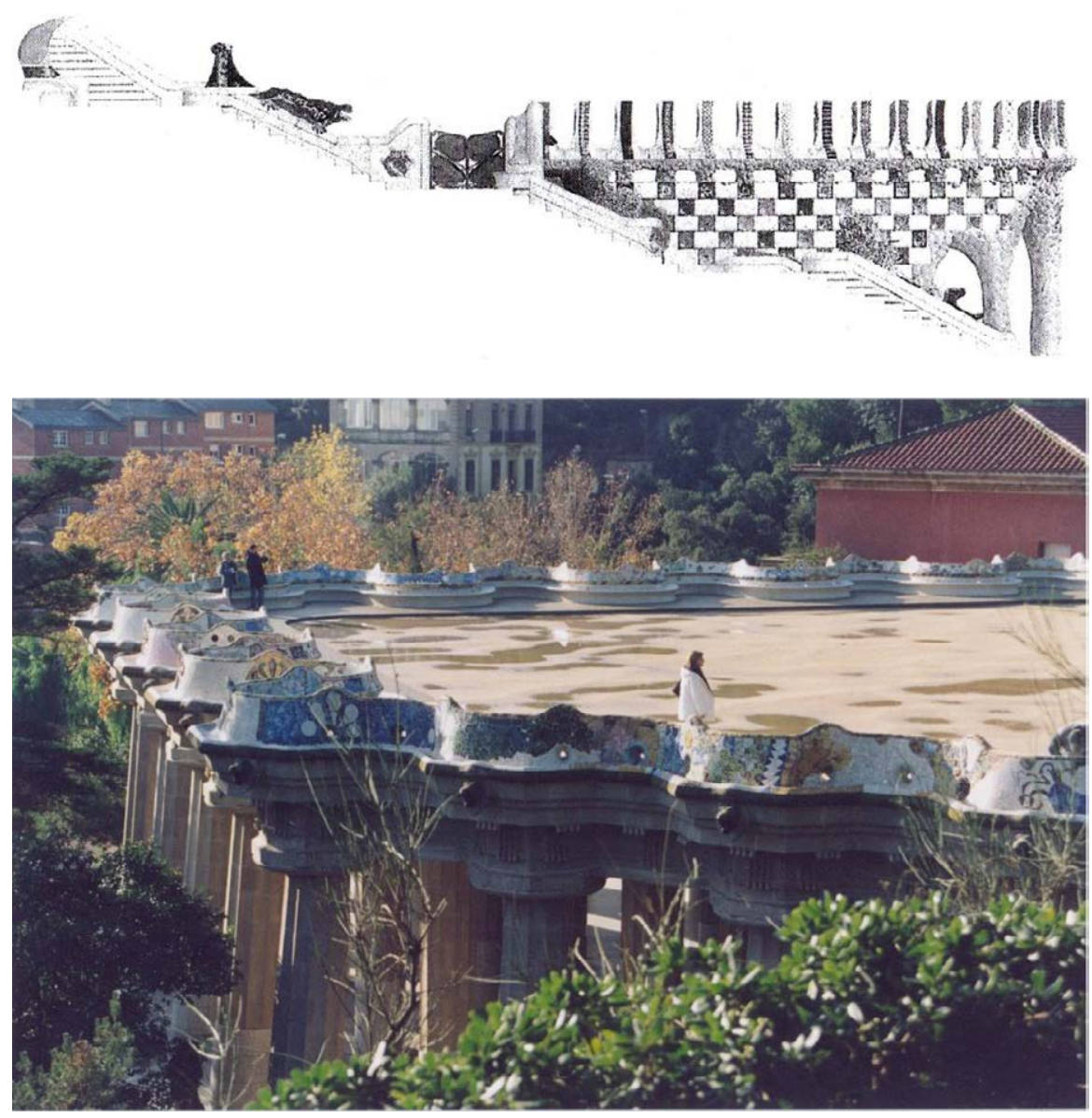

En el eje de acceso y separando la doble escalinata se concentra el elemento de agua, produciéndose una secuencia: sale del dragón, desciende a la serpiente y cae en los estanques, acompañados de vegetación en la parte central y en los laterales; el agua se presenta como un elemento en continuo movimiento.

\footnotetext{
${ }^{28}$ El propio Gaudí afirmaba: "He hecho la columna dórica arcaica del Park Güell tal y como la hubieran hecho los griegos de una colonia mediterránea". CIRLOT; VIVAS; PLA, 2002, p. 400.
} 


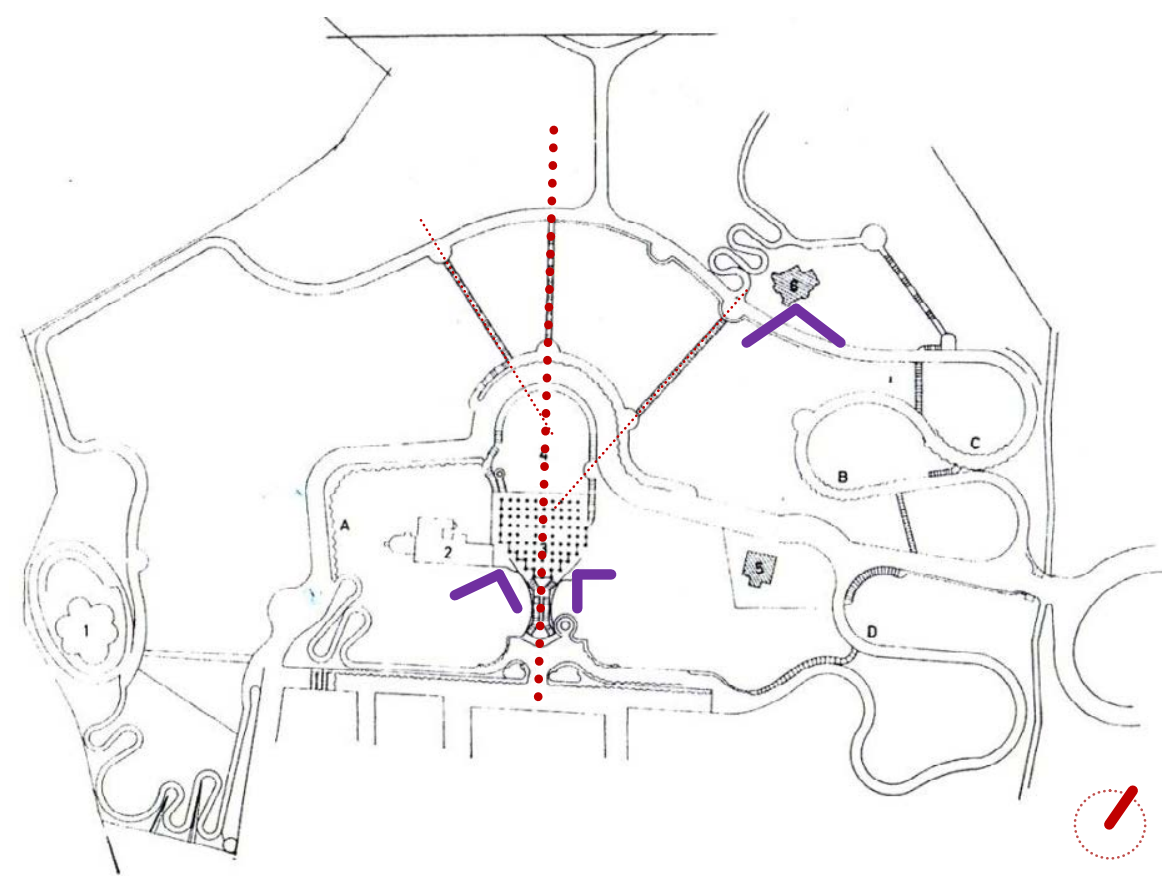

Sólo llegaron a construirse dos viviendas ${ }^{29}$, pero lo que sí se realizaron fueron casi todas las infraestructuras. En 1900 se ejecutó el sistema viario con tres accesos y una clara jerarquía: una calle principal para el tránsito rodado ( $10 \mathrm{~m}$ de ancho, paseo de carruajes que atraviesa por detrás de la explanada hasta salir por el otro extremo), dos calles secundarias ( $5 \mathrm{~m}$, llevan a la parte alta y salvan la topografía con formas onduladas y viaductos), tres calles menores $(3 \mathrm{~m})$ y varias escaleras radiales -de las cuales solo se hicieron tres- facilitando cruces rápidos para que los peatones llegaran antes a las viviendas. Este sistema franquea fuertes pendientes $\mathrm{y}$ es muy sinuoso para adaptarse al terreno tan accidentado y permitir el acceso a las parcelas previstas. Para salvar los fuertes desniveles se construyeron tres viaductos cuya parte inferior se utiliza como pasaje peatonal cubierto, sostenidos sobre pilares inclinados o arcos parabólicos que siguen las direcciones de carga; se crean espacios semioscuros y seminaturales que recuerdan a las grutas. Todo ello se acompañó de muros de contención inclinados para soportar mejor los empujes del terreno, realizados con piedra calcárea del lugar sin desbastar.

El recorrido del parque a través de los diferentes niveles que se adaptan a la topografía enlaza las distintas partes y ofrece una visión constantemente cambiante y dinámica; un recorrido en el que se

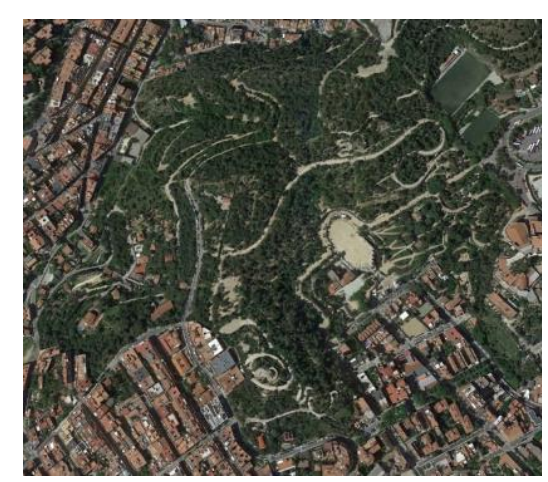

2.10 Park Güell: vista aérea actual y planta general. GoogleEarth. Herrero Matey, 1990, p. 115.

\footnotetext{
29 Junto a la casa existente desde principios del siglo XIX, casa Larrard, convertida en vivienda de Güell desde 1906, se construyó la casa Trías, obra de Gaudí; y la casa muestra, proyectada por Francisco Berenguer Mestres y comprada por Gaudí para su residencia en 1906. BASSEGODA NONELL, 2001, p. 324.
} 

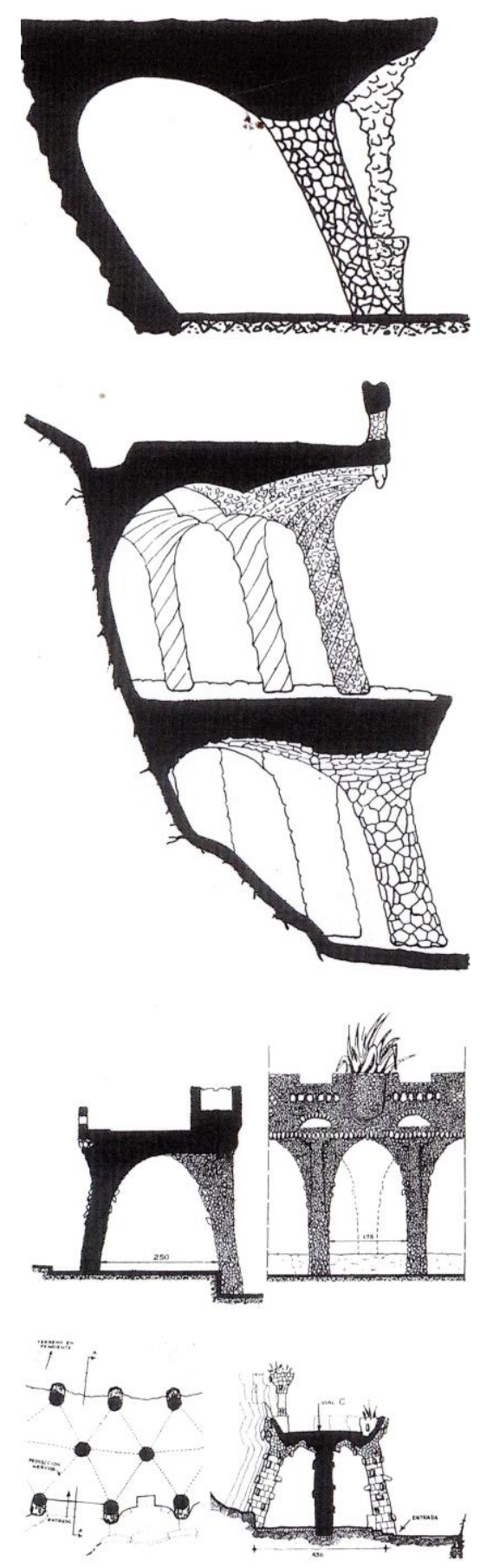

2.11 Park Güell: sección de un pórtico, sección por la rampa circular de un pórtico, y sección y alzado de un pórtico. Ruiz Vallés, Movilla, Pellicer, Recasens, Sarabia y Villanueva. GÜELL, X.: Antoni Gaudí. Colección obras y proyectos. Barcelona: GG, 1990, p.124 y 126. Vistas actuales de los pórticos. PHL, agosto 1998, diciembre 2006. entremezclan la arquitectura y la naturaleza. Miguel Ángel Aníbarro define el parque "como un trayecto desde la celebración cívica a la excursión campestre, que culmina en un peregrinaje místico" ${ }^{30}$. Hay un diálogo continuo entre lo artificial y lo natural como las columnas inclinadas del pórtico del viaducto de Bugadera que dialogan con los troncos de los pinos del bosquete de alrededor; o los contrafuertes del paseo de las Palmeras con formas fitomórficas pétreas que dialogan con las palmeras naturales que jalonan el paseo; o las rejas inspiradas en las hojas de palmitos, etc. Como el nombre de la montaña indica, no era muy abundante la vegetación, pero Gaudí insistió en conservar y aumentar los pinos y algarrobos existentes; lo completó con una plantación de especies mayoritariamente autóctonas (robles, encinas, laureles, retama, romero, tomillo, pitas, palmeras, hiedra, glicinia, etc.). Es muy interesante el intento de un jardín paisajista mediterráneo sin praderas ni estanques irregulares.

Al no venderse casi ninguna de las parcelas para la urbanización, en el recinto creció un auténtico bosque mediterráneo acompañado de un espeso sotobosque que se incorporó al paisaje singular del parque ${ }^{31}$. El conjunto se delimita con una cerca que sigue los accidentes del terreno, actuando a la vez de muro defensivo y se decora con grandes plafones cerámicos. En 1922 tras la muerte de Eusebi Güell, su hijo lo donó al Ayuntamiento convirtiéndolo en parque público ${ }^{32}$.
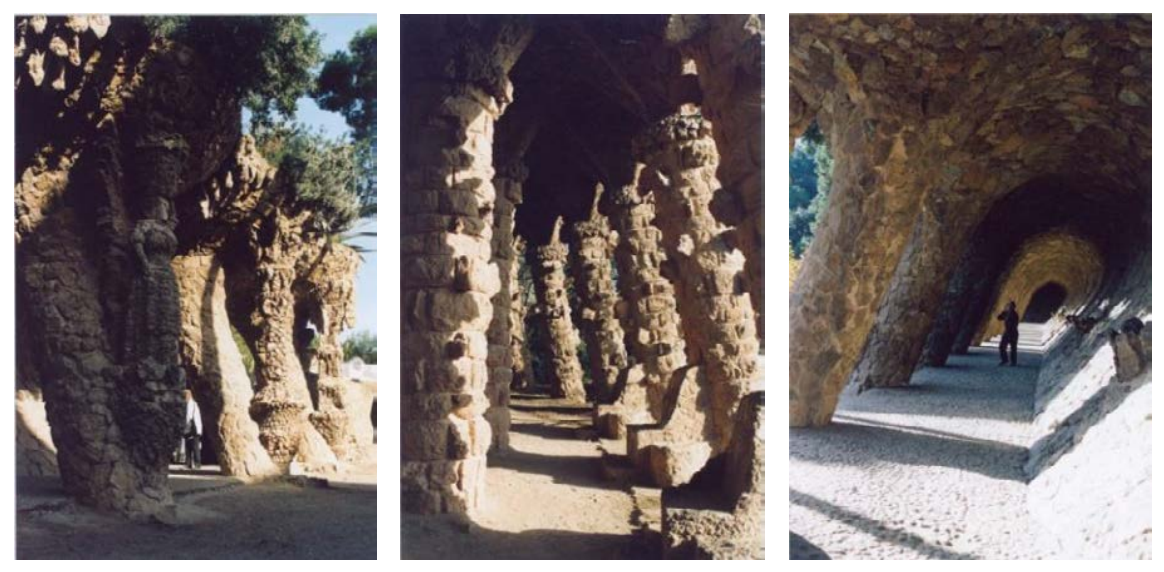

30 ANÍBARRO, M.A.: Los jardines del siglo XX. En: FARIELLO, F.: La Arquitectura de los Jardines.Madrid: Mairea/Celeste, 2000, p.314.

31 Durante la Guerra Civil los árboles se talaron para leña y a partir de 1940 se incorporaron nuevas especies: árboles (acacia, ailantum, albicia, cedrus, celtis, cercis, cupressus, eriobotria, eucaliptus, magnolia, morus, olea, parquinsonia, platanus, prunus, quercus, robinia, schinus, tuya, ulmus, etc.) y arbustos (artemisia, cneorum, cortaderia, cotoneaster, datura, evonimus, hybiscus, ibis, ligustrum, lonicera, nerium, pitacia, pittosporum, pyracantha, rhamnus, rhododendron, viburnum, wisteria, opuntia, etc). BASSEGODA NONELL, J.: El gran Gaudí. Barcelona: AUSA, 1989, p. 420.

32 En 1969 fue declarado Monumento Nacional y en 1984 Patrimonio de la Humanidad por la UNESCO. Fue rehabilitado por Elías Torres y José Antonio Martínez Lapeña entre 1985 y 1993, realizándose otra rehabilitación integral en 2006. 
Otros jardines modernistas en los que interviene el mismo autor son: el jardín de El Capricho (1883-1885) en Comillas con un patio en forma de herradura protegido por un muro de contención que recuerda al del Park Güell, una gruta escondida en el talud para guarecerse en verano -similar a la de la Ciudadela-, un puenteescalera y numerosos balcones y miradores para asomarse al jardín y al paisaje; el jardín de las Hespèrides (1884-1887) ${ }^{33}$; el diseño del Primer Misterio de Gloria del Rosario Monumental de Montserrat (1903), con camino pegado a la montaña y gruta artificial; y el jardín de la Magnèsia en la Pobla de Lillet (1903-1910), éste último atribuido con reservas a Gaudín ${ }^{34}$

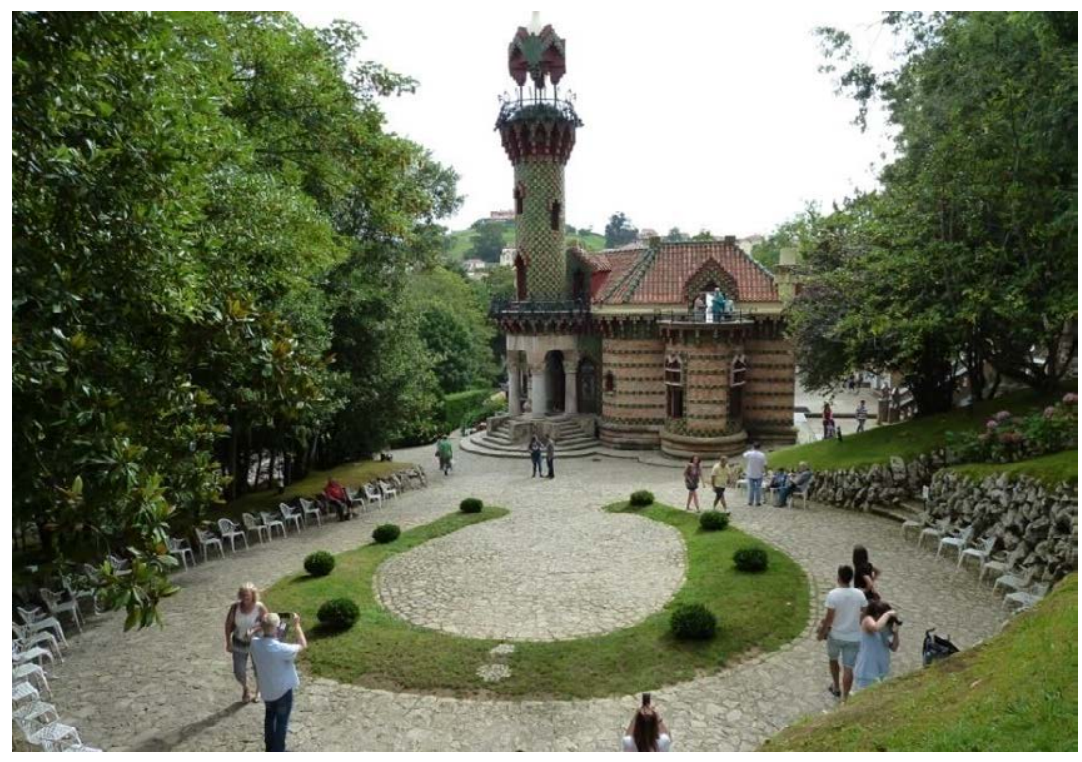

33 Este antiguo jardín de trazado paisajista, formaba parte de la finca de la familia Güell en Les Corts de Sarrià barcelonés, con casa de indianos e importantes ejemplares arbóreos (eucaliptos, pinos, olmos, cedros, cipreses, palmeras, etc.) acompañados de mosaicos de hiedra, abundantes arbustos y plantas de flor. Posteriormente Eusebi Güell Bacigalupi lo transformó en el jardín de las Hespérides en homenaje a su suegro, el marqués de Comillas, Antonio López y López, con referencias a la mitología griega, a la astronomía y a la poesía modernista. En él intervino Gaudí entre 1884 y 1887, realizando nuevas dependencias y equipamientos (portería, cuadra, cochera, picadero abierto, quiosco merendero, umbráculo de arcos parabólicos de hierro, sombrajo de cañas y hojas de palmera, fuentes - una dedicada a Santa Eulalia y otra con busto de Hércules y caño de dragón-, cerca y tres puertas del recinto). En 1918 tras la muerte de Eusebi Güell la finca se dividió en dos partes, la correspondiente a los alrededores del palacio será la que se transformó en el nuevo parque del Palau de Pedralbes. Ver capítulo de Los parques de Rubió en Barcelona. VIDAL PLA, M.: Jardins de Barcelona. Barcelona: Ayuntamiento de Barcelona, Àmbit, 2003, p. 36. BASSEGODA NONELL, J.: "Del Eclecticismo a la actualidad en los jardines de Cataluña". Historia de los parques y jardines de España. Grupo FCC, 2001, p. 320-323.

34 Joan Bassegoda en un artículo le atribuye el diseño, pero sin haber pruebas; sin embargo existe una alta probabilidad ya que parece que trabajó en el Chalet de Catllaràs (1904), refugio de montaña para los ingenieros de las minas de carbón que abastecían la vecina fábrica de cemento Asland, propiedad de Eusebi Güell en la vecina localidad de Castellar de n'Hug, en la misma época; y aunque parece que Gaudí no dirigió la obra sí trabajó alguno de los albañiles del Park Güell e incluso transportaron algunas yucas desde allí. "L'Erol" (revista cultural del Berguedà), no 29, 1990, p. 18-20. RIBAS IPIERA, M.; VIDAL I PLA, M.: Jardins de Catalunya. Barcelona: Edícola-62, 2002, p. 183.
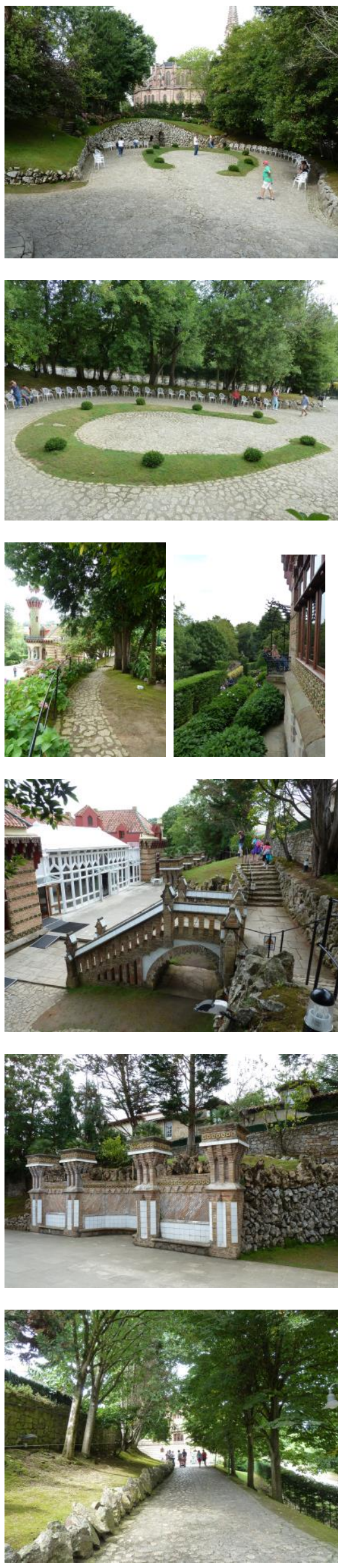

2.12 Jardín de El Capricho, Comillas. Gaudí, 1883-1885: patio en herradura, caminos, balcón, muro-mirador y camino de acceso. 

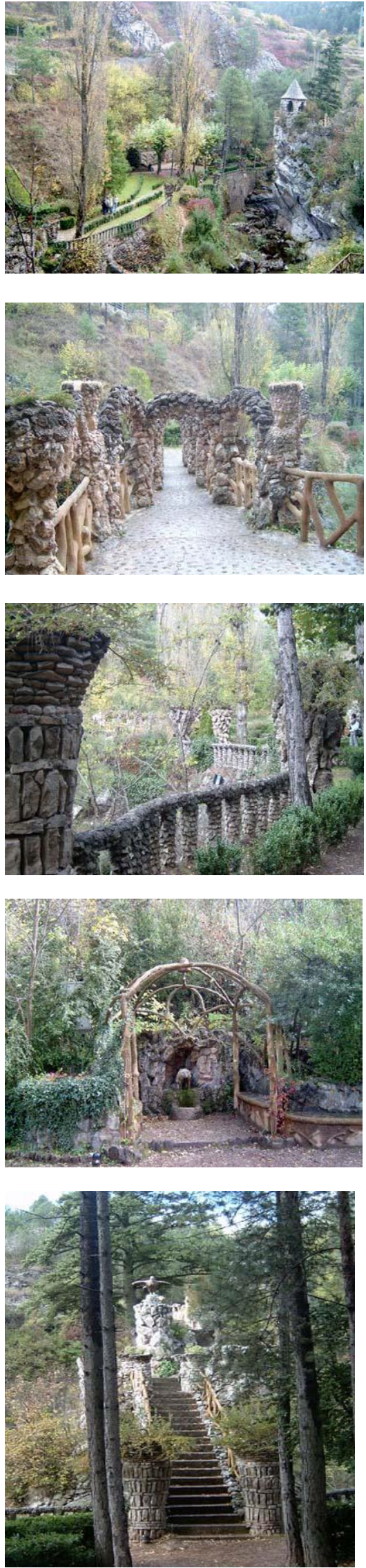

2.13 Jardín de la Magnèsia en la Pobla de Lillet: vistas actuales. Ayuntamiento de Pobla de Lillet.
Muchas de las colonias industriales de principios del siglo XX presentan unos jardines interesantes acompañando las viviendas de los trabajadores, concebidas como una prolongación de las fábricas. Una de ellas es la Pobla de Lillet, el Berguedà, en el valle alto del Llobregat, sobre un afluente de este río, donde se encuentra el jardín de la fábrica textil can Artigas de 4ha. Fue construido como regalo del propietario, Juan Artigas Alat, para su hija.

En este entorno forestal con vegetación autóctona mediterránea, el curso de agua que forma cascadas y los grandes riscos de piedra son los protagonistas; y junto a éstos compone un jardín rústico y natural uniendo ambas orillas. Se construyen: caminos; un puente de arco quebrado y otro que soporta la escalera que salva los pronunciados desniveles (Puente de los Arcos y Puente de la Escalera); una gruta artificial de grandes piedras sin labrar con un banco corrido y la fuente de agua ferromagnesiana, la Magnesia, que antiguamente le daba nombre a los jardines; una fuente de rocalla; una glorieta sobre un peñasco que hace de mirador sobre el jardín; un pabellón belvedere; balaustradas de cantos de río incrustados sobre hormigón armado y barandillas de cemento imitando troncos.

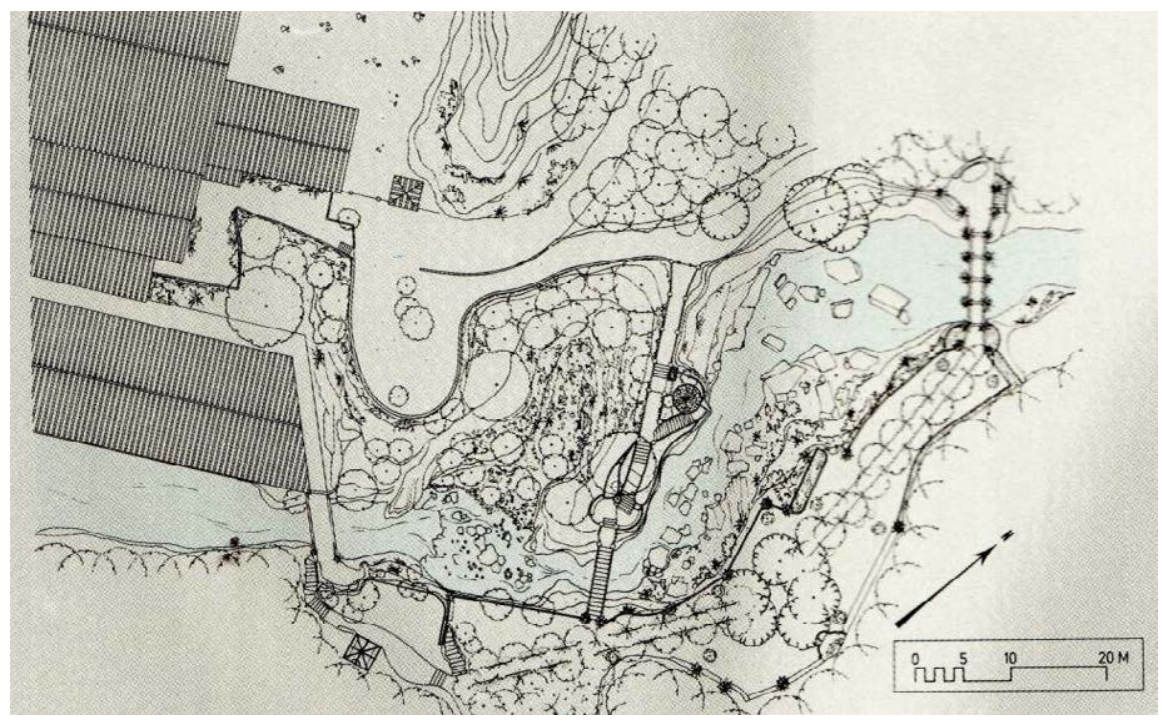

Todo decorado siguiendo la línea romántica y naturalista mediterránea, basándose en estructuras y formas naturales; se utilizaron materiales de esta zona prepirenaica, buscando una simbiosis entre arquitectura y naturaleza. Aprovecha los numerosos manantiales naturales y los decora convirtiéndolos en fuentes (la Cascada de piedra rústica cubierta de musgo, la Fuente del Buey, la 
Fuente del León con una pérgola rústica, la Fuente de la Gruta...). También aparecen figuras de animales y símbolos religiosos distribuidos por el jardín (serpiente, águila de San Juan, león de San Marcos, buey de San Lucas y el ángel desaparecido de San Mateo, etc.) acompañando el recorrido. Es muy respetuoso con el entorno y no se introduce apenas vegetación ${ }^{35}$ nueva sino que se aprovechan la exuberantes especies autóctonas, dejándolas crecer de forma natural ${ }^{36}$.

\section{Otros jardines modernistas}

Poco a poco y teniendo a Barcelona como modelo, se irradió el estilo modernista, ayudado por algunos arquitectos o artistas catalanes desplazados a otros lugares que van a realizar obras siguiendo la misma corriente. El Park Güell tendrá repercusión en algunos otros parques públicos coetáneos como el Parque del Pasatiempo de Betanzos en La Coruña (1893-1914), creado como parque enciclopédico didáctico por los hermanos García Neveira tras su vuelta después de varios años de emigración en Argentina. Aunque solo cuenta actualmente con una décima parte de su extensión original de $9 \mathrm{ha}^{37}$, todavía conserva alguna de sus grutas, terrazas-mirador, relieves zoomórficos y decoraciones entre románticas y modernistas, gracias a las restauraciones iniciadas en 1986, tras su adquisición por parte del Ayuntamiento. El parque se estructuraba con una amplia zona de recreo en la parte llana acompañada de paseos, estanques y una diversa vegetación. Y la zona del Pasatiempo se componía en terrazas que se adaptaban a la topografía de la montaña, e incluían estanques y todo tipo de construcciones y relieves conformando un parque enciclopédico

\footnotetext{
35 Chopos, bojes recortados, yucas, alguna palmera, hiedra y césped. BASSEGODA NONELL, J.: "Del Eclecticismo a la actualidad en los jardines de Cataluña". Historia de los parques y jardines de España. Grupo FCC, 2001, p. 332.

${ }^{36}$ Estos jardines fueron abandonados y la fábrica sufrió un incendio en 1939; pasaron desapercibidos hasta 1971 cuando R. Bonamusa, corresponsal del periódico El Correo Catalán, descubrió su existencia después de hablar con un albañil que había trabajado allí. Tras la cesión de los terrenos en 1983, se realizó un proyecto de parque público mejorando los accesos, en el que intervinieron los arquitectos Joan Bassegoda, Witold Burkiewicz y el arquitecto técnico Ramón Espel. Los trabajos de restauración se iniciaron en 1992 respetando la idea original y creando nuevas esculturas de Ramón Millet Domènech. BASSEGODA, J.; ESPEL, R.; ORRIOLS, R.: Gaudí en la Vall de Lillet. Àmbit de Recerques del Bergadà, Amalgama, 2002, p. 115. Ayuntamiento de Pobla de Lillet.

37 A lo largo de los años ha sido muy transformado (campo de concentración para prisioneros republicanos, zona de huertas, depósito de escombros...) y ha estado varios años abandonado.
}
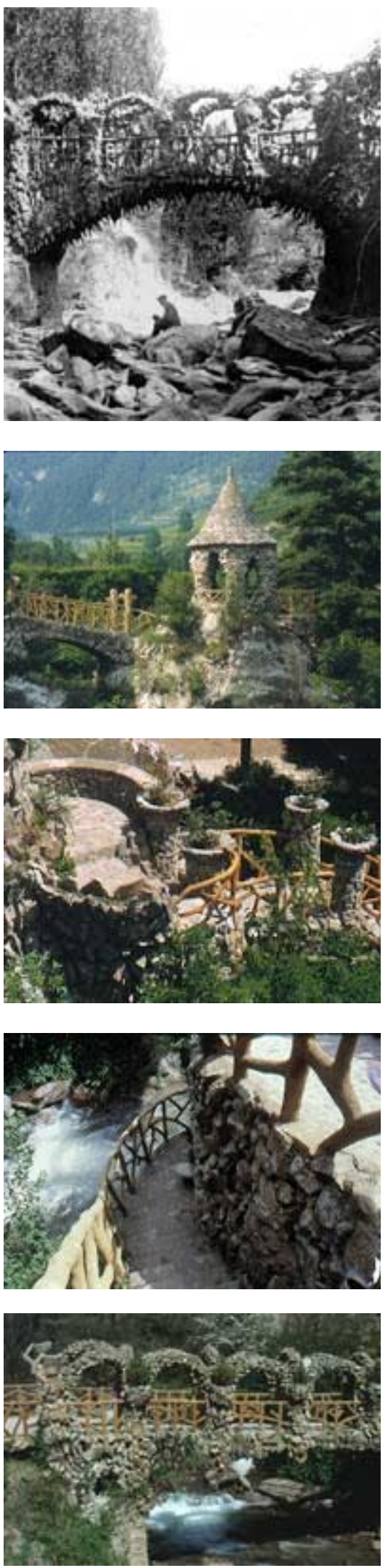

2.14 Jardín de la Magnèsia en la Pobla de Lillet: planta y vistas del jardín. RIBAS IPIERA, M.; VIDAL I PLA, M, 2002, p 187. Fotos colección de la señora Doña Rosario Costa Artigas BASSEGODA, J.; ESPEL, R.; ORRIOLS, R., 2002, p. 115. www.gaudiclub.com 


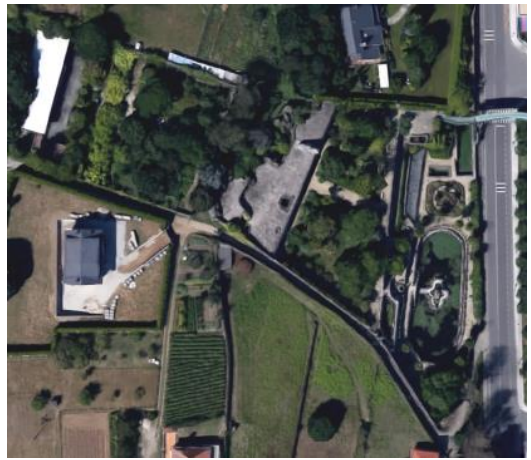

2.15 Parque del Pasatiempo de Betanzos, La Coruña: vista aérea actual, perspectiva y estanque. Googlemaps, ripadvisor.com y puntosgps.com. para enseñar a los habitantes de Betanzos los distintos lugares del mundo (La gran Muralla China, el Canal de Panamá, las pirámides de Egipto, etc.) y en la parte más alta había un mirador.
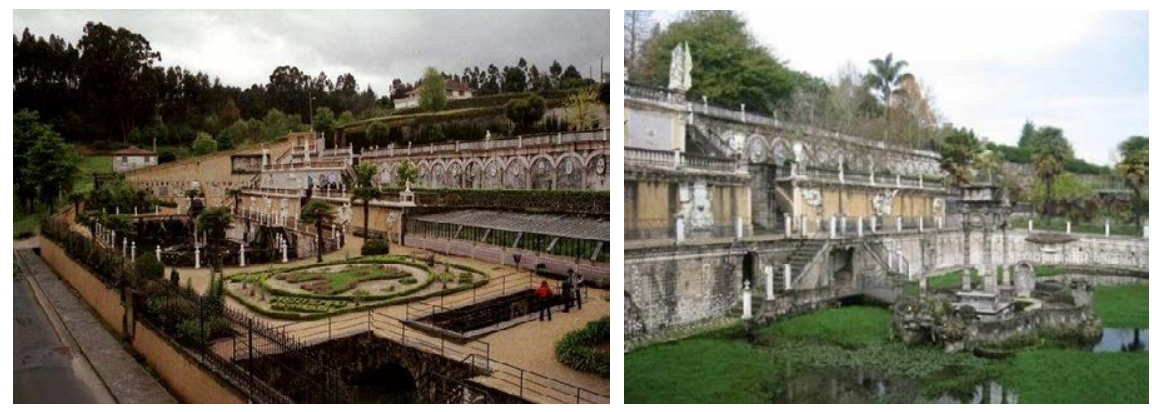

Otro jardín modernista con claras influencias gaudianas es el del recinto del Parque Sanitario San Juan de Dios de Sant Boi de Llobregat en Barcelona, donde antiguamente se ubicaba el antiguo Manicomio de Sant Boi. Se realizó entre 1903 y 1912 sobre un jardín preexistente de estilo inglés con un lago y caminos sinuosos. El jardín, orientado al valle del río Llobregat, estaba delimitado por dos avenidas, varios huertos y el muro perimetral del recinto. Cuenta con tres conjuntos arquitectónicos diferenciados de formas orgánicas: la Cueva Cascada -una construcción de 1906 de rocalla en forma de cueva con estalactitas y montaña coronada por un baldaquín-; la Capilla Inundada - de 1911, también de rocalla en forma de dragón conteniendo la escultura de una Virgen-; y la Plaza de los Bancos -de 1912, formada por una plaza más grande y otra adyacente más pequeña con bancos de trencadís similares al ondulante del Park Güell-. El recorrido se acompaña de muros de contención, jardineras y bancos pétreos que hacen de barandillas, viaductos, fuentes y plazoletas, algunos actualmente desaparecidos. Tanto los materiales como las técnicas constructivas empleadas guardan gran similitud con el Park Güell; se tiene constancia que algunos de los albañiles que trabajaron en el Park Güell eran de esta localidad 38 .

\footnotetext{
38 AGULLÓ GALILEA, D.; BeRBí, D.; MARTí, J.: “Un jardín invisible, Gaudí y el conjunto modernista de los jardines del antiguo Manicomio de Sant Boi". Mètode 65, primavera 2010, p. 30 y 33. Algunas fechas y datos se han obtenido de RODRÍGUEZ-MORINI, A.: «Boletín del Manicomio de San Baudilio. Marzo 1906». Revista Frenopática Española Barcelona, 40: 130-131.
} 


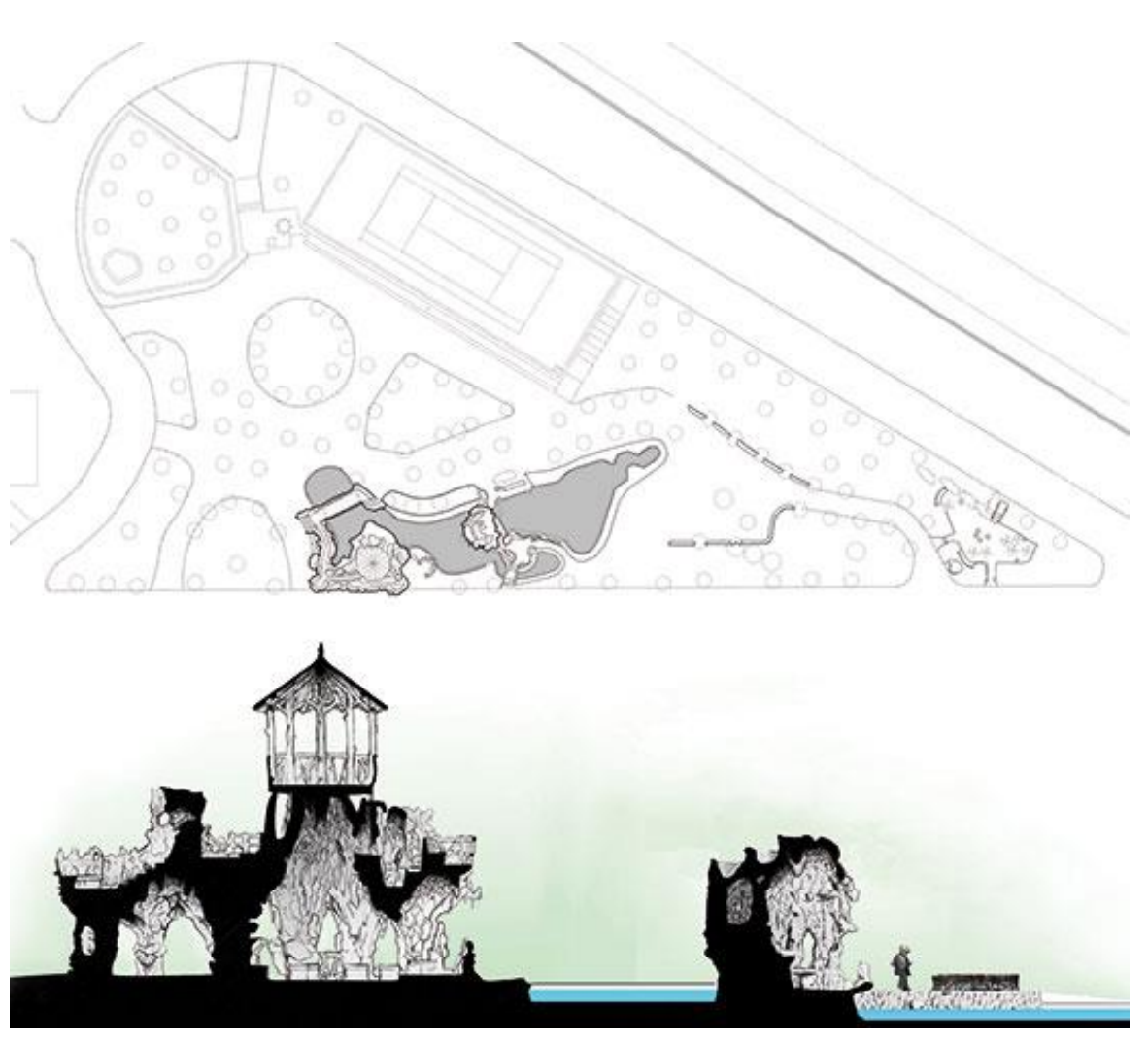

Al mismo tiempo se estaban realizando edificios modernistas en los que sus jardines seguían siendo tradicionales manteniendo un lenguaje clásico. Este es el caso de los jardines del Hospital de la Santa Cruz y San Pablo en Barcelona (1909-1914) de Lluis Domènech i Muntaner, finalizado por su hijo Pere Doménech $\mathrm{i}$ Roura. La necesidad de trasladar el antiguo hospital obligó a destinar nueve manzanas del ensanche sobre las que se proyectaron 48 pabellones orientados según el eje norte-sur y a 45응 respecto del Plan Cerdá rompiendo la "eterna monotonía" de la nueva ciudad como decía Doménech ${ }^{39}$ y obedeciendo a cuestiones de soleamiento.

El conjunto se organiza mediante dos ejes ortogonales ${ }^{40}$ que marcan las diagonales del cuadrado que ocupa: uno norte-sur señalado por el pabellón de Acceso y Administración, el pabellón Central- y otro este-oeste -marcado por la antigua Casa de Convalecencia y la Asunción-, cruzándose ambos en el antiguo convento y pabellones de servicios. También se aprecia una jerarquía viaria: los dos ejes principales con un ancho de $50 \mathrm{~m}$ y los

\footnotetext{
${ }^{39}$ AAVV: Twentieth-Century Architecture Spain. Madrid: Tanais, Sociedad Estatal Hanover 2000, S.A., 2001, p.40.

${ }^{40}$ La simbólica forma de la cruz le da el nombre al hospital.
}
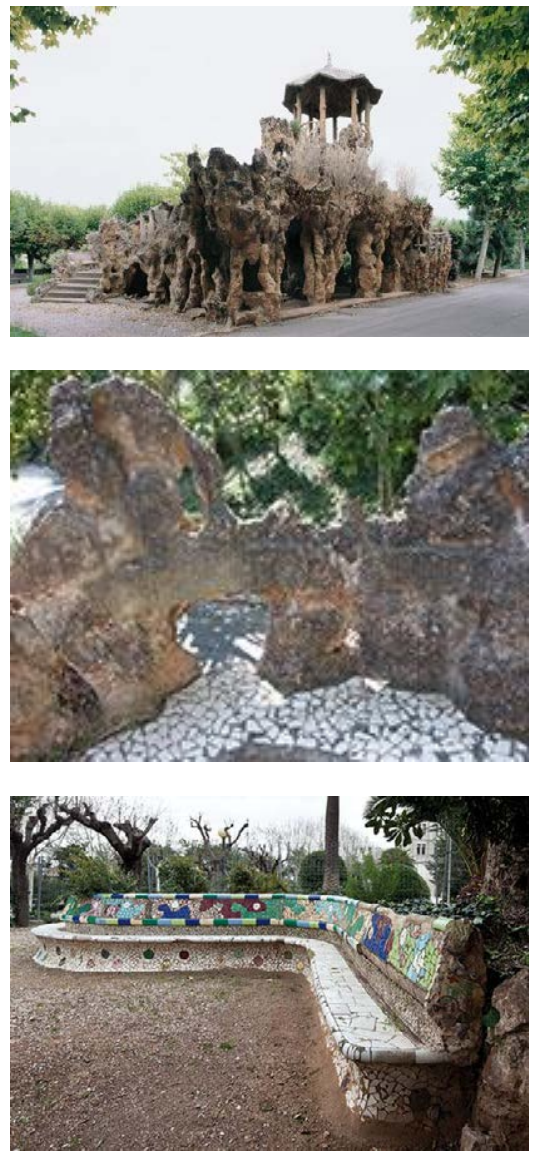

2.16 Jardín del antiguo manicomio de San Boi: planta del conjunto, sección de la cueva cascada, y vistas de la Capilla Inundada y detrás baldaquín en la Cueva Cascada, viaducto con banco perimetral pétreo y banco con trencadis. Fotos A. Bagué. AGUILÓ, BERBÍ, MARTí, Mètode 65, 2010, p.3239. 

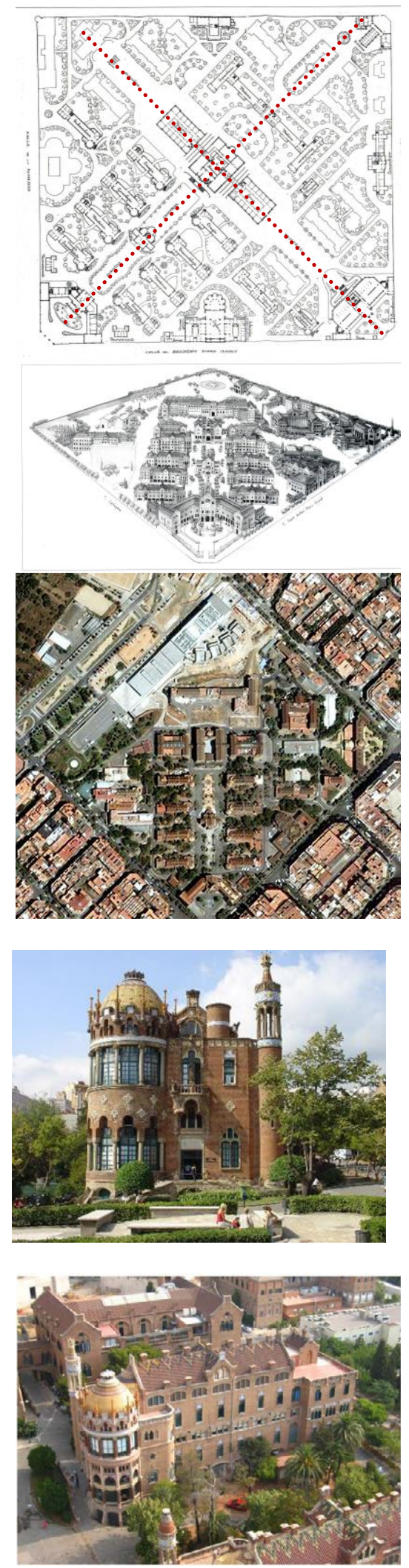

2.17 Hospital de San Pablo en Barcelona: planta original y alzado actual. Archivo Histórico H.S.C.S.P. Vista aérea y perspectivas. GoogleEarth y nnexperiences.com.

2.18 Hospital de San Pablo: perspectiva del conjunto. AAVV: Twentieth-Century Architecture Spain, 2001, p.40. secundarios de $30 \mathrm{~m}$. Como novedad los pasos de comunicación y las grandes dependencias de servicios de cada pabellón las construye en subterráneo ${ }^{41}$.

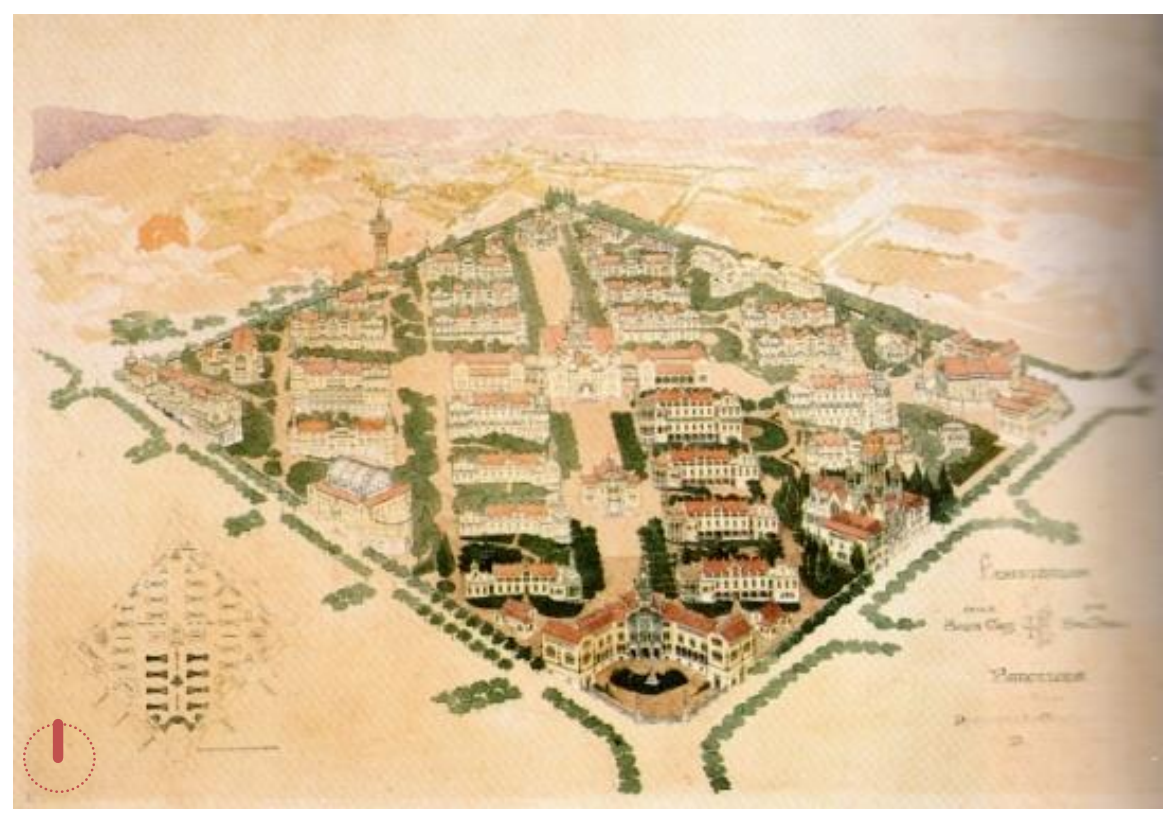

Entre los pabellones tipo y los edificios singulares, decorados según el Modernismo catalán, se sitúan los jardines que hacen de nexo de las distintas construcciones integrando la naturaleza en el conjunto arquitectónico. Se conforma como una auténtica ciudad jardín ${ }^{42}$, un recinto aislado e independiente dentro de Barcelona con una trama urbanística y personalidad propias. Se abandona el tradicional concepto de hospital-palacio y se opta por un nuevo concepto hospitalario moderno y funcional, a la vez que humano ${ }^{43}$.

Este hospital-jardín resulta novedoso en España durante esta época, ya que hasta entonces no se consideraban necesarios los espacios abiertos para la estancia, el paseo y el bienestar de los enfermos y sus familiares. En la memoria se describen los jardines: "...El terreno destinado a jardín comprendido entre dos pabellones

\footnotetext{
41 “El Hospital de San Pablo". Cuadernos de Arquitectura, 1963, no 52-53 2ㅇ y 3ㅇtrimestre, p.51.

42 Se aprecia la influencia de los hospitales ingleses en el uso de pabellones aislados comunicados exteriormente, de los hospitales americanos con pasillos cerrados generalmente sobre rasante (Peter Bent Brigham Hospital, 1907-1913 de Godman y Despradelle; Hospital General de Clncinati), del Hospital Bispebjerg de Copenhague con comunicaciones subterráneas y de otros hospitales higienistas europeos como el Hospital Lariboisière de Paría (1854) y el de Viena (Otto Wagner, 1907) con la iglesia presidiendo el conjunto. "El Hospital de San Pablo". Cuadernos de Arquitectura, 1963, no 52-53 2ㅇ y 3응 trimestre, p. 60.

43 SERRACALRA I PLÁ, Mạ T.; MARTí AYXELÁ, M.: Hospital de la Santa Cruz y San Pablo. Historia, arquitectura y arte. Fundació Privada Hospital de la Santa Creu i Sant Pau - OHL G\&O, Litocian, 2001, p.24.
} 
se dispone de manera que variando las rasantes entre dos cotas extremas ya fijas permitan la entrada a plan terreno en el punto medio de la sala de sótanos en los pabellones de Levante y por el punto medio de la sala de enfermería de planta baja de los de Poniente. Esto da lugar a un camino que serpentea en diagonal entre los dos pabellones y deja a cada lado de él un jardín expuesto al Norte y otro al Sur constituyendo para cada sala enfermería jardín de invierno a un lado y de verano al otro con acceso fácil desde la misma"44. La mayoría de los ventanales de los edificios, decorados con azulejos, cerámica vidriada y mosaicos, se abren a los jardines permitiendo vistas sobre ellos. El proyecto del edificio es de 1901 y los jardines se comenzaron en 1909 cuando se terminó la primera fase de construcción, prolongándose hasta $1930^{45}$. En esta obra al igual que en el Park Güell colaboraron arquitectos, pintores, escultores y otros artistas y artesanos.

En la misma época en Madrid se construyó el Hospital de San Francisco de Paula o de jornaleros (1908-1916) de Antonio Palacios Ramilo y Joaquín Otamendi Machimbarrena, también conocido como Hospital de Cuatro Caminos. Doña Dolores Arano, viuda de Curiel, encarga este hospital como sede de su fundación para "alojar todos los servicios correspondientes a un hospital de jornaleros, en que éstos reciban la medicación y cuidados necesarios desde su ingreso, hasta su completo restablecimiento" 46 , como indica la memoria del proyecto. Rompe con el esquema tradicional de centros hospitalarios y articula el espacio en torno a un patio central de planta octogonal, con un amplio deambulatorio del cual parten hacia fuera cuatro cuerpos radiales estrechos y largos de los pabellones clínicos. En vez de situar la iglesia en el espacio central, la desplaza a un lado, sobre la fachada del antiguo paseo de Ronda. En el patio hay una fuente también octogonal sobre una superficie pavimentada de la misma forma y rodeada de cuadros ligeramente inclinados con pradera y algunos pequeños árboles. Destaca el puente que une el patio con el pabellón de cirugía, utilizando una construcción metálica con un lenguaje tecnológico. También ajardina el resto de espacios exteriores entre los pabellones sin una estructura clara, tan solo

\footnotetext{
${ }^{44}$ Ibid., p.26. Nota 58

45 No llegaron a construirse todos los pabellones y el nuevo hospital inaugurado en 2009 no sigue la traza del proyecto original, distorsionando mucho la idea de conjunto.

${ }^{46}$ Extracto de la memoria del proyecto. "El hospital de Cuatro Caminos". Arquitectura. Madrid: Colegio Oficial de Arquitectos, 1967, no 106 octubre, p. 23.
}
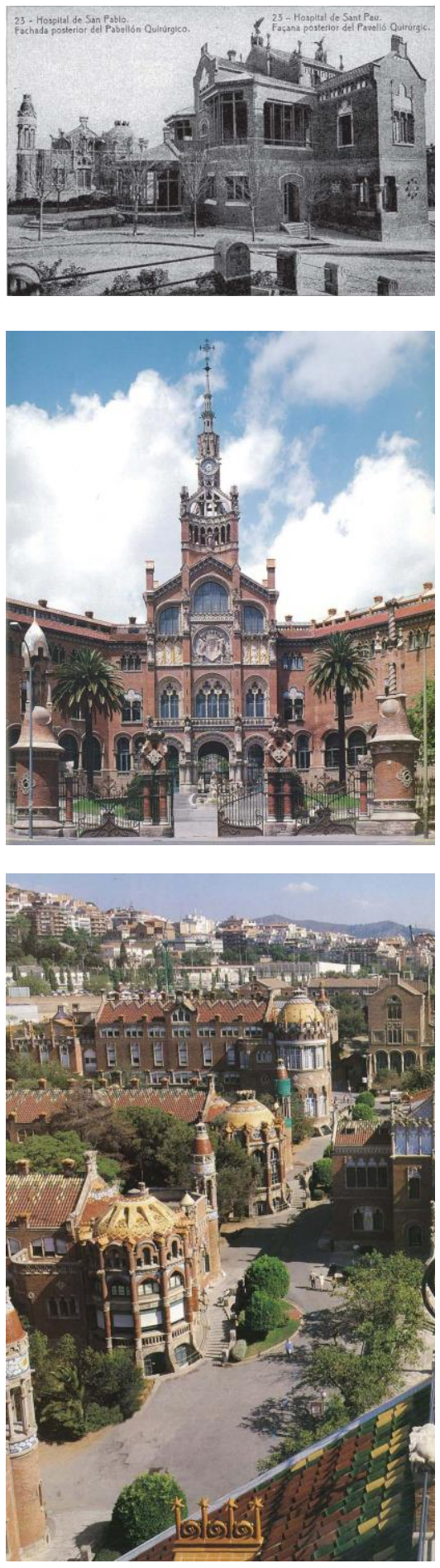

2.19 Hospital de San Pablo: fachada posterior del Pabellón Quirúrgico. Tarjeta postal, colección Ramón Martí. Vista del acceso principal, vista del conjunto. SERRACALRA I PLÁ, 2001, p. 73 y 81. 

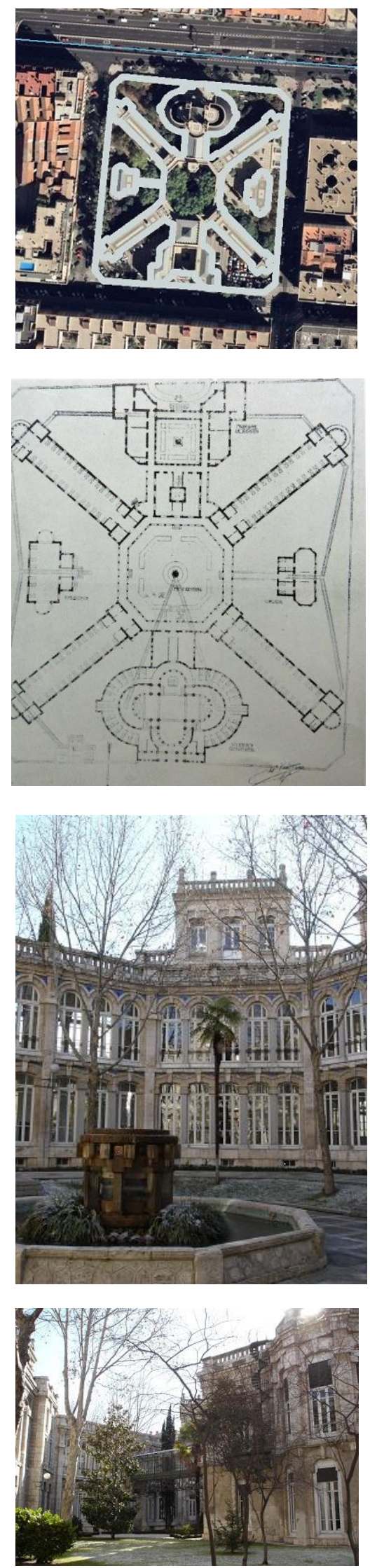

2.20 Hospital de San Francisco de Paula: planta y vistas actuales. Arquitectura, 1967, p. 24. Ayuntamiento de Madrid, monumentamadrid.es - Ref. 10322.

2.21 Patio central octogonal. "Hospital de San Francisco de Paula", Revista Nacional de Arquitectura. Madrid: Ministerio de la Gobernación, Dirección General de Arquitectura, 1945, n-47 y 48 noviembre, p.394. algunos árboles y cipreses sobre una pradera. Emplea un lenguaje ecléctico con una mezcla constante entre historicismoacademicismo y modernidad ${ }^{47}$.

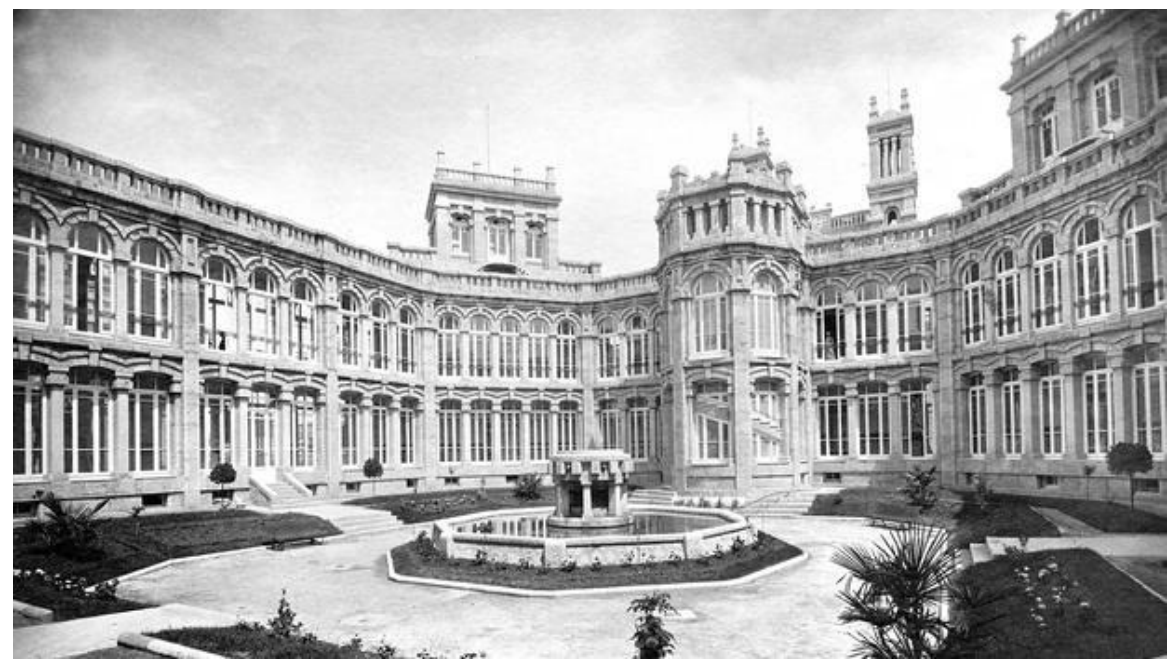

En ambos recintos hospitalarios de Barcelona y Madrid hay una disposición moderna de los edificios que buscan el máximo soleamiento siguiendo las corrientes higienistas modernas, aunque los jardines siguen siendo tradicionales con un lenguaje clásico.

Un caso singular es el de Julián Otamendi Machimbarrena (18891966); este arquitecto e ingeniero utiliza el jardín como telón de fondo decorativo de sus villas sin proponer trazados. No hay planos de jardines propiamente dichos, son sólo planos decorativos, como si se tratase de una mera escenografía. Aunque su arquitectura tiene en general rasgos modernistas, en los dibujos de sus jardines se aprecian líneas clásicas con perspectivas, estanques y setos recortados, acompañados de un paisaje de fondo con montañas y masas arbustivas y arbóreas entre las que se distinguen ejemplares de pinos y cipreses. Esto se aprecia en los alzados de los pequeños hoteles madrileños que realiza para la actriz Carmen Ruiz Moragas (1922), o el hotel de Miguel Arsuaga (1926) o el de Luis Martínez Crespo (1929).

47 En 1984 Andrés Perea inicia una rehabilitación vaciando el patio hacia la calle de Maudes, desmontando la escalinata y trasladando la fuente central, para crear un nuevo vestíbulo de acceso. 

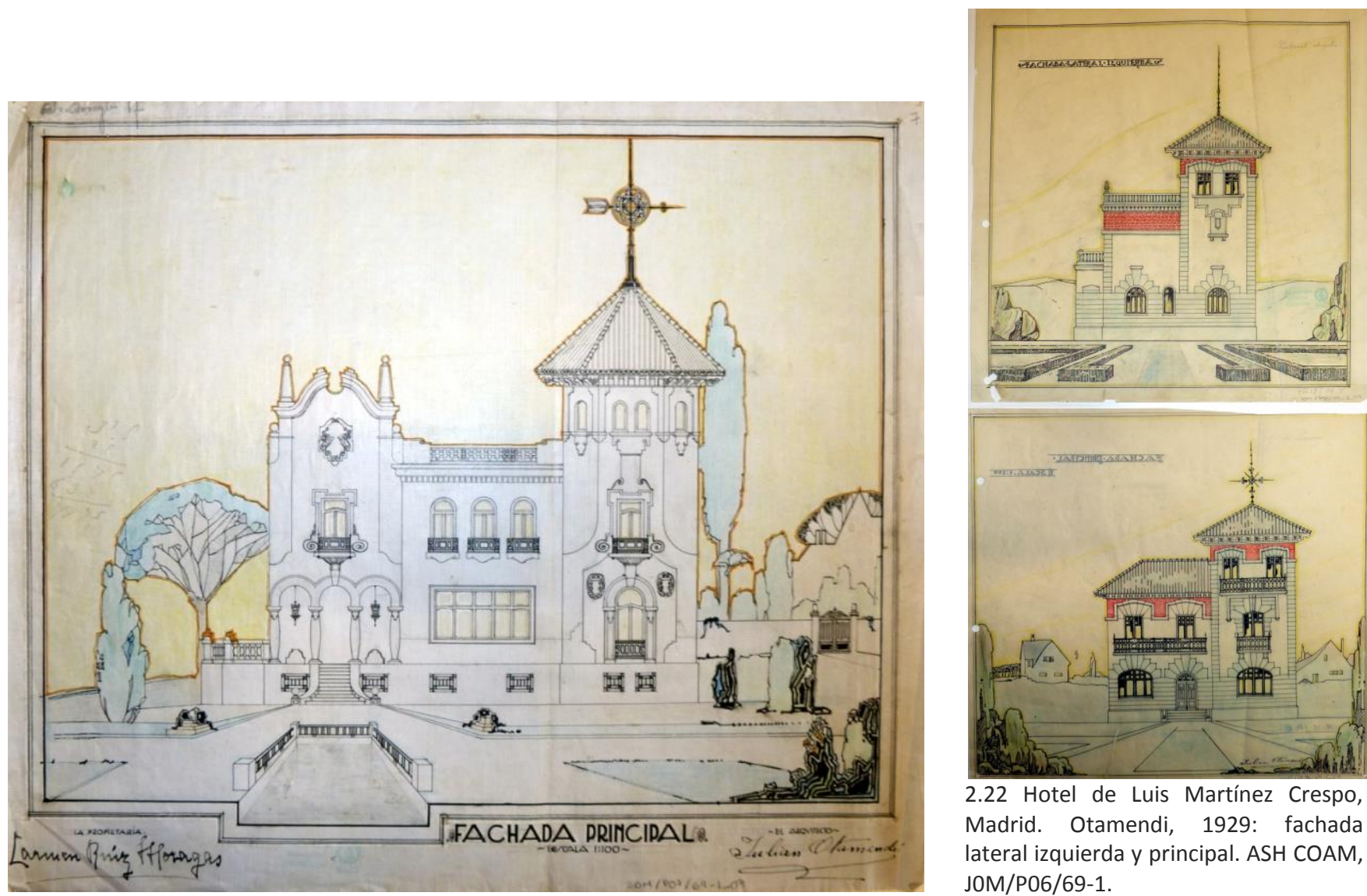

2.22 Hotel de Luis Martínez Crespo, Madrid. Otamendi, 1929: fachada lateral izquierda y principal. ASH COAM, J0M/P06/69-1.

2.23 Hotel de Carmen R. Moragas, Madrid. Otamendi, 1922: fachada

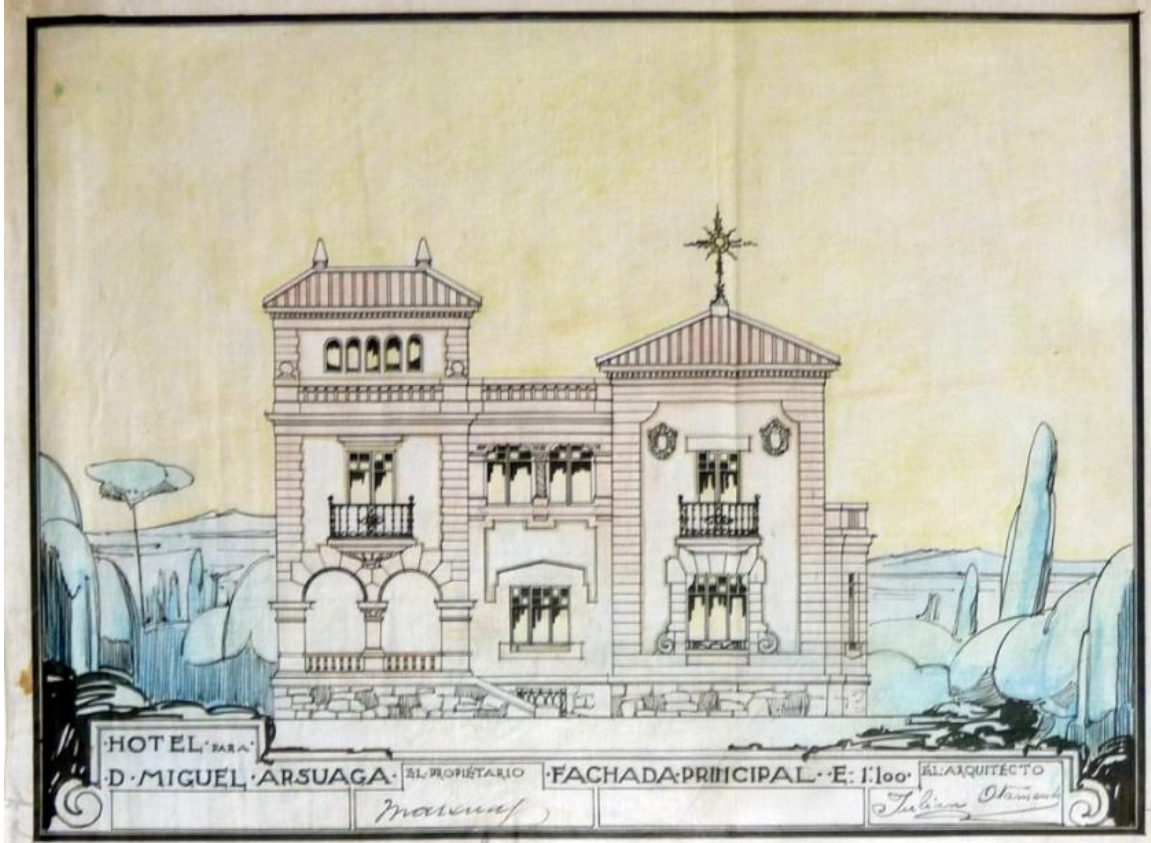

principal. ASH COAM, JOM/P07/69-1.

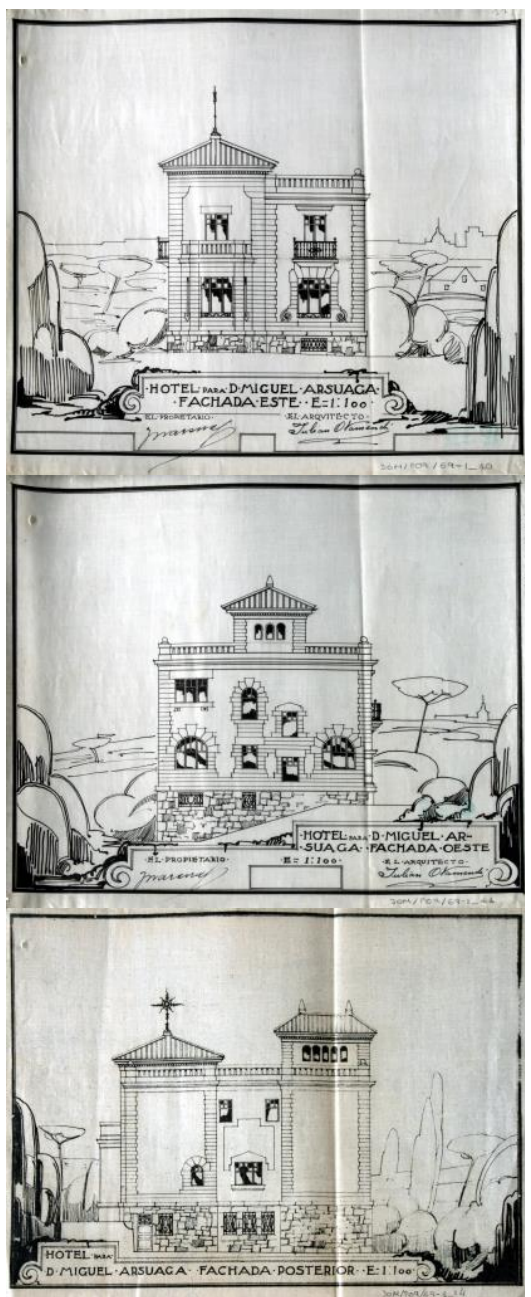

2.24 Hotel de D. Miguel Arsuaga, Madrid. Otamendi, 1926: fachada este, oeste, posterior y principal. ASH COAM, J0M/P09/69-1. 


\section{EL JARDÍN TRADICIONAL MEDITERRÁNEO}

La cuenca mediterránea con su clima suave pero soleado y su terreno seco y rocoso dan lugar a un paisaje con unas características comunes y con una vegetación específica, con la excepción de los jardines de aclimatación y botánicos ${ }^{48}$. En los jardines mediterráneos se van a ir superponiendo diversos estilos según los arquitectos y jardineros de cada época.

En España en este periodo de gran eclecticismo además de las figuras modernistas como Gaudí y Otamendi, surgen otras más clásicas, como Jean-Claude Nicolas Forestier. Éste forma parte de una larga tradición de jardineros extranjeros -franceses, italianos, flamencos...- que los monarcas españoles traían para realizar sus jardines. Forestier, impactado por los jardines granadinos $y$ sevillanos, elaboró un nuevo estilo propio neosevillano o neoandaluz. Tuvo gran repercusión en los jardines españoles posteriores, pues su vertiente mediterránea será el punto de partida de Nicolás María Rubió i Tudurí, tradición que él llamó el "jardín latino" profundizando en el origen de este jardín y el encuentro de la jardinería española con su tradición mediterránea; mientras que su reconsideración del jardín andaluz servirá de referencia a Javier de Winthuysen, que con sus escritos y realizaciones intentará recuperar el jardín clásico en España.

\section{Jean-Claude Nicolas Forestier (1861-1930)}

Diplomado en la Escuela Forestal de Nancy, Forestier se dedicó de lleno a la jardinería con gran equilibrio entre su perspectiva técnica de ingeniero y su gran sensibilidad. Influido por los patrones estéticos de l'École de Beaux Arts, fue continuador en ruptura de Adolphe Alphand, contemporáneo de Achille Duchêne, y gran admirador de Le Nôtre, pero consciente de la necesidad de evolucionar. Realizó importantes reformas en París con el barón Haussmann y organizó varias exposiciones universales. Como conservador de los Paseos y Parques de París (1887-1927) realizó la restauración y reforma del parque de Bagatelle en el Bois de Boulogne (1905) con la creación de una magnífica rosaleda, y la apertura de paseos y calles como la de Breteuil. Estableció su oficina en París y realizó parques por toda Europa, África y América, sabiendo coordinar el clasicismo francés con cada uno de los estilos

\footnotetext{
${ }^{48}$ Ver capítulo de Jardines Botánicos.
} 
y culturas jardineras de los países a los que iba, y aceptando la forma de cada jardín e incorporándolo a su forma de trabajar, siempre de forma responsable y exigente.

Conoció a Le Corbusier y ambos compartieron algunos planteamientos sobre la relación ciudad parque, aunque Forestier manifestó su preferencia por la ciudad jardín. El propio Le Corbusier comentaba: "He tenido la buena suerte de encontrar hoy mismo al señor Forestier, ingeniero de Aguas y Bosques, arquitecto-paisajista del Bois de Boulogne y de las plantaciones parisienses. Este hombre experimentado se ocupa de los árboles y las flores y aprecia por qué viven; sabe cosas que se refieren al condicionamiento mismo del ser físico. No conocía mis investigaciones sobre urbanismo; sus palabras fueron otras tantas confirmaciones procedentes del fenómeno natural a mis conclusiones resultantes de un sistema teórico"49. Forestier con sus ideas urbanísticas influirá en Le Corbusier y en el urbanismo funcionalista, adelantando ya algunos aspectos: la división funcional de la ciudad, el diseño de grandes avenidas convertidas en ejes de circulación, el recurso a las grandes masas de vegetación, y la ciudad concebida a escala regional ${ }^{50}$.

A través de sus artículos y libros teóricos difundió sus ideas: Grandes villes et Systèmes de Parcs $(1906)^{51}$, donde expuso los elementos teóricos sobre la ciudad difundiendo en Europa la concepción del sistema de parques, la protección de paisajes y la constitución de grandes reservas, partiendo de distintas experiencias, entre las que destaca la estadounidense de Olmsted; Jardins, carnet de plans et dessins (1920) ${ }^{52}$; Des jardins d'autrefois aux jardins d'aujourd'hui (1921), etc. Forestier en sus conclusiones afirma que los parques y los espacios libres son indispensables para la vida y el crecimiento de una gran ciudad, para ello es necesario una buena distribución y conservación de grandes reservas de parques y jardines. Estas reservas estaban previstas en los alrededores de la ciudad donde se encontraban "las bellezas

\footnotetext{
49 LE CORBUSIER. La Ciudad del Futuro [1924]. Buenos Aires: Ediciones Infinito, 1971, p. 121

50 CASALS COSTA, V.: "Barcelona, Lisboa y Forestier: Del Parque Urbano a la CiudadParque". Scripta Nova, vol. XIII, no. 296 (2), 1 de agosto de 2009, Universidad de Barcelona.

${ }^{51}$ FORESTIER, J.C.N.: Grandes villes et systèmes de parcs. France, Maroc, Argentine. Paris: Norma Ediciones, 1997. Primera edición: París, 1906.

${ }^{52}$ FORESTIER, J.C.N.: Jardines. Cuaderno de dibujos y planos. Barcelona: Stylos, 1985.
}

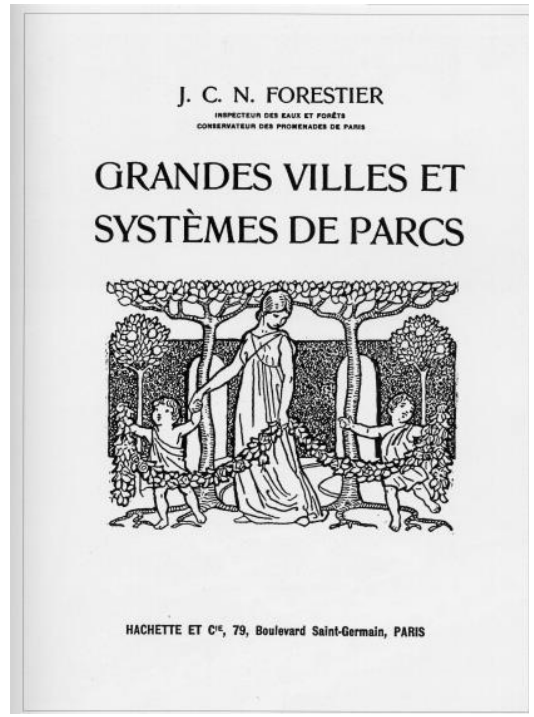

3.1 Portada de Grandes viles et Systèmes de Parcs, de J.C.N. Forestier, París 1906.
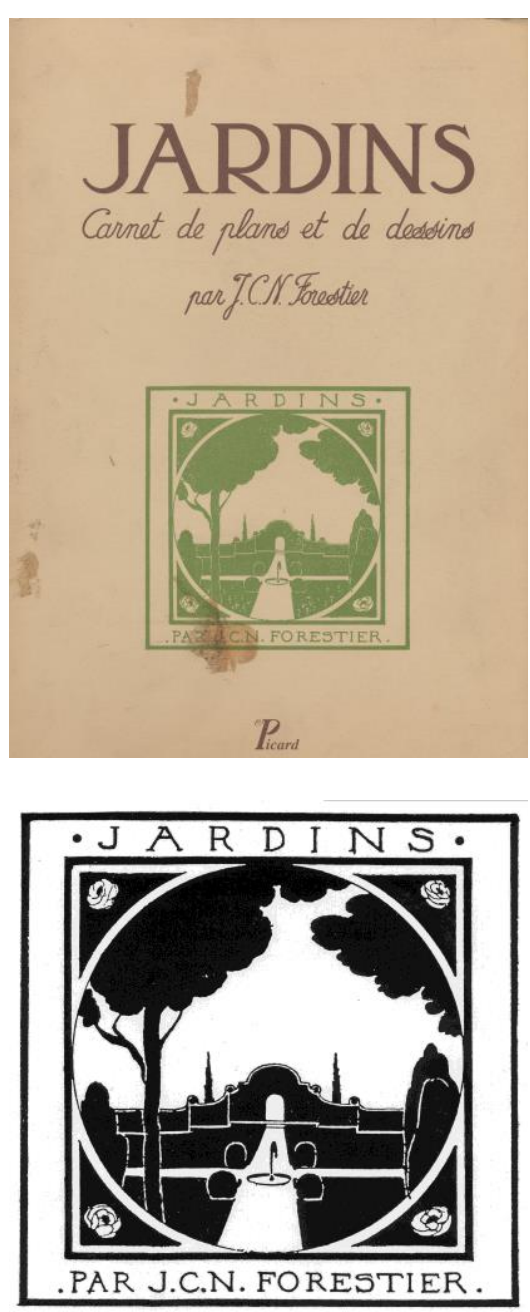

3.2 Jardins: carnet de plans et de dessins, de J.C.N. Forestier, 1920: portada del libro y detalle del dibujo. 


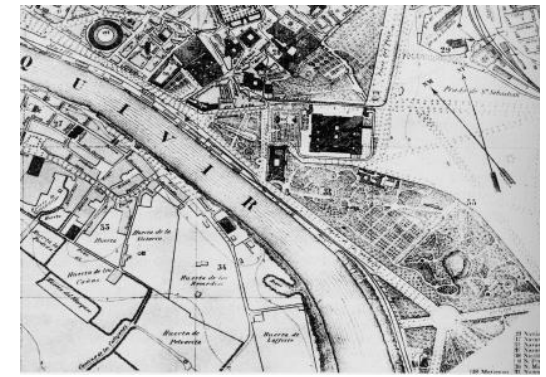

3.3 Detalle del plano de Sevilla, 1891, Antonio Padura. Jean Claude Nicolas Forestier 1861-1930. Du jardin au paisaje urbain, 1994.

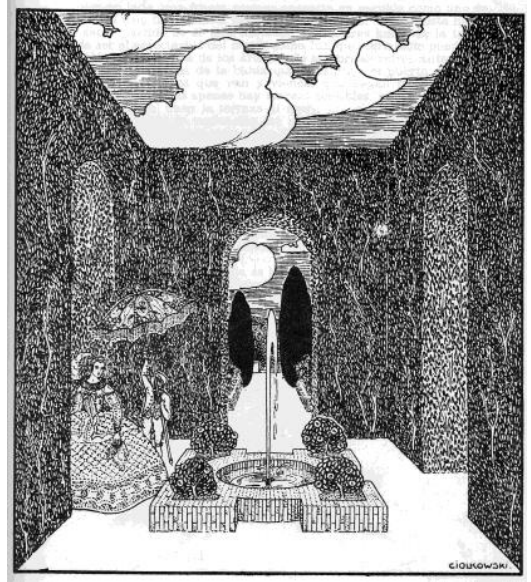

3.4 Proyecto para el parque de María Luisa de Sevilla: dibujo. Forestier, 1911. FORESTIER, J.C.N.: Jardines. Cuaderno de dibujos y planos. Barcelona: Stylos, 1985 , p. 66.

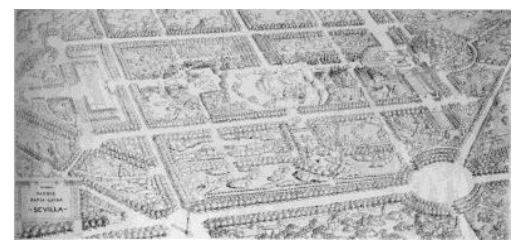

3.5 Perspectiva, Forestier, 1913. Archivo de parques y jardines de Sevilla. Jean Claude Nicolas Forestier 1861-1930. Du jardin au paisaje urbain, 1994.

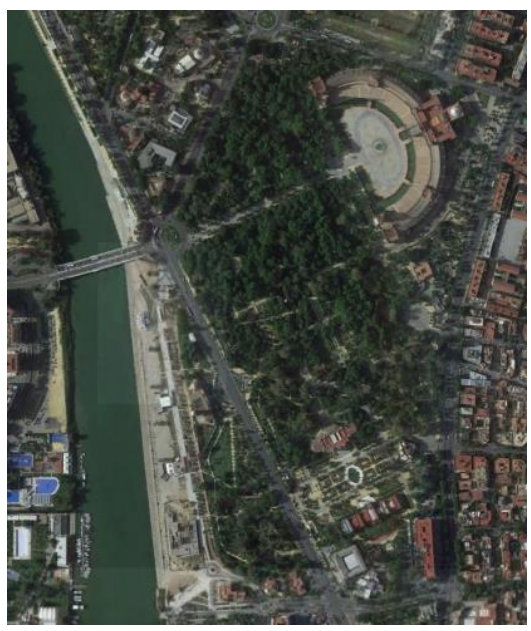

3.6 Parque de María Luisa: vista aérea actual. GoogleEarth. naturales o pintorescas dignas de ser conservadas"53 -como él mismo explicaba-, ya sea por el estado de la vegetación, por los aspectos o por las vistas a conservar.

Da a conocer una nueva filosofía de jardines, la cual pone en práctica en España en numerosos jardines privados (Santander, Madrid, Málaga, Córdoba, etc.) y sobre todo en dos parques públicos: parque de María Luisa en Sevilla y parque de Montjuich en Barcelona donde trabajó en estrecha colaboración con Nicolau Maria Rubió i Tudurís ${ }^{54}$. Éste siente gran admiración por Forestier: "Era minucioso y buscaba siempre las más audaces soluciones con tal de ser el mejor"55. Era un gran botánico y horticultor, y fue el introductor o reintroductor de nuevas especies y variedades de plantas en España (Tipuana, Fraxinus Berlandieriana, Echium Fastuosum, rosales, etc.).

En 1911 el Comité Ejecutivo de la Exposición Iberoamericana de 1929 invitó a Forestier a Sevilla para reformar el parque de María Luisa ${ }^{56}$, lugar de celebración de dicha exposición que buscaba transmitir un aire de "monumentalidad institucional" con pabellones de estilo ecléctico entre los que destacaban los españoles de estilo neomudéjar apostando por la tradición historicista que contrastaba con la arquitectura de vanguardia como la propuesta de Mies van der Rohe para el pabellón alemán de la paralela Exposición Universal de Barcelona.

Aunque de origen francés, Forestier supo adaptarse perfectamente al clima y a la historia de los jardines españoles, siendo un gran enamorado de los jardines de la Alhambra y el Generalife de Granada y del Alcázar de Sevilla, consigue un equilibrio entre estos precedentes históricos y su interpretación moderna "huyendo de impropios exotismos"57, como indica Winthuysen. Predomina la rígida ordenación geométrica y los trazados monumentales con ejes

\footnotetext{
53 FORESTIER, J.C.N.: Grandes villes et systèmes de parcs. France, Maroc, Argentine. Paris: Norma Ediciones, 1997, p. 96. (traducción del francés P. Hernández Lamas)

54 Ver capítulo de Los parques de Rubió $i$ Tudurí en Cataluña.

55 RUBIÓ I BOADA, M.: Nicolau María Rubió i Tudurí (1891-1981). Barcelona. Ayuntamiento de Barcelona, 1989, p. 49.

56 Este parque formaba parte de los jardines privados de corte romántico del Palacio de San Telmo, creados por el jardinero André Lecolant. La infanta Mạ Luisa Fernanda de Borbón, duquesa de Montpensier, tras la muerte de su marido, donó estos jardines que llevan su nombre a la ciudad de Sevilla en 1893, abriéndose al público en 1914 tras las reformas.

57 WINTHUYSEN: "El arquitecto paisajista M. Jean C.N. Forestier y su labor mundial". Revista de Obras Públicas, 15 diciembre 1930. En Javier de Winthuysen, 1986, p. 176.
} 
ortogonales, líneas de fuga y remates de perspectivas, propios de los jardines clasicistas franceses de Le Nôtre; pero se ve cómo promueve los valores tradicionales del jardín andaluz, superponiendo un trazado de glorietas y pequeñas estancias, con la habilidad de modificar la escala íntima y menor del jardín hispanomusulmán y llevarlos a la gran escala de parque público, logrando humanizar los monumentales ejes clasicistas. Este recurso lo utilizó mucho en sus parques públicos, donde introdujo espacios a escala doméstica, cada uno con un tratamiento especial, a modo de pequeños patios con paredes vegetales de setos de arrayán que proporcionan intimidad, fuentes bajas con surtidores y bancos para el descanso y disfrute. Esta combinación del trazado regular con el hispanoárabe va a ser una constante en sus proyectos.

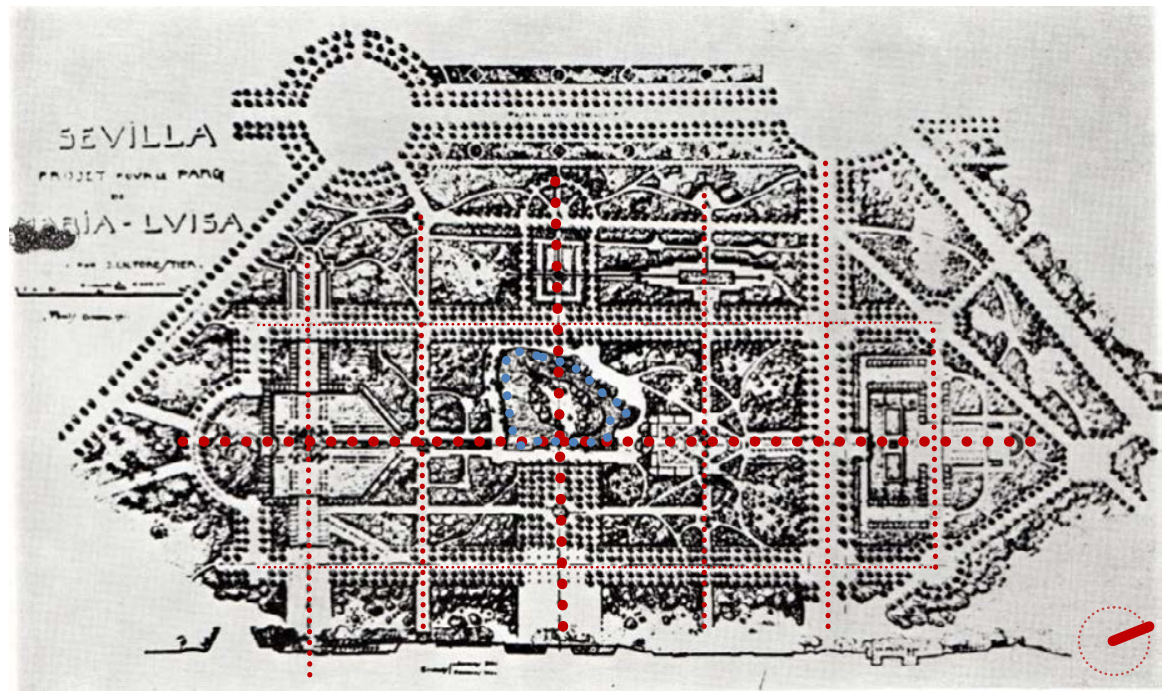

Los dos ejes principales del parque de María Luisa se cruzan en la isleta irregular del estanque de los patos de bordes sinuosos; este lago paisajista parece que ya existía. El eje transversal, además del lago y las calles longitudinales, cruza una serie de elementos: plaza cuadrada, estancia rectangular con dos acequias que remite al jardín hispanomusulmán y termina en una exedra arbórea. El eje longitudinal se remata en ambos lados por espacios absidiales: glorieta de Lotos y fuente de los Leones. La primera se basa en el Patio del Ciprés de la Sultana del Generalife ${ }^{58}$ y en el Patio de la Alberca de la Alhambra para crear un estanque central rectangular,

\footnotetext{
58 Una fuente central flanqueada por dos parterres de flores rodeados de setos de mirto originalmente, y a su vez rodeados de un estanque con varios surtidores, delimitado exteriormente con setos de mirto recortados. Forestier señala que antiguamente debía estar rodeado de una pared verde de cipreses. En su dibujo se muestra como la composición está basada en un cuadrado y sus sucesivas divisiones a 45․ FORESTIER, J.C.N.: Jardines. Cuaderno de dibujos y planos. Barcelona: Stylos, 1985, p.40.
}
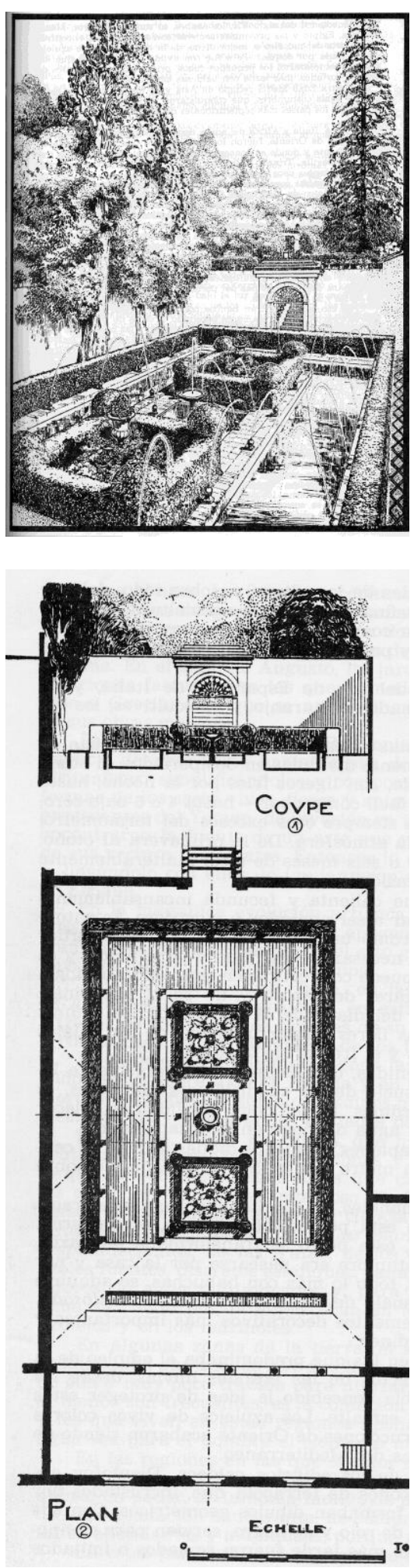

3.7 Patio del Ciprés de la Sultana en el Generalife granadino: perspectiva, planta y sección. Forestier. FORESTIER, 1985, p.40- 41.

3.8 Proyecto para el parque de María Luisa de Sevilla: planta. Forestier, 1911. FORESTIER, J.C.N.: Jardines. Cuaderno de dibujos y planos. Barcelona: Stylos, 1985 , p. 67. 


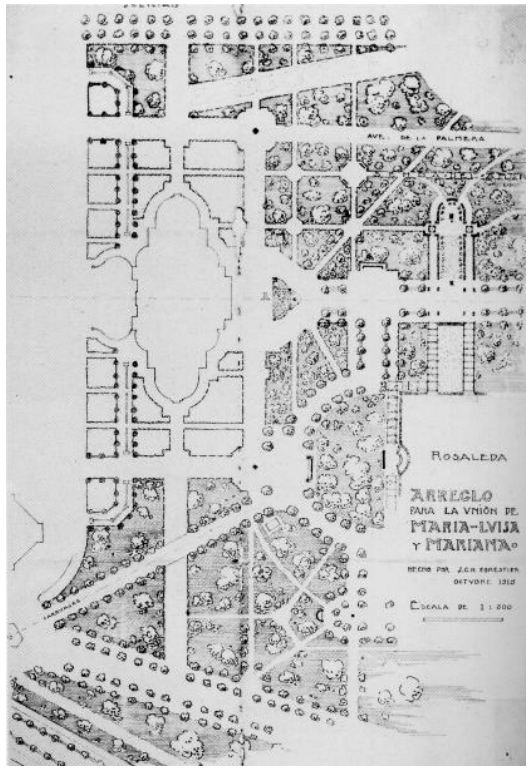

3.9 Plano para la unión del parque María Luisa con el huerto de Mariana. Forestier, 1915. Documentos Exposición Ibero-Americana, en Jean Claude Nicolas Forestier 1861-1930. Du jardin au paisaje urbain, 1994.

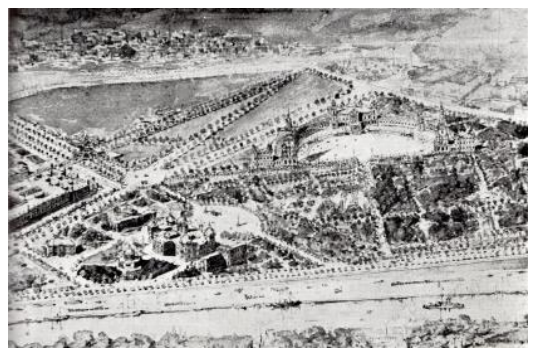

3.10 Perspectiva del río Guadalquivir y la Plaza de España, 1918. TRILLO DE LEYVA, M.: La exposición iberoamericana: la transformación urbana de Sevilla. Sevilla: Ayuntamiento de Sevilla, 1980, p. 79.
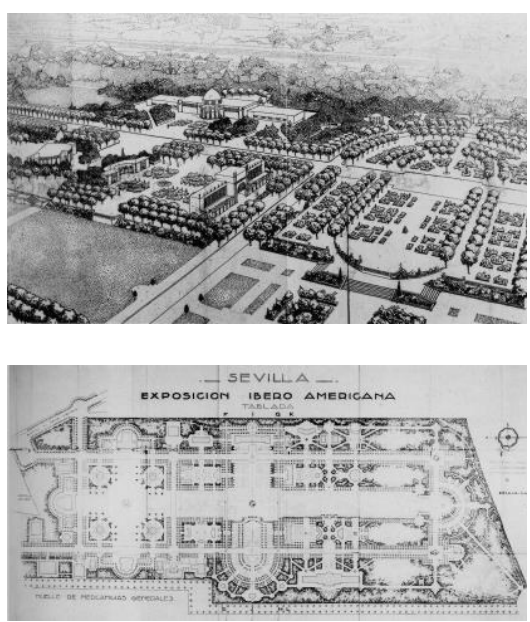

3.11 Proyecto de extensión del sector sur de la Exposición Ibero-Americana: perspectiva y planta. Forestier, 1924 Jean Claude Nicolas Forestier 18611930. Du jardin au paisaje urbain, 1994. tipo acequia y rodeado de una pérgola con bancos de ladrillo. La segunda se inspira en el Patio de los Leones de la Alhambra de Granada con una fuente central ochavada con leones y articulada con el eje principal mediante un estanque. Estos dos elementos de agua, junto con la Cascada y el estanque de los patos, refuerzan el eje central. Destaca la rosaleda en el extremo sur donde aprovecha un montículo cubierto de árboles de gran porte como telón de fondo ${ }^{59}$. Utiliza una ornamentación clásica y materiales tradicionales locales tanto en la construcción (mosaicos, azulejos ${ }^{60}$, etc.) como en la vegetación con especies autóctonas. Introduce una nota íntima en los parques públicos con una variedad de plantas en macetas, realizando la transformación inversa, del hortus conclusus al parque, multiplicando y agrandando los elementos que lo componen $^{61}$. Es muy respetuoso con el arbolado existente ${ }^{62}$, manteniendo también parte de los naranjos de las antiguas huertas y alternándolo con las nuevas plantaciones traídas de Granada, Valencia y Francia ${ }^{63}$. Además de la arboleda primitiva del parque original de Lecolant, conserva algunos de los caminos sinuosos que le restan rigidez al trazado geométrico, como el monte Gurugú con su cascada y el estanque de los Patos, de trazado irregular e isleta central con pequeño templete neomudéjar, aportando un aire naturalista ${ }^{64}$.

Preocupado siempre por los problemas urbanísticos, Forestier buscó la integración y continuidad con la trama urbana existente facilitando las conexiones; proyectó avenidas interiores y exteriores para carruajes y peatones, y se preocupó de la función social del jardín público, siguiendo las teorías norteamericanas de Olmsted. Además de una continuidad espacial entre parque y ciudad hay una

\footnotetext{
59 Ibíd., p. 179.

60 Todo se decora con azulejos y cerámicas tradicionales de las fábricas sevillanas más importante y se convocan concursos entre los más prestigiosos escultores de la época.

61 IMBERT, D.: "Tracé architectonique et poétique végétale", en Jean Claude Nicolas Forestier 1861-1930. Du jardin au paisaje urbain. Paris: Picard, 1994, p.74.

62 "La irregularidad de algunas avenidas obedece al hecho de que ya existían y que, bordeadas de árboles añosos y muy bellos, debían ser conservadas en aquel estado". FORESTIER, J.C.N.: Jardines. Cuaderno de dibujos y planos. Barcelona: Stylos, 1985, p.179.

63 Utiliza vegetación autóctona y entre sus preferencias están: arrayanes, evónimos, tamarindos, jazmines, campanillas azules, rosales, acacias negras, ailantos, moreras de papel, plátanos, palmeras, sicomoros, sóforas, tuliperos de Virginia, arces, magnolias, Júpiter, adelfas, abutilones, mirtos, laureles, lotos, nenúfares, buganvillas...Destacan los grandes ejemplares en el parque de plátanos, jacarandas, ficus dealbata, taxodium distichum, araucarias bidwilli, washingtonias robusta...AÑÓN, C.: "El s. XX". Historia de los parques y jardines de España. Grupo FCC, 2001, p. 378.

${ }^{64}$ NIETO CALDEIRO, S.: "La Sevilla reformada", en Jean Claude Nicolas Forestier 18611930. Du jardin au paisaje urbain. Paris: Picard, 1994, p. 103.
} 
continuidad en el trazado con la malla ortogonal de caminos. Respetó la avenida existente y creó otras organizadas mediante alineaciones dobles arboladas a ambos lados de la calzada como si fueran vías urbanas y siempre permitiendo la permeabilidad del parque con la ciudad. Además de los paseos fue introduciendo calles cada vez más estrechas de las que salen senderos irregulares que se van metiendo en la arboleda, combinando la trama ortogonal con caminos cada vez más libres. La posible monotonía del trazado regular se corrige con pequeños desniveles que le dan una mayor variedad. Como cerramiento del parque propuso una verja ligera convirtiéndolo en un espacio abierto para la ciudad. El nuevo parque se convirtió en el motor del nuevo crecimiento organizado de la ciudad hacia el sur de la ya existente, junto al Guadalquivir.

Winthuysen admiraba esta obra y la consideró el inicio del resurgimiento del jardín andaluz: "La modalidad andaluza, fraguada con los diversos estilos durante la historia ha llegado a constituir el tipo de jardín conocido con el nombre genérico de "Jardín Andaluz" que ha tenido en la modernidad la extensión mundial que es sabida, con las obras de Forestier en Sevilla y Barcelona, llevadas también al protectorado francés de Marruecos, y por los paisajistas americanos a las obras de los Estados de California y Florida, aprovechando así los extranjeros nuestra tradición, que pudiera ser una expansión para nuestros artistas, de existir en España una atención para nuestras obras del pasado (únicas) y una enseñanza especial artística de jardinería"65.

Le encargaron dos proyectos de extensión del parque: unión de María Luisa y Huerta de Mariana y nueva parcela incorporada desde S. Telmo a Mariana (ambos de 1915). Se organizaba en una trama paralela al Paseo de las Delicias; perpendicular a ésta se halla la Av. Rodríguez Caso, la cual culmina en la Plaza de España. El otro espacio público de importancia, la Plaza de América, se encontraba en el otro extremo de la exposición, también perpendicular al Paseo de las Delicias; ambas plazas fueron proyectadas por Aníbal González ${ }^{66}$. Al conjunto se incorporaron los jardines de las Delicias.

\footnotetext{
65 WINTHUYSEN, J. Memorias de un Señorito Sevillano. 1942. Nueva Edición. HÉCTOR VÁZQUEZ, M. et al. (edit.). Winthuysen Foundation, Inc, 2005, p. 275.

${ }^{66}$ Este arquitecto fue quien propuso la utilización del parque como biblioteca pública al aire libre con librerías de cerámica que permitían la lectura a los visitantes. La Plaza de España se convierte en una gran sala de lectura al aire libre y surgen varios monumentos a
}
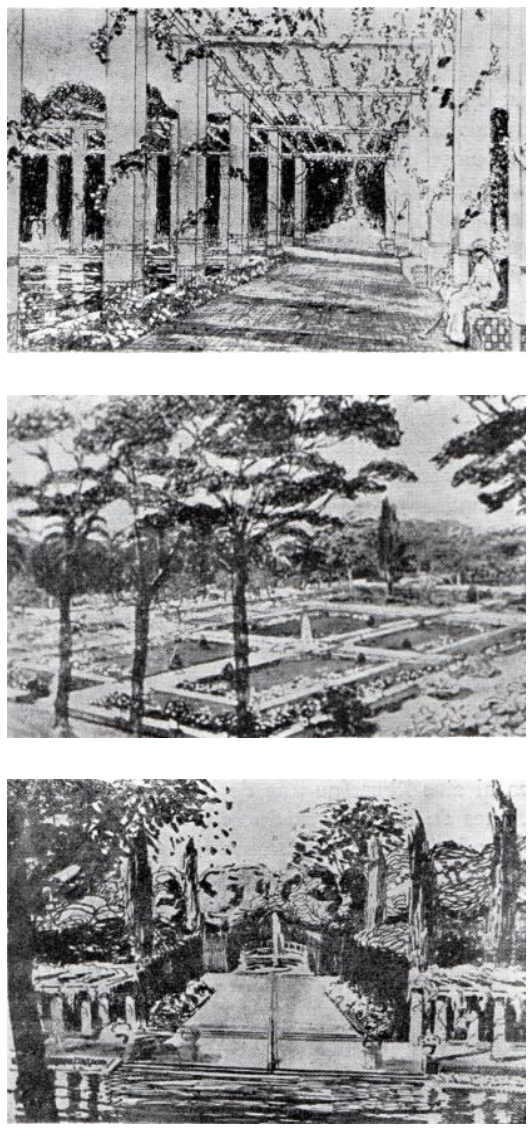

3.12 Perspectivas del parque de María Luisa: estanque de los nenúfares, jardín al oeste del estanque y extremo norte del eje principal. TRILLO DE LEYVA, 1980, p. 173.

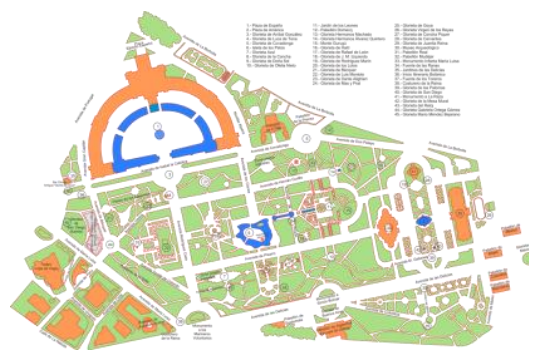

3.13 Plano actual del parque de María Luisa. Ayuntamiento de Sevilla. 

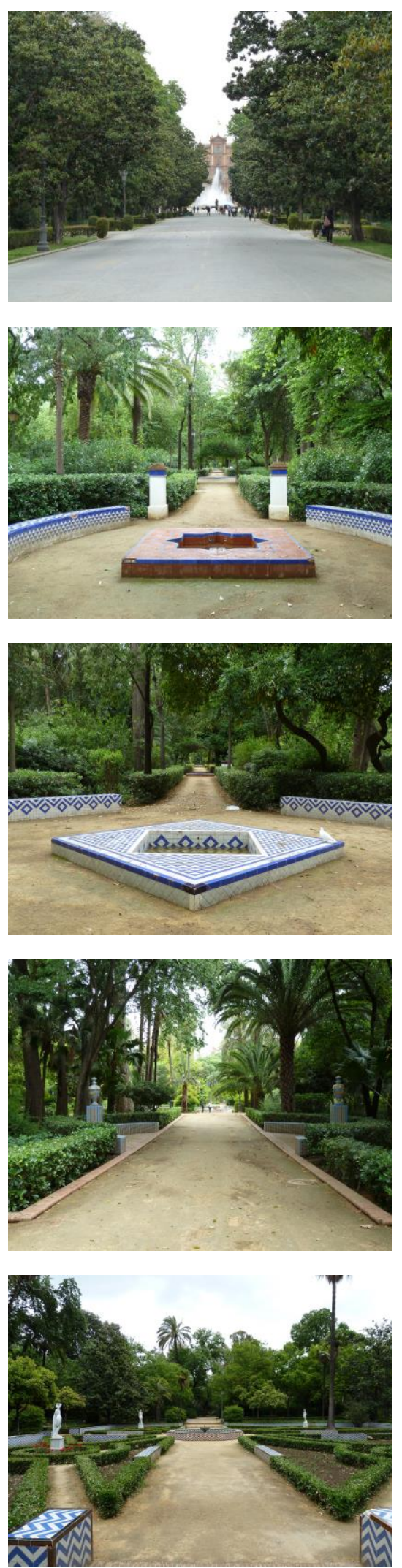

3.16 Parque de María Luisa: perspectiva de uno de los ejes principales y diferentes glorietas con fuentes $y$ bancos decorados con azulejos.
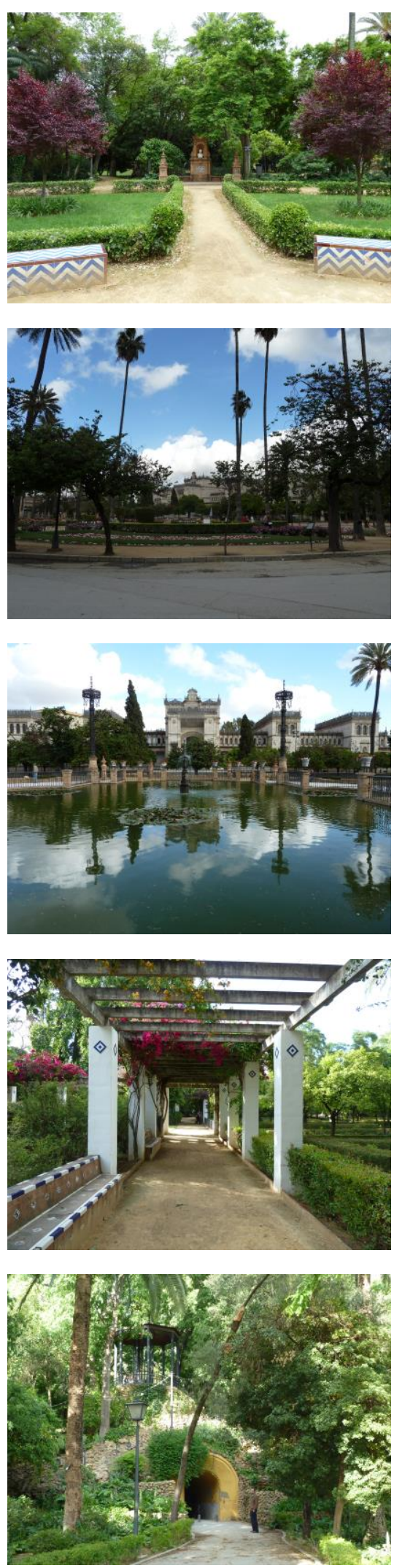

3.15 Parque de María Luisa: monumento como fondo perspectivo, Plaza de América con estanque con nenúfares y Pabellón Real al fondo, pérgola y paso subterráneo.
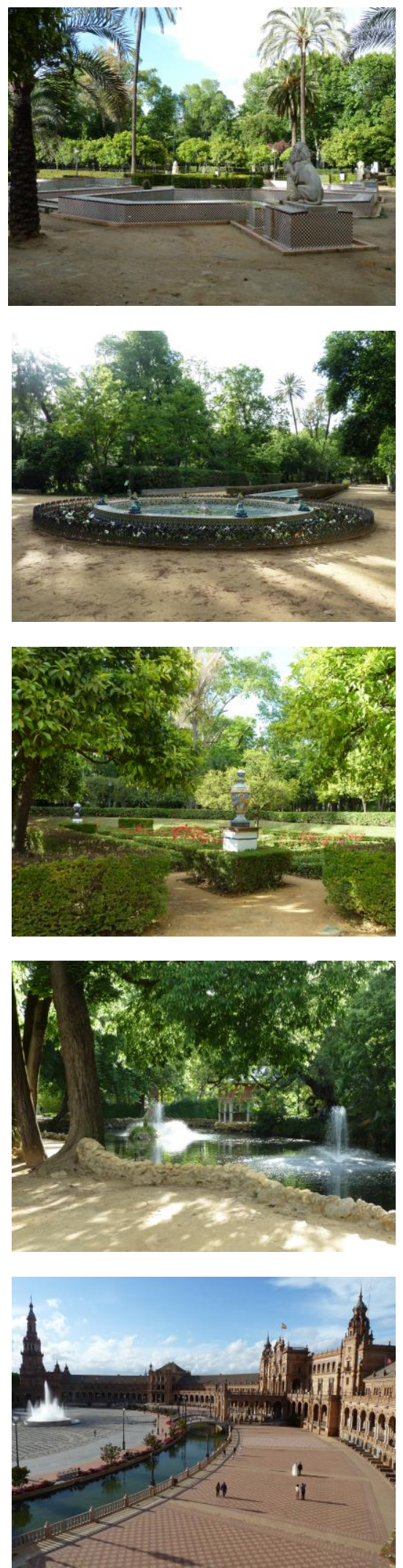

3.14 Parque de María Luisa: fuente de los Leones, fuente de las Ranas, jarrón de cerámica sevillana, estanque de los Patos y Plaza de España. PHL, mayo 2012.

literatos (Bécquer, hermanos Álvarez Quintero, J.Mạ Izquierdo, Fernán Caballero, etc.). AÑóN, C.: "El s. XX". Historia de los parques y jardines de España. Grupo FCC, 2001, p. 381. 
El Ayuntamiento de Sevilla también le encargó la reforma de la plaza de San Fernando o plaza Nueva donde vuelven a aparecer las reminiscencias hispanomusulmanas con una acequia y fuentes bajas octogonales en los extremos con surtidores manteniendo las tres hileras perimetrales existentes de arbolado.

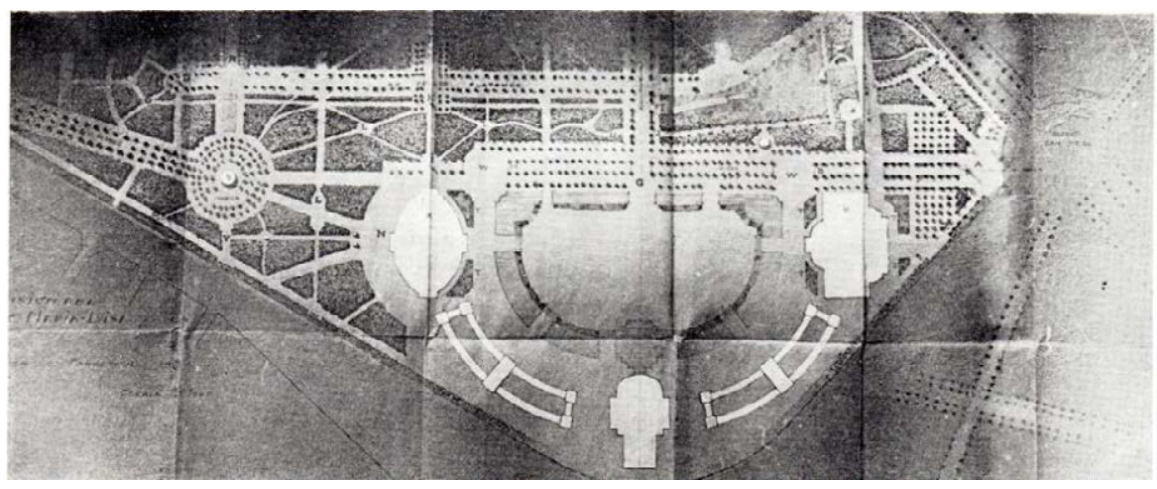

El parque de María Luisa tuvo gran acogida y le abrió la puerta en España, tras encargarle los proyectos de extensión del parque ${ }^{67}$, realizó numerosos jardines para la aristocracia del momento que yquería acompañar sus mansiones con jardines a la moda neosevillana o neo-árabe del momento. Este es el caso de la Casa del Rey Moro en Ronda (Málaga, 1912), propiedad de la duquesa de Parcent, quien instaló su residencia sobre un palacete del siglo XV, y encargó los jardines a Forestier. Éste desarrolló un jardín en una estrecha franja mediante planos escalonados que se adaptan a la fuerte pendiente sobre el Tajo del río Guadalevín y se conectan mediante escaleras. El agua es el hilo conductor del jardín que conecta las tres terrazas: la primera y más elevada rodea la casa con aire andaluz (fuente estanque, bancos de azulejos y pavimento de olambrillas); la segunda continúa el eje con una fuente de azulejo blanco y un canal longitudinal, acompañado de una pérgola con columnas de mármol blanco y travesaños de madera con rosales adosada a la tapia, y arriates rectangulares de rosales de pequeños boneteros enanos alternados con filetes de boj68; y la tercera con estanque que actúa como cisterna, y caminos de garbancillo entre setos recortados que conducen a una pequeña plataforma con vistas panorámicas sobre el espectacular barranco.

\footnotetext{
67 Dos proyectos de extensión del parque: Unión de Maria Luisa y Huerta de Mariana (1915), y nueva parcela incorporada desde S. Telmo a Mariana (1915); posteriormente se le encargó el proyecto para los jardines del Sector Sur de la Exposición (1924). DOMíNGUEZ PELÁEZ, C.: "Los jardines en España", en Jean Claude Nicolas Forestier 18611930. Du jardin au paisaje urbain. Paris: Picard, 1994, p.87.

68 FORESTIER, J.C.N.: Jardines. Cuaderno de dibujos y planos. Barcelona: Stylos, 1985, p.151-152.
}

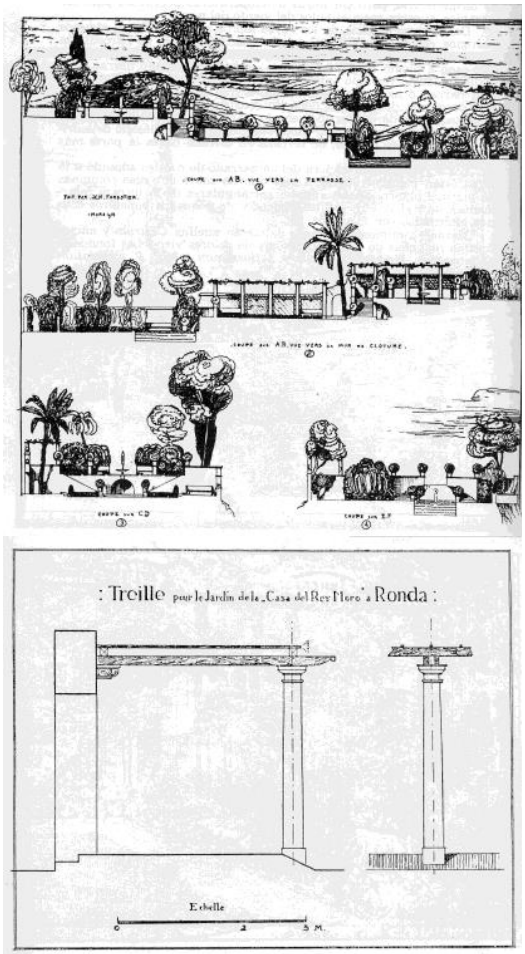

3.17 Proyecto para el jardín de la Casa del Rey Moro en Ronda: secciones y emparrado. Forestier, 1912. FORESTIER, 1985, p. 37 y 49.
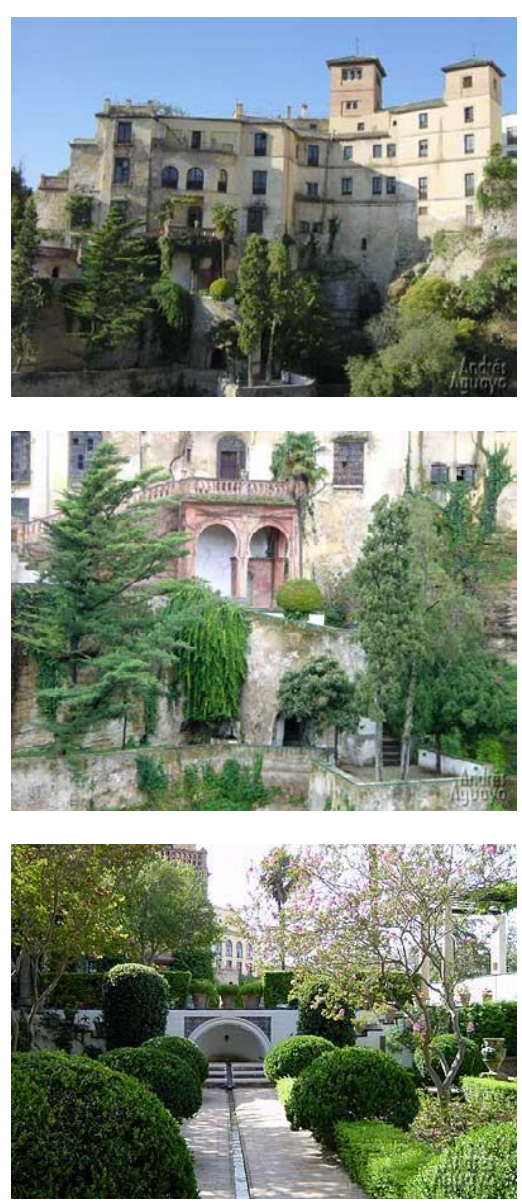

3.18 Casa del Rey Moro: vistas actuales. Turismoderonda.es.

3.19 Extensión del parque de María Luisa. Forestier, 1915. TRILLO DE LEYVA, 1980, p.80. 
3.20 Proyecto para el jardín de la Casa del Rey Moro en Ronda: planta. Forestier, 1912. FORESTIER, 1985, p. 50.
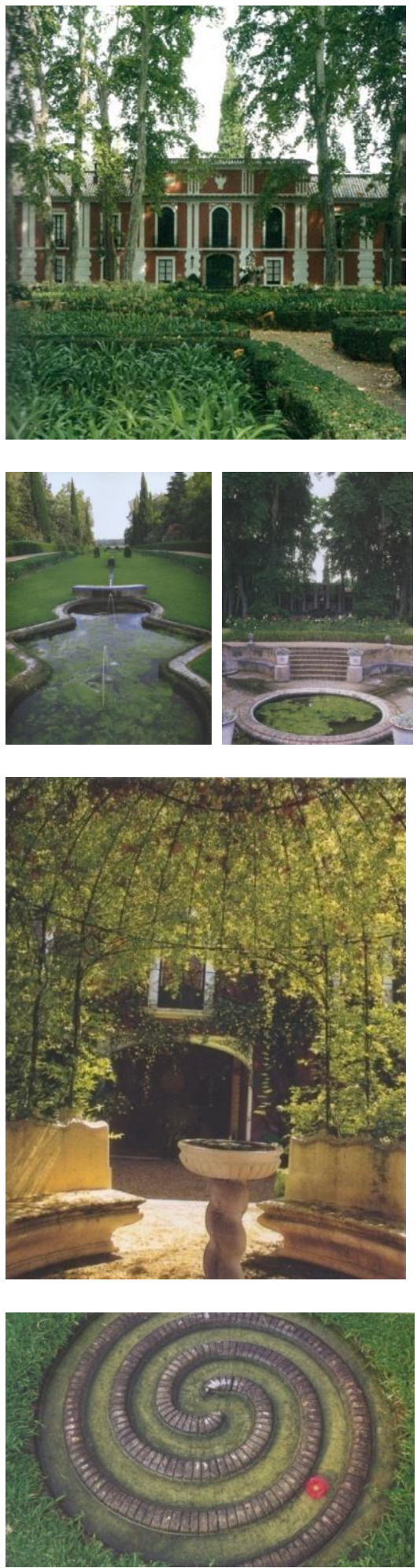

3.21 Hacienda de Moratalla: diversas vistas actuales del jardín. AÑóN, C.; et al.: Jardins en Espagne. Actes Sud, 1999, p. 173. MENCOS, E.: Jardines secretos de España. Barcelona: Blume., 2004, p. 88-93.
En todo el jardín se conjuga la perspectiva clásica con elementos islámicos.

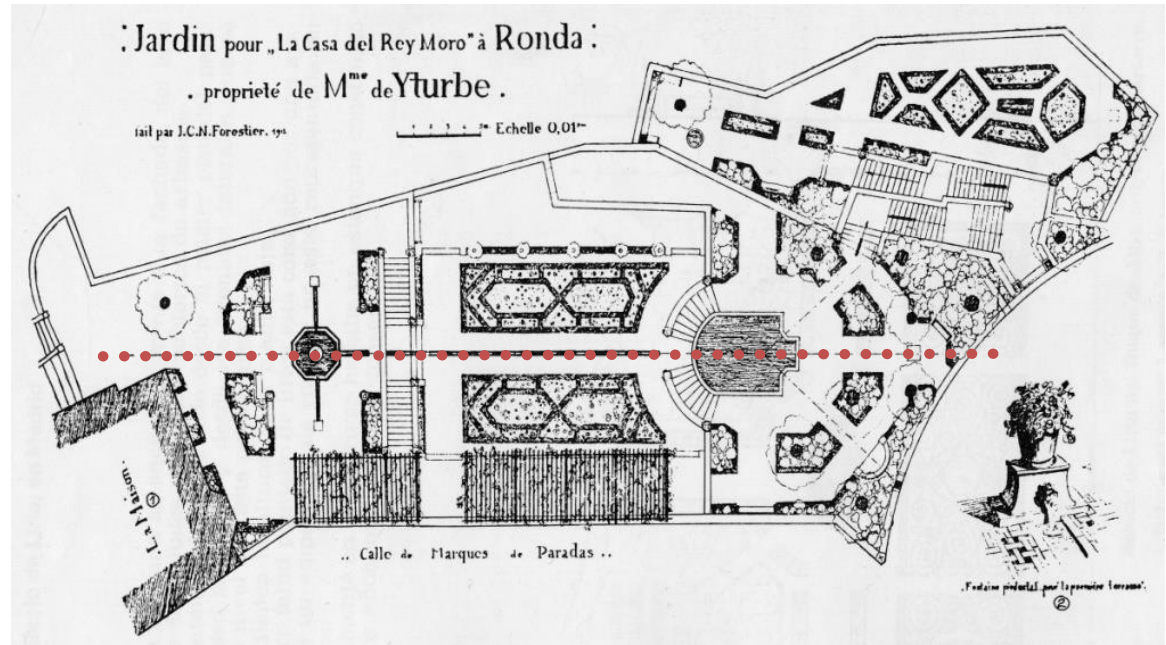

Otro ejemplo es la Hacienda de Moratalla en Hornachuelos (Córdoba, 1916), propiedad del segundo marqués de Viana, José Saavedra y Salamanca, quien encargó a Forestier la adecuación del entorno del palacio-cortijo que alojaba al rey Alfonso XIII y a su pequeña corte en sus viajes. En esta finca agrícola, ubicada a orillas del Guadalquivir, compuso un jardín de concepción francesa con algún detalle decorativo islámico. Se realizaron importantes movimientos de tierra y una conducción de agua potable de $10 \mathrm{~km}$ que llevaba el agua desde la sierra de Hornachuelos para el riego hasta una gran alberca rectangular en la parte posterior del palacio. Un largo eje central marca la perspectiva desde el palacio hasta la verja versallesca de entrada. Desde la verja parte un extenso boulingrin, en siete paratas, de rosales y césped en origen y a un nivel inferior respecto a los paseos laterales. En este eje se van sucediendo distintos motivos ornamentales: un gran estanque rectangular con pequeñas fuentes circulares con surtidor, varias fuentes de diversos trazados (mixtilínea, estrellada, espiral...) comunicadas mediante un canal de agua en ladrillo, mesa con reloj de sol rodeada de bancos. El eje continúa con un parterre central de mirtos con cuatro figuras de mármol en su interior representando las cuatro estaciones y un jarrón central. Los setos de mirto flanquean la avenida central acompañados de una densa arboleda, seguido por una fuente circular rehundida desde donde parten cuatro canalillos con cuatro pequeñas fuentes rodeados de parterres con magnolios. El eje termina frente al palacio en una glorieta circular rodeada de setos de boj. Todo está enmarcado por grandes plátanos y palmeras, y tiene decoraciones de azulejos y 
escaleras y bancos de ladrillo. En los alrededores de la casa se hicieron jardines más intimistas con fuentes, y de carácter boscoso y umbrío para defenderse del calor. Destaca el campo de polo, al que el rey y el marqués eran aficionados, siendo el primero que se realiza en España ${ }^{69}$.

Otro jardín que desarrolló en Andalucía es el Palacio del Conde de Castilleja de Guzmán (Sevilla, 1927), de corte clásico incorporando elementos eclécticos en la decoración. En Madrid trabajó en el jardín del desaparecido Palacio del Duque de Montellano, de corte francés y ubicado en la Castellana sobre el actual edificio de la Unión y el Fénix ${ }^{70}$; y en el Jardín del Palacio de Liria (1916), propiedad del duque de Alba, conserva un estanque existente y diseña un parterre con un trazado sinuoso similar a los franceses de los siglos XVII y XVIII, pensado para ser contemplado desde el primer piso del palacio ${ }^{71}$. En Santander realiza el jardín para la Terraza de las Caballerizas de La Magdalena (1917), propiedad de Ángel Pérez en Valdenoja, con trazado geométrico y carácter norteño por el uso de la piedra y la pradera ${ }^{72}$.

No se pretende estudiar exhaustivamente los jardines de Forestier ya que existe una tesis doctoral ${ }^{73}$ que profundiza en su figura y su obra -aunque tiene un enfoque más histórico que arquitectónico-, pero sí dar unas pinceladas de sus fundamentos teóricos que dan lugar a un estilo ecléctico debido a la heterogeneidad de influencias (clasicistas, paisajistas, orientales, francesas, románticas, arábigoandaluzas...) y a la adaptación al medio, tanto a nivel climatológico como histórico, respetando siempre los gustos y tradiciones de cada lugar. Adquirió un amplio repertorio y utilizó elementos de diversa índole según el tipo de jardín y su emplazamiento: "Cada paseo tendrá su carácter propio, y cada jardín presentará un objetivo interesante o una utilidad especial" 74 , afirmaba el propio Forestier. Buscó siempre la dimensión humana del jardín y su

\footnotetext{
69 AÑóN, C.: "El s. XX". Historia de los parques y jardines de España. Grupo FCC, 2001, p. 382-384.

70 GONZÁLEZ-VARAS IBÁÑEZ, I.: Los palacios de la Castellana: historia, arquitectura y sociedad. Madrid: Turner, D.L., 2010, p. 222-225.

71 FORESTIER, J.C.N.: Jardines. Cuaderno de dibujos y planos. Barcelona: Stylos, 1985, p.155.

72 Ver parque de Valdenoja en el capítulo de Winthuysen.

73 DOMINGUEZ PELAEZ, C.: Los jardines de Jean Claude Nicolas Forestier en España. Facultad de Geografía e Historia, Universidad de Sevilla, 1985. Aunque tiene un enfoque más histórico que arquitectónico.

${ }^{74}$ FORESTIER, J.C.N.: Grandes villes et systèmes de parcs. France, Maroc, Argentine. Paris: Norma Ediciones, 1997, p. 96
}
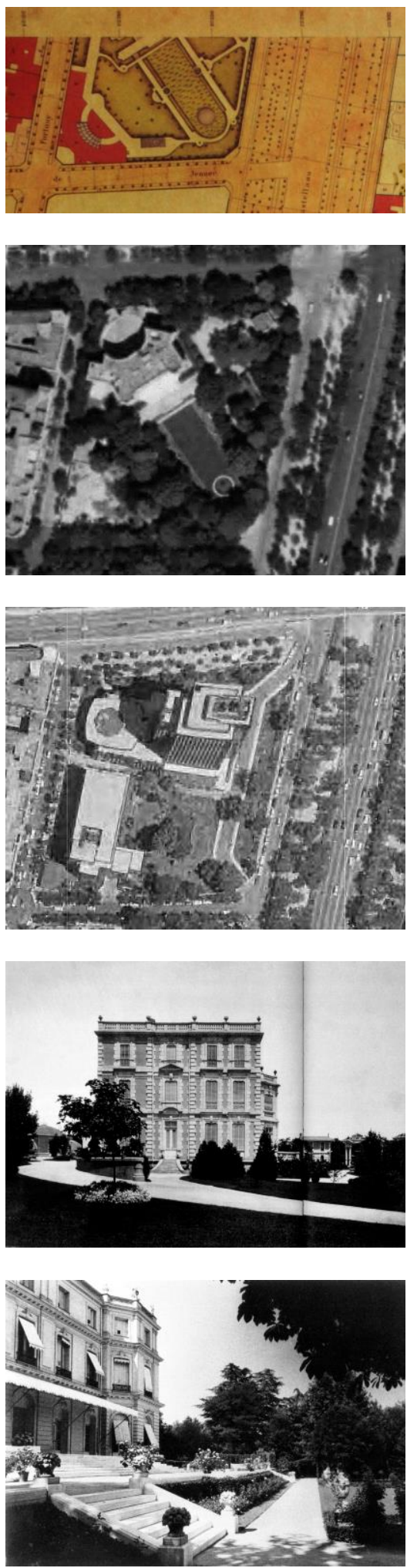

3.22 Jardín del desaparecido Palacio del Duque de Montellano: planta del parcelario de 1940. Fotos aéreas de 1961-1967 y 1975; Nomecalles, Nomenclator de la Comunidad de Madrid, IE. Vistas del jardín; GONZÁLEZ-VARAS, 2010, p. 222 y 224. 


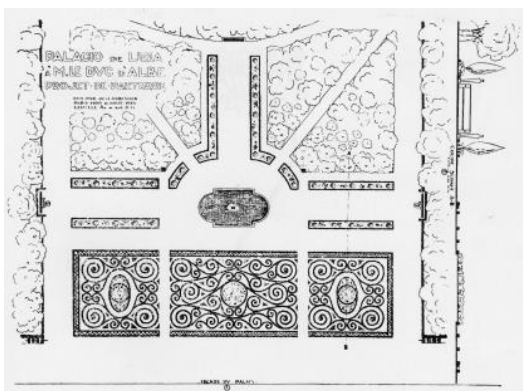

3.23 Jardín del Palacio de Liria en Madrid: planta y sección. Forestier. FORESTIER, 1985, p. 51.
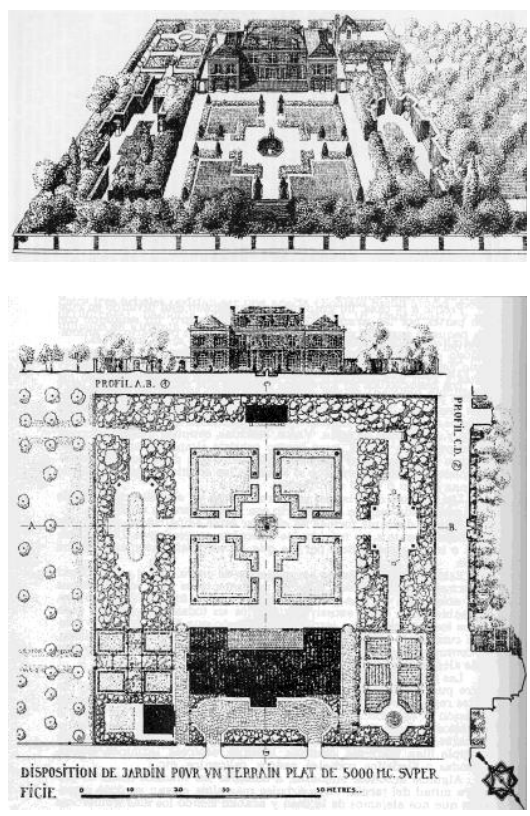

3.24 Disposición de jardín para un terreno llano de $5.000 \mathrm{~m}^{2}$ de superficie: perspectiva, planta y secciones. Forestier. FORESTIER, 1985, p. 11-12. disfrute. Todo ello hizo que se convirtiera en una figura clave para el paisajismo español del siglo XX y tuviera gran influencia en arquitectos y jardineros posteriores.

Expuso su concepto de jardín como una obra de arte, en oposición a la naturaleza libre, y el jardinero debía fijar el camino a seguir ${ }^{75}$. Le otorgó gran importancia al lugar, por eso en España se dejó llevar por lo mediterráneo y lo islámico; así lo publicó en una revista de la época: "En España, junto a los restos antiguos, subsisten las tradiciones. El arte de los andaluces, heredero de los jardines persas de Damasco, vuelve a florecer"76. De los antiguos jardines mediterráneos y sobre todo de los andaluces con una amplia tradición ${ }^{77}$, Forestier recuperó muchos de sus elementos que incluyó en sus proyectos.

Defendió los trazados geométricos claros y la simetría en la ordenación pero no de forma absoluta, "un orden preciso y muy aparente debe contener las plantas sin coaccionar su belleza natural"78, explicaba en su libro. Para dar movimiento al terreno utilizó terrazas geometrizadas y escaleras creando jardines dinámicos y atractivos pero sin parecerse a un decorado teatral. Predominan las perspectivas abiertas, pero a veces sorprende con caminos curvos enmarcados con tupida vegetación que rompen la rigurosidad de la línea recta y definida. Recuperó en muchas ocasiones el trazado general del jardín andaluz consistente en una serie de cuadrados o rectángulos formados por el cruce de paseos ligeramente más altos que el piso del jardín; estos pequeños muretes se recubrían de revestimiento y evitaban el polvo y el lodo en los caminos. Los jardines se disponen en terrazas horizontales "que imponen la repetición de algunas gradas, objetos también de decoración, encantadora variedad de niveles diferentes netamente asentados. / Y por eso también tienen su aspecto saliente estas avenidas y se diferencian de las de otros países de Europa: sirven

\footnotetext{
75 “Les jardins, tout en manifestant une pensé, une volonté humaine, son un hommage à la nature, /.../ les artistas jardiniers y mettront l'empreinte d'une main à la fois ca ressante et autoritaiere, mains non pas tyrannique". FORESTIER, J.C.N.: Des jardins d'autrefois aux jardins d'aujord'hui. Barcelona: Pulicacions de la Societat Cívica la Ciutat Jardí, 1921, p. 24. 76 FORESTIER, J.C.N.: "Jardines andaluces". Arquitectura, no 39. Madrid: Sociedad Central de Arquitectura, 1922, p. 301.

77 Tienen herencias de muchas civilizaciones y culturas: libios, fenicios, griegos, romanos, godos, normandos, persas, sirios, árabes, etc.

78 FORESTIER, J.C.N.: "Les Jardins modernes", Art et industrie, février 1911 -páginas no numeradas-. IMBERT, D.: "Tracé architectonique et poétique végétale", en Jean Claude Nicolas Forestier 1861-1930. Du jardin au paisaje urbain. Paris: Picard, 1994, p. 70.
} 
de avanzadas de tierras, de pequeños diques que facilitan el riego" 79 , como explica en un artículo.

Distingue el patio como la forma más elemental del jardín: "con los caminos en cruz, dibujando cuatro macizos regulares de relieve, bordeados por setos tallados, una puertecita en el centro, a veces canales de mármol o azulejos y el piso de color. / Los grandes conjuntos se obtienen multiplicando este elemento en un dibujo cuadriculado, ensanchando algunas avenidas, variando la forma de los estanques, combinando mil fantasías ingeniosas las corrientes de agua,..." ${ }^{\prime 80}$.

Forestier apoyó la intimidad y las altas paredes, concibiendo los jardines como recintos cerrados y secretos, que en muchos casos sólo se advertían porque sobresalían las puntas de los cipreses: "Los pueblos meridionales, exuberantes y desconfiados a la par, aman la intimidad de la vivienda. Semejante deseo excluye las amplias vistas hacia el exterior, salvo en las terrazas de terrenos montañosos, cuya pendiente es una protección, y desde las terrazas de pabellones y miradores" 81 . Al contrario que los jardines de palacios europeos destinados a la vida social y para el disfrute de multitudes, son jardines íntimos sólo para el disfrute de sus propietarios; así lo explica en un artículo: "Todo él es intimidad; sus rincones están dispuestos para el goce sensual que el agua, las flores y la luz proporcionan a su dueño. La gente de fuera, los que no habitan la casa, no tienen nada que hacer en el jardín, y éste es una dependencia de la vivienda, tan recatada, tan íntima como la que más. / Ello explica el fracaso de los que quieren hacer grandes parques a la andaluza; tan sólo es posible subdividiendo el terreno en numerosos y pequeños jardines, aislados unos de otros. $Y$ téngase en cuenta que al quitar el jardín andaluz las altas tapias que lo limitan, se le quita parte considerable de su fragancia e intimidad, y de ello sufren" 82 .

La presencia del agua es fundamental en el trazado de sus jardines; la riqueza de este fluido como bien escaso y deseable se multiplica en numerosas fuentes, pozos y pequeños surtidores y canales. Estos cursos de agua refrescan el suelo y el aire, además de proporcionar sonido al jardín. Las fuentes se suelen disponer en el

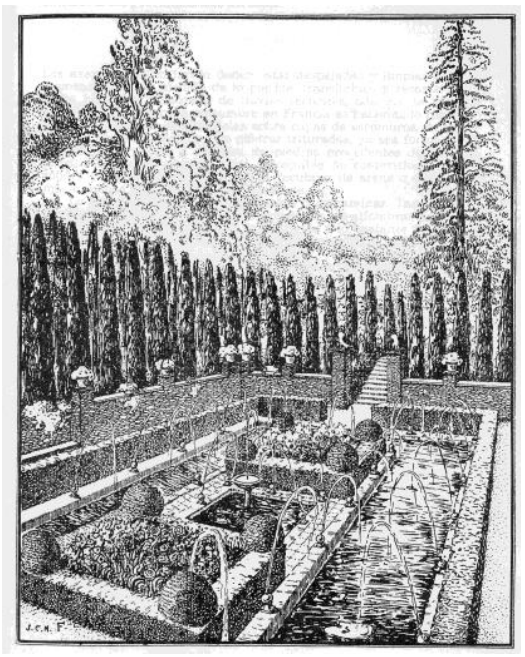

3.25 Imitación del patio del Ciprés de la Sultana en el Generalife de Granada rodeado de una pared de cipreses. Forestier. FORESTIER, 1985, p. 76.

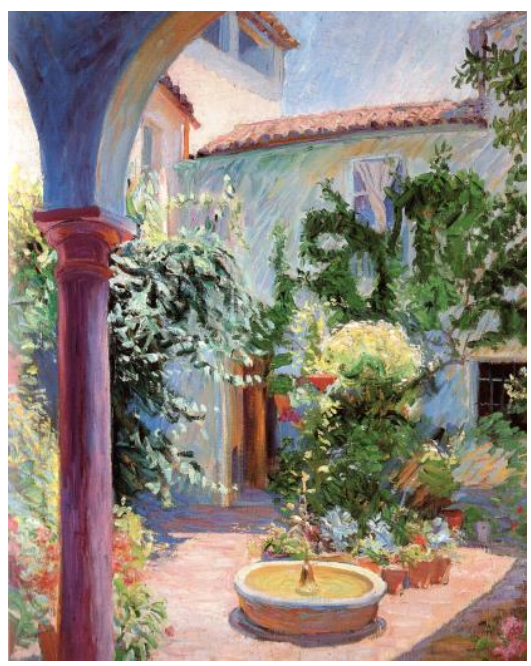

3.26 Patio de Córdoba, 1912. Javier de Winthuysen. Se observa la estructura de patio árabe: cerrado, enmarcado por la arquitectura, fuente baja con surtidor, macetas floridas, etc. Jardines de España (1870-1936), 1999, p. 241.

\footnotetext{
${ }^{79}$ FORESTIER, J.C.N.: “Jardines andaluces”. En Arquitectura, no 39, julio, 1922, p. 300.

80 Ibíd., p. 302.

81 lbíd., p. 302.

82 R.: "Ingreso". En Arquitectura, no 39, julio, 1922, p. 279.
} 

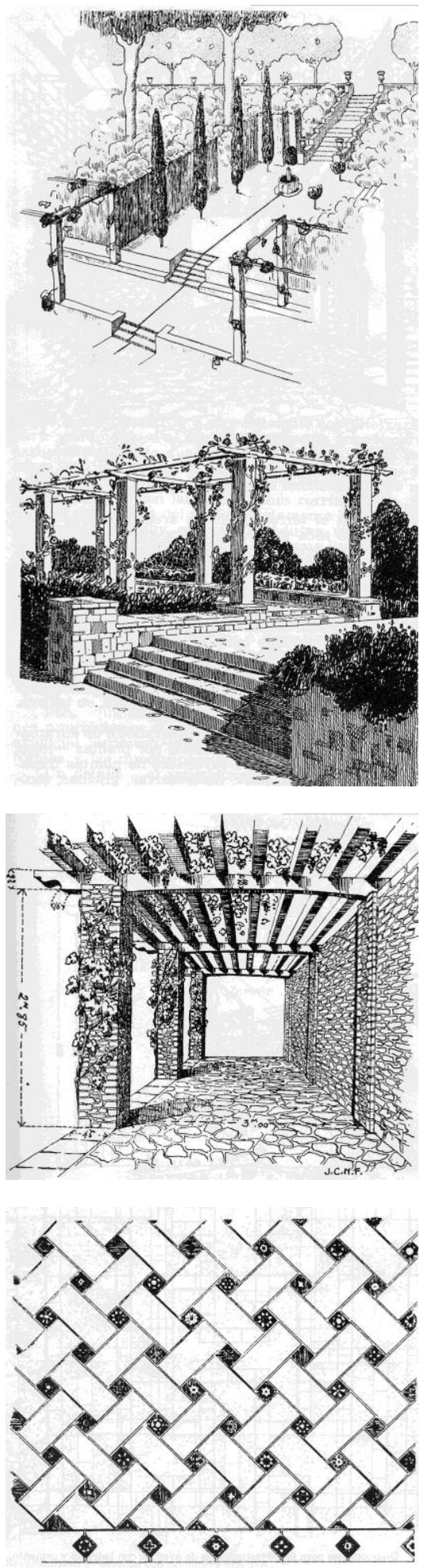

3.27 Avenida con emparrados y detalle. Ejemplo que muestra una de las maneras de la combinación de los ladrillos con baldosas esmaltadas. Forestier. FORESTIER, 1985. p. 35, $37 \mathrm{y}$ 78. cruce de las avenidas, muchas sirven tanto para la decoración como para el riego. "Un depósito alimentado por acueductos, por manantiales o por corrientes subterráneas elevadas por medio de norias, o, actualmente con aparatos más modernos, distribuye el agua, ya directamente en las regueras que bordean los caminos, ya en depósitos secundarios y fuentes" ${ }^{\prime 83}$, explica Forestier.

El jardín se acompaña de pérgolas -abandonadas en los jardines de los siglos XVII y XVIII ${ }^{84}$-, enrejados, emparrados y enredaderas de rosas, arcos de laureles, bojes, cipreses ${ }^{85}$, árboles ornamentales, frutales, altas paredes de mirto y setos espesos que limitan las flores. Huye de la monocromía y provecha la riqueza de colores vivos de las flores ${ }^{86}$ (rosas, claveles, geranios, jacintos...), los frutos y combinación de plantas olorosas (jazmines, madreselvas, mirtos, naranjos, laureles, magnolias, dondiegos y damas de noche...). Como amigo de Monet, en casi todos sus jardines incluyó nenúfares y lotos.

Recuperó la riqueza y el lujo de la utilización de azulejos, esmaltes y mármoles de los jardines islámicos. Tenía gran afición por el color, no sólo de elementos vegetales; utilizó también las cerámicas, predominando el color azul que destacaba sobre los muros blancos encalados y el rojo del ladrillo, lo justificaba diciendo que hay menos plantas de color azul. Estos azulejos muchas veces revestían los bancos que salpicaban los recorridos de sus jardines sirviendo de reposo al paseante, pero también utilizó otros materiales. Al igual que André Vera, alababa un jardín regular adaptado a las exigencias y a los gustos actuales: simple y pequeño, de mantenimiento fácil, construido con materiales contemporáneos y economía (materiales de desecho, de hierros galvanizados, cementos armados, y vasos de fundición, etc. $)^{87}$.

\footnotetext{
83 FORESTIER, J.C.N.: “Jardines andaluces”. En Arquitectura, no 39, julio, 1922, p. 303.

84 RUBIÓ I BOADA, M.: Nicolau María Rubió i Tudurí (1891-1981). Barcelona. Ayuntamiento de Barcelona, 1989, p. 54.

85 "Los cipreses sombríos, siempre verdes -árboles de la Venus asiria-, símbolos de la perpetuidad de la vida o de la inmortalidad del alma, realzaban con sus negras siluetas, veneradas siempre, las flores tiernas de los almendros, de los melocotoneros, de los duraznos que los sabios jardineros persas habían traído de Europa". FORESTIER, J.C.N.: "Jardines andaluces". En Arquitectura, no 39, julio, 1922, p. 299.

86 "Llenas están casas y patios; ennoblecen las viviendas más humildes, adornan ventanas y balcones, ponen una nota viva y delicada en el cabello de las mujeres, y, en pequeños recintos familiares cercados de altas tapias, agrúpanse en vergeles de inolvidable belleza". R.: "Ingreso". En Arquitectura, no 39, julio, 1922, p. 278.

87 IMBERT, D.: "Tracé architectonique et poétique végétale", en Jean Claude Nicolas Forestier 1861-1930. Du jardin au paisaje urbain. Paris: Picard, 1994, p.71.
} 


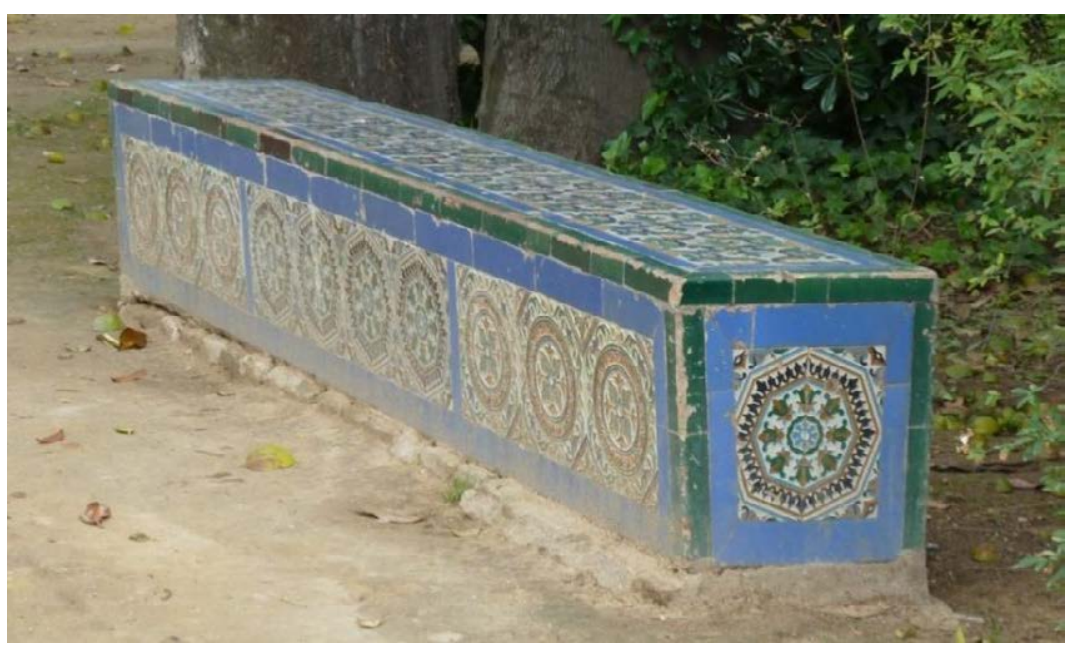

\section{Los seguidores de Forestier}

Los grandes trazados de jardines y parques urbanos españoles de esta época estaban influidos por el gusto francés y muchos los realizaban autores franceses como Forestier quien como apunta Mercadal: "ha influido sin duda alguna con sus obras en el más reciente renacimiento de nuestra jardinería, que por la intervención de arquitectos como Rubió y Talavera, o de ingenieros como Falero, Pérez Calvet y Bornas; jardineros como Clarisso y Ortiz, es de esperar vaya dejando de ser el fruto de practicones, pasando a ser nuestros jardines verdaderas obras de arte, dignas de parangonarse con las de arquitectos paisajistas de otros países" ${ }^{88}$.

Los parques de Forestier, realizados principalmente en Barcelona y Sevilla, tendrán gran repercusión en los proyectos y parques posteriores de diversas partes de España. Muchas de las grandes urbes carecían de extensos parques urbanos, espacios de esparcimiento y disfrute para los ciudadanos, y sobre todo para la reciente burguesía reformista de las ciudades. Estos nuevos lugares además permitían resolver problemas urbanos como la integración de infraestructuras (carreteras, ferrocarril, etc.), la incorporación de nuevos equipamientos colectivos, la ordenación de los territorios de borde, etc.

En Sevilla muchos de sus colaboradores seguirán sus esquemas, como el arquitecto municipal, Juan Talavera y Heredia, principal responsable de las transformaciones de la ciudad de Sevilla en aquella época, y alabado por Forestier: "todo el talento, la

\footnotetext{
${ }^{88}$ GARCÍA MERCADAL, F.: Parques y Jardines. Su historia y sus trazados. Zaragoza: Éntasis, CSIC, Diputación de Zaragoza, 2003, p. 274.
}

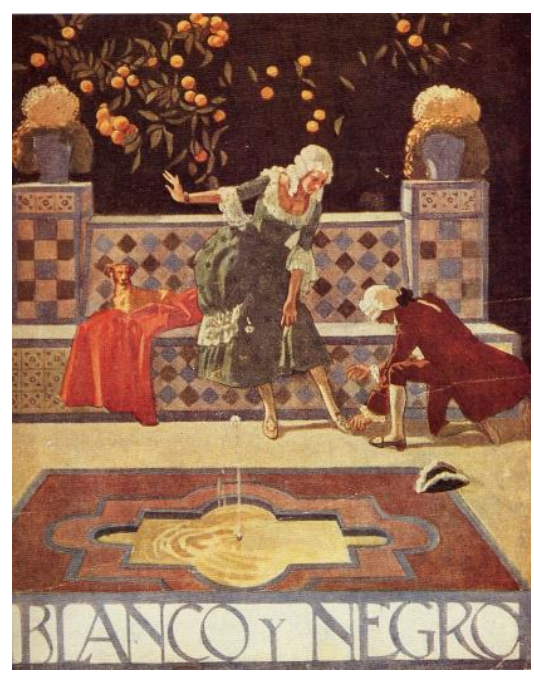

3.28 Cubierta de la revista Blanco y Negro. Banco del arquitecto Juan Talavera en los jardines de Murillo de Sevilla. Jean Claude Nicolas Forestier 1861-1930. Du jardin au paisaje urbain, 1994.

3.29 Banco del parque de María Luisa. PHL, mayo 2012.
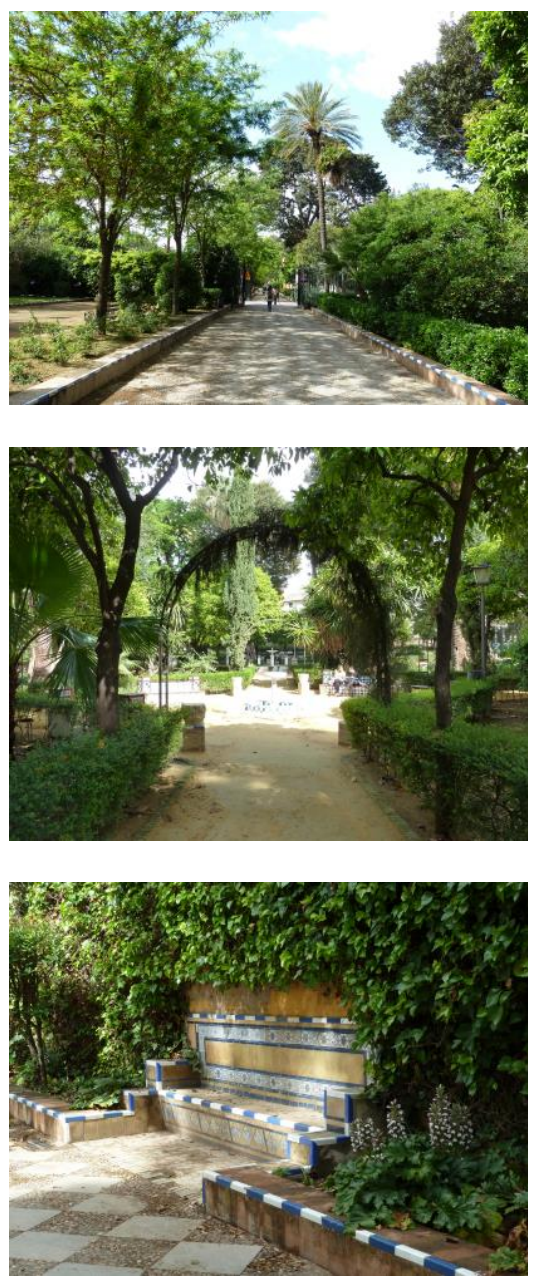

3.30 Jardines de Murillo: paseo, arco de entrada a una de las plazas-jardín y detalle de banco cerámico. PHL, mayo 2012. 

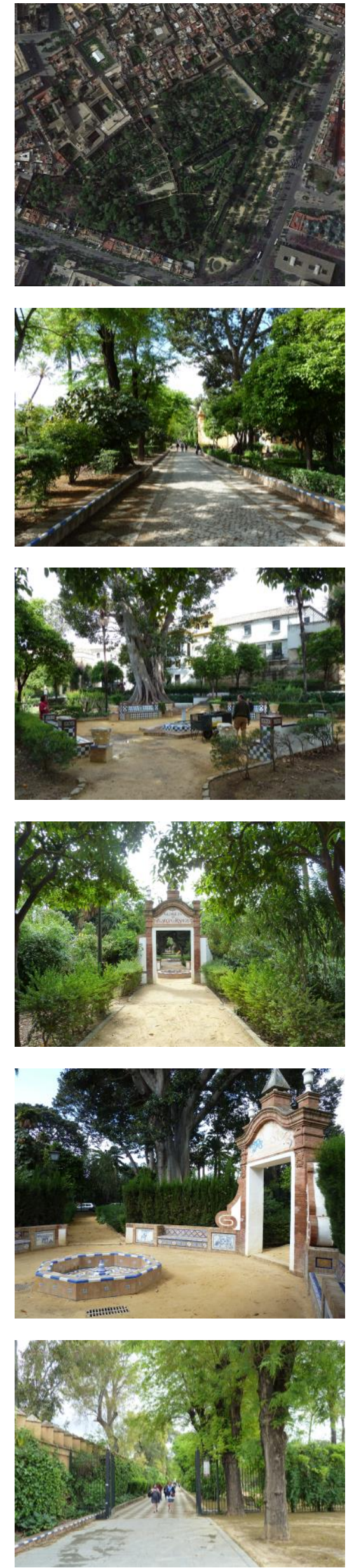

3.31 Jardines de Murillo: vista aérea, paseo, pequeñas plaza-jardín, glorieta de José García Ramos (1923) y uno de los accesos. Googlemaps, PHL, mayo 2012.

ingeniosidad y la extrema fineza de gusto" 89 . En el barrio de Santa Cruz Talavera y Heredia realizó varias de sus obras: plaza de Santa Cruz (1918), jardines de Murillo y Paseo de Catalina de Ribera (1920) y plaza de Doña Elvira (1924), entre otras. En muchos de ellos se distinguen las características del parque de María Luisa de Forestier como el parque público constituido por la suma de pequeños espacios que se aprecia en los Jardines de Murillo ${ }^{90}$, conectados directamente con los Reales Alcázares. Estos pequeños jardines con personalidad propia se enlazan mediante paseos en retícula delimitados por setos, y en los cruces se crean glorietas con fuentes centrales. Todo ello con decoración de azulejos y cerámicas en pavimentos, bancos y fuentes.

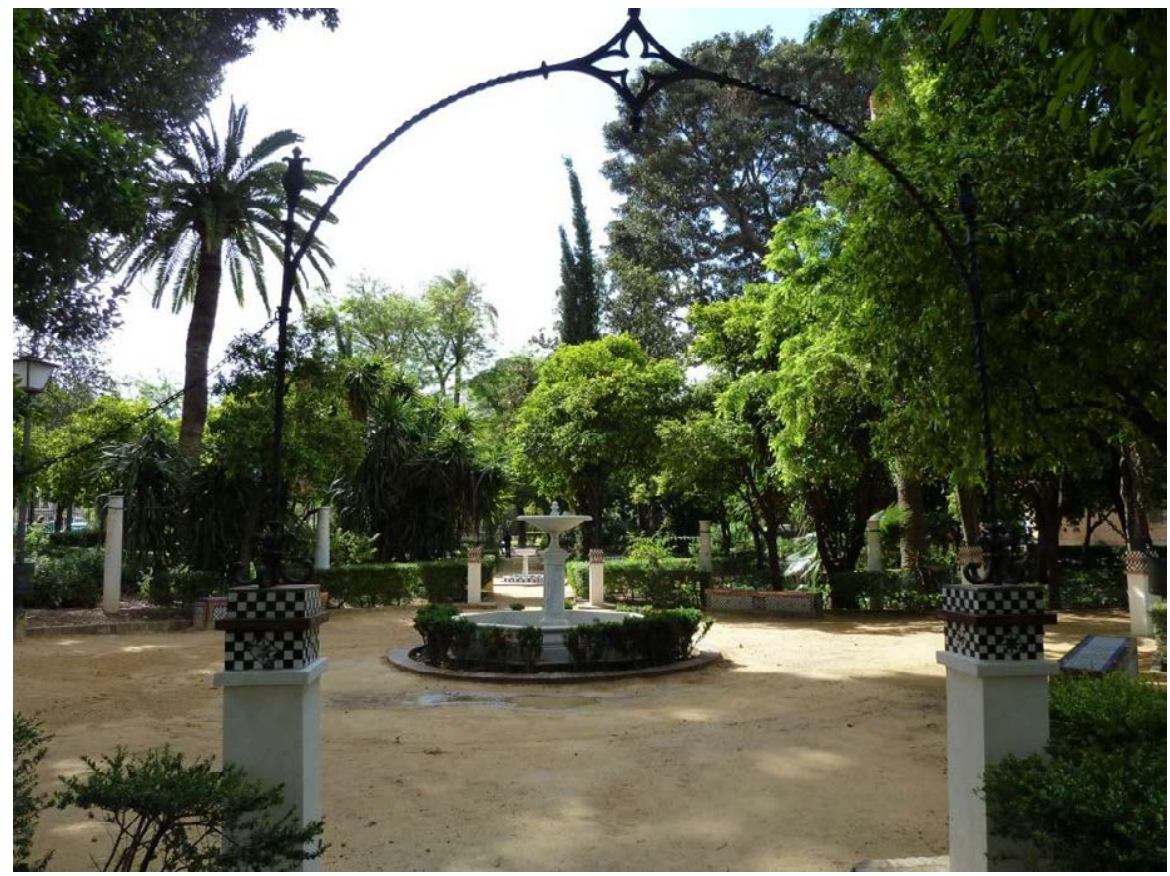

También José Gómez Millán (1878-1962) está influenciado por Forestier en su proyecto para una parte de los jardines del Alcázar sevillano (1915-1925). Asociado a la antigua Huerta (Campo de naranjos), presenta una trama cuadriculada de avenidas donde en cada intersección aparece una pila, una fuente, cuatro bancos, etc.;

\footnotetext{
${ }^{89}$ Hemeroteca de Sevilla, C62/10, no 9, carta de 12 de octubre de 1915. ASSASSIN, Sylvie: "L'Exposition Ibéro-Américaine de Séville", en Jean Claude Nicolas Forestier 1861-1930. Du jardin au paisaje urbain. Paris: Picard, 1994, p. 117.

90 A mediados de 1911 la Real Casa cede parte de la Huerta del Retiro para comunicar Santa Cruz con el Prado de San Sebastián. El nombre de los jardines de Murillo es sugerencia de El Liberal. En 1923 se añade una glorieta dedicada al pintor José García Ramos con una fuente de azulejos rodeada por bancos de cerámica. AÑóN, C.: "El s. XX". Historia de los parques y jardines de España. Grupo FCC, 2001, p. 374.
} 
todo ello acompañado de arcos y paredes vegetales (boj, tejo y ciprés) componiendo perspectivas ${ }^{91}$.

La reconsideración del jardín andaluz de Forestier también servirá de referencia a Javier de Winthuysen ${ }^{92}$, mientras que en Cataluña su tradición mediterránea será recogida por Nicolau Ma Rubió i Tudurí (1874-1956), arquitecto que empieza a trabajar como jardinero a las órdenes de Forestier en los jardines de Montjuïc haciéndole enamorarse del jardín mediterráneo latino ${ }^{93}$.

\footnotetext{
91 ASSASSIN, Sylvie: "L’Exposition Ibéro-Américaine de Séville", en Jean Claude Nicolas Forestier 1861-1930. Du jardin au paisaje urbain. Paris: Picard, 1994, p. 116.

${ }^{92}$ Ver capítulo de Winthuysen y la recuperación del jardín clásico en España.

${ }^{93}$ Ver capítulo de Los parques de Rubió i Tudurí en Cataluña.
} 


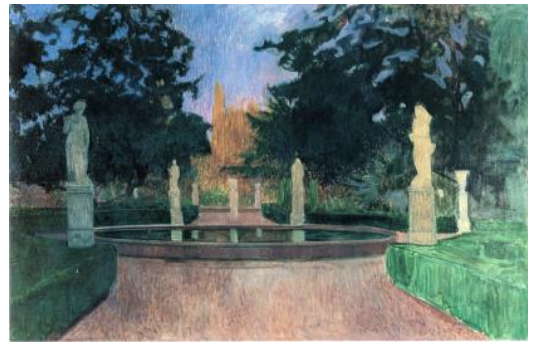

4.1 El jardín de los Mártires, Granada, 1912, José Ma Rodríguez Acosta. Panorámica del primer jardín desde el segundo. Jardines de España (18701936), 1999, p. 211.
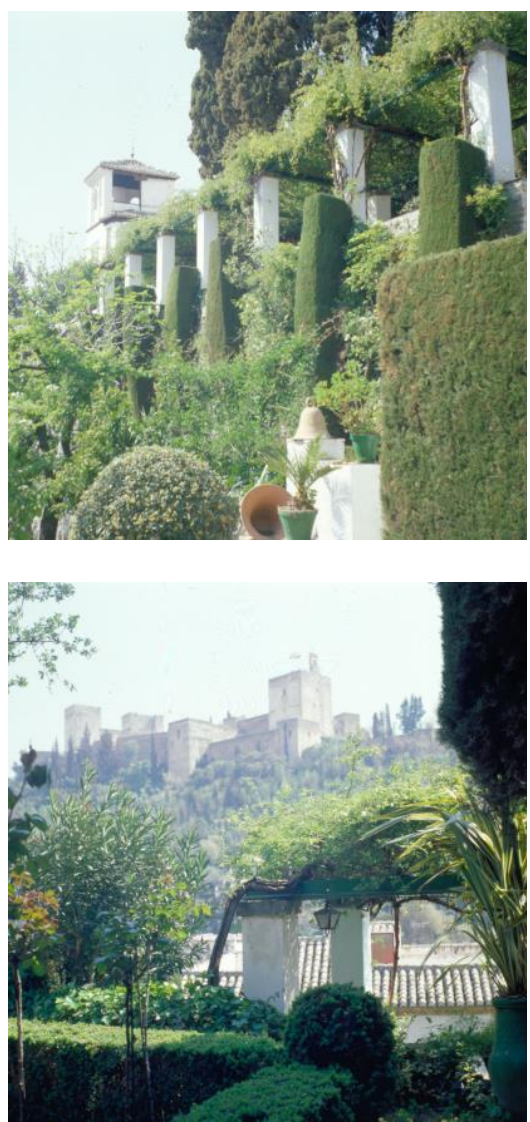

4.2 Carmen de los Mártires (1850-1860), Granada: se mezcla la jardinería romántica europea y la tradición de los cármenes granadinos. PHL, 2005.

\section{LOS NUEVOS CÁRMENES}

El jardín español está muy marcado por la gran diversidad geográfica y climatológica. Entre los siglos XVI y XVII comenzaron a surgir diversos modelos específicos de algunas regiones: pazos gallegos, cigarrales toledanos, sones mallorquines, etc. En el siglo XIX se produce un "revival" y la nueva burguesía vuelve a realizar o reformar los antiguos jardines.

Una de estas tipologías son los cármenes granadinos. La palabra "carmen", deriva de la palabra árabe Karm (jardín o viñedo), designa una finca rústica privada extramuros de la ciudad que comenzaron a surgir en época árabe ${ }^{1}$. Estas casas con huertos eran autóctonas de la colina del Albaicín y se exportaron a otros barrios. Así los describe Santiago Rusiñol: "En los cármenes de Granada debieron de nacer nuestros jardines, los más bellos, los más sencillos, los más floridos de la Tierra. Los cármenes de Granada no son clásicos, ni románticos, ni primitivos, ni modernos. Heredaron su carácter de los árboles, y tienen su tradición y estilos propios. /.../ Sugieren anhelos de recogimiento y guardan el encanto oriental de jardines soñados,...A orillas del Darro se ensanchan los jardines, $y$ en el monte de la Alhambra, se convierten en verdaderos parques, que pierden en intimidad lo que ganan en extensión. Y por todos lados, en las laderas y en la llanura, sus altas frondas rebasan las tapias..."2.

Generalmente están situados en una posición privilegiada desde la que se puede contemplar el panorama, como si se tratase de terrazas o balcones sobre el paisaje evocando a los jardines pensiles de Babilonia. Estos pequeños minifundios ajardinados se desarrollan en ladera, adaptándose al fuerte desnivel mediante un conjunto de terrazas o paratas escalonadas en las que prima el aprovechamiento de la cota de nivel, intentando conseguir la mayor superficie posible; por eso aparecen lugares muy diversos,

\footnotetext{
${ }^{1}$ Así describe Andres Navaggiero el karm árabe: "Por todas partes en torno a Granada, entre los muchos jardines que hay, así en la llanura como en los cerros, se encuentra, aunque no se vean por causa de los árboles, tantas casitas de moros esparcidas acá y allá que si se pudieran juntar compondrían otra ciudad no menor que Granada. Y aunque, es verdad, las más son pequeñas, tienen todas ellas sus aguas, sus fuentecillas, sus rosales, mosquetas y mirtos y toda gentileza". SECO DE LUCENA DE PAREDES, L.: Cármenes de Granada. Granada: Caja General de Ahorros, 1971. También en TITOS, Manuel: Nuevos paseos por Granada y sus contornos. Tomo 1. Granada: Caja General de Ahorros de Granada, 1992, p. 340-341.

2 RUSIÑOL, S: "Los cármenes de Granada". Arquitectura, no 39. Madrid: Sociedad Central de Arquitectura, 1922, p. 307-308.
} 
pero van a ser las circulaciones las que unifiquen los diferentes espacios. Constan de una vivienda generalmente pequeña, situada en el punto más alto con vistas a la ladera, a la que se accede a través de un patio; un huerto con terrazas de frutales; y un jardín en el que se mezclan elementos de tradición hispanoárabe (fuentes con surtidores, albercas, setos recortados de arrayanes, plantas aromáticas, frutales...) con otros elementos clásicos (columnas, jarrones...). Se distribuye en dos o tres terrazas artificiales, contenidas por muros de tierra o piedra, que se van descubriendo poco a poco en el recorrido por el jardín a través de senderos. Estos vergeles donde se mezcla la función ornamental y el autoabastecimiento, suelen utilizar pérgolas, emparrados, enredaderas y arbolado para mitigar el sol. La Alhambra va a aparecer como punto focal siempre en los giros y perspectivas. Según Prieto-Moreno en estos jardines se consigue "una entidad indisoluble: arquitectura, vegetación y paisaje"3.

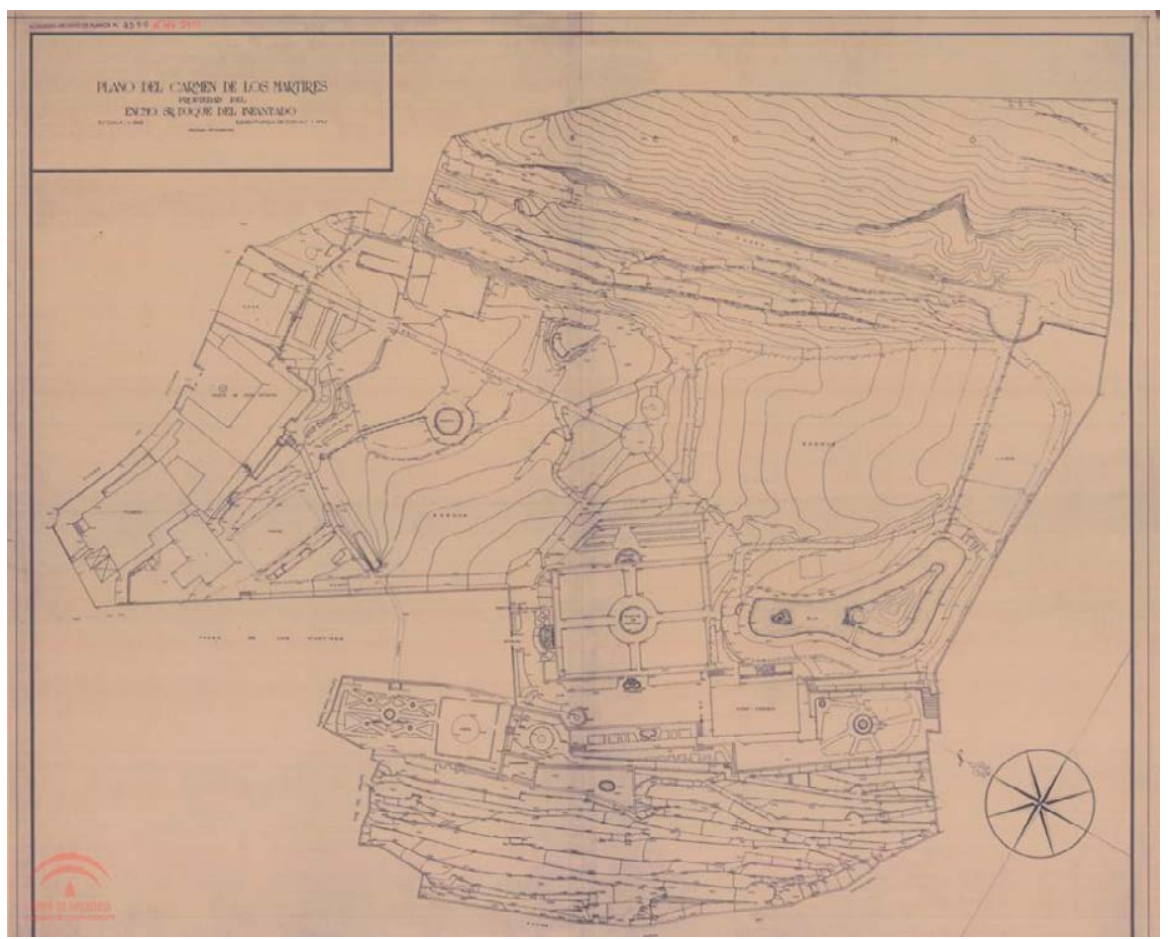

Fernando García Mercadal también los describe cuando los compara con los Omrahs indios: "Además de los jardines plantados por los Emperadores, Príncipes y Princesas para su propio placer, los hubo también en las residencias veraniegas de los Omrahs o nobles del Estado. Las más humildes moradas tenían-como los cármenes granadinos-un par de árboles, unos macizos de flores y

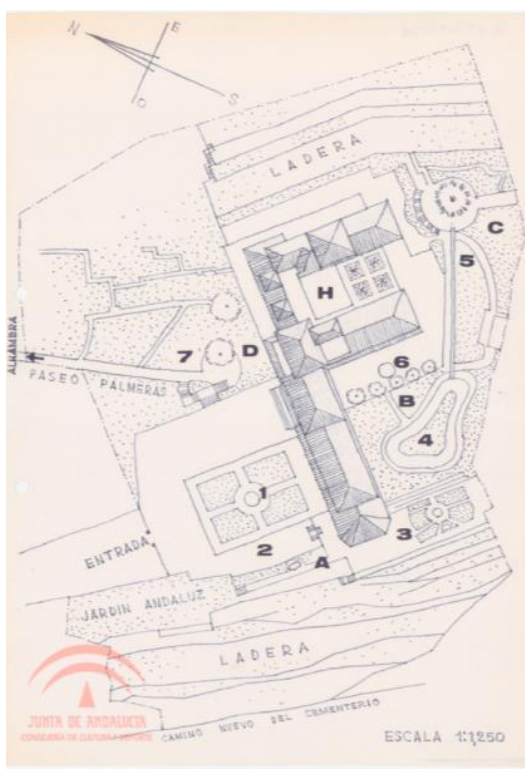

4.3 Carmen de los Mártires: croquis de planta del complejo hotelero, 1973-81. Procede del Archivo Histórico, Legajo 561/7. "Carmen de los Mártires (197381)". Patronato de La Alhambra y Generalife, APAG/ Colección de Planos/ P-008894.

4.4 Carmen de los Mártires (Propiedad del Excmo. Duque del Infantado). Plano topográfico (1948-sep.). APAG/ Colección de Planos/ P-005919.

\footnotetext{
3 PRIETO-MORENO, F.: Los Jardines de Granada. Madrid: Ministerio de Educación y Ciencia, 1973, p. 12-13.
} 

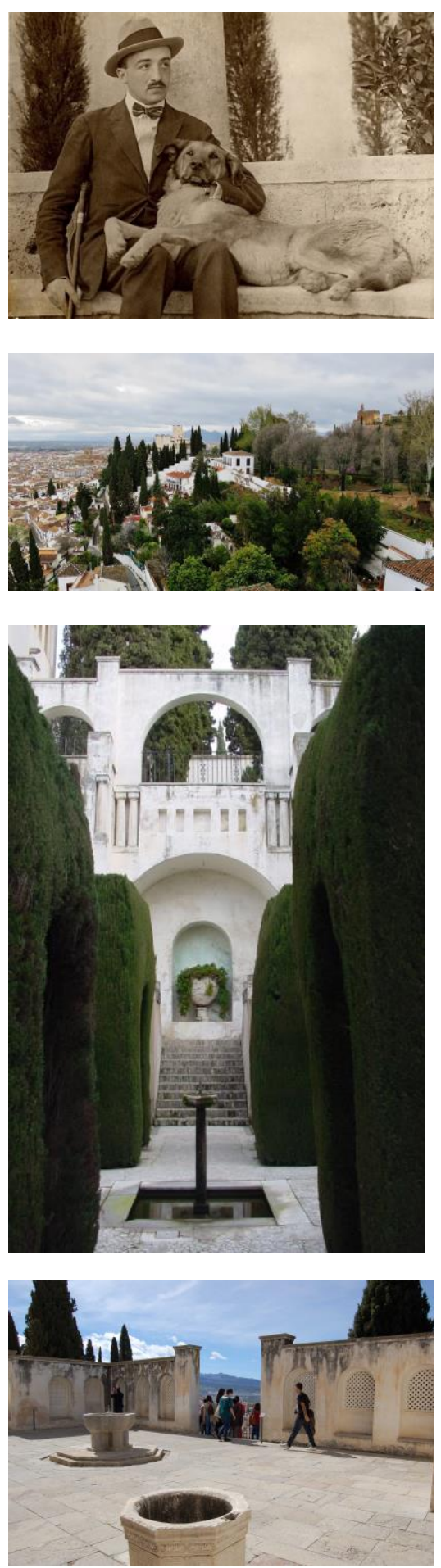

4.5 J.Ma Rodríguez-Acosta en la exedra del Patio de Baco. (h. 1930). Archivo fotográfico de la Fundación RodríguezAcosta. Vista desde el Hotel Alhambra Palace. Antonio Maldonado, fundacionrodriguezacosta.com.

4.6 Carmen del pintor J.Ma Rodríguez Acosta, Granada: eje transversal del jardín de Apolo y la Terraza. PHL, 2004 y fundacionrodriguezacosta.com. un surtidor, verdadero lujo de casas y sitios de recreo. Buscar un manantial, cultivar flores, trazar un jardín y plantarlo, tenía para el musulmán un significado y hasta el sentido de un acto religioso. / La residencia estival de los Omrahs disponía de terrazas ornamentadas con minaretes, torrecillas y alminares en los ángulos de cada una de ellas. Bordeando sus caminos existían arriates floridos $y$, entre éstos, parterres alineados con esmero. El caz para las aguas era de piedra labrada y del mismo material los surtidores y las fuentes" ${ }^{4}$.

Estos espacios van a ir evolucionando a lo largo del tiempo y se van a superponer diferentes etapas de la historia del jardín; así por ejemplo en el Carmen de los Mártires de época medieval se rehace en 1850, desarrollando un jardín francés sobre el antiguo convento carmelita. Pero en sus distintas partes se ven varias influencias: medieval islámica -Jardín Español o Andaluz-, barroca -Jardín Francés-, neoclásica paisajista -Jardín de las Palmeras- y naturalista propia del paisajismo europeo del siglo XIX -zona del lago y sus islas con falsas ruinas y gruta-.

En la primera mitad del siglo XIX con la repoblación de los barrios históricos y el romanticismo surgen los grandes cármenes urbanos en solares resultantes de la desamortización. Los jardines son muy variados, pues se conservan los recursos jardineros tradicionales y se incorporan formas nuevas. Con la entrada del siglo XX hay un aumento de la valoración del carmen por las élites culturales y económicas, marcada por la renovación regionalista de la tradición, el avance de los jardines frente a los huertos y la estética ruralizante.

Destaca como ejemplo singular en el primer tercio del s. XX el carmen del pintor José María Rodríguez Acosta (1914-1928), donde el propio artista granadino mezcló la tradición del carmen con un programa moderno -su estudio de pintura, sala de exposiciones y salón-biblioteca-, ocupando varios solares y casa entre las calles Aire Alta y Niño del Rollo. El jardín comenzó a construirse antes que la vivienda; Modesto Cendoya, arquitecto conservador de la Alhambra, se encargó en 1914 del inicio de las obras de consolidación de la ladera y ajardinamiento, bajo la dirección del propio Rodríguez-Acosta. Existe un primer proyecto historicista del

\footnotetext{
${ }^{4}$ GARCÍA MERCADAL, F.: Parques y Jardines. Su historia y sus trazados. Zaragoza: Éntasis, CSIC, Diputación de Zaragoza, 2003, p. 59-60.
} 
arquitecto malagueño Ricardo Santa Cruz de 1916", pero finalmente en 1921 se contrató un arquitecto más vanguardista: Teodoro de Anasagasti, modificando los diseños de Santa Cruz alterando las fachadas y articulando unitariamente los espacios interiores y exteriores, con claras alusiones a su proyecto de Cementerio Ideal (1910)-. En 1923 el arquitecto José Felipe Jiménez Lacal tomó el relevo y elaboró los planos definitivos, bastante próximos a la realidad. Las obras de la vivienda se finalizaron en 1928, aunque el trazado de los jardines ya se había terminado dos años antes, quedando solo remodelaciones del pavimento $y$ especies vegetales ${ }^{6}$.

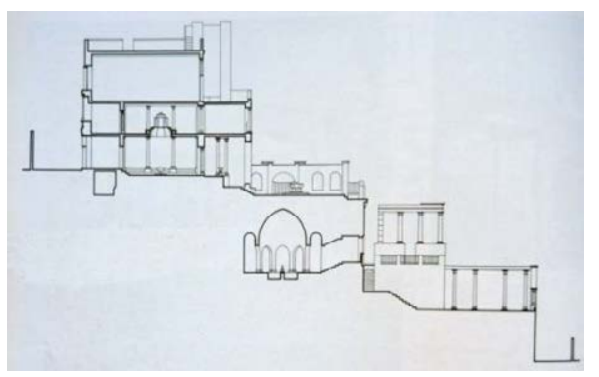

4.7 Carmen de la Fundación Rodríguez Acosta: sección levantada por Carlos Sánchez Gómez. Arquitectura, 1983, no 240, p. 26.

4.8 Carmen de la Fundación Rodríguez Acosta: planta general. Del.: Juan García Valverde, 1962-dic. APAG/ Colección de Planos/ P-002318.
1. Patio del Teatro
2. Jardín de Apolo o de Baco
3. La "Terraza"
4. Jardín de Venus
5. Jardín de la Monja
6. Jardín bajo - El Parterre
7. Templo de Psiquis
8. Glorieta de cipreses - La "Corona"
9. Templete
10. Jardín de la alberca

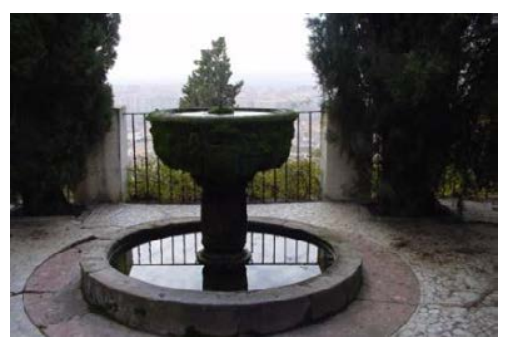

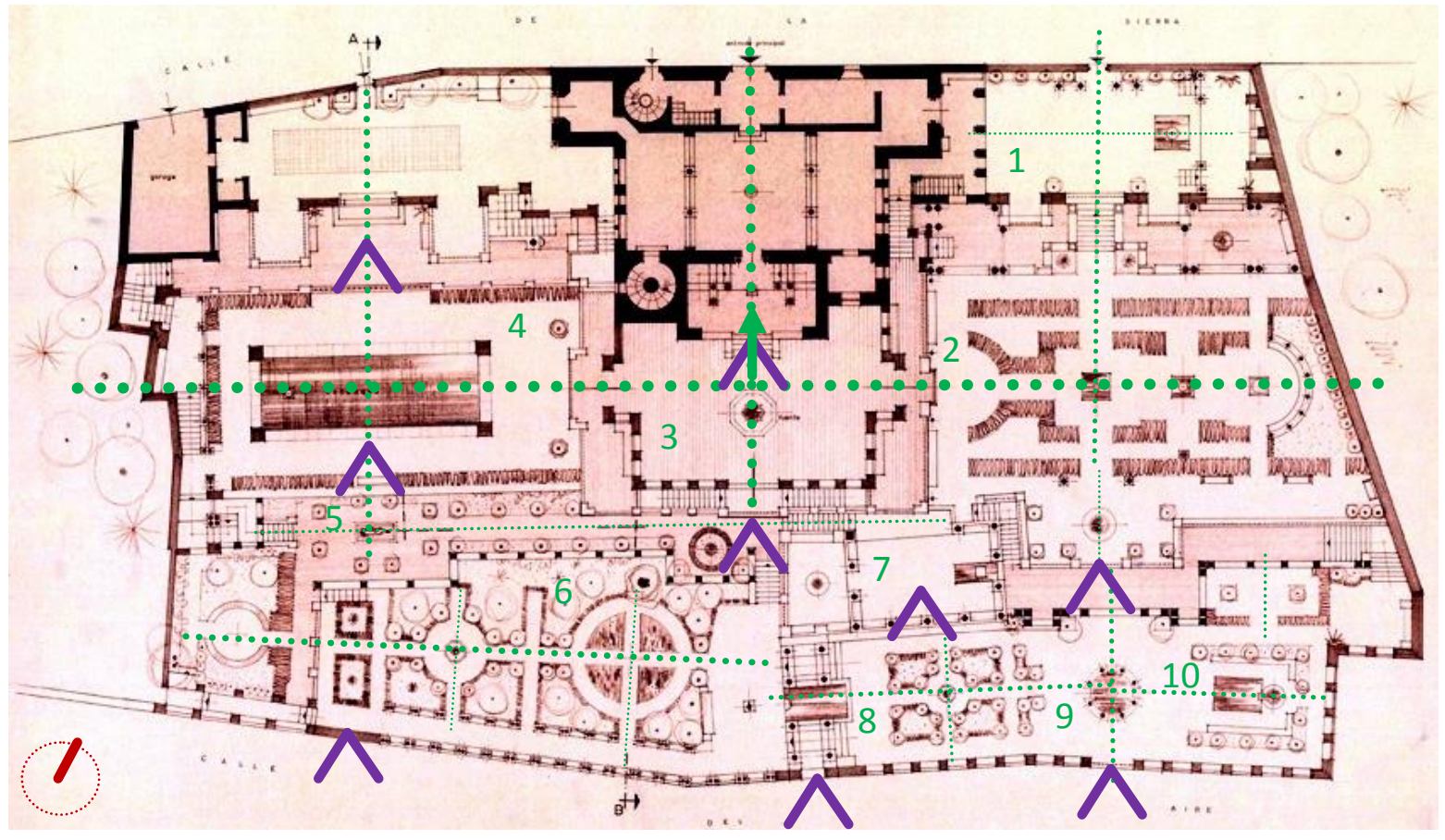

Se estructura en diversas terrazas escalonadas sobre la ladera de Antequeruela en las cercanías de la Alhambra y orientadas hacia la vega y Sierra Nevada. El edificio de tres niveles -vestíbulo clásico en

\footnotetext{
${ }^{5}$ Carmen de la fundación Rodríguez Acosta. Arquitectura, 1983, n240 ene-feb., p. 19. Previamente Ángel Casas diseñó una casa pensada coomo apoyo durante las obras.

6 TITO ROJO, J.; CASARES PORCEL, M.: Papeles de apoyo a la visita de los Jardines del Carmen Blanco (Carmen de la Fundación Rodríguez-Acosta) con motivo del Día Internacional de los Museos, 18 mayo de 2003.
}

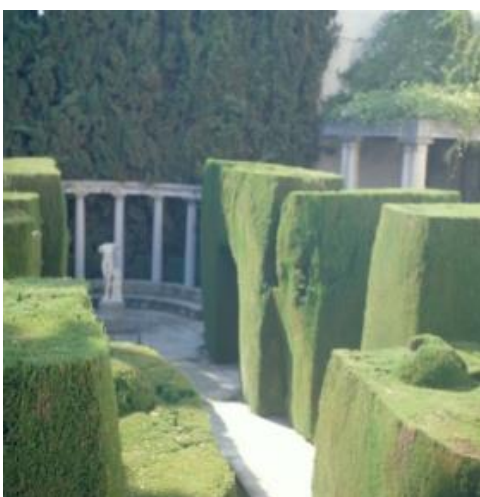

4.9 Carmen del pintor J.Ma Rodríguez Acosta: Jardín de Apolo. PHL, 2004. 

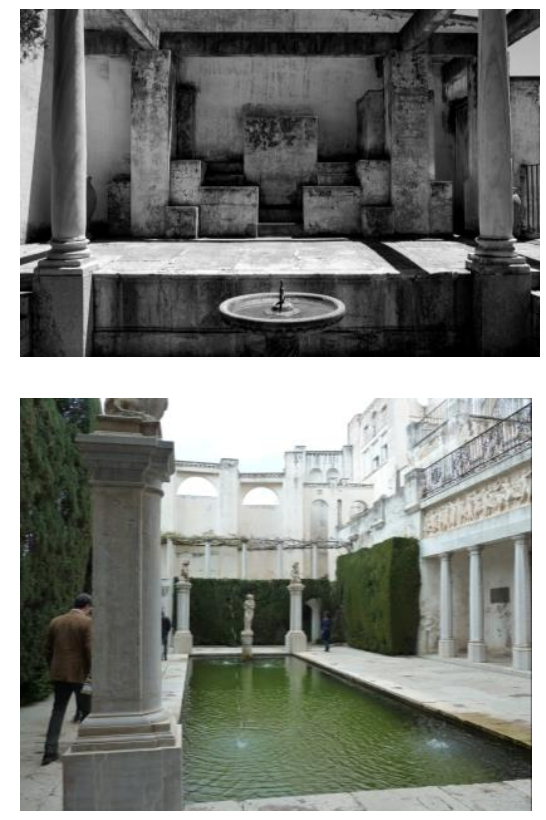

4.10 Carmen del pintor J.Ma Rodríguez Acosta, Granada: patio del Teatro y jardín de Venus. @FRodriguezAcost (Juanmi García) y PHL, 2016.
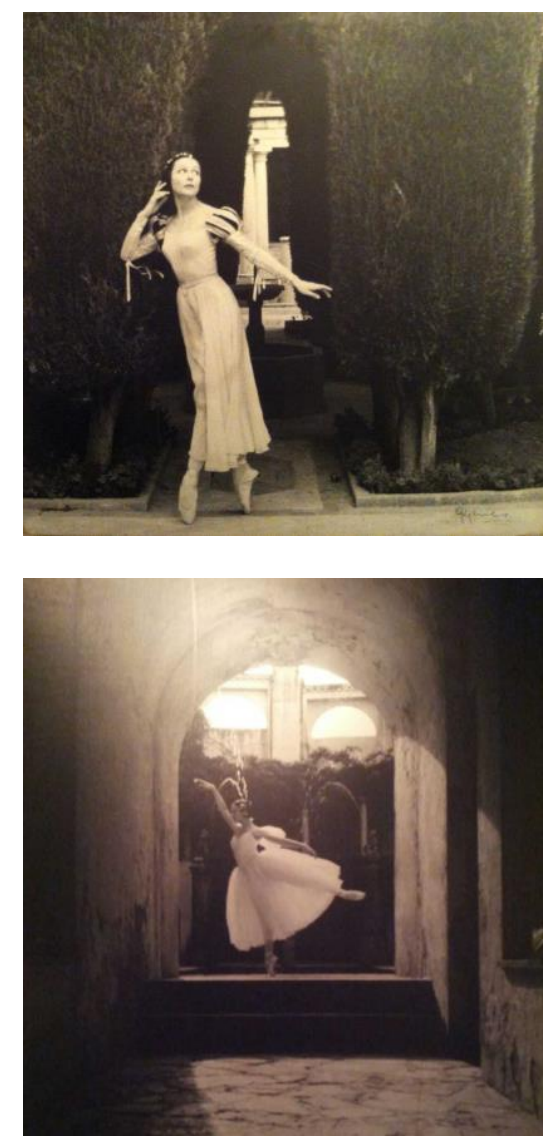

4.11 La bailarina Margot Fonteyn en los jardines de la Fundación para promocionar el Festival Internacional de Música y Danza de Granada. Fotógrafo: Gyenes, Archivo fotográfico de la Fundación Rodríguez-Acosta.

4.12 Carmen del pintor José María Rodríguez Acosta: montajes AntesDespués: jardín de Apolo y jardín de Venus. Foto: Archivo Fundación, Carmen López. planta baja, biblioteca en la primera y estudio en la segunda- se sitúa en la parte más elevada y en su eje central se accede mediante un arco de medio punto a La "Terraza" en un nivel inferior y con una pila bautismal sobre un basamento octogonal en el centro del espacio; se rodea de un muro con arcos y celosías y tiene vistas sobre el jardín y la ciudad de Granada. Al este de la Terraza se ubica el Jardín de Apolo o de Baco con un eje este-oeste marcado por dos fuentes y una escultura del dios Baco, rematado por una columnata en exedra y enfatizado por los altos muros de ciprés recortados. Una de las fuentes marca el eje transversal de este espacio que coincide con la escalinata que conduce al patio del Teatro al norte -con un espacio escénico con un juego de volúmenes art decó en uno de sus frentes creando una falsa perspectiva- y con una terraza que avanza al sur asomándose sobre las inferiores y el paisaje, con una pila bautismal renacentista a modo de fuente central entre los cipreses recortados. En el lado oeste atravesando un arco de piedra se accede al criptopórtico, un espacio circular cubierto y porticado con fuente central y abierto en el lado opuesto a un gran patio, generándose una perspectiva a lo largo del eje este-oeste.
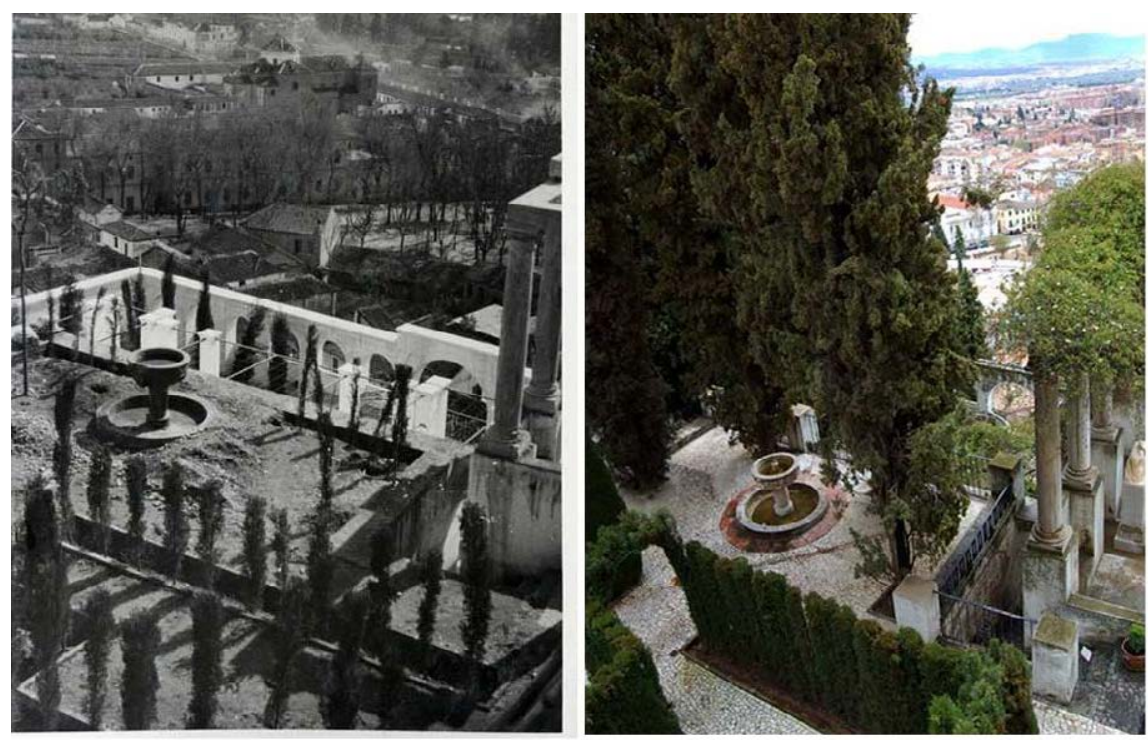

El eje longitudinal se prolonga al oeste de la Terraza en el jardín o patio de Venus con una alberca rectangular, en cuyo extremo se sitúa una escultura de la diosa, y las esquinas se enfatizan con columnas coronadas por esculturas de las que salen surtidores. El eje transversal viene marcado por el edificio y los grandes macizos de topiaria de ciprés en el perímetro sirven de fondo y ayudan a enfatizar los ejes. 

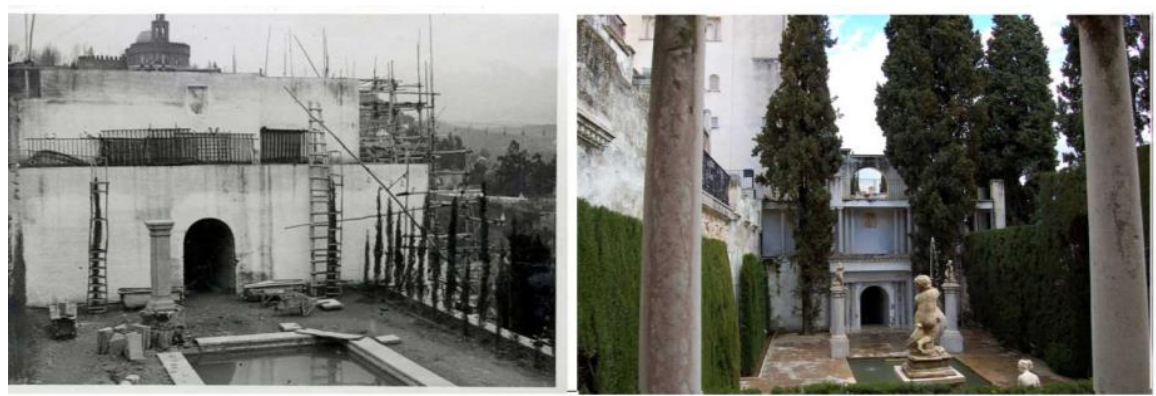

En un nivel inferior se desarrolla el jardín de la Monja, al que se accede a través de una estrecha avenida flanqueada por cipreses; cuenta en su centro con un túmulo sepulcral renacentista de una religiosa castellana, proveniente de un convento salmantino; está alineado con el Templo de Psiquis en una posición elevada. Éste se presenta como una ruina integrada en el jardín e invadida por la naturaleza; carece de cubierta y alberga el busto de Psiquis; su posición elevada le permite un amplio panorama desde su terraza. En el nivel más inferior se encuentra el Jardín Bajo o el Parterre al oeste con su seto recortado y árboles de gran porte, marcando el eje central del espacio y enfatizado por la fuente de base octogonal y la imagen de la diosa Diana; una serie de pórticos y columnatas enmarcan las distintas perspectivas del barrio del Realejo. Al este se ubica el Templete de planta circular ocupando una posición central y flanqueado por la Glorieta de cipreses -o la Corona- y el jardín de la alberca -con fuente en un extremo, banco perimetral y rematado por un muro con arcos y celosías-. El Templete va a marcar el acceso o salida de la galería subterránea y la mayor abertura en la tapia perimetral creando un mirador desde donde observar la ciudad y su vega.
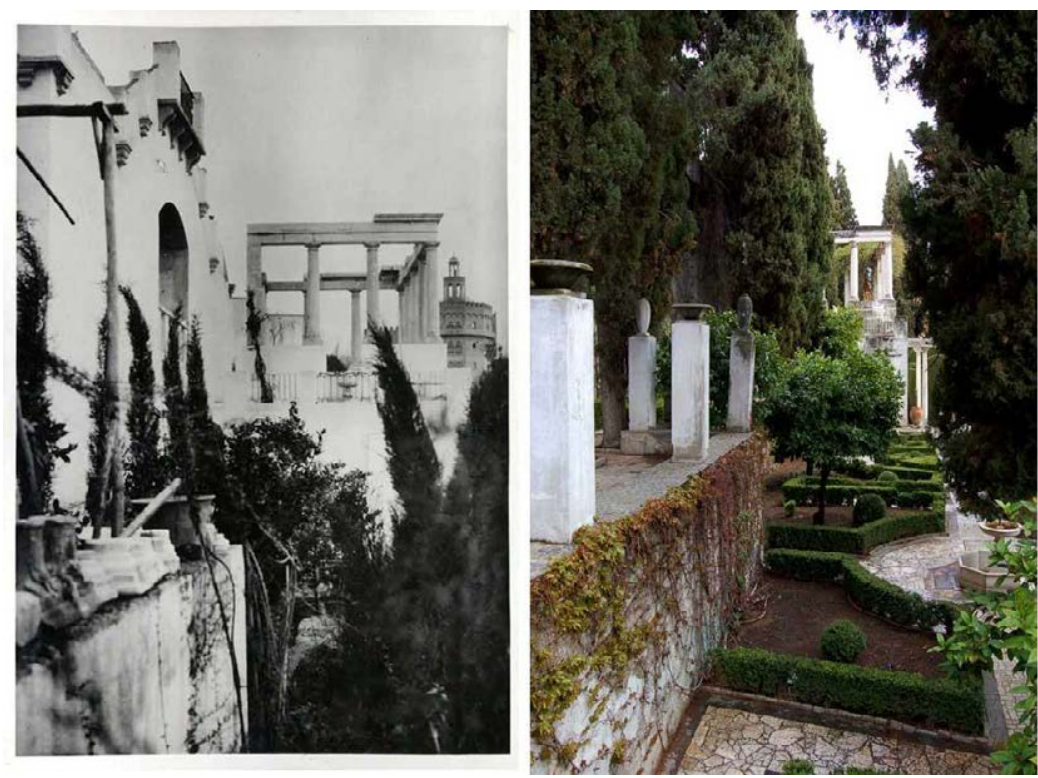
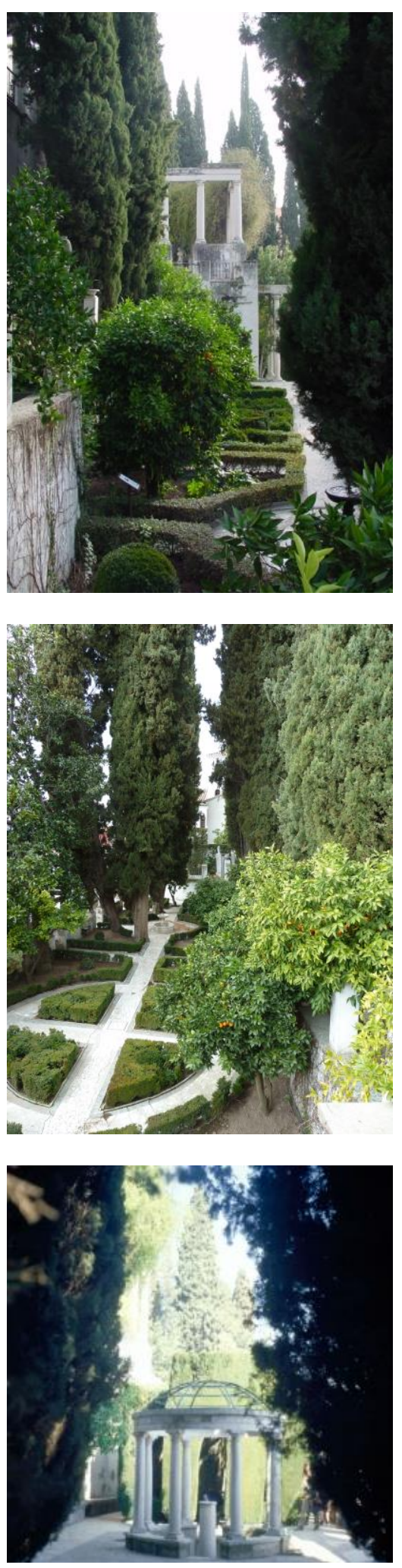

4.13 Carmen del pintor J.Ma Rodríguez Acosta, Granada: Templo de Psiquis, Jardín Bajo con el Parterre y Templete. PHL, 2004 y 2016.

4.14 Carmen del pintor José María Rodríguez Acosta: montajes AntesDespués: Templo de Psiquis y Jardín Bajo con el Parterre. Foto: Archivo Fundación, Carmen López. 
4.15 Vista del Carmen desde el barrio del Realejo. SECO DE LUCENA, 1992, p. 327. Perspectiva de Anasagasti. Arquitectura, 1983, no 240, p. 20. 4.16 Carmen de la Fundación Rodríguez Acosta: Fachada Suroeste y Sección transversal A-B. Del.: Juan García Valverde, 1962-dic. APAG/ Colección de Planos/ P-002319-20.
El conjunto es el resultado de un complicado proceso en el que intervinieron diversos personajes, aunque fue el propio RodríguezAcosta quien hizo de nexo entre ellos y fue el máximo responsable del proyecto. Actualmente alberga la sede de la Fundación Rodríguez Acosta desde 19417.
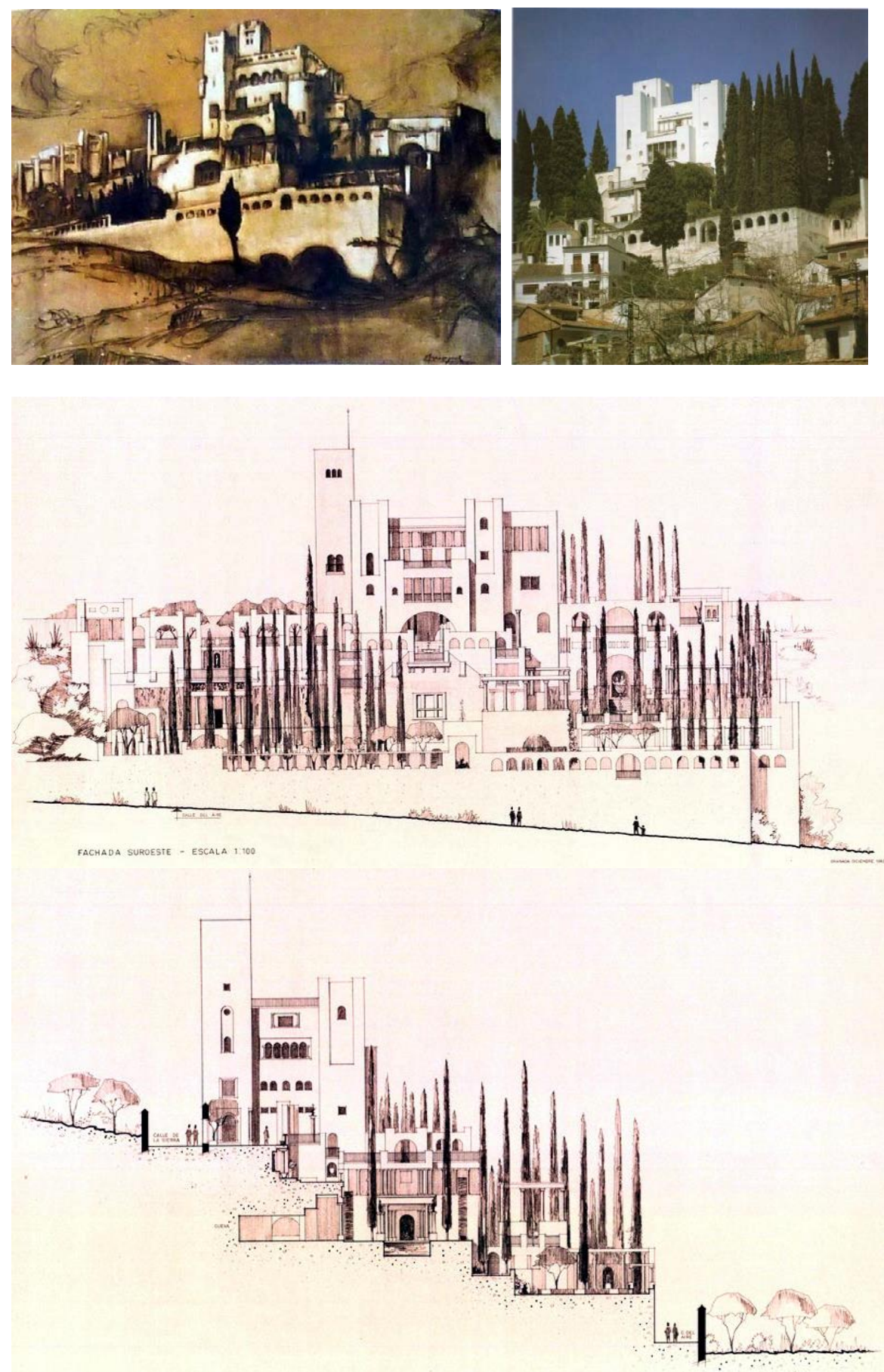

\footnotetext{
${ }^{7}$ En 1978 José Mạ García de Paredes inició una ampliación para albergar el legado del historiador D. Manuel Gómez Moreno, finalizando las obras en 1982 -año en que se declaró Monumento Histórico Nacional y posteriormente BIC-. El volumen principal de la sala de exposiciones se sitúa en el nivel del patio del estanque de la Fundación quedando oculto en gran medida por la pared coronada de arcos del fondo del estanque.
} 
El proyecto viene condicionado por el pronunciado desnivel y la adaptación mediante terrazas y miradores. Cada pequeño jardín se ajusta aprovechando el nivel correspondiente por lo que a veces los ejes de unas y otras no coinciden exactamente, al igual que los ejes quebrados de los jardines hispanomusulmanes; pero sin embargo hay uno principal muy claro que conecta lo masculino (Jardín de Apolo) con lo femenino (Jardín de Venus). El recorrido es el elemento que une $\mathrm{y}$ da sentido a todas las partes. Tiene una imagen moderna en la que la silueta de los edificios blancos ${ }^{8}$ se recorta en el paisaje, entremezclados con el verde de la vegetación, pero mantiene las principales características y la manera de dialogar con el entorno de los cármenes primitivos. Hay una síntesis entre los elementos arquitectónicos y la jardinería donde se intercalan elementos clásicos de fragmentos de muros y columnas pero organizados con un lenguaje moderno con setos de ciprés recortados. El elemento vegetal principalmente utilizado es el ciprés, tanto en su forma libre -principalmente se aprecian en el alzado y son indispensables en su diálogo con la Alhambra a la que miran- como en paredes y topiaria con un sentido ampliamente arquitectónico; prácticamente no se emplean otras especies ni flores como en los otros cármenes. Estos altos setos recortados enmarcan y sirven de telón de fondo sobre el que se recortan las esculturas que evocan el mundo clásico, señalan puntos de fuga y marcan ejes y simetrías. También hay una fuerte presencia de la estructura y la arquitectura en el jardín -pérgolas, pórticos, glorietas...- que van a guiar la vegetación.

Aparecen elementos de diferentes estilos: hispano-árabe (terrazas, albercas, celosías, patios...), la relación con las villas italianas como la exedra de columnas que recuerda a las de la Villa Adriana en Tívoli, y un equilibrado clasicismo del conjunto (orden, armonía, fuentes, esculturas, volúmenes de cipreses recortados...); pero todo ello con un lenguaje moderno, como la interpretación de la tradición de la pérgola como elemento clasicista que se asoma al paisaje. El jardín está tratado en la línea de la mejor arquitectura de la época y el pintor quiso imprimirle las tendencias más modernas de las villas y jardines más avanzados de principios de siglo en España y Europa.

\footnotetext{
8 También se le conoce como el Carmen Blanco.
}
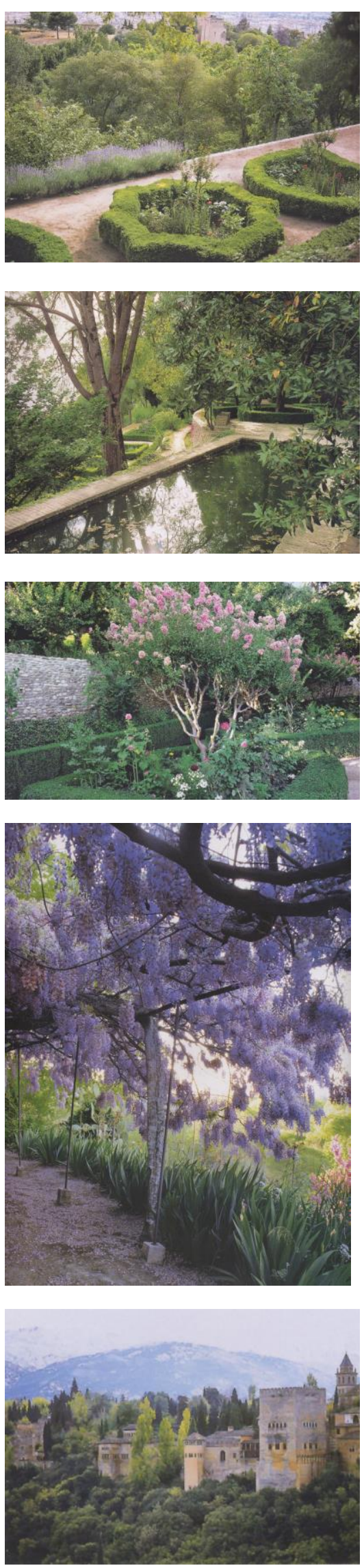

4.17 Carmen de la Justicia, Granada, 1939. MENCOS, 2004, p. 84-87. 
Siguiendo este modelo se realizarán y remodelarán nuevos cármenes, como el Carmen de la Justicia, realizado en 1939. Su propietaria conocía la Alhambra y el Generalife porque se había criado allí y los tenía muy presentes en el diseño. Reaprovechó las terrazas y muchos de los grandes árboles existentes, así lo explica: “Decidí dar una estructura a lo que estaba allí. En primer lugar, engrandecí la alberca hasta dejarla del tamaño de una piscina y le di una apariencia más bonita. A continuación planté boj con formas circulares y estrelladas para embellecer la terraza principal. Quería que cada seto contuviera sólo un tipo de flores, pero Manuel, mi jardinero, mezcló las plantas, que acabaron formando una amalgama de colores (dalias, malvarrosas, lavanda, peonías, etc.). /.../ En este lugar, con el sonido y la vista del agua, me di cuenta de que un jardín resume y condensa todo en una especie de música de los sentidos"9. Cuenta con una pérgola revestida de glicinia con lirios a sus pies; y la antigua torre de la Puerta de la Justicia, en la Alhambra, forma parte del jardín que se abre a las vistas de la Alhambra con Sierra Nevada al fondo.

${ }^{9}$ MENCOS, E.: Jardines secretos de España. Barcelona: Blume., 2004, p. 84-87. 


\section{LA RECUPERACIÓN DEL JARDÍN CLÁSICO EN ESPAÑA: PINTORES JARDINEROS}

Los pintores españoles a través de los procedimientos del realismo y de la pintura del paisaje entraron en contacto con las modernas tendencias francesas, belgas e inglesas, y como indica Frederick Hartt: "compartieron experiencias comunes, como la modernista, sin olvidar nunca referencias concretas a las tradiciones nacionales, con las que mantuvieron un coloquio constante, fecundo a veces, retardatario en otras ocasiones./.../...buena parte de la pintura luminista y de paisaje de esos años sirvió de tímido engarce con una modernidad atenazada por las tradiciones nacionales,..." ${ }^{10}$.

\section{Santiago Rusiñol y Prats (1861-1931)}

Al igual que en Europa los pintores impresionistas (Monet, Renoir, Caillebotte, etc.) plasmaron su amor por la Naturaleza, incluso muchos de ellos tenían un jardín donde se dedicaban a la horticultura, en España hubo pintores como Santiago Rusiñol que popularizaron los jardines clásicos españoles abandonados, reproduciéndolos en sus cuadros. Estos pintores tendrán un papel fundamental ya que realizan una importante labor de difusión al llevar sus cuadros de jardines al extranjero. En 1899 Rusiñol expuso con gran éxito su colección Jardines de España en París con pinturas de los jardines de Granada, Aranjuez, La Granja, Sitges, Tarragona y el Laberinto de Horta. Cuatro años más tarde publicará su libro Jardines Españoles ${ }^{11}$ donde recoge todas sus reproducciones de jardines que se caracterizan por una mirada misteriosa y melancólica, llenos de soledad y silencio. Winthuysen nos describe a este personaje: "En 1915 coincidí con don Santiago en Aranjuez una larga temporada. Entonces era ya distinta su pintura: sus lienzos eran decoraciones; parterres precisamente dibujados, árboles de siluetas precisas. Las vibraciones del impresionismo habían desaparecido para dejar escueta la arquitectura del jardín; la ordenación fría con el surtidor siempre centrado; la euritmia como motivo esencial" 12 .

\footnotetext{
10 HARTT, Frederick: Arte. Historia de la pintura, escultura y arquitectura. Madrid: Akal, Arte y Estética, 20, 1989, p. 1020 y 1022.

${ }^{11}$ RUSIÑOL, S: Jardins d'Espanya. Barcelona, Thomas, 1903.

12 WINTHUYSEN, J: Rusiñol y los Jardines de España, Crisol, Madrid, 18 de junio de 1931. En: Jardines de España (1870-1936). Catálogo de la Exposición 17-11-1999/9-1-2000. Madrid: Fundación Cultural Mapfre Vida, 1999, p. 291.
}

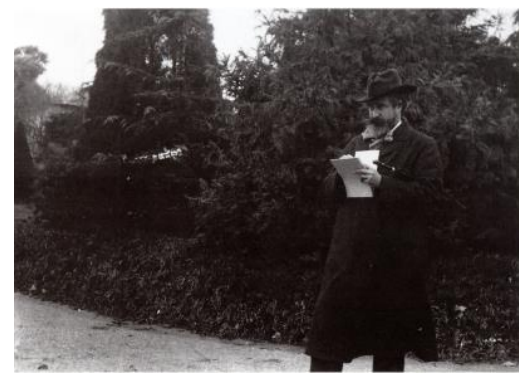

5.1 Santiago Rusiñol, 1903. AHCB-AF, Francesc Serra. Jardines de España (1870-1936), 1999, p. 50.

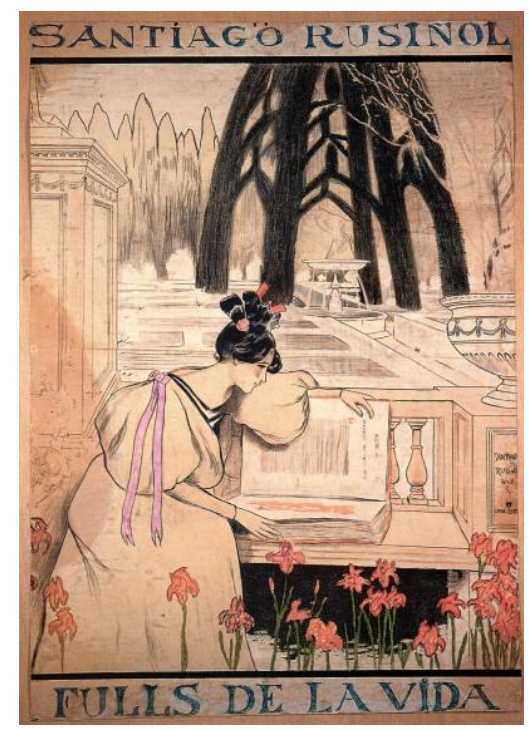

5.2 Cartel para el libro de Rusiñol: Fulls de la vida, h. 1898, Santiago Rusiñol. Representa un jardín a la francesa con fuente bajo cúpula de cipreses. Jardines de España (1870-1936), 1999, p. 145.

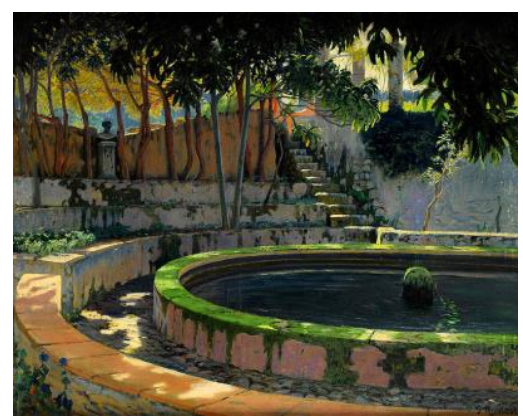

5.3 Jardín de las Elegías, Son Moragues en Mallorca. Santiago Rusiñol, 1903. Jardín y alberca. Artnet.com

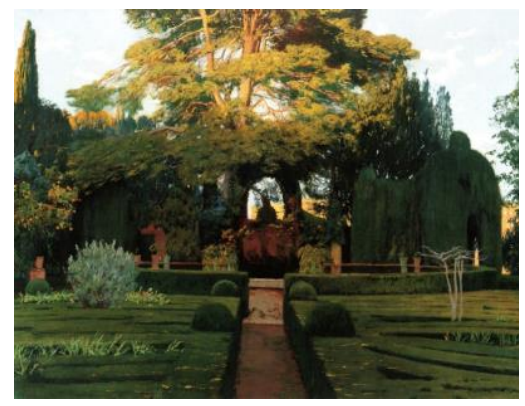

5.4 Jardines. Santiago Rusiñol. Jardines de España (1870-1936), 1999, p. 158 


\begin{abstract}
“...Silenciosos caminos, soñolientas arcadas,

inmóviles estanques y ventanas cerradas:

nada sirve entre medio de la intensa verdura,

-para tus cuadros tristes no queda una figura.

No queda una figura de las muchas que un día

prendieron como flores sus risas de alegría

en los ufanos árboles, buscando las arcadas

y huyendo en los kioscos de importunas miradas.../.../

Todo aquel mundo viejo, solitarios jardines,

que, bulliciosamente, llenó vuestros confines,
\end{abstract}

ha desaparecido sin darnos descendencia.

-iOh, abominados padres que no dejáis herencia!..."

5.5 Eduardo Marquina, "Los jardines de España", "A Santiago Rusiñol", Barcelona, 1900. En Santiago Rusiñol, Jardines de España, 1903. Jardines de España (1870-1936), 1999, p. 289.

“iJardín sin jardinero!

¡Viejo jardín,

viejo jardín sin alma...

jardín muerto! Tus árboles

no agitan el viento. En el estanque, el agua

yace podrida. ¡Ni una onda! El pájaro no se posa en tus ramas.

La verdinegra sombra

de tus hiedras contrasta

con la triste blancura

de tus veredas áridas...

¡Jardín, jardín! ¿Qué tienes?

¡Tu soledad es tanta

que no deja poesía a tu tristeza!

¡Llegando a ti, se muere la mirada!

Cementerio sin tumbas...

Ni una voz, ni recuerdos, ni esperanza.

¡Jardín sin jardinero!

¡Viejo jardín,

viejo jardín sin alma!"

5.6 El Jardín gris, Manuel Machado. Alma, 1902. LITVAK, L., 2000, p. 495496.
Principalmente pinta el parque clásico con su escala humana y una clara ordenación geométrica que se aprecia en el trazado de avenidas, parterres y macizos vegetales. Lily Litvak lo analiza en su artículo: "Se modela el espacio, privilegiando la arquitectura que define el lugar, la vegetación podada en formas regulares, y las estatuas que toman posesión del aire con su masa o empuje. Algunos cuadros muestran verjas, rejas y muros que cierran el lugar, o son protagonistas principales las fuentes y su ornamentación estatuaria. Otros lienzos destacan elementos escenográficos: niveles, terrazas que permiten la exploración del espacio, anfiteatros, pórticos, arcos, columnas, pérgolas /.../. Las arquitecturas vegetales ocupan mucho espacio; murallas de ciprés, setos de boj, arcadas, nichos, pilares y cornisas logrados con el ramaje de los arbustos, pequeños salones y cuartos de follaje domesticado por medio del <artificio de la poda"13. Le atrae el sentido arquitectónico del elemento vegetal; esta vegetación podada, generalmente perenne, contrasta con las formas libres del bosquete que se perfila detrás y añaden una nota de color y estacionalidad con sus especies caducas.

Este pintor desea rescatar al paisaje del tiempo, sin embargo también muestra señas de deterioro (esculturas rotas, fuentes sin agua, vegetación descuidada que invade muros y escaleras, etc.). Estos paisajes recogen el sentimiento de hastío existente a finales del siglo XIX y apoyaban la concepción pesimista de la existencia humana ${ }^{14}$. Esta visión de Rusiñol influirá en muchos poetas, escritores y compositores (Juan Ramón Jiménez, Pérez de Ayala, García Lorca, Manuel de Falla, etc.); así lo expresa Valle Inclán en su Sonata de Otoño: "Recorrimos juntos el jardín, las carreras estaban cubiertas de hojas secas y amarillentas, que el viento arrastraba delante de nosotros con un largo susurro; los caracoles inmóviles como viejos paralíticos tomaban el sol sobre los bancos de piedra; las flores empezaban a marchitarse en las versallescas canastillas recamadas de mirto, y exhalaban ese aroma indeciso que tiene la melancolía de los recuerdos. En el fondo del laberinto murmuraba la fuente rodeada de cipreses, y el amarillo del agua, parecía

\footnotetext{
13 LITVAK, Lily: El jardín abandonado. El tema del viejo parque en pintura y literatura. Espacio, Tiempo y Forma, Serie VII, Ha del Arte, t. 13, 2000, p. 489.

14 "Muchos consideraron a los cuadros de Rusiñol equivalentes a la crítica noventayochista, "los vergeles muertos de la España negra", jardines fin de siglo y fin de raza, que tienen la melancolía de los pueblos vencidos. Otros vieron en ellos la marca dela decadencia, restos de dinastías cuyo sudario se tiende por las rectas alamedas de Aranjuez, El Escorial y La Granja". Ibíd., p. 499-500.
} 
difundir por el jardín un sueño pacífico de la vejez, de recogimiento y de abandono"15.

En 1918 Joaquim Folch i Torres, hermano del director de la revista D’Ací d'Allá publica un artículo bajo el seudónimo "Flama"16 recogiendo las ideas de Rusiñol sobre la defensa de los viejos jardines españoles con matices propios del nacionalismo catalán, y señala de forma novedosa la mediterraneidad como característica de los jardines catalanes; posteriormente José Tito Rojo ${ }^{17}$ escribió dos artículos sobre este pintor como iniciador del nacionalismo jardinero. Rusiñol se convirtió en el abanderado del jardín regionalista ${ }^{18}$.

\section{Joaquín Sorolla y Bastida (1863-1923)}

Esta relación de la pintura y los jardines también se aprecia en Joaquín Sorolla, amante de la luz y del color, y apasionado por los patios y jardines de la Alhambra de Granada, del Alcázar de Sevilla y del Palacio de la Granja, motivos recurrentes de sus pinturas. Colaboró con el arquitecto Enrique María de Repullés y Vargas (1845-1922) en la realización del jardín de su estudio-vivienda de Madrid, actualmente sede del Museo Sorolla, donde cree realizar una interpretación del jardín hispanomusulmán destacando su interioridad con la armonía entre lo vegetal y el agua y rescatando elementos andaluces y mediterráneos. Lo que él encontró en sus viajes a Andalucía y creyó jardinería hispanomusulmana, fue rebatido posteriormente por Winthuysen quien demostró y publicó que se trataba de jardinería italiana, ya que tanto el emperador

\footnotetext{
${ }^{15}$ Valle Inclán, Sonata de otoño. Obras Completas II. Madrid, 1952, p. 139-140.

${ }^{16}$ FLAMA (FOLCH I TORRES, J.): Els nostres jardins. D'Ací d'Allà, 1918, vol.1, no5, p. 516525. TITO ROJO, J.: Artur Rigol i Riba, jardinero moderno. En: SEGARRA, S.; VALENZUELA, L.M.; ROSÚA, J.L.: Paisaje con+texto: naturaleza, jardín, espacio público. Universidad de Granada, 2016, p.72.

17 TITO ROJO, J.: El jardín de los regionalistas. Sobre la invención de la estética jardinera andaluza. En: GONZÁLEZ ALCANTD, J.A. (ed.): La invención del estilo hispano-magrebí. Presente y futuros del pasado. Barcelona: Anthropos, 2010, p. 339-378.

TITO ROJO, J.: Modernity and Regionalism in the Gardens of Spain (1850-1936): Form Radical Opposition to Misunderstood Synthesis, en O'MALLET, T.; WOLSCHKE-BULMAHN, J.: Modernism and Landscape Design, 1890-1940. Washington: National Gallery of Washington, 2015, p. 169-204.

18 "Pero antes de que muera del todo el recuerdo de las buenas tradiciones, para esperar esas nuevas que mejoren los presentes, hay que ver estos cármenes de ahora". RUSIÑOL, S: Impresiones de arte. Barcelona: La Vanguardia, 1897, p. 229.
}

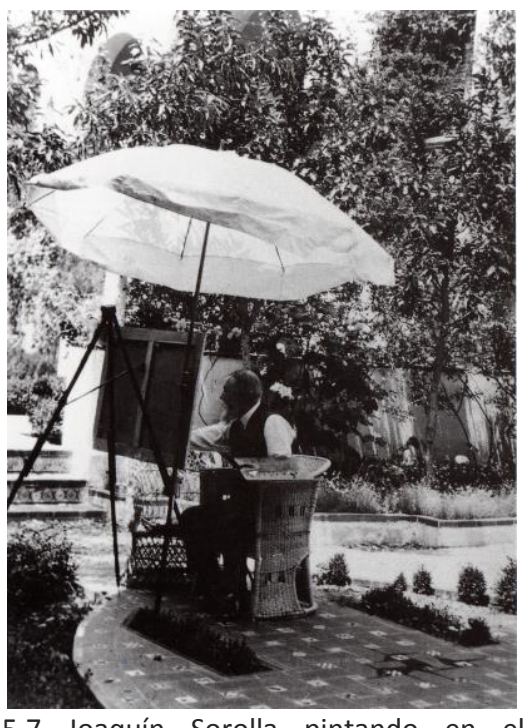

5.7 Joaquín Sorolla pintando en el segundo jardín de su casa madrileña, h. 1917-1918. Jardines de España (18701936), 1999, p. 70.
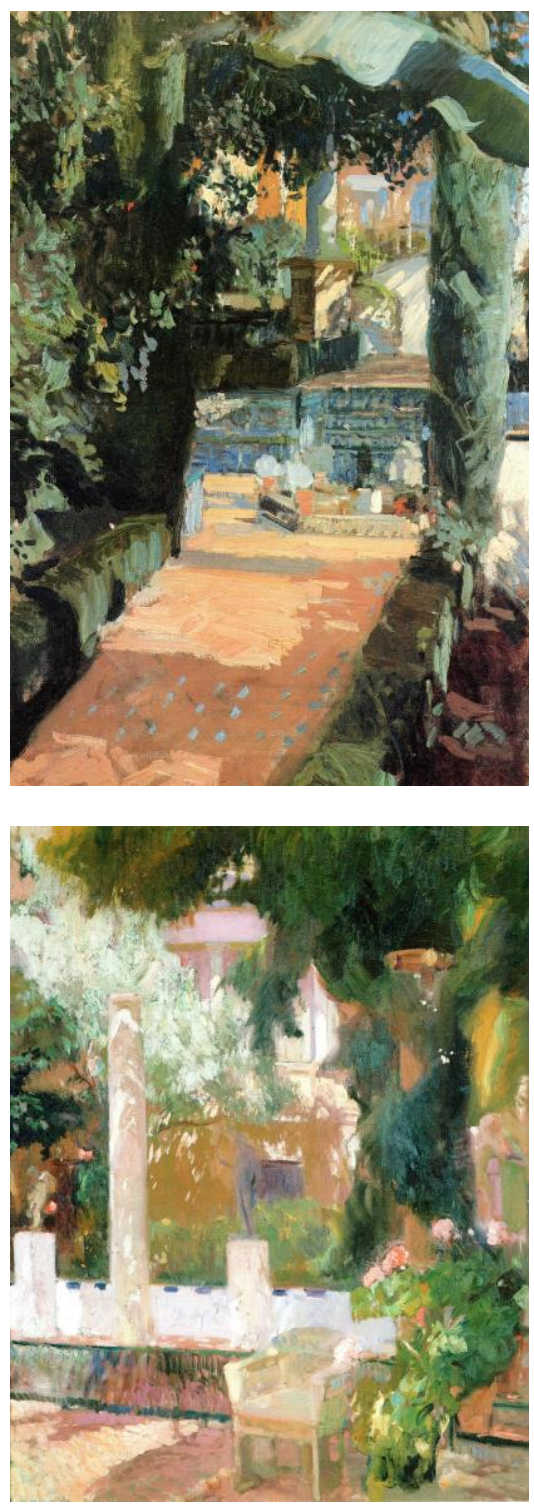

5.8 Patio de las danzas del Alcázar de Sevilla. Sorolla, 1910. Rosal de la casa Sorolla, 1918. PEEL, E.: Joaquín Sorolla. Barcelona: Ediciones Polígrafa, 1990, p. 160 y 174. 


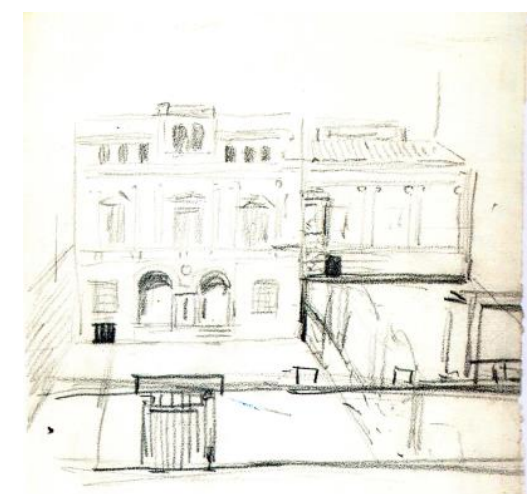

5.9 Alzado de la Casa Sorolla, 1910. La casa Sorolla - Dibujos, 2007, p. 33.

5.10 Plano de la planta principal, 1911. Enrique María Repullés y Vargas. La casa Sorolla - Dibujos, 2007, p. 37.

Plano actual. Base del Ayuntamiento de Madrid en el que se han marcado los tres jardines. Elaboración propia.
Carlos V como su hijo, Felipe II, hicieron replantar los jardines de Sevilla y Granada siguiendo modelos italianos ${ }^{19}$.

En 1905 se adquirió un primer solar ${ }^{20}$ en el Paseo del General Martínez Campos, y Sorolla comenzó a trabajar en los diseños iniciales de la edificación. En 1910 adquirió un segundo solar colindante a la derecha del anterior. El pintor intervino directamente en la organización de la casa, separando la vivienda familiar de la zona de taller formada por tres estudios encadenados en la parte posterior. Modificó el diseño de la fachada, añadiéndole un carácter más andalucista a los diseños clasicistas de Repullés. También creó el jardín que rodea gran parte de la casa, tomando ideas de la plantación de sus diferentes viajes a Andalucía, conservándose muchos de sus croquis. Pintó muchos de los rincones de su jardín y él mismo plantó muchos de sus árboles. El espacio del jardín se divide en tres espacios menores denominados: primer, segundo y tercer jardín.
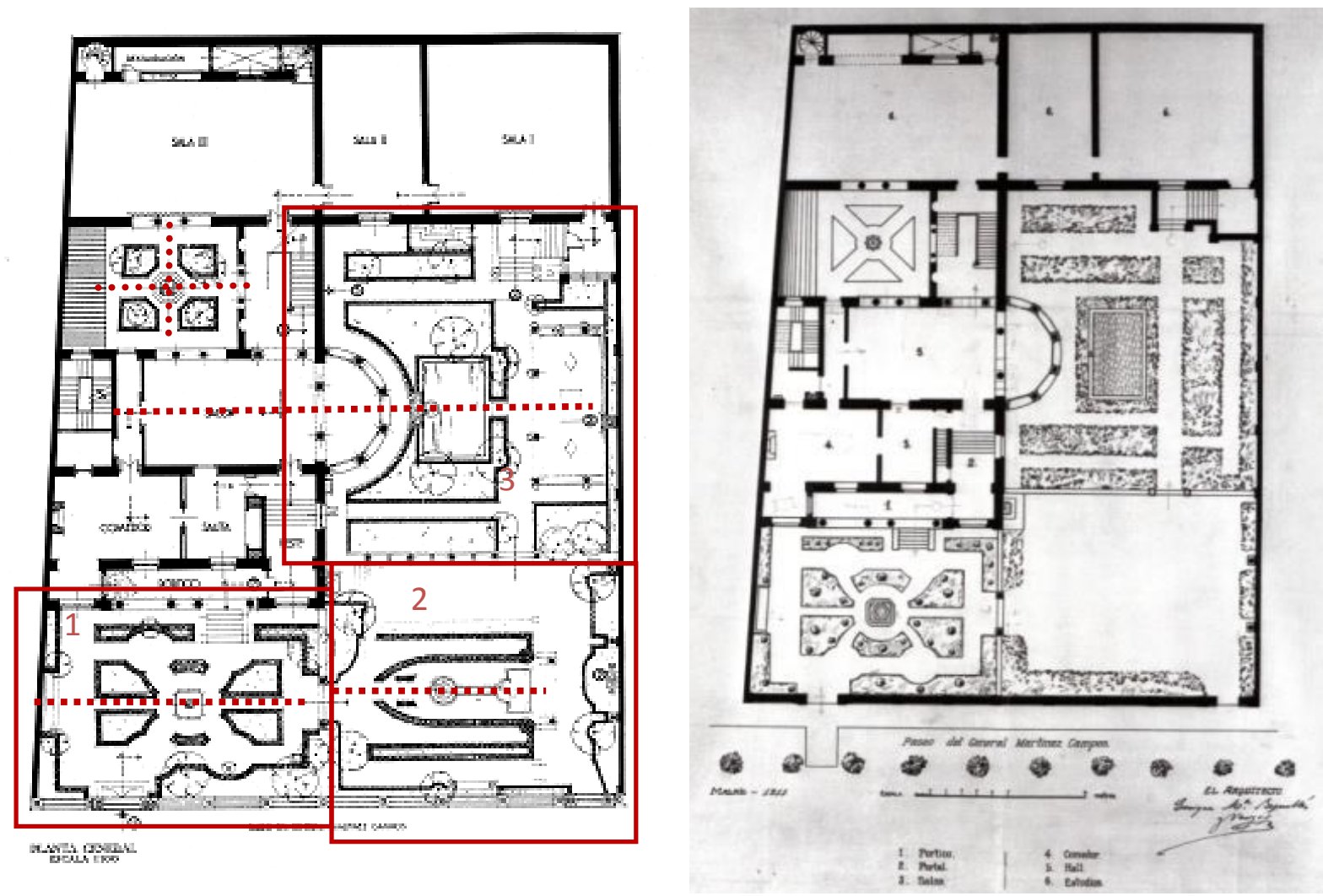

${ }^{19}$ WINTHUYSEN, J.: Jardines Clásicos de España - Castilla. Madrid, 1930. Nueva edición AÑÓN FELIU, C.; SANCHO GASPAR, J.L.: Jardines clásicos de España (2 vol.) vol. 1: Castilla. Madrid: Doce Calles, 1990, p. 22. Esta apreciación también al recoge Florencio de SantaAna en "Sorolla y el jardín de su casa madrileña", en Jardines de España (1870-1936), 1999, p, 73; y en La casa Sorolla. Dibujos. Del 11 de junio al 14 de octubre de 2007. Ministerio de Cultura, Fundación Museo Sorolla, 2007, p. 38.

${ }^{20}$ Corresponde prácticamente a la zona actualmente construida, salvo los dos primeros estudios y el segundo y tercer jardín. 
El primer jardín se sitúa delante de la fachada principal y se inspira en el Patio de Troya de los Reales Alcázares sevillanos, realizando un tratamiento similar en la forma de los arriates y el pórtico columnado que da acceso a la entrada principal acodada y con escalones para salvar el desnivel. Su planta aparece en el plano de Repullés de $1911^{21}$ y se desarrolla alrededor de una fuente central sobre pileta cuadrada excavada ${ }^{22}$, rodeada de cuatro macizos vegetales circulares. Diseña dos soluciones para el cerramiento oeste que se relacionan más con la jardinería italiana que con la andaluza. La primera tiene forma redondeada y con varias columnas, sustituidas en la segunda por cipreses, en la cual también se adelantan los setos de boj y se retranquea el banco. Actualmente el muro oeste no posee forma circular y sólo conserva el banco con cerámica de Triana y los tres escudos castellanos ${ }^{23}$. Este jardín, al que vuelcan las estancias principales de salón y comedor, fue ideado en principio como un patio delantero al no existir el segundo solar posteriormente adquirido. Se conserva sin muchas alteraciones, tan sólo se han añadido algunas esculturas.

En esta época Sorolla también realizó varios bocetos para el cerramiento exterior: un muro de ladrillo visto ${ }^{24}$ con pilastras coronadas con bolas de tipo escurialense. El muro, a dos aguas, se cubre con losetas vidriadas de color verde. Actualmente no existen rejas en la parte superior del muro sino un friso de ladrillos. También trabajó la puerta principal realizando varios dibujos. La actual es muy similar a la que diseña: una puerta de hierro inscrita en un arco muy rebajado, con pilastras a los lados sobre las que coloca unas ménsulas y en el dintel proyecta un escudo con ornamentación floral ${ }^{25}$. Respecto al pavimento, no retoma los

\footnotetext{
${ }^{21}$ Se conservan tres proyectos pero no se corresponden con la plantación definitiva.

${ }^{22}$ Sorolla colocó inicialmente una pila del s. XVI de forma circular y con tetones sobre un balaustre, que sustituyó en 1914 por una más moderna y estilizada, encargada seguramente en Sevilla. La pila pasó a la alberca del tercer jardín, donde se encuentra actualmente. La casa Sorolla, 2007, p. 12. Según Florencio Santa-Ana la nueva fuente con surtidor central y cuatro aliviaderos sigue modelos más granadinos que sevillanos. Florencio de Santa-Ana en "Sorolla y el jardín de su casa madrileña", en Jardines de España (1870-1936), 1999, p, 75.

${ }^{23}$ La casa Sorolla. Dibujos, 2007, p. 55.

24 De color similar al albero sevillano, para Florencio Santa-Ana resulta extraño que no se enluciera y considera la posibilidad que se pensara cubrir el muro con vegetación, extinguida en la intervención de 1979. SANTA-ANA, F.: "Sorolla y el jardín de su casa madrileña", en Jardines de España (1870-1936), 1999, p, 77.

25 En la parte superior dibuja "volutas que enlazan con el friso arquitrabado, donde en 1932 se colocó el título Museo Sorolla. Se coronan a ambos lados con unas bolas". La casa Sorolla. Dibujos, 2007, p. 54.
}

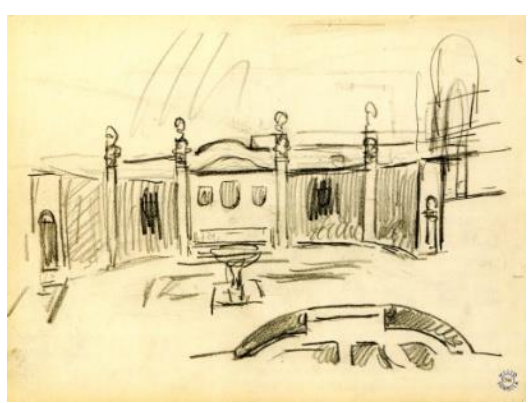

5.11 Proyecto para el muro oeste del primer jardín, 1911. La casa Sorolla Dibujos, 2007, p. 55.

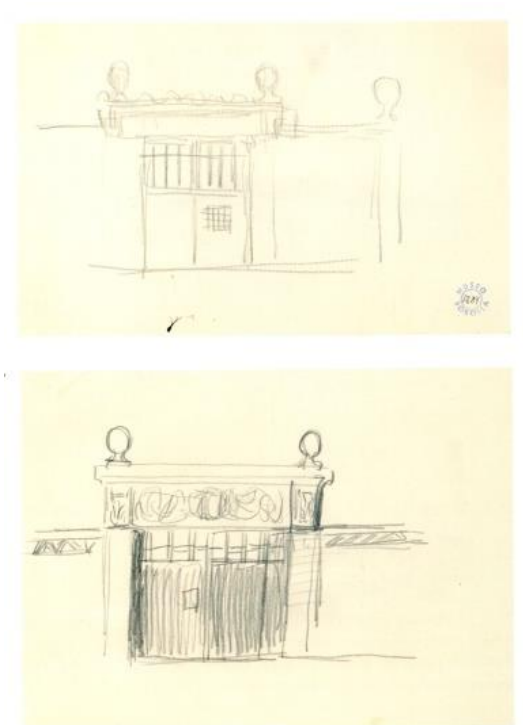

5.12 Alzados para la puerta principal, 1910-1911. La casa Sorolla - Dibujos, 2007, p. 53.

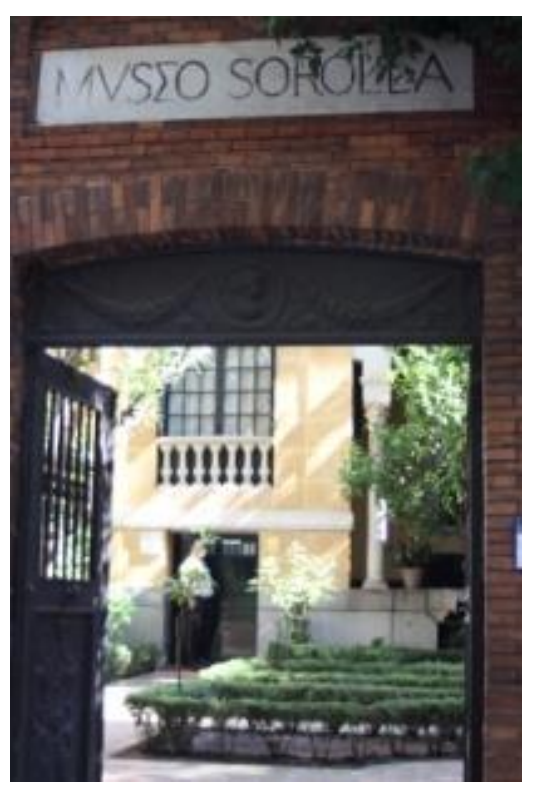

5.13 Acceso mediante un pórtico de ladrillo a la casa-taller de Sorolla, actual Museo Sorolla. PHL, junio 2011. 


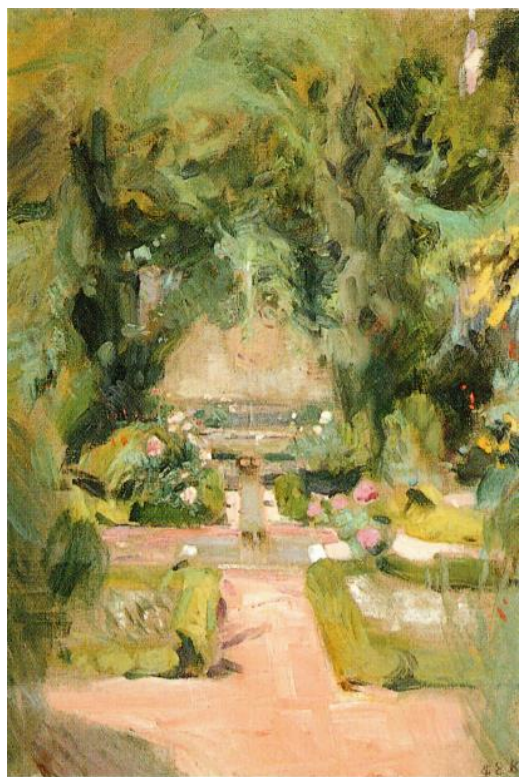

5.14 Jardín de la casa Sorolla, h. 1918. Joaquín Sorolla. Panorámica del primer jardín desde el segundo. Jardines de España (1870-1936), 1999, p. 74.
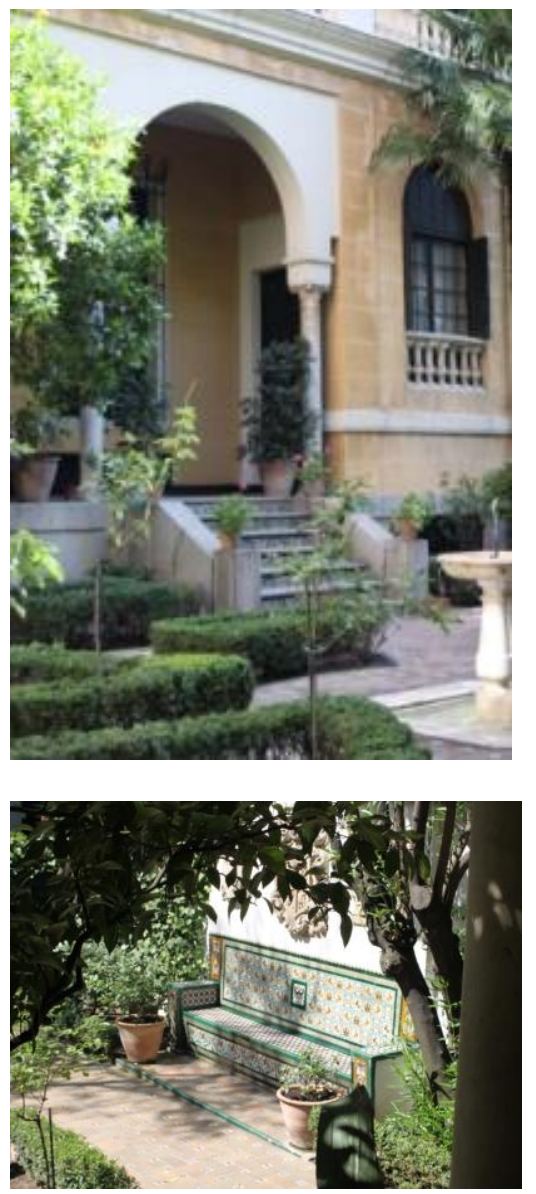

5.15 Vistas del primer jardín. PHL, junio 2011. pavimentos andaluces de guijos encastrados de diferente color formando dibujos y simplemente utiliza gravilla suelta ${ }^{26}$.

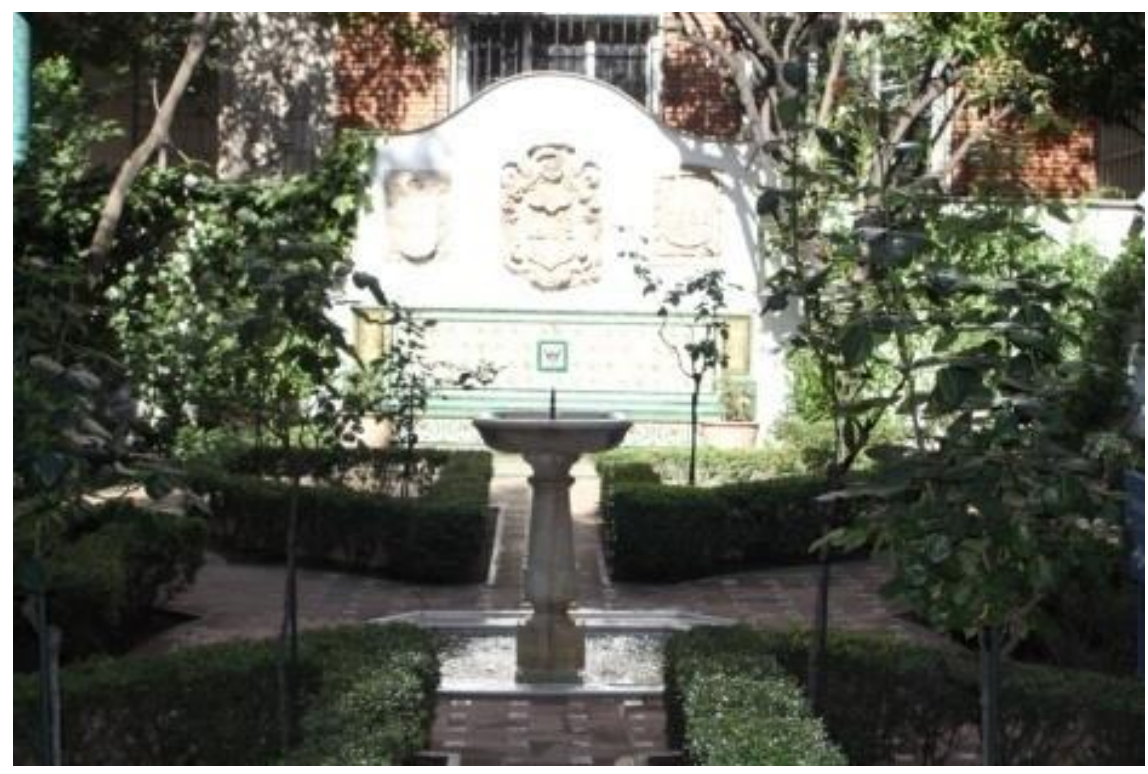

El segundo jardín, planificado en $1915^{27}$, se inspira en el Generalife de Granada, especialmente en el Patio de la Acequia, con su sucesión de pequeñas albercas y piletas, aunque tiene que adaptarse al espacio y reducir el tamaño guardando similitudes con el sevillano Parque de María Luisa, iniciado en 1916. Marcando el eje se ubica una pequeña alberca rectangular con un semicírculo en el enlace con el riad ${ }^{28}$ que conduce a un espacio redondo, donde colocó una pila circular antigua con surtidor y tres amorcillos. A lo largo del riad colocó una serie de surtidores que convergen en el canalillo que alimentan los dos extremos. Cierra el eje un banco de Triana, flanqueado por dos columnas antiguas, y sobre ellas dos capiteles califales. En la parte posterior hay un togado romano, flanqueado por dos cipreses, y sobre el muro tres reproducciones en yeso, actualmente destruidas ${ }^{29}$. Colocó un seto de boj en forma de $U$ bordeando la fuente, y separado mediante un pasillo plantó otro macizo de boj dejando rosales en medio.

\footnotetext{
${ }^{26}$ En 1988 para evitar el barro se colocan suelos de losetas de barro y guijos empotrados. Ibíd., p. 50.

27 Ya en 1911 había adosado a la pared del edificio un pilar, adquirido el año anterior en Granada, anuncio del carácter granadino que le quería dar a este espacio. No se plantó hasta bien avanzado el año 1916, cuando descansa del encargo de la decoración para The Hispanic Society of America. Ibid., p. 12.

${ }^{28} \mathrm{El}$ riad es un esquema monoaxial, típico de los patios hispanomusulmanes organizados por un eje muy desarrollado marcado por una acequia; los lechos de plantaciones son muy variados y en los extremos se sitúan construcciones y tapias o arcadas en los bordes largos.

${ }^{29}$ Ibíd., p. 58.
} 
La composición de este jardín también tiene un claro eje, aunque no coincide exactamente con el eje del primer jardín ya que el solar se adquirió posteriormente y se tuvo que adaptar al espacio y las preexistencias, sin embargo consigue obtener una perspectiva de ambos jardines. El paso del primer al segundo jardín se enmarcó mediante dos columnas sobre las que se colocaron dos esculturas, solución similar al Jardín de la Danza de los Alcázares ${ }^{30}$. Es el espacio que más trabajó Sorolla y del que se conservan numerosos bocetos con distintas opciones de diseño en la colocación de las fuentes y de la posibilidad de meter una pérgola. Incorporó elementos como las columnas y el togado romano ${ }^{31}$ que pertenecen más bien a la jardinería renacentista italiana ${ }^{32}$. los recursos espaciales que utiliza son italianos, pero sin articulación expresa entre todas las piezas, al modo hispano. Seguramente los azulejos utilizados en este jardín provienen de la primera decoración utilizada en los paramentos del comedor de la casa.
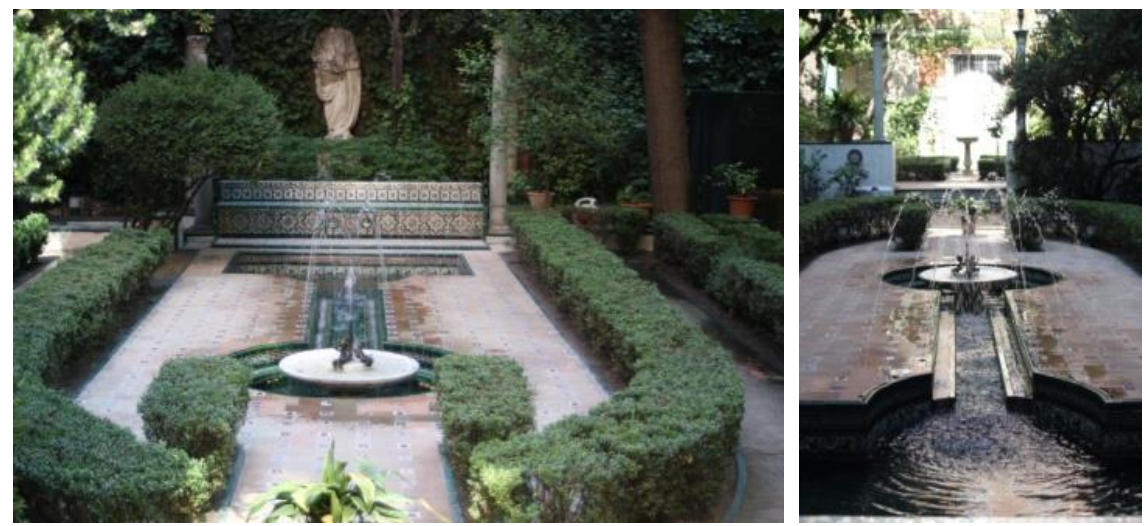

Finalizada la plantación del segundo jardín, alrededor de 1916 y 1917, acometió la remodelación del tercer jardín, situado en una plataforma en un nivel superior a la que se accede mediante unos escalones. Cambió la configuración que aparecía en el plano de Repullés de 1911, constituida por siete arriates rectangulares bordeados de boj y una alberca sin fuentes ni otros elementos decorativos, para instalar la pérgola con columnas reaprovechadas que había intentado instalar en el jardín anterior. La pérgola se cubre con un rosal trepador y aloja la réplica del busto de Sorolla de

\footnotetext{
30 SANTA-ANA, F.: "Sorolla y el jardín de su casa madrileña", en Jardines de España (18701936), 1999, p, 76.

31 Dio vueltas en los dibujos para ubicar esta pieza, regalada en 1916 por el marqués de Viana, procedente de Cástulo. La casa Sorolla. Dibujos, 2007, p. 12.

32 Realizó varios bocetos estudiando la jardinería italiana como la Villa Farnese en Roma. SANTA-ANA, F.: "Sorolla y el jardín de su casa madrileña", en Jardines de España (18701936), 1999, p. 78
} 

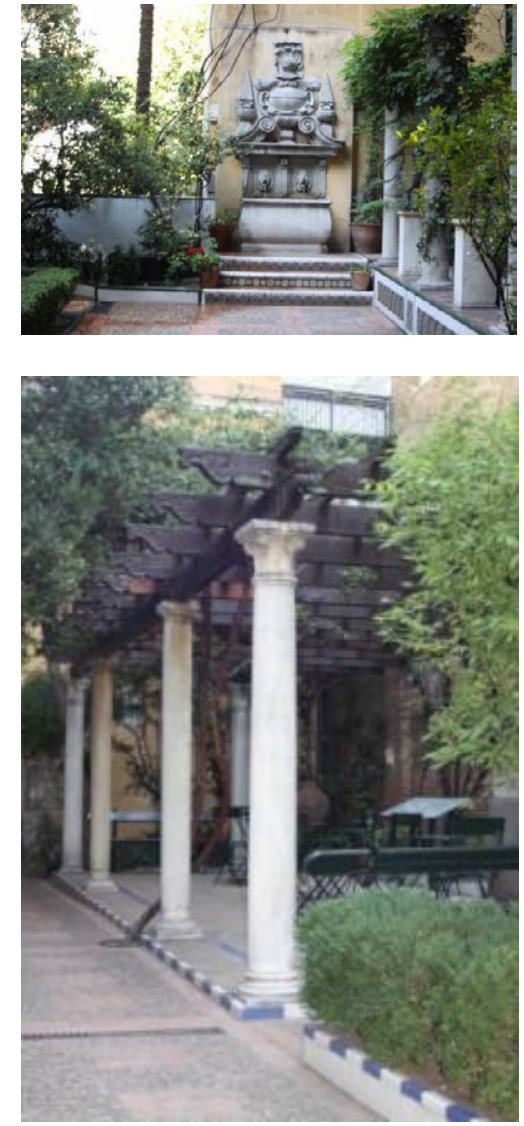

5.20 Vistas del tercer jardín. PHL, junio 2011.
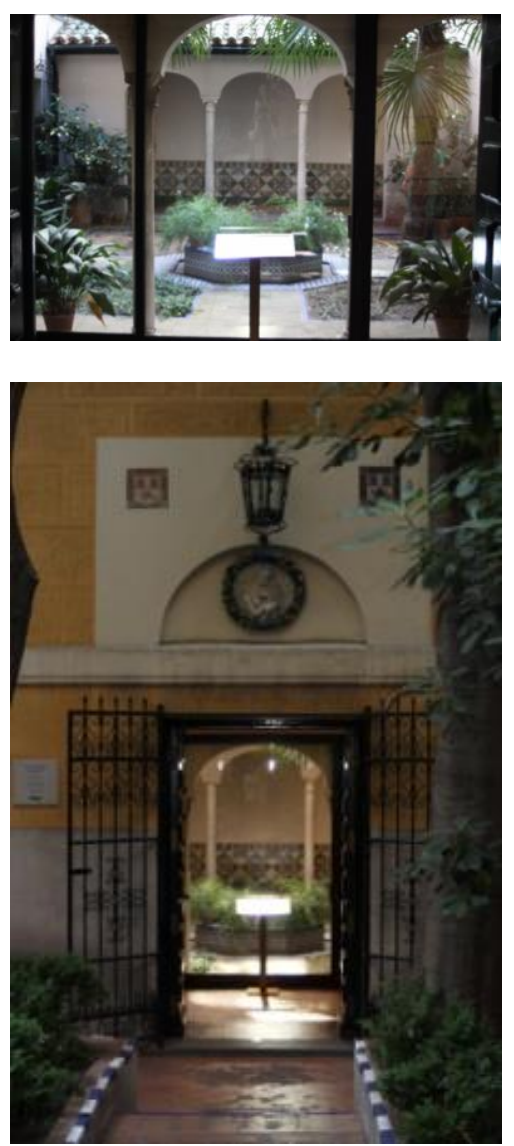

5.21 Vistas del patio andaluz. PHL, junio 2011.
Benlliure. Remodeló los arriates para adaptarse a la alberca rectangular que abrazan, presidida por la Fuente de las Confidencias $^{33}$ y colocó arrayanes procedentes del Patio de Comares de la Alhambra. La utilización de elementos mediterráneos como la pérgola recuerdan también a los jardines de Forestier donde se empleaban elementos como fuentes, surtidores, cerámicas, macetas, etc.

Tres columnas de granito $^{34}$, unidas mediante una viga con trepadoras, permiten el paso del segundo al tercer jardín, acompañadas con elementos escultóricos sobre plintos -las tres reproducciones pompeyanas que existen actualmente-. Delante de las columnas y adosada al muro de la casa se coloca otra fuente. Al fondo unos escalones dan acceso a la zona del estudio -actual entrada al museo-.
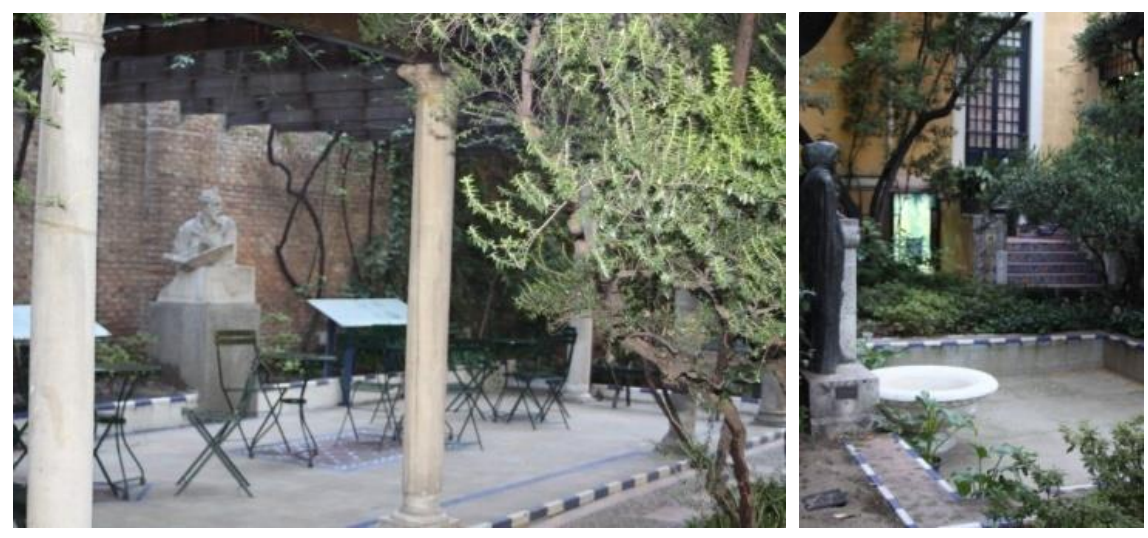

La casa también posee un patio andaluz o patio cordobés como Sorolla lo denominaba ${ }^{35}$ que ventilaba la parte posterior de la casa y actualmente tiene acceso desde el tercer jardín. Está rodeado de tres galerías porticadas con arcos de medio punto sobre columnas aprovechadas y un muro encalado que daba a la antigua cocina, actual Sala de Dibujos, donde se abren dos ventanas enrejadas. En el centro se ubica una fuente octogonal de azulejería de Triana con un potente surtidor que recuerda la fuente de Los Engaños del Jardín de las Damas de los Alcázares sevillanos. Está rodeada de

\footnotetext{
33 Comprada en la Exposición Nacional de Artes Decorativas de Madrid de 1911 e instalada ese mismo año. "Sorolla coloca el yeso original, en blanco, pero en 1975 es sustituido por un bronce donado por su autor en sustitución de la obra primitiva". La casa Sorolla. Dibujos, 2007, p. 12.

34 "Seguramente adquiridas en Andalucía en 1914 o anteriormente". Ibíd., p. 58.

35 SANTA-ANA, F.: "Sorolla y el jardín de su casa madrileña", en Jardines de España (18701936), 1999, p, 86 "Tenía justificación al dedicar en los jardines espacios dedicados a Sevilla y Granada, quedando Córdoba fuera de sus esquemas, ya que en el tercer jardín lo cordobés queda fuera al diseñar una pérgola y una acequia". La casa Sorolla. Dibujos, 2007, p. 14.
} 
cuatro macizos vegetales plantados con boj y cipreses actualmente sustituidos por aligustre y palmeras- ${ }^{36}$. El jardín fue inaugurado en 1932 como museo ${ }^{37}$.

\section{Javier de Winthuysen Losada (1874-1956)}

Otro de estos "pintores-jardineros" es Javier de Winthuysen ${ }^{38}$. Su vida giró siempre alrededor del jardín, pues durante los primeros años lo convirtió en el tema central de su pintura, y desde 1919 se dedicó al arte de la jardinería rescatando del abandono muchos de los jardines españoles. "Si Rusiñol idealiza los jardines, Winthuysen los humaniza"39, señala León Troyano. Fue Sorolla quien apoyó a Winthuysen en sus estudios sobre jardines históricos y, como miembro de la Junta para Ampliación de Estudios, consiguió que ésta le pensionase. Así lo describe su hija: "Winthuysen, sensibilidad para pintar, amor para hacer jardines. Rebelde a toda disciplina, a toda norma impuesta, era capaz de trabajar sin darse cuenta del tiempo que pasaba, ya que para él no era "trabajo" ni pintar ni hacer jardines, era poner en el lienzo y en la tierra todo lo que dentro de su ser llevaba"40. Esta poética y este arte es lo que traslada a sus jardines de fuertes rasgos andalucistas -en continuidad con la vertiente andaluza de Forestier- y clásicos, los cuales los imagina como una diversidad de planos, tonos, luces y sombras y en los cuales se implica no solamente en su diseño sino también en su construcción.

Todos estos personajes fueron los que poco a poco consiguieron despertar el interés por la jardinería, hasta entonces prácticamente inexistente, entre la población. Se pasó de la representación del jardín en la pintura en dos dimensiones a la creación de jardines en tres donde se trabajó con el volumen y se adquirió una dimensión espacial. Tanto la pintura como la jardinería "representan una

\footnotetext{
36 "En la decoración de este espacio va a primar la cerámica, que Sorolla instala sobre estanterías de madera, un alto zócalo cerámico de Ruiz de Luna y dos paneles de azulejos la acompañan. Lo arropa con muebles populares españoles y alguna escultura". La casa Sorolla. Dibujos, 2007, p. 93.

37 El muro este fue modificado en 1981 con la ampliación del museo: se arrancó al abrir una puerta el panel de azulejos y la cantarera y se trasladaron al muro oeste. De 1988 a 1991 se realizó una restauración, llevada a cabo por Lucía Serredi, para sanearlo y compatibilizarlo con las nuevas necesidades de dicho espacio público.

${ }^{38}$ Ver capítulo siguiente Winthuysen y la recuperación del jardín clásico en España.

${ }^{39}$ Francisco de León Troyano. En WINTHUYSEN, J.: Memorias de un Señorito Sevillano. 1942. Nueva Edición. HÉCTOR VÁZQUEZ, M. et al. (edit.). Winthuysen Foundation, Inc, 2005, p.164.

40 Salud de Winthuysen (hija de Javier de Winthuysen). "Recuerdos a mi padre". En AA.VV.: Javier de Winthuysen. Jardinero. Madrid: Real Jardín Botánico, CSIC, 1986, p. 9.
}

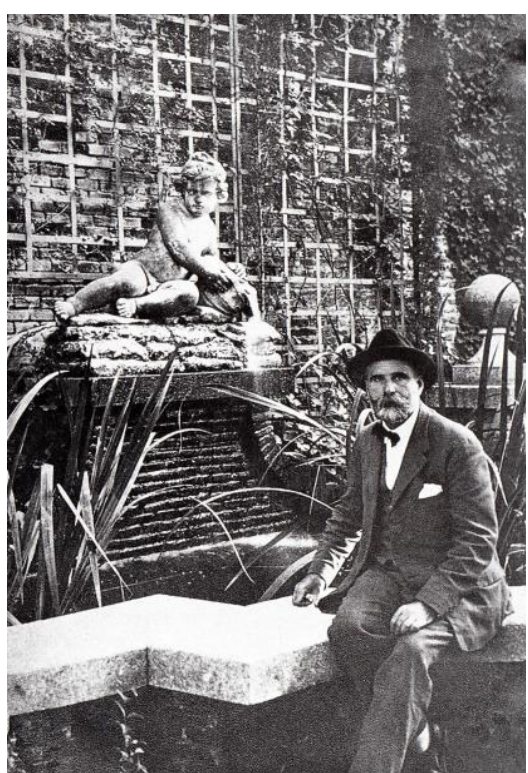

5.22 Javier de Winthuysen en los jardines de la Moncloa. Jardines de España (1870-1936), 1999, p. 90.

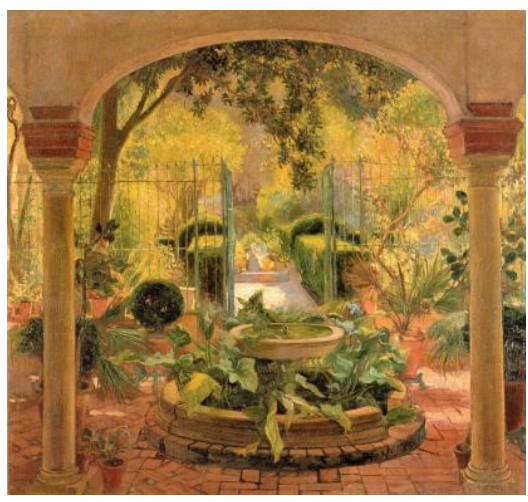

5.23 Cuadro "Entrada al jardín de la casa de los Cepero", vecinos suyos del barrio sevillano de Santa Cruz. Su primera gran obra. Se reflejan los diversos umbrales que hay que atravesar para llegar al jardín íntimo y cerrado de tradición hispanoárabe. El conjunto, donde la luz varía gradualmente, se encuadra en el elemento arquitectónico del arco y los pilares. Varios elementos se disponen en perspectiva ortogonal: una fuente con surtidor, los setos recortados de arrayán, macetones con palmeras y bojes esféricos, un pavimento de ladrillos y azulejos, etc. Jardines de España (18701936), 1999, p. 237. 
naturaleza modificada por la propia fantasía y por el arte, en busca de la belleza./.../ La naturaleza está hecha de realidad y de sensibilidad, y el jardinero-pintor trabaja con las dos para acabar ofreciéndonos "su imagen" elaborada, no de la realidad de esa naturaleza, sino de la transformación de esa naturaleza a través de su mente" 41 , explica Carmen Añón. El filósofo y pensador del jardín y del paisaje Rosario Assunto lo resume: "todo jardín es un sentimiento-pensamiento hecho lugar" 42 .

Esta diversidad de estilos en España dará lugar durante el primer tercio del siglo XX a una cultura artística propia que comenta Xavier Barral: "En un principio, gran parte de este movimiento de renovación consistió en un proceso de importación y emulación de las poéticas y los lenguajes de la vanguardia internacional, que fueron incorporados fragmentariamente sobre la base de los lenguajes visuales operantes en España 0 se mezclaron indiscriminadamente entre sí. Poco a poco se generó una tensión dialéctica entre esas referencias a la vanguardia foránea y la búsqueda de aquellas raíces propias susceptibles de ser aprovechadas en una dirección renovadora. Precisamente en esa tensión, cargada de contradicciones y lecturas frecuentemente sesgadas, radica el peculiar interés de esta "vanguardia interior"43.

En la arquitectura nacionalista había un fuerte debate entre lo neoandaluz (neomudéjar) y lo castellano o norteño, sin embargo en la jardinería triunfó lo andaluz o arabizante e incluso algunas jardinerías regionales buscaban a veces denominaciones mediterránea, latina, levantina- que no excluyesen lo andaluz. El nuevo jardín regionalista se presentaba como heredero del jardín árabe, una tradición en peligro y casi olvidada pero todavía viva. La defensa del jardín autóctono parte de la defensa del jardín tradicional. Propone una "aristocracia del arte"44 que luche para hacer nuevos jardines selectos y ajenos a los modelos paisajistas.

\footnotetext{
${ }^{41}$ AÑON, C. “Javier de Winthuysen”. En: Jardines de España (1870-1936), 1999, p. 109.

42 ASSUNTO, Rosario: Ontología y teleología del jardín. Traducción Mar García Lozano. Treviso, 1991.

43 BARRAL I ALTET, Xavier (dir.): Historia del Arte en España. Lunwerg, 1996, p. 436.

${ }^{44}$ Ibíd., p.46.
} 
PARTE I

LA LLEGADA DEL MOVIMIENTO MODERNO (1926-1936):

ENTRE LA TRADICIÓN ESPAÑOLA Y EL JARDIN RACIONALISTA 
El jardín ocupa un lugar más preferente cada día, porque es el lazo que une al hombre de la ciudad con la naturaleza; obra única que puede cobijar a todos en común bienestar y esparcimiento.

WINTHUYSEN, J. de: Resurgimiento de Jardines Clásicos. Julio 1924. En Arquitectura, no 99 julio, 1927, p. 269.

Hacer una obra de jardinería no es solo combinar ritmos como en otra construcción artística; los elementos que la constituyen tienen su vida, su expresión, sus particulares bellezas, su dinamismo; son seres vivos que al operar con ellos para un efecto ulterior se siente el temor de lastimarlos, de deformarlos quizás, de que la manipulación pueda restarles aquello que es esencial de su propia naturaleza, a lo que la creación artística no puede superar y, cerrando a los ojos y acudiendo a la imaginación, se figura uno lo que han de ser aquellos seres cuando, pasado el tiempo, desaparezca la huella grosera del trabajo y vuelvan a ordenarse por sí mismos presentando sus ingénitas bellezas. Con las obras de fábrica del jardín ocurre igual: ellas han de ser como allí nacidas, en armonía con el vegetal que las abraza y las vestirá; materias inertes en las que pronto la incansable Naturaleza irá depositando gérmenes de vida; puntos pequeñitos grises, rojizos o verdes que irán extendiéndose por sus superficies coloreándolas. La fuente del jardín se convierte en un mundo; la estatua no es la misma que la de un salón o una calle; nada de lo ulterior en una obra de jardinería presenta la huella de la mano de su artífice. Solo queda la ordenación en que haya podido encauzarlo la inteligencia... 


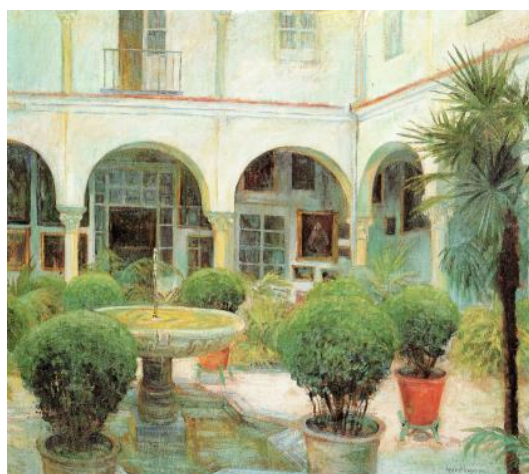

6.1 Patio de los Cepero. J. de Winthuysen, 1912. Jardines de España (1870-1936), 1999, p. 235.
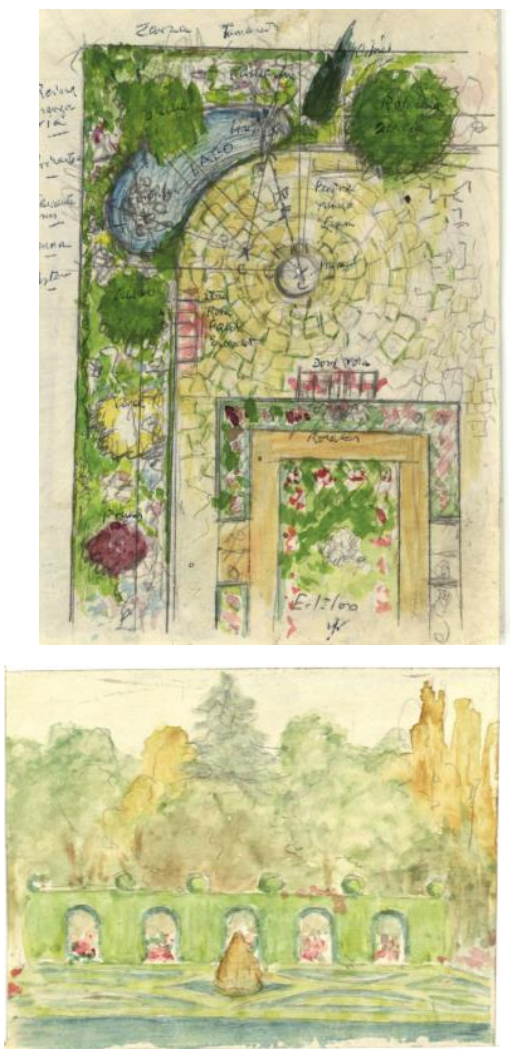

6.2 Planta de jardín con anotaciones sobre plantación. Boceto de jardín con arcos vegetales centrales que dividen la zona arbolada de los parterres. Winthuysen, 1874-1956. ARJB, Div.IX 67, 12-85.

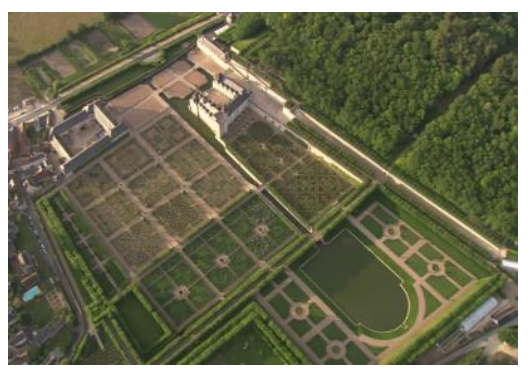

6.3 Vista aérea de los jardines del Château de Villandry, Tours, Francia. Footage.framepool.com

\section{WINTHUYSEN Y LA RECUPERACIÓN DEL JARDÍN CLÁSICO EN ESPAÑA}

\section{La recuperación de la tradición española}

Javier de Winthuysen y Losada (Sevilla, 1874 - Barcelona, 1956), de familia flamenca establecida en Cádiz, se crió en Sevilla donde estudió Bellas Artes y entró en contacto con varios pintores. Con una formación autodidacta orientada hacia la naturaleza y la pintura, heredó de su padre la afición por los jardines, concejal del Ayuntamiento de Sevilla encargado de los parques y jardines públicos. "La azotea de nuestra casa la tenía mi padre convertida en precioso pensil. En las cabezas de los muros, grandes barricas de naranjos, limoneros, nísperos, parras y trepadoras que se enredaban en graciosa pérgola $y$ en barandales multitud de macetas. Me llevaba de paseo a la Alameda Vieja que estaba cerca de casa"1 ${ }^{1}$ explica Winthuysen en sus memorias. En 1903 viajó por primera vez a París, tomó contacto con el impresionismo francés y el postimpresionismo, allí conoció a Santiago Rusiñol; también visitó los museos, los paseos y jardines de la ciudad ${ }^{2}$ donde tomó contacto con la obra de Forestier ${ }^{3}$ acentuándose su afición por la jardinería. Atraído por esa unión entre el Arte y la Naturaleza, pasará a transformar sus pinturas en croquis y dibujos de jardines que pudieran materializarse. Tendrá su primer contacto con la arquitectura de jardines colaborando con el doctor Carvallo, propietario y restaurador del castillo y los jardines del Château de Villandry, en el diseño de elementos cerámicos. Ante el desconocimiento de las técnicas, estudió e investigó: química, arquitectura, cerámica, horticultura, etc.

Regresó a Sevilla a causa de la Guerra y entre 1915 y 1918 recibió varios encargos de pequeños jardines particulares en Córdoba; en

\footnotetext{
1 Javier de Winthuysen. Memorias de un señorito sevillano. En AÑóN FELIU, C.; SANCHO GASPAR, J.L.: Jardines clásicos de España (2 vol.) vol. 2: Notas sobre la vida y escritos de Xavier de Winthuysen. Madrid: Doce Calles, 1990, p. 21.

2 Conoce los jardines de Le Nôtre, Saint Cloud, Chantilly, Versalles, etc. Se siente especialmente fascinado por los jardines de Luxemburgo. "Desde los jardines en donde juegan en competencia los gorriones y los niños parte la inmensa avenida del Observatorio. Nueva impresión de arte, aquí de arte paisajista. De lo que Morelle decía de Le Nôtre, "usurpador insigne que sustituye a la naturaleza ocupando su lugar". / Desde aquí, el Luxemburgo se extiende hasta perderse en la bruma de la lejanía en anchuroso tapiz verde entre las paralelas de enarenados paseos. Entre las perspectivas de corpulentos castaños tallados cuajados de flores blancas." WINTHUYSEN, J. Memorias de un Señorito Sevillano. 1942. Nueva Edición. HÉCTOR VÁZQUEZ, M. et al. (edit.). Winthuysen Foundation, Inc, 2005, p.110.

${ }^{3}$ Ver capítulo de Antecedentes - El jardín tradicional mediterráneo.
} 
esta etapa profundizó en el estudio de la jardinería andaluza con sus elementos característicos: patios, fuentes, surtidores, acequias, azulejería, mosaicos, etc. Gran admirador de la obra de Forestier autor de varios parques y paseos de París y del Parque de María Luisa de Sevilla-, estuvo a punto de volver a París para trabajar y aprender de él en 1916, pero las dificultades económicas se lo impidieron. El Parque de María Luisa, al que consideraba como la obra que inicia el resurgimiento del jardín andaluz, será una de sus referencias: "A Forestier debemos la iniciativa de nuestro resurgimiento, tanto más trascendental cuanto que en la actualidad la arquitectura del jardín implica, no solamente el particular recreo, sino también las estructuras de las obras públicas, a que tanta significación social se concede en todos los países. Francia fue siempre plantel de este género de artistas, que extendieron su acción a Inglaterra, Italia y España, creando esas bellas obras, que aún subsisten, desde hace siglos admiradas; pléyade de artistas a los que hay que unir el nombre de Forestier"

Finalmente se instaló en Madrid y se introdujo en el círculo de la Institución Libre de Enseñanza a través de Joaquín Sorolla, Antonio Machado y Juan Ramón Jiménez. En 1919, gracias a la beca de la Junta de Ampliación de Estudios, comenzó su investigación sobre los jardines españoles; realizó varios viajes visitando los jardines de España, levantó sus planos, los fotografió, los dibujó, estudió sus plantaciones y realizó anotaciones, reuniendo un fondo documental único. Así lo explica el propio Winthuysen: "Viajar en tercera y hasta pie, fotografías, dibujos, levantamiento de planos elevando en el suelo escarpias y triangulando con cuerdas, investigaciones con bibliotecas y un curso de Botánica que me exigieron./.../ Se me hizo una especie de examen, en realidad necesario puesto que por mi parte no poseía más títulos que abonasen mis pretensiones, que mi afición a hacer de los viejos jardines asuntos de mis cuadros y las observaciones y anotaciones hechas sobre estos modelos./.../ ... yo no pretendía estudiar cultivos de jardinería sino los trazados y significación estética e histórica de los antiguos jardines..." ${ }^{5}$.

Su primera oportunidad de intervenir como restaurador de jardines llegó cuando la Sociedad de Amigos del Arte Español le encargó la
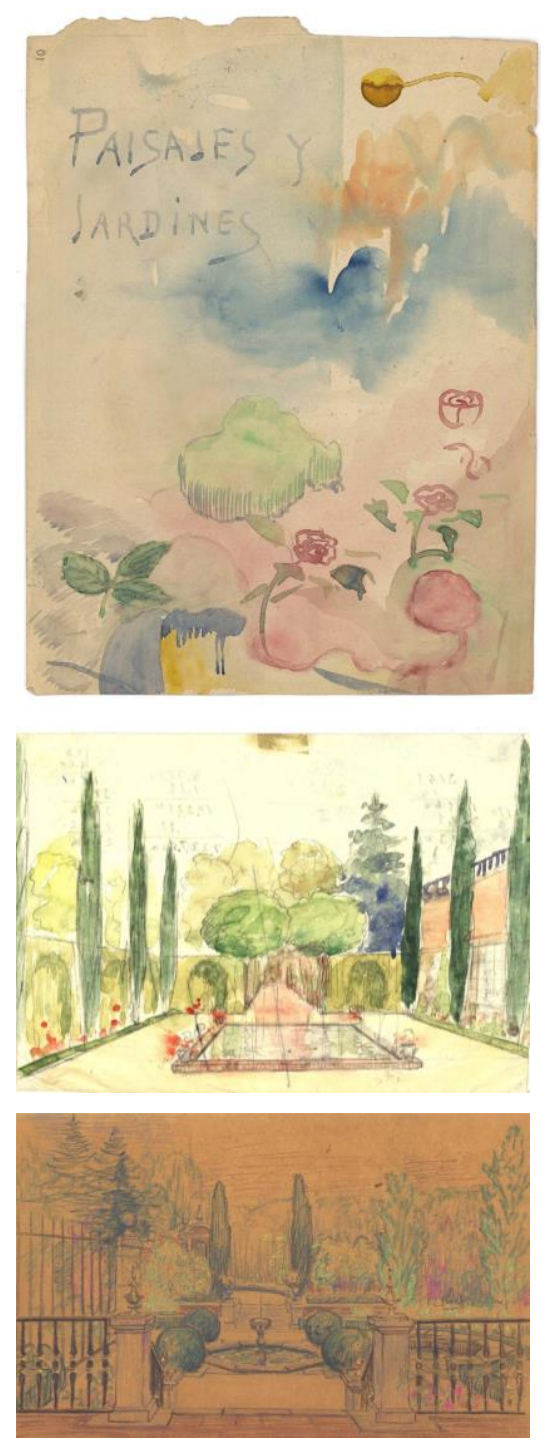

6.4 Dibujos de Javier de Winthuysen: Paisajes y jardines. Jardín con vivienda a la derecha y estanque en el centro. Jardín con numerosos detalles ornamentales, 1874-1956. ARJB, list. 10v; Div.IX 67,73127.

\footnotetext{
${ }^{4}$ WINTHUYSEN, J.: El arquitecto paisajista M. Jean C.N. Forestier y su labor mundial. Revista de Obras Públicas, 15 de diciembre de 1930. En AA.VV.: Javier de Winthuysen. Jardinero. Madrid: Real Jardín Botánico, CSIC, 1986, p. 176.

${ }^{5}$ Javier de Winthuysen. En AÑÓN FELIU, SANCHO GASPAR, 1990, p. 51-52.
} 

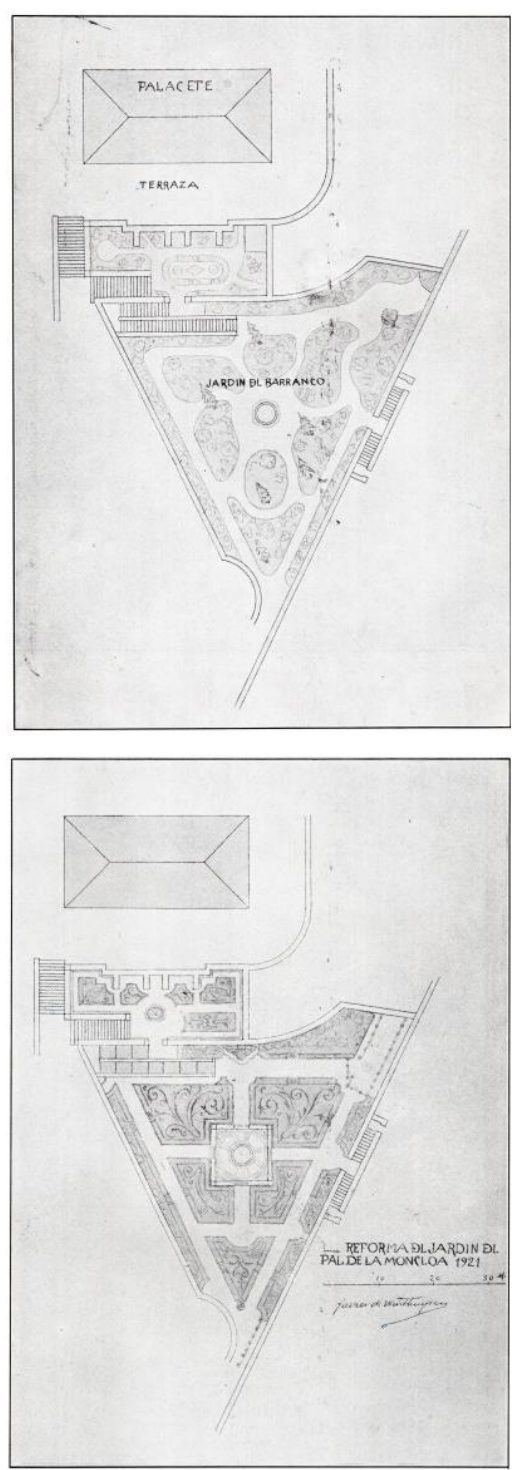

6.5 Jardín del Palacete de la Moncloa en 1920 y tras la reforma de Winthuysen en 1921 donde se recupera el trazado clásico. Jardines clásicos de España, 1990, p. 124-125.

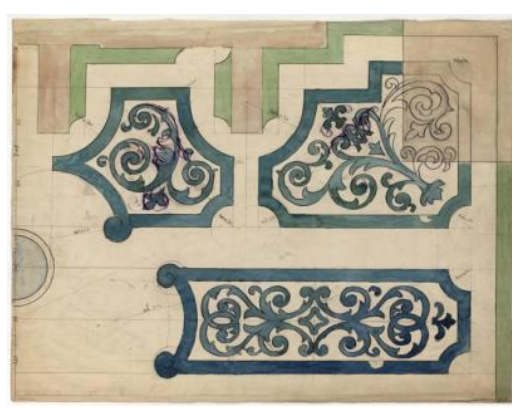

6.6 Parterres del Jardín alto del Palacete de la Moncloa con dibujos neoclásicos. Winthuysen, 1921. ARJB, Div.IX 2,24. reforma del jardín del palacete de la Moncloa que estaba completamente abandonado. En 1921 comenzaron las obras de la Moncloa, recuperó la antigua ordenación tanto en plantaciones como en las obras de fábrica, aunque respetó los grandes árboles plantados a mediados del siglo XIX. "Tanto los muros que lo encierran como las grandes coníferas, le daban un marcadísimo carácter de severidad española"6. Inició de esta forma un resurgimiento del jardín clásico español: "lo histórico ha de servir de ejemplo y guía, no como traba reaccionaria que ahogue las nuevas importaciones y excluya nuevos horizontes estéticos, sino en lo que la tradición nos muestra como esencia del carácter, poniéndonos de manifiesto lo que es consustancial a él y a la propia Naturaleza"7. "Esta fue mi primera obra de jardinería. Ya esto no era un trabajo de investigación sino de técnica constructiva. Afortunadamente mis aficiones arquitectónicas y aún mi práctica en ellas, hacían que estuviese capacitado y tras este encargo tuve otros varios..." ${ }^{\prime}$, explica Winthuysen.

Aunque no fue un gran innovador, fue un gran conservador de valores; uno de sus mayores logros es haber suscitado en España la toma de conciencia del patrimonio histórico constituido por los jardines, los cuales estaban infravalorados y olvidados y muchas veces en peligro de desaparecer. Plantea la recuperación de los jardines históricos como una toma real de conciencia ante la pérdida del patrimonio histórico y no como una moda cultural como sucedía en Europa. Realizó varios jardines pero principalmente fue el gran defensor de los jardines españoles, de su variedad y riqueza. Comenzó su inventariado y catalogación para dar a conocer y evitar la degradación y desaparición de numerosos ejemplos de jardines históricos españoles; se trataba de un legado recibido de generaciones anteriores que había que cuidar y conservar. Defiende el rigor y la precisión en este trabajo, la necesidad de elaborar un criterio definido y una reglamentación equiparando los jardines al resto de obras artísticas. Critica la implantación de "los nuevos estilos de jardines llamados ingleses, paisajistas, románticos y chinescos, en que la horticultura y las obras rústicas o de imitaciones de la naturaleza sustituyeron a las

\footnotetext{
${ }^{6}$ WINTHUYSEN, J. de: Jardines Clásicos de España - Castilla. Madrid, 1930. Nueva edición AÑóN FELIU, SANCHO GASPAR, 1990, p. 129.

${ }^{7}$ Ibíd., p. 131.

8 WINTHUYSEN, J.: Memorias de un Señorito Sevillano. 1942. Nueva Edición. HÉCTOR VÁZQUEZ, 2005, p.185.
} 
ordenaciones clásicas" ${ }^{\prime 9}$. Propone recuperar el carácter de las ordenaciones antiguas y volver a utilizar elementos propios españoles atendiendo a las exigencias de nuestro clima. En lugar de las extensas praderas inglesas defiende elementos propios de los jardines españoles: los recuadros bajos rodeados de setos vivos que conservan la humedad y sirven de marco a las diversas flores, los frutales alternados con cipreses y los arbustos diversos. De esta forma pretende "procurar un enlace con la tradición, para dejar al margen las obras de una época desdichada por incompatibles con nuestro clima y carácter, y poder llegar a un concepto moderno del jardín español"10.

Finalmente con todo el material recopilado de su investigación en 1930 consigue publicar su exitoso libro Jardines clásicos de España. Castilla ${ }^{11}$. Este estudio, prácticamente terminado seis años antes, resalta la importancia del jardín español y expone las primeras noticias históricas sobre muchos de los ejemplos estudiados ${ }^{12}$. Presenta el interés de publicar levantamientos de los jardines, así como detalles de elementos y fotos de gran valor, todos realizados por el autor e indispensables para realizar restauraciones de jardines históricos con rigor ${ }^{13}$. Este estudio es de gran importancia y trascendencia ya que hasta entonces solo había trabajos fragmentarios y estudios parciales de algunos jardines ${ }^{14}$, Winthuysen consigue reunir todo este material y analizar la historia y características de los jardines históricos españoles en profundidad y poniendo en relieve su importancia. Habla del "romanticismo de nuestros jardines clásicos, cuyos caracteres actuales no es ciertamente el que tuvieron cuando en tal o cual época se

\footnotetext{
${ }^{9}$ WINTHUYSEN, J. de: Resurgimiento de Jardines Clásicos. Julio 1924. En: Arquitectura, no 99 julio, 1927, p. 267.

10 lbid., p. 269.

11 WINTHUYSEN, J. de: Jardines Clásicos de España - Castilla. Madrid, 1930. Nueva edición - AÑÓN FELIU, SANCHO GASPAR, 1990. Dedicado a su amigo Juan Ramón Jiménez y a la memoria del pintor Joaquín Sorolla, las dos artes que para él completaban la jardinería. Premiado con la Medalla de Oro de la Sociedad de Horticultura de Madrid.

${ }^{12}$ El jardín de La Abadía en Cáceres, los jardines de El Escorial, de Aranjuez, de El Pardo, La Granja, Brihuega, Boadilla del Monte, Alameda de Osuna, La Florida y La Moncloa.

${ }^{13}$ La documentación que se conserva, cedida por sus hijas, se encuentra en el Archivo del Real Jardín Botánico de Madrid.

${ }^{14}$ Existían estudios que no se habían traducido al español: Spanish Gardens and Patios (Arthur Byne y Mildred Stapley, New York, 1924), Jardins d'Espagne (Georges Gromort, 1926), y Spanish Gardens (C.M. Villiers-Stuart, 1929). Solo había estudios parciales de la Marquesa de Casa Valdés, Rubió i Tudurí, García Mercadal, etc. Posteriormente, Teresa de Ozores y Saavedra, marquesa de Casa Valdés, escribirá otro libro de Jardines de España (segunda edición, Madrid, 1987).
}

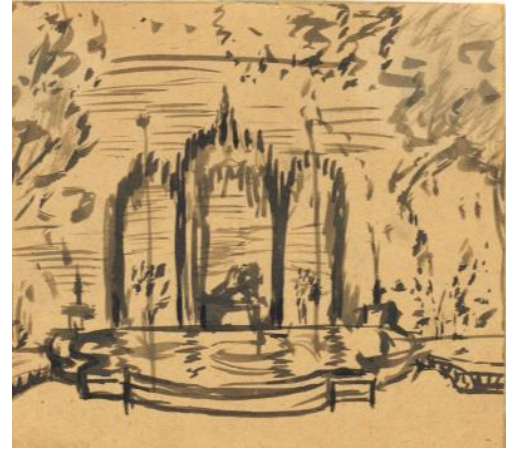

6.8 Boceto de la fuente lateral del Palacete de la Moncloa. Winthuysen, 1921. ARJB, Div.IX 2,24.

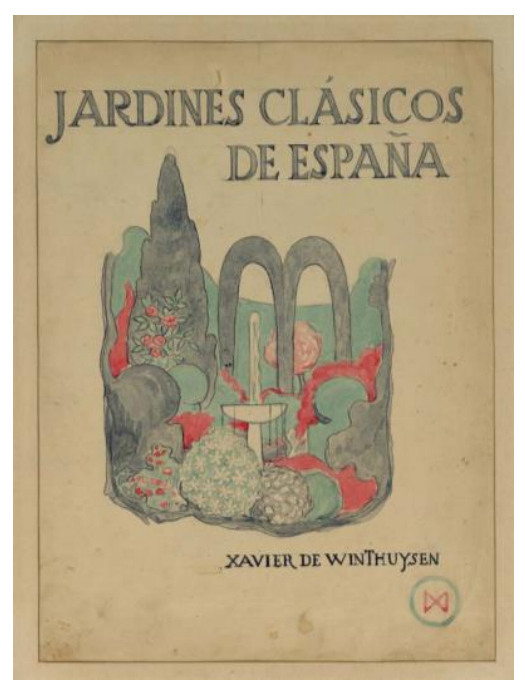

6.9 Dibujo original para la portada del libro Jardines Clásicos de España de Javier de Winthuysen. Madrid, 1930. ARJB, Div.IX 66,179.

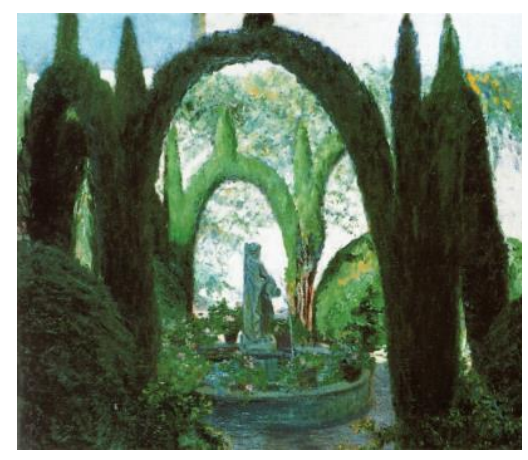

6.10 Patio del palacio del marqués de Viana, Córdoba. Javier de Winthuysen. Jardines de España (1870-1936), 1999, p. 105. 


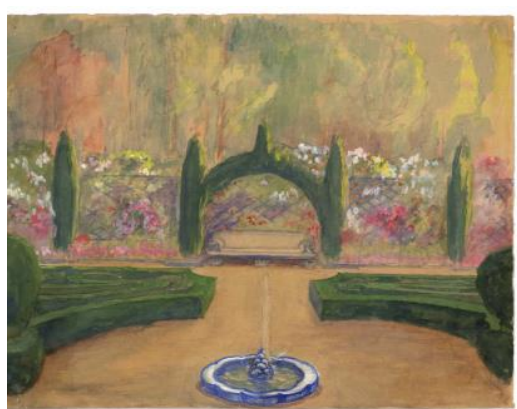

6.11 Dibujo de un jardín en tonos cálidos. Winthuysen, 1874-1956. ARJB, Div.IX 67,128 .

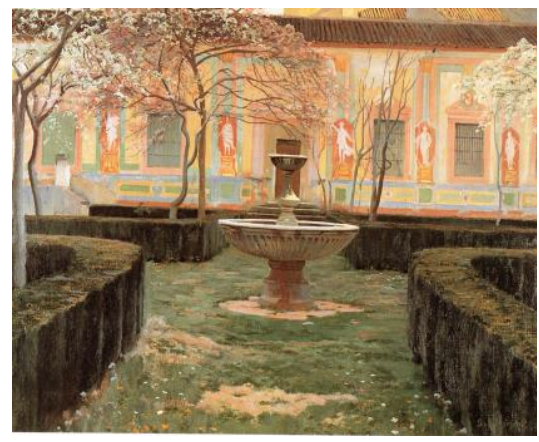

6.12 Jardín abandonado, Granada, 1898. Santiago Rusiñol. Jardines de España (1870-1936), 1999, p. 30.

\section{Vete al jardín de los mares} y plántame un madroñero entre los hielos polares, jardinero.

Para mi amada,

una isla

de cerezos estelares

rodeada de cocoteros;

y en mi corazón guerrero

plántame cuatro palmeras

a guisa de mastelero,

jardinero.

6.13 Rafael Alberti, "A javier de Winthuysen ", Marinero en tierra, 1923. En: Jardines de España (1870-1936), 1999, p. 295. plantaron, sino los que han surgido de ellos mismos al margen de la voluntad del arte por imposición de la Naturaleza"15.

Defiende que es el único país que encierra la historia completa del arte de los jardines con ejemplos de diversos estilos desde la Edad Media hasta la actualidad. Divide este ambicioso estudio en cuatro grupos según cada una de las distintas regiones geográficas españolas ${ }^{16}$ : Castilla, Andalucía, Levante y Norte; atendiendo a sus diferencias de suelos, climas, historias y costumbres. En la primera parte del libro analiza la historia del jardín español sin profundizar mucho pero poniendo algunos ejemplos, algunos de los cuales desarrolla en la segunda parte, y termina con un capítulo de consideraciones generales, haciendo hincapié en el resurgir del jardín clásico español y el caso práctico de un proyecto suyo de reforma: el Jardín del Barranco del Palacete de la Moncloa. Desgraciadamente tan sólo se finaliza y publica el estudio correspondiente al primer grupo. "El libro tuvo bastante éxito en un sector intelectual y de arte, pero económicamente, fue un desastre porque la "Cía. Ibero-Americana" quebró y casi toda la edición quedó embargada por los acreedores, de modo que a mí no me llegó casi nada y, descorazonado, dejé a un lado los trabajos que había comenzado para hacer los Jardines Andaluces y los Pazos gallegos. Todo quedó inédito y seguí refugiándome en hacer jardines"17. Sirvió para revitalizar muchos de los pequeños jardines y parques municipales de aquella época que Azorín los describe como abandonados, tristes y polvorientos al hablar de las ciudades castellanas $^{18}$.

\footnotetext{
${ }^{15}$ WINTHUYSEN, J. de: Jardines Clásicos de España - Castilla. Madrid, 1930. Nueva edición - AÑÓN FELIU, SANCHO GASPAR, 1990, p. 124.

${ }^{16}$ Esta división geográfica la toma del libro de Dantín Cereceda Regiones Naturales de España, Museo Pedagógico Nacional, 1922.

17 Javier de Winthuysen en AÑÓN FELIU, SANCHO GASPAR, 1990, p. 53

18 "Acaso en el centro se ve una fuente de piedra, una antigua y noble fuente de algún viejo palacio o caserón, traída aquí, sacada de su ambiente natural, y sobre el que se ha colocado, desfigurándola, mutilándola, humillándola, alguna absurda y tosca figura de hierro fundido, de hierro con sus ásperas junturas y granulaciones. El jardín está solitario; allá a lo lejos, por encima de la fronda de los olmos, se ve la torre de la iglesia; más cerca, aparecen los porches de la plaza y unos balcones panzudos, desnivelados". AZORín. Jardines de Castilla. En Arquitectura, no 39 julio, 1922, p. 295.
} 


\section{El estilo Winthuysen ${ }^{19}$, un estilo propio}

Durante toda su vida trabajó en la creación de nuevos jardines. Su principal característica es la incorporación de elementos y esquemas tradicionales de la arquitectura de jardines españoles. Al igual que en su pintura, se diferencian dos etapas en su trabajo como diseñador de jardines: en la primera, totalmente de influencia andaluza, pinta jardines y paisajes andaluces y sus jardines también poseen rasgos andaluces (bancos, azulejos, cuadros, arriates con flores...), y la segunda, tras la Guerra Civil, más mediterránea, influenciada por sus estancias en Barcelona e Ibiza, en su pintura plasma la luminosidad del Mediterráneo y en los jardines la tradición mediterránea.

En su primera etapa estudió los diferentes elementos de la jardinería andaluza que incorpora a sus jardines: los patios, las fuentes bajas de cerámica policromada, los surtidores, las acequias, los treillages cubiertos de trepadoras, los arriates, los bancos de azulejos, los mosaicos, etc. Así describe Winthuysen el jardín sevillano: "La antigua casa sevillana es tan acogedora que nos deja ver su interior a través de las cancelas de sus patios, tras las que suelen hallarse el jardín. En realidad toda la casa es jardín: patios, azoteas y ventanas. Pero además el jardín en Sevilla trasciende aunque se halle oculto. Frescura de jazmín y de arrayán; potencia de nardos y dondiegos, malvarrosas, heliotropos y caracol real, por no nombrar el periodo del azahar, que todo lo domina. /.../ Los pavimentos de barro, cocido o piedrecillas, los mosaicos con surtidores que mojan la policromía, haciéndolos resaltar como pedrería fastuosa o desgranándose sonoros en tazas de mármoles. /.../ El agua es uno de sus elementos principales y se nos presenta en surtidores y fuentes, que por canalillos alimentan las albercas que alimentan el riego..."20. En sus jardines no sólo va a introducir los elementos andaluces sino también los rasgos fundamentales del jardín andaluz: ocultación desde el exterior con el patio como articulación o intermedario; integración del jardín con la casa; agua con valores estético y funcional, etc.

\footnotetext{
19 SOUTO ALCARAZ, A.: La recuperación del jardín de Winthuysen de la antigua Escuela de Caminos en el Cerrillo de San Blas. Cuadernos de investigación, no 7. CEHOPU, 2010, p. 17.

20 Javier de Winthuysen. En: AA.VV.: Javier de Winthuysen. Jardinero. Madrid: Real Jardín Botánico, CSIC, 1986, p. 154.
}
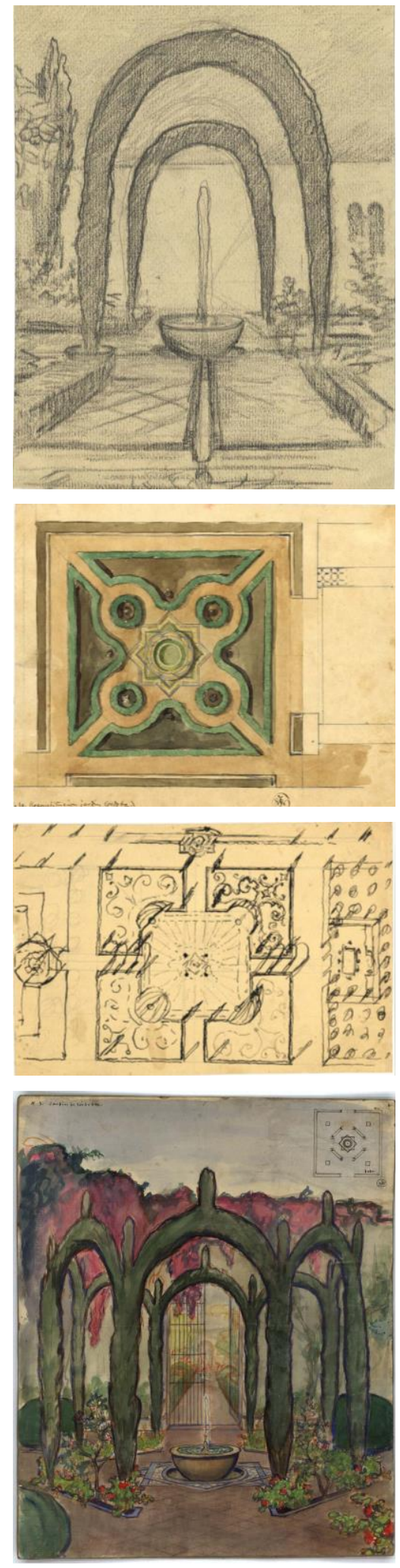

6.14 Detalle de una fuente con arcos vegetales, 1874-1956. Planta del Proyecto, boceto de la planta y boceto de la fuente y plantas ascendentes para un jardín en Córdoba, 1925. Winthuysen. ARJB, Div.IX 67,59; 15, 1-2$9 ; 18,8$ 

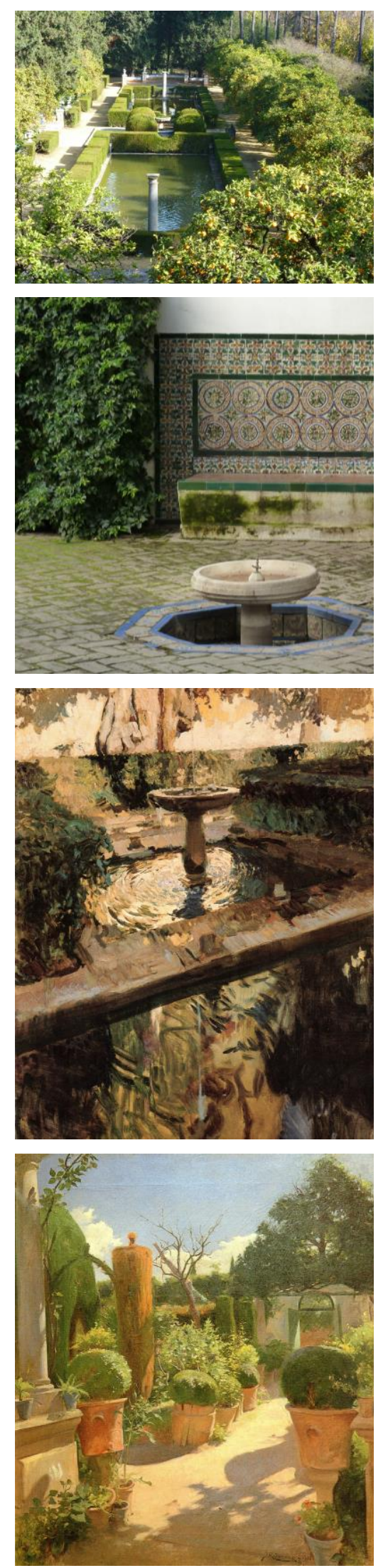

6.15 Jardines del Alcázar de Sevilla. PHL, enero 2015. Rincón del pato del Ciprés de la Sultana, Generalife, Granada, 1910, Joaquín Sorolla. Rincón de un carmen granadino, 1899, José Ma Rodríguez Acosta. Jardines de España (1870-1936), 1999, p. 175 y 209.
Entre 1910 y 1917 realizó los primeros apuntes sobre estos elementos de la jardinería hispanomusulmana en el Alcázar de Sevilla, la Mezquita de Córdoba o en jardines particulares. Apasionado de estos jardines árabes andaluces, destaca el Generalife: "Si no existiesen en España obras de jardinería, ella (el Generalife) sería suficiente para concedernos la categoría que nuestro país ostenta" ${ }^{21}$. Pone por ejemplo el jardín de la Acequia en el que la jardinería queda reducida a la mínima expresión, "y no obstante, a este lugar no podemos llamarlo de otro modo que jardín. Sería imposible suprimir en esta composición arquitectónica las plantas aunque el principal valor está en la obra de fábrica que las encuadra; pero sólo con ella, no hubiese podido producir el arquitecto tal efecto estético" 22 . Le fascinan también los cármenes granadinos ${ }^{23}$ : "un afilado y oscuro ciprés y algún rosal o frutalillo entre muros blanqueados, o una parra que cobija un surtidor y un fino mosaico entre menudas piedrecillas, semejantes a delicadas estrofas de García Lorca o Juan Ramón Jiménez" 24.

Defiende la estética de estos jardines: "cuya tradición perdura en lo que podemos llamar el folklore de la jardinería andaluza", y critica el neo-andalucismo basado en las simples decoraciones de azulejos y tiestos: "esos nuevos jardines amalgamados con colorines de azulejería y trazas ridículas de las chabacanas y pretenciosas obras modernas"25. Para Winthuysen el auténtico jardín sevillano es la "Lógica adaptación de la Naturaleza, y el artificio, para la necesidad. / Los recuadros de flores en planos bajos para aprovechar el riego, rodeados de setos vivos que impiden que el aire los deseque; los paseos enlosados, para mayor pulcritud. A la flora no se la atormenta ni se la rebaja a material constructivo, sino que se la deja libre con sus significaciones y sus bellezas particulares, y francamente alterna la planta noble con el frutal. El agua de muestra: espejos en los embalses, arroyos en los canalillos del pavimento, lluvia en el surtidor que refresca el ambiente. Arriates en los muros para el tapiz trepador. Acomodo para la siesta, para la reunión, para la intimidad, para el baño; nunca decoración vana, y en sus obras de fábrica, a veces, la azulejería, pero como cualquier otro elemento decorativo, y sin que constituya su característica

\footnotetext{
${ }^{21}$ Javier de Winthuysen. En: AA.VV.: Javier de Winthuysen. Jardinero, 1986, p. 45.

22 WINTHUYSEN, J.: Arquitectura paisajista. Arquitectura, no 105, 1928, p. 62.

${ }^{23}$ Ver capítulo de Antecedentes - Los nuevos cármenes.

24 Javier de Winthuysen. En: AA.VV.: Javier de Winthuysen. Jardinero, 1986, p. 45.

25 Ibíd., p. 44.
} 
hasta el extremo que en ciertos jardines ni aparece"26. El autor propugna la adaptación compositiva al medio físico: agua para control climático, recuadros de flores bajos para aprovechar el riego, setos que protegen plantaciones de los vientos cálidos, alternancia de la planta noble con el frutal, etc.

Es defensor de los jardines andaluces porque éstos al haber estado más aislados y alejados de la capital han conservado sus valores tradicionales, alejados de las modas importadas: "Si reciben influencias extrañas, no tienen éstas fuerza bastante para imponerse de un modo absoluto y son absorbidas por los antiguos valores fundamentales" ${ }^{27}$. Pero también en esta época se denuncia la moda de la época de hacer jardines andaluces por todas partes, especialmente en Madrid, sin tener en cuenta las características y el clima de cada región. La nueva burguesía se obsesiona por los azulejos, antes despreciados por considerarse humildes: "Todo el mundo quiere tener en su casa algunos azulejos, ya sea en una chimenea, en un banco, en un pavimento, o sencillamente dibujando una santa imagen en un muro". El jardín pierde su razón de ser al sacar los elementos de su contexto y transportarlos a otros lugares, "no se consigue crear más que ridículas parodias; si los azulejos no pueden brillar al sol cegador de las tierras meridionales, aménguase en gran parte su belleza decorativa. $Y$ sin las flores de perfume intenso y color subido, sin que el agua adquiera todo su valor expresivo al ser escasa y estar celosamente aprovechada, sin el ambiente cálido, que le envuelve, el jardín pierde lo más íntimo y profundo de su encanto"28.

Se propone no unificar las costumbres y los jardines sino valorar y realzar los aspectos de cada territorio. Por ejemplo en Madrid se propone recuperar las encinas que crecen en sus montes, los negrillos castellanos y los altos álamos: "Estos árboles, nuestros amigos de todos los días, están proscritos de los jardines madrileños. Pero en cambio, hay verdes prados de climas húmedos, flores que se agotan al sur de la meseta, palmeras que durante todo el invierno aparecen encapuchadas con paja para que no se hielen" ${ }^{29}$. Con ello se pretendía huir de la multitud de especies

\footnotetext{
${ }^{26}$ WINTHUYSEN, J.: Influencias de estilo neosevillano. La Voz, 5 de julio de 1929.

27 WINTHUYSEN, J. de: Jardines Clásicos de España - Castilla. Madrid, 1930. Nueva edición - AÑÓN FELIU, SANCHO GASPAR, 1990, p. 123.

${ }^{28}$ Las dos citas están extraídas de R.: Ingreso. En: Arquitectura, no 39, julio, 1922, p. 279.

${ }^{29}$ R.: "Ingreso". En: Arquitectura, no 39, julio, 1922, p. 280.
}

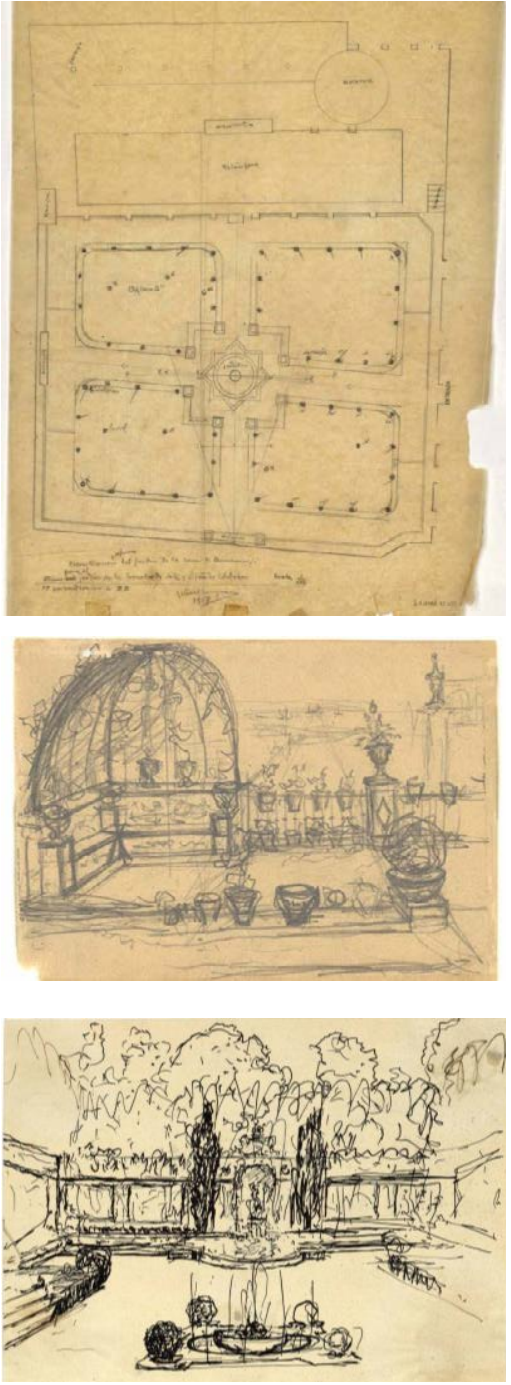

6.16 Plano de la reconstrucción del jardín y boceto de terraza con pérgola de la casa de Benamejí, Córdoba, 1917. Boceto del jardín de Benamejí, 18741956. Winthuysen. ARJB, Div.IX 1, 2-3; 67,55 .
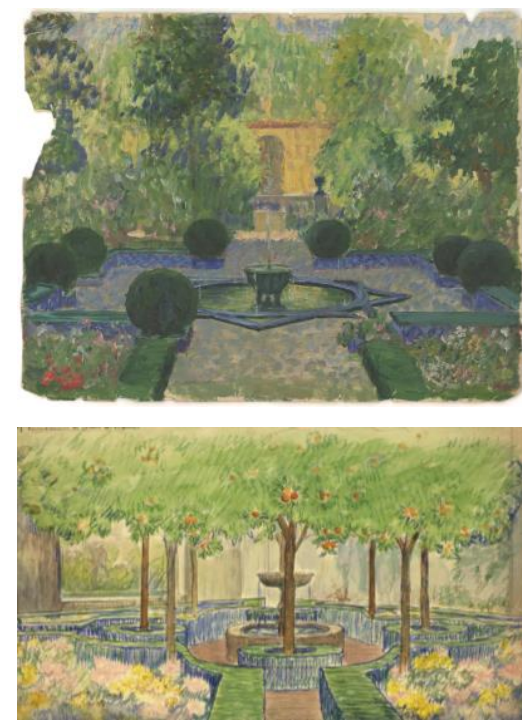

6.17 Dibujo de un jardín de inspiración árabe. Reconstrucción de un jardín en Córdoba. Winthuysen, 1874-1956. ARJB, Div.IX 67, 131; list. 2. 

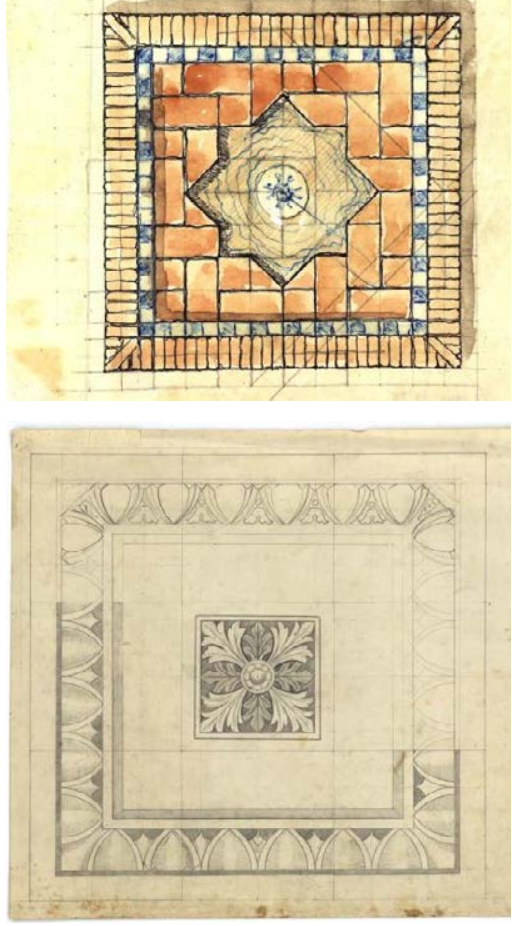

6.18 Plano de una fuente con acabado cerámico, 1874-1956. Dibujo de un panel cerámico del jardín de Boecillo, 1926-1930. Winthuysen. ARJB, Div.IX 3, 6; 67,95.

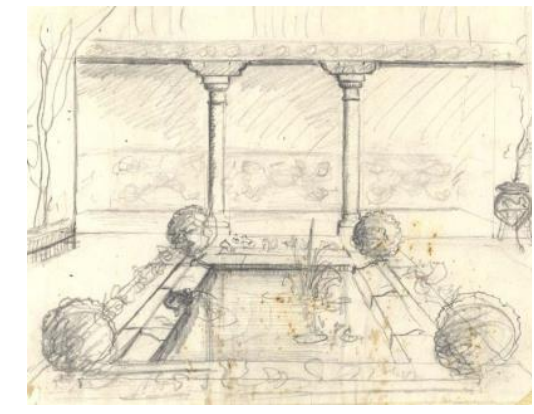

6.19 Plano del jardín y perspectiva lineal de la residencia de la Condesa de Medina y Torre, Madrid. Winthuysen, 1924. ARJB, Div.IX 18,3; Div.IX 9, 1-2.

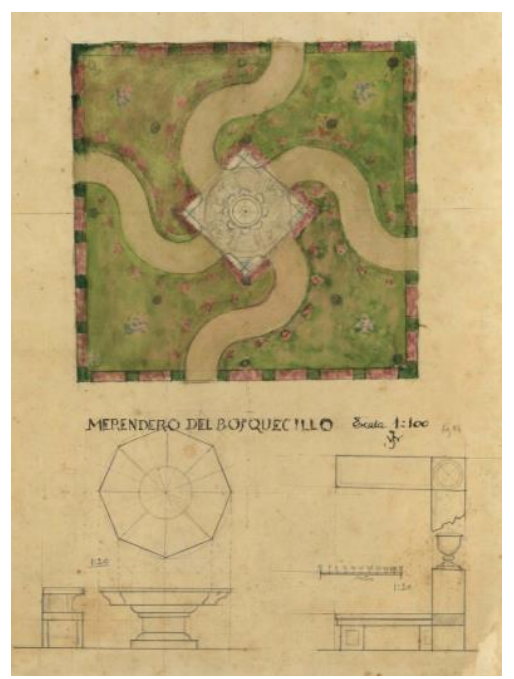

6.20. Planta de merendero y detalles ornamentales. Winthuysen, 1954. ARJB, Div.IX 18,3; Div.IX 67, 37.

nuevas y exóticas que habían entrado con la jardinería del siglo XIX y recuperar las plantaciones tradicionales españolas.

En la segunda etapa sus jardines tienen unas líneas puras y limpias, se podría hablar más de clasicista que de moderno, ya que entre sus referencias no estaban los jardines vinculados al Movimiento Moderno que se desarrollaron desde los años 1920 en Europa y América sino que va a inspirarse en jardines clásicos españoles. Todas sus composiciones poseen una definición espacial y una geometría clara, una regularidad, basadas en el uso de ejes de simetría, ortogonalidad, perspectiva y formas geométricas simples. Suelen ser jardines de líneas suaves para no competir con la arquitectura, y excepcionalmente, cuando la parcela lo exige utiliza trazados mixtilíneos combinando formas clásicas con líneas ondulantes.

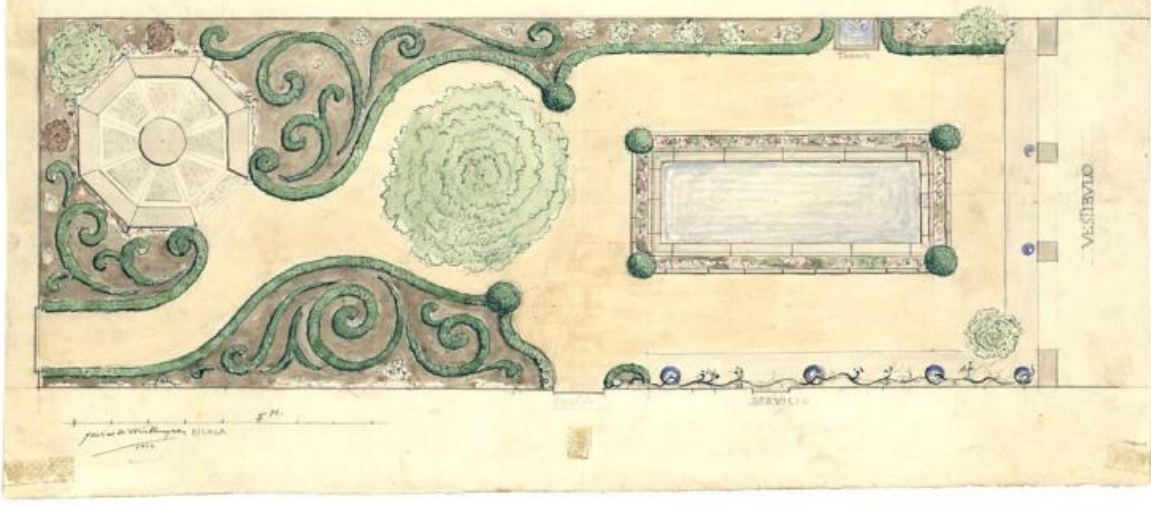

El jardín está constituido por unidades independientes que se relacionan entre sí por paseos y ejes perspectivos. Se adaptan a la topografía existente mediante varios niveles o plataformas que se conectan por escaleras y caminos en pendiente que salvan los diferentes desniveles y delimitan las diferentes partes del jardín. Hay una clara gradación de las partes: “...Así como los jardines de los príncipes guardaban un orden con arreglo a las necesidades de su señor, siendo en torno al palacio la continuación de éste, ...con sus parterres tallados y gradualmente iban al tapiz, verde, al bosquecillo artificioso, ...así gradualmente los de la casa modesta han de ser rodeados por sus necesidades, pasando gradualmente al disfrute del lujo que sólo mancomunadamente pueden disfrutar..., encontrando en el recinto del parque las grandes salas de reuniones y espectáculos, los campos de juego, la biblioteca, las 
colecciones botánicas y zoológicas, las escuelas, los templos..."30. A una escala menor consigue crear unos espacios estanciales más íntimos conectados mediante caminos y con carácter propio. Estos espacios de remanso, incluidos en el trazado general, aparecían en los jardines clásicos españoles que él estudió y dibujó, como en los jardines de la Real Fábrica de Paños de Brihuega en Guadalajara.

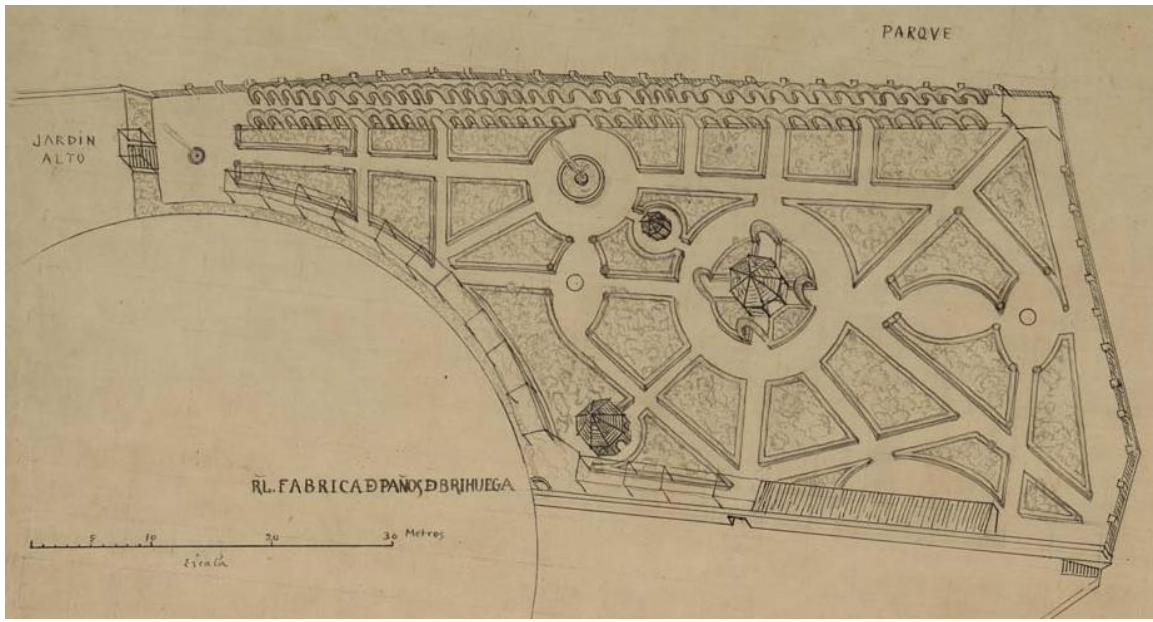

Utiliza recursos claramente clasicistas: remates de eje en exedra, conexión axial entre desniveles por medio de escaleras, delimitación de espacios con arquitecturas perimetrales como columnatas y arcos de ciprés, utilización de esculturas como remate o hito axial, recurso del agua como elemento centralizador en fuentes y estanques geométricos de piedra, empleo de jarrones sobre pilares como elementos decorativos, etc.

También se aprecia una preocupación por el entorno de sus obras, con la participación del paisaje exterior en el jardín a través del tratamiento de los miradores.

En cuanto a la vegetación a veces utiliza diseños más clásicos como alineaciones arbóreas que definen trazados y paseos, macizos bien delimitados con borduras y setos recortados con dibujos de broderies a la francesa; otras utiliza disposiciones más libres. Recurre al ciprés para crear alineaciones, formas arquitectónicas (pabellones, arcos, muros, nichos, etc.) y como elemento aislado puntual. Parece que prefiere la hoja persistente para crear la estructura del jardín. "Sus preferencias se inclinan por árboles con flor, frutales y de hoja persistente (árbol del amor, cítricos, ciprés, membrillo, kaki, níspero, nogal, laurel, magnolio, palmera, albaricoquero, ciruelo, almendro, granado). Entre los de sombra
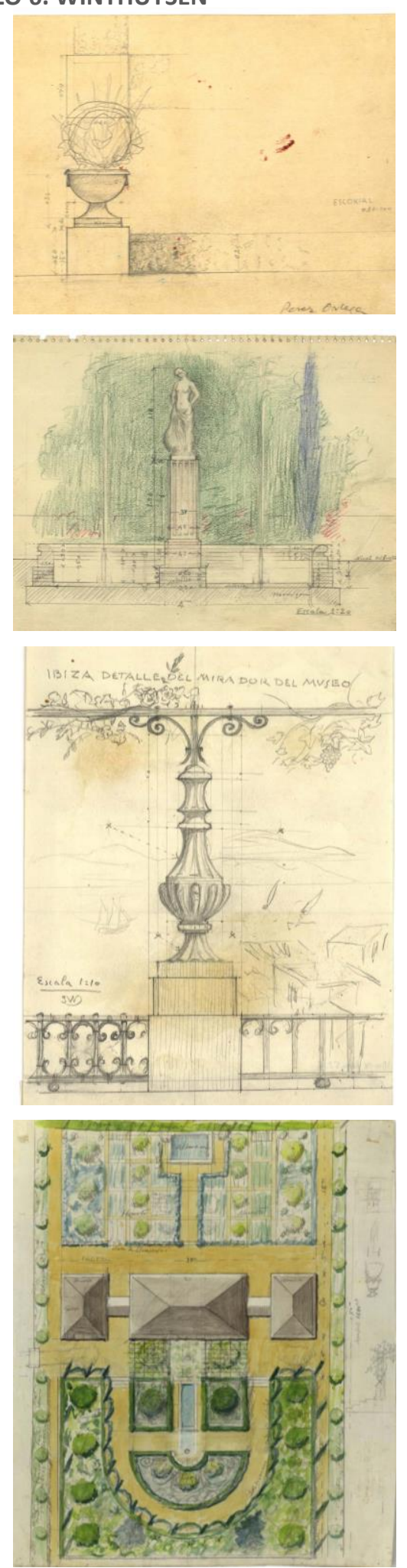

6.21 Planta y alzado de un macetero en el Jardín Pérez Ortega, 1929. Detalle de pedestal de la Fundación del Amo, 1933. Detalle del mirador del Museo Arqueológico de Ibiza, 1949. Proyecto ideal en el Escorial, 1950. Winthuysen. ARJB, Div.IX 19,3; 31,3; 55,7; 65,1.

6.22 Perspectiva axonométrica de los jardines de la Real Fábrica de Paños de Brihuega. Winthuysen, 1930. ARJB, Div.IX 66,73 .

\footnotetext{
30 Javier de Winthuysen en AA.VV.: Javier de Winthuysen. Jardinero, 1986, p. 101.
} 

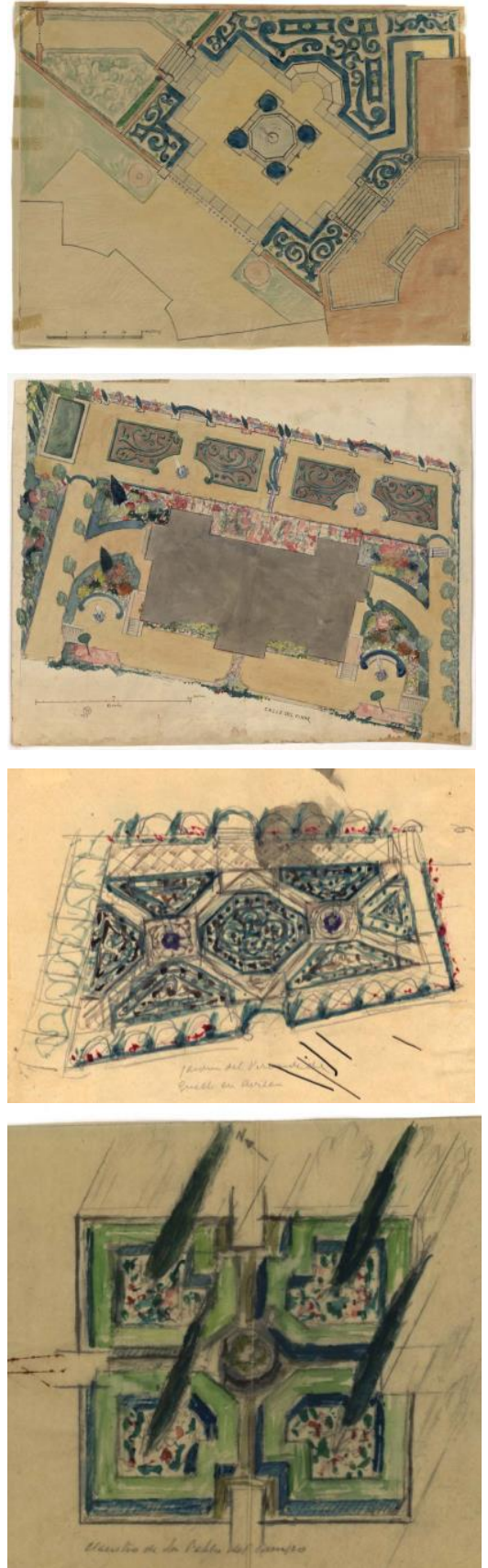

6.23 Planta del jardín de la residencia en la calle de Altamirano y vista axonométrica de los jardines de la residencia del Sr. Escriñá en Madrid, 1922. Dibujo de los parterres del jardín de San Segundo, en Ávila, 1922-1924. Boceto del claustro del Monasterio de San Pablo del Campo en Barcelona, 1950 (irrealizado). Winthuysen. ARJB, Div.IX 5,$2 ; 6,3 ; 10,3 ; 60,3$.

6.24 Proyecto ideal de un jardín con parterre central. Winthuysen, h. 1950. ARJB, Div.IX 63,1. son frecuentes la acacia de tres espinas, la falsa acacia y el tilo. En cuanto a los arbustos, se disponen formando setos recortados (boj, mirto, aligustre y bonetero) o bien aislados (dama de noche, hierba luisa, adelfa, celinda, rosal, espírea, lilo, bonetero y pitósporo). También son frecuentes las trepadoras que recubren muros, pérgolas y columnatas (buganvilla, celestina, hiedra, bignonia, jazmín, madreselva, glicinia, rosal y parra). / El tapiz vegetal se compone de plantas de flor cuando el soleamiento lo permite (agapanto, margarita, caña de indias, dalia, lirio, alhelí, dondiego, violeta y cala). También se disponen plantaciones en maceta, susceptibles de cambio en función de la luz: en espacios sombríos (hortensia de invierno, clivia, colocasia, esparraguera, begonia, aspidistra, helechos, ficus, costilla de Adán) y en espacios soleados (albahaca, cineraria, capuchina, clavel, geranio o gitanilla)"31, comenta Ángel a Souto.

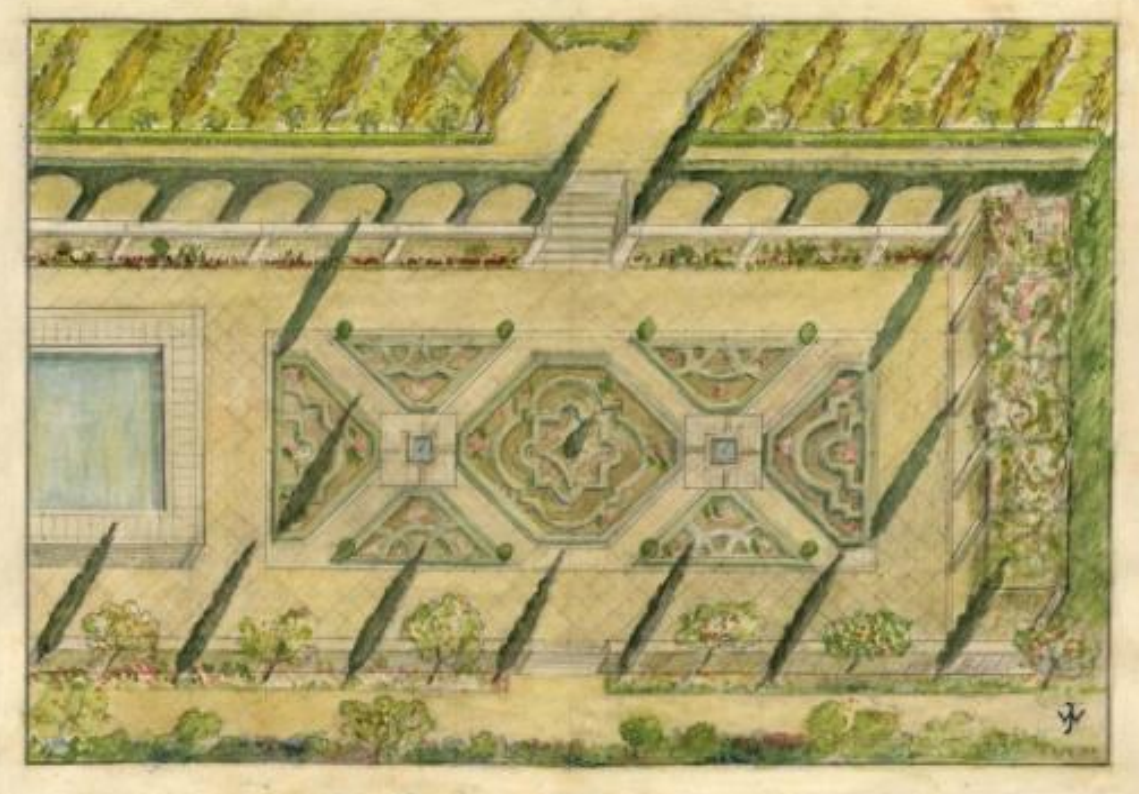

Winthuysen siempre defendió el carácter arquitectónico de la jardinería: "Armonizar espacios y macizos, sean éstos de la naturaleza que fuesen, no es otra cosa que Arquitectura en el más puro concepto estético. Y no solamente tratándose de las plantas o de sus conjuntos sometidos a formas regulares, sino en sus formas libres y disposiciones acordes con la naturaleza (sentido del parque paisajista) en que plantas, aguas, planos y hasta perspectivas ajenas al recinto han de formar, por virtud del arte, disposiciones rítmicas conscientes, aunque en toda obra de jardín necesariamente va

${ }^{31}$ SOUTO ALCARAZ, 2010, p. 18. 
ligada la emoción, podemos decir, sensual, a la emoción estética. Pero, en todos los casos, sea sometiéndose el arte a la naturaleza o ésta al arte, los productos -romántico o clásico- estarán informados por un mismo sentido: el sentido arquitectónico" ${ }^{32}$. Muchas veces se crea una especie de efecto escenográfico, una mezcla entre jardín y teatro, con la utilización de los niveles, terrazas, pórticos, arcos, pérgolas, columnas, etc.

A pesar de la oposición de ciertos arquitectos, realizará obras para instituciones públicas y privadas. Aquí no se trata de hacer un catálogo exhaustivo, pero sí se describen algunos ejemplos para ayudar a entender los argumentos generales de su composición.

\section{Jardines domésticos}

Su carácter polifacético le lleva a comenzar a publicar y difundir el material de su investigación en varios periódicos y revistas a partir de 1922, y da conferencias en el Ateneo de Madrid, Segovia y Zaragoza, compaginando estas tareas con su pintura paisajista, especialmente de la sierra madrileña y alrededores de la capital. Durante esta década también realizó varios jardines: “Por estos años del 24 al 29 hice jardines en Ávila, en Boecillo, Valladolid para los Condes de Gamazo, en Madrid para distintos aristócratas, en Ciudad Lineal para el señor Ribera Pastor y don Julio Casares y otros"33.

Son muchos los jardines unifamiliares que construye para los aristócratas de la época: "El jardín particular de las reducidas viviendas que la economía impone ha de ser desahogo, continuación de la casa, no nuevo adorno" ${ }^{34}$. Esto es interesante, pues descarta el jardín como añadido decorativo de la casa y lo ve como un espacio descubierto que se integra con el cubierto. Durante la guerra siguió haciendo jardines, aunque muchos de ellos no llegaron a pagárselos. Uno de ellos fue el jardín de Pérez Comendador: "Javier trazó el jardín de mi casa madrileña y aún hicimos juntos con nuestras propias manos, buena parte de sus plantaciones. Admiraba Eugenio Hermoso -a quien Winthuysen tenía en gran estima- estas faenas y gustaba también de ellas. Cuando el gran pintor extremeño que frecuentaba mi casa venía a

\footnotetext{
32 Javier de Winthuysen en AÑÓN FELIU, SANCHO GASPAR, 1990, p.26.

33 Ibíd., p. 192.

${ }^{34}$ WINTHUYSEN, J: El jardín y la Naturaleza, España Forestal, octubre 1927. En: Jardines de España (1870-1936), 1999, p. 276.
} 

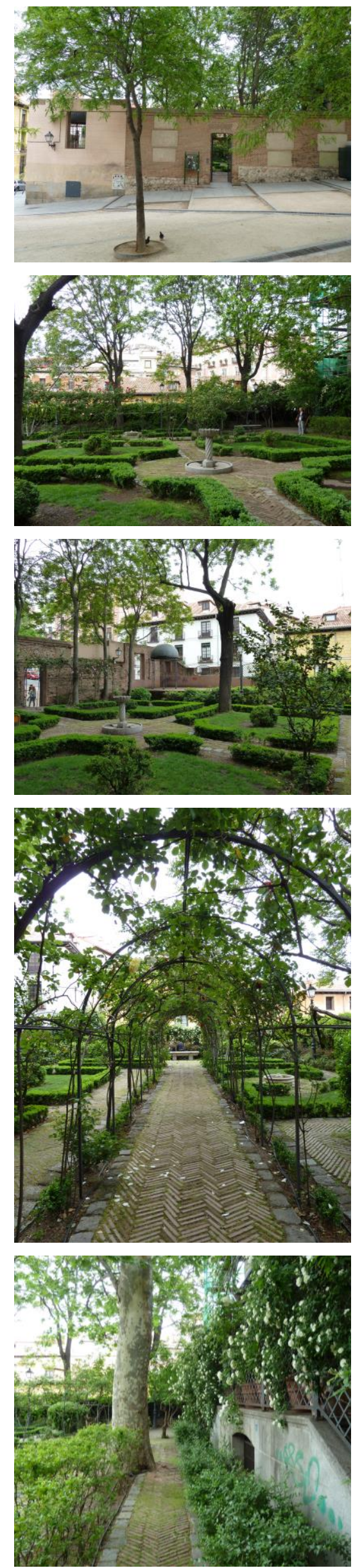

6.25 Jardín del Palacio de Anglona: vistas actuales. PHL, mayo 2015

6.26 Plano de Chalmandrier, 1761. Plano de 1750; Javier Ortega Vidal, La Forma de la Villa de Madrid, CAM, 2004.

ella, antes de entrar se llegaba al jardín y besaba el olivo, la higuera por nosotros plantados y entonces todavía joven..." ${ }^{35}$, explica el propietario.

Los jardines del Príncipe de Anglona o residencia de los marqueses de la Romana (1920) se trata de un pequeño jardín nobiliario ${ }^{36}$ ubicado en el casco histórico madrileño en el lado norte de la Plaza de la Paja, en un terraplén artificial que salva el desnivel entre esta plaza y la calle Segovia. En su origen el jardín estaba vinculado a la casa-palacio anexa del siglo $\mathrm{XVII}^{37}$, el palacio del Príncipe de Anglona, que ha sufrido diversas reformas. En el lateral de esta casa se trazó el jardín antiguo con carácter neoclásico y composición cuatripartita del que ya se tiene constancia en los planos del siglo XVIII. La imagen actual del palacio data de la reforma y adecuación en 1802 para ser residencia del XI Marqués de Peñafiel, primogénito de la casa de Osuna. En 1920, tras pasar por varias manos, los Marqueses de la Romana encargan a Winthuysen que reforme estos jardines. Con una superficie de $678 \mathrm{~m}^{2}$, está rodeado por muros de ladrillo que le confieren gran intimidad y al que se accede a través de una verja. Introduce los elementos de los jardines clásicos andaluces: fuentes, bancos de azulejos, pérgolas vegetales, etc.
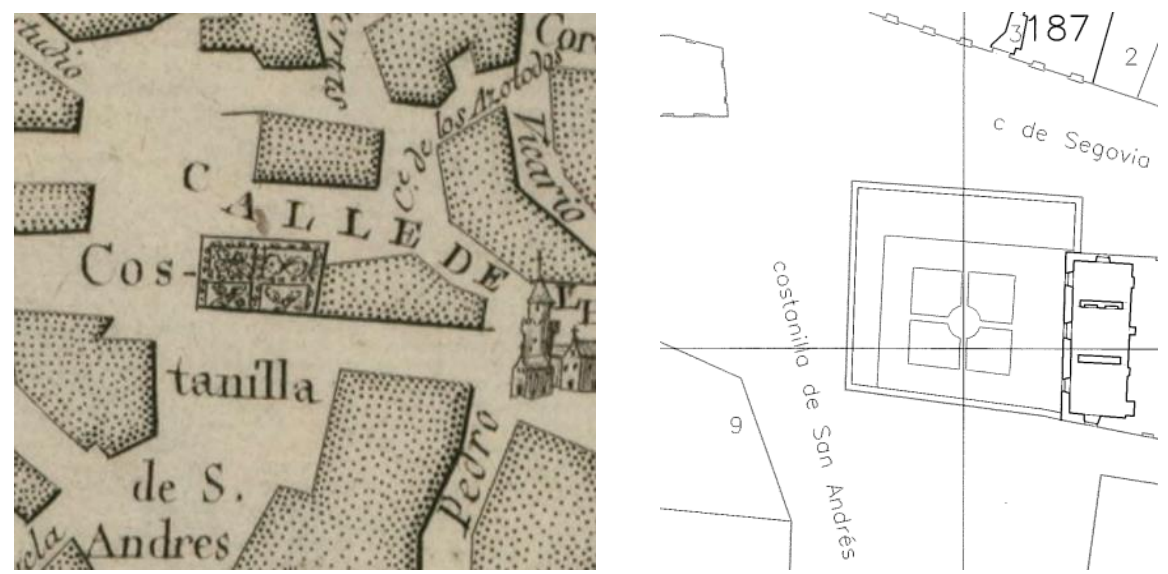

\footnotetext{
35 Enrique Pérez Comendador. En AA.VV.: Javier de Winthuysen. Jardinero, 1986, p. 29.

36 Tanto la casa palacio como el jardín toman su nombre de Pedro de Alcántara TéllezGirón y Alfonso-Pimentel, príncipe de Anglona y marqués de Jabalquinto, morador del lugar en el siglo XIX.

${ }^{37}$ En 1750 se le denominaba como "sitio sin labrar".
} 

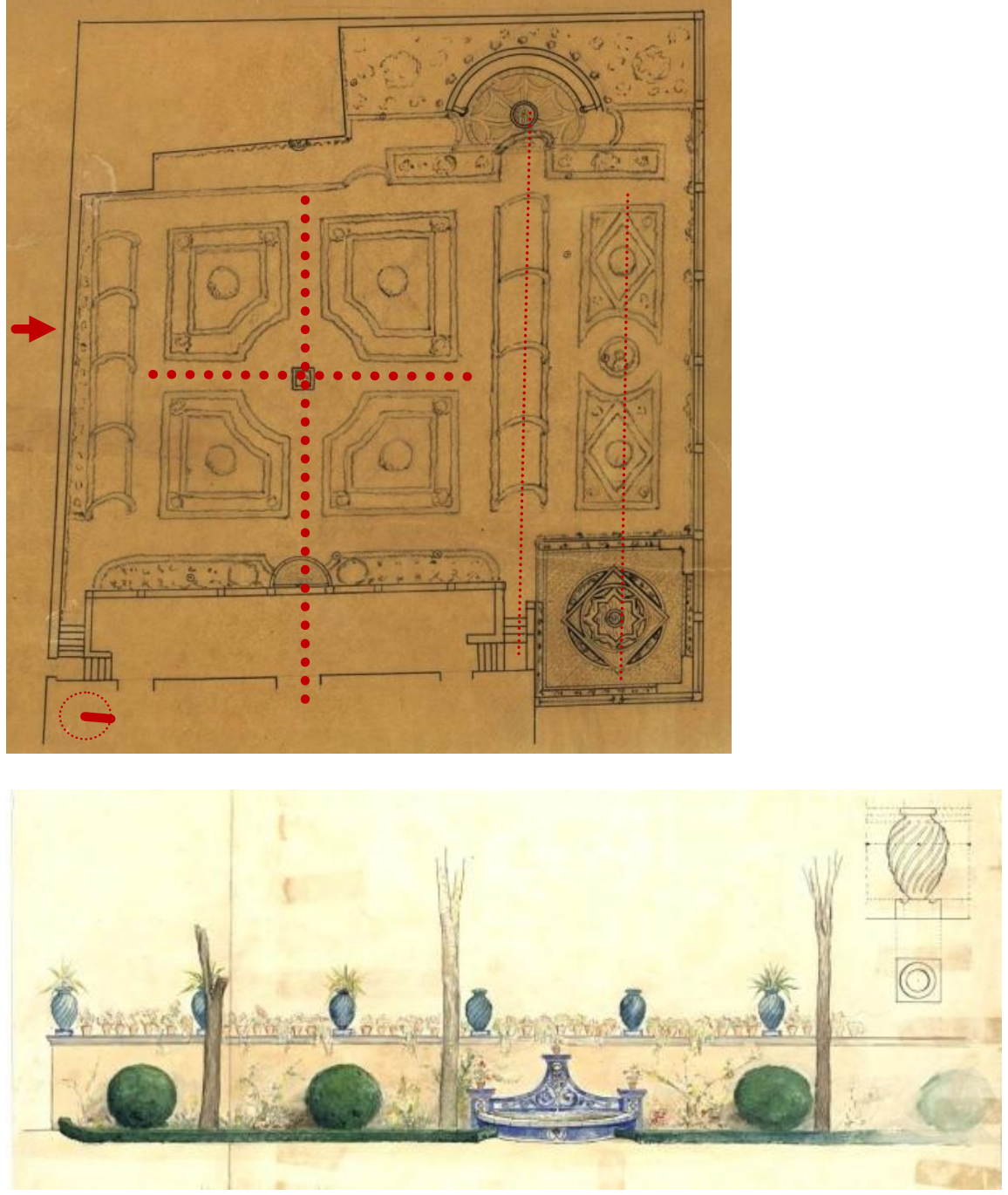

El cuerpo central está compuesto simétricamente con dos ejes perpendiculares que se cruzan donde se dispone una fuente central de piedra rodeada de cuatro cuadros y a cada lado coloca dos pérgolas con rosales trepadores. La pérgola más cercana a la calle Segovia se remata con un banco de azulejos y paralelo a esta pérgola se dispone un arriate alargado con otra fuente baja circular en medio. Rematando este eje se dispone un recinto cuadrado e íntimo que encierra una fuente de azulejos con diseño estrellado. En la fachada frente al palacio se dispone una doble escalera que conduce a una especie de terraza o porche previo al interior protegido con celosías con trepadoras y tiestos. Los cuadros, de pradera y setos recortados en su interior (laurel, berberis, cotoneaster) y pequeños frutales (madroños, caquis, granados y almendros), están delimitados con setos de boj. Los árboles (ailantos y acacias) se disponen principalmente en alineación siguiendo los dos muros perimetrales paralelos a las pérgolas. A lo largo del muro de cerramiento coloca una serie de pilastras que

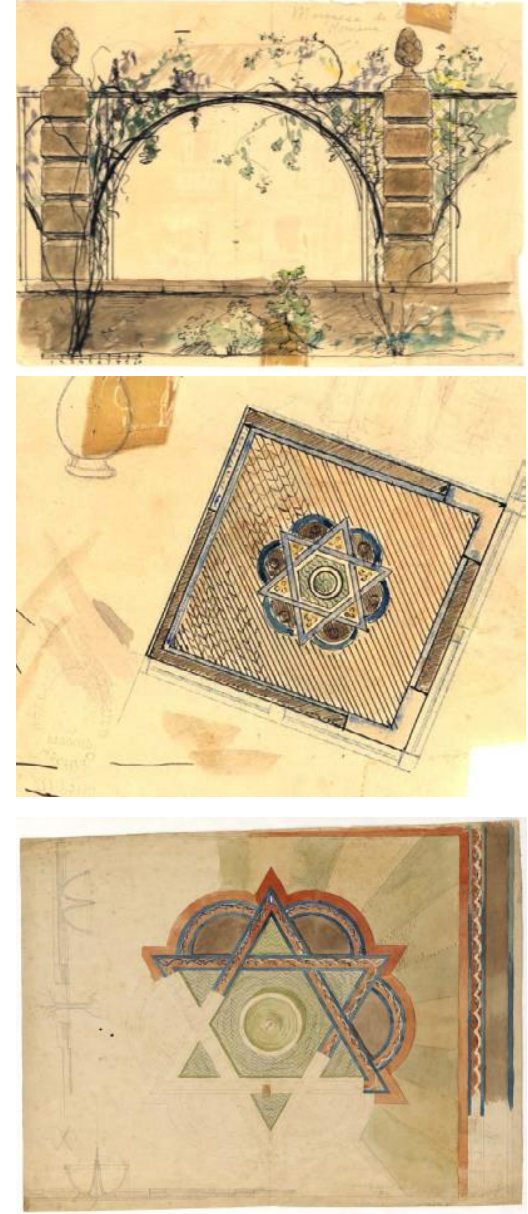

6.27 Planta del jardín del Palacio de Anglona. Bocetos de una parte del jardín. Planta de la fuente. Dibujo de la fuente. Planta y alzado de la fuente. Winthuysen, 1920. ARJB, Div.IX 3, 2-3-4-5-6.

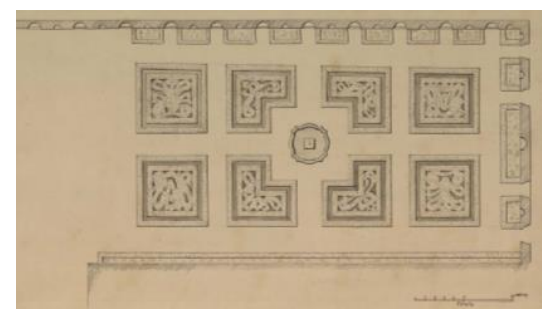

6.28 Plano del rincón herreriano del parterre del Jardín de la Isla, Aranjuez. Winthuysen, 1930. ARJB, Div.IX 66,20. 

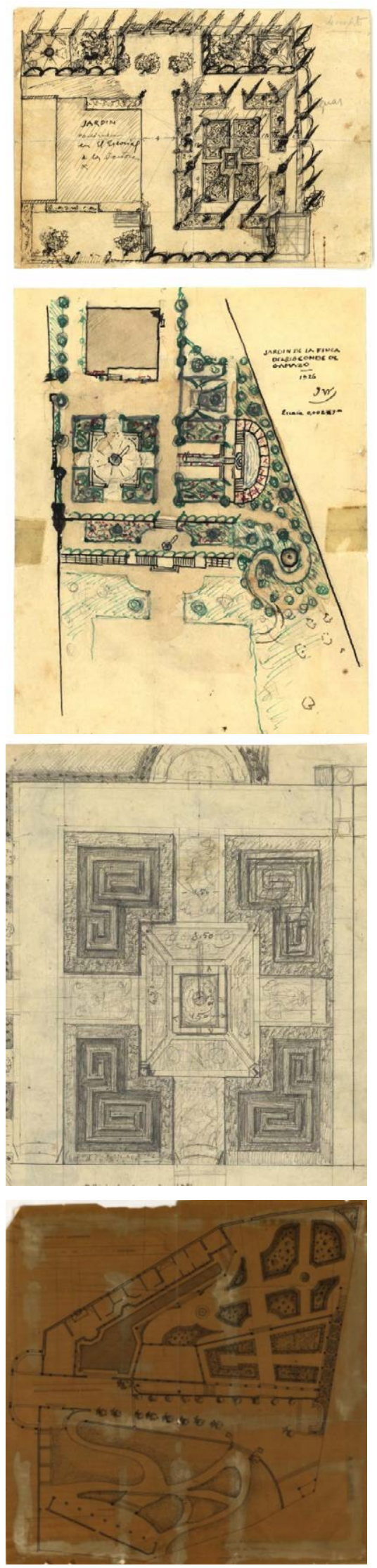

6.29 Jardín de la residencia del Sr. Pérez Ortega, 1920. Plano del jardín de San Segundo, 1922. Planta del jardín de Boecillo, 1927. Planta de un cuadrante del jardín del Pinarillo, 1934. Winthuysen. ARJB, Div.IX 18,3; 10,4; 19,1; 54,2 .

6.30 Jardín del Palacio de Anglona: vistas actuales. PHL, mayo 2015 une con treillages cubiertos de trepadoras. Los caminos se realizan con pavimento de ladrillo aparejado a sardinel ${ }^{38}$.
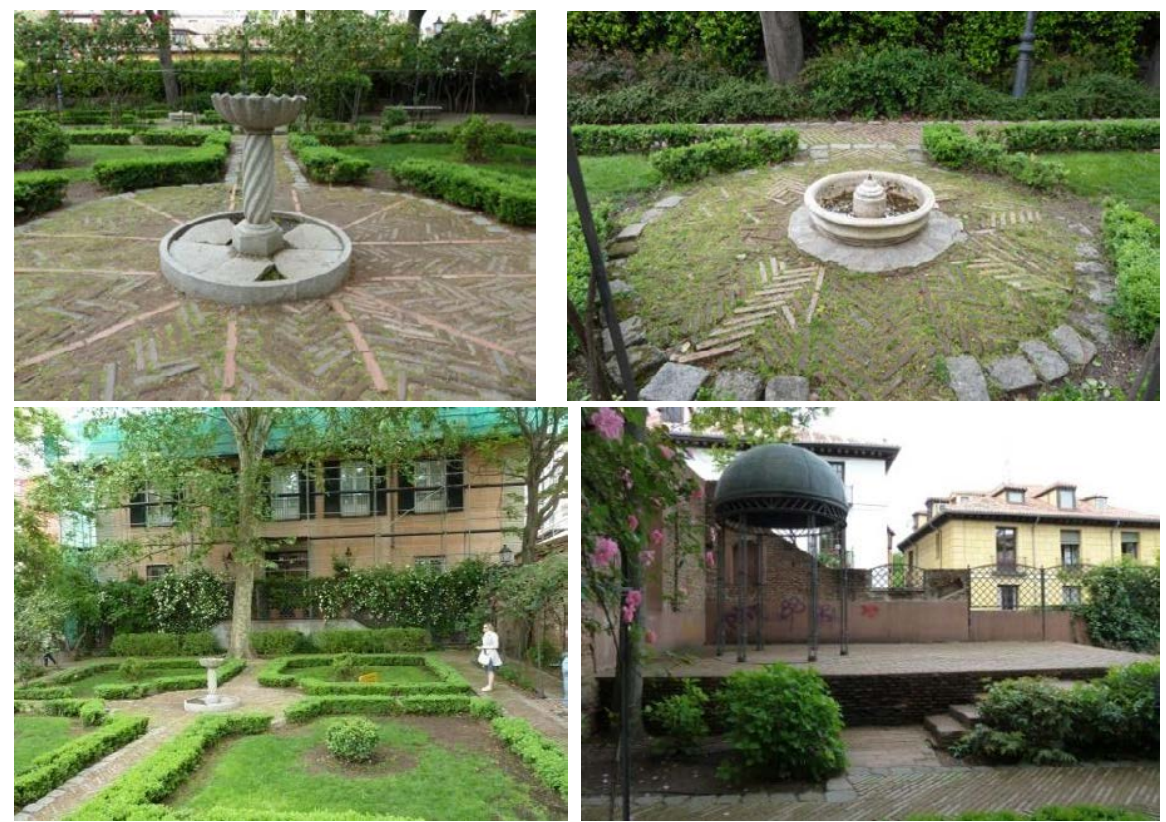

Con esta disposición cuatripartita, utilizada previamente en jardines clásicos como el parterre del Jardín de la Isla de Aranjuez, realiza otros jardines como la Casa de Benamejí (Córdoba, 1917), residencia de la calle Altamirano (Madrid, 1922), residencia del Sr. Escriñá (Madrid, 1922), residencia de la Condesa de Medina y Torre (Madrid, 1924), residencia del vizconde de Güell o San Segundo (Ávila, 1922-1924), residencia del Sr. Pérez Ortega (El Escorial, h.1920), residencia de los Sres. Arranz Adrada (Madrid, h.1920), residencia del conde de Gamazo o jardín de Boecillo (Valladolid, 1927-1932), residencia del Sr. D- Víctor de la Serna o EI Pinarillo (EI Escorial, 1934) y otros muchos jardines para las viviendas unifamiliares de las colonias jardín que se estaban creando en Madrid $^{39}$.

\footnotetext{
38 A principios del siglo XX el jardín quedó abandonado y en 1940 el Ayuntamiento de Madrid alquiló la Casa-Palacio para dependencia de la Sección de Estadística de Empadronamiento, pasando a titularidad municipal en 1978 y estando actualmente rehabilitándose. Al inicio del siglo XXI el jardín fue restaurado por Lucía Serredi y se abrió al público en el 2002; todavía conserva su espíritu de jardín escondido romántico en medio de la ciudad. Se ha intentado ser fiel al proyecto original; así el banco de azulejos que no se conserva se sustituye por uno de piedra rematando el eje de la pérgola; tampoco se conserva el recinto cerrado con la fuente estrellada y actualmente aquí hay una serie de pequeños árboles y arbustos. En una de las esquinas, junto a la Plaza de la Paja, se dispone un cenador de hierro que tampoco estaba en el plano original y se ha abierto un acceso desde esta plaza en uno de los muros laterales.

${ }^{39}$ Los jardines de las viviendas de las colonias se desarrollan en el capítulo siguiente EI jardín doméstico - Las ciudades jardín..
} 
Winthuysen realiza en 1920 el jardín del Panteón propiedad de los Sres. de Schneider en el Cementerio Civil del Este de Madrid. La entrada principal flanqueada por un ciprés conduce a un camino de piedra que dibuja una $L$ entre la superficie de hierba y lleva a una plazoleta poligonal y a la sepultura ${ }^{40}$. Junto a ella un banco liso de granito cercano a un pino (Pinus australis) permite contemplar el paisaje de la sierra del Guadarrama que recuerda al difunto, un joven alpinista extranjero fallecido en una escalada a los Pirineos. Todo está limitado por un muro bajo de la misma piedra con dos accesos protegidos por cancelas. Winthuysen dibuja cuidadosamente el despiece del pavimento y los muros de piedra. También diseña las plantaciones: hiedras y rosales trepadores blancos adosadas al muro que flanquea el camino, tejos de $2 \mathrm{~m}$ para el otro muro, un evónimo y una glicinia en el rincón junto al pino, un desmayo (almendro desmayo) rosa o amarillo y un rosal rojo junto a la tumba, y en el centro un tapiz de hierba rodeado de flores bajo el cual se sitúan las tumbas.

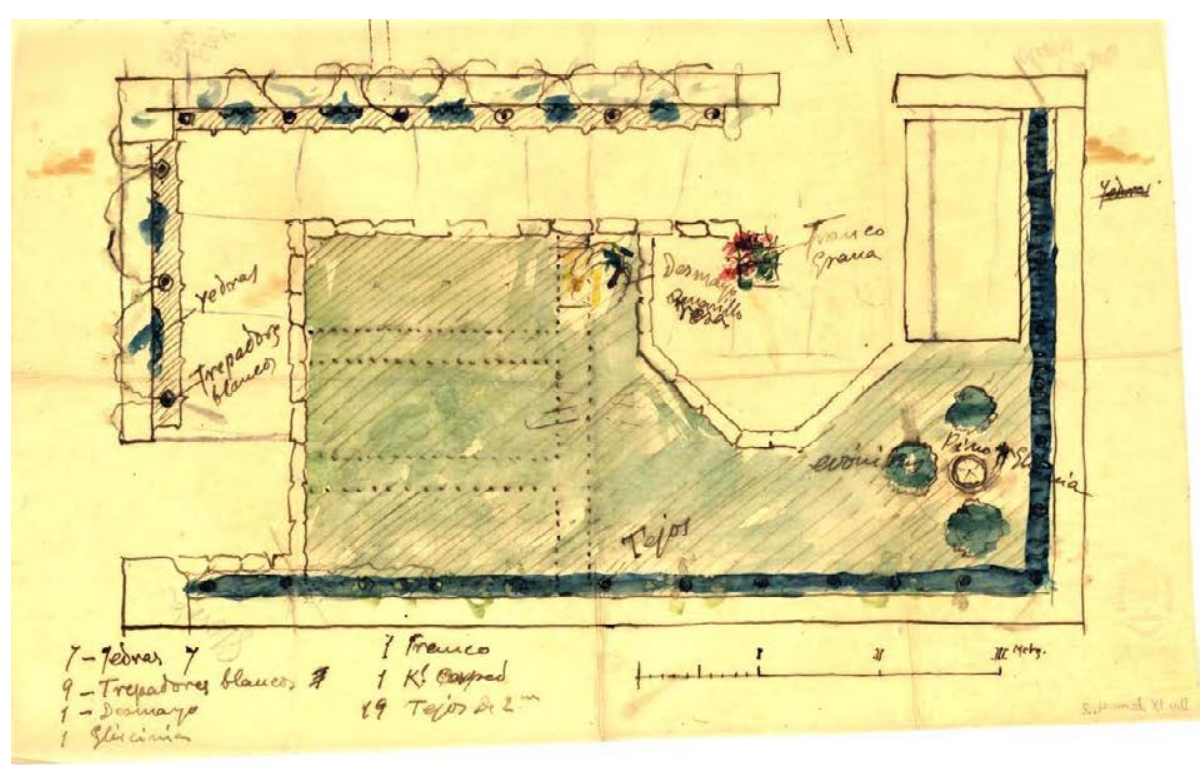

El diseño vegetal se integra al conjunto final, sin romper con la austeridad y enfatizando la composición arquitectónica, creando un todo armónico. El árbol se ubica frente al acceso, rematando el eje visual; los setos y las trepadoras se disponen perimetralmente, delimitando el recinto; y las flores bordean la pradera y enmarcan los caminos.
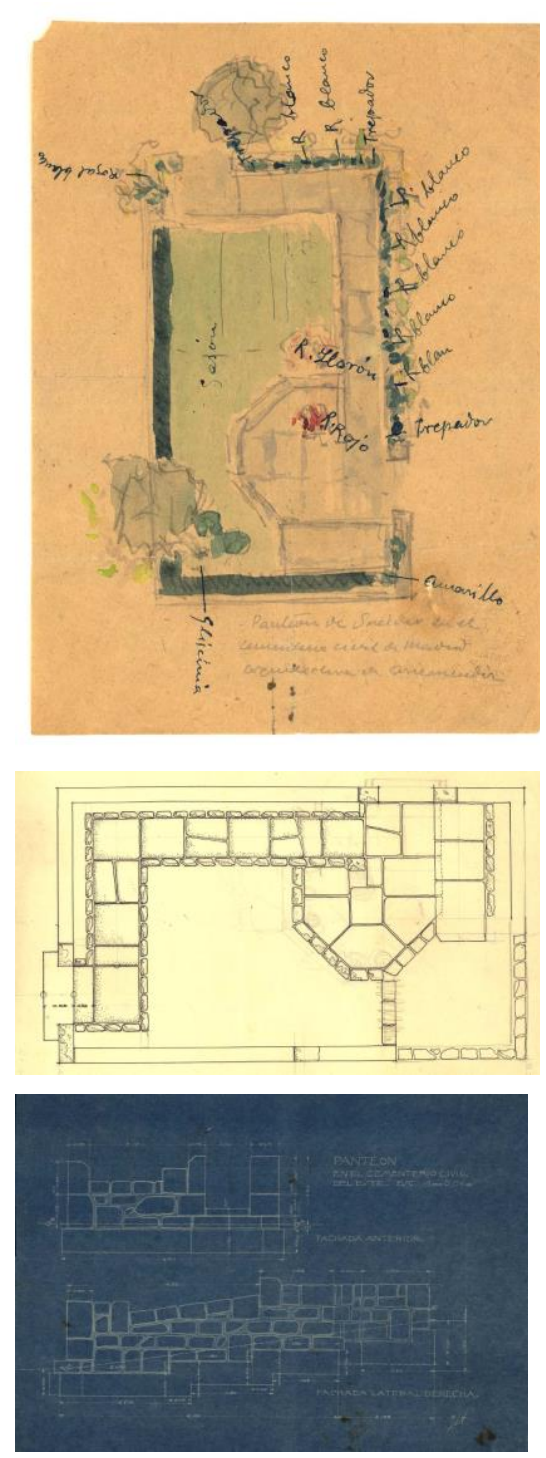

6.31 Dibujo del jardín del Panteón Schneider en el cementerio civil. Plano del jardín del Panteón Schneider exponiendo la disposición de las plantas. Planta en el cementerio Schneider. Alzado de la fachada anterior y lateral derecha del Panteón Schneider en el Cementerio Civil. Winthuysen, 1920. ARJB, Div.IX 4, 1-4.

\footnotetext{
${ }^{40}$ El autor de la sepultura es José Sanz Arizmendi, arquitecto sevillano formado en la Escuela Politécnica de Zurich.
} 


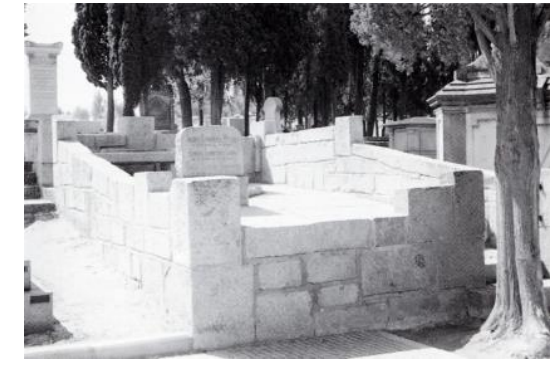

6.32 Vista actual. AA.VV.: Javier de Winthuysen. Jardinero, 1986, p. 107.

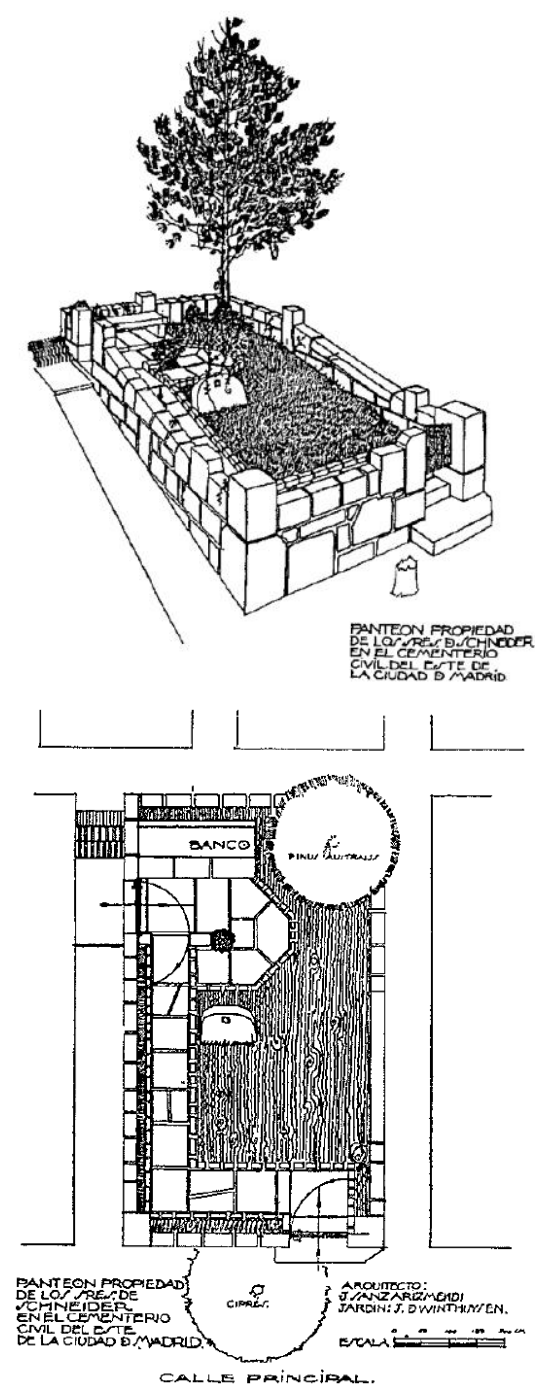

6.33 Vista y planta del Panteón de los Sres. de Schneider. Nueva Forma, 1967, p. 121.

6.34 Sección longitudinal A - B. Winthuysen, 1920. ARJB, Div.IX 4,5.

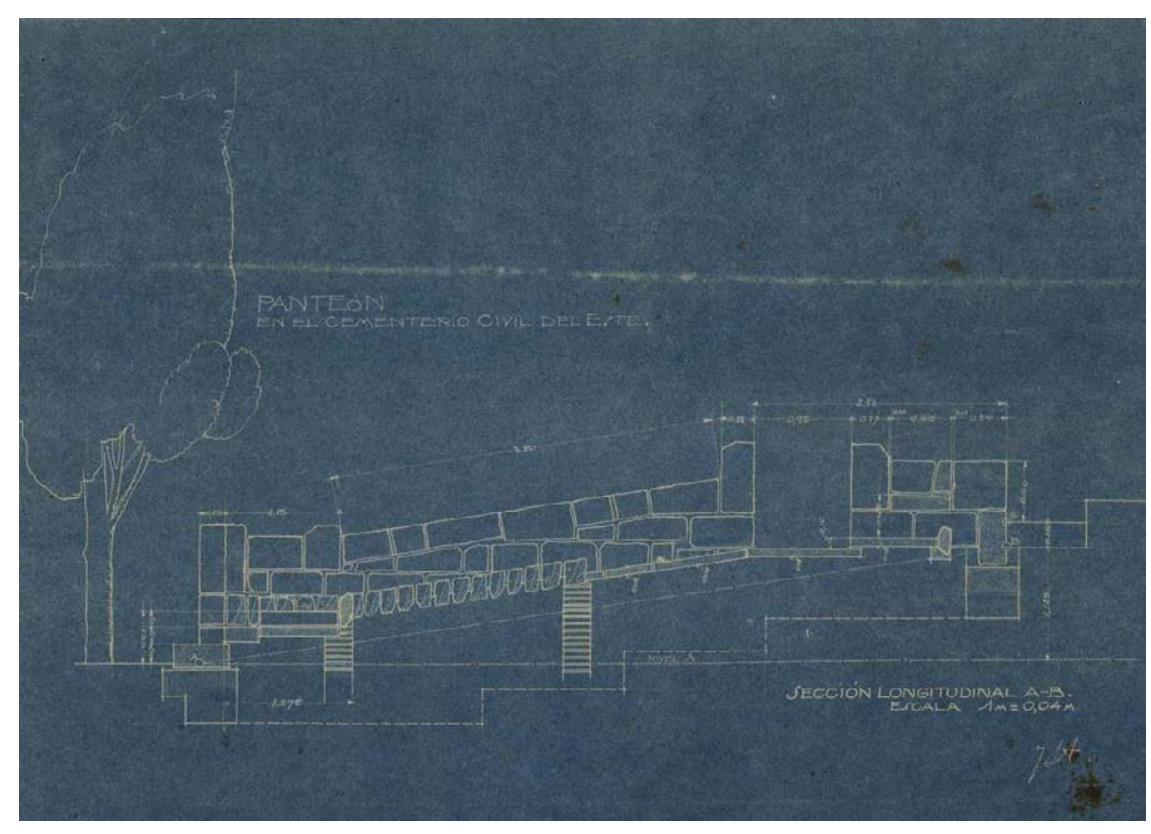

Torres Balbás hace alusión a la ausencia de ornamentación, austeridad y simplicidad de líneas del conjunto que lo distinguen del resto de panteones y en el que se aprecia el espíritu moderno que vuelve la mirada hacia arquitecturas más primitivas y elementales: "Es tan grande la simplificación que evoca las sepulturas de algunos pueblos primitivos cuyos cadáveres son enterrados debajo de un árbol rodeado de grandes piedras./.../ Ninguna forma plástica, ninguna de estas alharacas fúnebres que tanto abundan en nuestros cementerios, se interpondrá entre la poesía melancólica y consoladora a la par del recuerdo y la belleza eterna de las montañas. $Y$, sin sugestiones extrañas, fina $y$ sutilmente, esta sepultura casi terrena, lisa y humilde será lo que esencialmente debe ser un monumento funerario: emoción"41. Winthuysen sigue la corriente de los enterramientos nórdicos tradicionales carentes de figuras representativas, donde en vez de hileras de nichos hay un cementerio-jardín.

La finca Puente San Miguel (1950), propiedad de la familia BotínSanz de Sautuola ${ }^{42}$, se ubica en Reocín, a $31 \mathrm{~km}$ de Santander. El conjunto de estilo ecléctico se divide en dos grandes áreas, una de bosque y otra de jardín. La zona de bosque está situada en la zona más elevada y cuenta con 20ha. Se ha extendido en los últimos años con pequeñas fincas plantadas de nuevos árboles. Esta gran

\footnotetext{
41 TORRES BALBÁS, L.: Arquitectura Española Contemporánea. Un panteón. En: Nueva Forma no 23/24, dic. 1967-enero 1968, p. 121. En: Arquitectura, 1922, octubre no 42, p. 411-413.

42 Durante más de 300 años ha sido propiedad a esta poderosa familia, a la que pertenecía Marcelino Sanz de Sautuola, descubridor de las cuevas de Altamira.
} 
masa arbórea consigue aislar del ruido y dotar al jardín de privacidad.

El jardín, al que se accede por un magnífico portalón de 1910, obra de J. González Riancho, rematado por una cruz y decorado con el blasón familiar, tiene una superficie de más de 10ha y se divide en tres zonas. La primera es el antiguo jardín donde se encuentra la casona familiar que data del $1900^{43}$ y fue reformada en los 1950 . De carácter naturalista, con caminos ligeramente sinuosos y una zona clásica para la estancia familiar, despejada y frente a la casa, propia de los jardines del Norte. Destaca el respeto hacia el medio natural, todos los ejemplares se dejan crecer libremente sin poda alguna y las ramas llegan hasta el suelo. El recorrido se inicia por una avenida flanqueada de hayas -antiguamente eran unos tilos monumentales que fueron derribados por el viento sur en los 1970- Luego aparecen tejos de Irlanda, pinsapos y ejemplares de Araucaria araucana, entre otros, formando un denso conjunto. Los mejores ejemplares botánicos se encuentran en esta zona con varios árboles centenarios y algunas especies exóticas ${ }^{44}$-magnolio, sequoias, taxodium, cedros del Atlas, Ginkgo biloba, etc.-; varios miembros de la familia gracias a su interés por los árboles introdujeron nuevas especies en la provincia, especialmente Marcelino Sanz de Sautuola.

La segunda zona es el jardín de Winthuysen, un pequeño jardín familiar frente a la capilla del siglo XVIII cercana a la casa y diseñado por el pintor y jardinero sevillano con todo detalle. El espacio, lindando actualmente con la carretera CA-353, se divide en cuatro estancias en diferentes niveles que van descendiendo y se comunican mediante escaleras, compartiendo un mismo eje longitudinal. El primer espacio y más elevado, que conecta con el desaparecido Paseo de los Tilos, es un pequeño patio rectangular de $6 \mathrm{~m}$ de ancho con un estanque central de $2,4 \mathrm{~m}$ que juega con la

\footnotetext{
${ }^{43}$ Mandada construir por Emilio Botín López y María Sanz de Sautuola en el mismo lugar que ocupaba la antigua residencia familiar. Finca Puente San Miguel, folleto explicativo proporcionado en la visita al jardín.

44 "Una Magnolia grandiflora L. de más de 200 años, considerada la más grande de Europa, cubriendo más de $700 \mathrm{~m}^{2}$; una Sequoia sempervirens centenaria cuyo tronco mide 5,40m de circunferencia; un cedro del Atlas de más de $30 \mathrm{~m}$ de altura; una Cryptomeria japonica y otra de la variedad "Elegans"; plátanos, Acer negundo L. de $3 \mathrm{~m}$ de circunferencia; un ejemplar raro de Cephalotaxus harringtonia; un Abies pinsapo de más de $25 \mathrm{~m}$ de altura, un espécimen único de Metasequoia glyptostroboides traido de Londres en los 1950, Araucaria araucana, Taxus baccata, etc". AÑÓN, C.; LUENGO, M.; LUENGO, A.: Jardins en Espagne. Actes Sud, 1999, p. 186-187. AÑóN, C.; LUENGO, M.; LUENGO, A.: Jardines artísticos de España. Madrid: Espasa Calpe, 1995, p. 198.
}
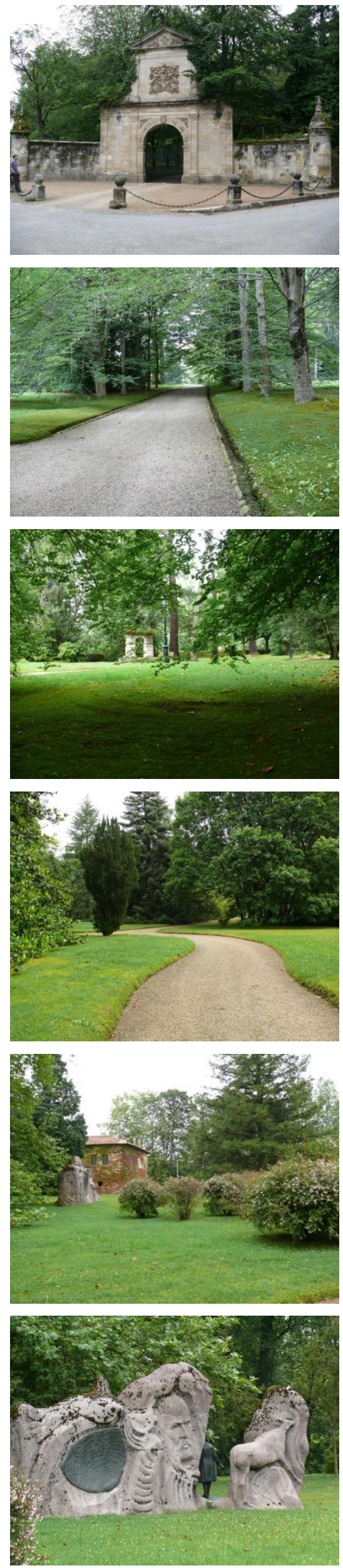

6.35 Puente de San Miguel, zona de acceso y jardín antiguo. Detalle del monumento a las Cuevas de Altamira. PHL, julio 2013. 


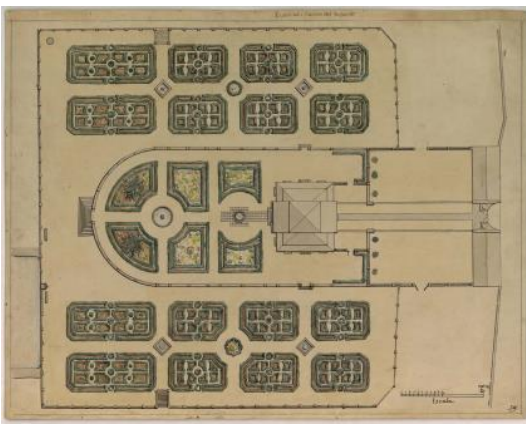

6.36 Plano del jardín del Casino del Infante, El Escorial. Winthuysen, 1930. ARJB, Div.IX 66,83.
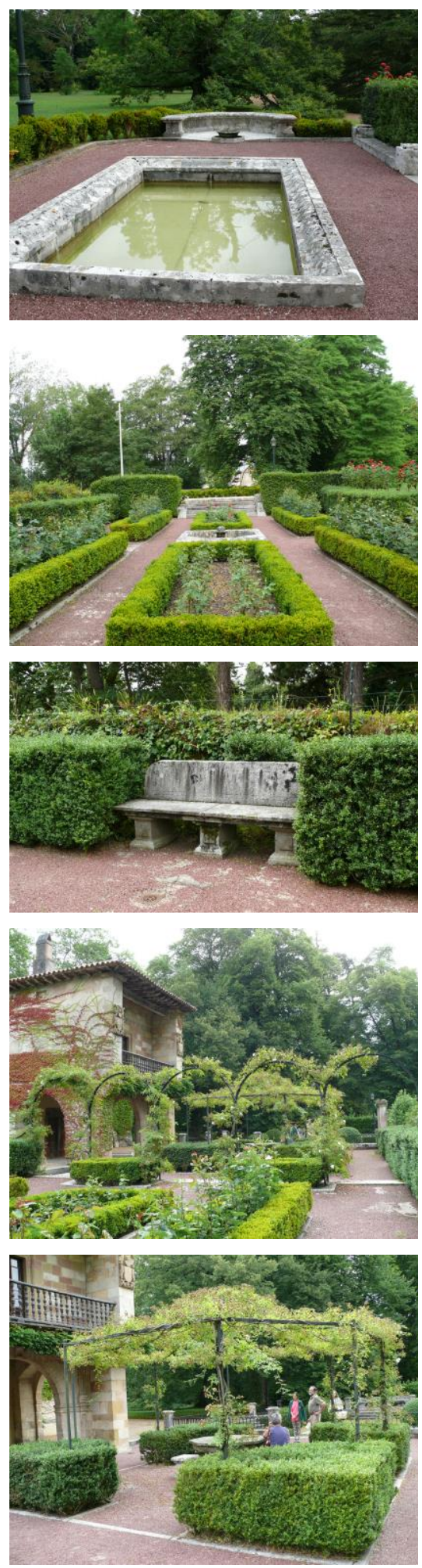

6.37 Jardín de Winthuysen en Puente de San Miguel. PHL, julio 2013.

6.38 Planta y sección de los jardines, 1950. Planta de los jardines con dibujos de arbolado, 1955. Winthuysen. ARJB, Div.IX 64, 2 y $16 r$.

escalinata de acceso; el eje transversal está rematado por un surtidor abrazado por un banco semicircular de piedra sobre mosaico y un balcón ${ }^{45}$.
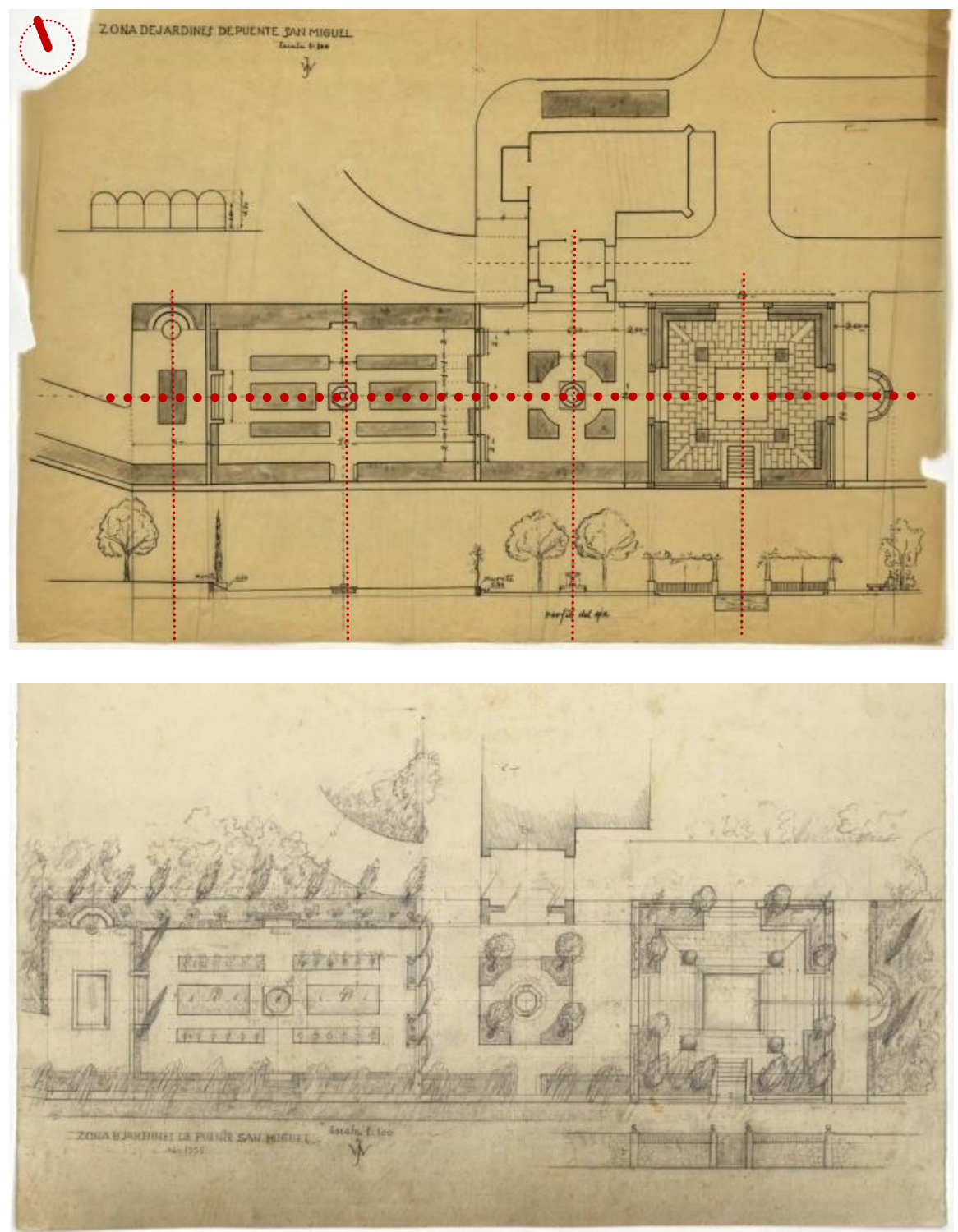

El segundo espacio al que se desciende a través de una escalera, antiguamente flanqueada por cipreses, cuenta con una rosaleda (20 $x 10 \mathrm{~m}$ ) con seis cuadros rodeados de seto de boj, los dos centrales más anchos de rosales bajos y los laterales de rosales altos; y en el eje transversal es donde se sitúa un estanque central cuadrangular de piedra con un pequeño surtidor y dos bancos a cada lado o banco y balcón según el boceto. Una arcada vegetal de cinco arcos sobre murete de $30 \mathrm{~cm}$ y donde trepan rosales cierra este espacio y hace de transición al siguiente nivel.

45 En bocetos previos en vez de un estanque es un tapiz florido o una glorieta con un ciprés, y en algunos croquis al otro lado del surtidor hay un balcón. 
En este tercer nivel hay un patio cuadrado $(6,5 \times 6,5 \mathrm{~m})$ alineado con el eje de los arcos de la capilla, en cuyo centro hay una glorieta de $5 \mathrm{~m}$ con un merendero ${ }^{46}$ en su centro formado por una mesa octogonal de piedra con asientos sobre un mosaico con diseño en cruz, flanqueada por cuatro melias y olmos negros rodeados de boj. Actualmente una pérgola ligera, no contemplada en el proyecto original, cubre el espacio central con una trepadora. En el eje transversal en algunos bocetos aparece otro balcón; actualmente hay un monumento con medallón dedicado a Víctor de la Serna Espina, quién propuso la creación del jardín de Winthuysen y el acondicionamiento de la casa-capilla donde residía cuando era invitado a la finca.

El último espacio es un patio cuadrado rodeado con barandal de hierro y seto perimetral de boj, con un impluvium central con cuatro bolas de boj en las esquinas El proyecto original tenía árboles, un peristilo y doce columnas sosteniendo un emparrado de lo que no se conserva nada. En su eje transversal hay una escalinata que da a una puerta de salida a la calle flanqueada por laureles y en el otro lado otra escalinata conecta con el paseo superior arbolado del parque. Rematando el eje longitudinal aparece una pequeña plataforma con un banco semicircular, flanqueado por dos cipreses desaparecidos, y una fuente de la que parte un canalillo que conecta con el impluvium. En la axonometría se aprecia cómo actualmente se han perdido los cipreses perimetrales y la hilera de sauces del perímetro sur que hacían de filtro vegetal cerrándose a la calle y proporcionando privacidad al jardín. Todos estos espacios siguen la línea característica de Winthuysen incorporando elementos y esquemas tradicionales de la jardinería española y con influencia sevillana y del Casino del Infante de El Escorial; de este último además del esquema general se copian algunos elementos como la mesa con sillas de piedra.

Se aprecian similitudes con los diseños de Forestier: adaptación a la topografía existente mediante plataformas que se conectan por escaleras, utilización de recursos clasicistas -remate de ejes en exedra, conexión axial mediante escaleras, delimitación de espacios con arquitecturas vegetales perimetrales como arcos de ciprés, agua como elemento centralizador en fuentes $y$ estanques geométricos de piedra...-, combinación de la escala del conjunto

\footnotetext{
${ }^{46}$ En algunos de los bocetos iniciales en vez de una mesa hay un surtidor central.
}
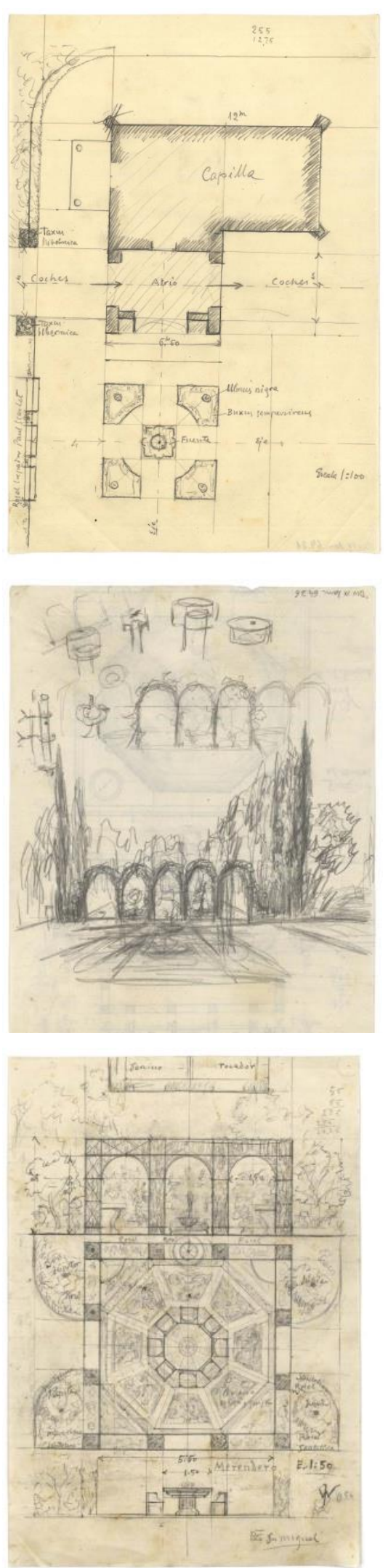

6.39 Planta del jardín que rodea la capilla del Puente de San Miguel, 1950. Planta y alzado de la fuente, 1954. Dibujo del merendero, 1954.Winthuysen. ARJB, Div.IX 64, 21-26v -27. 

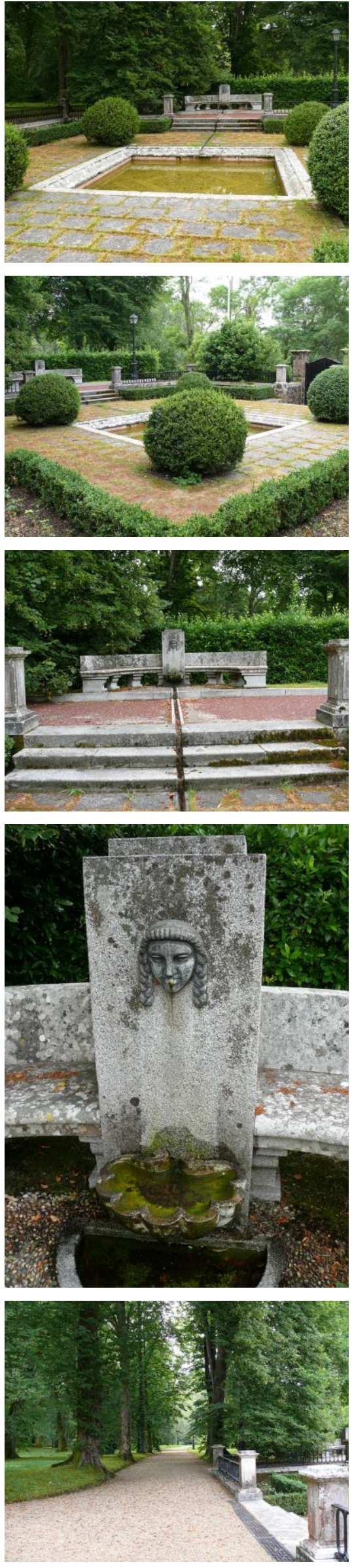

6.40 Jardín de Winthuysen en Puente de San Miguel. PHL, julio 2013.

6.41 Planta de los jardines y entorno del Puente de San Miguel. Winthuysen, 1954. ARJB, Div.IX 64,7. con otra menor de espacios estanciales más íntimos, etc. Estas unidades independientes se relacionan mediante los paseos y ejes perspectivos. Cobran importancia los desarrollos perpendiculares a lo largo del eje principal sirven para conectar las distintas partes del jardín con otros espacios como la casa, la capilla o el parque. Empiezan a aparecer rasgos más modernos como las asimetrías de las distintas partes y la respuesta a la integración con el entorno. Se observa bastante diferencia entre los dibujos, más tradicionales, y el resultado, de gran pureza espacial y austeridad.
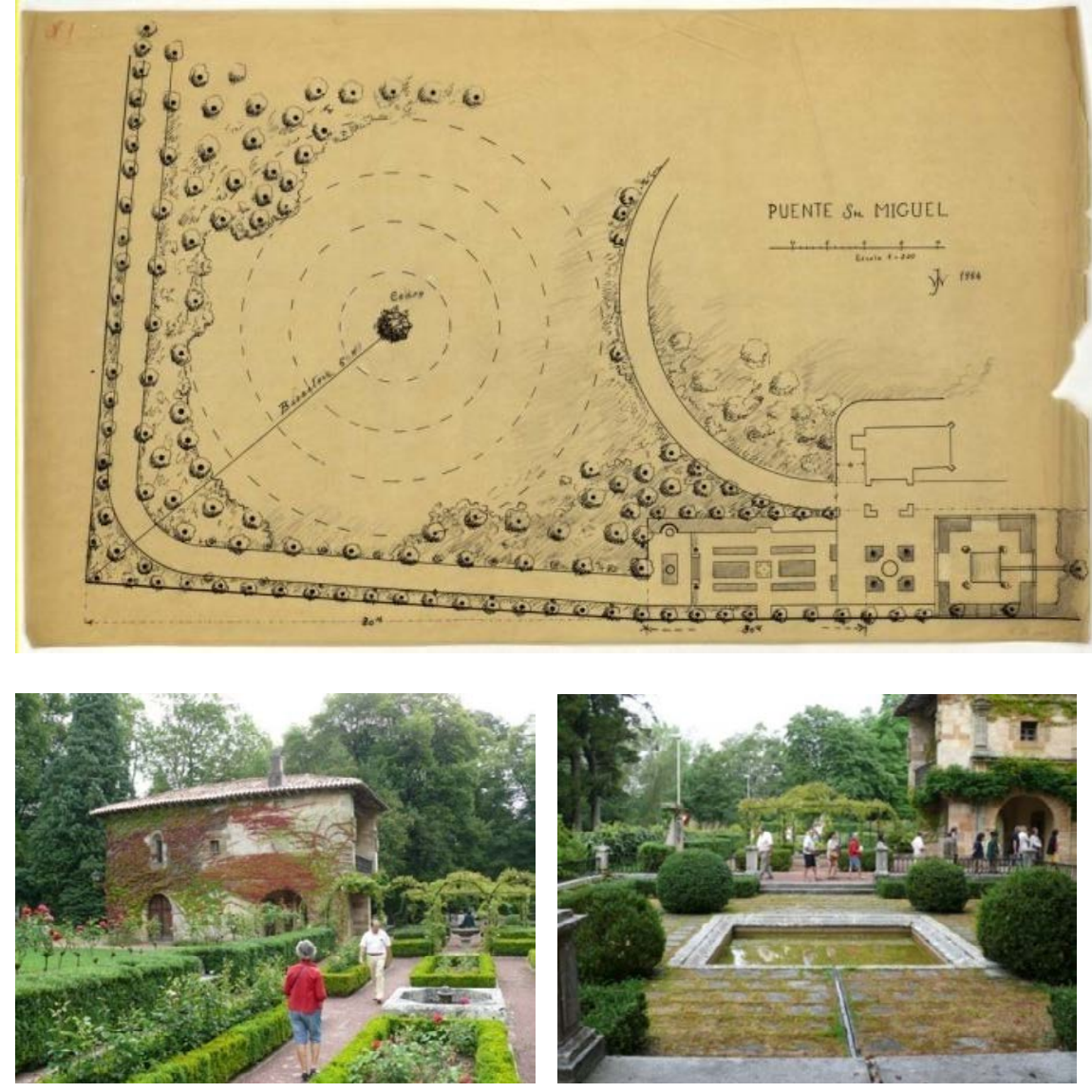

Próximo se encuentra el monumento mandado construir por Emilio Botín Sanz de Sautuola en memoria de su abuelo, Marcelino Sanz de Sautuola, y su madre, María, descubridores de las Cuevas de Altamira, obra de La Herrán. Fuera de las tapias, complementa el conjunto una pequeña capilla, diseñada por Fernando Chueca y en cuya cripta está el mausoleo de la familia. Desde esta zona se accede al tercer área: es el jardín nuevo que surge como ampliación del jardín de Winthuysen del que se separa por una antigua tapia. Realizado por Carmen Añón en los años 1980, en homenaje al 
pintor, contiene varios espacios: el estanque de los espejos ${ }^{47}$; una larga avenida de alcornoques con un alineación a cada lado y flanqueada por abelias y rosales blancos conduce a una rosaleda circular con diseño cuatripartito y setos radioconcéntricos, especialmente dedicada a Winthuysen, rodeada de una pérgola de rosales trepadores; en su interior una celosía de hierro protege una fuente central. $Y$ un último espacio, al norte de la rosaleda, formado por un gran lago naturalista con una cascada en piedra rematada por una escultura en bronce de una niña contemplando correr las aguas, y una isla con un pabellón cenador también circular con columnas de piedra labradas del escultor montañés Ramiro Varela y conectado mediante un puente de madera ${ }^{48}$.

Finalmente una zona de huerta y grandes invernaderos donde se cultivan plantas para el propio jardín: verduras, arbustos, jóvenes árboles y flores, especialmente los nardos, predilectos del propietario ${ }^{49}$.
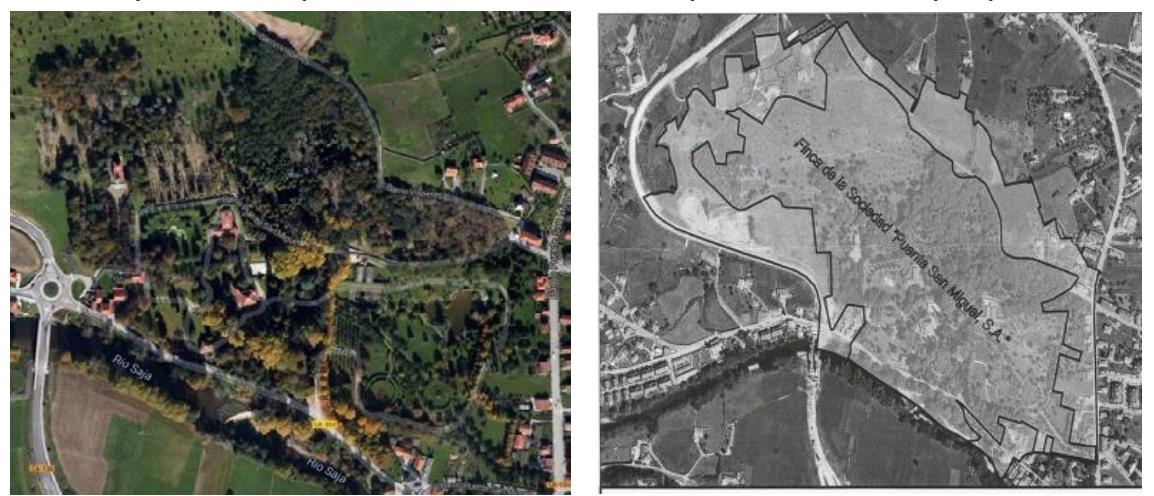

47 Está constituido por una amplia rotonda circular a la que se accede mediante un camino sinuoso limitado por seto de laurel, dispuesto alrededor de un estanque de la misma forma con nenúfares y encerrado por dos círculos concéntricos formado el más externo por altos setos de la misma especie creando un pasadizo, y el círculo interior por grandes espejos con enrejados donde crecen jazmines chinos acompañados de columnas labradas por artesanos de la zona y bancos, ambos de piedra de Boñar. Este jardín de los espejos recuerda por su planta circular y seto alto a alguna de las estancias del Jardín Musical de Sorensen, aunque los espejos, que a su vez recuerdan a obras cubistas, no están presentes en el jardín danés.

48 En la isla hay ejemplares de sauce llorón, una Gleditsia triacanthos 'sunburst' y abelias, y desde aquí hay unas espectaculares vistas de la finca. En toda esta parte nueva predominan los grandes espacios abiertos cubiertos de pradera y acotados por alineaciones de pinos piñoneros, liriodendros y liquidámbar. Hay un continuo juego de reflejos del propio jardín y su entorno, ya sea en las superficies de agua o en los propios espejos que además consiguen dar mayor sensación de amplitud. Los bancos dispersos por el jardín son del mismo escultor montañés e imprimen un carácter romántico al conjunto. Este jardín nuevo recibió algunas críticas por parte de los vecinos que defendían el haber mantenido el carácter agrícola de la finca frente a este nuevo espacio ornamental.

${ }^{49}$ Declarado Bien de Interés Cultural con la categoría de Jardín Histórico en 1986. Hoy en día la finca sufre las presiones de las edificaciones colindantes y las carreteras que la circunvalan: CA-133, CA-353 y CA-136, junto con el antiguo camino Real, actualmente asfaltado. Actualmente hay conflictos ya que la propiedad quiere ampliar la categoría de BIC y su entorno de protección a las propiedades anexas adquiridas en los últimos años y los vecinos se oponen.
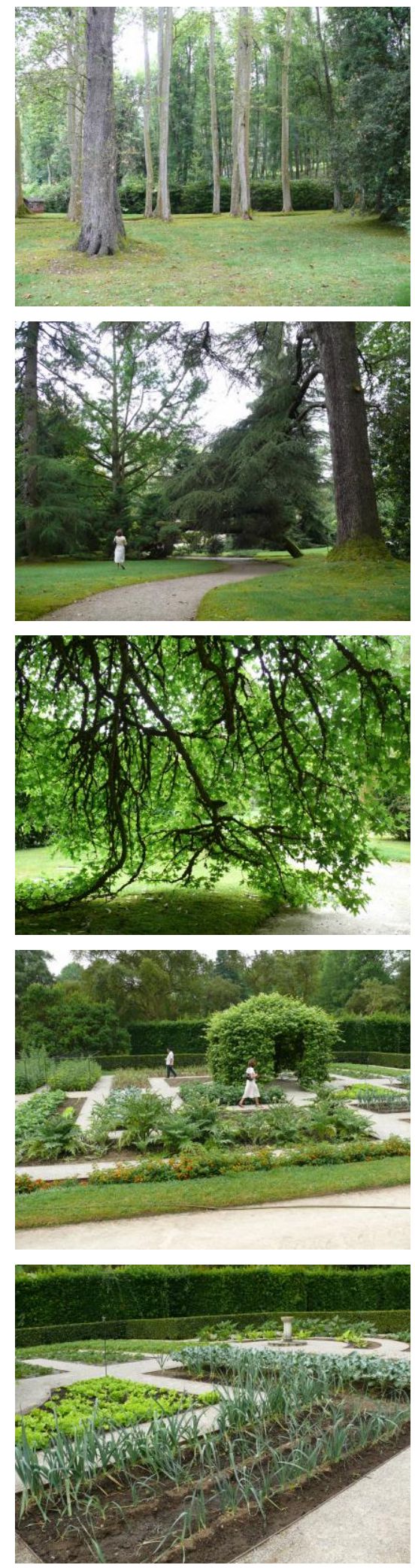

6.42 Zona del bosque y de la huerta. PHL, julio 2013.

6.43 Vista aérea actual y zona de ampliación del entorno de protección de la finca Puente San Miguel. Googlemaps y tanea-arqueología.com. 

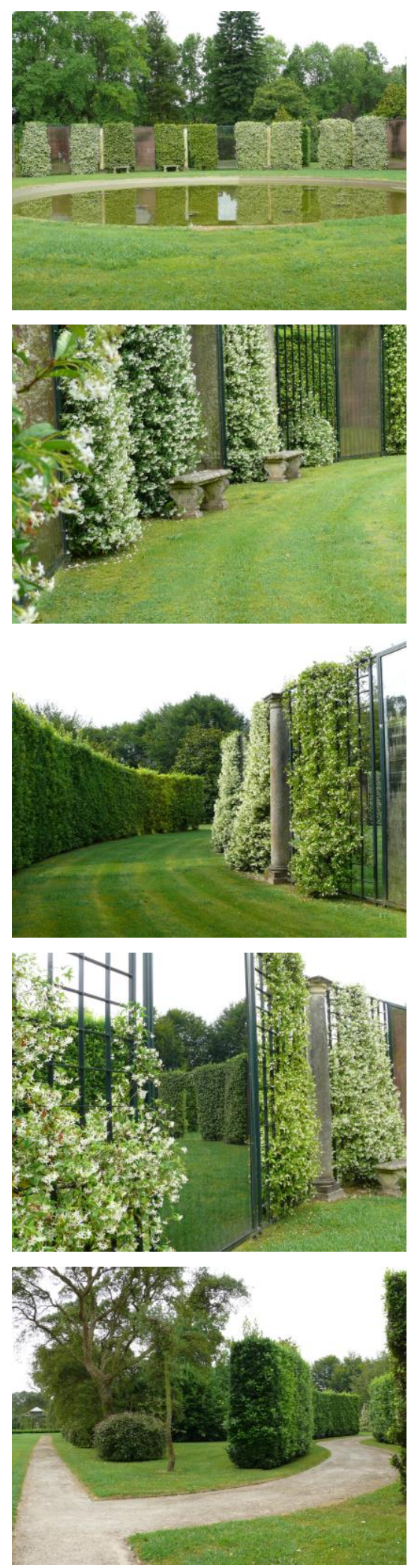

6.46 Zona del estanque de los espejos: estanque circular, espejos, enrejados con jazmines, columnas labradas, bancos de piedra y seto de laurel Carmen Añón, 1980. PHL, julio 2013.
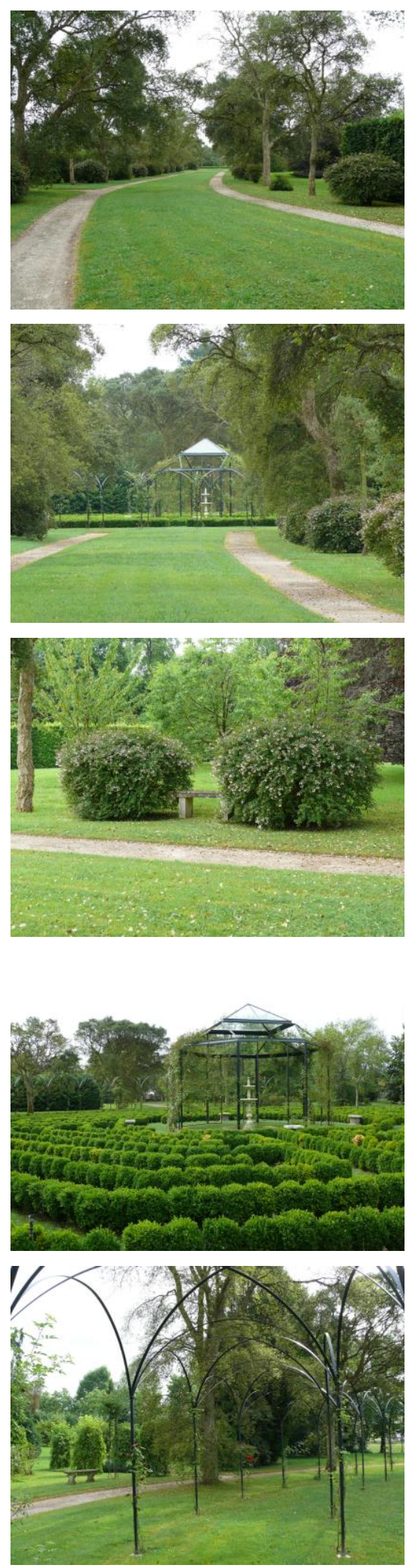

6.44 Zona de la rosaleda: acceso por la avenida de los alcornoques, abelias flanqueando los bancos, setos radioconcéntricos, fuente central y celosía de hierro. Carmen Añón, 1980. PHL, julio 2013.
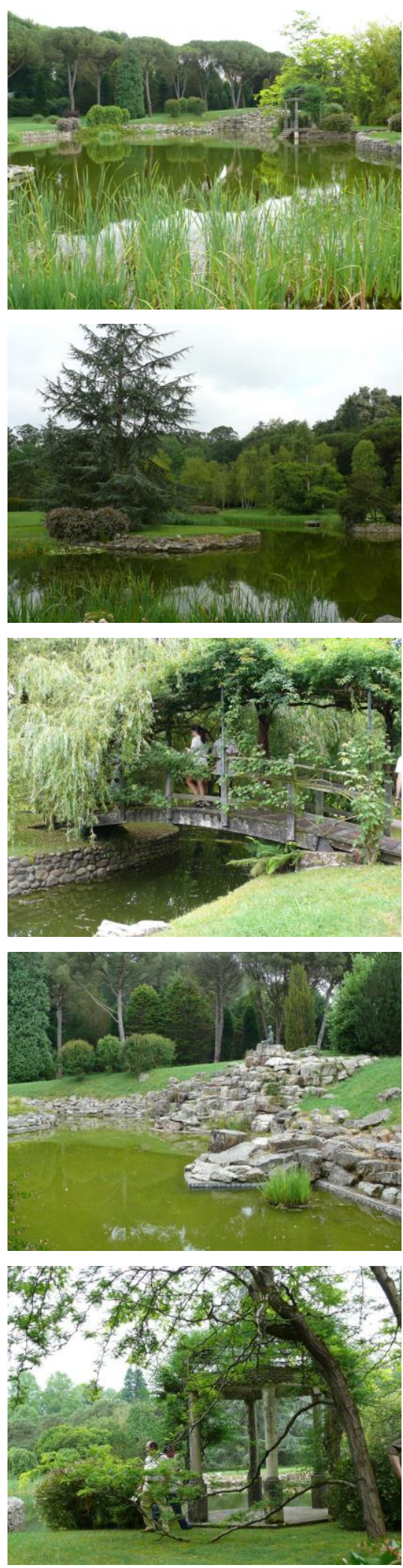

6.45 Zona del lago: isla, puente, cascada con escultura y cenador. Carmen Añón, 1980. PHL, julio 2013. 


\section{Jardines urbanos}

Winthuysen es un defensor de la creación de nuevos jardines como medio para armonizar los aspectos antiguos y modernos de la ciudad. Se opone a la eliminación de la vegetación acusada de ocultar el valor arquitectónico de las edificaciones históricas; defiende que se creen rincones sugerentes y duda de la exacta delimitación de las zonas ajardinadas del urbanismo moderno: “...En el aspecto general de las ciudades en que ha de prevalecer la dualidad de carácter por las reformas sucesivas, la jardinería juega un papel de armonización y transforma ciertos aspectos. Unida su nota de color a las viejas construcciones cambia el sentido de su ambiente, y así obras del pasado, que disonaban dentro de la modernidad, se funden al concepto actual de la vida..." ${ }^{50}$.

Consciente de la importancia y valor social de los espacios verdes, escribe varios artículos en la prensa sobre jardinería y planificación urbana -cinturón verde madrileño, Plan General del 29, Vistillas, Recoletos, etc.-, y temas más concretos como la defensa del arbolado - plantaciones, podas, etc.-, por lo que el Ayuntamiento de Madrid le encarga un estudio sobre los espacios libres para la "Memoria sobre la Ciudad" 51 . Este documento es uno de los pasos principales en Madrid para el desarrollo del nuevo urbanismo, de donde surgió la ampliación de la Castellana y todos los trabajos de Zuazo y tantos arquitectos pioneros. El hecho de que se escogiera a Winthuysen indica mucho a su favor como teórico. Critica la mala planificación urbana, el abandono y destrucción de los espacios verdes y anima a su conservación: “...al volver encontramos que han surgido agrupaciones de hotelitos rodeados del pequeño jardín que la verja limita... y difícil nos sería apreciar en cuál de ellos nos hallamos. Tan anodinos son todos que no podríamos señalar la diferencia entre ellos y tampoco podríamos establecerla entre sus calles ni aún entre sus particulares edificaciones. /.../ La importancia mundial del urbanismo que exige por razones de higiene, expansión y estética, espacios proporcionados de verdor dentro de las ciudades, determina un resurgimiento en las obras de jardinería" 52. "Las plantaciones públicas urbanas han de armonizar

\footnotetext{
50 Javier de Winthuysen. En AA.VV.: Javier de Winthuysen. Jardinero, 1986, p. 75.

51 También trabajó en el proyecto de ajardinamiento del Museo del Prado con Victorio Macho, y en el de las Antiguas Caballerizas del Palacio Real. Ver capítulo de Actuaciones urbanas - Jardines y espacios públicos madrileños: Mercadal clasicista.

52 Javier de Winthuysen. En: AA.VV.: Javier de Winthuysen. Jardinero, 1986, p. 51.
} 


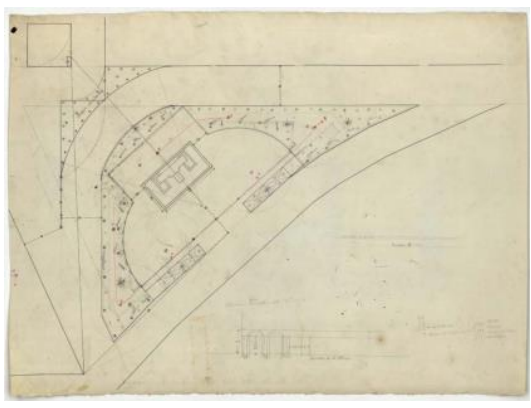

6.47 Proyecto del Monumento a Arias Miranda, Aranda del Duero. Winthuysen, 1929. ARJB, Div.IX 22,3.

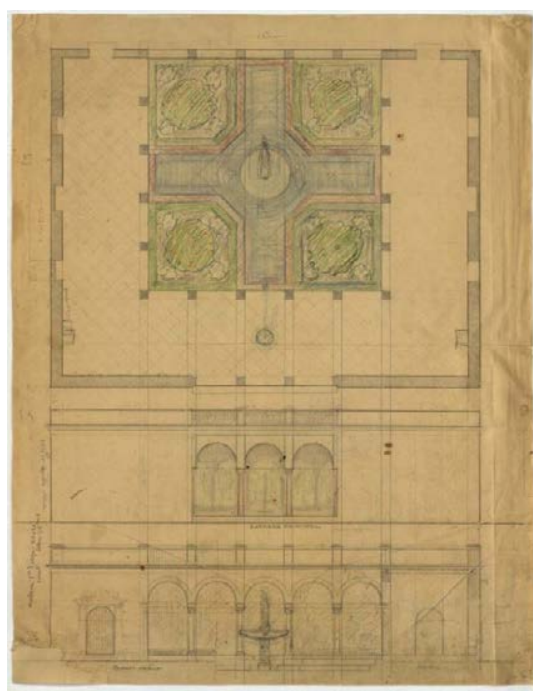

6.48 Planta, alzado y sección del Patio de los Poetas, Sevilla. Winthuysen, 1930. ARJB, Div.IX 47,2.

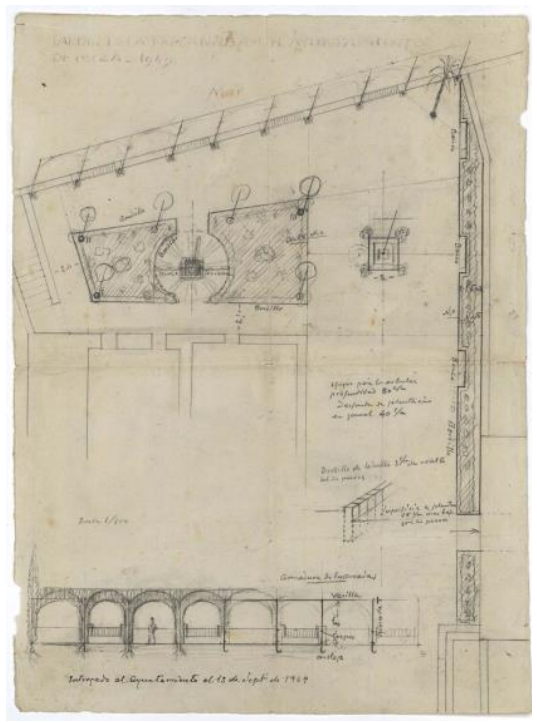

6.49 Planta y sección del jardín de la Explanada, Ibiza. Winthuysen, 1940. ARJB, Div.IX 57,1. con las construcciones, sobre todo en el arbolado de plazas y vías"53.

Sus cientos de artículos en diversos periódicos y revistas de la época ${ }^{54}$ serán fundamentales para sensibilizar a la población y a las administraciones públicas de la importancia de los jardines; precisamente esto corrobora lo anterior como dinamizador de estos temas en España. Denuncia el uso abusivo en las ciudades de las praderas impracticables en nuestro clima; "La jardinería, además de su misión higiénica, tiene sin duda la de recreo y ornato; pero ante la capital importancia de lo preciso, todo lo demás debe posponerse, aparte de que la estética surge, debe surgir, de un orden de razón./.../ No vamos a discutir que el verde tapiz de las praderas sea un recreo para la vista ni que las habilidades de dibujos y canastillas tengan mayor o menor encanto. Lugares apropiados existen donde pueden lucir; pero los reducidísimos espacios con que cuenta este hacinado núcleo no pueden ser tratados de modo tan irracional. Los niños pequeños, los ancianos y los mismos adultos a quienes la jornada rinde necesitan un lugar de expansión no más distante que diez minutos de marcha, y las plazas mencionadas deben ser para el vecindario, no para el jardinero. / Para la frescura basta el árbol. El árbol a propósito y de propósito emplazado para dar sombra sin quitar aire ni servir de estorbo. Las pérgolas o emparrados, los surtidores, completan la obra. $Y$ no es necesario ser un mago para disponer una plaza con plantas menores en torno que aíslen del polvo y bulla del tráfico y escoger especies arbóreas suficientes para que, elegida orientación, sombreen en proyecciones diagonales sin ahogar el conjunto, y bancos, muchos bancos, todo el contorno de bancos y todo el centro libre de estorbos. Las fuentes, accesibles, no, como ahora, defendidas por plantaciones en torno. / Se habla ahora de piscinas, hasta de playas, duchas, columpios, etc., etc. Muy bien: eso y más se necesita; pero lo primero que hace falta es poder respirar; poder moverse al aire libre y poder sentarse; y en cuanto a detalles del momento, sin tantas historias, un par de carradas de arena cuestan menos que mantener (pongo por preciosidad) el bordado de la puerta de Alcalá, que pugna con su severo y noble clasicismo. /.../

\footnotetext{
53 WINTHUYSEN, J: “El jardín y la Naturaleza”, España Forestal, octubre 1927. En: Jardines de España (1870-1936), 1999, p. 276.

54 Periódicos como: Crisol, Luz, La Voz y el Diario de Madrid; y revistas como: Arquitectura, La Esfera, La Estampa, Arriba, Revista de Obras Públicas y Revista Española de Arte.
} 
Los técnicos municipales de higiene y arquitectura son quienes tienen que dictaminar en este problema de urbanismo, que no admite dilación, que en todo el mundo está resuelto y que aquí tratamos como si viviéramos en otro planeta" 55 .

Esto demuestra su inteligencia y buen hacer. Comprende perfectamente la adaptación al clima español y cómo se han de solucionar compositivamente el control del impacto medioambiental. Demuestra estar bastante al día en las necesidades de la ciudad moderna y manejar los criterios funcionales básicos aplicados a la jardinería, lejos de los ornamentales decimonónicos; preludia por tanto aspectos que reaparecerán más tarde, tras la guerra civil.

Participa en varios concursos urbanos e interviene en algunos proyectos. Se ayuda de la jardinería para ordenar los espacios urbanos, cuidando las vistas y perspectivas desde la calle. Utiliza los elementos vegetales para crear un marco o fondo urbano adecuado a los edificios o esculturas. Este es el caso del proyecto de jardín a Valera (Madrid, 1925) ${ }^{56}$, monumento a Arias de Miranda (Aranda del Duero, 1929), proyecto para el Patio de los Poetas (Sevilla, 1930), concurso para los jardines de las antiguas caballerizas (Madrid, 1935) y concurso para los jardines del Museo del Prado (Madrid, 1935) ${ }^{57}$, La Explanada (Ibiza, h.1940), etc.

Winthuysen considera los parques públicos y los jardines como obras de arte de disfrute común necesarias para las ciudades. Los parques creados en la democracia para el solaz público permiten al hombre respirar en plena naturaleza dentro de las ciudades gozando de todos sus beneficios: "El jardín de la ciudad es la remembranza de los campos; es el lazo que nos une a la naturaleza"58. Se aprecia la influencia de Olmsted y la de César Cort que ya había empezado a introducir en España estos conceptos. "Aparte de la trascendencia social que tienen los parques y jardines

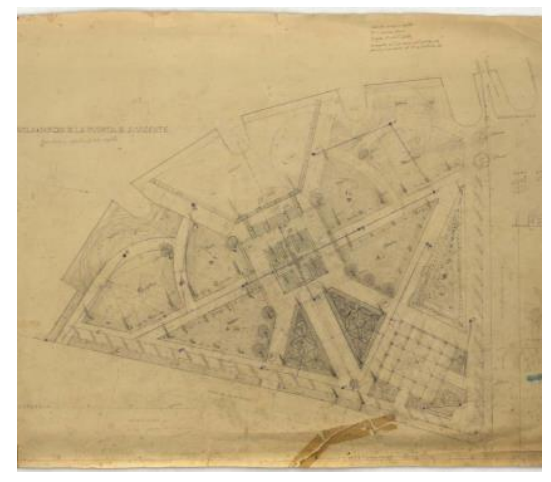

6.50 Planta del jardín de la Puerta de S. Vicente en Ávila. Winthuysen, 1934. ARJB, Div.IX 36, 1.

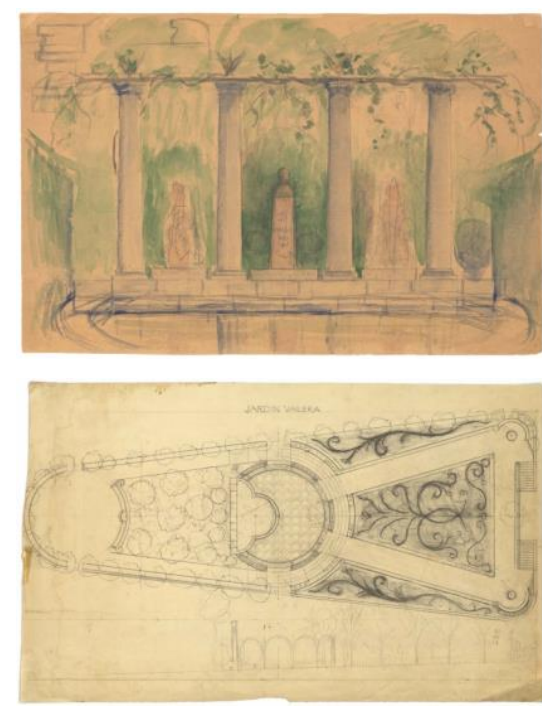

6.51 Boceto y planta del jardín del monumento a Valera en la Plaza de Santo Domingo. Winthuysen, 1925. ARJB, Div.IX 12, 3-4.

\footnotetext{
55 WINTHUYSEN, J.: Los espacios libres de Madrid. Un problema que por humanidad no admite dilaciones. La Voz, 1 de septiembre de 1930. En: AA.VV.: Javier de Winthuysen. Jardinero, 1986, p. 170.

56 Ver capítulo Jardines urbanos y espacios públicos madrileños: Mercadal clasicista Jardines de plazas urbanas.

57 Ver capítulo Jardines urbanos y espacios públicos madrileños: Mercadal clasicista Reforma del jardín del Museo del Prado.

58 WINTHUYSEN, J.: Arquitectura paisajista. Arquitectura no 105, 1928, p. 62.
} 


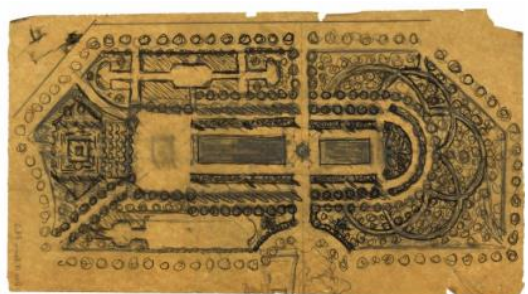

6.52 Boceto de la planta del parque de Huesca. Planta del parque en Huesca. Winthuysen, 1929. ARJB, Div.IX 21, 2-3.

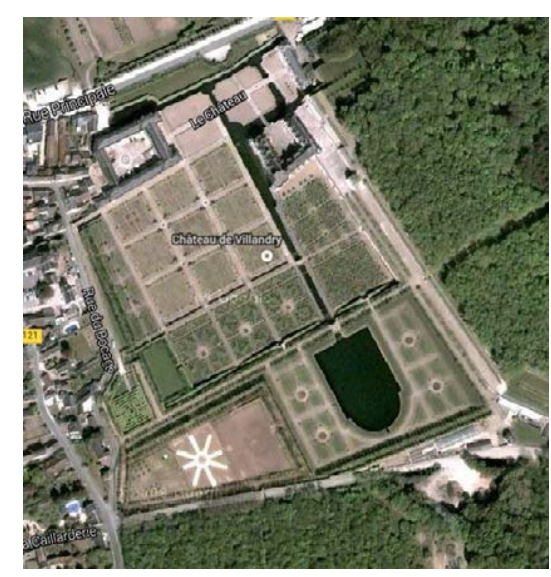

6.53 Vista aérea de los jardines del Château de Villandry, Tours, Francia. Googlemaps.
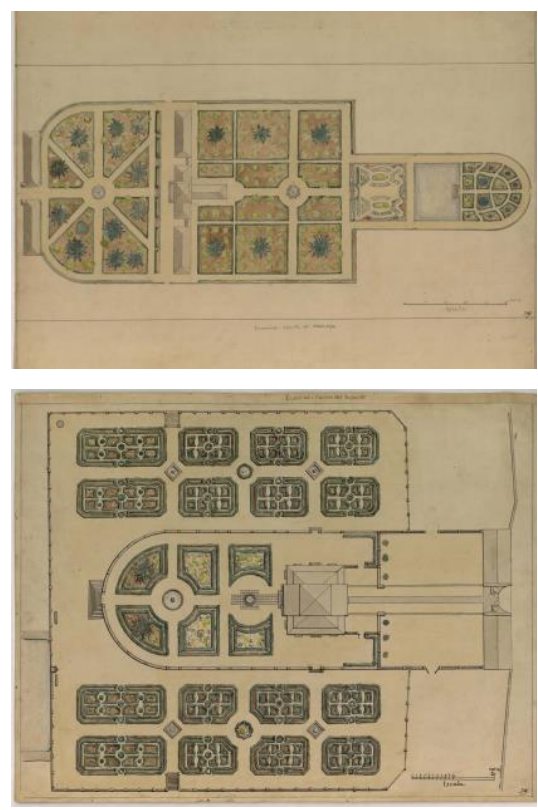

6.54 Plano del jardín de la Casita del Príncipe en el Escorial y plano del jardín del Casino del Infante. Winthuysen, 1930. ARJB, Div.IX 66, 82-83.

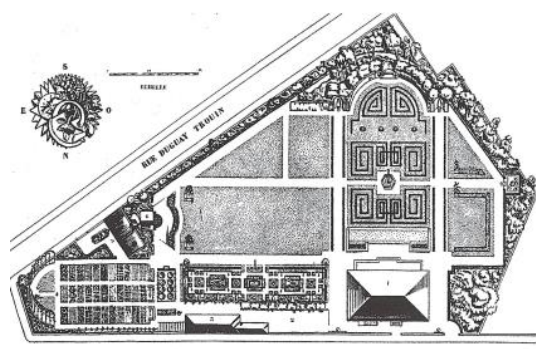

6.55 Jardín en Saint-Germain-en-Laye. André y Paul Vera, 1920. ÁLVAREZ, 2007, p.98. como expansión pública y relación con las ordenaciones urbanas, no es menor la que representan obras de arte" ${ }^{29}$.

Winthuysen defiende que para conseguir estos parques necesarios para el disfrute público no se deberían utilizar modelos ajenos a ellos, como sucede en España con los grandes parques a la andaluza, con pequeños espacios a otra escala; "tan sólo es esto posible subdividiendo el terreno en numerosos y pequeños jardines, aislados unos de otros. $Y$ téngase en cuenta que al quitar al jardín andaluz las altas tapias que lo limitan, se le quita parte considerable de su fragancia e intimidad, y de ello sufren" ${ }^{\prime 60}$.

En el proyecto para un parque público en Huesca (1929) la composición geométrica tiene un gran eje longitudinal que conecta los diferentes estanques y fuentes, flanqueados por parterres bordeados con seto y un arbusto central recortado, y en una banda más exterior aparece una alineación de chopos que enmarca las vistas. El eje se remata por una fuente circular rodeada de parterres con la misma forma, y un estanque semicircular rodeado de un seto en el que se recortan arcos vegetales y unos parterres que juegan con similares formas entrelazadas. La vegetación arbolada más densa se reparte en el perímetro y se crean verdaderas estancias dentro de la masa vegetal. Un eje transversal conecta con la rotonda de acceso principal. Entre la vegetación destacan los plátanos, olmos, coníferas, romero, rosales, membrillos, etc. ${ }^{61}$

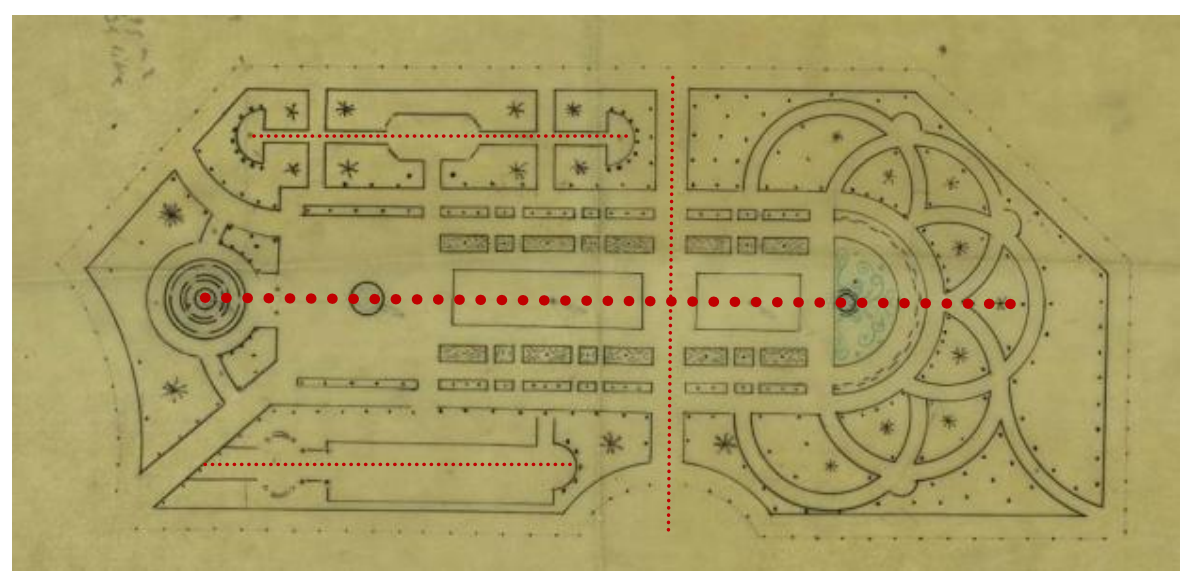

59 WINTHUYSEN, J.: Nuestros jardines históricos deben ser considerados como monumentos. Crisol de Madrid, 4 de junio de 1931. En AA.VV.: Javier de Winthuysen. Jardinero, 1986, p. 173.

${ }^{60}$ R.: “Ingreso”. En Arquitectura, no 39, julio, 1922, p. 279.

${ }^{61}$ AA.VV.: Javier de Winthuysen. Jardinero, 1986, p. 77. 


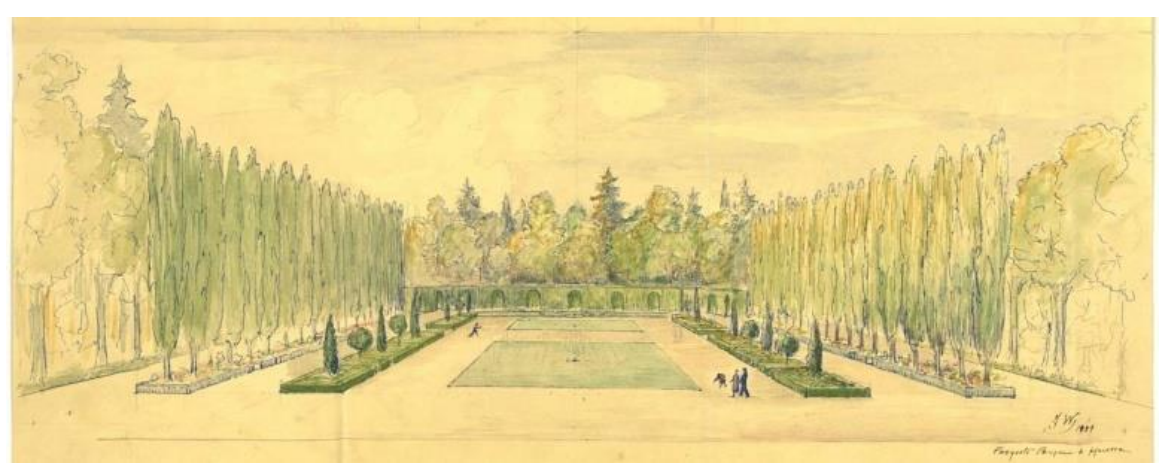

Recuerda a los parques de Forestier que provienen del esquema clásico francés de zona abierta central con parterres y elementos acuáticos y laterales de bosquetes con salas excavadas y arboledas extremas. Guarda también cierta relación con los parterres clasicistas y la exedra de Villandry y los dibujos geométricos de los parterres recuerdan los diseños mudéjares. La exedra semicircular cuenta con muchas referencias clásicas -como los hipódromos de Plinio el Joven, las exedras renacentistas italianas y francesas, o la Casita del Príncipe o de Abajo de El Escorial-, constituyendo un dispositivo de adaptación del jardín formal al paisaje exterior ${ }^{62}$. En el caso del parque de Huesca la forma semicircular aprovecha para pasar del jardín más formal a la zona con arbolado más denso que hace de telón de fondo de la perspectiva del gran eje longitudinal. El esquema tripartito con un eje principal y otros dos laterales menores que se esboza en el parque de Huesca podría guardar relación con el esquema de la Casita del Infante o de Arriba de El Escorial y que también estudia Winthuysen. Esta obra contrasta con los ejemplos que estaban realizando los hermanos Vera en ese momento con una fuerte geometrización de todos los elementos parterres con grecas geométricas $y$ bosquetes recortados- $y$ ausencia total de formas ornamentales, más alejados de los principios del jardín clásico, y más próximos a los jardines del Movimiento Moderno.

Este trazado con fuertes ejes de simetría que ordenan la composición y con un área central en la que se colocan los elementos acuáticos (estanques, fuentes, surtidores) distribuidos a lo largo del eje longitudinal que se remata con formas circulares y se rodea de sucesivas bandas de vegetación con setos y alineaciones es un esquema que se repite en otras de sus composiciones como el jardín de la residencia de los Srs. Arranz

62 SANZ HERNANDO, A.: El jardín clásico madrileños y los Reales Sitios. Madrid: Ayuntamiento de Madrid, 2009, p.399.
6.56 Proyecto de un Parque en Huesca. Winthuysen, 1929. ARJB, Div.IX 21, 1.
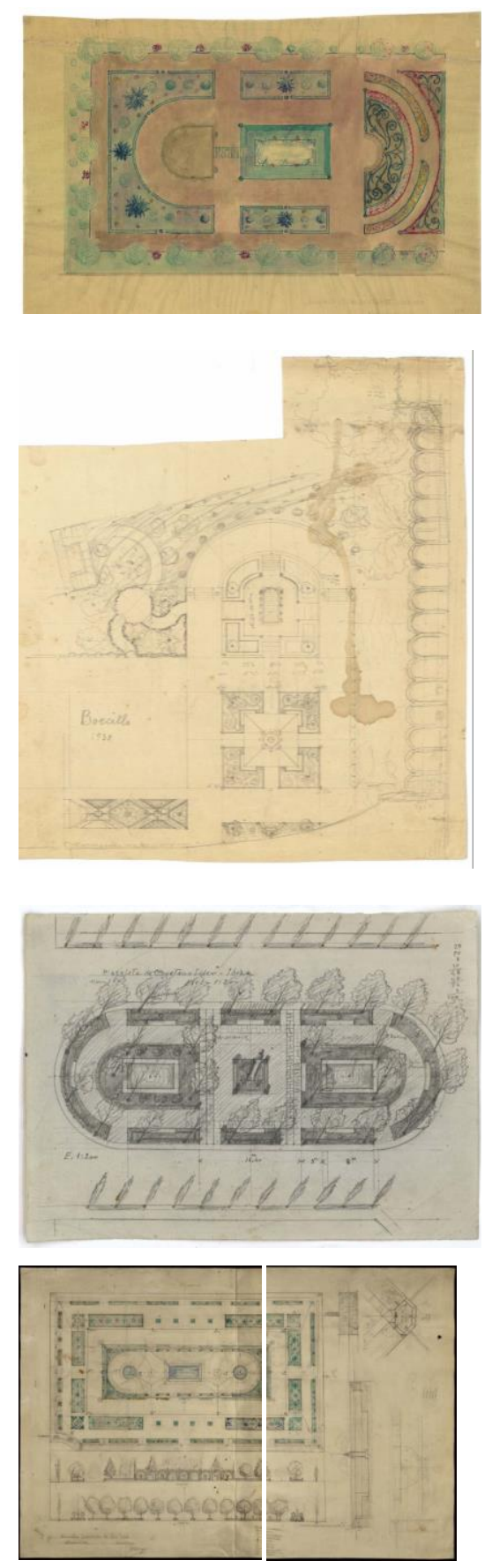

6.57 Residencia de los Srs. Arranz Adrada, Madrid, h.1920. Planta del Jardín de Boecillo, Valladolid, 1930. Perspectiva axonométrica del jardín de la Plaza de Cayetano Soler, Ibiza, 194?-1950. Proyecto del jardín de las Escuelas Salesianas de San José de Zamora, 1951 Winthuysen. ARJB, Div.IX 24,1; 18,9; 56,1; 61,5 . 

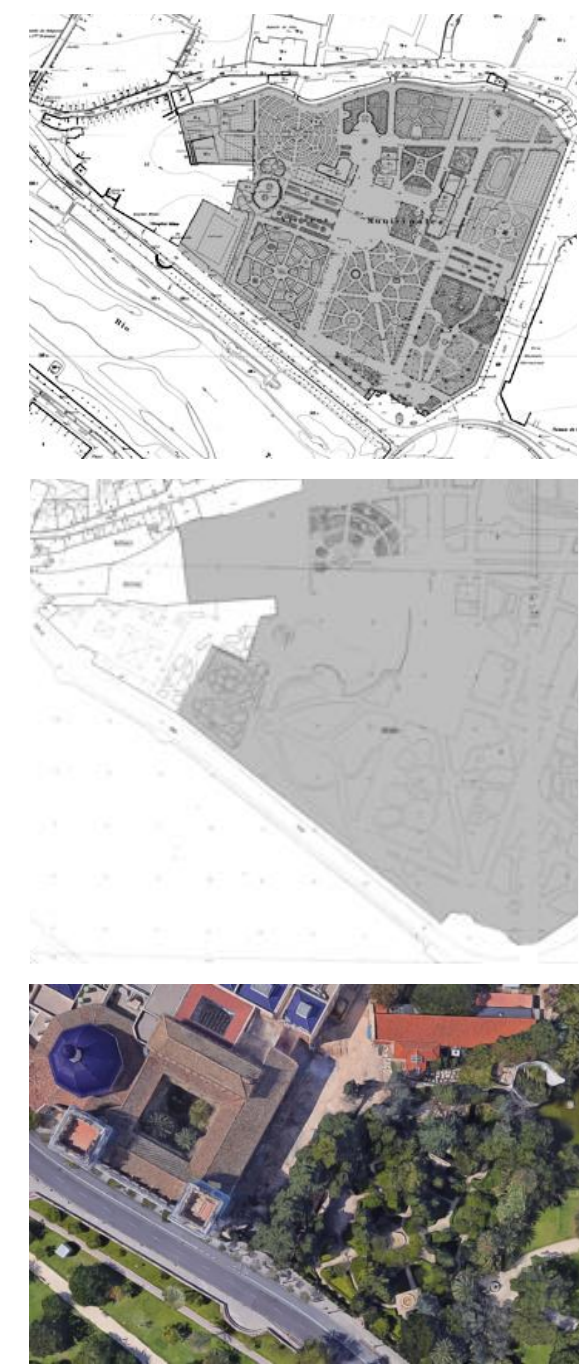

6.58 Jardín de Viveros o del Real: cartográfico municipal 1929-1945, cartográfico C.G.C.C.T 1980 y vista aérea actual. Ayuntamiento de Valencia. Googlemaps.

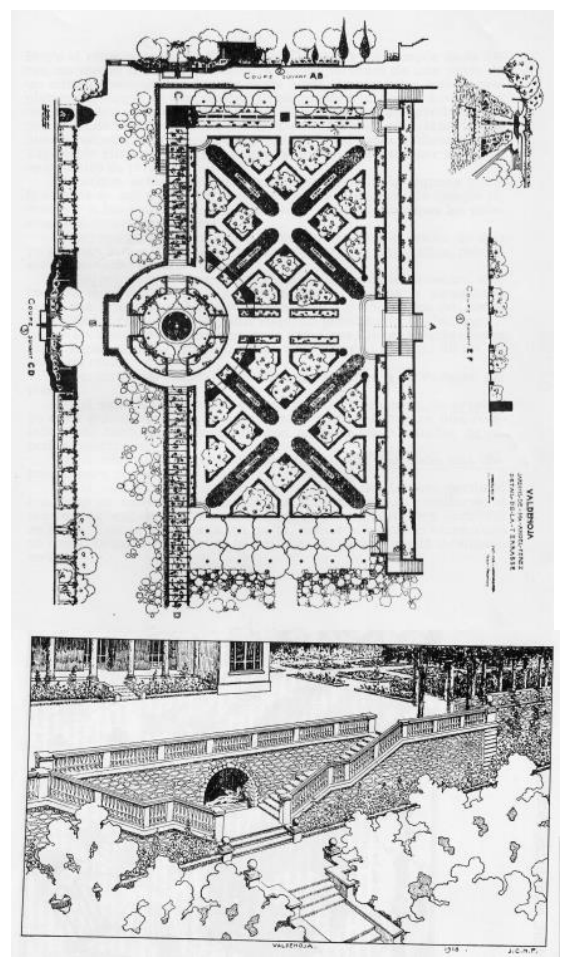

6.59 Parterre de Valdenoja para D. Ángel Pérez en Santander. Forestier, 1919. FORESTIER, 1985, p. 177.

Adrada (Madrid, h.1920), el jardín del Boecillo (Valladolid, 1930), la Plaza de Cayetano Soler (Ibiza, 1950) o los jardines de las Escuelas Salesianas de San José (1949-1951) en Zamora. Actualmente estas Escuelas son un centro de Formación Profesional e Ingeniería Técnica cuyos jardines conservan bastante bien su estructura original: “...en esencia, queda como lo tracé y aún mejorado"63; a pesar de algunos desperfectos, marras y desaparición de las arcadas de cipreses originales, explica Winthuysen.

A Winthuysen se le atribuye también la intervención en el valenciano jardín de Viveros o antiguos jardines del Real que inician su transformación en parque público a principios del siglo $\mathrm{XX}$. Deben su nombre a la cercana Huerta de Vivel, cedida al Ayuntamiento en 1903 para viveros de árboles. En el parque se acusa una falta de diseño global debido a la adquisición de la finca en distintas fases originando espacios con gran variedad de estilos que se van adaptando a las necesidades de ocio y culturales de la ciudad. Winthuysen realizó un pequeño y sencillo jardín en forma de cruz $^{64}$, contiguo al Museo S. Pío V, al que se accede por la portada de 1697 . El jardín realizado en $1952^{65}$, aún conserva su trazado y parte de la vegetación, con alusiones a los jardines musulmanes que recuerdan el origen de este antiguo Generalife valenciano -cítricos, fuente baja...-.

El proyecto del parque de Valdenoja en Santander (1930) ya le permite aproximarse a los problemas de la gran escala y a preocuparse por temas de paisaje como: perspectivas, vistas, miradores, accesibilidad, conexiones, etc. Todo ello le valdrá para ser considerado como uno de los primeros paisajistas españoles de su generación.

Este jardín se sitúa en un lugar privilegiado del Cabo Menor con vistas sobre la playa de Mataleñas y el mar Cantábrico, al norte del municipio de Santander en la localidad de Cueto. Se realizó sobre la finca de Ángel Pérez de Eizaguirre, importante armador y naviero. J.C.N. Forestier realizó un proyecto previo en 1919 del que se conservan dos planos. Se trata de un "parterre de flores (plantas

\footnotetext{
${ }^{63}$ WINTHUYSEN, J.: Memorias de un Señorito Sevillano. 1942. Nueva Edición. HÉCTOR VÁZQUEZ, 2005, p.262.

64 Guía de jardines históricos y parques urbanos de la ciudad de Valencia. Valencia: Ayuntamiento de Valencia, 2009, p. 31 y 71.

65 Jardines del Real/Viveros. Catálogo de Bienes y espacios protegidos. Revisión simplificada del Plan General de Valencia. Ayuntamiento de Valencia, 2010, p.2. www.valencia.es (Consultado 5-4-2016).
} 
herbáceas y arbustos), organizado en arriates, ha sido de entrada planteado como una rosaleda. Las avenidas están embaldosadas. Cada compartimiento está ribeteado con boj, boneteros o mirtos" ${ }^{\prime 66}$, como explica el propio Forestier, quien manifiesta su voluntad de asimilarse al carácter norteño en la utilización de la piedra y la pradera ${ }^{67}$.

En 1930 interviene Winthuysen que no sólo se centra en la zona próxima a la casa, situada en el centro de una pradera, sino que estudia el conjunto de la finca. En los planos diseña el acceso a través de una avenida que recorre el paisaje. Estudia las masas de arbolado y las vistas sobre la ensenada de Mataleñas y el faro. “...Debajo de la pradera se ve el lago rodeado de una faja de $6 \mathrm{~m}$ de anchura completamente plana y de ray gras para hacer el tapiz perfectamente practicable. Bordeando el lago y su isla de especies apropiadas, en esta composición destaca sobre la ladera el pinar existente y árboles aislados de los que escogemos especies de tonos claros y alegres... /.../ Desde la calzada o balcón del lago y antes de las rampas, parte un paso de piedras para rodaje que buscando los niveles por una doble curva puede conducir los coches hasta el porche del edificio, y entre dichas curvas, y otra superior lindante con el bosque se desarrollarían grandes masas de color que exaltarían el blanco del edificio ante el cual, queda la pradera libre y descendente para dejar la vista de la Bahía..." ${ }^{68}$.

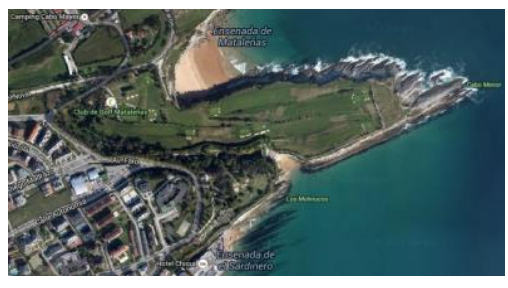

6.60 Vista aérea actual de la zona. Googlemaps.

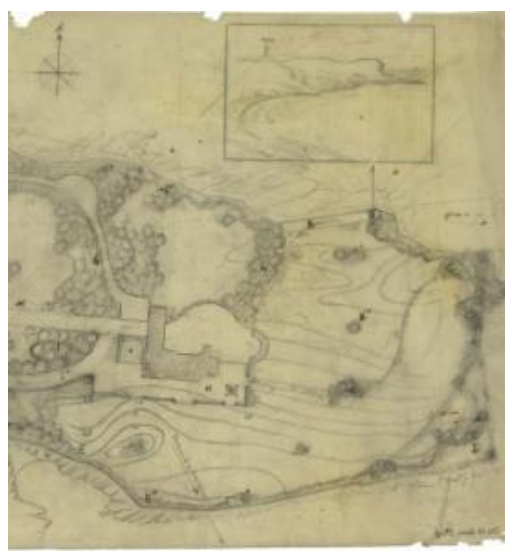

6.61 Planta del jardín del Parque de Valdenoja dibujado sobre un mapa topográfico. Winthuysen, 1931. Se ve la vista sobre la ensenada y el faro. ARJB, Div.IX 29,6.
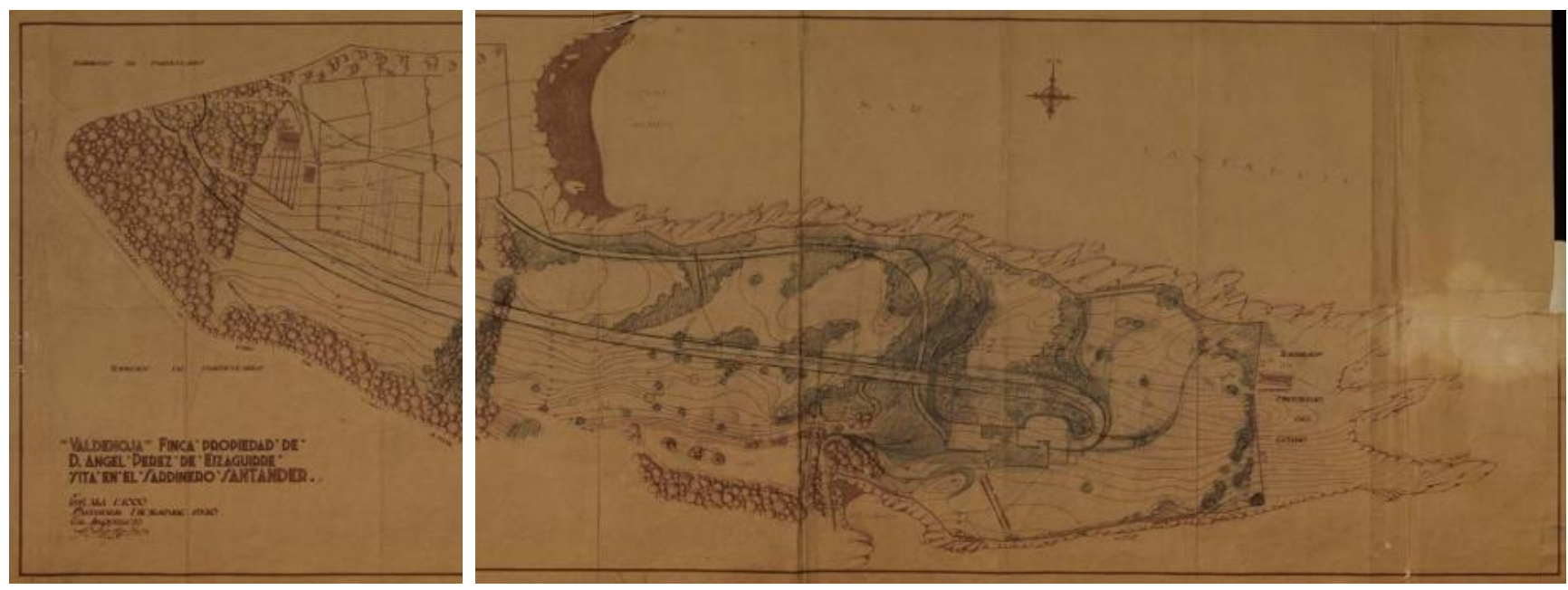

6.62 Parque de Valdenoja: copia del plano de la finca, sobrepintado a lápiz las sendas y arbolados. Winthuysen,

${ }^{66}$ FORESTIER, J.C.N.: Jardines. Cuaderno de dibujos y planos. Barcelona: Stylos, 1985, p. 1930. ARJB, Div.IX 29, 9.

${ }^{67}$ DOMínGUEZ PELÁEZ, C.: Los jardines en España, en Jean Claude Nicolas Forestier 18611930. Du jardin au paysage urbain. Paris: Picard, 1994, p. 89.

68 Javier de Winthuysen, en AA.VV.: Javier de Winthuysen. Jardinero, 1986, p. 113-114. 

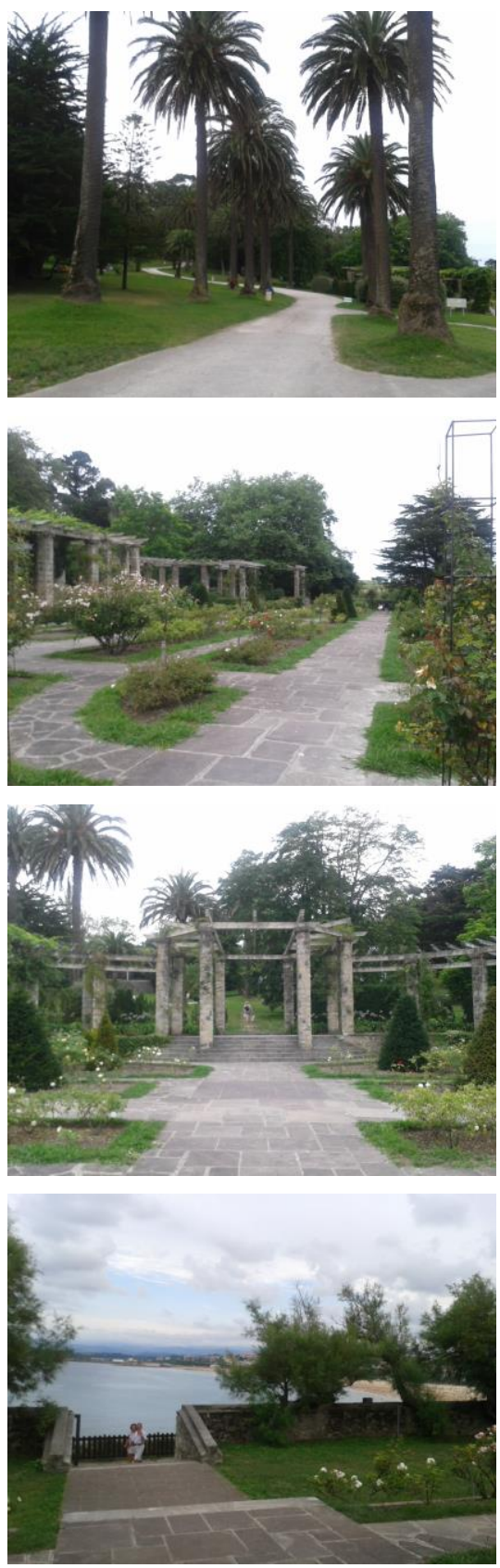

6.63 Vistas actuales del parque de Mataleñas. PHL, agosto 2013.

6.64 Planta del parque de Valdenoja, 1931. Panorámica de la finca de Valdenoja, 1930. Winthuysen. ARJB, Div.IX 29, 1 y 10.
En el plano en que se desarrolla el jardín próximo a la casa aparecen una serie de plataformas conectadas mediante escaleras y en las que se desarrollan unos parterres geométricos entre paseos. En la parte superior dibuja una piscina utilizada también para el riego. En el siguiente nivel albercas y pequeñas fuentes se van alternando rodeadas de cuadros vegetales. Unas arcadas sirven de paso a la siguiente plataforma que denomina vergel con cuatro grandes cuadros de vegetación con unas albercas en medio; separados por un pasillo aparecen otros cuatro parterres rectangulares más estrechos. En el lado oeste junto a una zona boscosa, ubica la caseta del jardinero y un umbráculo. La composición tiene dos ejes de simetría, uno parte de la piscina y el otro permite repetir la composición hacia el sureste. De todo esto tan solo se ven las huellas de algunos caminos de acceso a la finca y parte de las zonas boscosas del suroeste, ya que se ha convertido en el actual Campo de Golf Mataleñas.
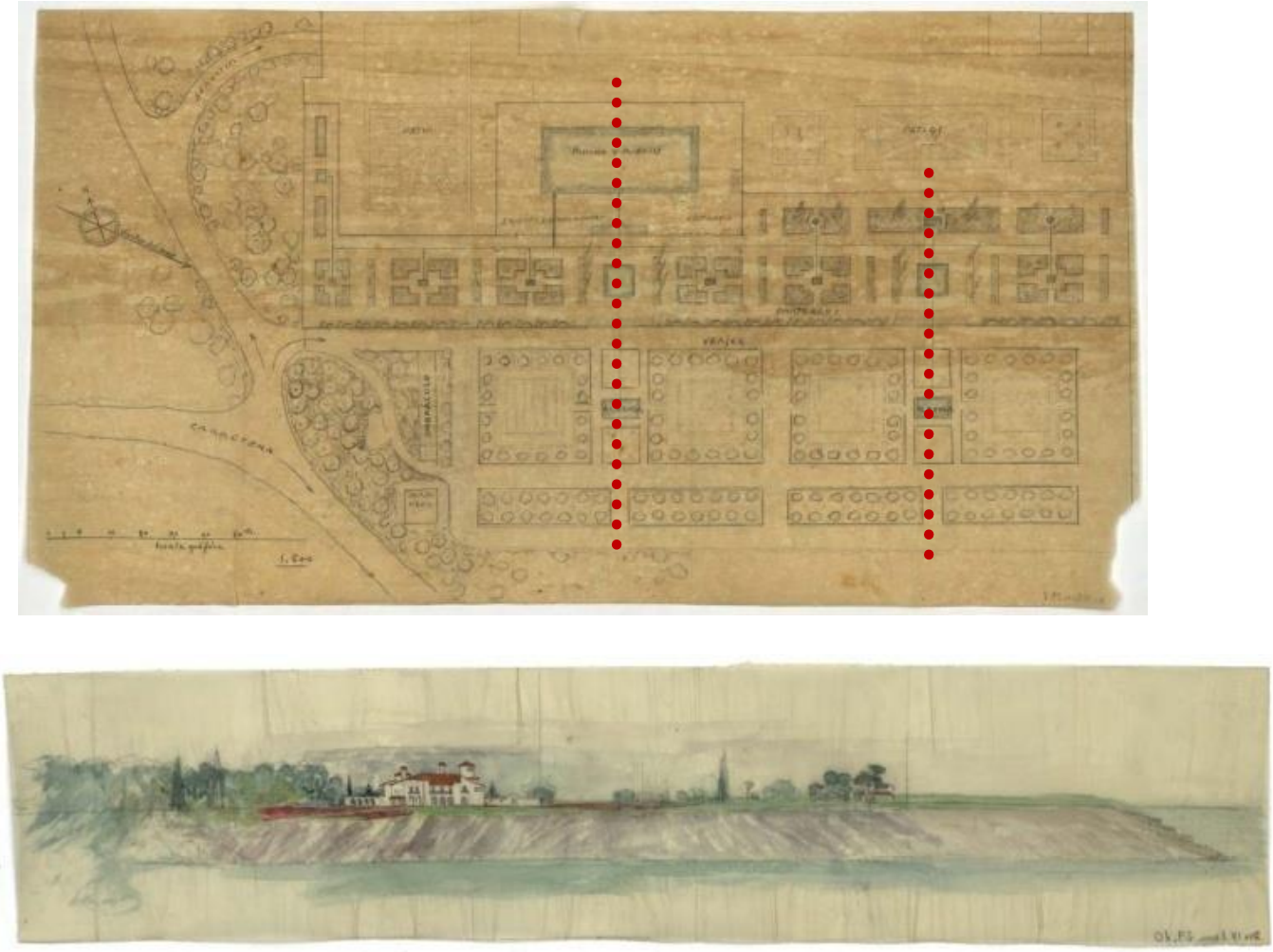

Winthuysen enmarca las vistas del paisaje con arbustos: "Macizos que cortan los vendavales del noroeste dejando entre sí, praderas que por el sentido diagonal toman extensas y variadas perspectivas, que se cierran ya con altura de grandes árboles o con cortinas más bajas de arbustos a fin de descubrir en parte el horizonte, y 
ofreciendo toda esta gran variedad y efectos distintos por las especies de arbustos y árboles empleados..." ${ }^{\prime 69}$.

Este proyecto combina la composición geométrica en el jardín junto a la casa, con una composición más irregular en el resto de la finca con masas arbóreas y sendas que se adaptan a la topografía. Muestra una clara preocupación por el paisaje circundante: potencia las mejores vistas y las enmarca con arbustos y masas arbóreas, cuida las perspectivas, dispone miradores en los sitios más adecuados, se preocupa por la accesibilidad y las conexiones entre las diferentes partes de la finca y con el exterior como la gran avenida de acceso. Hay muchas similitudes con la Laboral de Gijón -también con terrazas escalonadas que se abren al paisaje-, con el Jardín de los Frailes de El Escorial, así como claros gradientes, recursos clásicos de aterrazamiento, etc.

Del proyecto original solo se conserva la zona suroeste de acceso secundario al jardín, lo que actualmente se denomina parque de Mataleñas, de $230.000 \mathrm{~m}^{2}$ y abierto al público en $1983^{70}$.

\footnotetext{
${ }^{69}$ Ibíd., p. 113.

70 Se mantiene la explanada de acceso con el paseo de palmeras y la zona de plataformas que descienden hacia el mar a través de escalinatas que se adaptan a las praderas. También se conserva el paseo de borde que rodea la costa hasta el faro, limitado por la tapia de piedra que hace de cerramiento del parque, y que recientemente se ha acondicionado como Senda de Mataleñas. Actualmente sigue conservando algunos árboles de gran porte y su estanque con alto valor ecológico por su población de carpas y patos silvestres. Recientemente se ha añadido un circuito deportivo con máquinas para realizar ejercicios.
} 

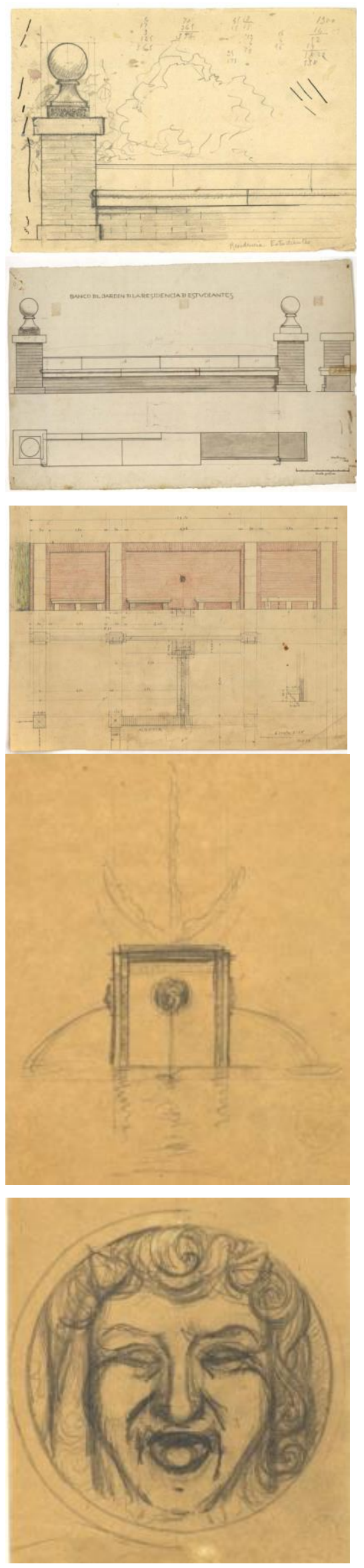

6.65 Alzado de banco y barandilla Fuente mural con bancos. Boceto de la fuente $y$ del surtidor del jardín de la Residencia de Estudiantes. Winthuysen, 1923. ARJB, Div.IX 7, 1r-4-6-7-8.

\section{Jardines de instituciones y servicios públicos}

Winthuysen recibe encargos de fundaciones, escuelas, residencias y centros de salud para diseñar sus jardines. Adapta sus diseños a las exigencias de cada centro y estudia con detenimiento cada proyecto. Estos jardines generalmente contaban con una zona de carácter representativo que se correspondía con la entrada del edificio y otras zonas de expansión con carácter más utilitario (campos deportivos, huertas, etc.) en los terrenos adyacentes. Procura que la jardinería y la arquitectura formen un conjunto armónico. En los edificios de carácter monumental donde predominaba la regularidad geométrica y la simetría armonizaban mejor los jardines geométricos regulares que los diseños sinuosos de los jardines paisajistas; sin embargo Winthuysen recurrirá a estos trazados cuando la topografía o el proyecto se lo pida. Tiene en cuenta las vistas de las fachadas de los edificios y las perspectivas del jardín desde ventanas y balcones, por lo que no pone árboles altos que las tapen cerca de los edificios de valor arquitectónico. Procura facilitar un camino recto y con una amplia perspectiva desde la entrada hacia el edificio.

A continuación se describen y analizan algunos de los jardines.

Don Alberto Jiménez Fraud, director de la Residencia de Estudiantes, la institución docente más avanzada y progresista de la época, le encargó la construcción del jardín de la Residencia (19231924). El solar, situado en el número 21 de la calle Pinar de la capital, en los Altos del Hipódromo, tiene forma triangular y su topografía plana permite un diseño geométrico con un eje y simetría en la zona del estanque principalmente. El eje se remata con una fuente mural y a través de una acequia se conduce el agua hasta un estanque cuadrado. Apoyados en el muro de la fuente y límite con la calle, aparecen varios bancos de piedra para el descanso. Los paseos ortogonales encierran espacios de plantación rectangulares o triangulares según la forma de la parcela. No se sabe si estos jardines llegaron a realizarse o se destruyeron, ya que no se conservan; lo que sí se conserva es el banco que realizó Winthuysen para su entrada junto con unos muretes y barandillas en el borde que protegía del pequeño desmonte existente en los márgenes del canalillo en su lado oeste, frente a la entrada de la residencia. Los materiales utilizados son el ladrillo y el granito. El 
banco cuenta con dos pilastras laterales coronadas por una bola de granito. Tiene una inscripción con el año de su construcción y el nombre del Duque de Alba, quien lo subvencionó ${ }^{1}$. Actualmente el jardín de entrada cuenta con un camino de acceso flanqueado por arbustos aromáticos, cuatro parterres cuadrados rodeados de seto recortado con un árbol en medio entre los edificios paralelos y el talud vegetal que desciende hacia el canalillo con recorrido nortesur, reminiscencia del canalillo del Lozoya que discurría por ese límite, y que conserva grandes ejemplares arbóreos. Destacan los castaños de indias sobre la superficie de grava de la parte delantera de los edificios. Cumple con las características antes mencionadas: regularidad geométrica y simetría en la zona del estanque, adaptación a la topografía, camino de acceso con amplia perspectiva enmarcada por la vegetación, etc.
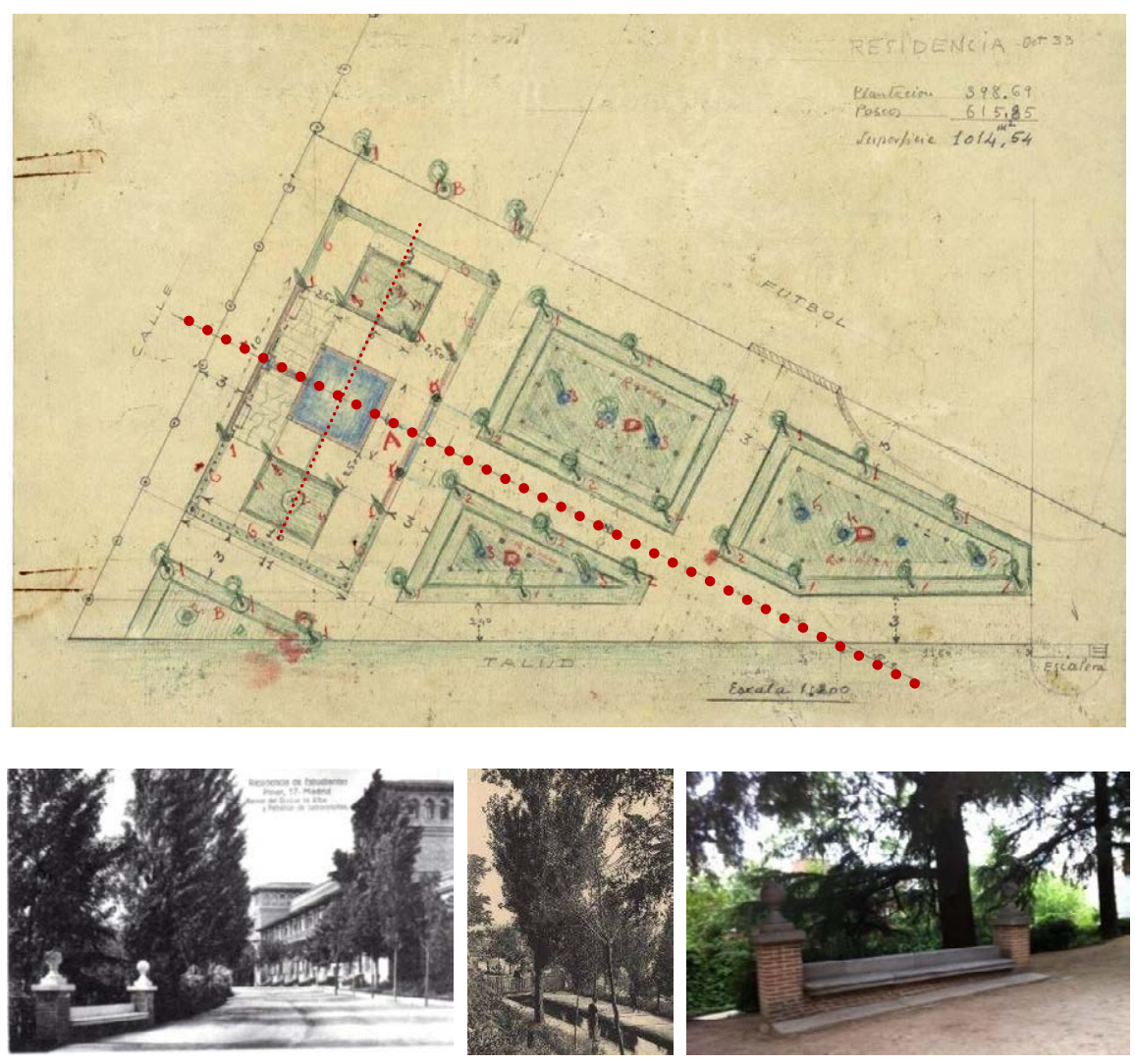

En 1887 se realizó un jardín de acceso al edificio de la primera Escuela de Ingenieros de Caminos, Canales y Puertos de Madrid, construido entre 1881 y 1882 por Mariano Carderera, arquitecto e ingeniero de Caminos y profesor de dicha Escuela, en el Cerrillo de San Blas, sobre unos terrenos segregados del Observatorio Astronómico. El jardín de estilo inglés y con una superficie de media

\footnotetext{
${ }^{1}$ AA.VV.: Javier de Winthuysen. Jardinero, 1986, p. 83-84.
}
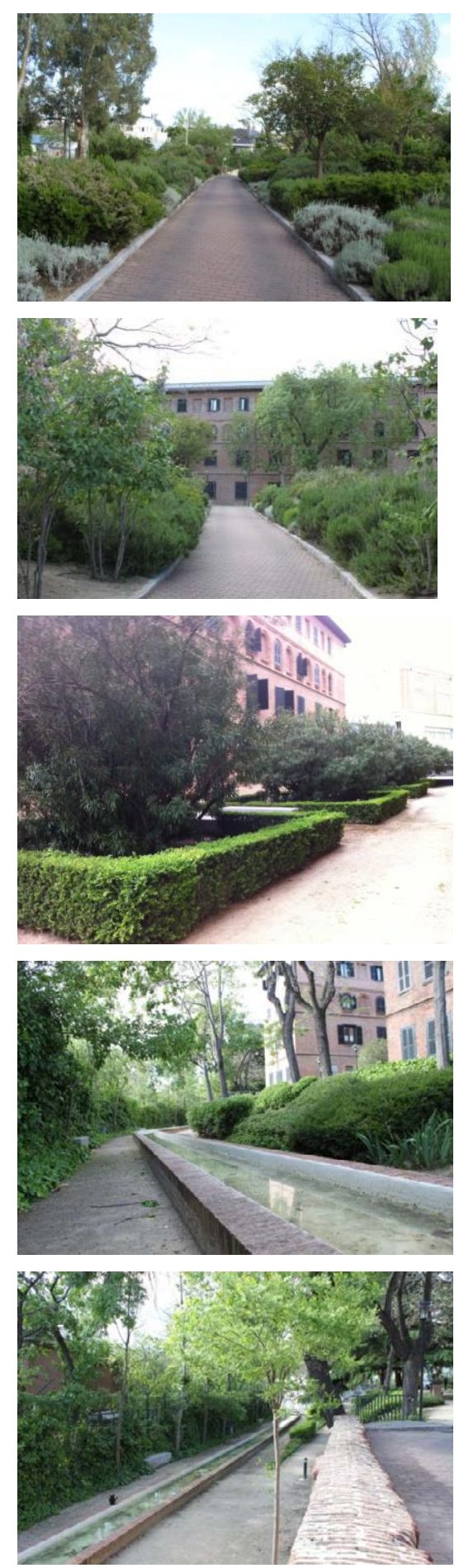

6.66 Jardín de la Residencia de Estudiantes en la actualidad. PHL, mayo 2013 y abril 2015.

6.67 Planta del jardín de la Residencia de Estudiantes. Winthuysen, 1923-1924. ARJB, Div.IX 7,2.

6.68 Banco del Duque de Alba y Pabellón de Laboratorios. Los edificios de la Residencia de Estudiantes con el pabellón Trasatlántico en el medio. AA.VV.: Javier de Winthuysen. Jardinero, 1986, p. 84. Cristina Fanjul, Diario de León. Es, 13-062004. 


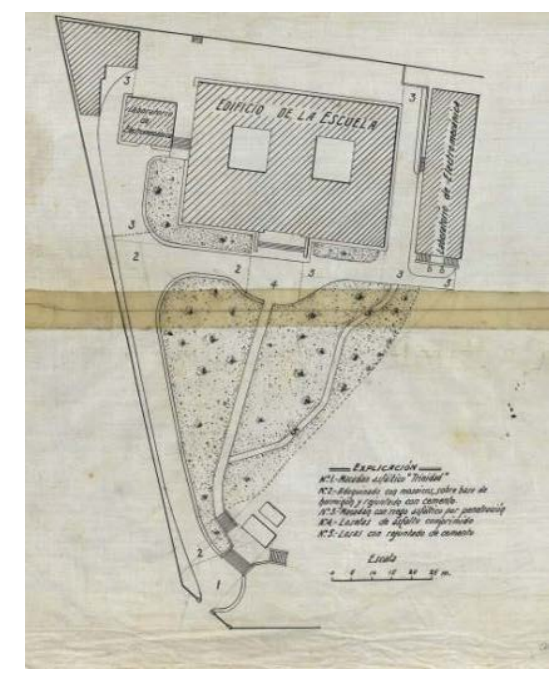

6.69 Planta del jardín de la Escuela de Caminos. Winthuysen, 1925. ARJB, Div.IX $14,1$.
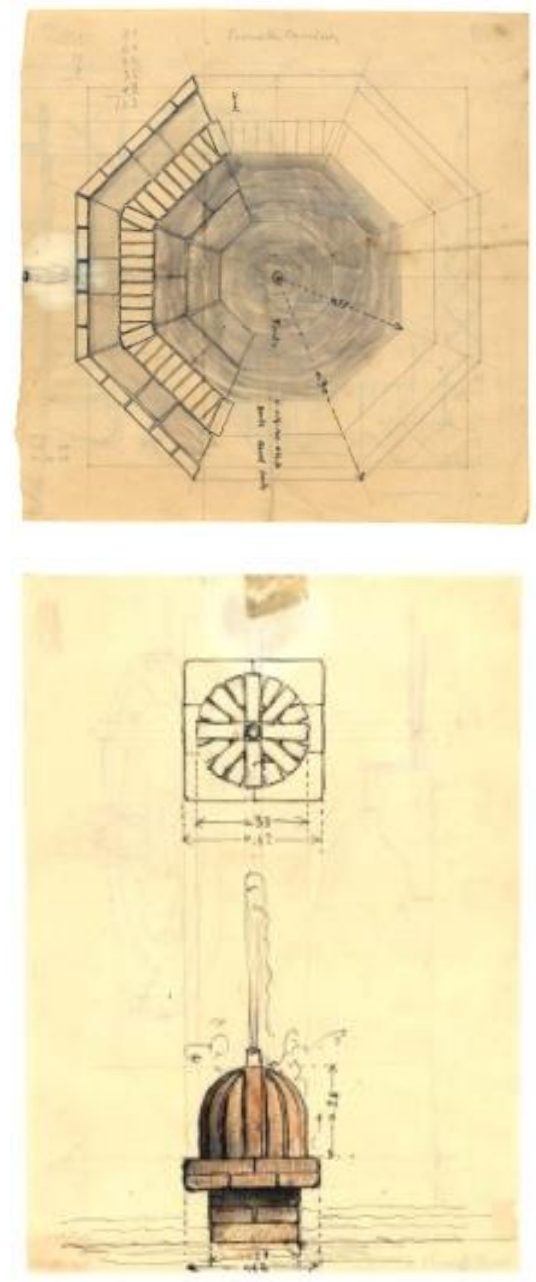

6.70 Jardín de la Escuela de Ingenieros de Caminos: planta de la fuente para la glorieta cuadrada o andaluza, y sección del surtidor de la fuente de la fuente cuadrada. Winthuysen, 1925. ARJB, Div.IX $14,6 r-7 r$. hectárea, se desarrolla en un solar triangular acorazonado con un desnivel de $10 \mathrm{~m}$ que desciende en pendiente desde la Escuela hasta la calle Alfonso XII y en cuyo vértice se sitúa la puerta de entrada, contigua a la Puerta del Ángel Caído del Parque del Retiro. Consta de un camino de carruajes, adoquinado y paralelo a la verja del paseo de Fernán Núñez, y otro peatonal, con un primer tramo de escaleras y pavimentado con losas de granito, entre una pradera con grandes coníferas (cedros, pinos y tejos) y eucaliptos ${ }^{2}$ y que desembocan en una plazoleta horizontal frente al edificio, pavimentada con macadán asfáltico. En el borde sur de la calle de carruajes se plantaron acacias de flor blanca alternadas con arces ${ }^{3}$, y el camino peatonal rectilíneo se flanqueó con alineaciones de castaños de indias y tilos formando un túnel vegetal que partía de Alfonso XII y desembocaba en el eje del edificio. En la entrada se desarrolla una pequeña plaza de $12 \mathrm{~m}$ de diámetro donde se ubica la casa del guarda a la que se accede por una escalinata central y tiene dos escaleras laterales de menor anchura que conducen a los dos caminos peatonales.

En 1925 se iniciaron unas obras de reforma que modificaron la traza, pendientes y pavimentación de los caminos de acceso. Se ensancha el camino de carruajes creando aceras y nueva pavimentación con pavimentos asfálticos; también se realizó un nuevo camino con losa granítica y de acceso directo al Laboratorio de Electromecánica. Y al año siguiente se contrató a Javier de Winthuysen para completar la reforma y que recuperase la imagen del jardín ya que estaba desordenado y descuidado. Winthuysen creó un vestíbulo verde de plantación frente al edificio, trazó nuevos caminos utilizando el trazado de caminos existentes, proporcionó sombra al recorrido principal y abrió pequeñas plazas estanciales en el interior de la masa vegetal siempre conservando los árboles existentes. Estos ejemplares antiguos quedan en el interior de los macizos, dando la sensación de haber sido plantados con posterioridad a la traza y, logrando aislarlos, realzar así las especies nobles y lograr nuevos puntos de vista ${ }^{4}$.

\footnotetext{
${ }^{2}$ Fueron plantados previamente a la construcción del edificio y actualmente todavía se conservan algunos.

3 MACHIMBARRENA, V.: "El jardín de la Escuela de Caminos, parte I". Revista de Obras Públicas, 1928, p. 9.

4 MACHIMBARRENA, V.: "El jardín de la Escuela de Caminos, parte II". Revista de Obras Públicas, 1928, p. 22.
} 

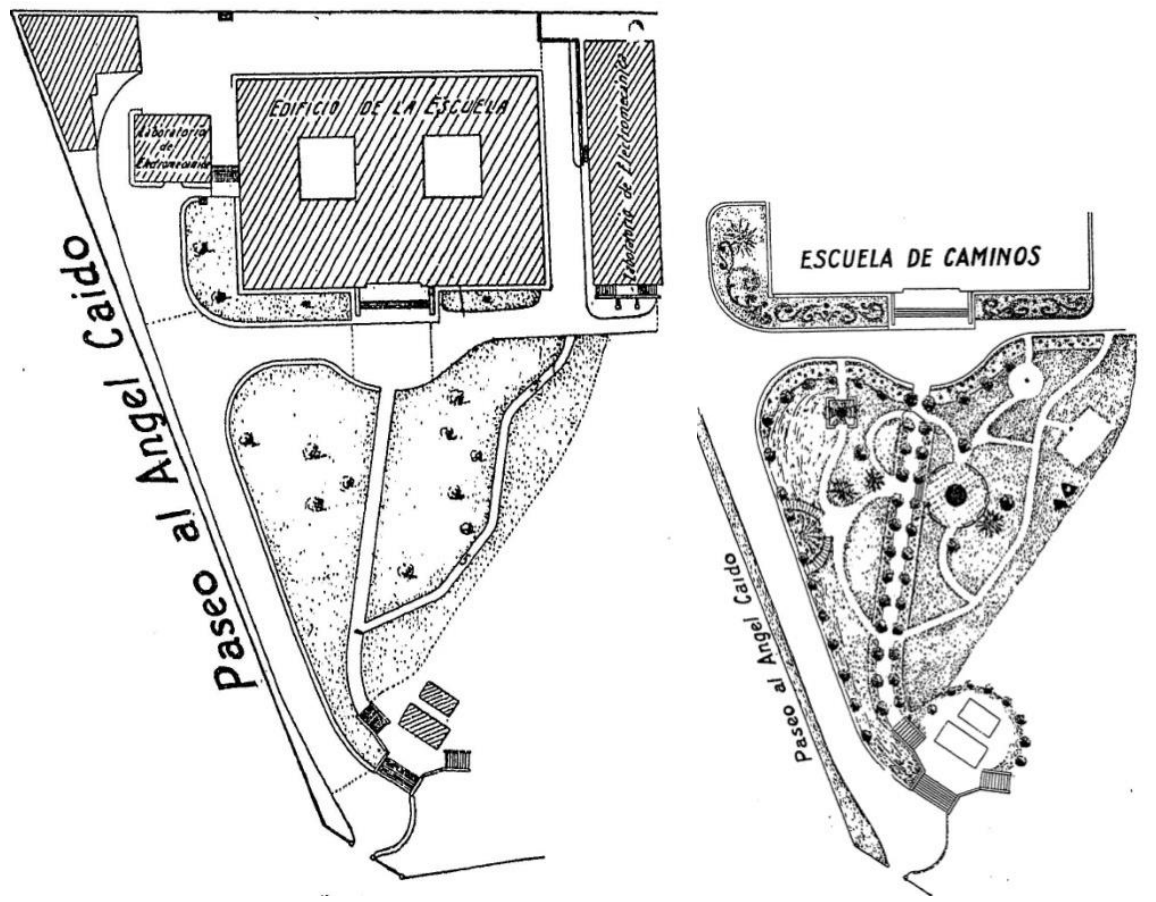

El diseño de Winthuysen es de carácter paisajista -menos habitual en él-; superpone un trazado paisajista pero con elementos formales sobre el original, que se mantiene. Los nuevos caminos curvilíneos enlazan con el camino central rectilíneo previo y conducen a una serie de plazas estanciales y de esparcimiento, necesarias para el centro docente. Aprovechando una porción de terreno horizontal en el sector sur, tangente al camino central, construyó la glorieta de Saavedra, de corte clasicista y forma circular con estanque igual de granito -fuente de los leones ${ }^{5}$-, con dos leones a modo de surtidores, propios del jardín andalusí, que sostienen los escudos de armas de España y del Cuerpo de Ingenieros de Caminos. Está pavimentada con un damero de guijarros claros y oscuros, también con reminiscencias de los jardines hispanomusulmanes, y en su mitad norte se cierra con una arquería vegetal formada por cinco arcos de cipreses enlazados y en su arco central se sitúa el busto del ingeniero Eduardo Saavedra, esculpido por Mateo Inurria. En los arcos laterales colocó bancos de piedra caliza de Colmenar y otros dos en el lado opuesto, inspirados en los que estudió de la Isla de Aranjuez, y flanqueados por un seto bajo de ciprés que jalona los escalones de acceso. Se preocupa por las vistas y para permitir la visión desde el paseo peatonal el seto en el lado sur es bajo, mientras que en la mitad norte es alto y forma un telón vegetal. En general el jardín al estar elevado sobre

\footnotetext{
5 Esta fuente tiene analogías con la fuente de los leones realizada por Forestier para el Parque de María Luisa en Sevilla. SOUTO ALCARAZ, 2010, p. 52.
}

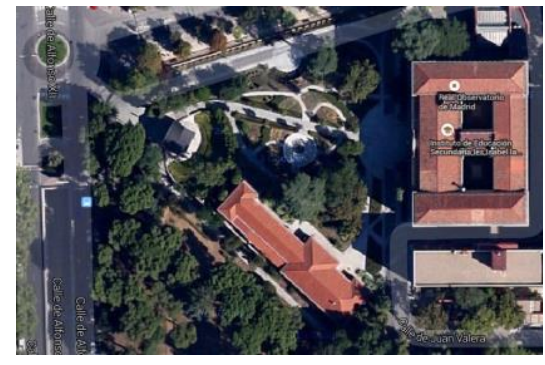

6.71 Jardín de la Escuela de Ingenieros de Caminos: vista aérea actual, trazado previo paisajista de 1887 y el proyecto de Javier de Winthuysen de 1925. Googlemaps. MACHIMBARRENA, parte II, 1928, p. 22.
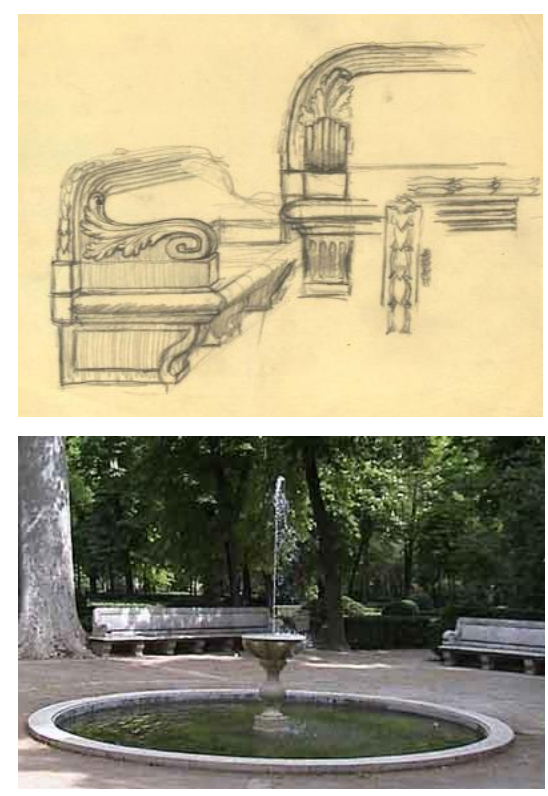

6.72 Dibujo de uno de los bancos del jardín de la Isla de Aranjuez, Winthuysen, 1930. ARJB, Div.IX 66,37. Vista actual de los bancos del Jardín de la Isla de Aranjuez. PHL, septiembre 2009.

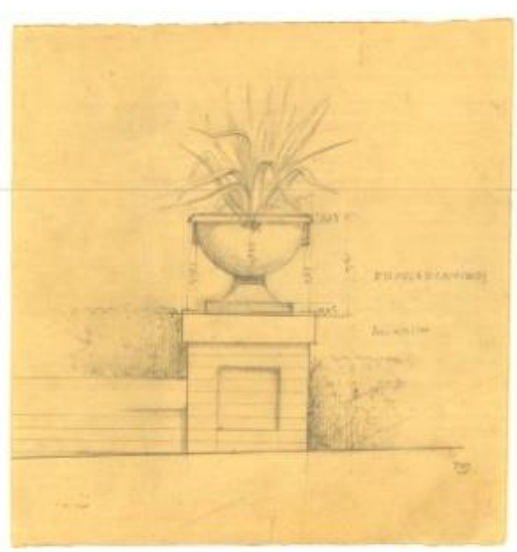

6.73 Alzado de copa decorativa para la Escuela de Caminos. Winthuysen, 1925. ARJB, Div.IX 14, 3. 

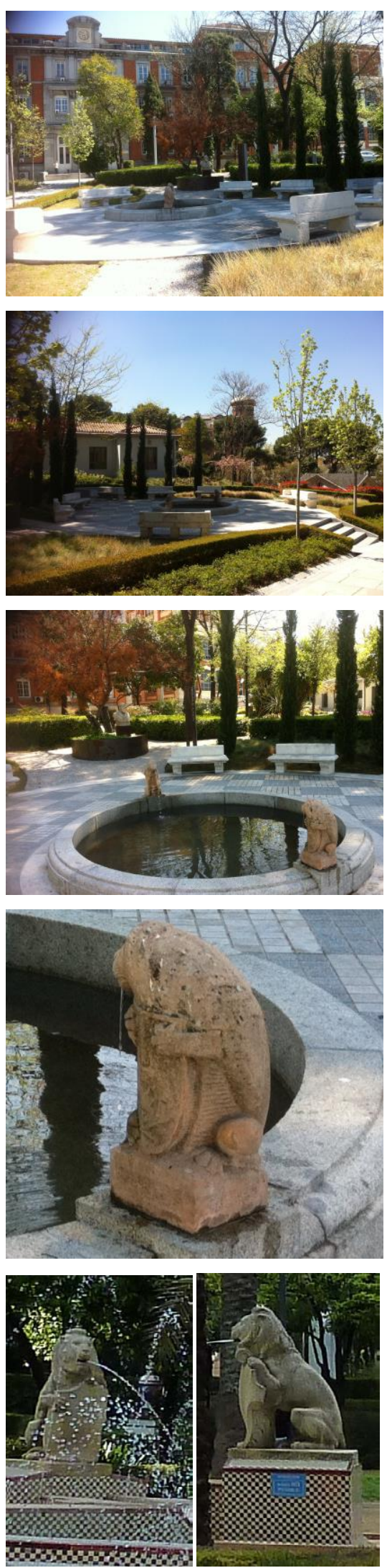

6.74 Estado actual de la glorieta de Saavedra tras la reforma: fuente, bancos y detalle del león surtidor comparándolo con el del Jardín de los Leones del Parque de María Luisa en Sevilla. PHL, abril y mayo 2012.

6.75 Plano del proyecto del jardín de la Escuela de Caminos con bocetos de la glorieta de Saavedra. Detalle de la arquería de ciprés para la glorieta de Saavedra. Winthuysen, 1925. ARJB, Div.IX $14,2 v-5$. un cerro cuenta con vistas sobre la vaguada del Paseo de Recoletos. En la documentación gráfica original se aprecian algunos elementos ornamentales clásicos que no llegaron a realizarse, tal vez por falta de presupuesto, como las columnas clásicas rematadas por jarrones y los jarrones sobre basa ante los vanos del muro.
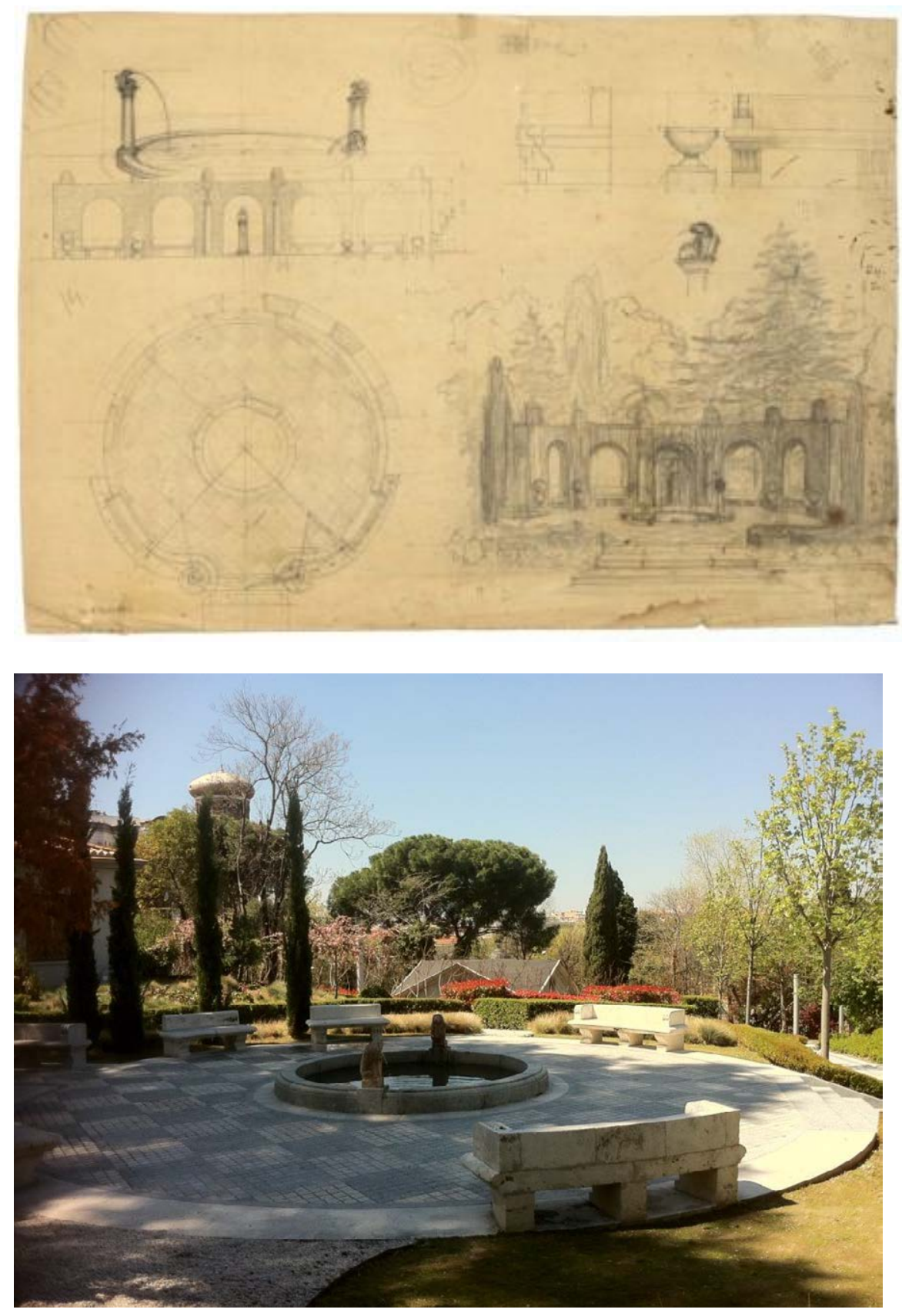


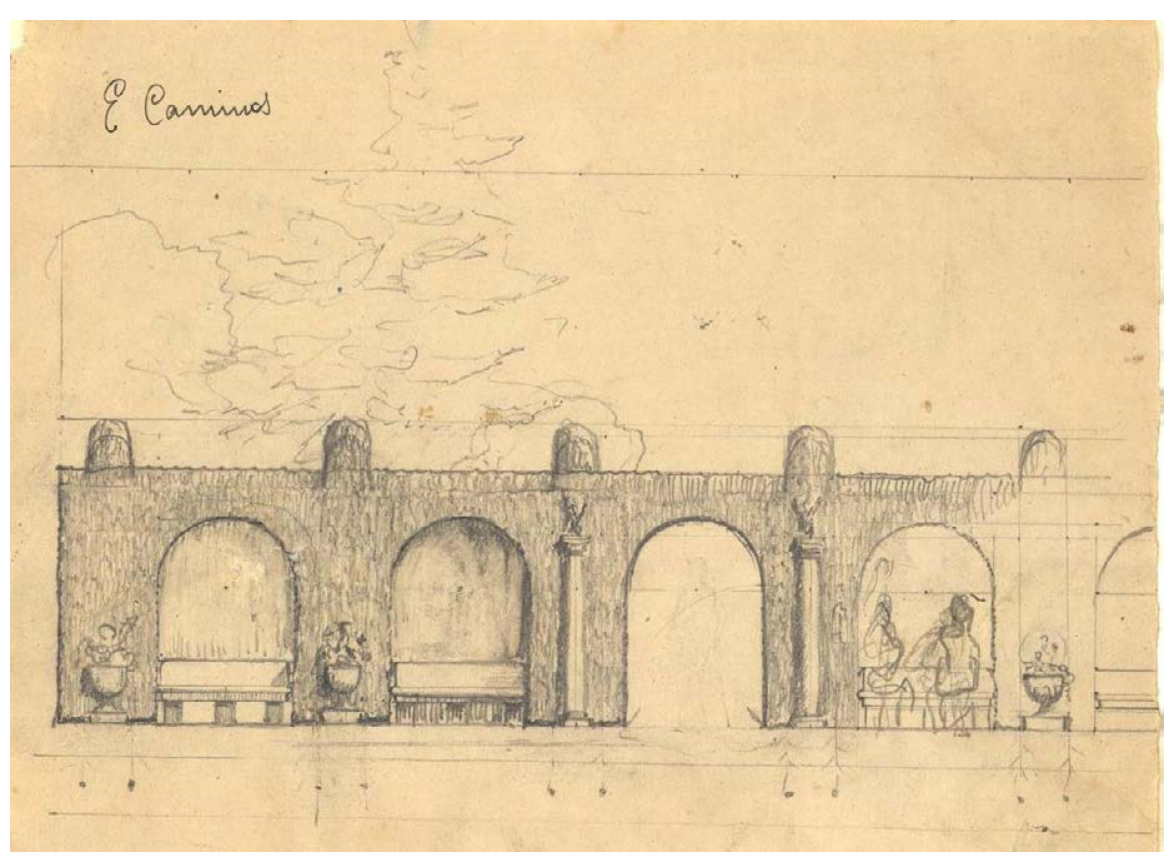

Estableció otra glorieta de cerámica o "andaluza" al otro lado del camino peatonal y más apartada; de forma circular en el plano de Winthuysen, finalmente se construyó cuadrada. Cuenta con cuatro entradas enfrentadas enmarcadas con arcos de ciprés enlazados formando una plazuela típica de los jardines hispanomusulmanes, muretes de ladrillo al modo regionalista andaluz, fuente baja octogonal con surtidor central de ladrillo, bancos recubiertos de azulejería y distribuidos dejando libre los caminos de acceso a la glorieta y pavimento en damero. Aparece una glorieta circular secundaria en la parte alta del sector sur que podría albergar un futuro pabellón.

Proyectó un parterre semicircular, adosado al límite norte del jardín, con diseños de broderies clásicos, y otro al pie de la fachada oeste. Bordeando estos espacios introdujo plantas tapizantes (romeros, vincas, violetas y lirios) y arbustos (adelfas y lilos) que marcasen la estacionalidad y aportaran color, e incluyó los árboles preexistentes dentro de bandas lineales de seto. Diseñó dos tramos de escalera curvos simétricos con carácter decorativo que conectaban el camino peatonal y el de carruajes. Para dar sensación de mayor anchura del camino peatonal se plantaron setos rectilíneos de boj a ambos lados delimitando macizos de hortensias; y el mismo esquema con platabandas se repitió en el límite este con rosales. Dispuso una alineación de chopos en el contorno de la rotonda semicircular de acceso.
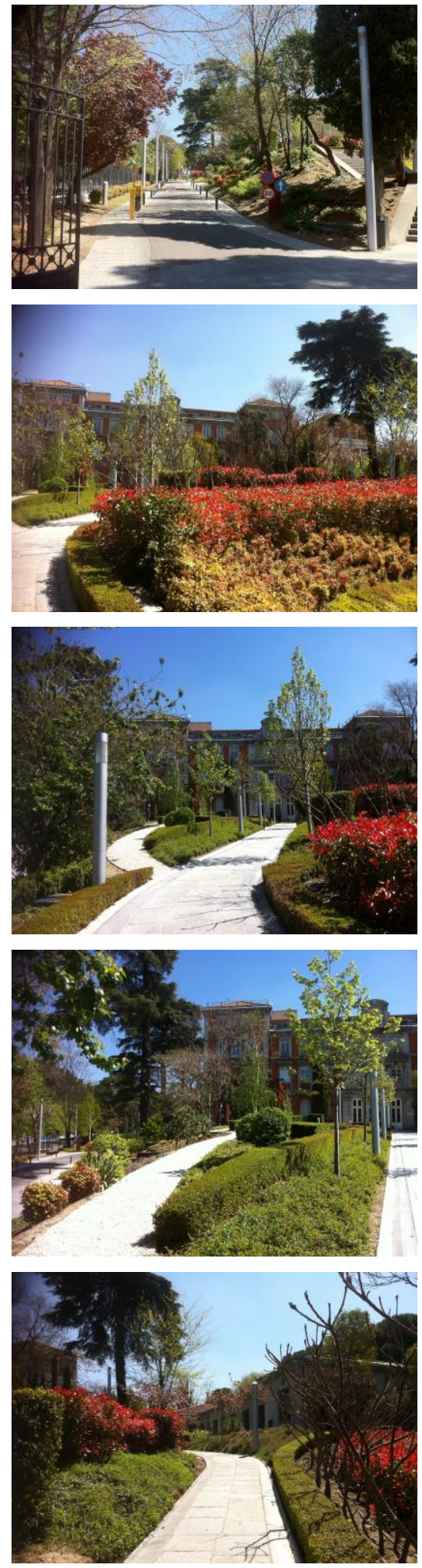

6.76 Estado actual del jardín tras la reforma: antiguo camino de carruajes y caminos peatonales. PHL, abril 2012. 

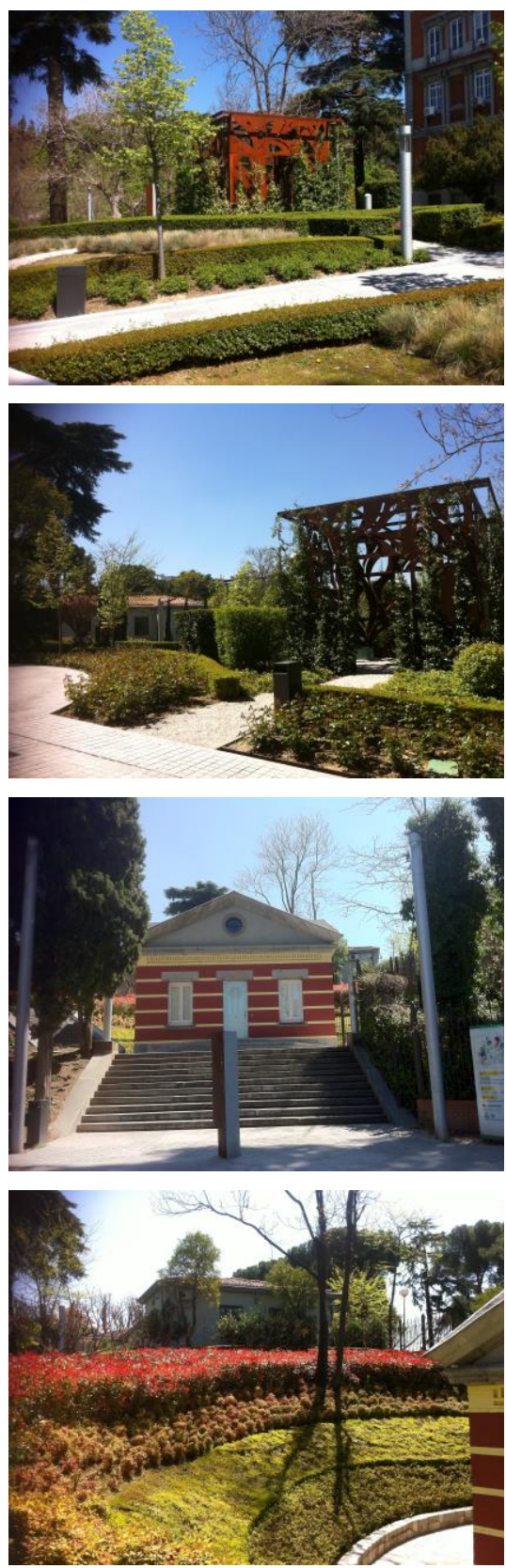

6.77 Estado actual del jardín tras la reforma: folie sobre la antigua glorieta andaluza, anillos vegetales, casa del guarda y anfiteatro vegetal. PHL, abril 2012.

6.78 Plano del proyecto del jardín de la Escuela de Caminos. Winthuysen, 1925. ARJB, Div.IX 14, 2 r.

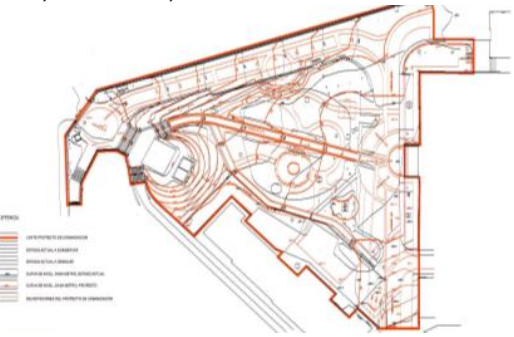

6.79 Estudio de ordenación y proyecto de ejecución para el acondicionamiento y urbanización de los espacios libres del Cerrillo de San Blas, el jardín de Winthuysen y su entofrno: topografía modificada. Gerhard Loch, ETTP, CEDEX, 2008.

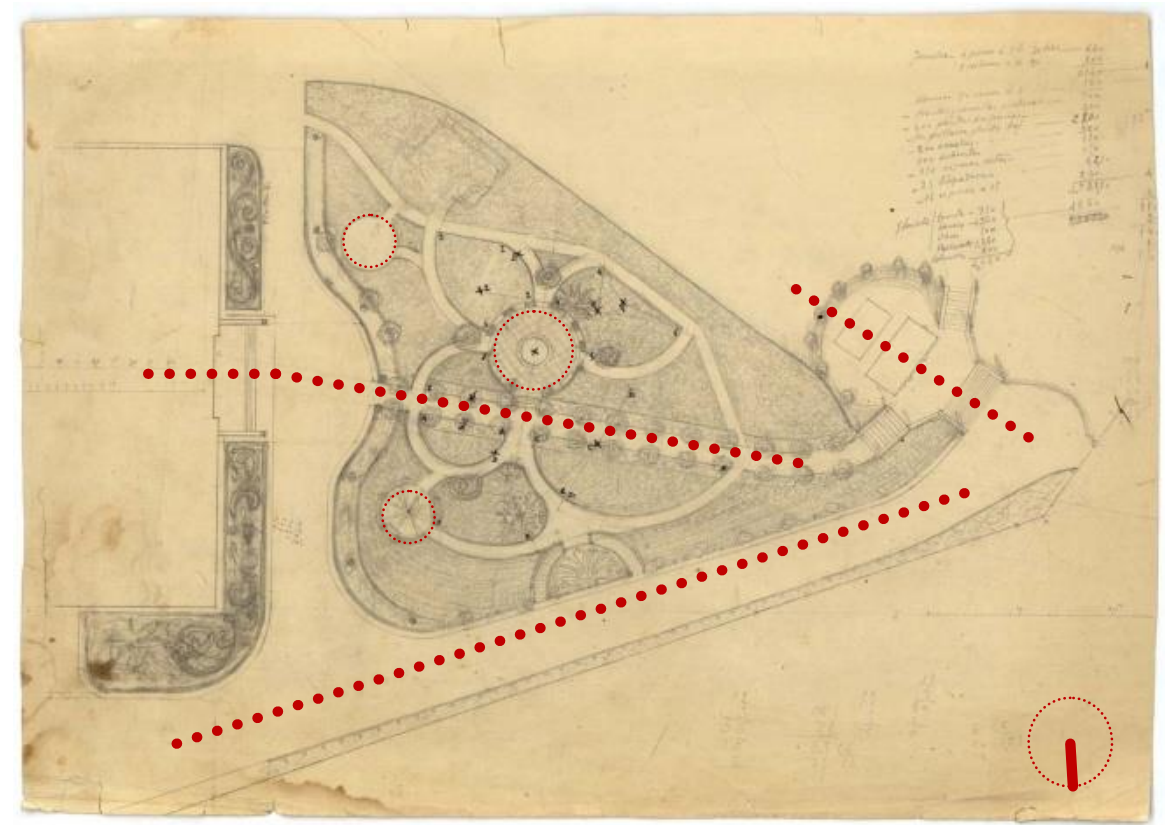

En 2008 se inició la recuperación del jardín que había sido transformado a finales del siglo XX en un aparcamiento de coches perdiendo su configuración original. Se realizó un estudio previo ${ }^{6}$ analizando la evolución histórica del jardín y el estado de la vegetación, las circulaciones y los usos. El proyecto urbanístico de Gerhard Loch ha conservado los trazados y pavimentación de los caminos originales y ha recuperado la desaparecida alineación de arbolado con tilos dispuestos a tresbolillo para optimizar su desarrollo y soleamiento. Se ha recuperado la traza y elementos de la glorieta de Saavedra y el resto de elementos singulares introducidos por Winthuysen se han interpretado de forma innovadora. En la desaparecida glorieta de cerámica o andaluza se ha levantado un elemento singular coincidiendo con la planta original a modo de folie ${ }^{7}$. A través de una superficie curva de acero cortén que contiene el talud, con huellas vegetales tapizantes y contrahuellas de acero cortén, se recupera el trazado de la doble escalera semicircular a modo de escalera vegetal ${ }^{8}$. Respecto a la vegetación, el suelo se cubre casi por completo con tapizantes, se

\footnotetext{
${ }^{6}$ Mediante un convenio de colaboración con la Universidad Politécnica de Madrid a través de los Departamentos de Composición Arquitectónica, Urbanística y Ordenación del Territorio e Ideación Gráfica Arquitectónica.

7 Se trata de un volumen cúbico, a modo de jaula formado por planchas de acero cortén perforado con motivos florales, que rememora los componentes desaparecidos originales, con bancos cúbicos luminosos verdes.

8 Se rehabilitan la antigua casa del guarda y la garita de vigilancia transformándose respectivamente en un Centro de Información al Público del Cerrillo de San Blas y en un pequeño almacén. Se incorporan dos zonas en el borde sur, antiguamente inaccesibles: el aparcamiento de la Subdirección General de Programación Técnica y Científica del CEDEX y el talud vegetal detrás de la casa del guarda donde se crea un nuevo anfiteatro vegetal.
} 
conserva parte del arbolado existente y se introducen nuevas especies arbóreas y arbustivas con diversas formas, tamaños, texturas y colores, pero sin perturbar la unidad compositiva. Se aporta un elemento nuevo de jardinería consistente en una superposición de anillos vegetales concéntricos elipsoidales sobre la red de caminos de la parte alta que van creciendo en altura con diversas plantaciones ${ }^{9}$. La rehabilitación es bastante respetuosa y mantiene el diseño de Winthuysen que combina la gran avenida recta de acceso -comunicando directamente con la entrada principal del edificio y desde la que se tiene una amplia perspectiva del mismo- y espacios estanciales de menor escala.

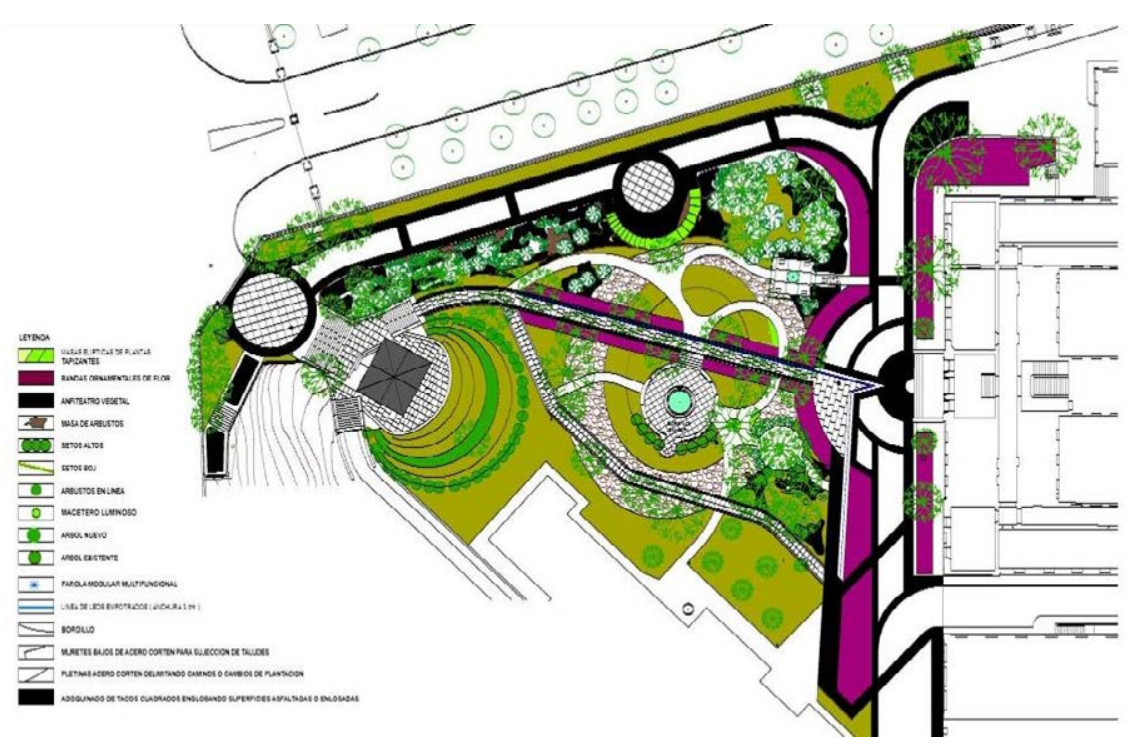

El Patronato Nacional de Turismo encargó a Winthuysen la realización de una serie de jardines para los Albergues y Paradores Nacionales: Albergue de Almazán (Soria, 1935), Benicarló10 (Castellón, 1935), Medinaceli (Soria, 1934), Aranda del Duero (Burgos) y Parador Nacional de Enrique II de Ciudad Rodrigo (Salamanca, 1935). En ellos intercala los trazados libres con otros más geométricos. Muchos de ellos han sido modificados posteriormente perdiendo su carácter original.

\footnotetext{
${ }^{9}$ El jardín fue abierto al público en 2009 y actualmente el edificio lo ocupan dependencias del Ministerio de Cultura.

${ }^{10}$ Así habla Winthuysen del Albergue de Turismo de Benicarló: "ya replanteado y casi realizadas mis plantaciones sufrió la intervención del arquitecto que a pretexto de acomodar las obras de desagüe de la gran piscina, que estaba proyectada más que como tal como un espacio de la composición, dio al traste con el conjunto con tales obras improcedentes". WINTHUYSEN, J. Memorias de un Señorito Sevillano. 1942. Nueva Edición. HÉCTOR VÁZQUEZ, M. et al. (edit.). Winthuysen Foundation, Inc, 2005, p.206.
}

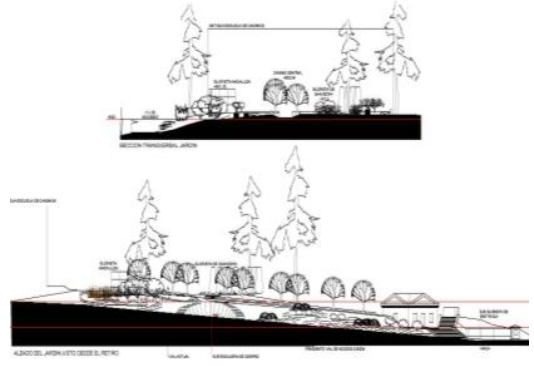

6.80 Estudio de ordenación y proyecto de ejecución para el acondicionamiento y urbanización de los espacios libres del Cerrillo de San Blas, el jardín de Winthuysen y su entorno: ordenación general, alzado y sección. Gerhard Loch, ETTP, CEDEX, 2008.
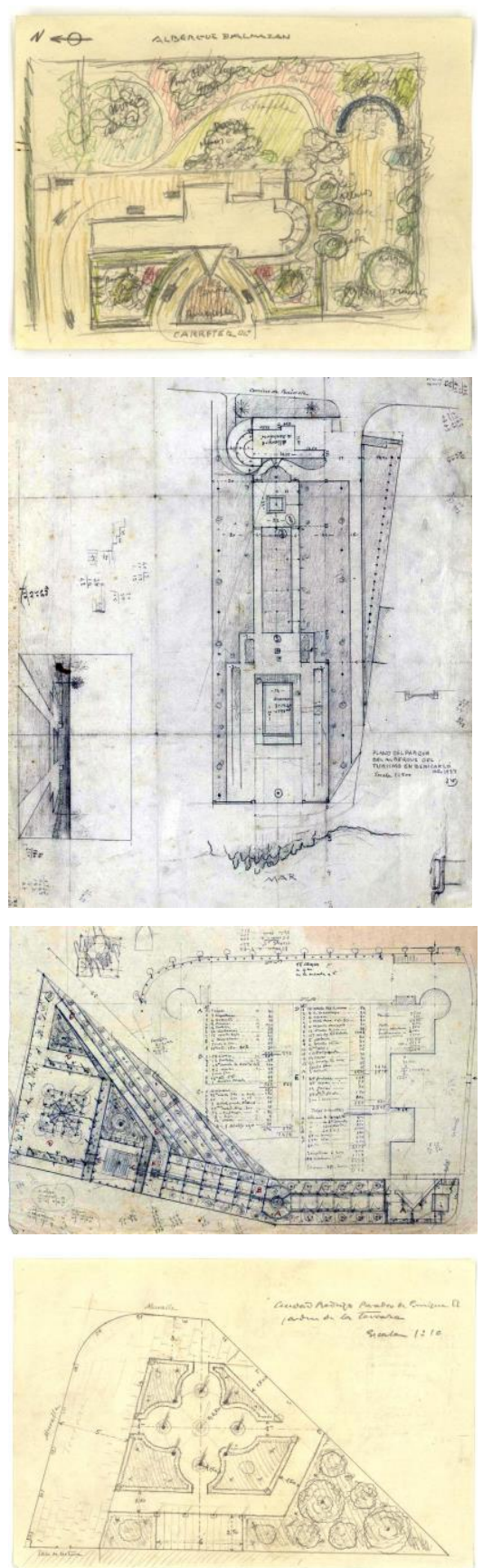

6.81 Boceto del jardín del albergue de Almazán con anotaciones sobre la plantación, 1935-1936. Planta de los jardines del Albergue de Benicarló, 19351936; Ciudad Rodrigo y detalle de éste último, 1935-1936. Winthuysen. ARJB, Div.IX 40,1; 41,2; 43,2-4. 
6.82 Planta de los jardines del Albergue de Almazán, 1935-1936 y Medinaceli, 1934-1938. Winthuysen. ARJB, Div.IX 40.3: 42.3 .
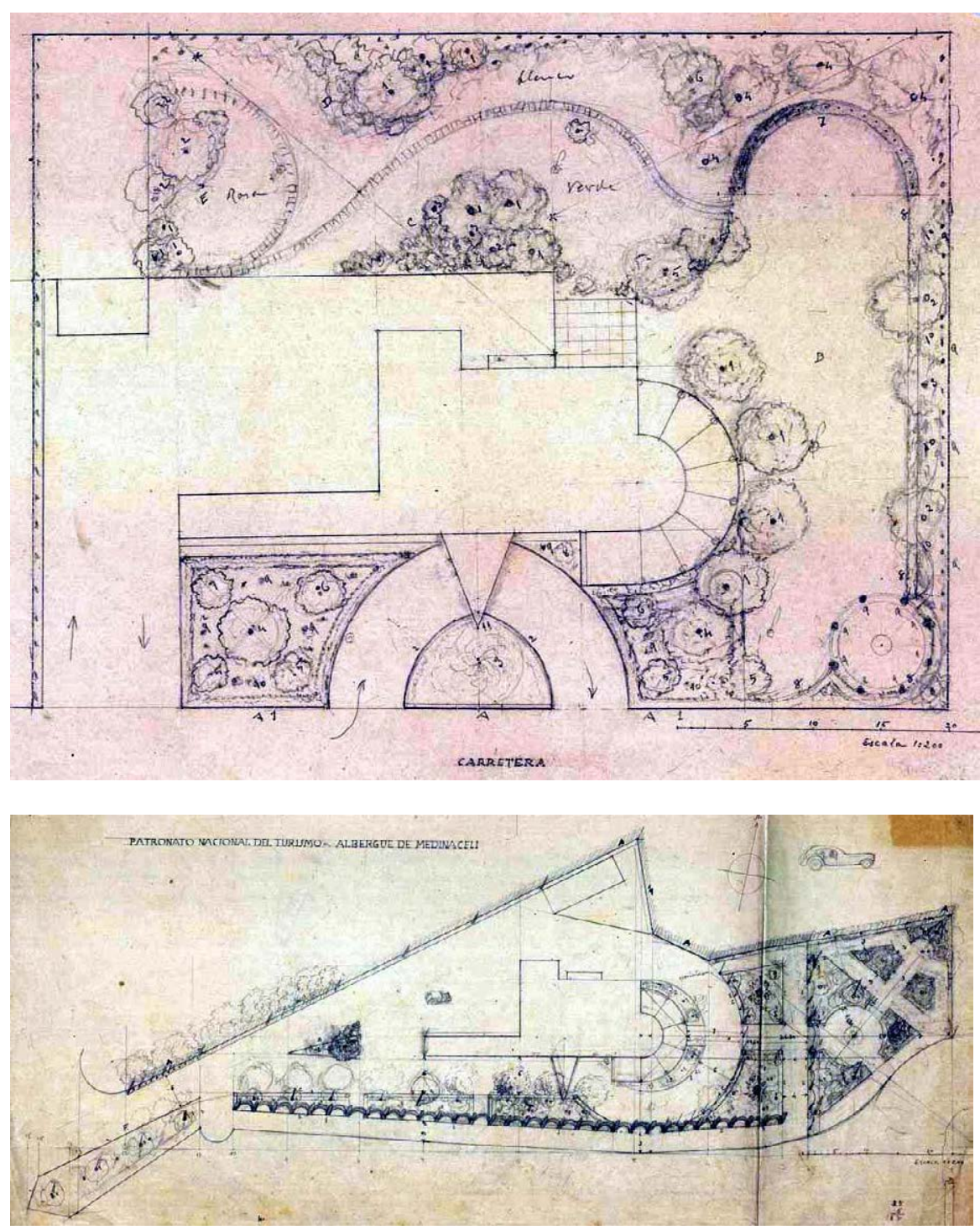

En 1950 Winthuysen invitó a su hija Beatriz, que había iniciado su formación en paisajismo, a colaborar con él en el diseño de los espacios alrededor de la Universidad Laboral de Somió en Gijón. La universidad está emplazada en el magnífico valle de Somió, en una colina elevada y sin edificaciones ni árboles, lo que facilitaba la cimentación. El complejo se adapta a la topografía estando el acceso de la plaza principal a mitad de altura con respecto a los edificios. El edificio, pensado en origen como gran colegio de huérfanos para mineros y luego convertido en Universidad Laboral, es obra bien conocida de los arquitectos Luis Moya, Pedro R. de la Puente, Ramiro Moya y José Díez Canteli, que abandonaron la idea de pabellones sueltos con comunicaciones horizontales y optaron por la solución de edificio único con comunicaciones verticales. Sin embargo, los autores conciben la universidad "como una pequeña 
ciudad con su plaza mayor, a cuyo alrededor se agrupan las casas, cada una con su portal y escaleras" ${ }^{11}$.

El edifico se protege del viento noroeste obligando a que la fachada principal esté de espaldas a Gijón. Al igual que en la Alhambra o en El Escorial no se accede de frente. La entrada principal es el patio corintio que proporciona dignidad en el acceso a la gran plaza y prepara su escala. "Como en este patio, de constante uso por los alumnos, es inútil pensar en la jardinería, no se podía contar con los elementos naturales para su adorno y variedad, y, por consiguiente, podría quedar frío y duro, de sólo piedra. / Por esta razón se cortó con estas galerías, detrás de las cuales, en las pequeñas zonas que quedan hasta el fondo de la plaza, habrá jardines con algunos árboles altos, que quiten la monotonía de color de esa pieza arquitectónica; salvo este detalle, es la clásica "plaza mayor" a la española. Las galerías de Palladio son como celosías o cancelas, que dejan ver el jardín a su través"12, explica Luis Moya.

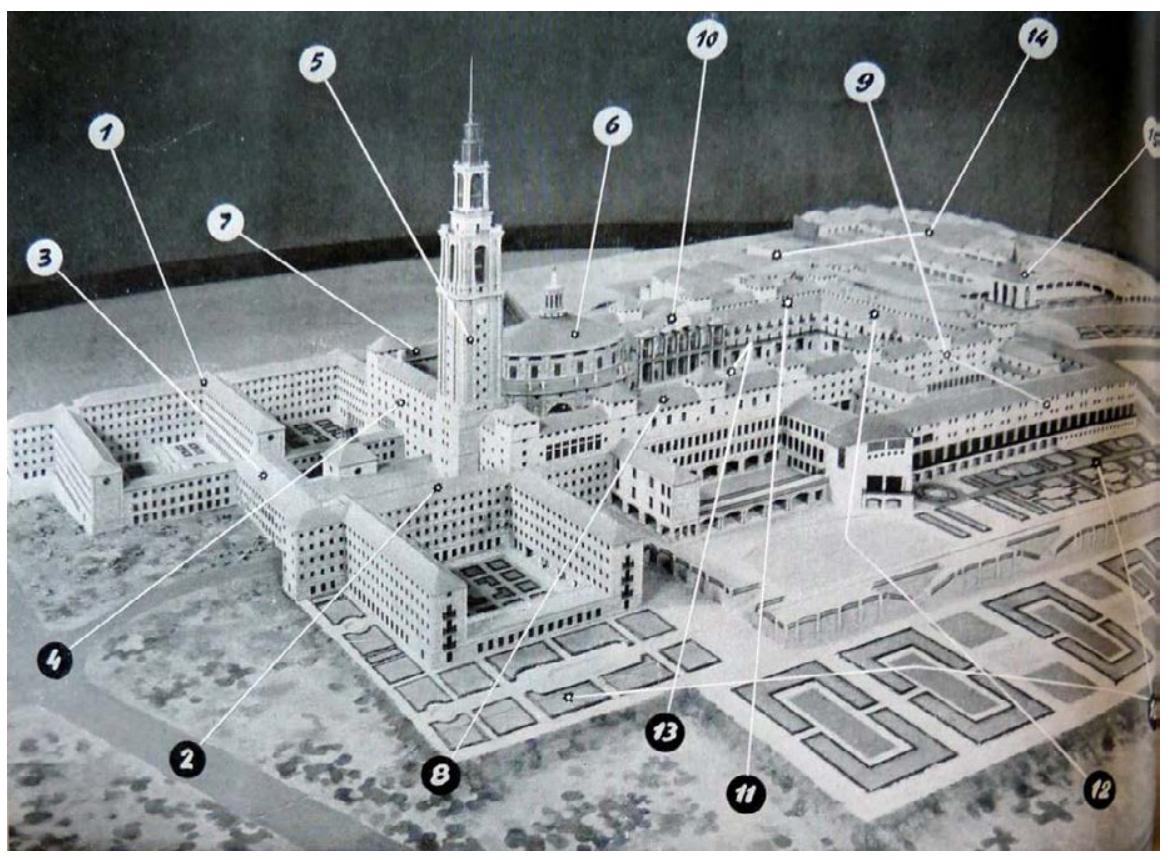

Una parte importante del complejo por tanto son los jardines y los campos de deportes. Cuando se describe la zona de talleres la memoria señala: "muros de mampostería, que llevan en su zona baja, a la altura de la vista, ventanales corridos para contemplar el paisaje, en las naves exteriores del bloque, y para contemplar los

\footnotetext{
11 Universidad Laboral José Antonio Girón, en Gijón. Revista Nacional de Arquitectura. Madrid: Consejo Superior de Colegios de Arquitectos de España 1955, nำ168, diciembre, p. 40.

12 Palabras de Luis Moya. Ibíd., p. 46.
}
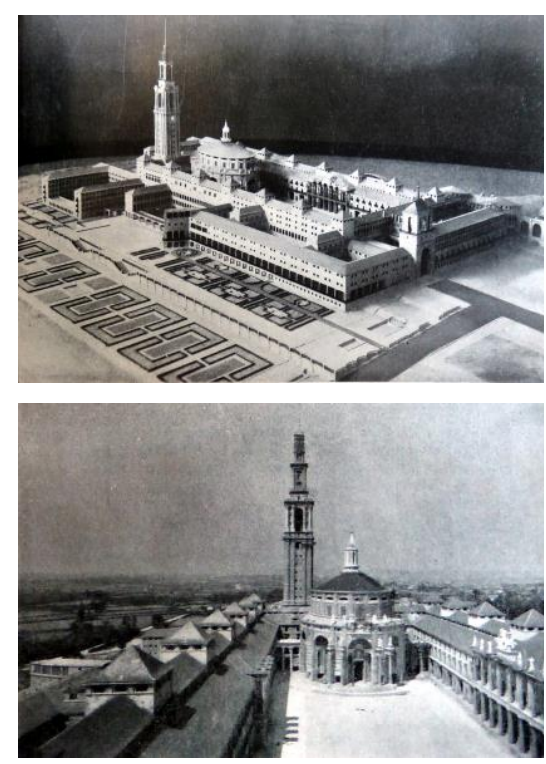

6.83 Universidad Laboral de Gijón: maqueta y patio principal. Revista Nacional de Arquitectura, 1955, p. 35 y 45

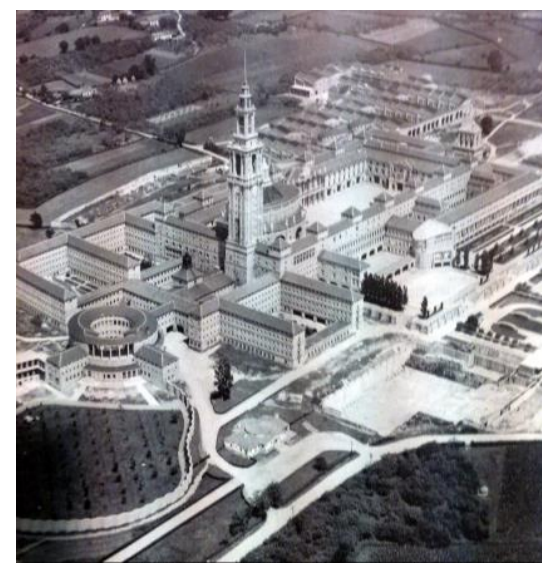

6.84 Universidad Laboral de Gijón: visión panorámica. NARBAIZA, J.: El día en que volvimos a la universidad laboral Editorial Provisional Para Códigos, 1999, p. 65.

6.85 Universidad Laboral de Gijón: maqueta. Revista Nacional de Arquitectura, 1956, p. 10.

1-Pabellones internado universitario 2-Pabellones del internado de Enseñanza media y elemental 3-Pabellón de servicios

4-Residencia de la Comunidad Religiosa

5-Torre principal

6-Iglesia

7-Aulas de Enseñanza media laboral 8-Aulas de Enseñanza profesional 9-Escuela de Capacitación Social y Residencia de antiguos alumnos 10-Aula Magna

11-Biblioteca y Laboratorios 12-Pabellón de Dirección 13-Gran patio central 14-Pabellones de Talleres 15-Torreón entrada y atrio corintio 16-Jardines y campos de Deportes 

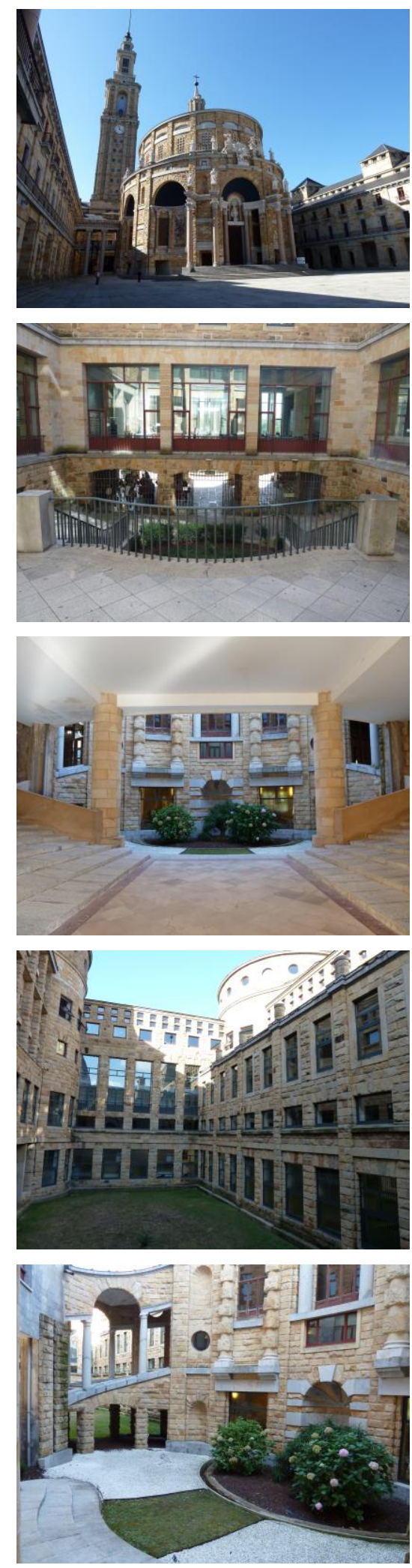

6.86 Universidad Laboral de Gijón: gran patio central y patios menores ajardinados. PHL, septiembre 2012. jardines que llevarán los patios, en las rasantes"13. En el proyecto original los campos de deportes quedaban empotrados entre los edificios. Los frontones eran los muros de los talleres y otros pabellones, mientras que las piscinas y campos de fútbol estaban tan unidos al edificio que sus vestuarios formaban parte del mismo.

Moya expresa que hay dos tendencias en la arquitectura de ese momento: el 'optimismo-paz'-abriendo la arquitectura a la naturaleza y utilizando formas orgánicas- y el 'terror-inquietud'defendiendo la arquitectura de la Naturaleza y utilizando formas abstractas geométricas de gran escala, inhumanas-. Defiende el clasicismo como el equilibrio entre estas dos tendencias y por eso opta por una arquitectura clásica de escala humana. Sin embargo Luis Gutiérrez Soto considera que no lo ha conseguido: "Encuentro una equivocación importante en esta obstinación a hacer un edificio cerrado defendiéndose de la Naturaleza, por entender Luis Moya que la Naturaleza es un elemento hostil que ataca al hombre. Me parece que una de las conquistas verdaderamente indiscutibles de la arquitectura actual es su incorporación a la Naturaleza. / El plantear este edificio diciendo que la Naturaleza es un enemigo me parece una equivocación. Espero que dentro de unos años, cuando la Naturaleza conquiste estos muros y estos patios, serán más humanos"14. El edificio será también criticado por su pesadez y excesivo eclecticismo con estilos (Palladio, Vitruvio, barroco, etc.) que no responden a una institución moderna, además de haberse demorado su finalización 25 años. Sin embargo, no resulta un edificio cerrado; se le percibe un alto sentido paisajista a Moya, como los pórticos palladianos como filtros al jardín o el carácter de la plaza mayor española, sin jardines. Es interesante cómo concibe la visión del primer plano y de los planos medio y de fondo.

Winthuysen era asiduo colaborador del arquitecto Luis Moya en sus proyectos. Sus conocimientos de paisajismo se complementaban con los del ingeniero agrónomo Ignacio Chacón ${ }^{15}$ y los de Ramón Ortiz Ferré, jardinero mayor del Ayuntamiento de Madrid. Los jardines se distribuyen en tres terrazas aprovechando la pendiente natural del terreno. La inferior alberga los campos de deporte y las pistas de atletismo. La central acoge las piscinas y canchas de juego

\footnotetext{
13 Ibíd., p. 36.

${ }^{14}$ Palabras de Luis Gutiérrez Soto. Ibíd., p. 48.

15 RUILOPE URIOSTE, B.; SUÁREZ MENÉNDEZ, M.: La arquitectura religiosa de Luis Moya: El legado. Archivo Digital de la UPM, 2013, p. 77.
} 
(baloncesto, balonmano, tenis, etc.). La superior alberga el jardín propiamente dicho con cuadros, estanques, fuentes, etc. El patio con pérgolas de orden dórico y coronado por arcos escarzanos está presidido por el Paraninfo y a través de él se efectúa la unión entre el patio central y los jardines, mediante una escalinata presidida por la fachada trasera del patronato donde se disponen cuatro estatuas ${ }^{16}$. También diseñó los jardines y patios interiores del edificio.
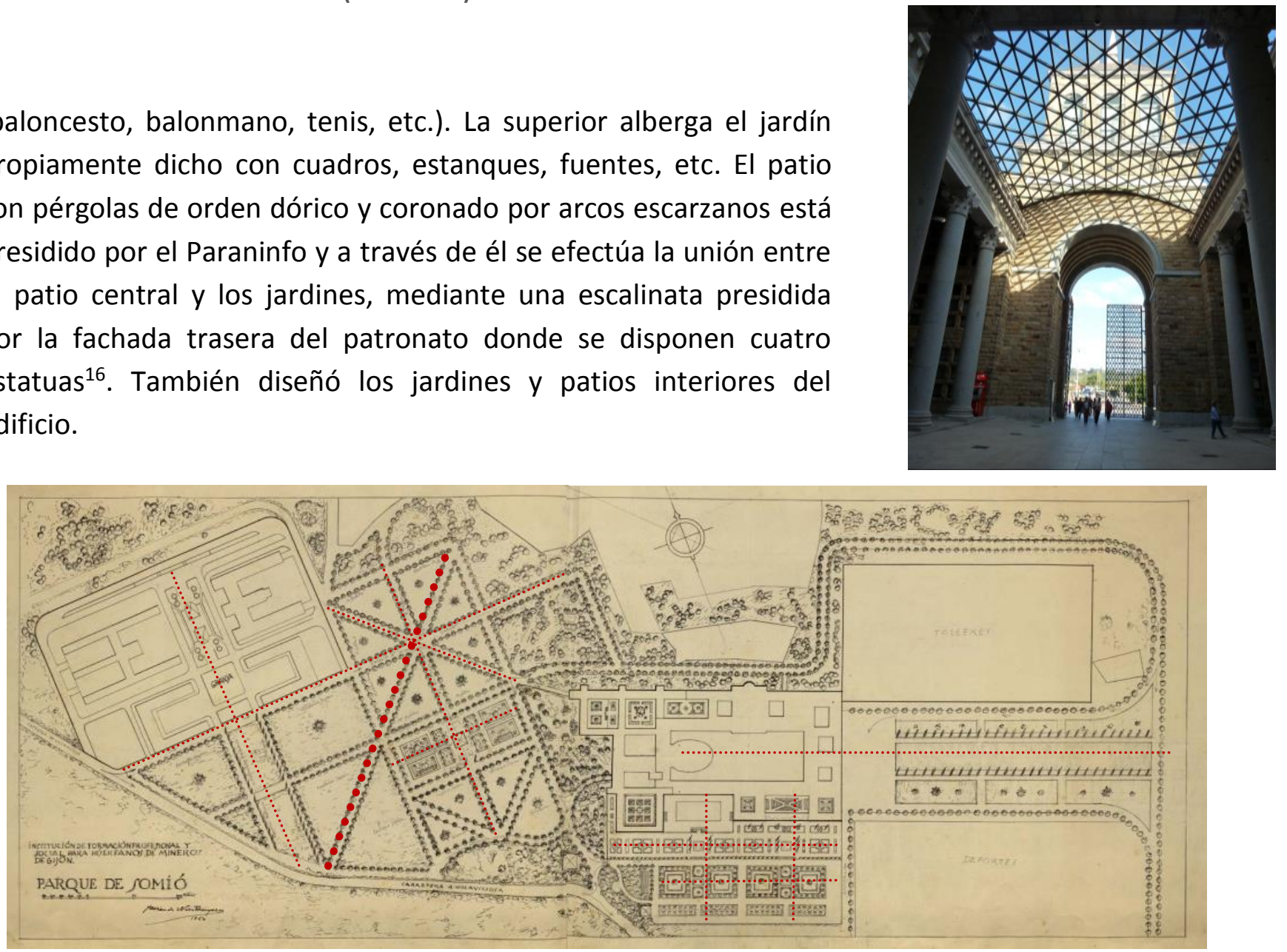

En la zona norte y en relación con la granja proyecta un jardín de grandes cuadros y paseos con ejes geométricos que van componiendo y conectando las distintas partes. Próximo al gran cuadro dividido en ocho partes diseña un pequeño jardín de estufas. La composición es simétrica con dos ejes, uno longitudinal y otro transversal. En el centro se dispone una pequeña edificación con un estanque y dos pequeños cuadros bordeados con setos, y a continuación dos cuadros a cada lado que incluyen las cocheras. Anexos se distribuyen otros mayores que incluyen los umbráculos, cajoneras y estufas. Todo ello se rodea de un seto perimetral y arbolado cerrando el recinto. De toda esta parte solo se conservan del proyecto original los edificios del norte, ocupados por la UNED actualmente, y se aprecia la huella de alguno de los cuadros vegetales, seguramente desaparecido por la presión de las nuevas infraestructuras e instalaciones como la de Radio Televisión del Principado de Asturias.

\footnotetext{
16 Obra de Manuel Álvarez-Laviada, los cuatro personajes masculinos juveniles representan a las alegorías del trabajo, estudio, deporte y milicia. RIOS GONZÁLEZ, S.; GARCÍA DE CASTRO, C.: La Laboral de Gijón: de Orfanato Minero a Ciudad de Cultura. Ménsula Ediciones, 2008, p. 81.
}

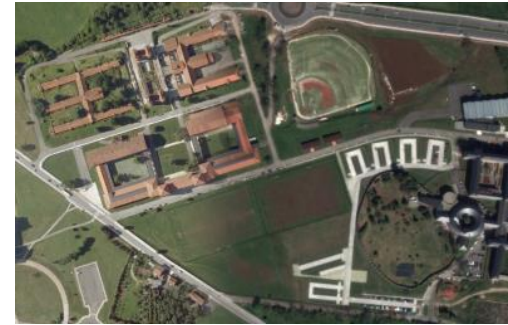

6.87 Universidad Laboral de Gijón: vista aérea actual de la zona norte. Acceso por patio corintio. GoogleEarth. PHL, septiembre 2012.

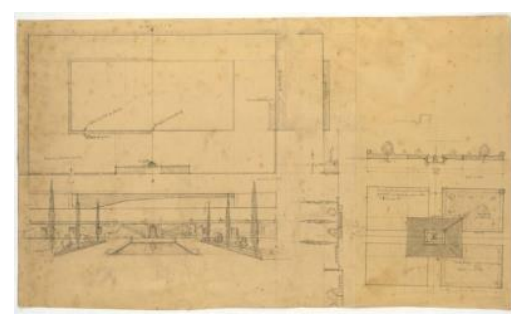

6.88 Planta, alzado y perfil de las fuentes del jardín de la Universidad Laboral de Gijón. Winthuysen, 1950. Planta general del parque. ARJB, Div.IX 59,7 y 59,3 .

6.89 Planta del jardín de las Estufas del Jardín de la Universidad Laboral de Gijón. Winthuysen, 1950. ARJB, Div.IX 59,8 . 

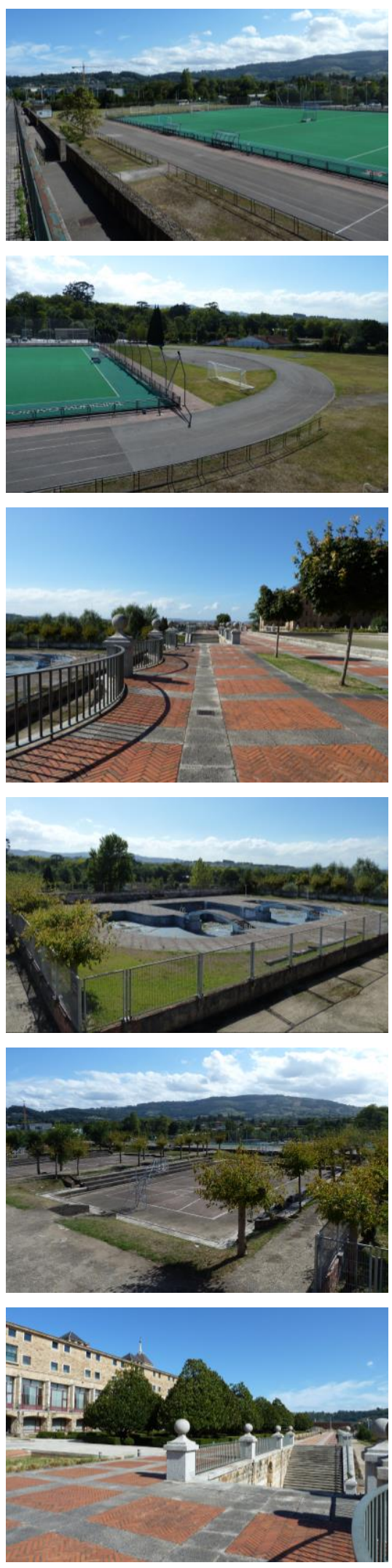

6.90 Universidad Laboral de Gijón: gradación de las partes - campos deportivos y vista de los mismos desde la terraza del jardín de parterres. PHL, septiembre 2012.

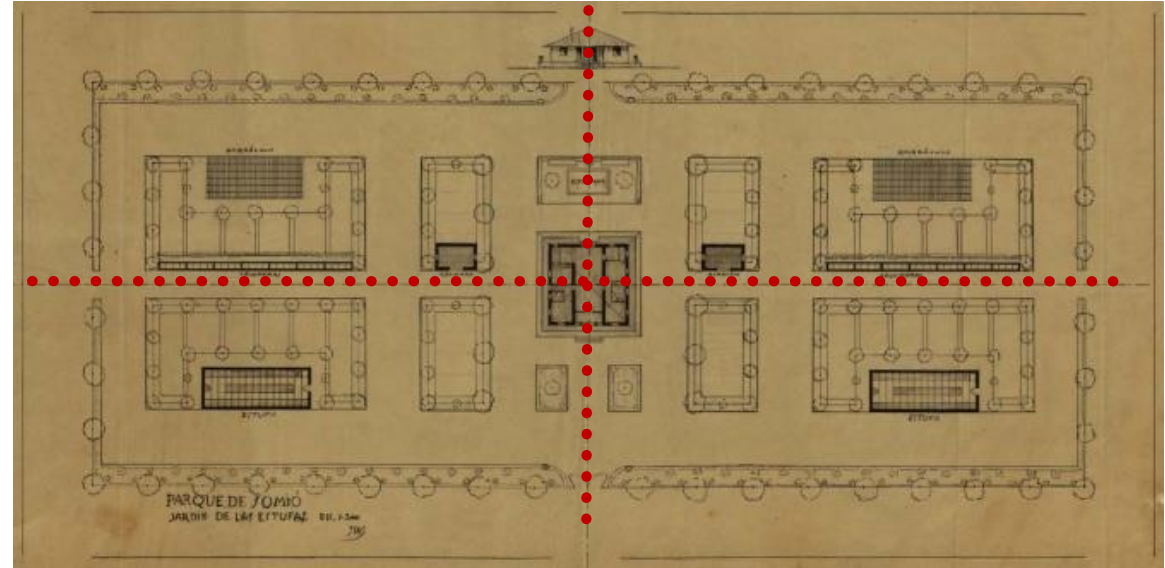

Mantiene la idea de gradación del jardín, dejando los jardines más adornados junto a la edificación para luego ir pasando gradualmente a otros recintos mayores y con otras necesidades que en este caso serían los campos deportivos. En este caso el jardín más ornamentado sería el jardín de cuadros adosado a la fachada sur del edificio. Su composición también es muy geométrica con un claro eje longitudinal paralelo al edifico y unos ejes transversales que conectan la piscina, estanque y escalinatas. Los jardines se relacionan con la edificación por medio de paseos, miradores, patios abiertos al paisaje y accesos. Tiene como fuente de inspiración el modelo de jardín andalusí, como el Generalife de Granada, siendo la primera vez que se introduce en Asturias un jardín de corte hispanoárabe. Hay dos acequias de ladrillo paralelas al edificio, una con fuentes bajas circulares y otra con cuadradas. En todos los elementos de agua aparecen juegos de surtidores. En el proyecto la plantación predominante consiste en cuadros bajos, setos perimetrales recortados de boj que encierran trazados florales en su interior, complementados puntualmente con pequeños árboles o cipreses. Actualmente la acequia exterior está flanqueada por magnolios y en el interior de los parterres hay rosales. En el recinto también destacan los ejemplares de: cipreses, álamos, arces, sabinas, tuyas, etc.

WInthuysen utiliza el sistema que conoce: el regular, y éste exige un gradiente que pasa por el jardín de cuadros con la terraza; por eso utiliza esta solución en vez de una paisajista más norteña. El edificio, tan clásico, también parecía exigir unos ritmos geométricos y una apertura al paisaje, pues su baza compositiva es la percepción impresionante de su silueta desde el entorno, como El Escorial. En realidad guarda muchas similitudes con el Monasterio de El Escorial con la terraza perimetral, los jardines de cuadros, el eje marcado 


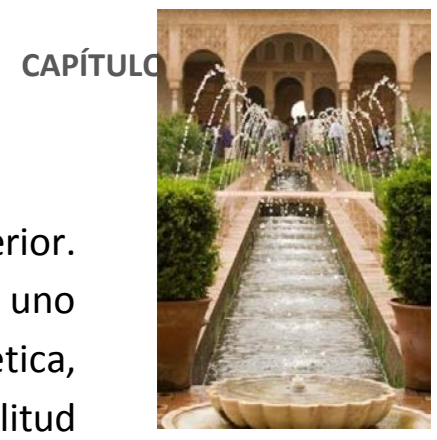

por el agua -los fontines en El Escorial- y las vistas hacia el exterior. Un jardín clasicista parece que acompaña más, aunque con uno paisajista el contraste sería aún mayor. Es una adaptación estética, compositiva, más que climática. También se aprecia una similitud con los jardines del Puente de San Miguel. Los jardines son capaces de integrar los diferentes edificios, y éstos con el paisaje. En el plano general de la Laboral se aprecia como la articulación de las dos mallas ortogonales giradas se realiza mediante las zonas

6.91 Jardines del Generalife, Granada, Panoramio.

6.92 Planta de los parterres y estanques de la Universidad Laboral de Gijón. Winthuysen, 1950. ARJB, Div.IX 59,4. boscosas.

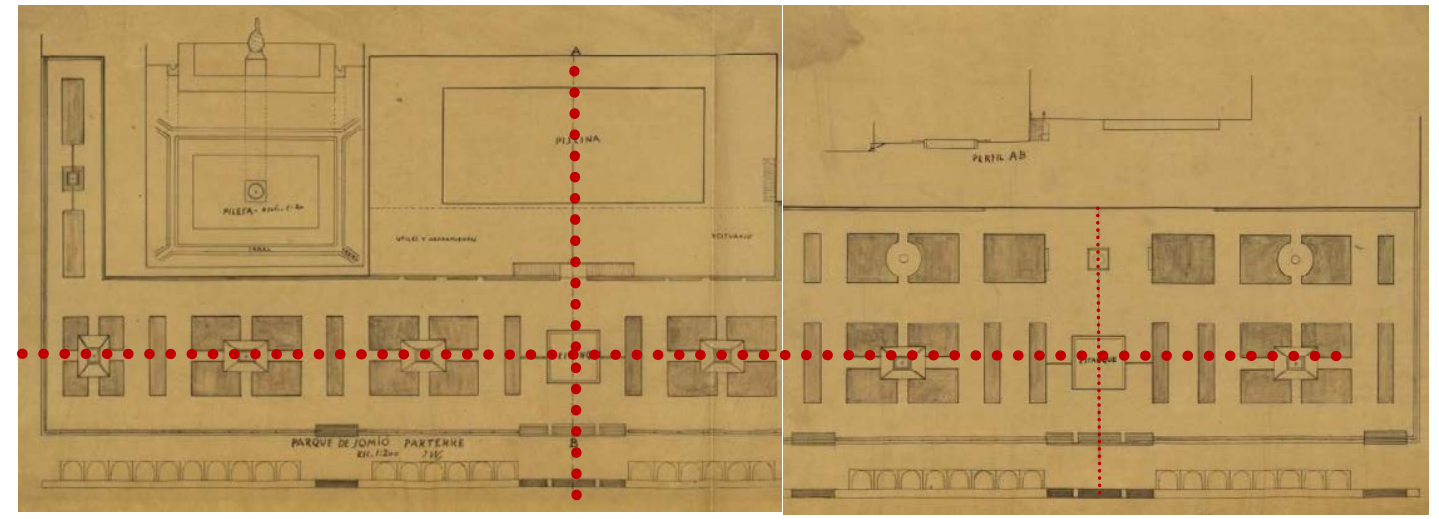

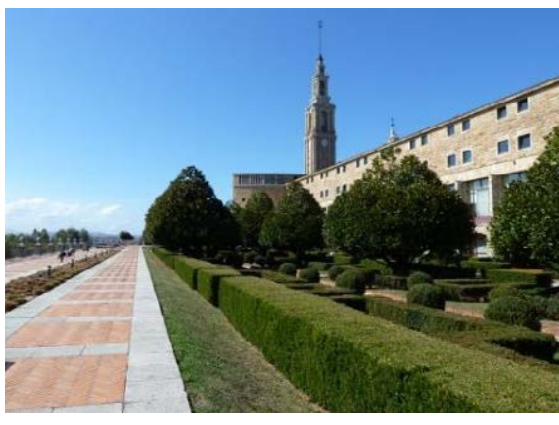
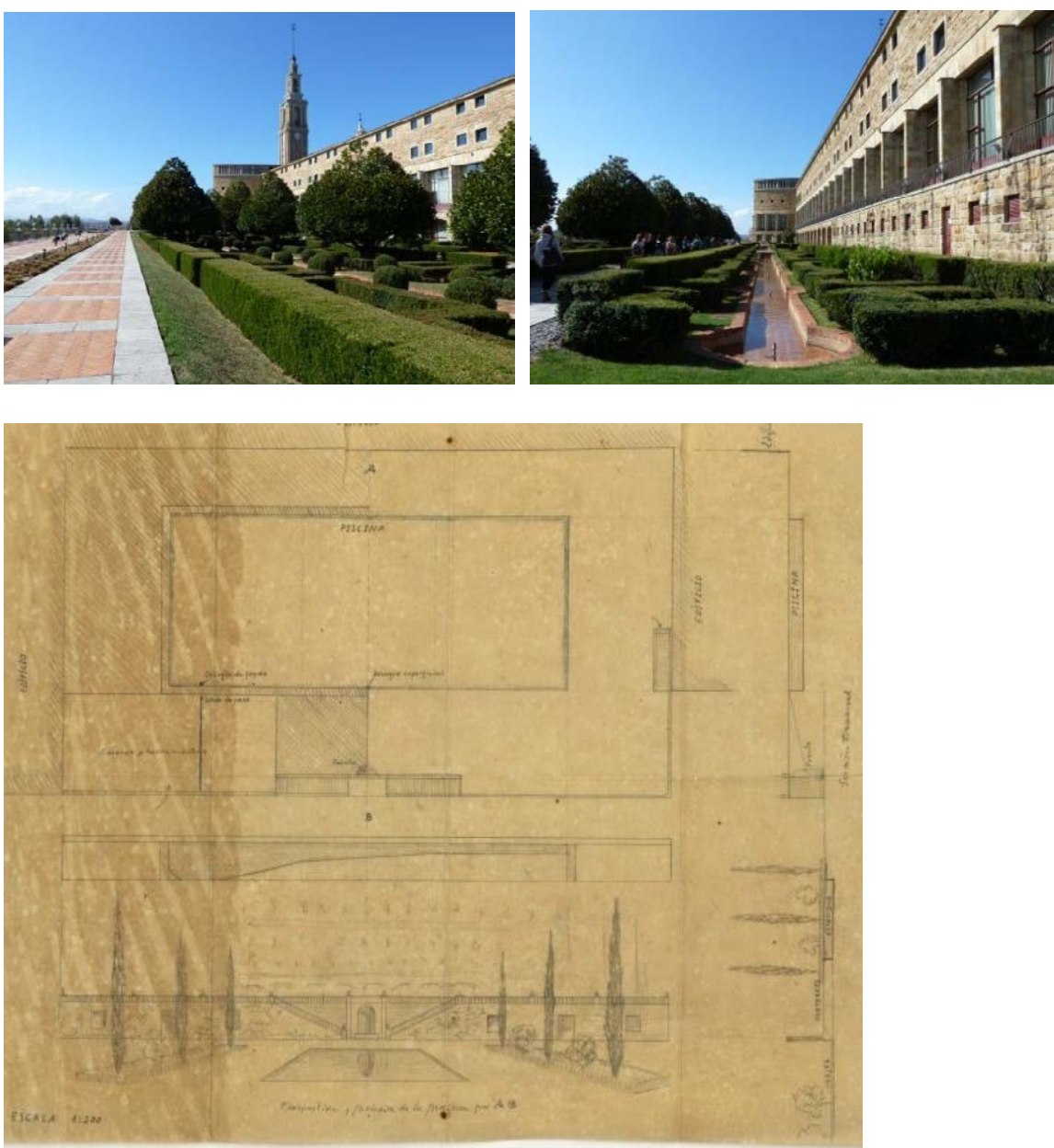
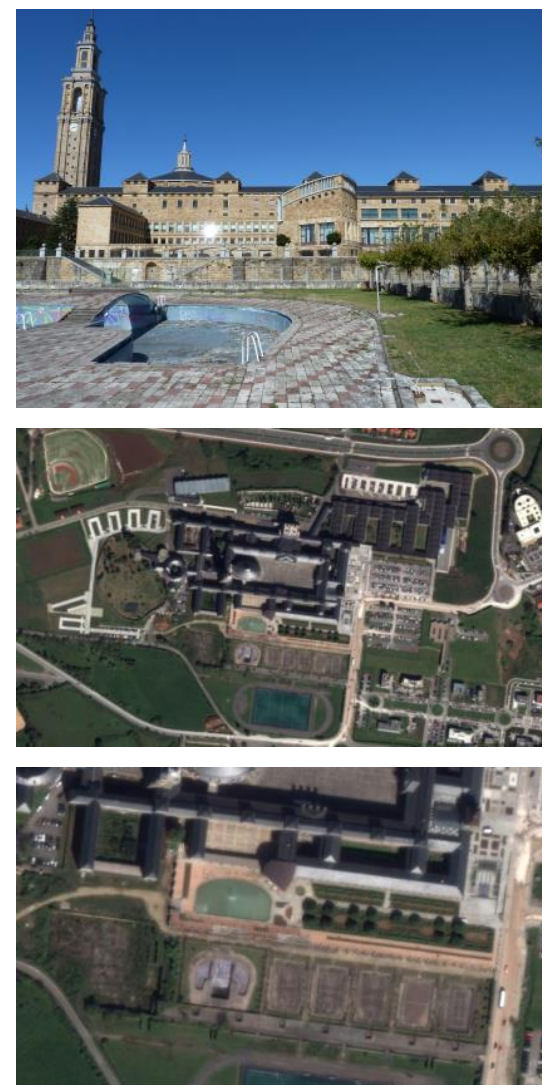

6.93 Universidad Laboral de Gijón: vistas aéreas y actuales. Googlemaps. PHL, septiembre 2012.

6.94 Detalles de frente y estanque de la Universidad Laboral de Gijón. Winthuysen, 1950. ARJB, Div.IX 59,1. 

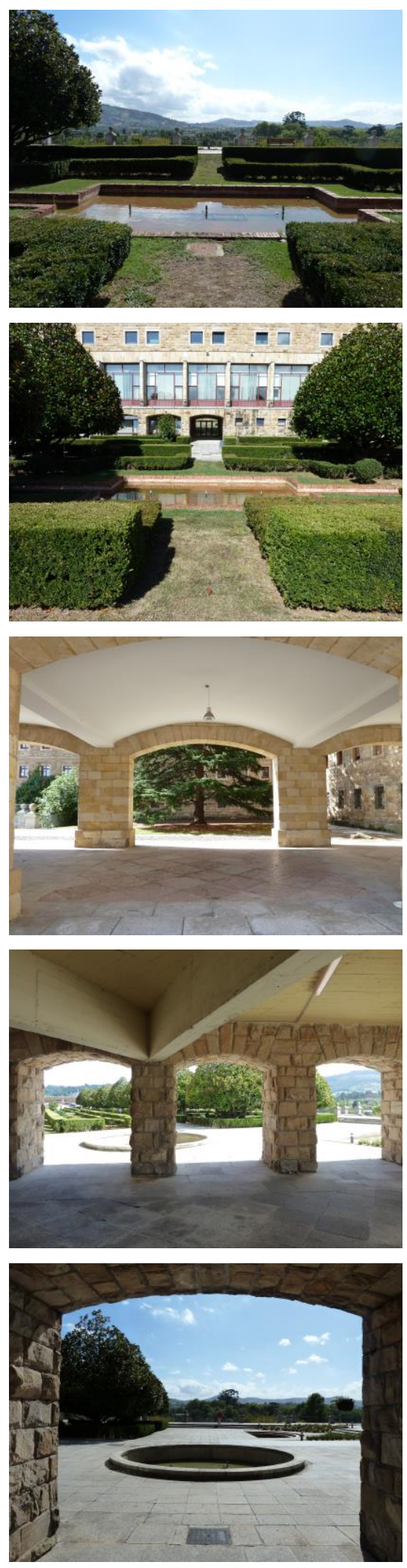

6.95 Jardín de parterres, estanque principal y vistas concatenadas. PHL, septiembre 2012.
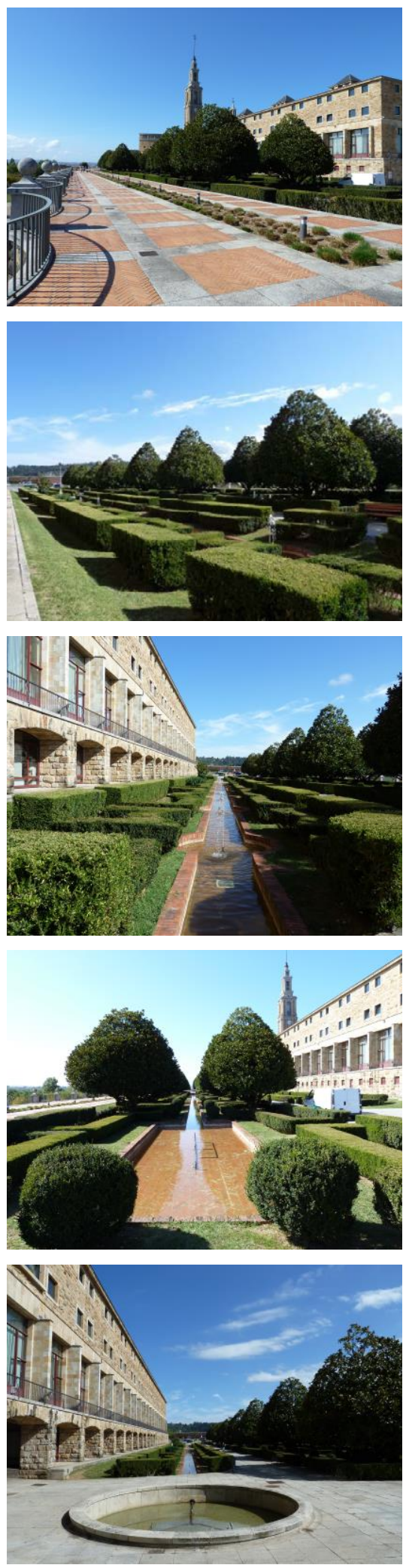
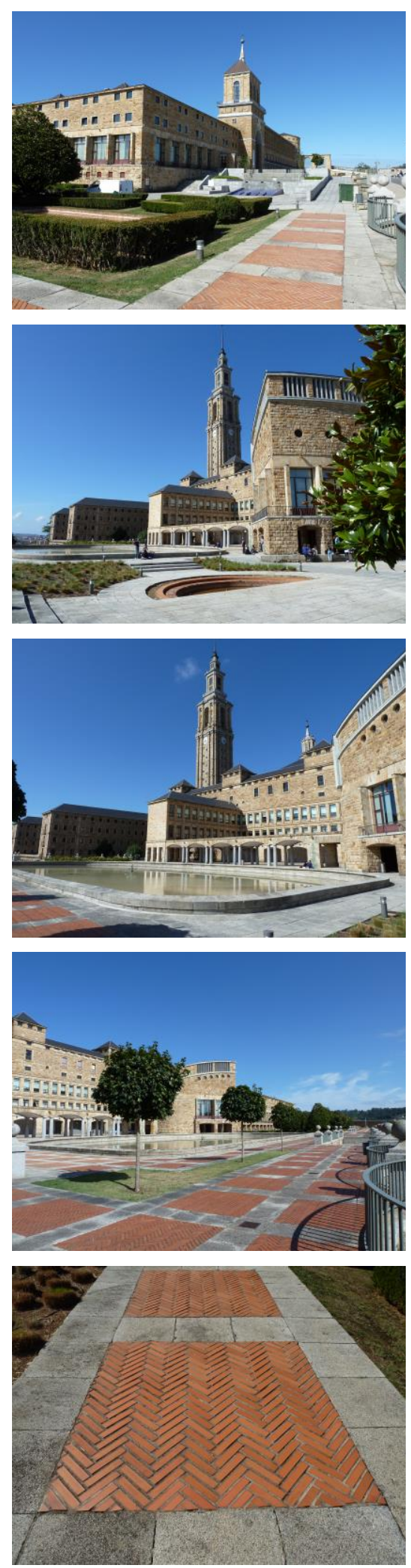
Hay una preocupación por los ejes visuales y el paisaje. Se observa cómo en el eje del gran estanque hay una sucesión de espacios y vistas concatenados: desde la arquería del patio se ve el estanque, una vez atravesado este filtro se llega al jardín de cuadros y más allá en un nivel inferior los campos de deporte con la piscina y el paisaje como fondo de la composición. Esta concatenación de vistas se completa con la creación de miradores desde donde contemplar el panorama.
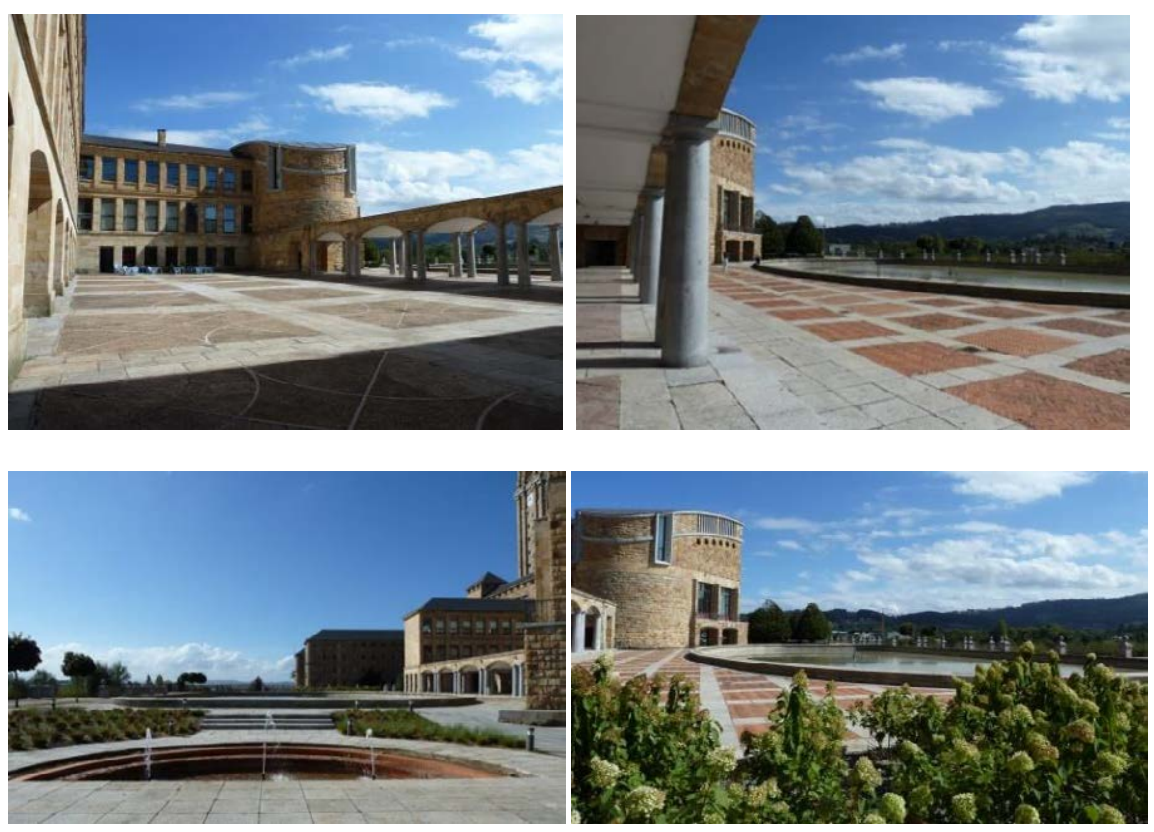

El parque ha sufrido enormes modificaciones; el mismo Winthuysen dice de él que es un hijo falso: "El proyecto del parque de Somió con las correcciones de arquitectos, etc., no lo conocería ni el padre que lo engendró. Suponiendo que el padre fuese a verlo realizado, que no irá, porque lo considera como hijo espurio"17. El diseño del proyecto original se ha visto bastante alterado; se construyó un gran estanque de bordes redondeados acortando los cuadros longitudinales y rematándolos con una fuente baja semicircular, y los cuadros de la terraza inferior desaparecen para dar lugar a los campos deportivos. A lo largo de los años el recinto ha sufrido numerosas ampliaciones y remodelaciones convirtiéndose en el actual complejo "Laboral ciudad de la cultura"18.

\footnotetext{
17 WINTHUYSEN, J.: Memorias de un Señorito Sevillano. 1942. HÉCTOR VÁZQUEZ, 2005, p.262.

${ }^{18}$ Se han construido unos grandes aparcamientos al este y el acceso se ha acompañado con nuevas zonas ajardinadas. Declarado BIC en 2016.
}
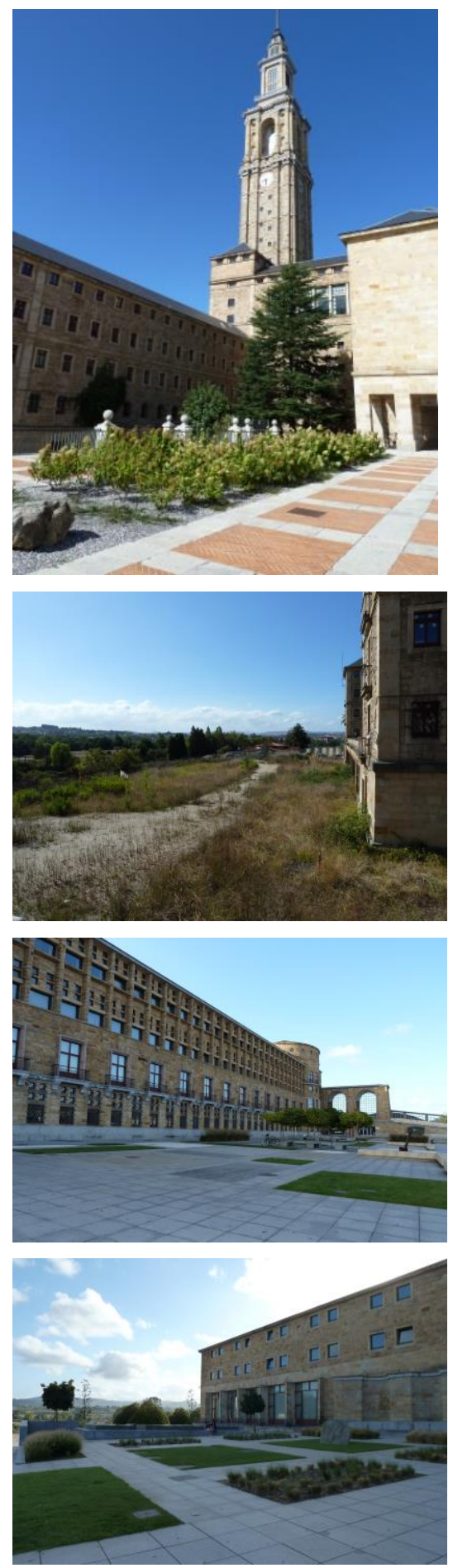

6.96 Universidad Laboral de Gijón. Solar sin ajardinar en el límite suroeste y nuevas zonas ajardinadas de acceso al recinto. PHL, septiembre 2012. 

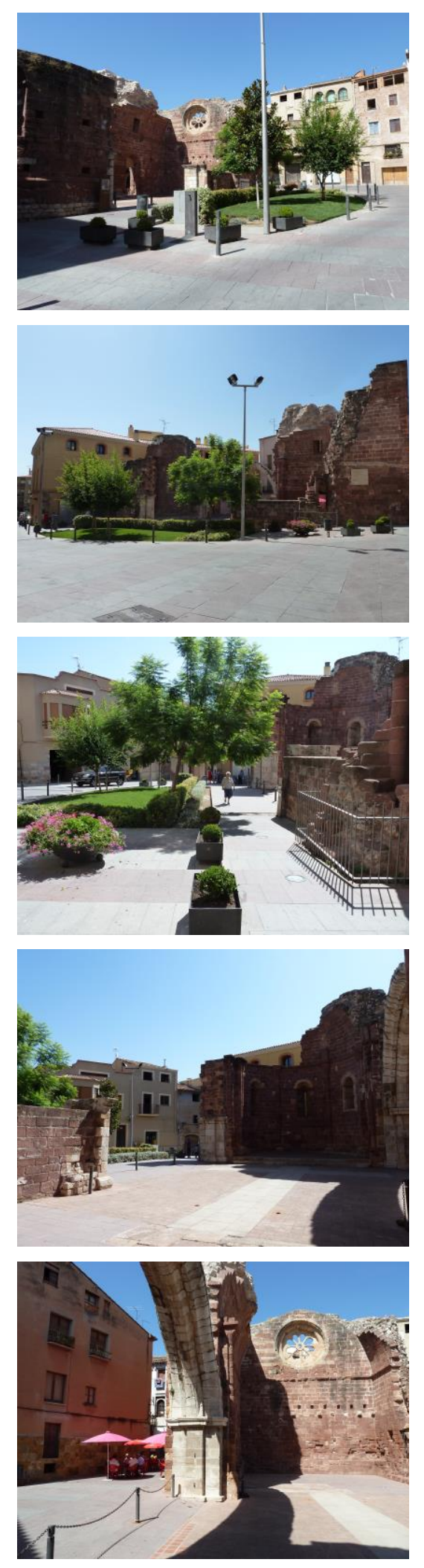

6.97 Vistas actuales del jardín de la iglesia románica de Alcover. PHL, agosto 2012.

6.98 Planta del jardín situado entre las ruinas de la Iglesia Románica de Alcover. Winthuysen, 1952. ARJB, Div.IX 62.1
Winthuysen realizó un pequeño jardín sobre las ruinas de la Iglesia Románica de Alcover en Tarragona (1952). La composición tiene dos ejes perpendiculares, uno de los cuales coincide con el eje longitudinal de la antigua iglesia y el otro es transversal centrado en el hueco entre las ruinas. El eje longitudinal une una alberca rectangular junto a un gran sauce llorón y una fuente circular con un surtidor. En el eje transversal coloca otra fuente cuadrada con surtidor y simétricamente planta dos acacias triacanto y dos cipreses piramidalis como si creara un cerramiento vegetal en las partes que falta el muro de la iglesia.

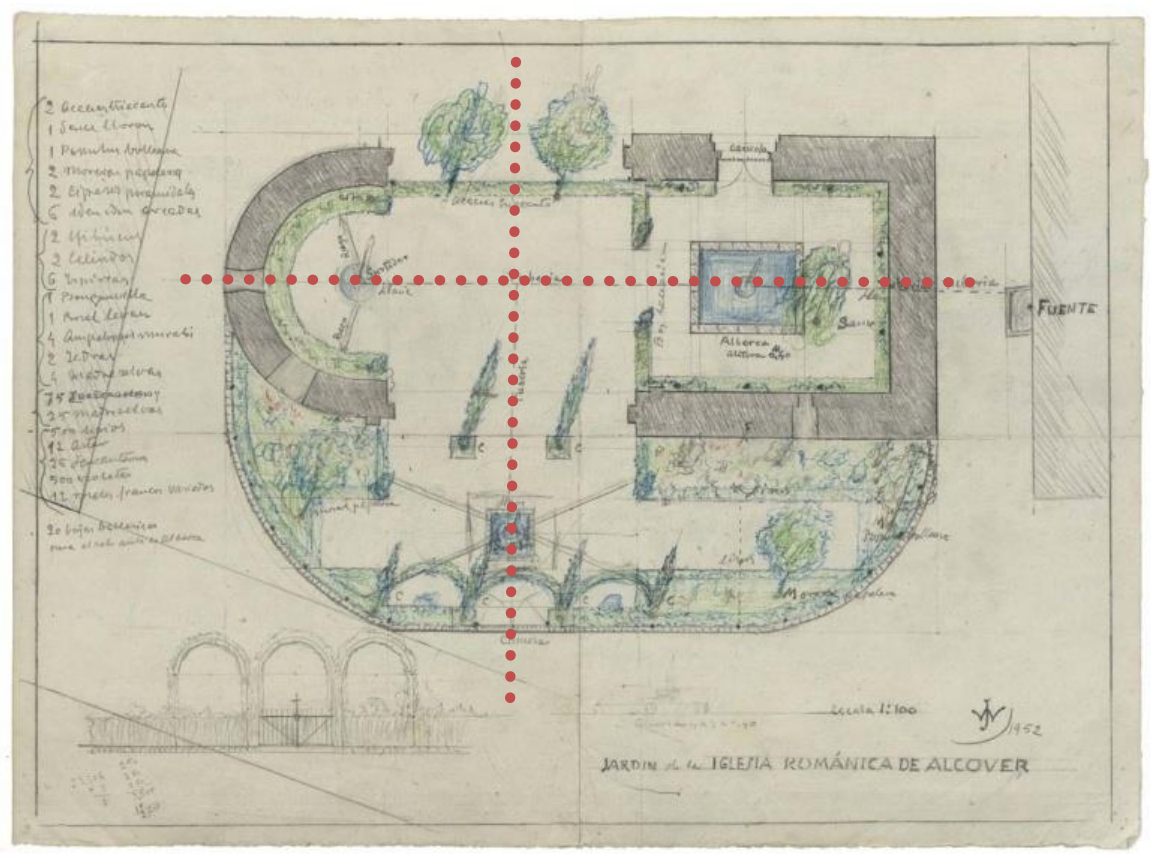

Delante crea una pequeña plaza alargada con bordes curvos, donde ubica la fuente cuadrada con surtidor y proyecta un elemento en el cerramiento para rematar el eje transversal y marcar el acceso utilizando cuatro cipreses y tres arcos vegetales con trepadoras, colocando en el central una cancela. Dibuja un pequeño boceto de este alzado con todos los elementos. Coloca otra cancela en la parte opuesta para cerrar las ruinas. La plaza está limitada por un tapiz verde en el que coloca: arbustos, flores y algún árbol -dos moreras del papel y un chopo (populus bolleana)-. El cerramiento de este espacio se realiza con un muro vegetal formado por un seto de la misma altura que la cancela: "un cerramiento al modo de los 'quarters' ingleses"19. Especifica también el resto de plantaciones: arbustos (espírea, celindos, hibiscos...), trepadoras (madreselvas, ampelopsis, buganvilla, rosales...), flores (lirios, aster, violetas...),

\footnotetext{
${ }^{19}$ AA.VV.: Javier de Winthuysen. Jardinero, 1986, p. 104.
} 
veinte bojes para formar el seto alrededor de la alberca, etc. Aprovecha una fuente existente cercana para llevar el agua a los nuevos elementos acuáticos; en el plano detalla de forma esquemática las tuberías de conexión y el riego. Desgraciadamente de todo esto no se conserva nada ${ }^{20}$.

Son varios los jardines que proyectó y realizó Winthuysen para instituciones públicas donde se encuentran similares características: fuerte geometría, adaptación a la topografía, separación y resolución de circulaciones peatonales y de carruajes, creación de espacios estanciales y de recogimiento integrados en el trazado general, trazados clásicos combinados con otros irregulares, utilización de especies mediterráneas, realización de miradores desde los que contemplar el paisaje, etc. Estas constantes se aprecian en proyectos contemporáneos o posteriores como: la fuente para el patio del Instituto San Isidro (Madrid, 1923), el jardín de la Escuela de Cerámica (Madrid, 1925), el jardín para las desaparecidas escuelas en la calle Ávila (Madrid, 1929), jardines de la Fundación del Amo (Madrid, 1933), los proyectos no realizados de los antiguos Jardines del antiguo hospital de Santa Cruz y el jardín para la Sinagoga de Santa María la Blanca (Toledo, 1935), el Instituto Fray Bernardino Álvarez (Madrid, 1950), el Jardín del Museo Arqueológico de Ibiza (1949-1951) que sirve de enlace entre la ciudad alta y la baja, etc. ${ }^{21}$

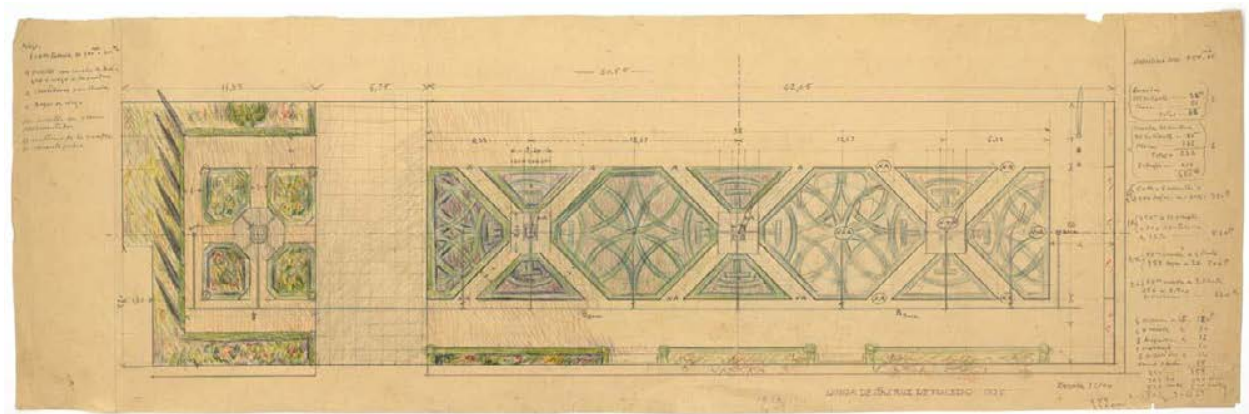

\footnotetext{
${ }^{20}$ Actualmente hay un pavimento continuo que conecta la plaza y las calles adyacentes. El pavimento cambia de color en el interior de las ruinas de la iglesia. La vegetación se reduce a un pequeño cuadro de césped que forma una calle interior, y está limitado interiormente por arbustos bajos y con algún pequeño árbol, estando protegido en el lado exterior mediante bolardos. En los extremos hay maceteros rectangulares de hormigón con pequeñas bolas de arbustos y en un lado se ubica una fuente del mismo material. El paso a las ruinas está parcialmente cerrado mediante bolardos con cadenas. En la calle posterior se ha instalado incluso alguna pequeña terraza de un bar.

${ }^{21}$ El jardín de la Central Eléctrica de Alcalá del Río (Sevilla, 1931) se analiza en el capítulo de Jardines industriales modernos - Precedentes.
}

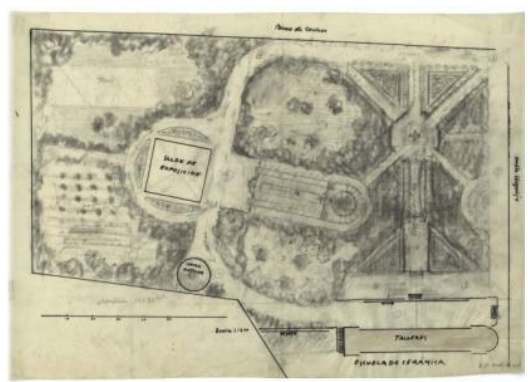

6.99 Plano de la Escuela Cerámica de Madrid. Winthuysen, 1925. ARJB, Div.IX 13,1 .
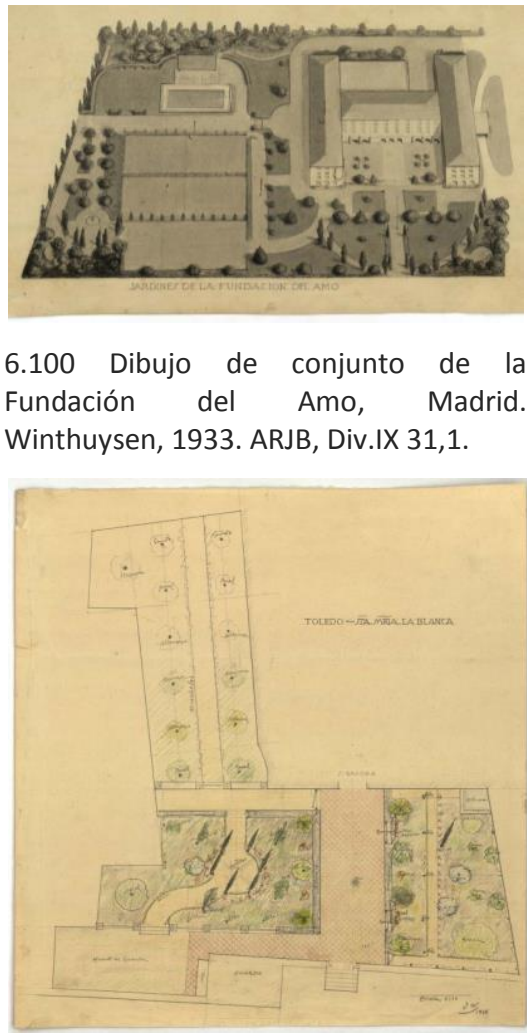

6.101 Jardín para la Sinagoga de Santa María la Blanca, Toledo. Winthuysen, 1935. ARJB, Div.IX 45,1.

6.102 Planta del jardín del antiguo Hospital de Sta. Cruz con anotaciones de riego, Toledo. Winthuysen, 1935. ARJB, Div.IX 44-1. 

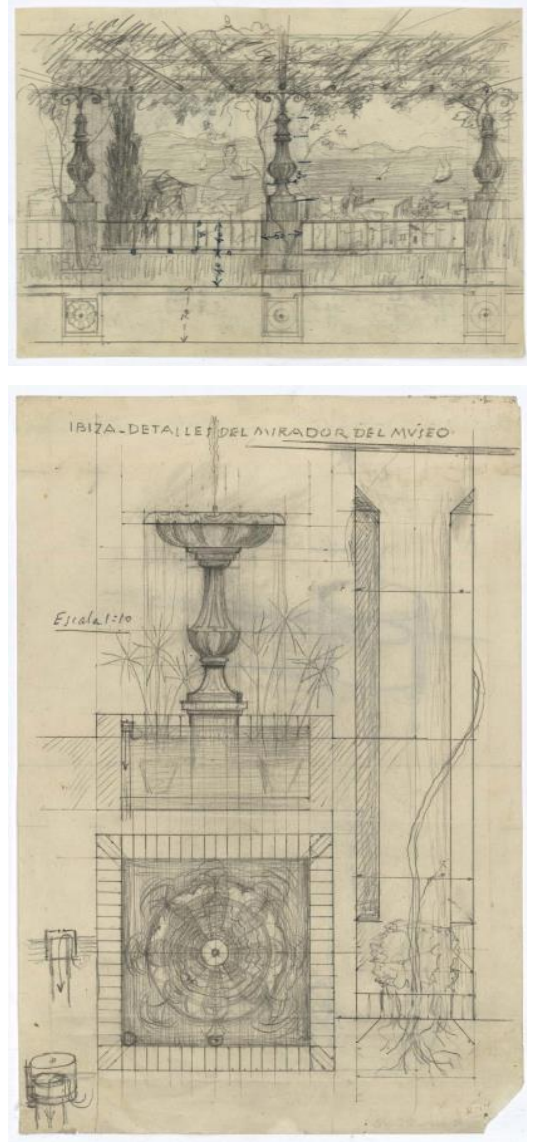

6.103 Jardín del Museo Arqueológico de Ibiza. Winthuysen, 1949: vista de Ibiza desde el Mirador del Museo Arqueológico y detalles del mirador. Plano de riego y vista general del jardín.. ARJB, Div.IX 55,5-10-12-13.
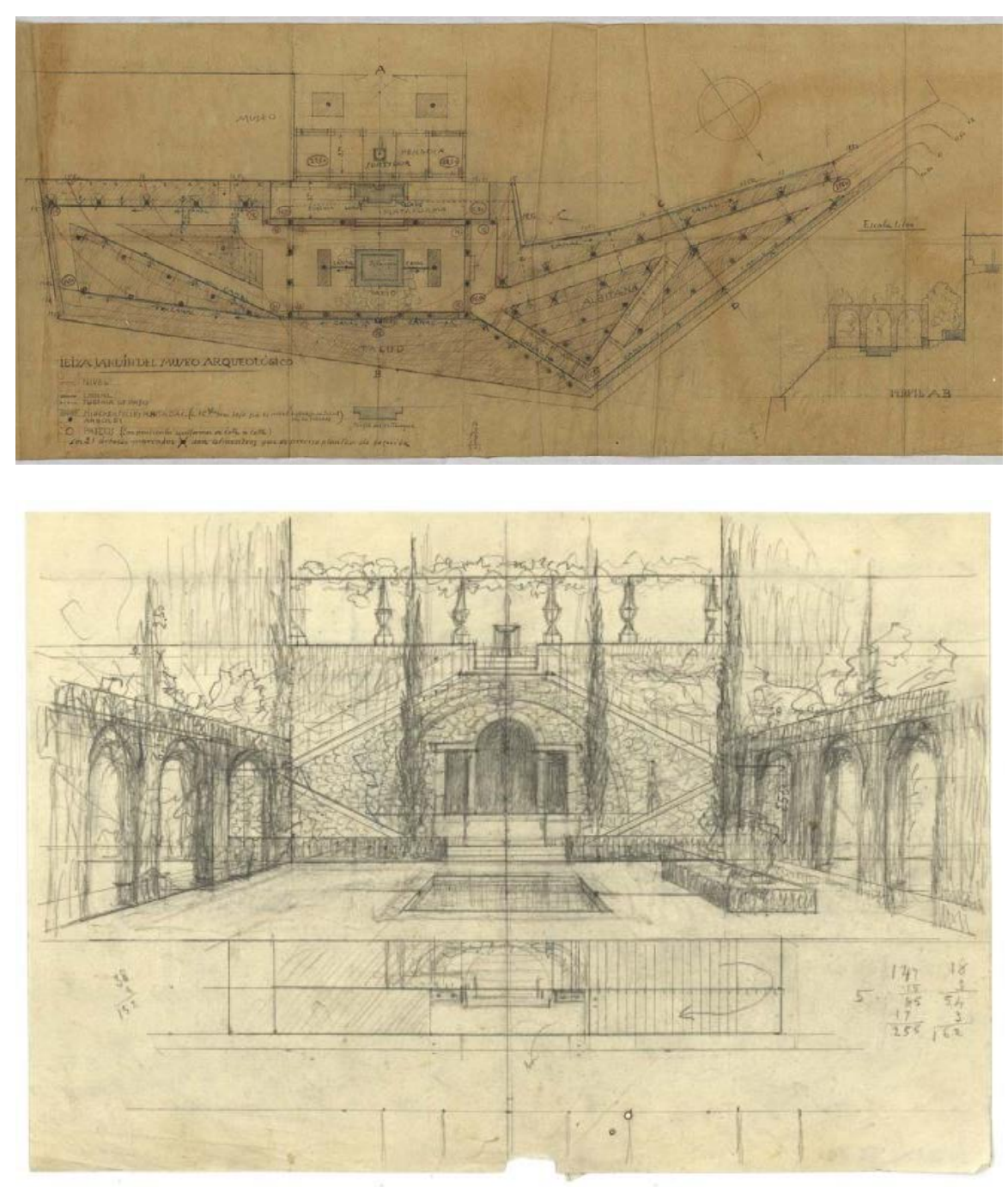

Salvar y proteger los jardines. Los parajes naturales y pintorescos

Durante los años anteriores a la guerra Winthuysen dejó de lado la pintura ya que no compartía las nuevas tendencias como el cubismo, para dedicarse a las tertulias intelectuales con sus amigos y a hacer jardines ${ }^{22}$.

En 1934 la Dirección General de Bellas Artes le encomendó la formación del Patronato de Jardines Históricos de España. Winthuysen era considerado un experto en el tema, ya que había publicado su libro Jardines clásicos de España (Madrid, 1930) que recogía toda su investigación. Desde dicho Patronato llevó a cabo sus reivindicaciones y veló por la integridad de los jardines. Numerosos jardines se inventarían, catalogan y declaran como

22 "Los absurdos de las múltiples tendencias modernas con sus pretendidas originalidades ajenas a toda razón estética, pesaron sobre mí en el sentido de preocuparme si yo era un anticuado incapaz de evolucionar y como yo no aceptaba la pintura sino como dilettanti aquello no solamente no lo aceptaba sino que me repelía y me refugié en absoluto en mis jardines". AA.VV.: Javier de Winthuysen. Jardinero, 1986, p. 24. 
"jardines histórico-artísticos", los cuales según él debían ser considerados como "monumentos". Es el primero que dignifica el jardín reivindicándolo "como obra de arte". Adelantándose a su tiempo intenta proteger los "lugares pintorescos" y los "sitios y lugares de belleza particular reconocida". Para conseguir la protección que les correspondía monta una legislación nueva, pionera en Europa ${ }^{23}$.

Los años posteriores a la guerra estuvieron muy marcados por la muerte de su hijo durante la contienda; se instaló en el barrio barcelonés de Les Corts con su segunda mujer María Héctor Vázquez y sus dos hijas viviendo en condiciones muy duras. Fue entonces cuando el marqués de Lozoya, Director General de Bellas Artes, reorganizó el Patronato de Jardines Artísticos y Parajes pintorescos de España, devolviéndole su cargo de Inspector General de Jardines en 1941. En esta etapa restauró otros jardines importantes como el jardín de Monforte en Valencia, El Capricho en la Alameda de Osuna. Este trabajo de restauración lo compagina con sus labores de investigación, la pintura y la difusión de los jardines mediante sus publicaciones. Su labor de conservación de los jardines históricos será continuada por el arquitecto Leopoldo Torres Balbás (1888-1960) ${ }^{24}$ quien realizó importantes aportaciones sobre la conservación patrimonial en la que se incluyen los jardines. Torres Balbás introdujo en España los nuevos conceptos de restauración monumental que inauguraron la disciplina de forma científica en España. Precisamente Winthuysen se sumó a esta tendencia $y$, de forma similar, restauró jardines sin intenciones imitativas sino conservadoras.

Después de la Guerra Civil, ante las destrucciones ocasionadas, volvió a su empeño de salvar y proteger los jardines. Empezó a trabajar en la recuperación y protección de parajes naturales y pintorescos como el Lago de Bañolas o el de Sanabria y el Palmeral de Elche, preocupándole que se viesen afectados por los nuevos

\footnotetext{
23 "Considerando la importancia estética e histórica de estas obras, la no menor para el interés social y la trascendencia que para el arte moderno se derivan; estando todo por hacer en este orden y creyendo de conveniencia nacional el desarrollo de una política de nuestra jardinería, sería necesario proceder a la catalogación de los jardines para fijar lo existente, declarando monumento de interés artístico estas obras, que, por su cualidad especial de vitalidad y continuado desarrollo, no pueden ser consideradas como otra clase de obras inertes, y que necesitan un régimen especial e idóneo para ser conservadas e inspeccionadas por la Dirección General de Bellas Artes...". WINTHUYSEN, J.: Memorias de un Señorito Sevillano. 1942. HÉCTOR VÁZQUEZ, 2005, p.275-276.

${ }^{24}$ Ver capítulo Actuaciones urbanas-Jardines reinventados.
} 
crecimientos urbanos, la construcción de grandes obras de ingeniería y las nuevas infraestructuras. Los informes que realiza para estos lugares son "un modelo de cómo se debe proceder para proteger bellezas paisajistas" 25 . Propone una serie de medidas preventivas para evitar el uso abusivo y el turismo masivo en estos lugares: “...hoy, universalizado el jardín, extendido más allá de lo urbano, en el sentido, no de jardín propiamente dicho, sino de solar general, de parque total, en que los medios de locomoción han convertido lo que antes eran bosques infrecuentados y temerosos, hay necesariamente que unir a toda aquella ciencia y arte la cooperación del ingeniero, del urbanista, del higienista, del sociólogo. / Montes públicos convertidos en parques nacionales son hoy algo más que utilitarismo, y no basta en ellos solamente los conocimientos de selvicultura. Las plantaciones de las carreteras, si han de ser respetadas, si no han de ser destruidas por el interés particular (en ocasiones enteramente sagrado), han de acomodarse a la compatibilidad de cultivos colindantes" 26 .

Hasta entonces en España no había ninguna política respecto de tales cosas, pero sí interés -preocupación por el paisaje en la Institución Libre de Enseñanza, sus excursiones anuales a Guadarrama, las descripciones de paisajes de la generación del 98, etc.-.

Un antecedente en estos temas, aunque bastantes años antes, lo encontramos en la figura del Frederick Law Olmsted Sr. (18221903), principal paisajista y defensor de la belleza natural americana, trabajando para el servicio público en las áreas de planificación y paisajismo. Su hijo Frederick Law Olmsted Jr. (18701920) fue su sucesor en la lucha para la conservación y preservación del paisaje americano, siendo los impulsores de leyes, planes y programas para los parques nacionales, estatales y locales en EEUU. En 1916 Olmsted Jr. contribuyó a darle forma a la legislación al crear el Servicio Nacional de Parques, con el espíritu de "conservar los escenarios y los objetos naturales e históricos y la vida silvestre existente para proveer su aprovechamiento de tal manera que puedan permanecer intactas para el disfrute de las generaciones futuras...". "Trabajando con paisajes reales

\footnotetext{
25 WINTHUYSEN, J.: Memorias de un Señorito Sevillano. 1942. HÉCTOR VÁZQUEZ, 2005, p.266.

${ }^{26}$ WINTHUYSEN, J: El jardín y la Naturaleza. España Forestal, octubre 1927. En: Jardines de España (1870-1936), 1999, p. 276.
} 
existentes, me guía la inducción impresa en mí por mi distinguido padre: cuando uno se hace responsable de tales paisajes, su primer deber es proteger y perpetuar lo que de bello y de inspirador existe inherente en ellos gracias a la naturaleza y a circunstancias fuera de nuestro alcance, y así, humildemente subordinar a tal propósito cualquier impulso de ejercer sobre éstos las propias habilidades como diseñador"27. Olmsted padre era miembro del Park Movement ${ }^{28}$; esta comisión desarrolló documentos en los que se afirma el principio de la apropiación pública del patrimonio nacional y su mantenimiento; vastas extensiones de territorio pasan a ser de dominio público para formar parques naturales debidamente organizados y protegidos, evitando efectos destructores y el mal uso del territorio ${ }^{29}$. En 1872 la zona externa del valle y el bosque de secoyas de Yellowstone se convirtió en el primer parque nacional. La ley retiraba de la venta esas tierras para "colonización, tenencia o venta" y protegía "todos los bosques, depósitos minerales, atracciones naturales o maravillas", también prohibía la "destrucción desenfrenada de pesca y caza y su captura o destrucción para propósitos de venta o lucro", siendo la primera vez que el gobierno federal reservaba tierras para tal propósito; fue el inicio de la idea de parque nacional ${ }^{30}$.

Según Javier de Winthuysen: "España, país de inefables y variadísimas bellezas paisajistas, nos ofrece en su aspecto lacustre dos grandes lagos cuyo interés estético se une al geológico que representan./.../ Si el lago de Sanabria por su nivel altísimo puede ser desangrado por la ingeniería moderna, consumiendo su enorme embalse, en cambio el de Bañolas ofrece sus posibilidades económicas sin menoscabo de su nivel”31. En 1940 realizó un

\footnotetext{
${ }^{27}$ National Park Service, U.S. Departments of the Interior, www.nps.gov/frla/espanol/index.htm. Consultado el 4-1-2016.

28 Movimiento de defensa a favor de la conservación y protección de los recursos naturales, consolidado en 1864 con la cesión al Estado de California del Yosemite Valley y el Mariposa Big Tree Grove y la constitución de la comisión para el estudio y formulación de propuestas de organización y gestión del área territorial del Estado de California.

29 SEGUÍ PÉREZ, V.: El reformismo paisajista del "Park Movement". Revista Geometría Digital de Arquitectura y Urbanismo, 23 marzo 2015.

30 Yosemite: Official National Park Service Handbook (no. 138), Division of Publications, National Park Service. En 1890 se unieron Yosemite -incluyendo la cuenca hidrográfica completa de los ríos y eliminando el pastoreo- y Sequoia para crear un "sistema". Gracias al esfuerzo de Olmsted surgirán muchos otros parques. National Parks for the Future. An appraisal of the National Parks as they begin their second century in a changing America. The Conservation Foundation, Washington, D. C., 1972, p. 3-4.

${ }^{31}$ WINTHUYSEN, J.: Memorias de un Señorito Sevillano. 1942. HÉCTOR VÁZQUEZ, 2005, p.262-263.
} 


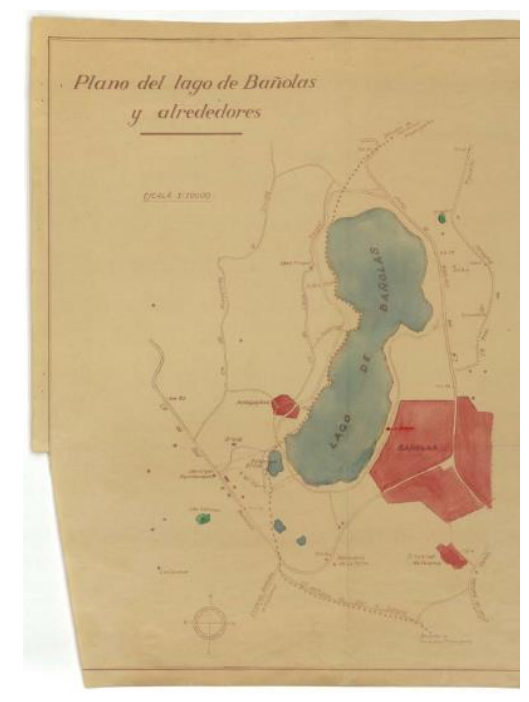

6.104 Mirador del Lago de Bañolas: plano general del lago de Bañolas y alrededores (destacando algunas zonas con color), 1940; planta, sección y emplazamiento del Lago de Bañolas, 1911. Winthuysen. ARJB, Div.IX 51, 1-2.
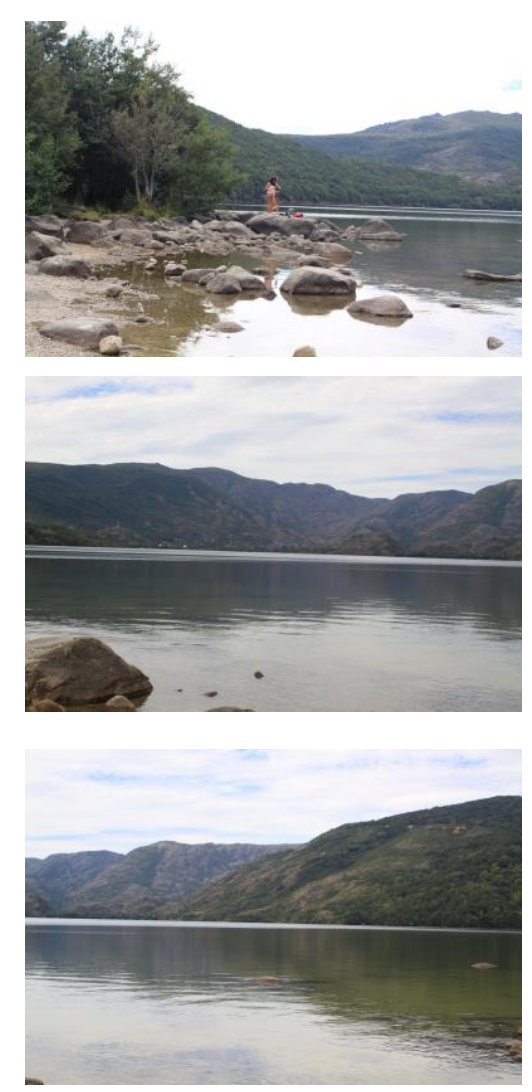

6.105 Lago de Sanabria: vistas actuales. PHL, septiembre 2010. informe ${ }^{32}$ sobre el lago de Bañolas en Gerona, amenazado por el desarrollo urbano, para el Patronato del Lago. Es el mayor lago de Cataluña, también conocido como L'Estany (el estanque); con forma de ocho y una longitud aproximada de $2 \mathrm{~km}$, se sitúa al noroeste del núcleo de población. Winthuysen se interesa por este paraje, declarado paisaje pintoresco en 1951, por ser el humedal más importante de la región con un gran valor medioambiental al acoger un gran número de aves y anfibios ${ }^{33}$. El ayuntamiento de Bañolas construyó un camino perimetral que permitía recorrer su contorno "en sus orillas que en la prehistoria ocuparían los palafitos se han construido pesqueras. /.../ Desde la ciudad de Bañolas, las carreteras próximas y la Font Pudosa, se han construido también amplios accesos, por un canal, se ha unido el Lago con el Estanyol, fomentando la cría de peces, y esta labor cultural que los monjes iniciaron en la Edad Media, aún continúa..."34. Señala los distintos tipos de vegetación que se puede encontrar en el recorrido: hileras de frondosos plátanos, frondosas plantaciones de sauces llorones, alamedas, cipreses que rodean la ermita, robledales y pinares. En colaboración con el Patronato por él creado y el Patronato Local de Bañolas realiza varias obras de acondicionamiento: "el belvedere o "Mirador del Lago", canalillos, puentes, accesos, plantaciones, etc., para la necesaria expansión pública de aquellos lugares cada vez más concurridos" ${ }^{\prime 35}$. Ubica el mirador sobre el lago en un lugar donde se pudiera contemplar todo el conjunto. Es de planta elíptica y se desarrolla en dos niveles limitados con muretes de piedra que conforman bancos y protegido en la parte superior con arbustos y árboles. Cuenta con espectaculares vistas sobre los bosques $y$ montañas que lo rodean ${ }^{36}$.

\footnotetext{
32 Recogido en la propuesta para la declaración de paraje pintoresco presentado por el Patronato del Lago en 1944. AA.VV.: Javier de Winthuysen. Jardinero, 1986, p. 115.

33 Declarado por la Generalitat de Cataluña como zona integrante del Plan de Espacios de Interés Natural y en 2003 se incluyó en la lista Ramsar de Zonas Húmedas de Importancia Internacional. Varios colectivos han pedido la catalogación de Parque Natural.

34 WINTHUYSEN, J.: Memorias de un Señorito Sevillano. 1942. HÉCTOR VÁZQUEZ, 2005, p.264.

${ }^{35}$ Completadas por los trabajos de la Comisión de Urbanización de la Provincia de Gerona, teniendo en cuenta los contornos del lago para la conservación de su carácter paisajista. WINTHUYSEN, J.: Memorias de un Señorito Sevillano. 1942. HÉCTOR VÁZQUEZ, 2005, p.267.

36 Fue acondicionado con motivo de ser sede de las Olimpiadas de 1992 construyéndose unas instalaciones de remo, y sede del Campeonato Mundial de remo en 2004, siendo actualmente un lugar privilegiado de práctica de deportes acuáticos.
} 


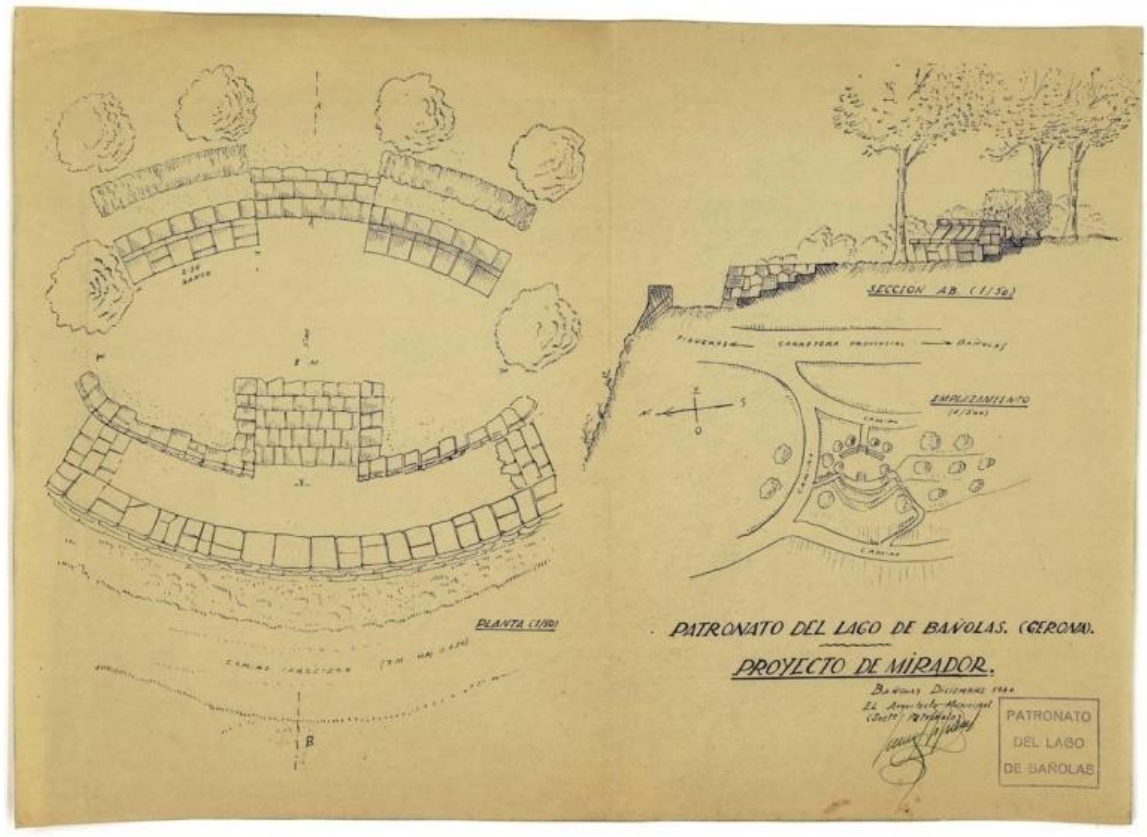

En 1946 se declaró paisaje de interés el Lago de Sanabria en Zamora y en 1952 el Patronato de Jardines artísticos y Parajes Pintores de España le encargó un informe sobre la conveniencia de declarar al lago paraje pintoresco, declaración que consigue un año más tarde. "Al visitar estos lugares, quedamos sorprendidos y admirados de su grandiosa y singular belleza. Su gran masa de agua, queda encerrada por altos montes cuya vegetación baja desde las cumbres hasta las orillas del Lago, albergando una fauna en la que hallamos desde la caza mayor, corzos y jabalíes, hasta las especies anfibias entre ellas las nutrias, palmípedos y zancudas..." ${ }^{37}$. Esta superficie de agua de $7 \mathrm{~km}^{2} 38$ y origen glaciar, se denominaba originalmente Lago de San Martín de Castañeda. Su acceso se realiza por una carretera en su lado sur rodeada de robles y castaños naturales y en sus recodos hay playas. Winthuysen señala que con la desaparición de los antiguos monjes y con la construcción de las nuevas comunicaciones, la amenaza de la tala de árboles y la pesca y caza de trucha abusiva son mayores ${ }^{39}$.

Otro ejemplo es el Palmeral de Elche en Valencia con un paisaje singular que recuerda a un oasis oriental. Un complejo sistema de regadío tradicional islámico con canales que abastecen al área de Huertos conocida como "El Palmeral" con miles de alineaciones de

\footnotetext{
37 WINTHUYSEN, J.: Memorias de un Señorito Sevillano. 1942. HÉCTOR VÁZQUEZ, 2005, p.266.

38 3,5km de largo x 2,5km de ancho, una profundidad máxima de $53 \mathrm{~m}$ y una altitud de $1.028 \mathrm{~m}$.

39 Este espacio fue declarado parque natural en 1978.
}

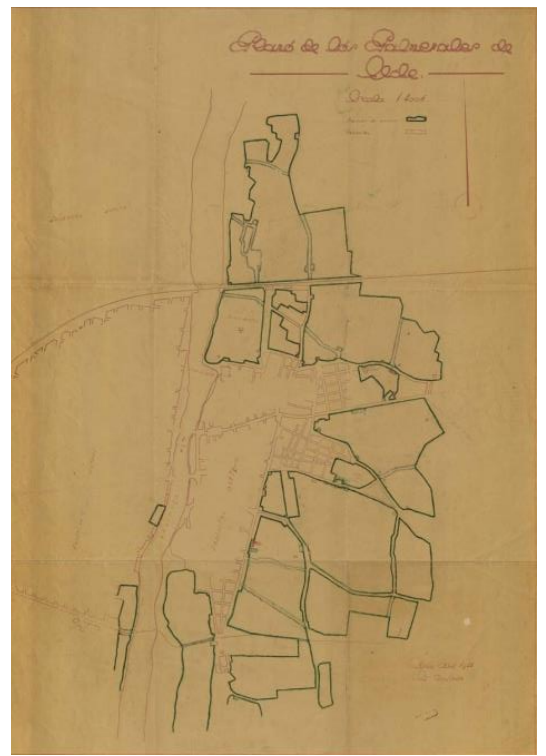

6.106 Plano de los palmerales de Elche. Winthuysen, 1944. ARJB, Div.IX 52,1.

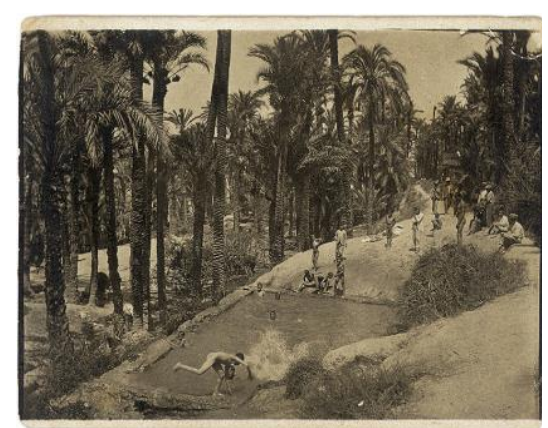

6.107 El chapuzón en el Palmeral de Elche. Archivo del Museo Escolar Agrícola de Puçol. Generalitat Valenciana.

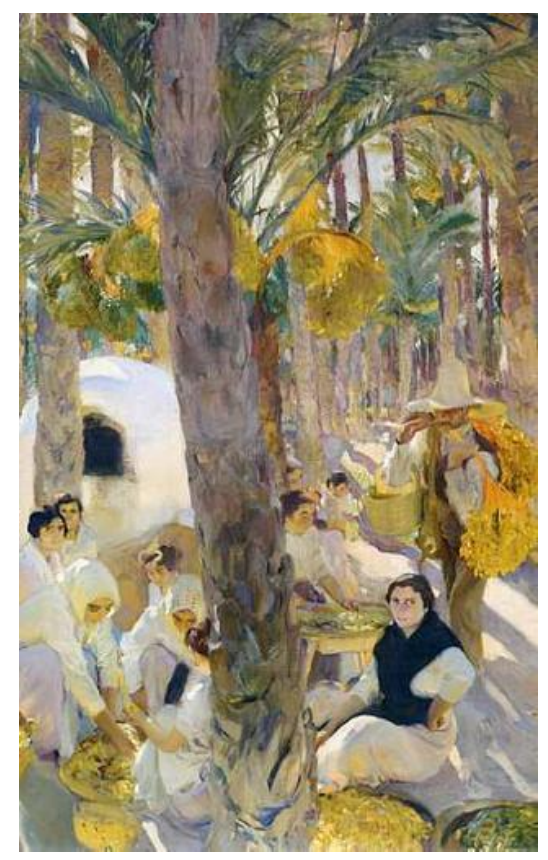

6.108 El Palmeral de Elche. Joaquín Sorolla, 1918. Óleo sobre lienzo, The Hispanic Society of America, New York. 

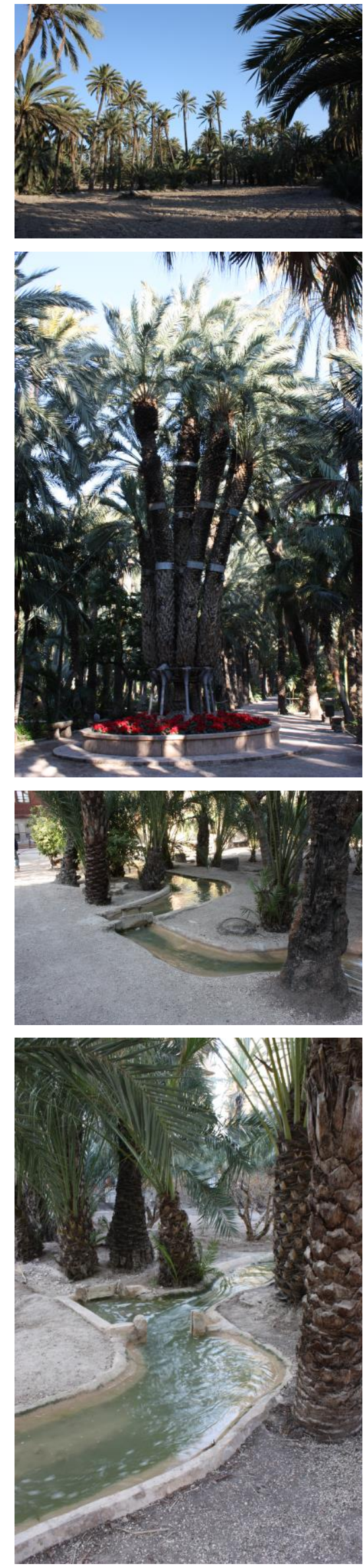

6.109 Palmeral de Elche: vistas actuales. Adrià Besó Ros, 2014, trabajo sobre la visión cultural del Palmeral de Elche, Universidad de Valencia (en realización). palmeras datileras (Phoenix dactylifera) agrupadas formando un continuo mar vegetal de más de 500ha que ayudan a crecer al resto de cultivos de regadío: "Los afueras de la población -escribía Madoz en 1850- son bastante deliciosos: en primer lugar se encuentra rodeada de un bosque de extensas palmeras que se elevan a una altura sorprendente, las cuales impiden que se vea el caserío hasta casi estar dentro de él: desde lejos hace esta faja una vista hermosa, pues se destaca como un punto oscuro a manera de un grande desierto. Sucesivamente van extendiéndose fajas circulares de huerta seguidas de sembrados sin riego. Los árboles de secano reducidos a higueras, algarrobos y a tal cual almendro; la blancura y aridez aparente de los campos hacen un contraste admirable con el bosque de olivos, y este con el de las palmas, por mediar entre ellos multitud de huertas con variedad de producciones. Los canales de riego serpentean por todas partes, las muchas casas de campo que pueblan todo aquel terreno, la animación continua que se nota en los caminos y veredas, aquel sol hermoso que ostenta siempre sus dorados resplandores, todo causa sorpresa y una agradable sensación"40.

En un Decreto de $1933^{41}$ ya se recoge la preocupación por mantener este auténtico paisaje cultural: "Es un deber del Gobierno, por la Constitución de la República Española, proteger los lugares del territorio nacional notables por su belleza natural y por su reconocido valor histórico y artístico. Este deber se hace más imperioso cuando tales riquezas están a punto de desaparecer y la opinión cultural y artística española señala únicamente el peligro, solicitando que pronto se remedie. Este es el caso que actualmente se presenta con los palmerales de Elche, donde las talas persistentemente continuadas durante los últimos años, por no existir ninguna disposición legal que ponga coto a la codicia individualista de los propietarios, vienen destruyendo un tesoro tan bello de arte y cultura, excepcional en Europa [...]".

En 1946 el Patronato de Jardines artísticos y Parajes Pintores de España encargó a Winthuysen un informe sobre el estado del Palmeral de Elche ${ }^{42}$. En él indica que la especulación del terreno y el progresivo crecimiento de la ciudad son unas de las principales

\footnotetext{
40 MADOZ, P.: Diccionario Geográfico-Estadístico-Histórico de España y sus posesiones de Ultramar. 1850 , p. 461

41 Decreto firmado por el Presidente de la II República Española, Niceto Alcalá-Zamora, y el Ministro de Agricultura, Industria y Comercio, Marcelino Domingo y Sanjuán.

42 Declarado Jardín Artístico Nacional en 1943.
} 
causas de su deterioro, y elabora una serie de propuestas: "1‥- La protección debe extenderse a todos los palmerales del término municipal...2ㅇ.- Los huertos de palmeras, todos y cada uno son partes integrantes del Palmeral y su carácter ha de subsistir...3‥Los dueños de palmerales deben de abstenerse de operaciones de cultivos o actos que puedan impedir o perjudicar su normal desarrollo y vegetación...Las palmeras aisladas deben considerarse principalmente como belleza natural prohibiéndose el atado de sus copas y la poda de las ramas inferiores...4\%‥- Los dueños de huertos no podrán destinarles más que a los cultivos usuales... 5․- Las cercas o cerramientos de los huertos han de ser dispuestas en forma que no quiten la visualidad del conjunto..." ${ }^{43}$.

\section{La jardinería como disciplina docente}

Por último, no hay que olvidar la labor docente de Winthuysen, que imparte cursos en la escuela Nacional de Sanidad de ampliación de estudios a arquitectos e ingenieros. Considera que una de las causas de la degradación de los jardines españoles es la falta de profesionales en el campo de la jardinería. Otra causa que señala es la carencia de un plan docente adecuado que forme estos profesionales preparados y competentes. "Todos los países que poseen jardines de importancia tienen sobre ellos una literatura y una enseñanza especial. Ocuparía mucho espacio citar los volúmenes antiguos y modernos sobre los jardines franceses e italianos. En España carecemos de estas publicaciones y escuelas, y como consecuencia, nuestras obras de jardinería desaparecen o decaen al quedar en manos de empíricos o de horticultores ajenos a toda cultura estética"44, expone el propio Winthuysen. Estas preocupaciones junto con la defensa de la cultura de los horticultores españoles, le llevan a promover una Escuela Nacional de Jardinería hacia 1927: “...aquí podría hacerse un portento de amenidad, pero no con poco trabajo, sino con una labor previa, intensísima, de cultura, de formación de personal adecuado. Y en lo que a jardinería se refiere, sería esto enteramente factible. Con los medios de que dispone el Municipio madrileño, y contando con la organización actual de los trabajos de jardinería, que es magnífica, exceptuando lo que a estética se refiere, se podría, a muy poca

\footnotetext{
43 AA.VV.: Javier de Winthuysen. Jardinero, 1986, p. 118. En el año 2000 es declarado Patrimonio de la Humanidad por la Unesco. Actualmente parte del palmeral está embebido en la ciudad formando un enorme y singular jardín urbano.

${ }^{44}$ Javier de Winthuysen. AA.VV.: Javier de Winthuysen. Jardinero, 1986, p. 186.
} 

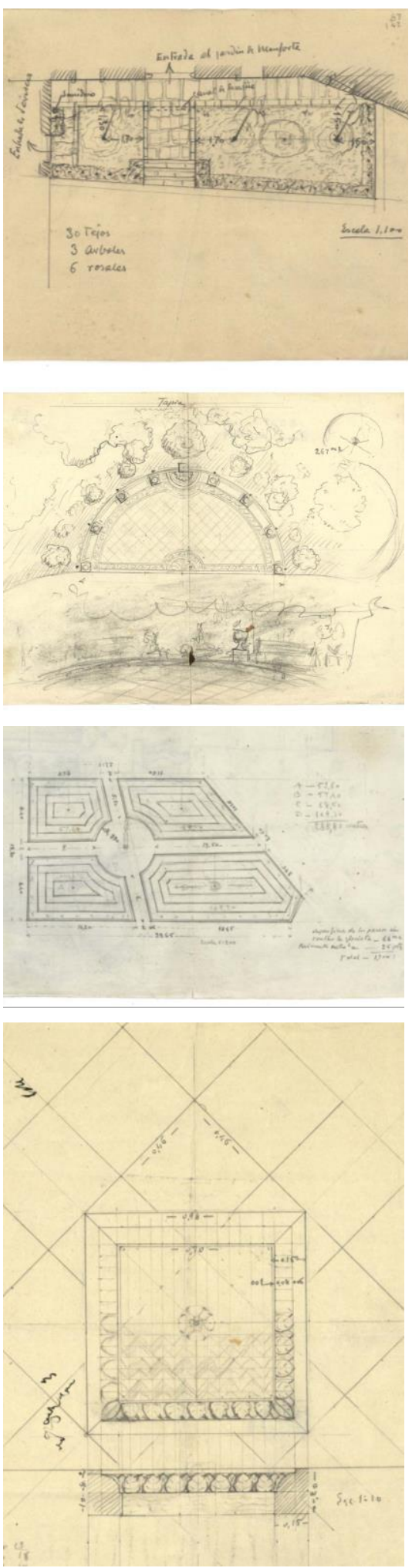

6.110 Jardín de Monforte, Valencia. Winthuysen, 1943: plano del jardín de entrada (marca la entrada principal y de servicio y anota el canal de desagüe y la plantación: 30 tejos, 3 árboles y 6 rosales), planta y perspectiva de la exedra, detalle de un cuadrante (detallando el presupuesto de la obra) y detalle del revestimiento cerámico de una fuente (1934). ARJB, Div.IX 48,2-3-58. costa, organizar una Escuela especial de Jardinería, donde se educasen oficiales, capataces, y se llegasen a formar en pocos años directores de parques y jardines con la cultura necesaria para que sus obras fuesen un acierto, y en armonía con las necesidades de una ciudad histórica, que, además de serlo, crece, se desarrolla y tiene necesidad de vivir una vida enteramente moderna. /.../ una Escuela de Jardinería Española, pero no una imitación de las extranjeras (en casi todos los países las hay), sino una creación basada en nuestro arte del jardín, que, propio o adaptado, tiene mayor importancia, por sus múltiples aspectos, que los de nación alguna. Una creación original en armonía con nuestro arte y con nuestra naturaleza, y mediante esta labor previa, labor sencilla, dependiente sólo de una buena voluntad y un sano criterio, sería posible convertir a Madrid, y aun a España entera, en un portento de amenidad" 45 .

Basándose en las necesidades de la profesión ${ }^{46}$ propone un programa de enseñanza muy avanzado para su época y que aún conserva su actualidad, en el que diferenciaba claramente las tres figuras de la profesión estableciendo una gradación en la enseñanza: maestro de jardín, arquitecto-paisajista y auxiliar ${ }^{47}$. Al maestro de jardín se le considera auxiliar del arquitecto-paisajista y ha de tener no solo una preparación técnica sino también artística; "para estar compenetrado con la dirección de su misión, digamos así, constructiva y decorativa: vida y desarrollo, cultivos, riegos y también flora que de continuo hay que renovar"48. "Para planear y atender cierta clase de obras donde los espacios libres y sus plantaciones tienen capital importancia se necesita de quien entienda del paisaje: del arquitecto paisajista que sepa armonizar con la Naturaleza. Porque coger un plano dentro del estudio y trazar sobre él calles y glorietas y saltarse a la torera niveles, perspectivas, plantaciones $\mathrm{y}$ accidentes que el terreno ofrece presentando en esos mismos inconvenientes la acentuación de

\footnotetext{
45 Winthuysen: "A muy poca costa podría ser Madrid ciudad amenísima". La Voz, 5 de mayo de 1923. En: AA.VV.: Javier de Winthuysen. Jardinero, 1986, p. 165 y 166.

${ }^{46}$ Tenía la información de los cursos que se impartían en l'Ecole du Paysage de Versalles. "Estoy medio enterado que en Francia la profesión de urbanista-paisajista es independiente de la de arquitecto, y constituye una carrera corta...".Carta de J. de Winthuysen a su hija Beatriz. Barcelona, 23 julio 1950. En: Javier de Winthuysen, padre y maestro. AA.VV.: Javier de Winthuysen. Jardinero, 1986, p. 13.

47 WINTHUYSEN, J.: Arquitectura paisajista. Arquitectura no 105, 1928, p. 63. Este programa irá evolucionando y posteriormente encontramos tres grados en su programa de enseñanza: horticultores-jardineros, maestros de jardín y directores de parques y jardines. En: AA.VV.: Javier de Winthuysen. Jardinero, 1986, p. 26-27.

48 Javier de Winthuysen. En: AA.VV.: Javier de Winthuysen. Jardinero, 1986, p. 26.
} 
originales bellezas, es tanto como proceder al margen de todo conocimiento, de todo criterio, y estamos por decir que de toda moral"49. "El arquitecto paisajista no hay duda que debe saber Botánica, pero enfocado a la Morfología vegetal, la que nada tiene que ver con la misión del ingeniero (agrícola). Que unos y otros principalmente el Arquitecto estén capacitados, ¿qué duda cabe? Siempre y cuando a los conocimientos de sus profesiones reúnan otros que los complementen, porque la jardinería artística exige una cultura más que profunda complejísima"50.

Señala que en épocas pasadas el jardín tenía casi exclusivamente importancia en las mansiones señoriales, pero que al haberse generalizado aparecen una serie de problemas de órdenes diversos que aconsejan crear la especialidad de Arquitecto-paisajista. Para llegar a ser Arquitecto-paisajista no se tiene que pasar antes por las dos figuras inferiores, sino que propone presentar "articulados los conocimientos que constituyen el conjunto, para tal grado, que necesita no sólo el conocimiento de las materias con que ha de construir, sino de las posibilidades, y de la guía de lo que necesariamente ha de regir hasta la obtención del efecto propuesto, que no está formado por materia inerte" ${ }^{51}$.

Dividía los estudios de Arquitectura Paisajista y Jardinera en cuatro grupos. El primero se refería a las Ciencias físicas y naturales: Botánica Descriptiva (Anatomía y Fisiología Vegetal), Geografía Botánica, Geología, Patología Vegetal, Zoología, Física y Química, Higiene Pública, etc. El segundo corresponde a la Morfología Vegetal en cuanto al aprendizaje de pintura paisajista mediante los modelos vegetales a través de ejercicios de dibujo y color ${ }^{52}$. El tercero engloba la planimetría y construcción: Geometría, planos y niveles, perspectiva, dibujo lineal y topográfico, trazados, y nociones de construcción. El último grupo corresponde a la cultura general "que basta con lecturas" y engloba: Literatura jardines, Historia General del Arte, Estilos diversos de jardinería, Urbanismo, Parques Naturales, Decoraciones y Prácticas de cultivos de estufa y aire libre. Para estas prácticas proponía poder obtener pensiones o

\footnotetext{
49 WINTHUYSEN, J.: La reforma de las Vistillas. Crisol de Madrid, 31 de julio de 1931. En: AA.VV.: Javier de Winthuysen. Jardinero, 1986, p. 175.

50 WINTHUYSEN, J. Memorias de un Señorito Sevillano. 1942. HÉCTOR VÁZQUEZ, 2005, p.261.

${ }^{51}$ WINTHUYSEN, J.: Arquitectura paisajista. Arquitectura no 105, 1928, p. 63.

52 Detalles de hojas, flores, etc. acusando color y forma, Plantas arbusto y árboles acusando sus caracteres, Representaciones vegetales en relación con el paisaje.
} 
becas para centros extranjeros y lo mismo para visitar jardines, como explica en $1949^{53}$. Al no haber una Escuela Especial donde sólo se impartiera lo referente a la jardinería, propone estudiar las asignaturas en diversas Facultades.

Con este nuevo programa que estaba seguro tendría una gran trascendencia pretendía no solo armonizar las especialidades sino "la transformación de un pueblo"54. Debido a las circunstancias de la época y a las múltiples trabas que le ponen no consigue implantar su plan de estudios y desgraciadamente esta Escuela Nacional de Jardinería no llegó a existir. Winthuysen quería que su hija Beatriz continuara sus pasos, pero no como un jardinero sin estudios sino como un Arquitecto Paisajista. Para ello la animó a cursar la única especialización a nivel de máster -tras una carrera universitaria- que por aquella época se impartía en la Universidad de Harvard en Estados Unidos. “...Si a mí no me hubieran puesto tantos estorbos a estas horas había en España una escuela paisajista como la de Harvard y unos jardines tan buenos como los de mejores épocas y aún mejores" 55 , se quejaba Winthuysen.

Esta intención suya se recogerá en futuras propuestas para los planes de estudios de Arquitectura, como en el de 1937 para la Escuela de Barcelona donde se intentó introducir una asignatura de "Paisaje y Jardinería" dentro de los cursos libres de especialización para la especialidad de arquitecto urbanista, aunque por cuestiones políticas no se llevó a término ${ }^{56}$.

\footnotetext{
${ }^{53}$ Carta de J. de Winthuysen a su hija Beatriz. Barcelona, 16 octubre 1949. En: Javier de Winthuysen, padre y maestro. AA.VV.: Javier de Winthuysen. Jardinero. Madrid, 1986, p. 12-13.

54 WINTHUYSEN, J: El jardín y la Naturaleza. España Forestal, octubre 1927. En: Jardines de España (1870-1936), 1999, p. 276.

${ }^{55}$ Carta de J. de Winthuysen a su hija Beatriz. Barcelona, 7 noviembre 1952. En: Javier de Winthuysen, padre y maestro. AA.VV.: Javier de Winthuysen. Jardinero, 1986, p. 14.

56 Escola d'Arquitectura de Barcelona: documentos y archivo. (Antoni Ramon, Carmen Rodríguez, eds.) Barcelona: Edicions UPC, c 1996, p. 121.
} 


\section{Conclusiones}

Winthuysen fue una figura clave en la jardinería española en el primer tercio del siglo XX. Gran defensor de los jardines españoles, planteó la recuperación de los jardines históricos -infravalorados y olvidados y muchas veces en peligro de desaparecer- como una toma real de conciencia ante la pérdida del patrimonio histórico y no como una moda cultural como sucedía en Europa. Su trabajo de inventariado y catalogación de los mismo culminó con su libro Jardines clásicos de España (Madrid, 1930), investigación de gran importancia y trascendencia, ya que hasta entonces solo había trabajos fragmentarios y estudios parciales de algunos jardines; sus levantamientos y material fotográfico serán indispensables para realizar restauraciones de jardines históricos con rigor. Gran dinamizador de estos temas en España, publicó y difundió el material de su investigación en varios periódicos y revistas de la época, que fueron fundamentales para sensibilizar a la población y a las administraciones públicas de la importancia de los jardines. Fue quien dio rango arquitectónico a la jardinería -que, como Olmsted, denominaba arquitectura paisajista-.

Su trabajo de velar por la integridad de los jardines le llevó a la formación del Patronato de Jardines Históricos de España; numerosos jardines se inventariaron, catalogaron y declararon como "jardines histórico-artísticos". Fue el primero que dignificó el jardín reivindicándolo "como obra de arte". Winthuysen restauró numerosos jardines sin intenciones imitativas sino conservadoras, siguiendo la tendencia de Torres Balbás quien introdujo en nuestro país los nuevos conceptos de restauración monumental que inauguraron la disciplina de forma científica en España. Después de la Guerra Civil, ante las destrucciones ocasionadas, volvió a su empeño de salvar y proteger los jardines; empezó a trabajar en la recuperación y protección de parajes naturales y pintorescos Palmeral de Elche, Lago de Bañolas y de Sanabria-. Propone una serie de medidas de protección -frente a los nuevos crecimientos urbanos y las nuevas infraestructuras- y preventivas para evitar el uso abusivo y el turismo masivo en estos lugares. Sus informes para estos lugares fueron un modelo para futuras protecciones del paisaje.

Durante toda su vida trabajó en la creación de nuevos jardines. Su principal característica es la incorporación de elementos y 
esquemas tradicionales de la arquitectura de jardines españoles. Critica los modelos extranjeros que se aplican en España y propone recuperar el carácter de las ordenaciones antiguas y volver a utilizar elementos propios españoles atendiendo a las exigencias de nuestro clima. En lugar del uso abusivo de las praderas impracticables en nuestro clima, defiende elementos propios de los jardines españoles: recuadros bajos rodeados de setos vivos que conservan la humedad y sirven de marco a diversas flores, frutales alternados con cipreses y arbustos diversos. Propugna la adaptación compositiva al medio físico: agua para control climático, recuadros de flores bajos para aprovechar el riego, setos que protegen plantaciones de los vientos cálidos, alternancia de la planta noble con el frutal, etc. Huye de la multitud de especies nuevas y exóticas que habían entrado con la jardinería del siglo XIX y recupera las plantaciones tradicionales españolas. Denuncia la moda de la época de hacer jardines andaluces por todas partes sin tener en cuenta las características y el clima de cada región, y propone no unificar las costumbres y los jardines, sino valorar y realzar los aspectos de cada territorio.

Acomete una actualización del jardín tradicional, diferenciándose dos etapas en su trabajo. En la primera, totalmente de influencia andaluza, estudió los diferentes elementos de la jardinería andaluza que incorpora a sus jardines -patios, fuentes bajas de cerámica policromada, surtidores, acequias, treillages cubiertos de trepadoras, arriates floridos, bancos de azulejos, mosaicos...-, junto con sus rasgos fundamentales -ocultación desde el exterior con el patio como articulación o intermedario, integración del jardín con la casa, agua con valores estético y funcional...-. La segunda, tras la Guerra Civil, más mediterránea, influenciada por sus estancias en Barcelona e Ibiza, en los jardines plasma la tradición mediterránea. Plantea el reconocimiento de un jardín hispano procedente del mediterráneo formulado por Forestier y que también defenderá su contemporáneo Rubió, independiente de los distintos modelos jardineros o modas estilísticas y que surge de una forma de proyectar basada en la adaptación compositiva al medio físico y que luego retomará García Mercadal.

Sus jardines tienen unas líneas puras y limpias, se podría hablar más de clasicista que de moderno, ya que entre sus referencias no estaban los jardines vinculados al Movimiento Moderno, sino que va a inspirarse en jardines clásicos españoles. En muchas ocasiones 
utiliza recursos claramente clasicistas: remates de eje en exedra, conexión axial entre desniveles por medio de escaleras, delimitación de espacios con arquitecturas perimetrales como columnatas y arcos de ciprés, utilización de esculturas como remate o hito axial, recurso del agua como elemento centralizador en fuentes y estanques geométricos de piedra, empleo de jarrones sobre pilares como elementos decorativos, etc. Hay que resaltar el gran valor de sus numerosos dibujos, aunque decimonónicos, ornamentados y poco modernos.

Todas sus composiciones poseen una definición espacial y una geometría clara, una regularidad, basadas en el uso de ejes de simetría, ortogonalidad, perspectiva y formas geométricas simples. Suelen ser jardines de líneas suaves para no competir con la arquitectura, y excepcionalmente, cuando la parcela lo exige utiliza trazados mixtilíneos combinando formas clásicas con líneas ondulantes. El jardín está constituido por unidades independientes que se relacionan entre sí por paseos y ejes perspectivos y a una escala menor consigue crear unos espacios estanciales más íntimos con carácter propio y conectados mediante caminos. Se adaptan a la topografía existente mediante varios niveles o plataformas que se conectan por escaleras y caminos en pendiente que salvan los diferentes desniveles y delimitan las diferentes partes del jardín. Se aprecia una clara gradación de las partes. Todas estas características las aplicará a los jardines que construye para los aristócratas de la época; descarta el jardín como añadido decorativo de la casa y lo ve como un espacio descubierto que se integra con el cubierto.

Defendió el carácter arquitectónico de la jardinería. En cuanto a la vegetación a veces utiliza diseños más clásicos como alineaciones arbóreas que definen trazados y paseos, macizos bien delimitados con borduras y setos recortados con dibujos de broderies a la francesa; otras utiliza disposiciones más libres. Recurre al ciprés para crear alineaciones, formas arquitectónicas -pabellones, arcos, muros, nichos...- y como elemento aislado puntual. Parece que prefiere la hoja persistente para crear la estructura del jardín.

Fue considerado como uno de los primeros paisajistas españoles de su generación. Se aprecia una preocupación por el entorno de sus obras, con la participación del paisaje exterior en el jardín a través del tratamiento de los miradores. En proyectos como Valedenoja y 
la Laboral de Gijón se aproxima a los problemas de la gran escala y se preocupa por temas de paisaje como: perspectivas, vistas, miradores, accesibilidad, conexiones, etc. Los jardines son capaces de integrar los diferentes edificios, y éstos con el paisaje.

Procura que la jardinería y la arquitectura formasen un conjunto armónico. En los edificios de carácter monumental donde predominaba la regularidad geométrica y la simetría armonizaban mejor los jardines geométricos regulares que los diseños sinuosos de los jardines paisajistas, sin embargo Winthuysen recurrirá a estos trazados cuando la topografía o el proyecto se lo pida. Tiene en cuenta las vistas de las fachadas de los edificios y las perspectivas del jardín desde ventanas y balcones, por lo que no pone árboles altos que las tapen cerca de los edificios arquitectónicos. Procura facilitar un camino recto y con una amplia perspectiva desde la entrada hacia el edificio. Son varios los jardines que proyectó y realizó para instituciones públicas donde se encuentran similares características: fuerte geometría, adaptación a la topografía, separación y resolución de circulaciones peatonales y de carruajes, creación de espacios estanciales y de recogimiento integrados en el trazado general, trazados clásicos combinados con otros irregulares, utilización de especies mediterráneas, realización de miradores desde los que contemplar el paisaje, etc.

También trabajó la escala urbana, siendo un gran defensor de la creación de nuevos jardines como medio para armonizar los aspectos antiguos y modernos de la ciudad; criticó la mala planificación urbana, el abandono y destrucción de los espacios verdes y anima a su conservación. Realizó un estudio sobre los espacios libres para la "Memoria sobre la Ciudad" para el Ayuntamiento de Madrid, fundamental para el desarrollo del nuevo urbanismo y de donde surgieron proyectos de arquitectos pioneros. Comprende perfectamente la adaptación al clima español y cómo se han de solucionar compositivamente el control del impacto medioambiental. Demuestra estar bastante al día en las necesidades de la ciudad moderna y manejar los criterios funcionales básicos aplicados a la jardinería, lejos de los ornamentales decimonónicos; preludia por tanto aspectos que reaparecerán más tarde, tras la Guerra Civil. Winthuysen defiende que para conseguir estos parques necesarios para el disfrute público no se deberían utilizar modelos ajenos a ellos, como sucede en España con los grandes parques a la andaluza. Promueve el uso 
de la vegetación autóctona de bajo mantenimiento. Generalmente sus composiciones urbanas tienen fuertes ejes de simetría que ordenan el conjunto y con un área central en la que se colocan los elementos acuáticos (estanques, fuentes, surtidores), distribuyéndose a lo largo del eje longitudinal que se remata con formas circulares y se rodea de sucesivas bandas de vegetación con setos y alineaciones.

La labor docente de Winthuysen también fue fundamental impartiendo numerosos cursos. Considera que algunas causas de la degradación de los jardines españoles son la falta de profesionales en el campo de la jardinería y la carencia de un plan docente adecuado que los forme, por lo que promueve una Escuela Nacional de Jardinería Española, basada en nuestro arte del jardín y no una imitación de las extranjeras. Propone un programa de enseñanza muy avanzado para su época y que aún conserva su actualidad, en el que diferenciaba claramente las tres figuras de la profesión -maestro de jardín, arquitecto-paisajista y auxiliar-, estableciendo una gradación en la enseñanza. Debido a las circunstancias de la época y a las múltiples trabas no consiguió implantar su plan de estudios y desgraciadamente no se creó la Escuela; pero su intención se recogerá en futuras propuestas para los planes de estudios de Arquitectura.

A pesar de su gran labor, es necesario señalar la posición relativa de Winthuysen como precedente en la introducción del jardín moderno en España. Su aportación al jardín moderno consiste en crear un método proyectual basado en la adaptación compositiva al medio español según las necesidades funcionales y ambientales y sin utilizar elementos exóticos ajenos o propios sin razón. Defendió la búsqueda del origen de este jardín hispano y sus características invariantes que le hacen ser único; esta labor la continuará posteriormente Rubió y Mercadal. 
La idea, un tanto romántica, de la ciudad-jardín, consistía en ofrecer constantemente a sus habitantes las ventajas de la ciudad y las del campo, tendiendo a la formación de una ciudad modelo, tanto desde el punto de vista estético como higiénico./ La ciudad-jardín debe comprender, además de los barrios de habitación para la población burguesa, obrera e intelectual, centros industriales y comerciales que den trabajo y ocupación a la población trabajadora. Debiendo ser previstas extensiones agrícolas próximas que procuren los elementos de consumo inmediato para satisfacer las necesidades de la población. En una ciudad-jardín bien organizada no faltarán las escuelas, tanto primarias como secundarias, centros de educación moral y física del pueblo, obras de mutua asistencia y de higiene social, lugares de diversión, campos de juego.

GARCÍA MERCADAL, F.: El urbanismo nueva técnica del s. XX. Arquitectura, Año XVI, no 5, junio-julio de 1934. Madrid: Colegio Oficial de Arquitectos, p. 126. 


\section{EL JARDÍN DOMÉSTICO}

\section{Las colonias jardín}

\section{Antecedentes}

Durante los años veinte del siglo pasado comenzaron a realizarse una serie de asentamientos de viviendas unifamiliares en el extrarradio de Madrid, que prácticamente era campo sin edificar. Estas agrupaciones seguían una serie de normas que les otorgaban un carácter uniforme; son las llamadas "colonias", que sirvieron de modelo y fueron extendiéndose por el resto de la península.

Se mezclan varios factores: la carencia de vivienda, las nuevas ideas higienistas y la falta que tenía la capital de zonas verdes a distancias apropiadas para el uso diario de la población de los distintos barrios. Esto se intentaba paliar, en parte, por la introducción de algunas áreas de ciudad jardín en contacto con zonas de edificación densa. En Madrid Arturo Soria refleja estas ideas de ciudad-jardín en un artículo de la revista Ciudad de 18991; mientras que en Barcelona, Cebriá Montoliú ${ }^{2}$ en 1912 fundó la Sociedad Cívica La Ciudad-Jardín, dependiente del Museo Social y publica el libro La Ciudad Jardín. Ya en 1917 el arquitecto municipal, Emilio de Alba, aplica estos conceptos a la zona del ensanche madrileño próxima a El Viso madrileño: "Este concepto de crear un parque urbanizado no es otro, a mi juicio, que la creación de un barrio urbano dentro de un terreno destinado en su mayor extensión a parque, aunque éste no sea del dominio público, sino un conjunto de parques particulares o privados, cuyos beneficios alcanzan al público avecindado, lo que en lenguaje más vulgar y nuevos procedimientos de urbanización se llama un barrio jardín"3.

Sin embargo el modelo de las colonias españolas se asemeja más bien el de los suburbios jardín; aunque algunas no tienen ningún edificio ni espacio comunitario -iglesia, escuela o plaza- integrado en su trazado; tampoco presentan generalmente viviendas en hilera, esquinas abiertas, jardines comunes ni otros elementos característicos de los suburbios jardín. Las primeras colonias, de tiempos de Primo de Rivera, son exclusivamente agrupaciones de

\footnotetext{
${ }^{1}$ SORIA Y MATA, A.: La ciudad ideal. The Garden City, La Ciudad Lineal, no 56, 5 agosto 1899.

2 Jurisconsulto y sociólogo vinculado a la Institución Libre de Enseñanza. Arquitectura de Madrid. Introducción. Madrid: Fundación COAM, 2003, p. 80.

3 Memoria del plan de ensanche de Emilio Alba, 1917. BERGAMín, R.: El Viso: un poco de historia. Arquitectura. Madrid: Colegio Oficial de Arquitectos. 1967, № 101 mayo, p. 29.
} 
casas baratas, aisladas y con un minúsculo jardín alrededor. Las posteriores de más postín, como El Viso, tienen terrenos mayores para la casa y el jardín, y presentan en proyecto algunos elementos comunes club de tenis, iglesia...-, pero no logran tener la unidad que requiere un suburbio jardín.

En comparación con otros modelos europeos se aprecia cómo las limitaciones del momento redujeron sus intenciones sociales, sus posibilidades organizativas y la composición de la forma urbana, a las soluciones, tan pobres, de las colonias españolas.

Las primeras colonias iban principalmente destinadas a obreros, apoyadas por la Ley de Casas Baratas de 1911, y se concentraron en la periferia; durante la II República se destinaron a las clases medias acomodadas y se localizaron mayoritariamente en el Ensanche. Es en estos años 1930 cuando empiezan a surgir en la capital un segundo grupo de colonias de hotelitos con jardines ${ }^{4}$. Esta arquitectura experimental de nuevas viviendas sigue las líneas del Movimiento Moderno: austeridad compositiva, volúmenes sencillos y ausencia de ornamento. Al exterior suelen contar con un sencillo zócalo de revoco pétreo y fachada enfoscada y pintada en colores. Se desarrolla un programa cubriendo las necesidades de una vivienda e intentando buscar el máximo confort; pretenden ser viviendas cómodas adaptadas a las necesidades de la vida moderna. Generalmente constan de tres plantas: semisótano con zona de servicio, garaje e instalaciones; planta baja, ligeramente elevada sobre el jardín, con las habitaciones comunes; planta primera con los dormitorios y planta de terraza que a veces alberga un estudio. Frecuentemente los huecos de la planta baja son mayores $y$ empiezan a aparecer amplios ventanales de vidrio que permiten una mayor relación interior-exterior además de asegurar la higiene y buena iluminación. Así lo explica Bergamín: “París. Año 1925. La Exposición de Artes Decorativas. Lo descubrimos todo, desde Hoffmann a L'Esprit Nouveau. Los holandeses...Todo lo que intuíamos durante largos años. A partir de entonces, vemos nuestro camino. Viene a casa Theo Van Doesburg, conozco a Bruno Taut, a Le Corbusier...Ya hablamos el mismo lenguaje" ${ }^{\prime 5}$.

\footnotetext{
${ }^{4}$ Parque Residencia, El Viso, colonia para la Unión de Funcionarios Civiles en el barrio de Pacífico, etc.

${ }^{5}$ Entrevista a Rafael Bergamín. Amann, Eduardo: Paseo por "El Viso" madrileño del brazo de Bergamín. El Inmueble. 1966, no 2 marzo, p. 19.
} 


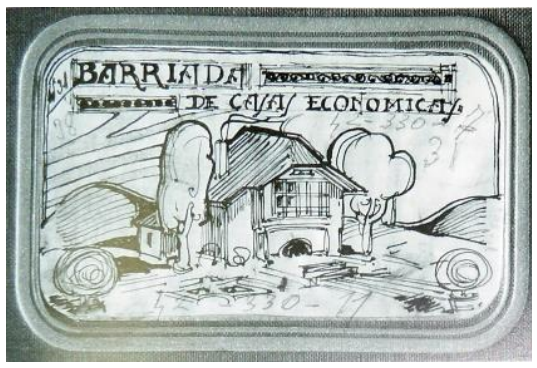

7.2 Dibujo de una vivienda en barriada de casas económicas. J. López Salaberry, 1921. SAMBRICIO,, 2003, p. 53.

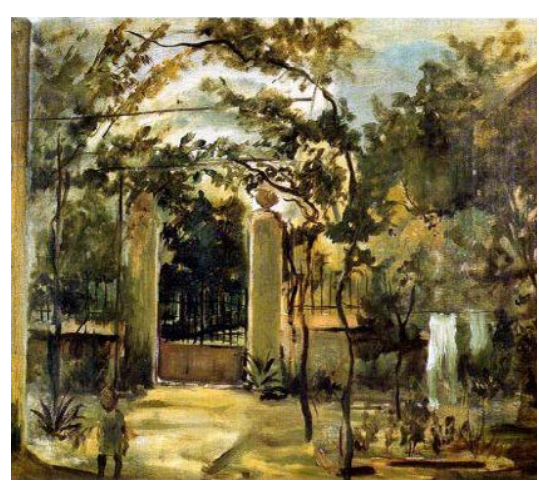

7.3 Casa del pintor en Ciudad Jardín de Madrid, Eduardo Vicente, 1943. Foroxerbar.com
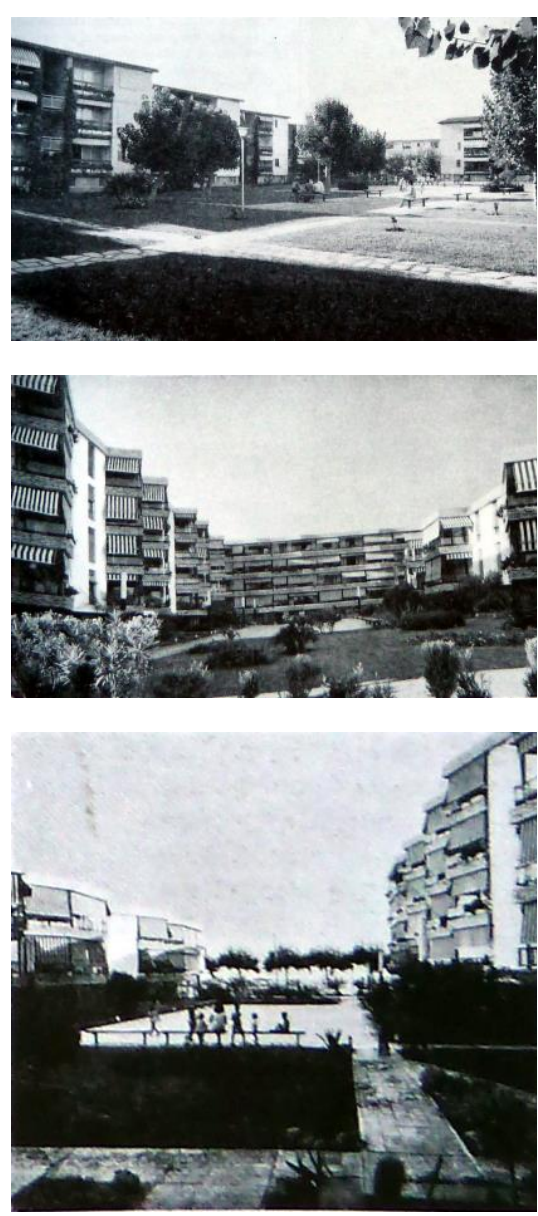

7.4 Jardines mancomunados de la sociedad Salou Mediterráneo en Salou, Tarragona. CORREA, 1965-1967, p. 23.
Los bloques buscaban la orientación óptima y seguían un funcionalismo humanista en el que la gente desarrollaba sus actividades dentro de la vivienda. La casa se retranqueaba por medio de sus jardines, de dimensiones suficientes para conseguir el aislamiento necesario. Se responde al concepto de artista de vanguardia que concibe el arte como un todo $y$ en el que el arquitecto y la arquitectura no se hallan separados de las demás manifestaciones artísticas. Se entiende la vivienda como un conjunto, diseñando no solo la edificación sino también su mobiliario y sus jardines. Estos se desarrollan alrededor de la casa prolongando el espacio vividero en el exterior y se componen con sus propios ejes y geometría; en muchos casos son los propios ejes de la casa los que se prolongan al exterior. Procuran adaptarse al terreno y a los desniveles de las calles perimetrales desarrollándose en diferentes plataformas conectadas mediante escaleras. Generalmente son las estancias comunes y los dormitorios principales los que dan al jardín y disfrutan de sus vistas. En las viviendas entre medianeras el jardín se desarrolla en dos partes: un jardín delantero y otro trasero; mientras que las viviendas en esquina al disponer de mayor terreno suelen constar de cuatro partes: un patio con entrada de coches, un jardín particular elevado, un patio-jardín o terraza protegido de las vistas del vecino y la calle y con salida directa desde el comedor o el estar, y el patio de servicio, independiente con entrada directa a la zona de servicio en semisótano y que alberga el garaje.

A pesar de estar destinadas en origen para clases modestas, actualmente muchas de estas colonias se han convertido en auténticos barrios residenciales de lujo. Aunque están protegidas, muchas de ellas han perdido su carácter y cualidades visuales debido a la reducción de las dimensiones de sus jardines por la presión urbanística y el aumento de las superficies de aparcamientos. Esto lleva a la falta de intimidad de los espacios ajardinados que disminuyen su utilidad y conduce a su consiguiente abandono. A partir de los años 1960 se proponen soluciones que responden a las necesidades económicas y sociales del momento que muestran las posibilidades que poseen los espacios resultantes de la unificación de los lotes de las ciudades jardín, sustituyendo las edificaciones por pequeños bloques de mayor densidad edificatoria que aunque no disfrutan de jardín privado sí tienen un espacio central ajardinado con otras grandes ventajas. Los resultados son muy diferentes pues los espacios libres, al ser comunes, son mayores, ampliándose las 
visuales, lo que no sucede en el entramado de la ciudad-jardín. En realidad es el bloque abierto, el concepto contrario.

Un antecedente de estas colonias se encuentra en las avenidas barrocas europeas flanqueadas de palacios, tan comunes en Viena, Berlín o París; también los paseos de las distintas estaciones de los balnearios europeos que estaban rodeados de mansiones señoriales a modo de villas con sus correspondientes jardines particulares. Son los elementos vegetales los que hacen de unión de estas edificaciones eclécticas con estilos diversos (villas campestres italianas, chateaux franceses...). Esto mismo sucede en los barrios jardín como indica Correa: "Una serie de rosario de edificios a modo de rosario de elementos independientes, unidos por la vegetación de sus jardines" 6 .

El gran ejemplo español y a escala mundial que sirve como antecedente a estas colonias es la Ciudad Lineal (1882-1906) del arquitecto urbanista Arturo Soria y Mata, anterior al movimiento de las ciudades jardín de Howard. Pretendía eliminar los problemas de hacinamiento, higiene y transporte de las ciudades europeas de aquella época favoreciendo la saludable vida en el campo pero con todas las comodidades de la vida moderna en las grandes poblaciones. Ya Ángel Fernández de los Ríos había señalado la necesidad de conectar la periferia, cada vez más habitada y con un crecimiento desorganizado, con el centro urbano, a través de medios de transporte. Para solucionar este problema, Soria proponía una ciudad alargada que se extendiera varios kilómetros con un crecimiento longitudinal y paralelo a una vía principal para conseguir minimizar la suma de trayectos de todos los puntos entre sí. Su estructura, basada en razonamientos naturalistas y geométricos, estaba formada por un eje principal ancho de $50 \mathrm{~m}$ con una doble línea por la que circulaba el ferrocarril-tranvía y a cuyos lados habría calles transversales con solares del mismo tamaño donde se construyeran casas $\mathrm{u}$ hoteles aislados, separados por masas vegetales y complementados con equipamientos. De esta forma conseguía separar el tráfico lineal descongestionando los centros de las ciudades; éste era uno de los factores clave por los cuales Soria defendía la superioridad de la ciudad lineal frente a la ciudad jardín, que no prestaba atención a las líneas de transporte y donde el tiempo empleado en los desplazamientos era mayor. En sus ideas

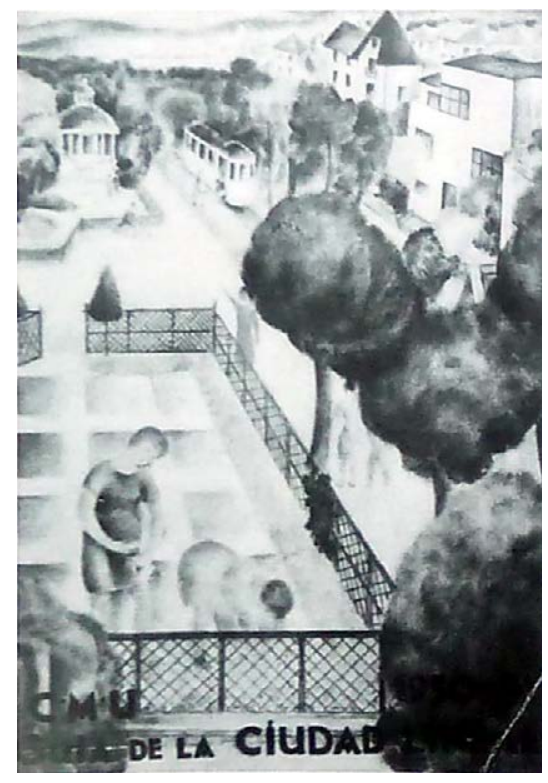

7.5 Portada del folleto divulgativo de la Ciudad Lineal, 1930. SAMBRICIO, 2003, p. 52.

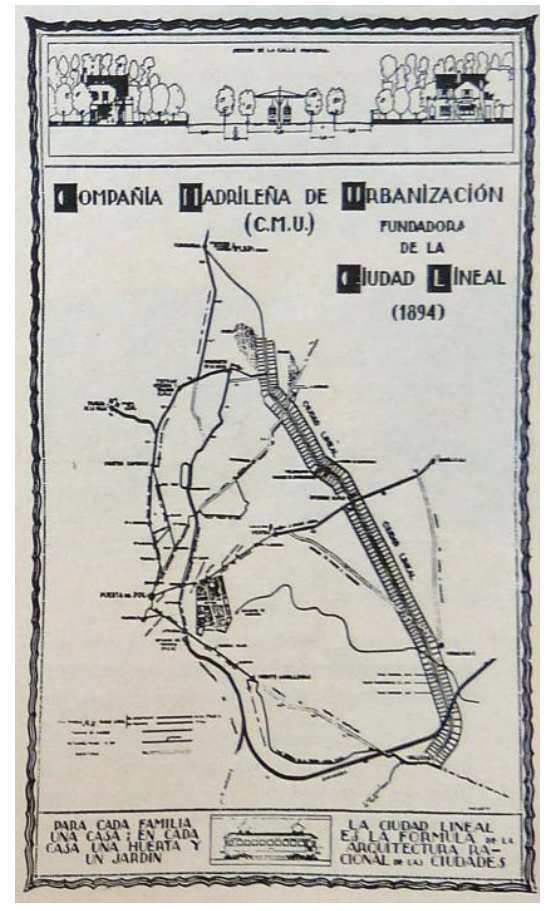

7.6 Plano de la Ciudad Lineal en relación con la ciudad de Madrid. Compañía Madrileña de Urbanización, 1894. TERÁN, 1964, no 72, dic., p.13.

\footnotetext{
${ }^{6}$ CORREA, F.: Consideraciones visuales sobre la Ciudad-Jardín. Cuadernos de Arquitectura y Urbanismo, 1965-1967, p. 20.
} 


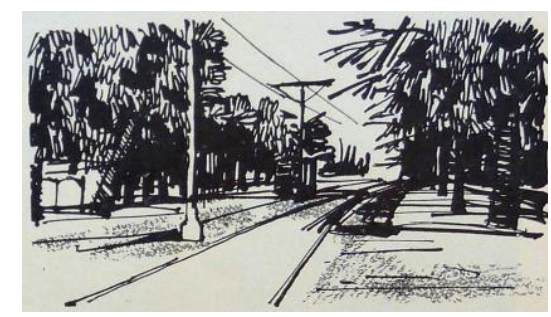

7.7 Dibujo de la vía principal con tranvía. TERÁN, 1964, p.15.

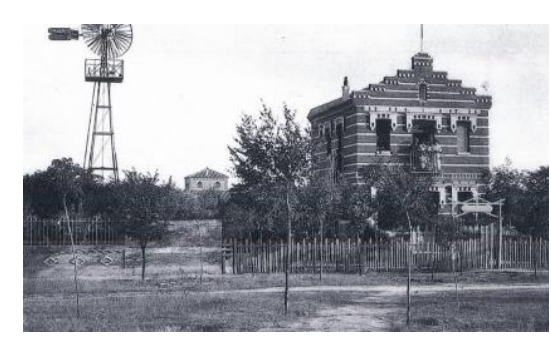

7.8 Hotel llamado "Villa Concha", en la manzana 98 de Ciudad Jardín. Archivo fotográfico de la Comunidad de Madrid.

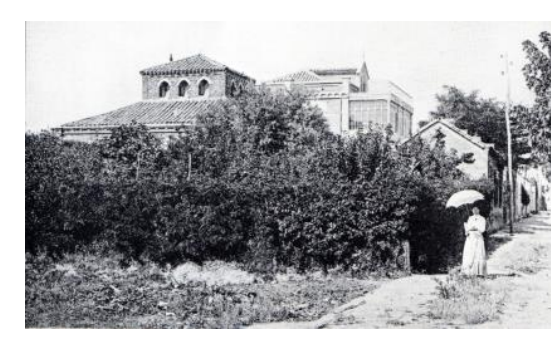

7.9 №82, Ciudad Lineal, Madrid. Finca cercada con seto vivo, manzana 98. Los planes de ordenación urbana de Madrid. Coplaco. Madrid: MOPU, 1981, p.23.

7.10 Compañía Madrileña de Urbanización, 1894. Ejemplo de ciudad lineal enlazando dos ciudades aglomeradas con banda a cada lado de $100 \mathrm{~m}$ de bosque. SAMBRICIO, 2003, p. 49.

7.11 Perfil transversal antiguo de la calle principal en la 1 a barriada de la Ciudad Lineal con ocho filas de árboles y aceras ajardinadas. TERÁN, 1964, p. 10. pensaba que el planeamiento urbano era indispensable para ordenar el crecimiento urbano y que esta estructura lineal con crecimiento indefinido se podía extender uniendo ciudades: "el tipo de ciudad casi perfecta sería aquella extendida a lo largo de una sola vía, en un ancho de 500 metros, y que llegara, si fuera necesario, de Cádiz a San Petersburgo, de Pekín a Bruselas"7.
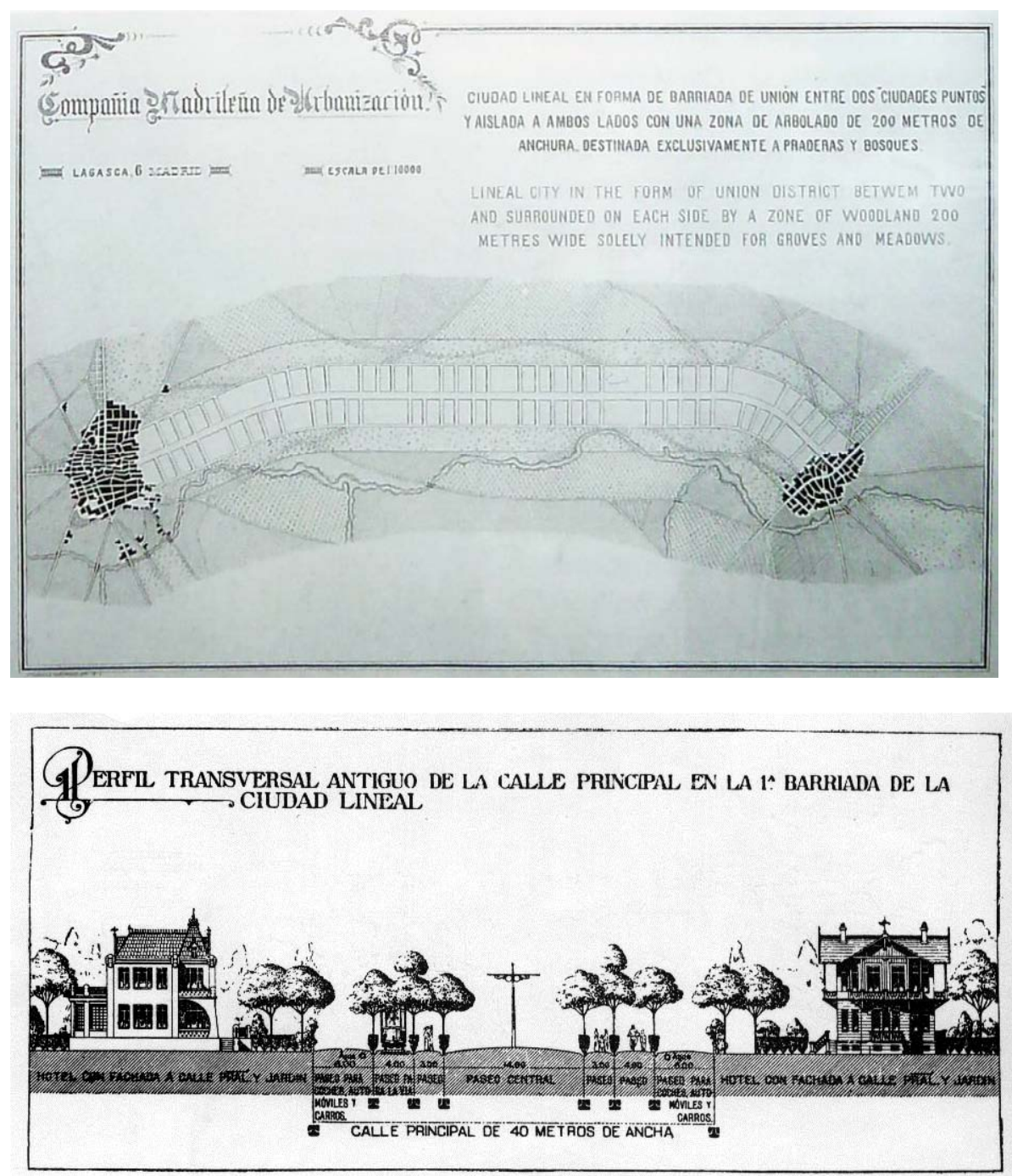

En la sección tipo que propone se muestra la importancia del ajardinamiento, pues integra los bulevares con la línea de transporte y con los jardines de las villas. Según la importancia de la ciudad propone que aumente el ancho de la franja central con mayor número de vías de circulación. Esta banda central se acompañaba de jardines con macizos de flores, estanques y árboles, algunos de los cuales todavía se conservan en la actualidad. Entre la alineación de las tapias de las fincas que marcaban el límite de la calle y la

\footnotetext{
${ }^{7}$ Arturo Soria. En BENÉVOLO, L.: Historia de la Arquitectura moderna. Barcelona: Gustavo Gili, 1999, p. 390.
} 
alineación de las viviendas se reservaba una distancia mínima de $5 \mathrm{~m}$ dedicada a jardines y a objetos artísticos no sólo por razones estéticas, sino en previsión de un futuro ensanche de la calle. En sus desarrollos de ciudades lineales también aparece, una banda externa a ambos lados de las manzanas edificadas de $100 \mathrm{~m}$ de bosque. Arturo Soria señaló la importancia de los pinares que rodeaban la Ciudad Lineal. Las viviendas paralelas a la vía principal estaban destinadas a familias de mayor poder adquisitivo, en las fachadas de las calles transversales, de $20 \mathrm{~m}$ de anchura ${ }^{8}$ con arbolado abundante, vivía la clase modesta y las demás clases en la parte más lejana de la vía principal. Los grandes espacios centrales se destinaban a los usos colectivos (fábricas, mercados, iglesias, teatros, museos, colegios, etc.); éstos se situaban generalmente dando a la calle Arturo Soria o concentrados a lo largo de la carretera de Aragón como el caso de los comercios.

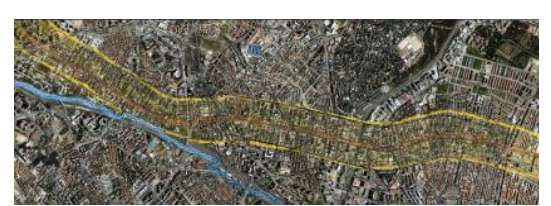

7.12 Vista aérea actual marcando el antiguo arroyo del Abroñigal, actual M30. Urbancidades.wordpress.com

7.13 Parcelario de la zona con superposición del trazado de la Ciudad Lineal. Plano de la Ciudad Lineal. TERÁN, 1964, no 72 , dic., p.7 y 12 .
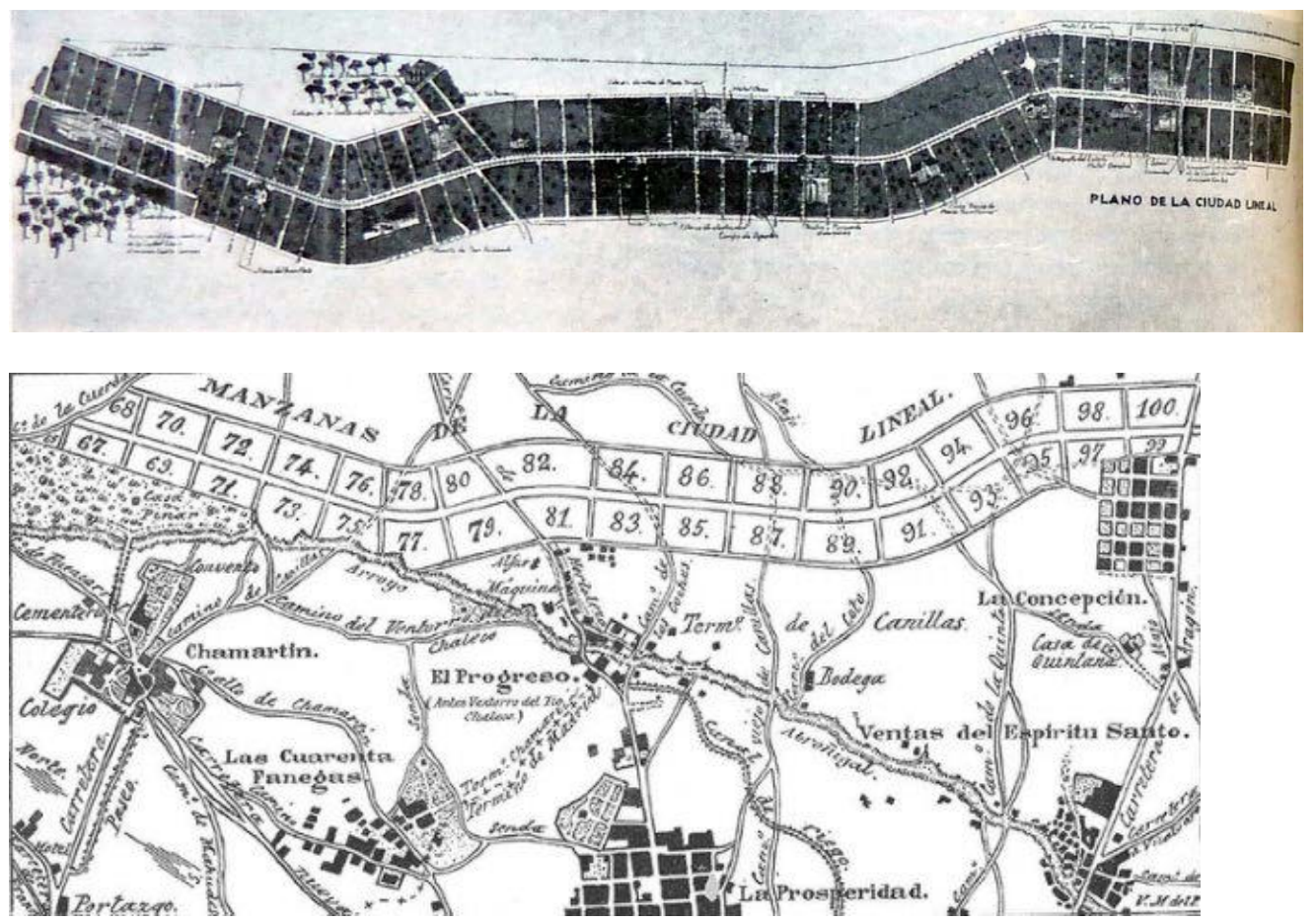

Intentó llevar su teoría a la práctica en unos terrenos ubicados en una zona que por aquel entonces estaba a las afueras de Madrid, donde el suelo era mucho más barato, aunque actualmente sus calles están integradas dentro del entramado urbano madrileño. Pretendía rodear la capital con un anillo de $58 \mathrm{~km}$, de los cuales solo llegaron a construirse $5 \mathrm{~km}$ con 680 casas unifamiliares y 4.000 habitantes fijos.

\footnotetext{
${ }^{8}$ Las manzanas de 80 a $100 \times 200$ m de fondo, separadas por calles de $20 \mathrm{~m}$, inicialmente, en 1892 eran 300×200 con calle principal de 40m y transversal de 15m. Arquitectura de Madrid, Introducción. Madrid: Fundación COAM, 2003, p. 78.
} 

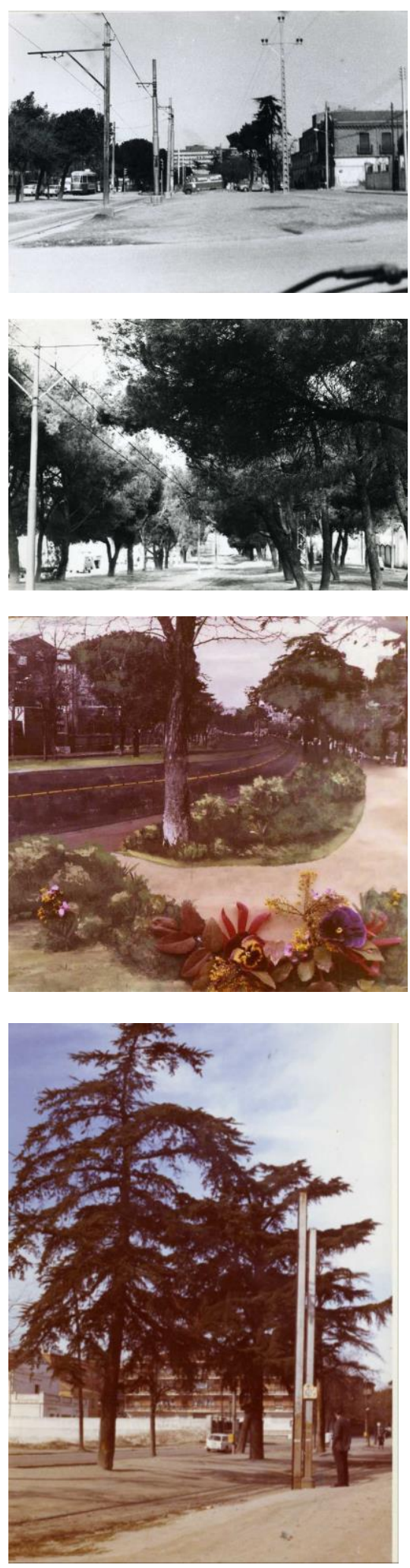

7.14 Avenida Arturo Soria, 1960. Archivo fotográfico de la Comunidad de Madrid. Fotos antiguas. Colección Javier Spalla.
En 1892 consiguió que las Cortes aprobasen su proyecto de "ferrocarril-tranvía de circunvalación de Madrid a Canillas, Hortaleza, Fuencarral, Vicálvaro, Vallecas, Villaverde, Carabanchel y Pozuelo"9. Proponía una forma alternativa al crecimiento radial de Madrid, enlazando entre sí los pueblos que rodeaban la capital y dejando el anillo abierto por el norte hacia la sierra. En 1894 y para poder acometer la construcción, Soria constituye la Compañía Madrileña de Urbanización para "el establecimiento y la explotación de ciudades lineales"10; se estudian diferentes tipologías y métodos de construcción para abaratar costes. De esta forma Soria no solo se queda en la teoría como Howard y su ciudad jardín sino que evoluciona el concepto, introduciendo la movilidad en la ciudad y realizando también labores de propaganda y difusión. Para ello en 1896 fundó la publicación periódica La Ciudad Lineal: Revista de Higiene, Ingeniería y Urbanización, que duró 35 años. En 1906 ya se habían construido los primeros kilómetros de la vía férrea partiendo del barrio de la Concepción hacia el norte y las primeras 300 viviendas. En 1909 se electrificó la línea y en 1911 se finalizaron los primeros $5 \mathrm{~km}$. Los trazados de la segunda y tercera fase, proyectados entre 1903 y 1904, no se llevaron a cabo por las dificultades en la adquisición de los terrenos.

Este proyecto ideal buscaba "ruralizar la vida urbana y urbanizar el campo" 11; Soria propone una corrección de los males de las ciudades existentes absorbiendo su crecimiento mediante una ciudad lineal que las conectara. En esta nueva ciudad el papel de la jardinería es fundamental. El lema que aparece en sus carteles publicitarios es: "Para cada familia una casa; en cada casa una huerta y un jardín. La Ciudad Lineal es la fórmula de la arquitectura racional de las ciudades". Propone con estos nuevos tramos lineales de crecimiento formar tramas triangulares dejando el campo en su interior junto a la ciudad: "unir entre sí las ciudades actuales o ciudades puntos por medio de ciudades lineales, formando así, con el tiempo, en cada país una vasta red de triangulaciones en las que la superficie de cada triángulo urbano formado por los vértices de las ciudades antiguas y

\footnotetext{
${ }^{9}$ El ferrocarril partía de un quiosco en el Salón del Prado, cerca del Jardín Botánico, y a través de un túnel bajo el Parque de El Retiro accedía a Canillas. Quedaba pendiente la unión entre Fuencarral y Pozuelo que cerraría el anillo de circunvalación.

${ }^{10}$ Compañía Madrileña de Urbanización, Escritura de constitución de la Sociedad, estatutos, Ley de Concesión de ferrocarril-tranvía de circunvalación de Madrid y datos varios. Madrid, 1894. En TERÁN, F.: La Ciudad Lineal de Arturo Soria. Arquitectura. Madrid: COAM, 1964, no 72, dic., p. 9.

${ }^{11}$ Arturo Soria, 1882. Ibíd., p. 8.
} 
los lados de las ciudades nuevas se dedicará a las explotaciones agrícolas e industriales". De la superficie total de la ciudad solo un quinto se destina a viviendas y el resto para la industria, pero sobre todo para la agricultura cultivando la tierra en huertas, jardines y bosques. Las parcelas mínimas unifamiliares eran de $400 \mathrm{~m}^{2}$ (cuadrado de $20 \mathrm{~m}$ de lado) y destinaban $80 \mathrm{~m}^{2}$ para la vivienda-taller y $320 \mathrm{~m}^{2}$ para crías de animales domésticos, huerta, jardín y árboles frutales; también había parcelas de 800 y $1.200 \mathrm{~m}^{2}$. "Es menester que cada familia tenga su hogar completamente separado de los demás; un pedazo de terreno, por pequeño que sea, exclusivamente suyo, su parte de sol y de aire. Vivan juntos el palacio del poderoso, adornado de magníficos jardines, y la cabaña del pobre, provista de modesta corraliza y ensalzada con útiles plantas y perfumadas flores; pero no vivan superpuestos. Ni sótano, ni buhardilla, ni aglomeración de miserias que en las modernas construcciones benéficas se juntan y procrean nuevas miserias" ${ }^{12}$.

En los carteles de las distintas construcciones de los hoteles de la Ciudad Lineal aparecen dibujados los jardines con un trazado clásico al modo francés con parterres geométricos; aunque en los planos de la época también se aprecia que hubo bastantes al modo paisajista. Por lo tanto aunque el moderno urbanístico que se propone es bastante novedoso muchos de los jardines siguen teniendo un lenguaje clásico. La mayor parte de los jardines de las calles y chalets grandes los hizo Tomás Cuesta y posteriormente en esta zona se concentraron muchos de los grandes viveros de la capital ${ }^{13}$.

En su libro sobre parques y jardines, Margarita Jiménez la denomina "vía parque" madrileña14 en recuerdo a las parkways americanas de Olmsted que conectaban parques entre sí o zonas residenciales con parques. Se concibe también como un proyecto de carácter cívico con muchas ventajas sociales y sicológicas, ya que promovía los ideales masónicos de su Hermandad de igualdad y fraternidad. No había distinción de zonas diferenciadas ni de clases sociales, se igualaba a los ciudadanos. El desarrollo de la cultura y el entretenimiento eran partes indispensables del proyecto; todos los vecinos podían disfrutar por igual de los equipamientos comunes que se fueron construyendo con los años (velódromo, teatro cubierto y al

\footnotetext{
${ }^{12}$ Ambas citas en TERÁN, 1964, no 72, dic., p.15.

13 Entrevistas personales con Javier Spalla. y otros viveristas en los viveros del Retiro, mayo 2012, septiembre 2012, enero 2013 y julio 2013.

14 JIMÉNEZ, M.: Madrid, en sus plazas, parques y jardines. Madrid: Abaco, 1977, p.454.
}
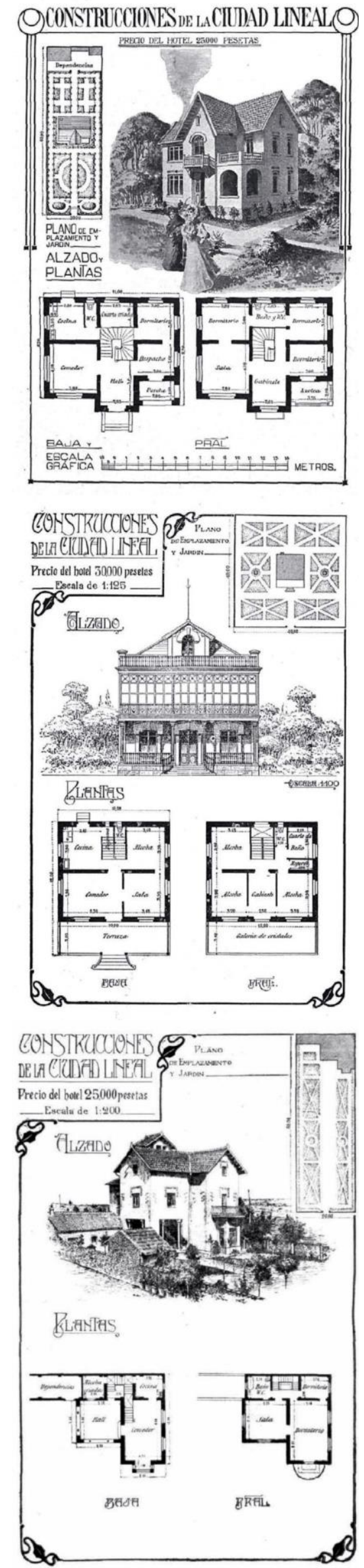

7.15 Distintas construcciones de hoteles de Ciudad Lineal, 1900. Plano de emplazamiento con jardín y plantas. Urbancidades.wordpress.com 

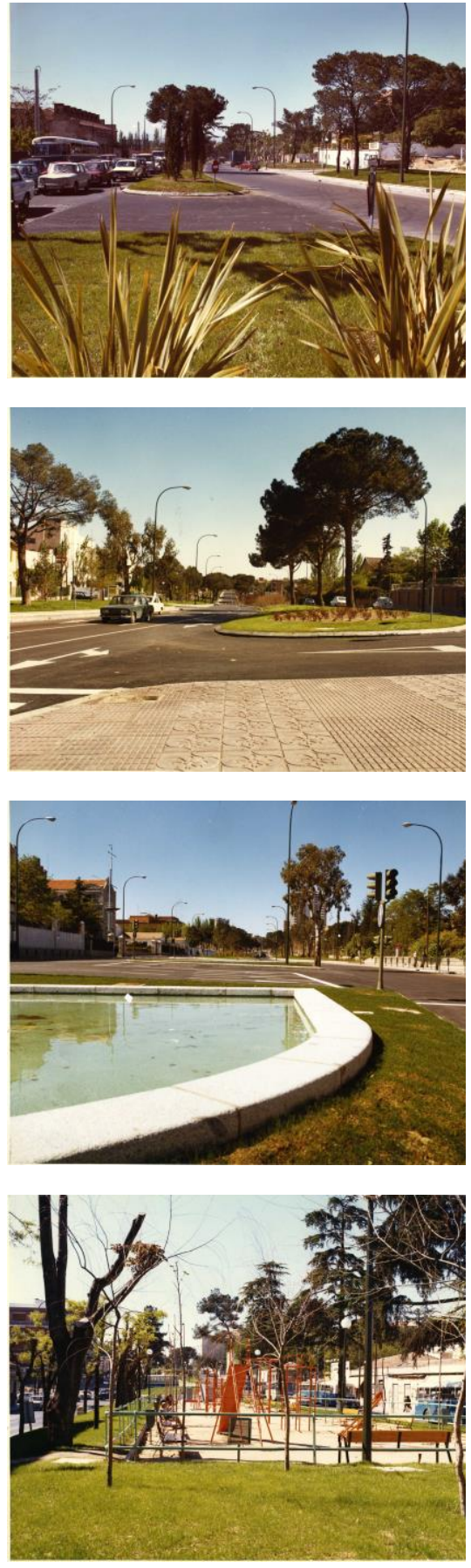

7.16 Arturo Soria, mayo 1973. Colección Javier Spalla. aire libre, parque de diversiones de estilo modernista, kursaal para conciertos y espectáculos, iglesia-escuela, etc.). La Ciudad Lineal acogía numerosas fiestas y espectáculos (Fiesta del Árbol, verbenas populares...), eventos deportivos y comunitarios, etc. No solo era un proyecto urbanístico sino que pretendía cambiar la mentalidad de los habitantes, un medio para modificar la sociedad a través de la manera en que se vivía; todo ello, junto con la lejanía de la ciudad y la baja densidad y edificabilidad constantes, le valió múltiples críticas de los conservadores. Sin embargo fue todo un modelo de inspiración para desarrollos posteriores en Europa y América ${ }^{15}$.

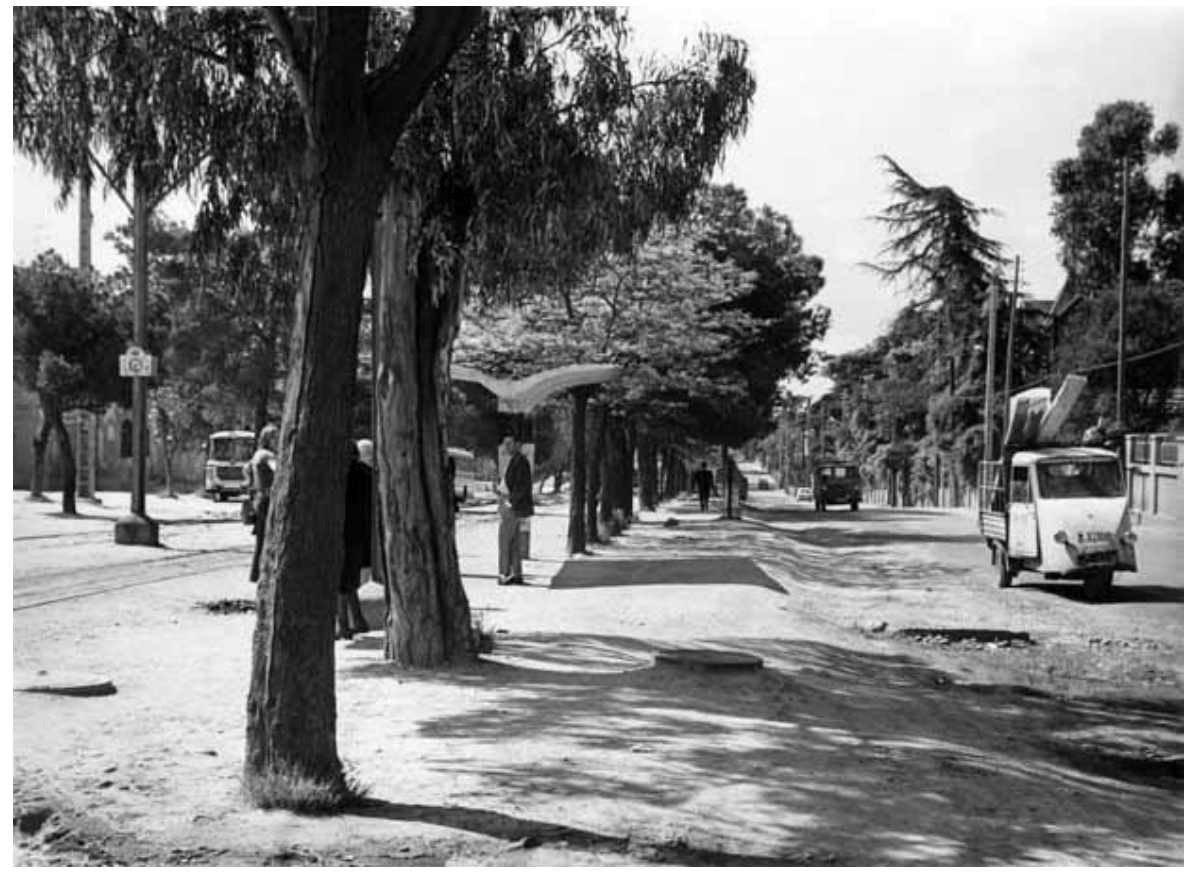

Paulatinamente se fue destruyendo su carácter original por falta de protección: el Plan General de Madrid de 1946 permitía la construcción de viviendas colectivas y pretendía convertir el eje central en una vía de circunvalaciones; el Plan de Ordenación de la Ciudad Lineal de 1960 incorporó el Estudio de Detalle para cualquier tipo de actuación, estableciendo polígonos coincidente con las manzanas originales; la desaparición de los tranvías en 1950 convirtió el eje en una vía de tráfico rápida impidiendo la relación entre ambos lados; fueron desapareciendo los antiguos hoteles planteándose unos índices de ocupación muy superiores para las nuevas edificaciones ${ }^{16} y$ poco a poco las áreas ajardinadas se fueron degradando. Por ello en 1972 se acometen unas obras de acondicionamiento y equipamiento

15 En los años 1920 los alemanes desarrollaron estudios teóricos que se aplicaron parcialmente en Rusia en la década posterior, La cité linéaire industrielle de Le Corbusier, etc. BENÉVOLO, 1999, p. 391.

${ }^{16}$ Arquitectura de Madrid. Introducción. Madrid: Fundación COAM, 2003, p. 79. 
de la calle Arturo Soria para procurar la máxima comodidad y utilidad de todos los usuarios, llevadas a cabo por Manuel Herrero Palacios, arquitecto Director de Parques, Jardines y Estética Urbana de aquella época. En las zonas ajardinadas de la calle, separadas del tráfico rodado por una cortina arbórea, se colocaron bancos fijos, papeleras y fuentes para beber creando zonas de descanso. A lo largo de la calle se reparten cuatro zonas para el juego con equipamiento infantiles y tres quioscos de bebidas. Se retiraron los pinos y cedros secos o en mal estado existentes y se completaron con nuevas especies para las zonas estanciales: plátanos, robinias, chopos, gleditchias, ailantos, pomilas, olmos, castaños, fresnos, moreras y eucaliptos ${ }^{17}$. Actualmente destacan los grandes ejemplares de cedros y pinos, muchos de ellos originales, que forman una frondosa mediana central acompañados de eucaliptos, plátanos, álamos, arces y otros ejemplares, junto con diversos arbustos.
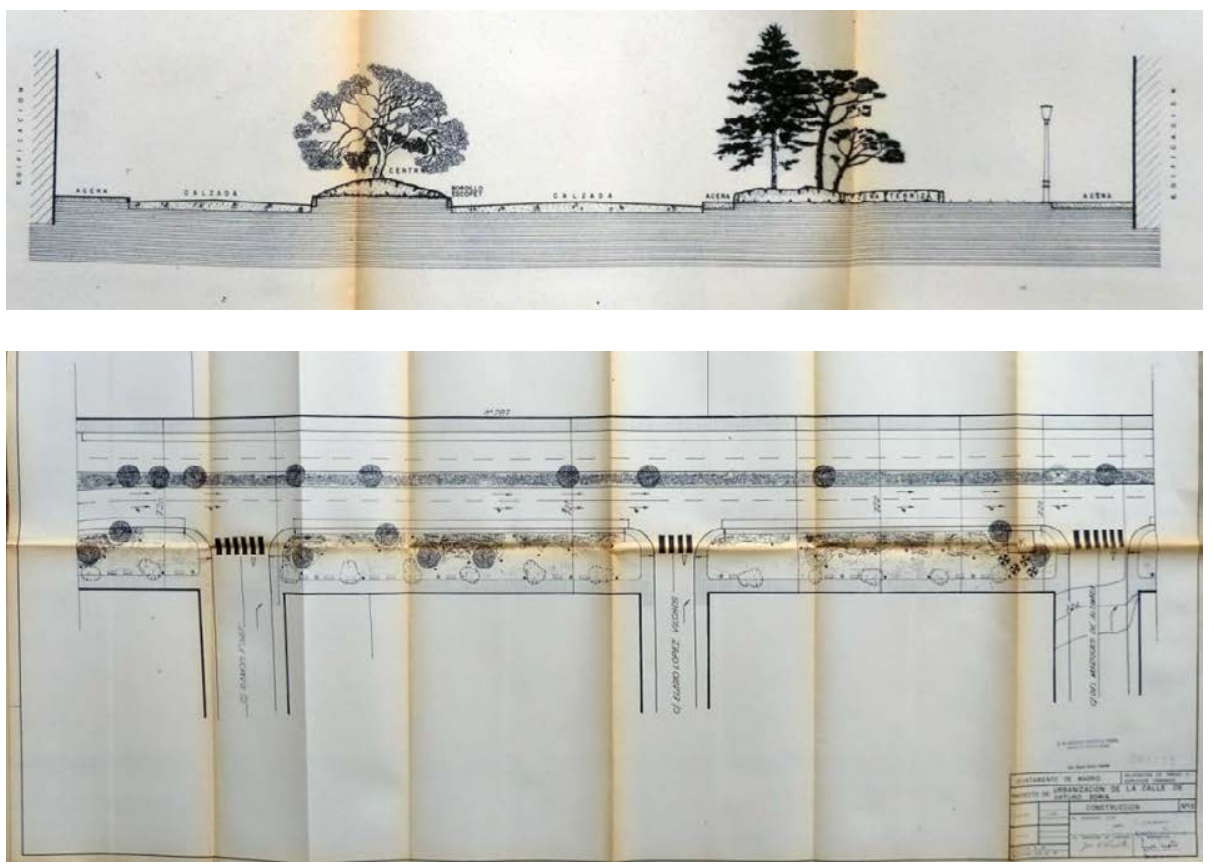

Comparándolo la nueva sección con la original se aprecia cómo hay una preocupación por mantener el arbolado central -los dos bulevares originales que flanqueaban el tranvía- y no se presta casi atención al arbolado de las calles y jardines privados de las casas que hacían que el conjunto tuviese unidad. En las fotografías antiguas se aprecia como estas zonas centrales eran de arena, mientras las nuevas se diseñan con grandes cuadros de pradera bajo los árboles y sólo las áreas

\footnotetext{
${ }^{17}$ Memoria del proyecto de las obras de jardinería y equipamiento para la calle de Arturo Soria. Ayuntamiento de Madrid, M. Herrero Palacios, junio 1972. Archivo Parques y Jardines del Ayuntamiento de Madrid.
}
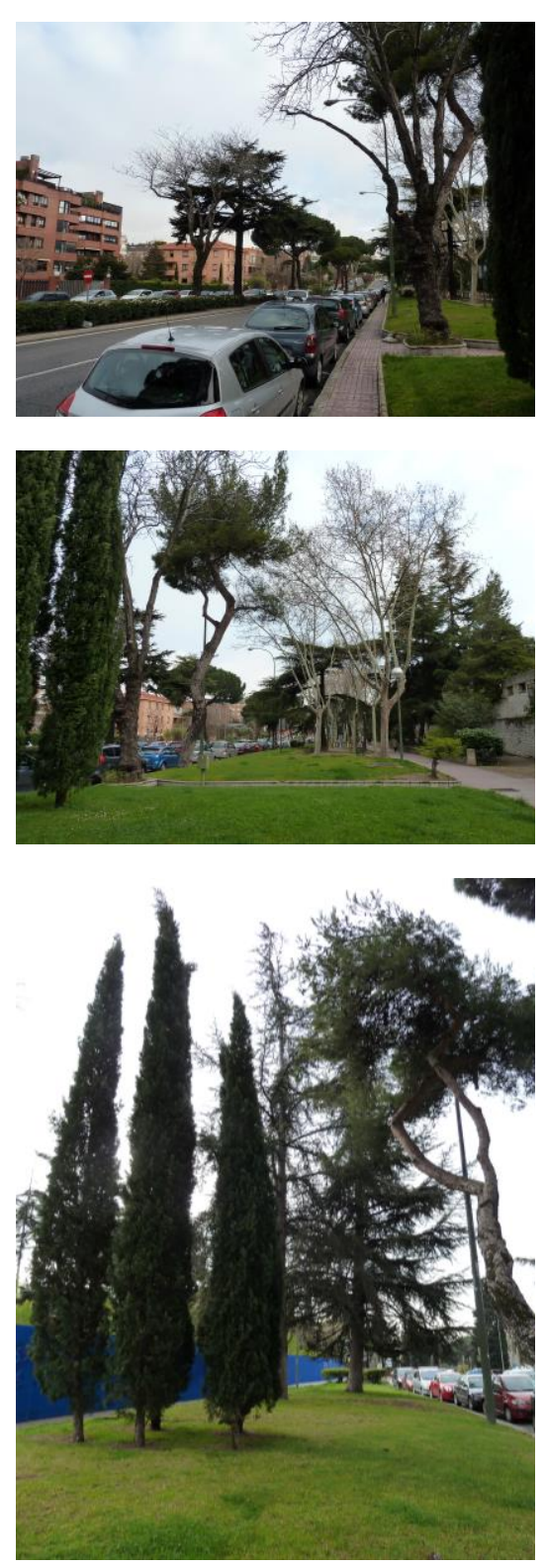

.7.17 Arturo Soria: vistas actuales, PHL, abril 2013.

7.18 Proyecto de las obras de jardinería y equipamiento para la calle de Arturo Soria. Ayuntamiento de Madrid, M. Herrero Palacios, junio 1972: urbanización de la calle sección tipo y planta de los tramo 1. APJM. 
estanciales e infantiles están enarenadas. Analizando ambas plantas se aprecia como la rotundidad de la linealidad del espacio central flanqueado por los grandes bulevares, se pierde al desaparecer el tranvía; el espacio central se fragmenta tanto por los espacios estanciales interiores como por los nuevos viales de cruce para los automóviles, creándose nuevas rotondas y glorietas.
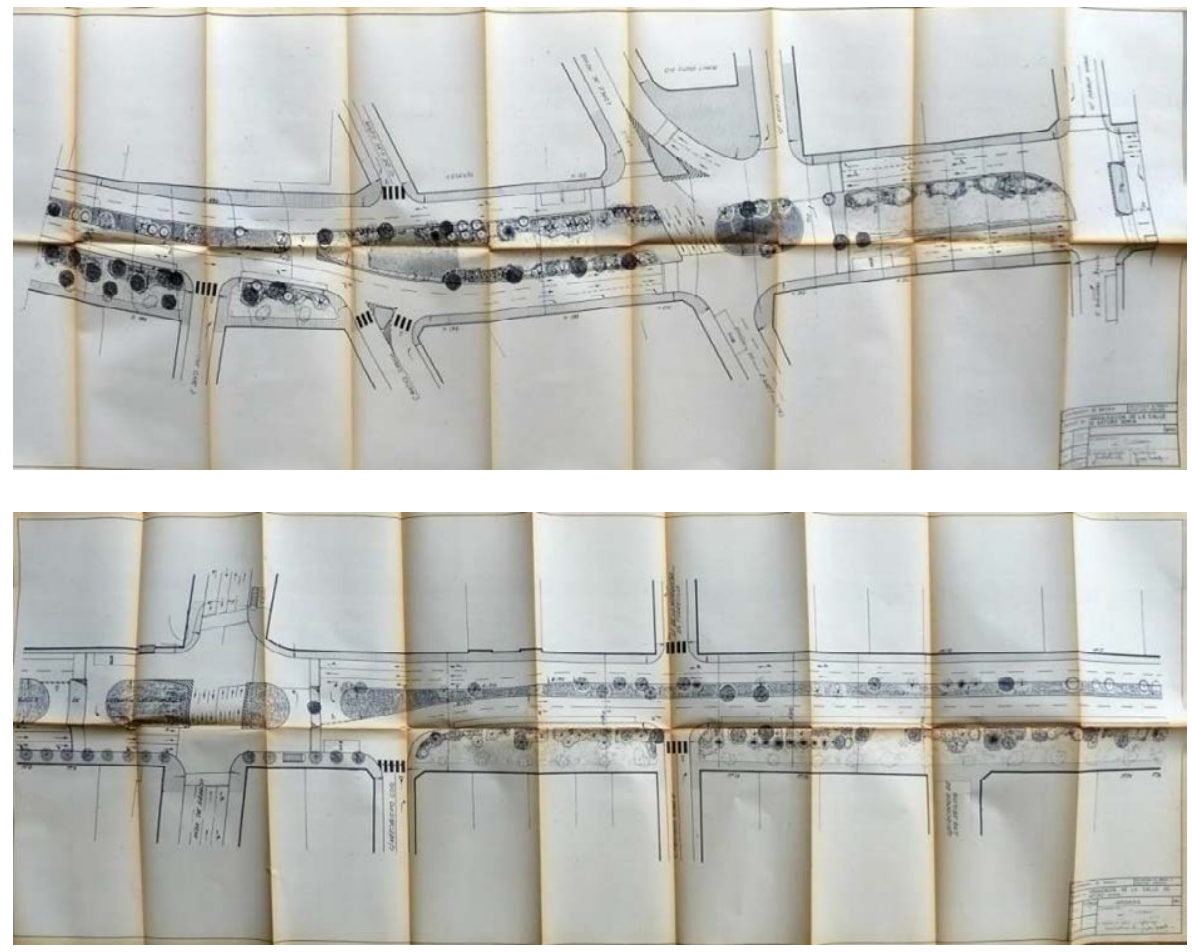

7.19 Proyecto de las obras de jardinería y equipamiento para la calle de Arturo Soria. Ayuntamiento de Madrid, M. Herrero Palacios, junio 1972: planta de los tramos 10 y 15 , detalle constructivo del estanque. APJM.

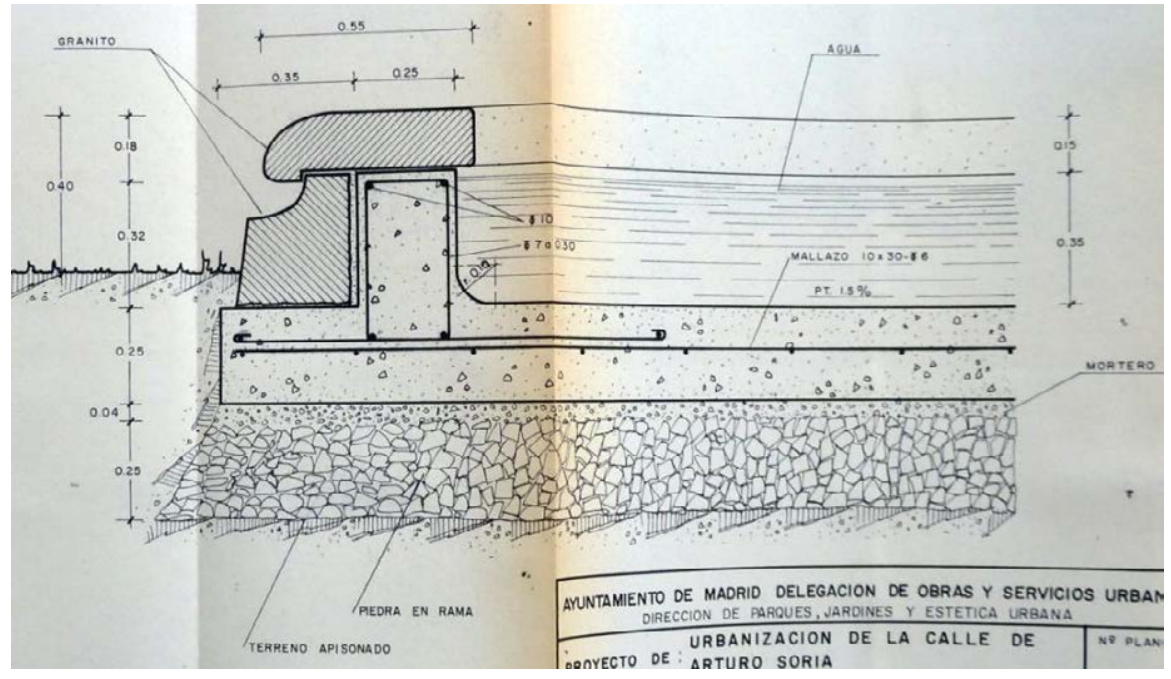




\section{Los ejemplos madrileños}

Ya Winthuysen en los primeros años del siglo XX se había hecho eco de la ciudad jardín y de sus posibilidades de implantación en España: “En nuestros tiempos ha nacido la ciudad-jardín, llegando las personas de posición modesta, al pleno goce de las bellezas naturales... ${ }^{18}$. /.../ En nuestras calles y paseos contrastando con el, en general, pobre arbolado, vemos como asoma, airoso y magnífico otro árbol de la misma especie de algún jardín contiguo. /.../ En épocas pretéritas, el jardín tenía casi exclusivamente importancia en las mansiones señoriales pero en la actualidad se ha generalizado constituyendo una parte esencial en las ciudades-jardín. /.../ Las ciudades-jardines de unos climas no pueden ser las mismas que los otros, como el paisaje natural tampoco lo es y como tampoco lo son los gustos ni los hábitos. ¿Cómo habríamos de llegar a implantar nuestras ciudades-jardines enteramente acordes con nuestra naturaleza?..."19.

Winthuysen $\mathrm{y}$ otros jardineros $\mathrm{y}$ arquitectos realizaron en Madrid varios jardines para algunas viviendas en la Ciudad Lineal de Arturo Soria y en algunas colonias jardín como El Viso, Parque Residencia, Cruz del Rayo, etc. En ellos se observa una dialéctica continua entre las viviendas de estilo moderno y los jardines que continúan realizándose con un estilo bastante tradicional. A continuación se analizan algunos ejemplos de jardines en la Ciudad Lineal como evoluciones de las propuestas en proyecto de Soria en sus villas tipo y otros casos en algunas de las colonias madrileñas. No se profundiza en las colonias ya que merecería un estudio independiente; tan sólo se dan algunas directrices generales para entender la inserción de los jardines unifamiliares analizados.

Dentro de la Ciudad Lineal el Sr. Dantín de Cereceda encargó a Winthuysen en 1911 un jardín unifamiliar para su casa de la calle López de Hoyos que por aquella época estaba situada a las afueras de la capital, en una zona donde se distribuían pequeñas residencias rodeadas de terreno. En los $2000 \mathrm{~m}^{2}$ de superficie dispone una plantación ordenada de olmos entre los que diseña un camino serpenteante que conduce a la vivienda y otro que comunica con un pequeño claro entre los árboles donde sitúa una fuente flanqueada por dos bancos en forma de cuarto de circunferencia.

\footnotetext{
18 Javier de Winthuysen. En AA.VV.: Javier de Winthuysen. Jardinero. Madrid: Real Jardín Botánico, CSIC, 1986, p. 65.

19 Ibíd., p. 59-60.
} 


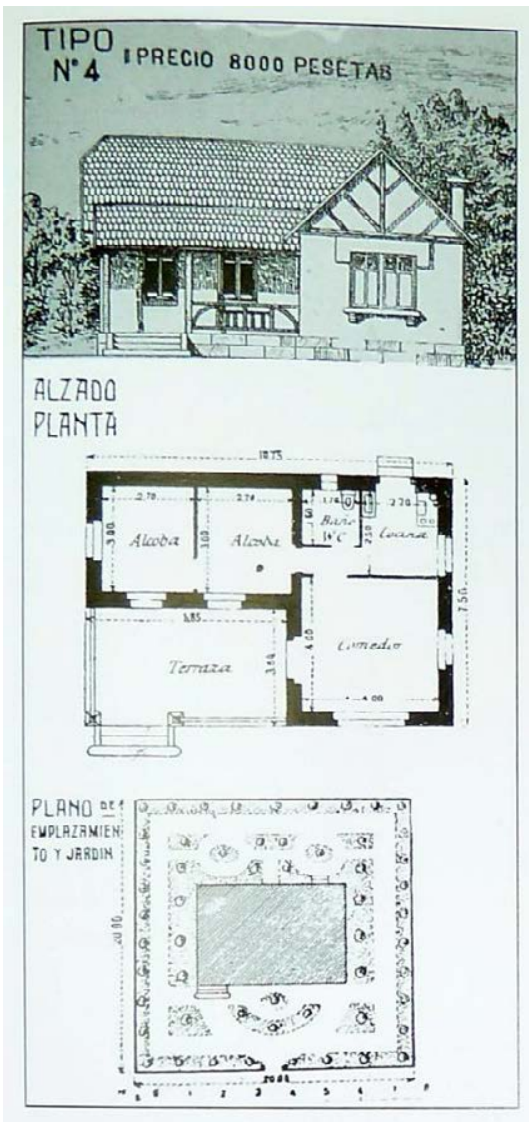

7.20 Propuesta de vivienda unifamiliar en Ciudad Lineal, A. Soria.1900. SAMBRICIO, 2003, p. 49.

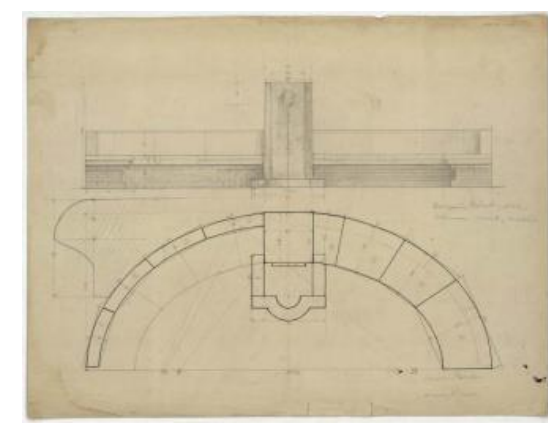

7.21 Jardín para la residencia del Sr. Dantín Cereceda. Winthuysen, 1911: planta y alzado de una fuente y planta del jardín. ARJB, lám. 27, 1-3.

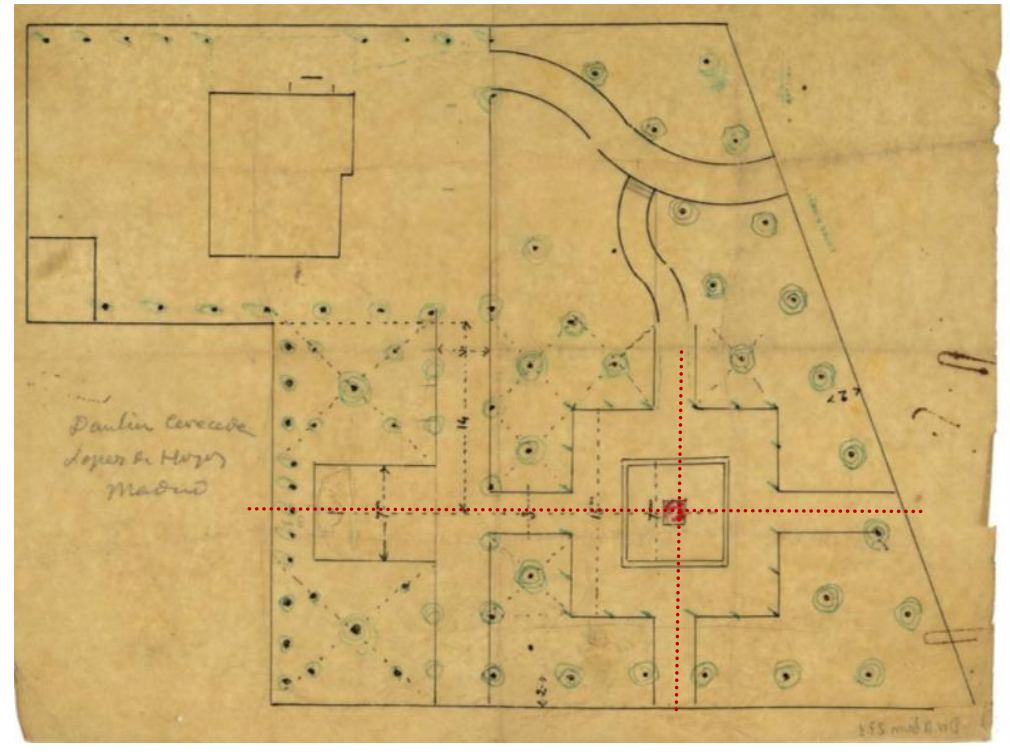

Winthuysen respeta la teoría de la Ciudad Lineal de Arturo Soria donde las viviendas además de jardín debían tener un espacio destinado a huerta. Generalmente en la Ciudad Lineal se sitúa siempre el jardín más decorativo en la zona de acceso de la vivienda resolviéndolo generalmente con cuadros delimitados por setos de boj con dibujos florales.

Uno de estos ejemplos es el jardín que encarga el Sr. Ribera Pastor a Winthuysen en 1925 para su casa de la Ciudad Lineal. La casa está en una esquina del cercado y la entrada no es frontal, sino tangencial. Zonifica la superficie de $1.420 \mathrm{~m}^{2}$ en tres zonas: una de recreo, una de paseo y otra de huerta. El paseo ancho lo subdivide geométricamente con triple arcada de cipreses que termina en una plaza rectangular con fuente central. El parterre está subdividido en cruz de San Andrés y está relacionado con la casa al coincidir el eje con su centro. El otro eje de la vivienda conecta con una parte cerrada con esquema en cruz y gran cuadro central, flanqueado en dos de sus lados por una arquería de cipreses. En estas zonas dispone cuadros con dibujos florales, fuentes en el cruce de los ejes y pérgolas con trepadoras. El huerto se ubica en la esquina diagonalmente a la vivienda y en relación con la parte cerrada; se dispone geométricamente y los árboles frutales marcan las intersecciones de las líneas de plantación. 


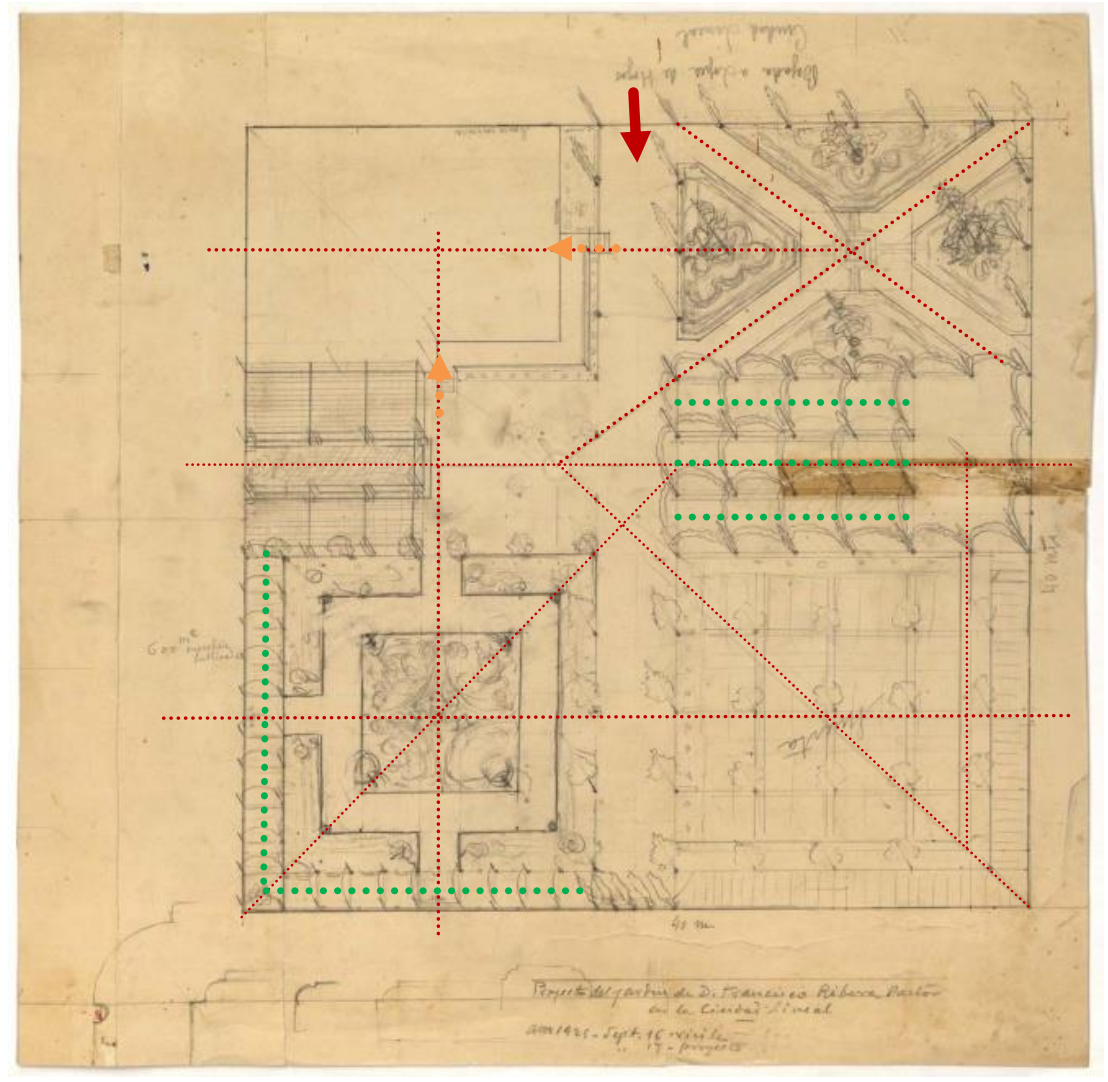

En la residencia del Sr. Casares (1926) en Ciudad Lineal se mantienen los terrenos de huerta y Winthuysen se encarga del jardín de acceso con un parterre de diseño clásico. Esta zona de entrada se divide en dos niveles conectados mediante una escalera. En el nivel inferior se sitúa una fuente rodeada de un parterre y en un lateral una arcada de cipreses junto con unos escalones comunica con la zona de huerta. Mientras en el nivel superior una gran pérgola con trepadoras y unas arcadas de cipreses ayudan a cerrar la estancia con una alberca central. En los sucesivos bocetos se ven las distintas opciones que maneja para este espacio con parterre o alberca, finalmente desarrolla la opción de la gran alberca y una fuente circular que articula los dos espacios y éstos con la casa. También diseñó el paseo de acceso subdividido en tres vías por alineaciones de árboles y al que se entraba atravesando una arcada de cipreses. El paseo posterior de la vivienda lo remata con una pequeña alberca flanqueada por cipreses. Realizó también un estudio de los pavimentos.

Esta curiosa la composición en zigzag, muy hispana, persigue la privacidad y aumenta el tamaño del jardín buscando nuevas visuales y cambiando el recorrido.

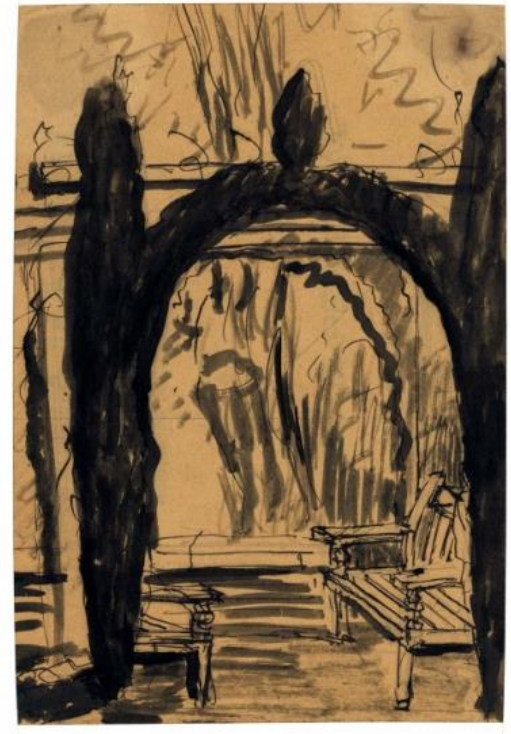

7.22 Vista axonométrica del jardín de la Residencia de D. Francisco Ribera y Pastor. Dibujo del jardín, pérgola, banco y arco del jardín. Winthuysen, 1925. ARJB, lám. 11, 1-2. 

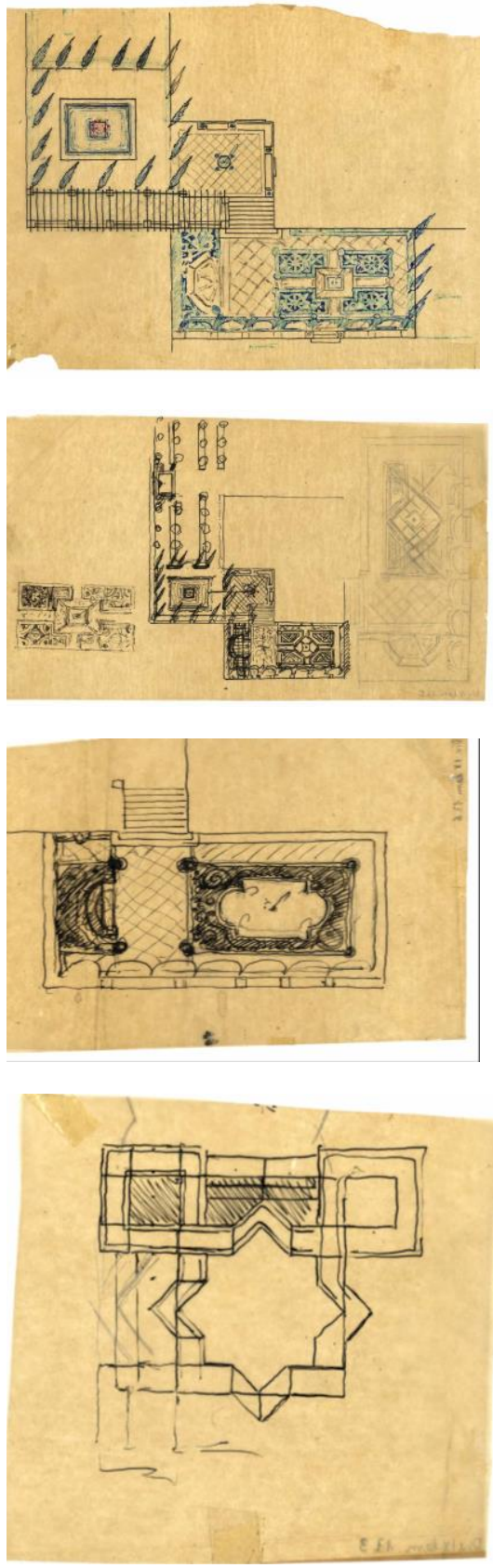

7.23 Plano del jardín, detalle del parterre, apunte del jardín y boceto de la fuente de la residencia del Sr. Casares. Winthuysen, 1926. ARJB, lám.17,4-5-6-3. 7.24 Planta del jardín de la residencia del Sr. Casares. Planta de la superficie del jardín. Proyecto de la zona ajardinada. Winthuysen, 1926. ARJB, lám. 17, 1-2-7.

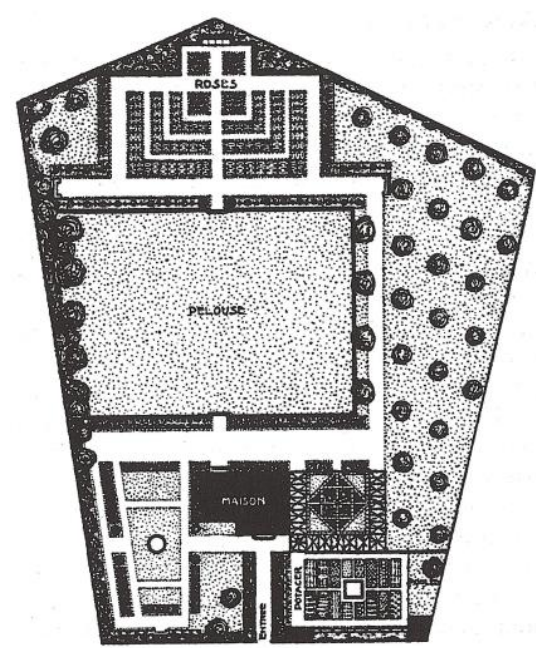

7.25 'Un pequeño jardín', André y Paul I/nm ÁII/ADET Inก7 n 02
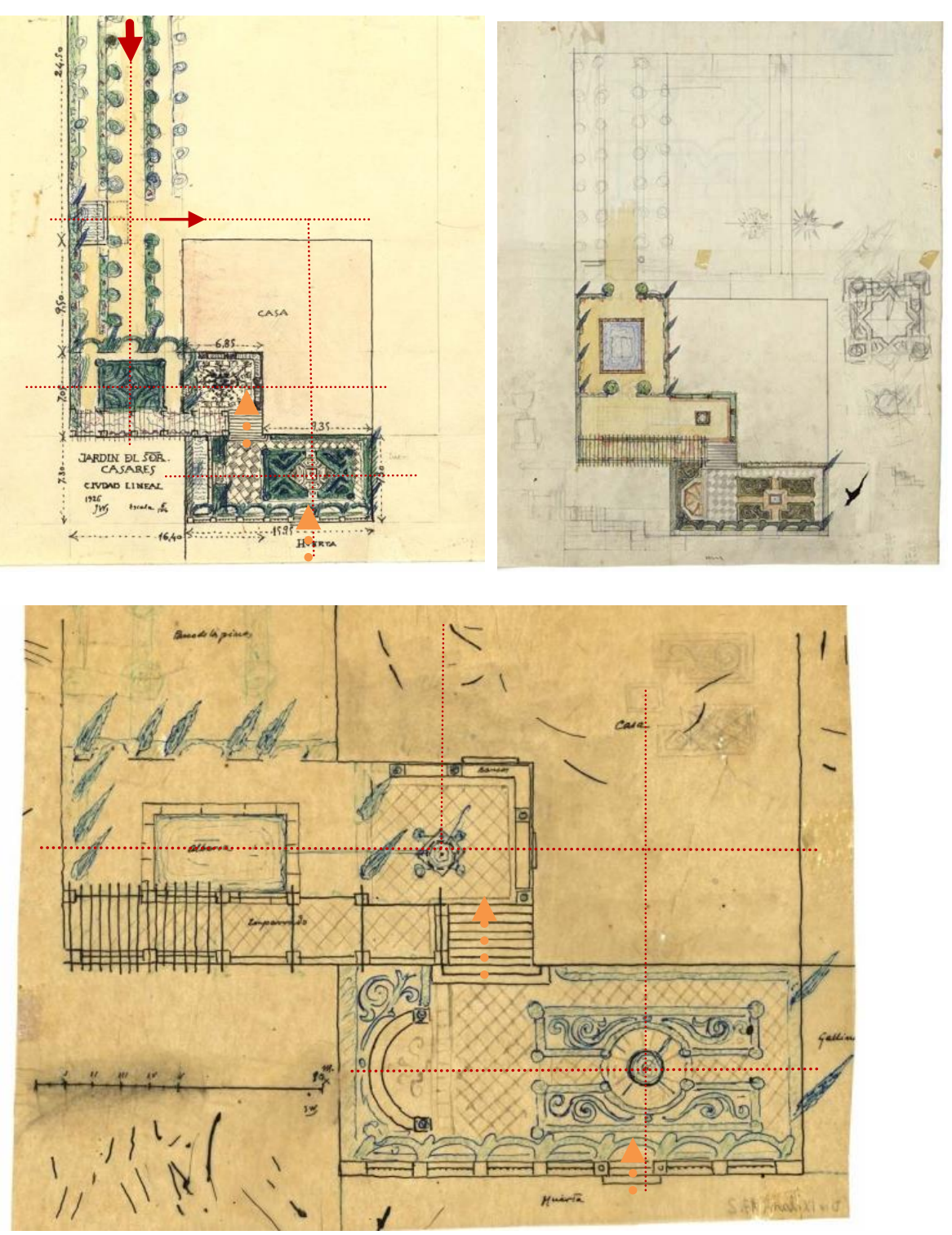

En estos dos últimos ejemplos de Winthuysen se aprecia en el esquema en planta cómo hay un trazado que relaciona las distintas partes y éstas a su vez con la vivienda; es la casa la que ordena las partes del jardín. Esta curiosa manera de componer las partes del jardín respecto a la casa se observa en ejemplos de Forestier terrazas para lugares de uso, setos y empalizadas para delimitar zonas, emparrados y arquerías de cipreses...- y de los hermanos Vera con una fuerte presencia de la geometría y un trama rectangular que compartimenta el jardín en diversos espacios.

Dentro de estas intervenciones destaca la de Ramón Ortiz Ferré, oriundo de Reus y mano derecha de Cecilio Rodríguez, tomó el relevo en la Oficina de Parques y Jardines del Ayuntamiento de Madrid tras 
Celedonio Rodrigáñez ${ }^{20}$. Ortiz había trabajado anteriormente con Aldrufeu y había sido ayudante de Forestier en la Ciudadela; trabajó para el Duque de Alba en el jardín del Palacio de Liria. Permaneció como jardinero del Duque de Alba y en los años 1920 fue nombrado presidente de la Asociación de Horticultura, fue conocido como el "abanderado de las rosas" 21 y cuyo nombre llevaban los Concursos Internacionales celebrados en la Rosaleda.

Ortiz será colaborador asiduo de la revista Cortijos y Rascacielos escribiendo sobre varios temas relacionados con los jardines. En uno de los números nos describe el madrileño jardín, propiedad de José Pérez Stella (h.1930), en Ciudad Lineal como ejemplo tipo de jardín de mediana extensión. Propone aprovechar los accidentes y elementos naturales y luego realizar el movimiento de tierras "en forma que proporcionara al jardín el mayor número de perspectivas y le dotara de cuantos detalles atrayentes pudieran acoplarse bajo la más estricta sencillez de líneas"22.

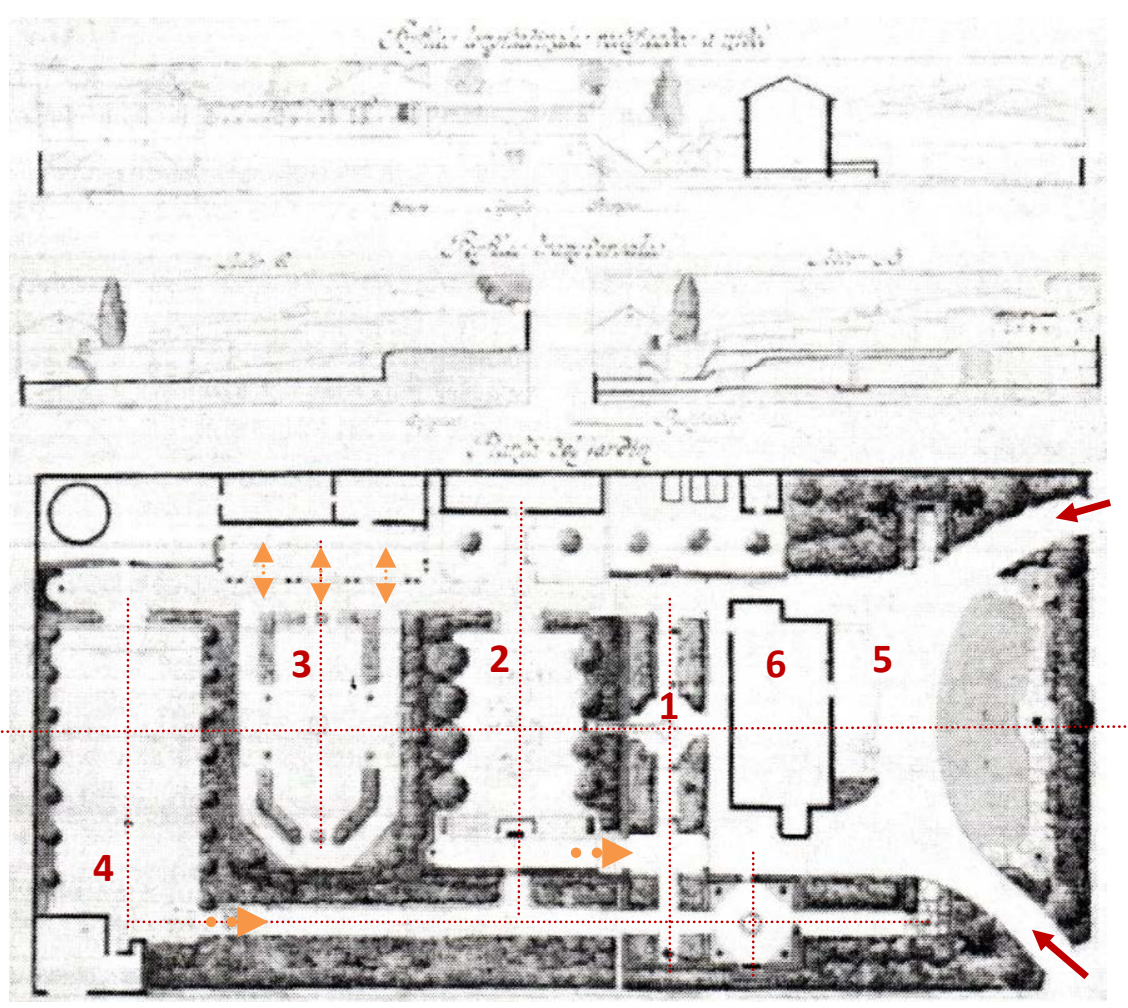

\footnotetext{
20 Ortiz realizó y colaboró en numerosos parques públicos: plaza de Oriente, plaza de España, jardín ducal del palacio de Liria, jardines de Sabatini, parque Isabel la Católica en Gijón, jardines de la Laboral de Gijón, jardines del Altozano en Albacete, jardines de Cecilio Rodríguez, jardines del Prado, palacete de la Moncloa, rosaleda del Retiro y lleva su nombre la del parque del Oeste. Ver capítulos Actuaciones urbanas - Jardines y parques madrileños.

${ }^{21}$ CORTÉS-CAVANILLAS, J.: Psicoanálisis de Ramón Ortiz, Jardinero Mayor de la Villa y Corte y abanderado de las rosas. $A B C, 29-03-1964$, p. 35.

22 ORTIZ FERRÉ, R.: Jardines. Cortijos y Rascacielos, no 7, invierno 1931-32, p, 15.
}
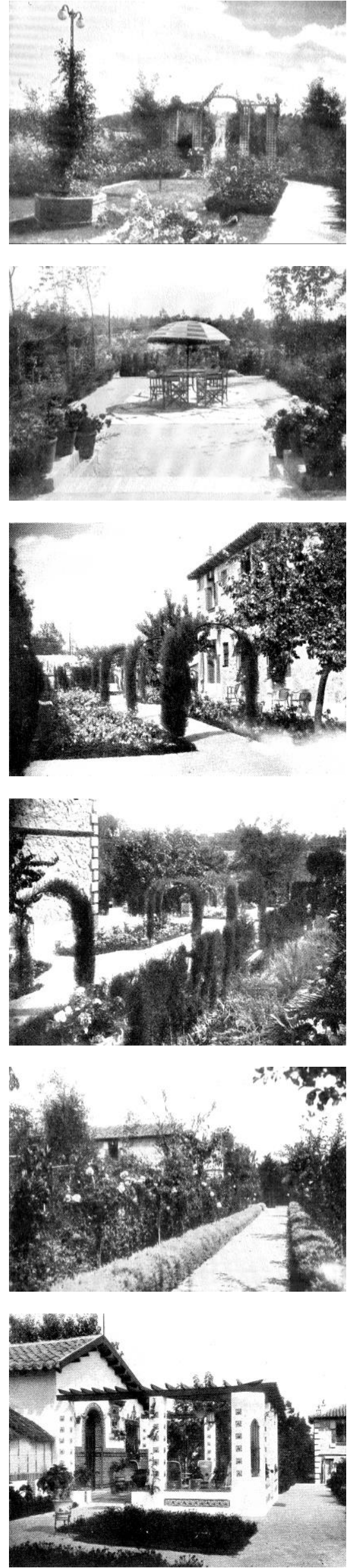

7.26 Jardín propiedad de D. José Pérez Stella, Ciudad Lineal. Planta, secciones y vistas del jardín. Ramón Ortiz Ferré. ORTIZ FERRÉ, 1931-32, p, 15-17. 

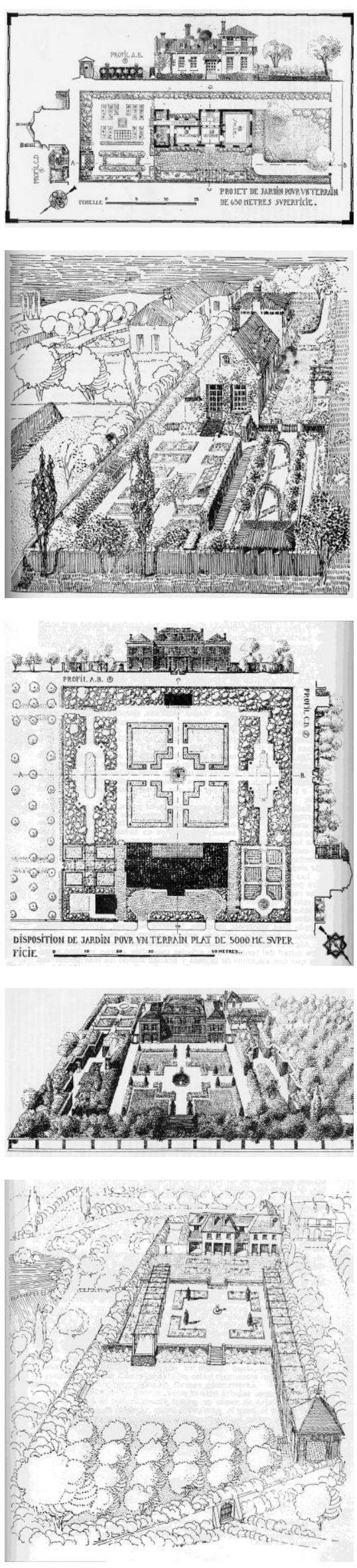

7.27 Proyecto de un pequeño jardín para un terreno de $650 \mathrm{~m}^{2}$ : planta y perspectiva. Disposición de un jardín en un terreno llano de $5000 \mathrm{~m}^{2}$ : planta y perspectiva. Proyecto de jardín para un terreno en pendiente de $3000 \mathrm{~m}^{2}$ : perspectiva. FORESTIER, 1985.
Leyenda: 1.Rosaleda, 2.Jardín de verano, 3.Jardín de invierno, 4.Huerta,

5.Jardín paisajista, 6.Casa.

Establece una zonificación del jardín con cuatro partes diferenciadas. La Rosaleda se realiza sobre una base geométrica sencilla; para contrastar el colorido de las platabandas de rosales se rodean con praderas de césped, plantas y macetones cerámicos con geranios de yedra. En el centro se ubica una farola en la que se enrosca un rosal trepador y al fondo un "trillaje" o celosía con cuatro columnas y figura central flanqueada por dos tinajas naranjas con geranios de yedra. A ambos lados de la celosía una florida mimosa y arbustos variados rodeados por bordura de boj. El Jardín de verano consta de una sencilla plazoleta enlosada en su parte central a la que se accede desde el paseo central descendiendo tres escalones. Está rodeada de varios arbustos con bordura perenne y una alineación de castaños de indias en los laterales. Al fondo, junto a la huerta y eras de flor para cortar, se sitúa un banco adosado abrazado por una escalinata y sobre el que penden plantas en flor. En frente se halla un arco de ciprés que corresponde al muro de la misma especie que rodea el Jardín de invierno. Este jardín se ubica en una zona resguardada de los vientos y soleada; en su centro se sitúa una pequeña glorieta con cuatro grandes platabandas y dos más adicionales de flor de temporada, bordeadas de boj enano recortado. Cuatro arcos de ciprés se colocan en el paseo central y otros interrumpen la tapia de ciprés que rodea este jardín para permitir el acceso desde los paseos. La Huerta o eras de hortaliza y flor para cortar, que contienen frutales diversos y numerosas plantas de huerta, destaca por su colorido y variedad, y está recorrida por un paseo central que salva los distintos niveles del terreno mediante escalinatas. El Jardín de paisaje o Jardín paisajista alberga un paseo circular para acceso de carruajes con dos salidas; aprovecha los cedros existentes poniendo únicamente como fondo una sencilla pradera de césped. Coloca una estufa resguardando la pared y un pequeño edificio delante del cual construye una pérgola-patio de ambiente andaluz frente a la rosaleda.

Analizando la planta resulta interesante, pues la organización de espacios es serial pero utiliza recursos axiales transversales para ordenar el conjunto, introduciendo pequeñas estancias que proporcionan variedad a la repetición sucesiva de espacios. Éstos dialogan con las edificaciones laterales mediante pérgolas o arquerías que apoyan los ejes transversales. Recuerda un poco a los jardines 
tipo de Forestier y algunos de Vera donde hay una secuencia de espacios concatenados que se relacionan mediante ejes.

La Colonia Residencial Cruz del Rayo (1927-1929) se proyecta en 1928 por el arquitecto Eduardo Ferrés y Puig y consta de 300 pequeños hoteles residenciales. Tiene reminiscencias de la ciudad jardín de Howard y algunos proyectos franceses como la Ciudad Jardín PlessisRobinson de París (1919-1955) -pequeña escala y baja densidad, vías tranquilas y sin tráfico, gran porcentaje de zonas verdes, un jardín para cada casa, servicios comunes, carácter social...-. La Compañía Anónima de Casas Baratas ya había realizado anteriormente algunas colonias en terrenos cercanos con malla ortogonal de viviendas en hilera de una o dos plantas con pequeños jardines delanteros y patios traseros: colonia de Prosperidad (Luis Larrainza Vignan, 1919-1926), colonia Primo de Rivera (Fernando de Escondrillas y López de Alburquerque, 1919-1925), colonia Jardín de la Rosa (Augusto Sanz Marcos, 1919-1923), etc.

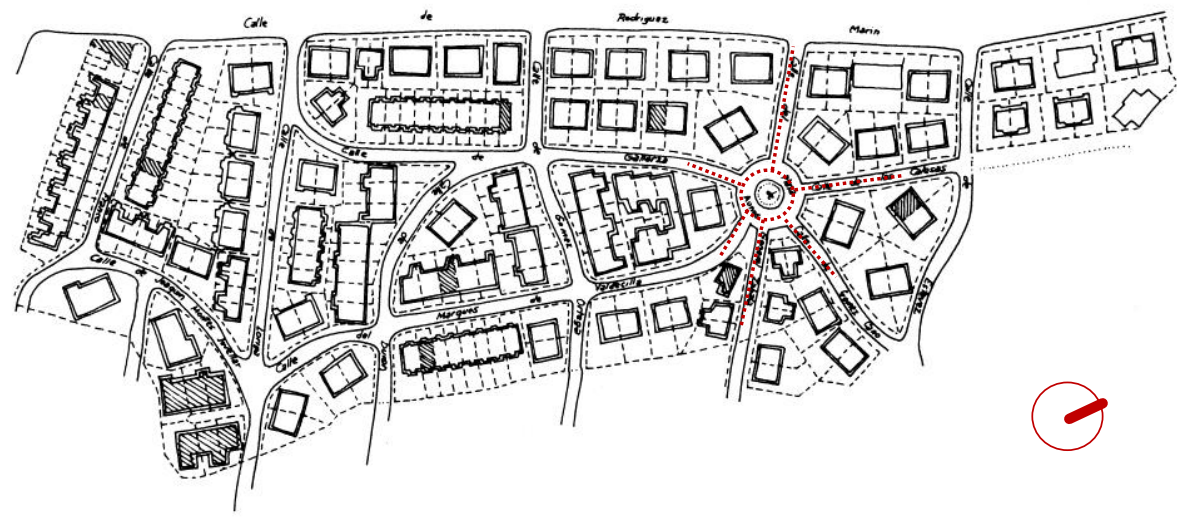

La colonia Cruz del Rayo ${ }^{23}$ fue promovida por la Real Institución Cooperativa de Funcionarios del Estado, Provincia y Municipio en unos terrenos adquiridos por Gregorio Iturbe. Está limitada por las calles Príncipe de Vergara, Gabriel Lobo, Rodríguez Marín y A. Rodríguez Villa. El trazado viario, cuyo antecedente es la colonia de El Palau de Mataró del mismo autor, se articula a partir de la plaza de Aunós, situada al norte y conectada con la calle Príncipe de Vergara, foco principal del que parten seis vías en forma de estrella, dos de las cuales, curvas, recorren de norte a sur la colonia, y está cortada por cuatro calles transversales, pero no paralelas; también cuenta con una vía perimetral que va del paseo de Ronda hasta el final de la colonia. Se proyectaron una serie de servicios comunes: jardín

${ }^{23}$ Se dice que el nombre le viene de una cruz de piedra, dañada por un rayo en una tormenta, que aquí existió.
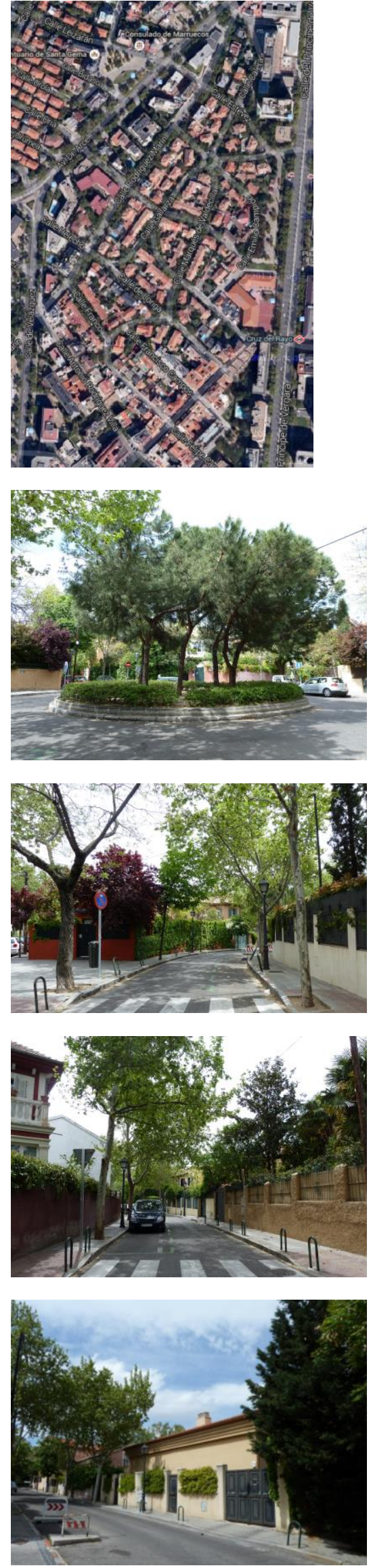

7.28 Plano de situación de la colonia Cruz del Rayo. Dibujo de Crsitina García Pérez. Registro Arquitectura de Madrid. COAM, 2003, F2.221B. BARREIRO PEREIRA, P.: Casas Baratas. La Vivienda Social en Madrid 1900-1939. Madrid, 1991. Vista aérea actual, Googlemaps. Plaza de Aunós y calles adyacentes. PHL, abril de 2012. 
colectivo, guardería, grupo escolar, campos deportivos, baños, central telefónica, etc. -algunos de ellos parecen estar situados en el espacio central, junto a la plaza-. Cuenta con una amplia variedad tipológica, desde pequeños bloques de dos plantas de viviendas en hilera hasta viviendas unifamiliares aisladas de una o dos plantas. Todas las viviendas tienen un pequeño jardín delantero y un patio trasero de servicio ${ }^{24}$.

El trazado está influido por la organización jardinera ya que las viviendas se suelen disponer con los patios traseros al interior de forma que todos los jardines delanteros dan a las calles arboladas y sin mucho tráfico, por lo que estas vías disfrutan de estas zonas verdes y ayudan a crear la sensación de estar alejados de la ciudad. Las viviendas se disponen en el centro del solar y adosadas a la contigua, aprovechando toda la superficie libre para zonas verdes. La composición del trazado es bastante paisajista con calles curvas que marcan itinerarios flanqueados por jardines. Existen puntos focales como la plaza de Aunós a donde se dirigen las vistas en sus calles radiales. El arbolado de las calles junto a los jardines de las residencias ayudan a crear un microclima en la zona.

Dentro de la colonia Cruz del Rayo los Sres. Monfort (1931) encargaron a Winthuysen el jardín de esta vivienda unifamiliar situada en el $n \circ 8$ de la pequeña plaza de Aunós. El hotel se sitúa en el centro de la parcela triangular de $180 \mathrm{~m}^{2}$ y se rodea de jardines; aquí también se aprecia un aprovechamiento máximo de la parcela. La zona de acceso consta de un paseo central flanqueado por dos parterres simétricos con dibujos de boj. El eje de simetría coincide con el eje de la vivienda y el acceso se produce en un lateral. Una arcada metálica con trepadoras separa el paseo perimetral junto a la casa. Las partes ajardinadas laterales a la vivienda se disponen como zonas estanciales con una fuente central, como la que se desarrolla junto a la fachada norte prolongándose el eje longitudinal de la vivienda; éste se remata con una mesa y un banco semicircular rodeado de una densa vegetación; Winthuysen especifica el pavimento de esta zona con mosaico de piedras.

\footnotetext{
24 Colonia Cruz del Rayo. Registro Arquitectura de Madrid. FCOAM, 2003, F2.221B. El proceso de expropiación para la prolongación de la calle Príncipe de Vergara motivó su destrucción y a pesar de su protección algunas de las viviendas fueron demolidas para construir bloques.
} 


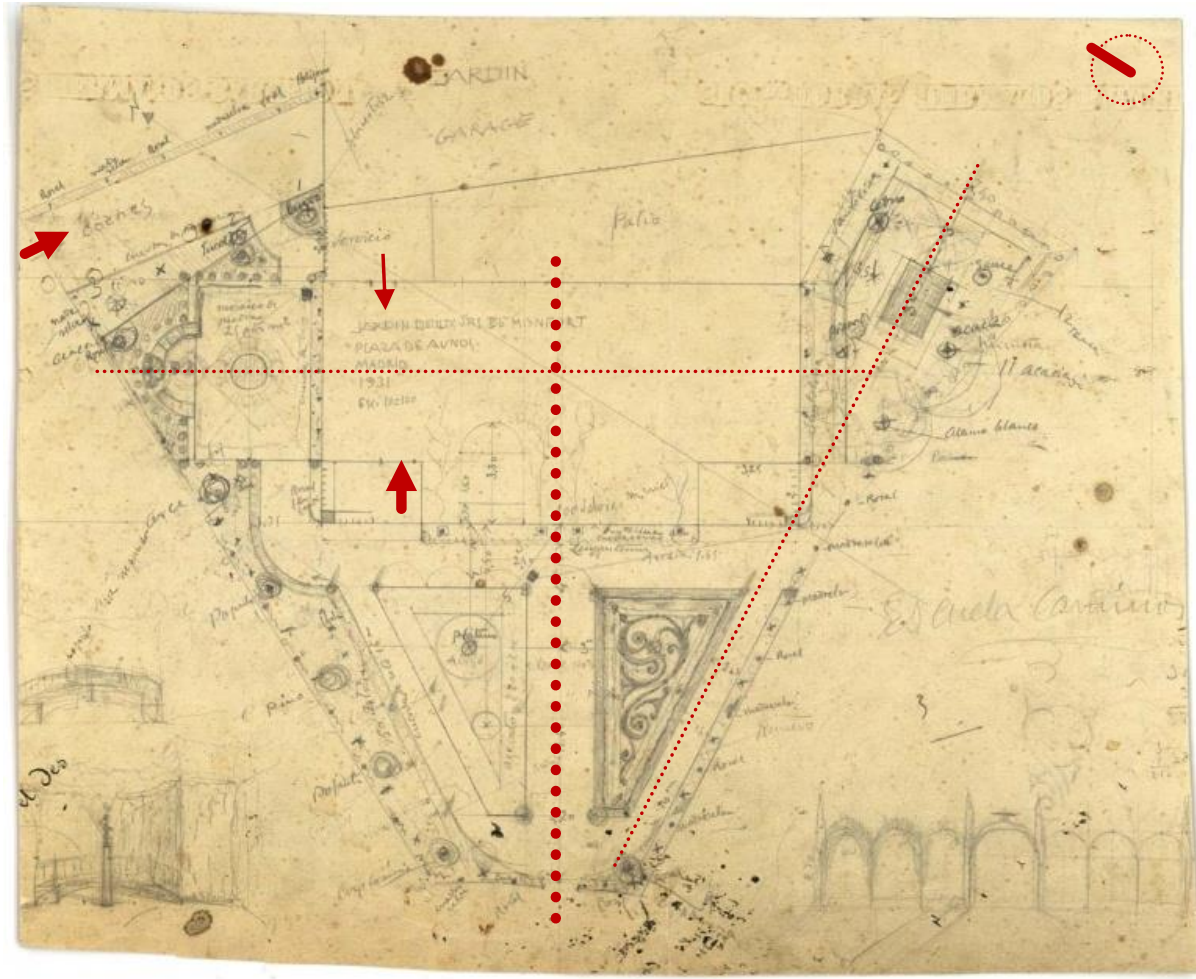

El paseo que conduce desde el acceso a esta plazoleta se acompaña de árboles como pinos y chopos que hacen de filtro vegetal frente a las edificaciones colindantes. El otro paseo lateral diagonal siguiendo el límite del solar se flanquea con rosales y majuelos alternados y conduce a una estancia con una alberca rectangular central con cuatro árboles que marcan las esquinas. En la parte posterior junto a la casa se organiza un patio de servicio junto a la entrada del mismo y a continuación un jardín-garaje comunicado con el acceso de coches $^{25}$. Parece que respeta la vegetación existente, ya que en el plano señala el nombre de algunos árboles de gran porte como el plátano en el parterre noroeste o el álamo blanco y la acacia en el acceso de la estancia oriental.

La colonia Parque Residencia es promovida por Gregorio Iturbe y Javier Gómez de la Serna y construida entre 1931 y 1934 por los arquitectos Luis Blanco-Soler Pérez y Rafael Bergamín Gutiérrez ${ }^{26}$ quienes se encargan del proyecto general y de urbanización. Está delimitada por el paseo de la Castellana y las calles Carbonero Sol,
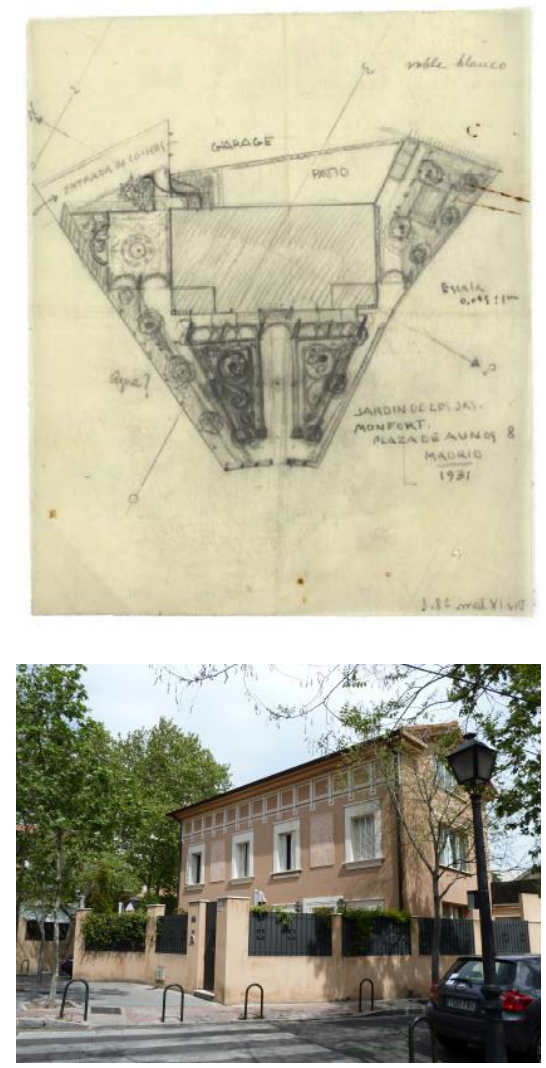

7.29 Jardín de la Residencia de los Sres. Monfort. Winthuysen, 1931. Planta del jardín. ARJB, lám. 28, 1-2. Vista actual. PHL, abril de 2012.

\footnotetext{
${ }^{25}$ Actualmente se conserva solo parte del jardín.

${ }^{26}$ Alumnos de Anasagasti y Palacios. Bergamín estudió, junto con Javier Gómez de la Serna, ingeniero de Montes en El Escorial compatibilizándolo con arquitectura y fue creador de la revista España Forestal. AMANN, E.: Paseo por "El Viso" madrileño del brazo de Bergamín. En: El Inmueble. 1966, no 2 marzo, p. 18.
} 


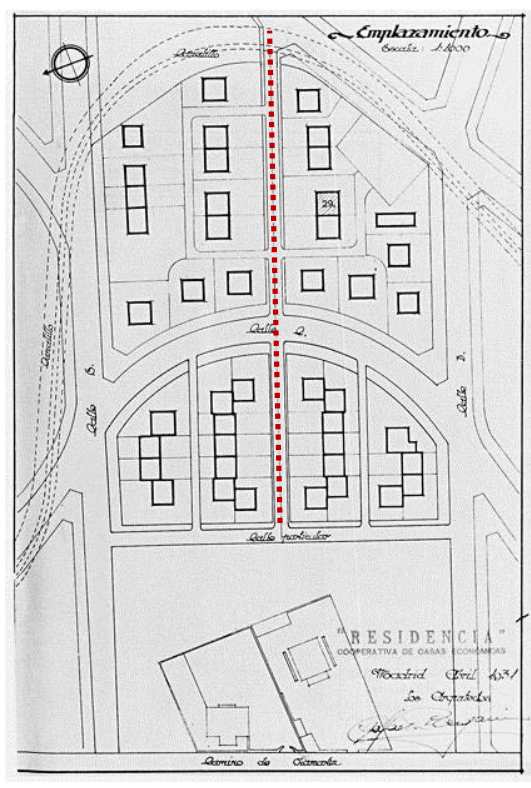

7.30 Colonia Parque Residencia. Plano de emplazamiento. Archivo DOCOMOMO Ibérico.

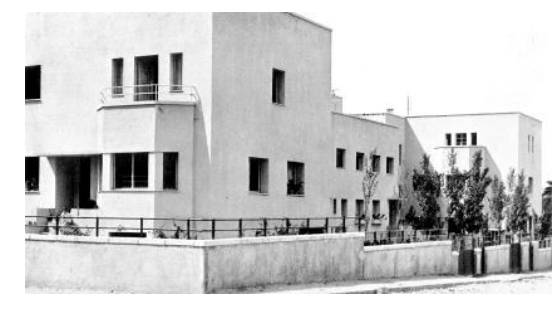

7.31 Colonia Parque Residencia, vía central. Los Arquitectos Blanco-Soler y Bergamín /prólogo por Manuel Abril. Madrid: Ediciones de Arquitectura y de Urbanización Edarba, [1933?], p. 39.

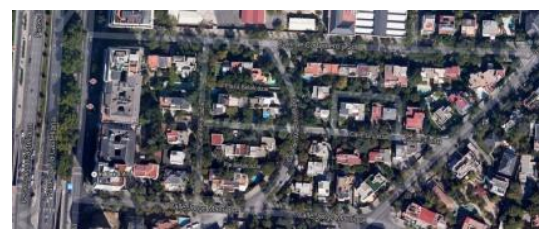

7.32 Colonia Parque Residencia, vista aérea actual. Googlemaps
Vitrubio y Jorge Manrique ${ }^{27}$. Según el arquitecto José Luis Picardo, que vivía en la colonia, "gracias al auténtico bosque que en este barrio se ha desarrollado, no obstante el seco clima de Madrid, se pueden conseguir estos agradables e íntimos recintos" 28 .

Concebida como un ensayo para intentar por primera vez la aplicación de la Ley de Casas Económicas y buscando el máximo aprovechamiento de la ordenanza de Parque Urbanizado proyectaron este conjunto de 69 viviendas de semilujo para profesionales liberales ${ }^{29}$ con una ocupación en planta, incluyendo viales del $28 \%$. Tomando como referente la vanguardia centroeuropea y especialmente la holandesa, la parcelación contemplaba dos modelos: los bloques en hilera, generalmente de cuatro unidades, sobre una parcela media de $250 \mathrm{~m}^{2}$, y las viviendas aisladas con jardín y cuatro fachadas diferentes. Esta colonia sirvió de modelo para la de El Viso y para algunas de las casas próximas ${ }^{30}$. Su emplazamiento y la limitación de altura le concedían cierto aire rural dentro de la ciudad. Cuando el arquitecto Jaime López de Asiain describe su casa en esta colonia dice: "La rodea un jardín pequeño, pero suficiente para creerse transportado muy lejos de la ciudad agotadora" 31 .

No hay plantas de los jardines pero las fotografías de la época muestran una jardinería muy formal, incluso con parterres, existiendo un gran contraste estilístico entre la arquitectura moderna de las casas y los jardines clásicos. Da la sensación que los jardineros intentan decorar o rellenar el vacío ornamental dejado por la arquitectura.

\footnotetext{
${ }^{27}$ En aquella época esta zona no estaba construida y ocupan el solar denominado Altos del Hipódromo por estar junto al antiguo hipódromo de la Castellana, propiedad de Gregorio Iturbe. "...Encontramos unos terrenos en los "altos del hipódromo", a la derecha de la carretera de Chamartín, en lo que llamaban "el tendido de los sastres", desde donde se podían ver gratis las carreras de caballos". BERGAMín, 1967, p. 22.

28 PICARDO, J. L.: Vivienda del arquitecto. Revista Nacional de Arquitectura. Madrid: Ministerio de la Gobernación, Dirección General de Arquitectura, 1958, no 201 sept., p.36.

${ }^{29}$ Era conocida como la "Colonia de los Arquitectos", ya que muchos profesionales residían allí.

30 DOcomomo: La vivienda moderna, 1925-1965. Registro DOCOMOMO Ibérico. Arquia/temas 27. Barcelona: Fundación DOCOMOMO Ibérico, Fundación Caja de Arquitectos, Ministerio de Vivienda, 2009, p.202. Texto de Vicente Patón Jiménez y Alberto Tellería Bartolomé. proviene del libro Arquitectura de Madrid, que luego se pasó a este libro. 31 Hotel en la Colonia Residencia, para su propio arquitecto. Cortijos y Rascacielos: arquitectura, casas de campo, decoración. 1944, no 26 nov-dic. 2o época, p. 13.
} 

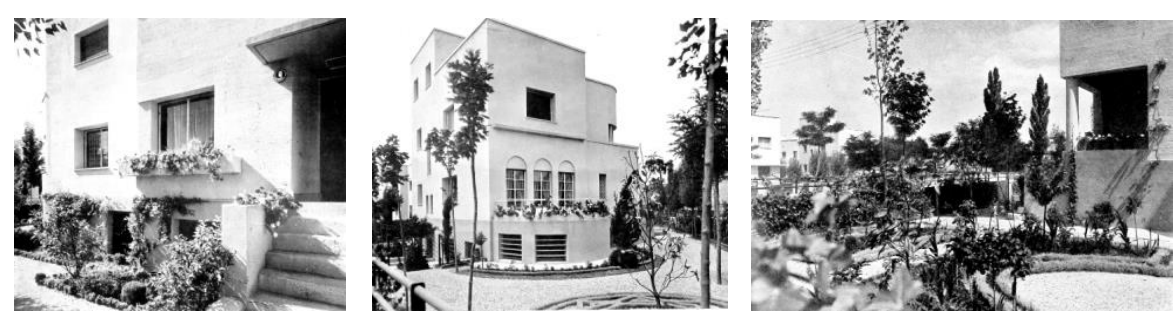

El Sr. D. Julio Blanco escogió a Winthuysen para el diseño del jardín (1934) de su vivienda ubicada en esta colonia. La parcela en esquina con chaflán de $386 \mathrm{~m}^{2}$ cuenta con un acceso peatonal en la esquina y otro de vehículos que comunica con el garaje. El espacio estrecho y alargado que deja la vivienda en el noreste es utilizado para el servicio y el acceso de coches; mientras que la zona más ajardinada para uso y recreo se ubica al otro lado de la casa organizándose en dos partes diferenciadas pero dispuestas en continuidad. Próxima a la zona de acceso crea una zona estancial triangular con un banco semicircular de ladrillo y granito para el descanso ${ }^{32}$ bajo la sombra de un arce y un magnolio. El espacio se delimita por cuadros perimetrales con rosales y plantas aromáticas encintados por un seto de boj. El paseo -bordeando un cuadro con el magnolio en su centroarticula la composición rematándose en una segunda estancia más privada con una mesa de piedra y sillas protegida por una pérgola metálica semicircular, cubierta de parra y rodeada por un seto de cipreses. El perímetro se conforma con una densa vegetación de mimosas y romeros que acompañan las alineaciones de chopos (Populus alba). Como indica Juan Tuset en su artículo: "Este árbol estaba presente a lo largo de la ribera del arroyo el Canalillo que existía en el lugar y condicionó el trazado y la organización de toda la colonia. Winthuysen lo utiliza como elemento que conservaba la memoria del lugar al mismo tiempo que construía los fondos del jardín"33.

Otra vez se aprecia cómo Winthuysen organiza sabiamente las plantas pequeñas: articula muy bien los espacios mínimos, cada uno de ellos con su personalidad y autonomía compositiva, pero integrados en el todo. Prolonga el eje transversal de la vivienda que coincide con una fuente circular del jardín, donde a su vez se cruza ortogonalmente el eje longitudinal del jardín que se remata en la

\footnotetext{
32 Único elemento junto con algunas plantaciones que se conserva en la actualidad del proyecto original. AA.VV.: Javier de Winthuysen. Jardinero. Madrid: Real Jardín Botánico, CSIC, 1986, p. 59-69.

33 TUSET, J.J.: Hacia lo moderno. Adaptación del jardín español a la arquitectura racionalista. Ra. Revista de Arquitectura. Universidad de Navarra, 2013, vol.15, p.80.
}
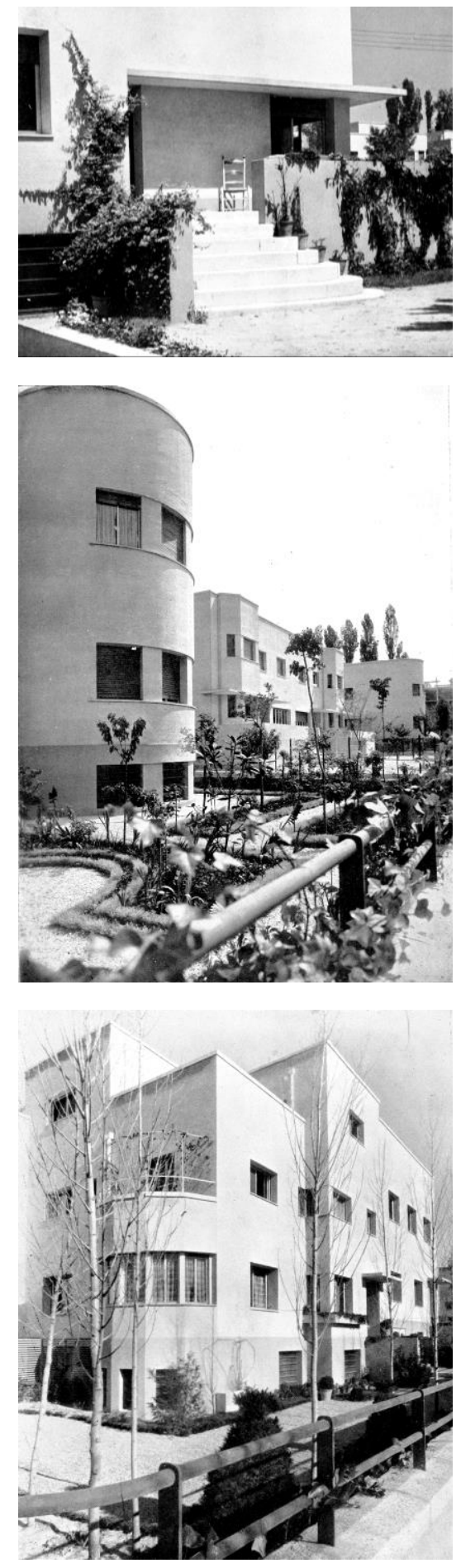

7.33 Colonia Parque Residencia, jardines y casa Bergamín y Blanco-Soler. Los Arquitectos Blanco-Soler y Bergamín, [1933?], p. 21-41.

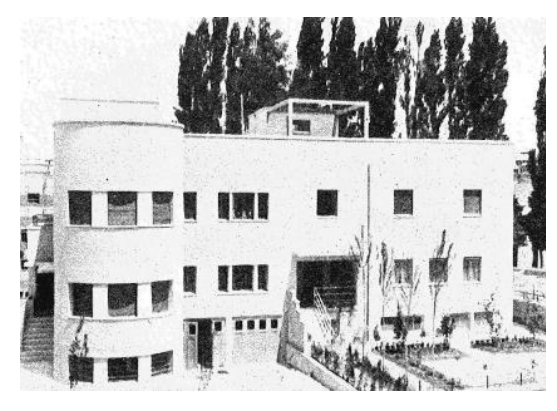

7.34 Jardín de la vivienda del arquitecto Fernando Salvador en Colonia Residencia, Viviendas: revista del hogar. 1933, no 8 febrero p.22. 


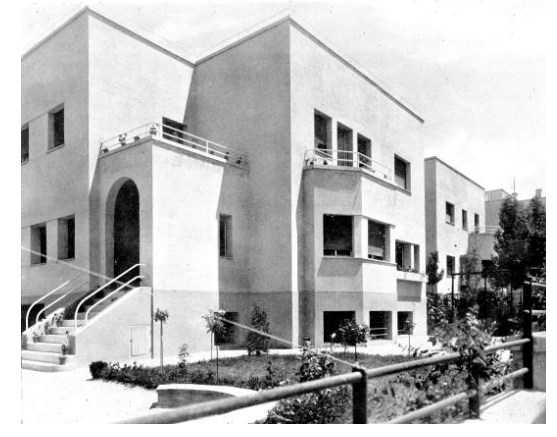

7.35 Jardín de la residencia del Sr. Blanco. Winthuysen, 1934: jardín delantero, planta y detalle. Revista Nacional de Arquitectura, 1958, p.35. ARJB, lám. 37, 3.

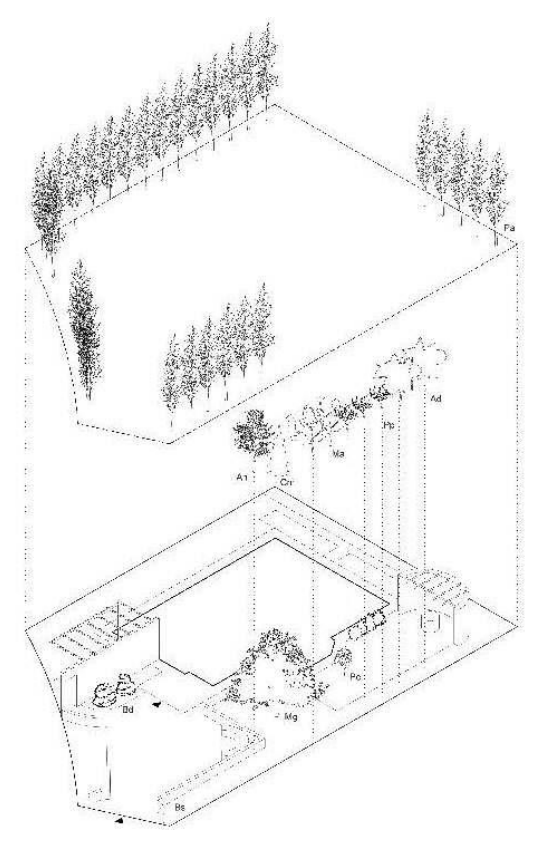

7.36 Jardín de la residencia del Sr. Blanco. Winthuysen, 1934: axonometría realizada por J. Tuset. TUSET, 2013, p.80.

pérgola semicircular y por el otro lado termina en el banco de la zona estancial junto a la entrada.

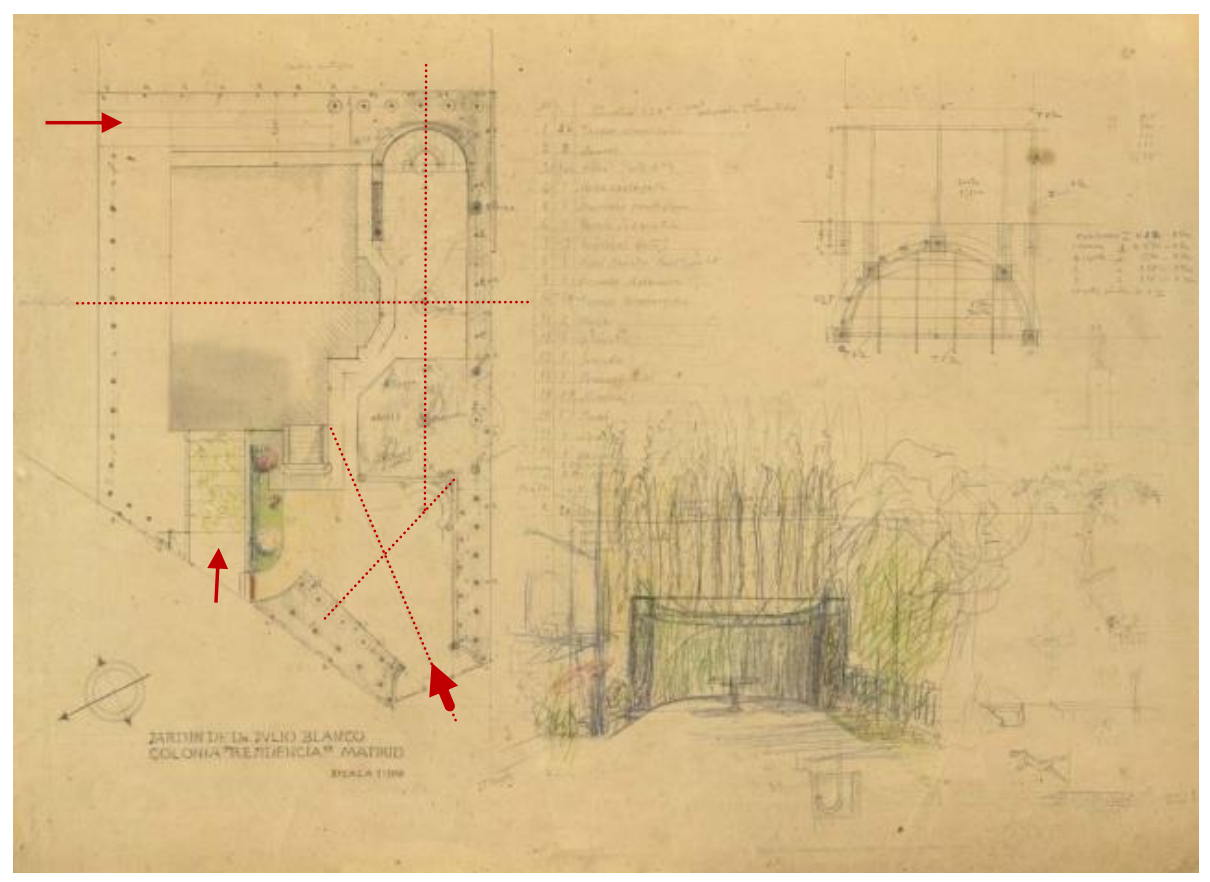

Paralelamente a los jardines andalucistas de las colonias madrileñas realizados por Winthuysen, aparecen otros de algunos arquitectos pertenecientes a la denominada generación de 1925, que conocedores del Movimiento Moderno, serán los que introduzcan en España unas ideas y una actitud renovadora frente a los regionalismos y al eclecticismo ${ }^{34}$.

Fernando García Mercadal proyectó en 1932 el conjunto de casas más pequeñas de esta colonia con sus jardines delanteros y traseros, de mayor tamaño y orientados a mediodía. Se trata de tres casas medianeras y él mismo residió en una de ellas. La distribución es muy sencilla y funcional, probablemente de las más modernas de Mercadal; se desarrolla en cuatro plantas de forma similar a la del resto de las viviendas de la colonia y el comedor con un gran ventanal comunica directamente con el jardín mediante una pequeña terraza con su escalera metálica. En la última planta el estudio da a una terraza orientada a norte con una jardinera bajo la ventana, utilizándose ésta solamente en verano.

La vivienda de 7,45m de fachada consta de dos jardines, uno delantero de $5 \mathrm{~m}$ de fondo $\mathrm{y}$ otro trasero mayor, orientado a mediodía, de $17 \mathrm{~m}$ de fondo. Mercadal indica que el "trazado ha sido

\footnotetext{
${ }^{34}$ Ver capítulo El jardín doméstico- Fragmentos de modernidad.
} 
especialmente cuidado, con vistas no sólo a un entretenimiento fácil y económico, sino a una utilización diaria de su superficie en el buen tiempo, disponiendo para ello, junto a la casa, una parte enlosada, con objeto de poder estar en él sin humedades" ${ }^{35}$. Estas baldosas se prolongan en el camino que delimita en uno de sus laterales la pradera que remata el jardín. En el jardín delantero dispone un seto lineal para ocultar las vistas de la rampa colindante con acceso al garaje de una única plaza. Del jardín trasero no se dispone de una planta pero seguramente tendrá mayor presencia vegetal creando una agradable zona estancial.

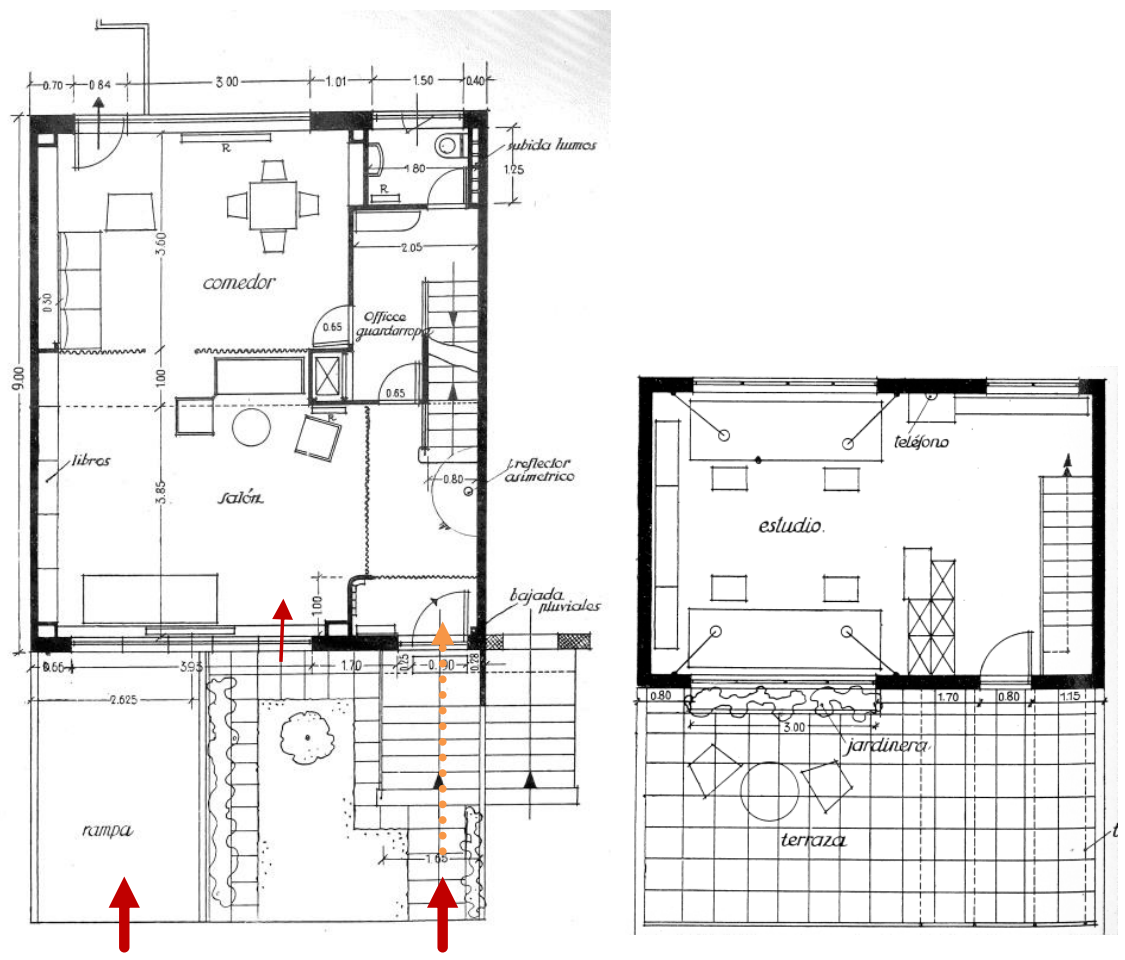

En su libro de Parques y Jardines (1949) Mercadal recoge un ejemplo de una vivienda en Viena con un pequeño jardín delantero que permite el acceso y otro trasero un poco mayor con una organización similar con una escalera, una zona pavimentada junto a la casa, un camino lateral y unos cuadros ajardinados o de plantaciones.

También el arquitecto José Luis Picardo va a realizar el jardín de su propia vivienda (casa h. 1934, jardín h.1958). Éste consta de dos partes: una delantera en la zona de acceso dando a la calle Carbonero y Sol, y otra en la parte posterior de la vivienda de carácter más privado dando a la calle interior. El jardín de acceso tiene una rampa flanqueada por muros de hiedra para permitir que

\footnotetext{
35 La Vivienda del arquitecto García Mercadal, en la colonia "Residencia". Viviendas: revista del hogar, 1933, no 8 febrero, p. 12.
}

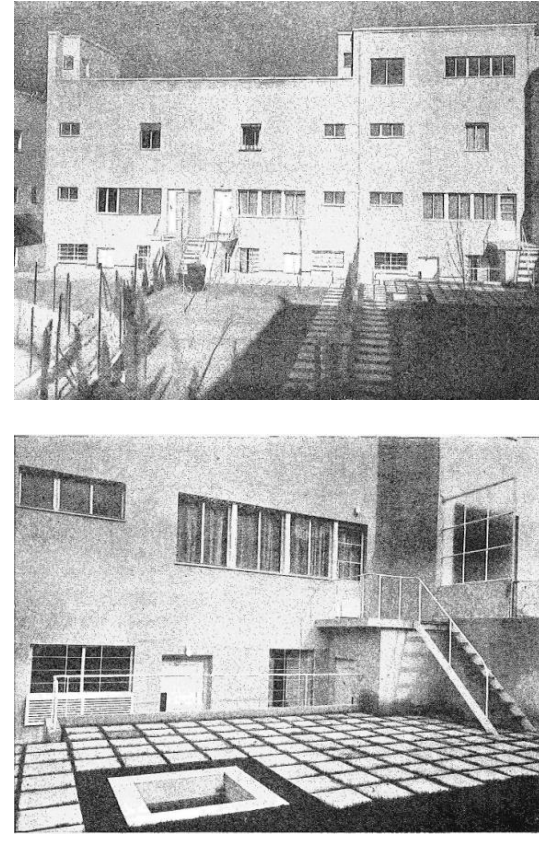

7.37 Planta baja y planta de estudio con terraza. Vistas del jardín delantero de la vivienda del arquitecto García Mercadal, en la colonia "Residencia". Cortijos y Rascacielos, 1933, p. 25-26. Viviendas: revista del hogar, 1933, no 8 febrero, $\mathrm{p}$. 10.

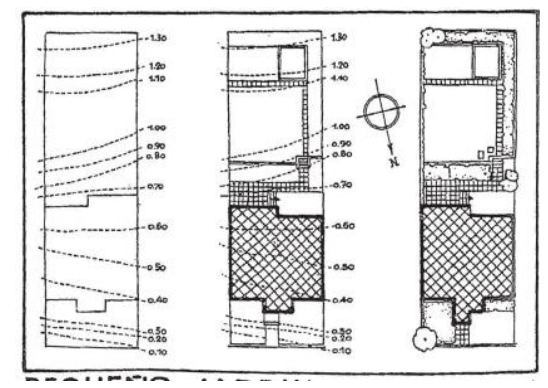

7.38 Pequeño jardín en Viena, Esch. GARCÍA MERCADAL, F.: Parques $y$ Jardines, 1949 (original) 2003, p. 268. 

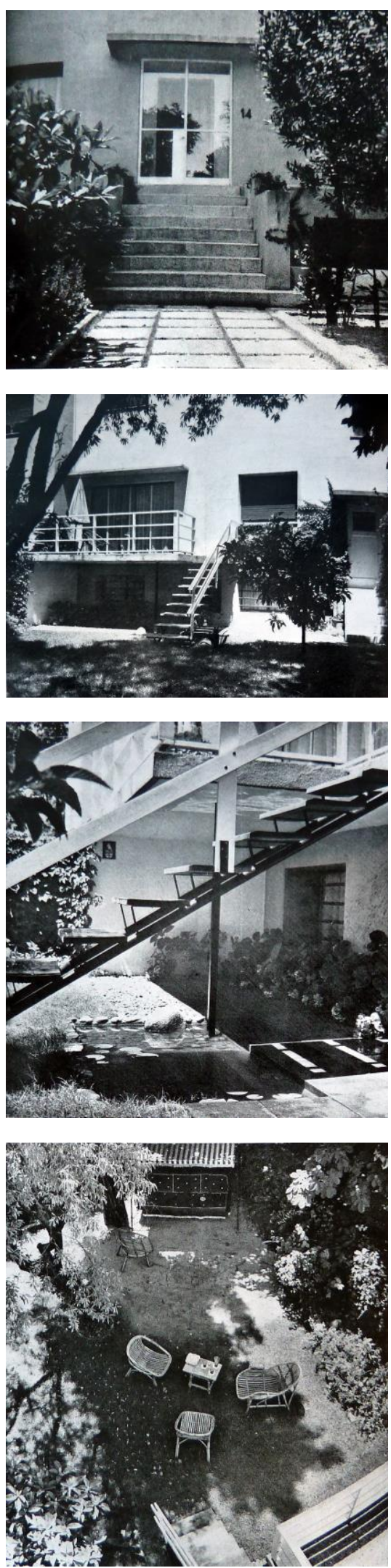

7.39 Jardín delantero y posterior de la vivienda del arquitecto José Luis Picardo. Revista Nacional de Arquitectura, 1958, p.35-38. los coches accedan al garaje. Este jardín delantero está todo pavimentado y conecta con el acceso a la vivienda, salvo un estrecho cuadro con un magnolio al este y uno más grande al oeste con olivos, laurel, chopos y adelfas que deja una pequeña estancia lateral en correspondencia con el estudio. Mientras, el jardín privado al sur tiene una gran superficie de césped salpicada por algunos árboles (níspero, almendro, celindo) que aportan sombra, y en un rincón al fondo una zona estancial con arena bajo la sombra de un chopo donde se han colocado un sofá y unos sillones. Junto al muro del lado oeste se crea una masa de bambú y en la zona próxima a la casa una rocalla. Una terraza volada hace de zona de transición entre interior y exterior y junto a ella baja la escalera que comunica con el jardín; bajo la escalera y la terraza se ubica un estanque en $L$ con nenúfares, separado de la vivienda por un parterre con hortensias ${ }^{36}$.

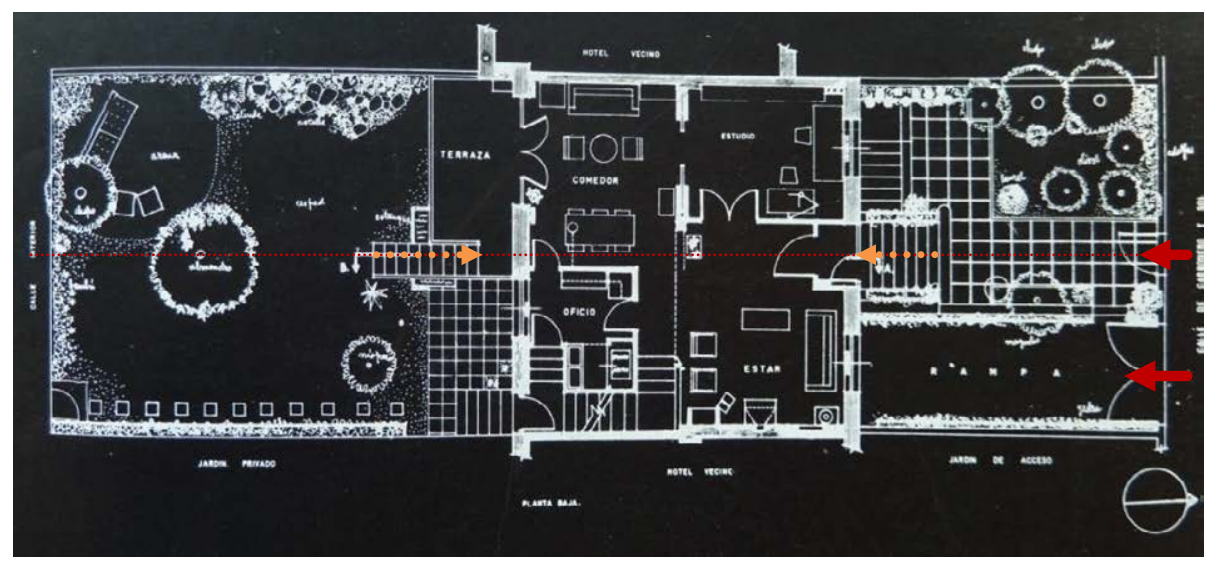

Tanto el jardín de Mercadal como el de Picardo son mucho más modernos que los anteriores y responden claramente a la arquitectura y están diseñados al tiempo. Ambos son funcionales respondiendo a las distintas necesidades: los jardines delanteros son lugares de tránsito por lo que están pavimentados, tanto del automóvil -con su rampa protegida por la vegetación- como de los peatonales con sus accesos enfrentados con el acceso a la vivienda. En los jardines delanteros la vegetación principalmente acompaña los accesos y estos recorridos con cuadros meramente decorativos, y tapa las vistas, como las de los garajes; mientras que en los posteriores la vegetación es la protagonista con grandes superficies de césped y zonas estanciales protegidas por árboles que dan sombra. Aparecen elementos como terrazas y escaleras, prolongaciones de la casa que relacionan interior y exterior.

\footnotetext{
${ }^{36}$ Se modificó en el año 1958 para adecuarla a las necesidades de la época, construyendo una pequeña terraza al jardín y algunas reformas interiores de la vivienda.
} 
Una de las colonias más avanzadas es la Colonia Residencial El Viso (1933-1936). Con 130 hoteles fue construida en 1933 por Rafael Bergamín Gutiérrez, ayudado por su sobrino Felipe Vivanco; ambos le ponen el nombre por estar situada en un terreno de trigales con una de las cotas más elevadas de Madrid desde donde se veían todos los alrededores (vaguada de la Castellana, barrio de Salamanca, otras colonias de casas baratas y estupendas vistas al norte de la Sierra de Guadarrama); era un magnífico otero. Promovida por la Propiedad Cooperativa y financiada por Gregorio Iturbe, fue ampliada posteriormente a 242 viviendas con parcelas medias de $352 \mathrm{~m}^{2}$. Está limitada por las calles Daniel Urrabieta, Tormes, Sil, Francisco Alcántara, Turia, Madre Carmen del Niño Jesús, Arga y Nervión, quedando prácticamente integrada la colonia Iturbe IV ${ }^{37}$.

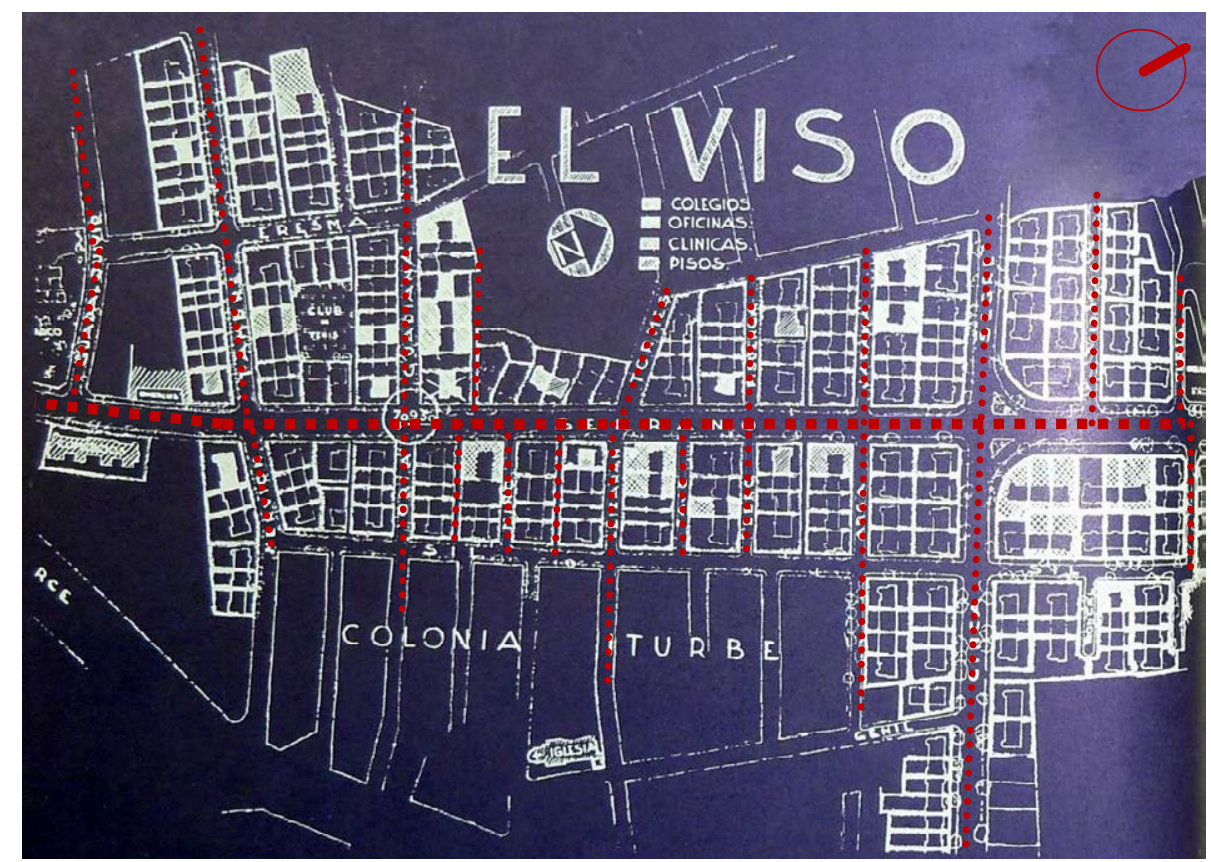

Está edificada en un terreno por aquella época alejado del centro urbano, buscando el aire libre, el sol, la tranquilidad y el aislamiento de ruidos. Una vía central -la calle Serrano-, proyecto del plan de ensanche del Ayuntamiento y por la que en breve circularía el tranvía, cruza la barriada, aunque ya existía una parada a $300 \mathrm{~m}$. Consigue una sensación de ciudad-parque con un bajo aprovechamiento edificatorio; los espacios libres, incluidas las calles, ocupaban más del $80 \%$ de la superficie y la densidad era $136 \mathrm{hab} / \mathrm{ha}$. Se entiende como una especie de continuación de la cercana colonia

\footnotetext{
37 Esta colonia (Enrique Pfitz, 1930) situada entre las calles del Doctor Arce, Nervión, Sil y Arga se sitúa muy próxima a la colonia de El Viso y también fue construida por Gregorio Iturbe.
}
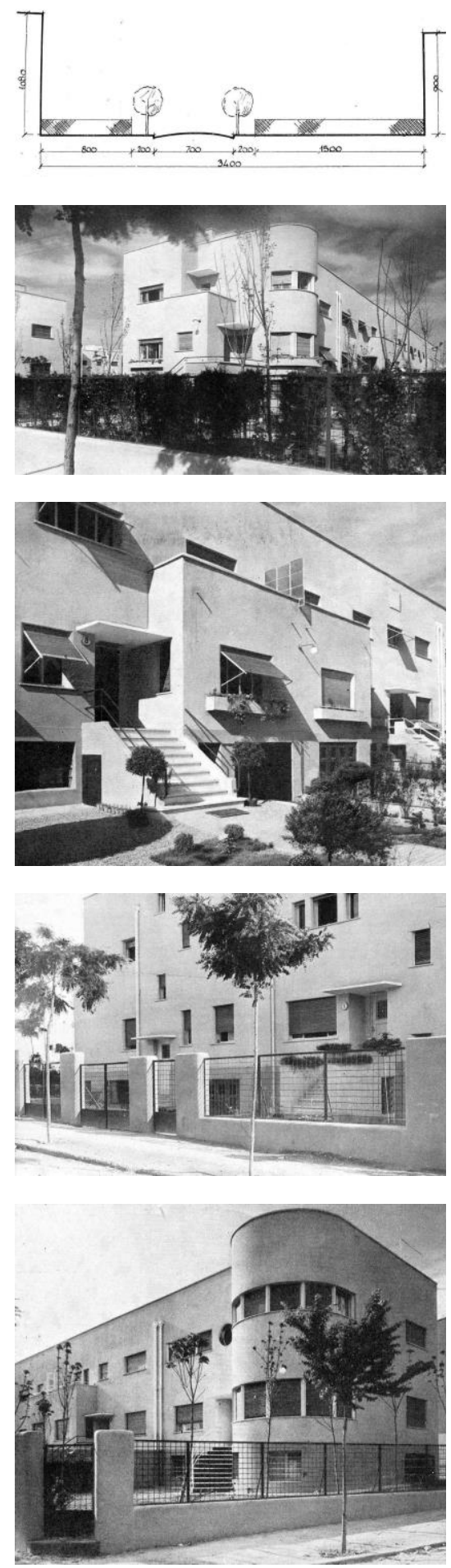

7.40 Colonia de El Viso: perfil de las calles, extremo poniente, detalle de la entrada del tipo $B$, entrada principal del tipo A y fachada sur de otro bloque. Nuevas Formas, 1934, p.181-189.

7.41 Colonia de El Viso: planta de 1967 con indicaciones de los nuevos usos. Arquitectura, 1977, n-204-205, p. 50. 

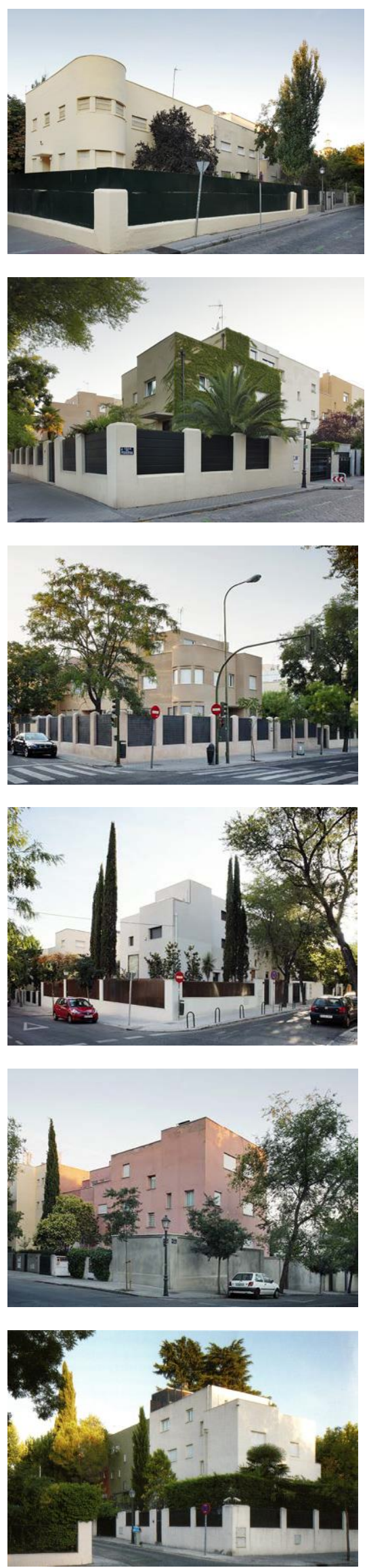

7.42 Vistas actuales de los jardines de la colonia de El Viso. DOCOMOMO, 2009, p.203.

7.43. Vista hacia el norte de los bloques situados a la izquierda de la calle principal. Nuevas Formas, 1934, p.182.
Parque Residencia, aunque el planteamiento del promotor fue más especulativo que en Parque Residencia jugando con la máxima edificabilidad, por lo que Blanco-Soler, inicialmente en el proyecto, lo abandonó; pero sí contaba con el apoyo de unos cuantos propietarios que compartían la idea general de la colonia.

Consigue un alto grado de equilibrio social gracias a la igualdad espacial entre lo individual y lo colectivo. Según Bergamín: "El Viso, dentro de su modestia, tenía entonces, y creo que tiene aún ahora, la importancia de un concepto nuevo que desgraciadamente no ha tenido seguidores dentro de la ciudad. Ahora se habla de arquitectura social, y yo pienso que, sin proponérnoslo, nosotros la hicimos. /.../ El Viso, por otra parte, estaba basado en el contraste de unos volúmenes muy puros, de diferentes colores, con una espesa vegetación que los tapara casi por completo"38. Por tanto la arquitectura plástica, limpia, horizontal, desornamentada y racional, siguiendo las ideas de Mercadal, se aprecia a través de un filtro vegetal de arbolado y es la propia vegetación la que busca romper la monotonía de la arquitectura; así lo explica el propio Bergamín: "Se hizo una arquitectura muy simple, muy cúbica, quizá inspirada en las cosas que habíamos visto en Alemania y en Holanda, arquitectura un poco "seca", pero que yo esperaba compensar con los distintos colores con que se pintaron las fachadas de los diferentes bloques $y$, sobre todo, pensando en la vegetación que pronto habría de crecer y romper la monotonía de aquella arquitectura repetida" 39 .

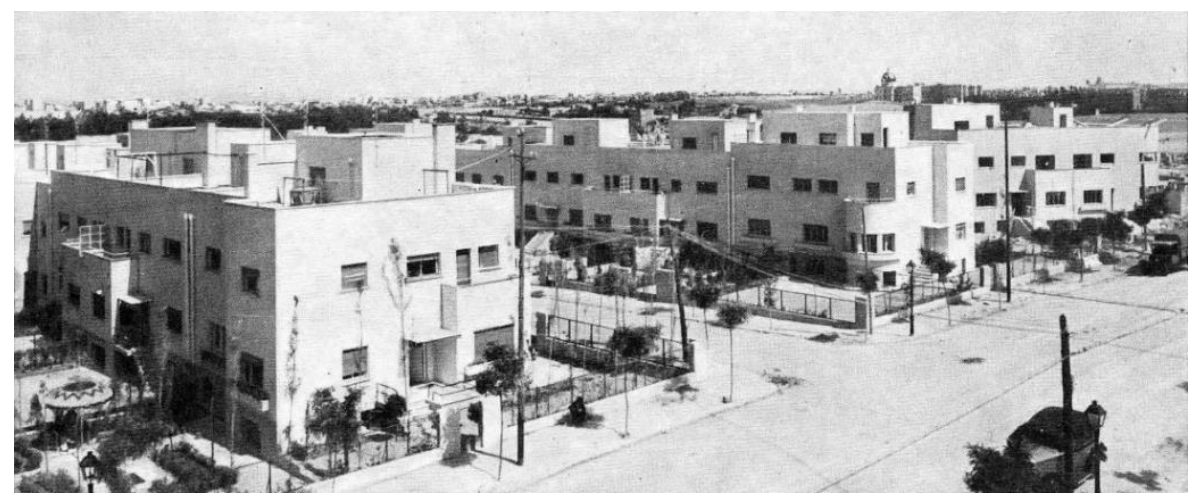

La colonia sigue una organización geométrica y abstracta, una trama ortogonal en espina de pez, siendo el eje principal la calle Serrano; esta arteria no tiene una gran afluencia de tráfico ya que discurren otras calles de mayor capacidad paralelas a ella -Paseo de la Habana y Doctor Arce-. Se procura que el resto de calles transversales tengan

\footnotetext{
38 Entrevista a Rafael Bergamín. AMANN, 1966, p. 20.

39 BERGAMín, 1967, p. 23.
} 
poca continuidad con la trama urbana existente para evitar el tráfico pasante. Los bloques se orientan con sus fachadas principales al sur y separados $20 \mathrm{~m}$. Cuentan con doble acceso por una calle principal y otra de servicio al lado del garaje, y albergan de cinco a ocho viviendas. Esto permite que por primera vez se separe la circulación rodada de la peatonal permitiendo el paseo tranquilo. En el interior de una de las manzanas y separado de la vía pública se proyectó un pequeño conjunto deportivo con dos campos de tenis, y en algunas otras, terrenos libres de juego, representando por primera vez en España la separación de funciones dentro de un conjunto urbano ${ }^{40}$ alternando zonas activas (deportivas, juegos) con zonas tranquilas de descanso (jardines, paseos). En la leyenda de la planta sólo se especifican los colegios, oficinas, clínicas y pisos; no se señalan los espacios libres, solo aparece marcado un club de tenis en el interior de una gran manzana entre las calles Guadiana, Eresma, Tambre y Serrano. Es de suponer que igual que equipamientos como la iglesia ocupan solares menos edificados no dando a Serrano, estas zonas ajardinadas y deportivas debían estar previstas también en estas parcelas.

Esta distribución ya no presenta tanta similitud con los suburbios jardín, guarda más relación con las siedlungen más racionalistas, como la de Stuttgart, porque, como en ella, aquí se hacen no para alojar a los obreros industriales (Berlín, Francfort), sino para dar distinguida vivienda a profesionales de clase elevada.

La distribución en planta de las viviendas es similar a la del resto de colonias con diferentes tipos; algunas en planta alta tienen un dormitorio o estudio con salida a la terraza y otras solo terraza alta practicable con salida por la caja de escalera. Las viviendas de los extremos cuentan con un comedor bow-window, con una cristalera dando al jardín y acompañado de una jardinera con la misma forma. Al estar las viviendas entre medianerías cuentan con un jardín delantero y otro trasero, y en el caso de las que hacían esquina se tenía una zona adicional; en estas parcelas se dispone de mayor espacio, aumentando las posibilidades de configurar las zonas ajardinadas. Se alternan especies caducas y perennes, predominando en el proyecto original especies arbóreas como acacias y chopos y trepadoras como hiedras y vides. Los cerramientos principales constan de zócalo y pilastras de fábrica de ladrillo con revestimiento

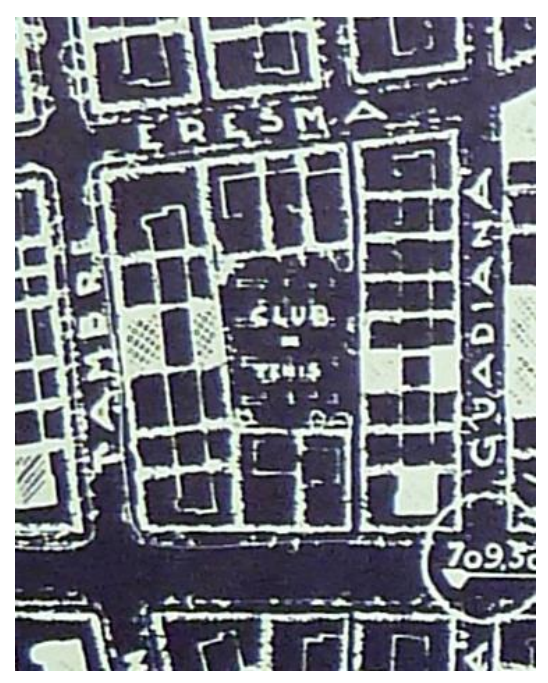

7.44 Colonia de El Viso: club de tenis. Fragmento de la planta de 1967 con indicaciones de los nuevos usos. Arquitectura, 1977, nำ204-205, p. 50

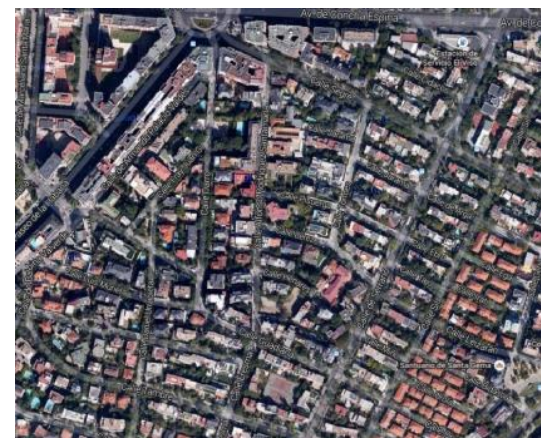

7.45 Colonia de El Viso: vista aérea actual. Googlemaps

\footnotetext{
40 FERNÁNDEZ ALBA, A.: El Viso: apuntes para un análisis socio-arquitectónico. Nueva Forma.
} 1973, no 93 octubre, p. 25. 


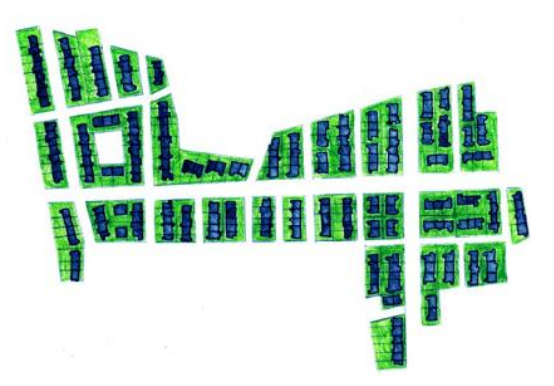

7.46. Colonia El Viso: malla jardines privados. PHL, 2016. pétreo y puertas y paneles de rejilla metálica. Los cerramientos secundarios son de tela metálica con malla cuadrada ${ }^{41}$.

Posiblemente debido a la formación de Bergamín como ingeniero de Montes se aprecia una preocupación por el paisaje en el proyecto: el estudio del terreno ${ }^{42}$, las vistas a la sierra, el arbolado de las calles y los jardines; todas estas plantaciones crean un microclima propio con cuatro grados menos que el resto de la ciudad. El espacio exterior se desarrolla en dos niveles: dominio público (calles peatonales y tráfico controlado) y dominio semiprivado (jardines y patios). Como cuenta Antonio Fernández Alba: "Todo el espacio exterior está tratado como una entidad urbanística, en forma de malla, que favorece una interacción entre espacio público, espacio semiprivado y espacio interior. /.../ La vegetación con una diferenciación muy simple de espacios, logra un valor de diseño tan complejo como el diseño arquitectónico; el espacio exterior se transforma creándose un microclima, que elabora un nuevo paisaje urbano". El espacio interior es el tercer nivel espacial, que lo relaciona con los otros dos Es importante resaltar lo del nuevo paisaje urbano; esta diferenciación la consigue con una malla vegetal en donde por un lado están las alineaciones arbóreas de las calles interiores y por otra parte los jardines privados que a su vez suelen presentar un seto perimetral que ayuda a preservar las vistas y crear intimidad, cuadros ajardinados y algún árbol como contrapunto vertical a la arquitectura horizontal, destacando los cipreses. Así que aunque parece indicar que sólo se buscaba un control climático sin mayor interés compositivo, las fotos muestran alguna intención de diseño en algunos.

El uso de los jardines fue cambiando adaptándose a las necesidades de la época. Como prosigue Fernández Alba: "Los jardines eran unos árboles con canto rodado, durante la guerra se transforman en huertos y después en jardines ingleses" 43 . Aunque fue proyectada para funcionarios de clase elevada, ha terminado convirtiéndose en una colonia de viviendas de lujo para profesionales e intelectuales relevantes. Con los años se ha ido modificando su carácter conservándose pocos rincones intactos; por un lado al quedar

\footnotetext{
41 Barriada de casas económicas “El Viso”, en Madrid. Nuevas Formas, 1934, p. 180.

42 Su nombre y el nombre de las calles de ríos de distintas cuencas. "Esta idea ya estaba lanzada por Iturbe, que siendo de origen navarro, nórdico, también muy aficionado a valorar la Naturaleza, denominó las calles del primitivo núcleo de la Colonia Iturbe con nombres de ríos de la zona navarra principalmente y de Aragón”. BERGAMíN, 1967, p. 27.

43 FERNÁNDEZ ALBA, 1973, p. 25.
} 
encerrada en el crecimiento del resto de la ciudad, le quita sus vistas y la sensación de tranquilidad, siendo un factor clave la transformación de la calle Serrano en gran vía de circulación hacia 1955; y por otro por las múltiples modificaciones y derribo de algunos de los edificios adaptándose a los nuevos usos y necesidades. El peatón ha perdido importancia frente al tráfico rodado, se pierden espacios de estancia y juego como la calle, a favor de aparcamientos al resultar insuficientes los garajes de las viviendas. Los enfoscados exteriores se han cambiado por chapados de ladrillo, mármol o piedra y se ha perdido la unidad global de la imagen exterior. Los cerramientos se han ido sustituyendo por muros de ladrillo, piedra, sillarejo, etc. En los proyectos reformados los jardines pasan a ser utilizados como zona de juegos en los colegios, almacenes exteriores en edificios de oficinas y ampliación de espacios de uso diverso. También se han introducido nuevas especies vegetales diferentes al proyecto original (cedros azules, magnolias grandiflora, abetos, tejos aurea...).

Winthuysen realiza el pequeño jardín de uno de los hotelitos de esta colonia para el escritor y político Salvador de Madariaga (1934). Con una extensión de $310 \mathrm{~m}^{2}$ se subdivide en zonas estanciales articuladas por paseos. El primer espacio vinculado al acceso es un cuadrado de $5 \mathrm{~m}$ de lado, pavimentado con losas de mármol y con un surtidor central de reminiscencias hispanoárabes; un seto de ciprés en $L$ lo delimita y protege de las vistas en dos de sus lados y un banco se ubica en una esquina. A continuación paralelo al eje de acceso se desarrolla el jardín con una estancia en continuidad con la primera constituida por dos cuadros rectangulares simétricos con tres naranjos cada uno y surtidores en medio, rodeado todo por un seto de boj. Una arcada de cipreses hace de transición al siguiente nivel de inspiración clásica donde se desarrolla una explanada rectangular de tierra con un surtidor central y rematada en su eje longitudinal por un seto de tuyas con un nicho semicircular que rodea una escultura sobre pedestal; alineado con el eje principal del jardín coloca otro banco. Ya en la esquina de la parcela y cerrando el eje principal se sitúa un gran cuadro con un cedro ${ }^{44}$ en su centro y delimitado por seto de boj. Este árbol de gran porte era la charnela donde el eje principal del jardín cambia de dirección 90 y y conduce a la última

\footnotetext{
44 Juan Tuset indica que este árbol además tenía un valor simbólico rememorando que Madariaga, como Ministro de Instrucción Pública y Bellas Artes, había intercedido para evitar la tala de los cedros del Paseo del Prado. TUSET, 2013, p.82. VEGUE Y GOLDONI, A.: La supuesta tala de los cedros del Salón del Prado. La Voz, 12 abril 1934, p.1.
}

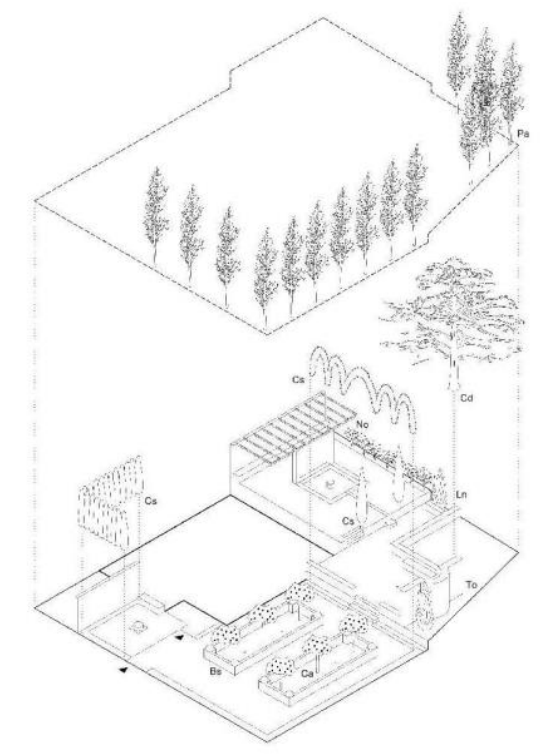

7.47 Jardín de la residencia de Salvador de Madariaga. Winthuysen, 1934: axonometría realizada por J. Tuset. TUSET, 2013, p.81. 

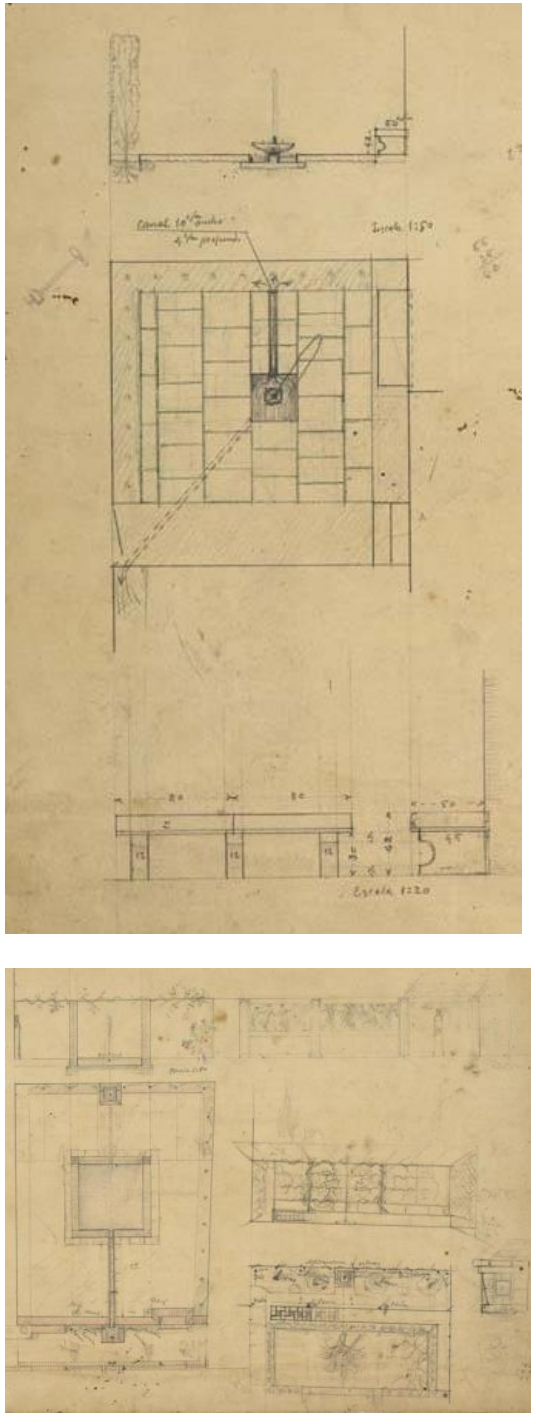

7.48 Planta de Jardín del hotel de Sr. Madariaga. Winthuysen, 1934: detalles del surtidor y banco, y planta del conjunto. ARJB, lám. 34, 1-2. estancia con un cuadrado de $7 \mathrm{~m}$ de lado con una alberca cuadrada central. Se remata con otro eje paralelo al principal donde se desarrolla el emparrado. Bajo la sombra de esta estructura hay un banco corrido y pavimento de azulejos; se crea un rincón de influencia hispanoárabe -agua en movimiento, cerámica colorida, ladrillo rojo, plantas aromáticas...-. Eran importantes los fondos, por lo que reviste la tapia del emparrado con hiedras y parras, y un grupo de adelfas hace de fondo en el otro muro perpendicular frente a la vivienda.

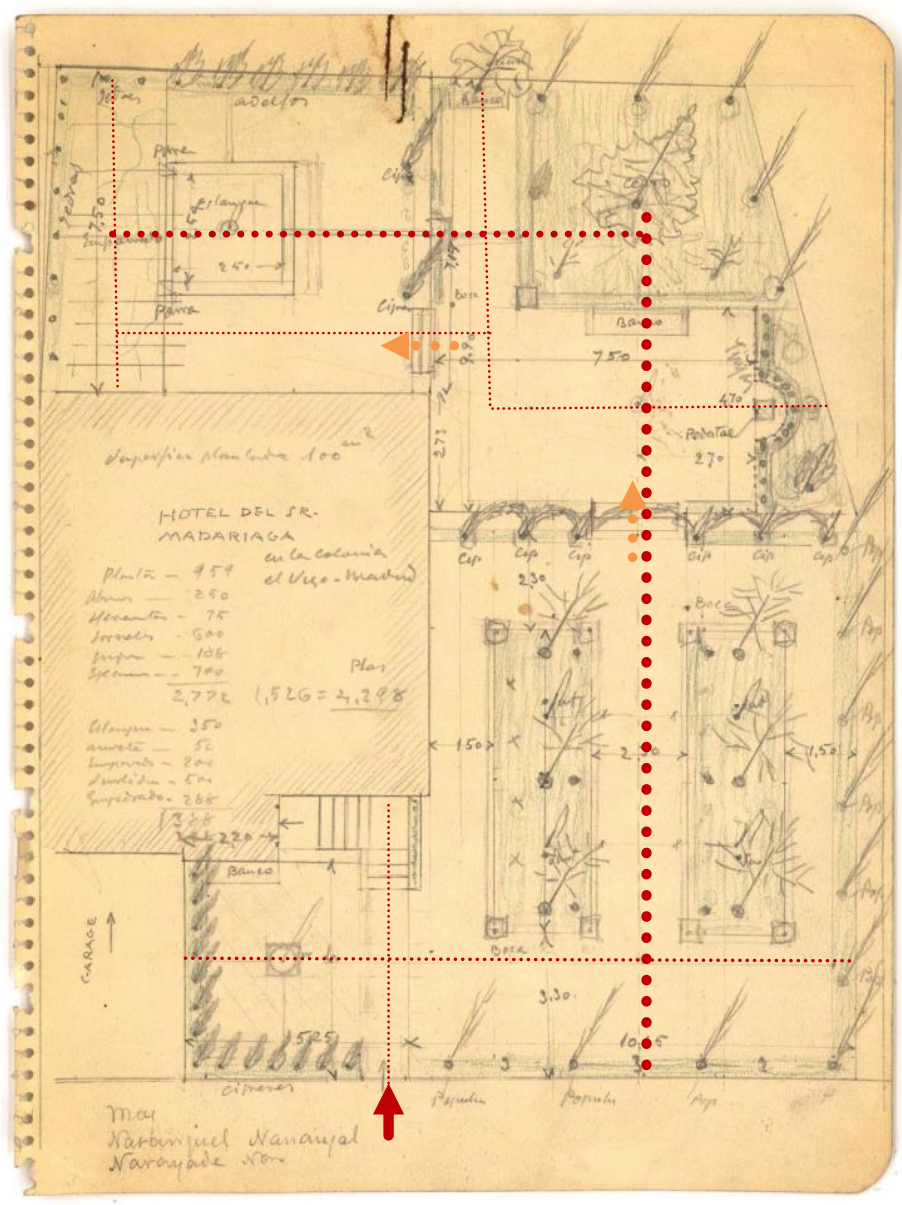

En este ejemplo se aprecia muy bien lo hablado antes: organización en fragmentos identificables y autónomos en su diseño, pero conectados, generalmente por los extremos, con ejes quebrados muy hispanos, pero todos conectados e integrados con la casa. Es impresionante la cantidad de rincones que crea, todos diferentes, y asociados a la casa y a los recorridos. La formalización parece más anticuada, pero la articulación da la impresión de ser muy moderna, como en las casas. Se observa cómo los distintos espacios están conectados, por ejemplo el eje transversal de la estancia del nicho que se quiebra para subir a la zona de la alberca. Destaca la numerosa plantación de árboles, principalmente los seis naranjos y la alineación 
perimetral -donde vuelve a utilizar chopos- y la presencia constante del agua a lo largo del recorrido con varias fuentes y surtidores.

Winthuysen realiza otro jardín en la calle Guadalquivir de la misma colonia para el Sr. Olarra (1934). Al estar este hotel entre medianeras, el jardín está dividido en dos zonas claramente separadas: una delantera con acceso desde la calle y función representativa, y otra en la parte posterior de la calle con carácter más privado y protegido por una valla alta.

El jardín delantero cuenta con espacios estanciales quedando la vegetación concentrada en el perímetro para liberar el espacio. El acceso peatonal al jardín está alineado con el acceso al hotel y acompañado por un seto de romero con glicinias que lo separan de la rampa del garaje. En la zona junto al acceso se dispone un banco de piedra flanqueado por vasos de mármol y protegido por un seto de boj; en la esquina de éste se ubica un busto sobre pedestal. Al fondo junto a la casa se ubica otra estancia rectangular con una mesa central y resguardada por una plantación perimetral de cipreses. Entre la vegetación perimetral destacan dos magnolios, un naranjo, laureles, madreselvas y varios rosales.

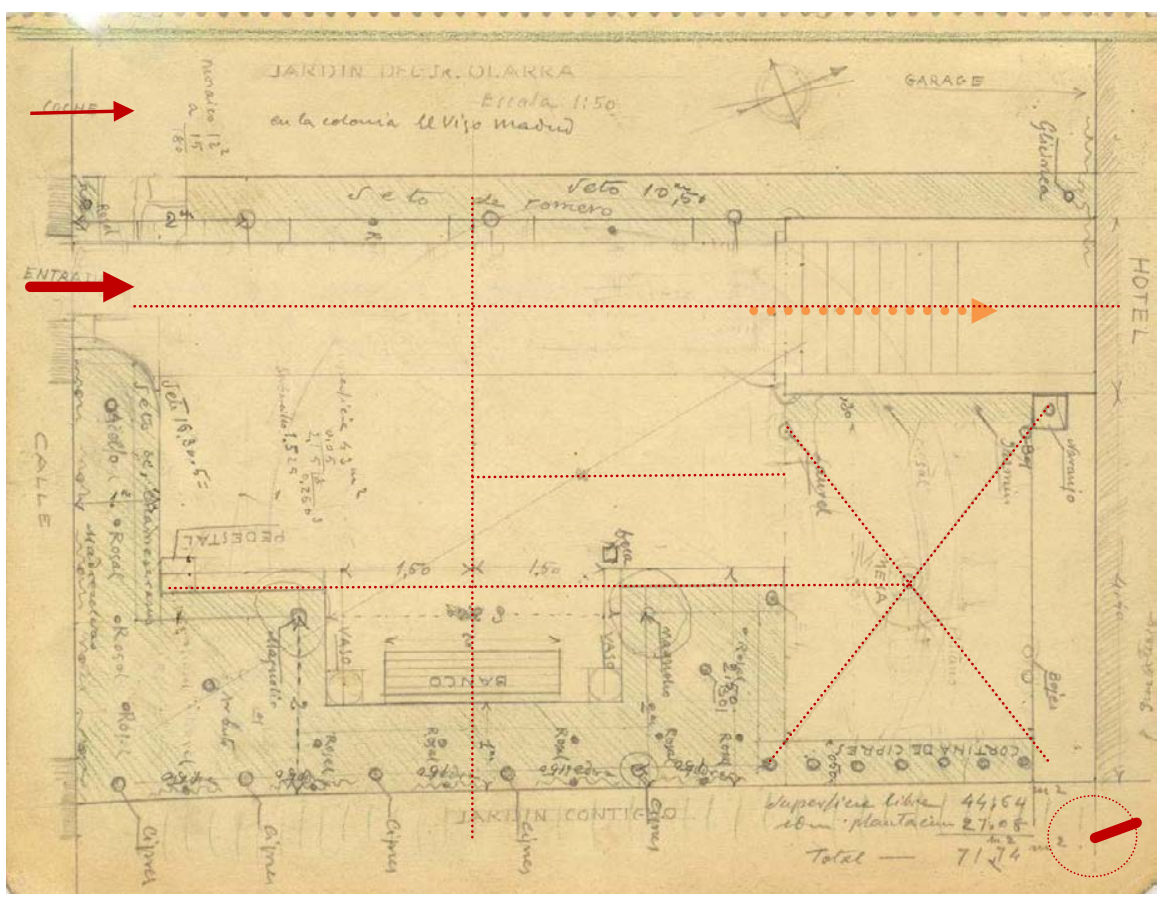

El jardín posterior es más sencillo con una entrada de servicio desde la calle y protegido por un seto perimetral en sus tres lados menos en la fachada del hotel donde coloca hortensias. El elemento central es una alberca cuadrada de $3 \mathrm{~m}$ de lado de ladrillo, con un paseo concéntrico perimetral de piedra, acompañado de vegetación en el
7.49 Jardín de la residencia del Sr. Olarra. Winthuysen, 1934: planta del jardín delantero. ARJB, lám. 33, 1. 


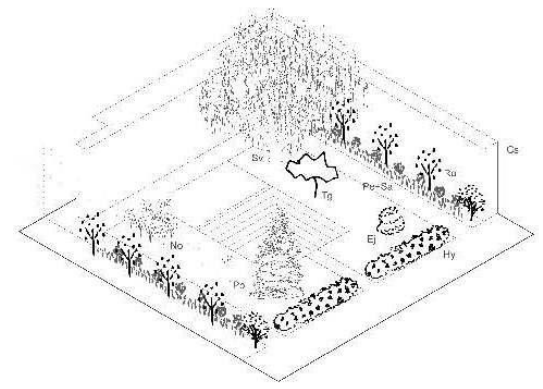

7.50 Jardín de la residencia del Sr. Olarra. Winthuysen, 1934: axonometría y planta del jardín trasero. TUSET, 2013, p.83. ARJB, lám. 33, 2. borde -rosales, santolinas, geranios...-. En el eje del hotel se encuentra el acceso al mismo mediante un camino de piedra y al otro lado de la alberca una zona de arena; en la esquina este sitúa un banco en $L$ integrado en el cuadro vegetal. Señala las cuatro esquinas de la explanada central con árboles singulares: un sauce, una adelfa rosa, una conífera azul y un evónimo dorado. También los cuadrantes laterales los significa con un tamarindo y en el otro lado un surtidor rodeado de hiedra y calas.

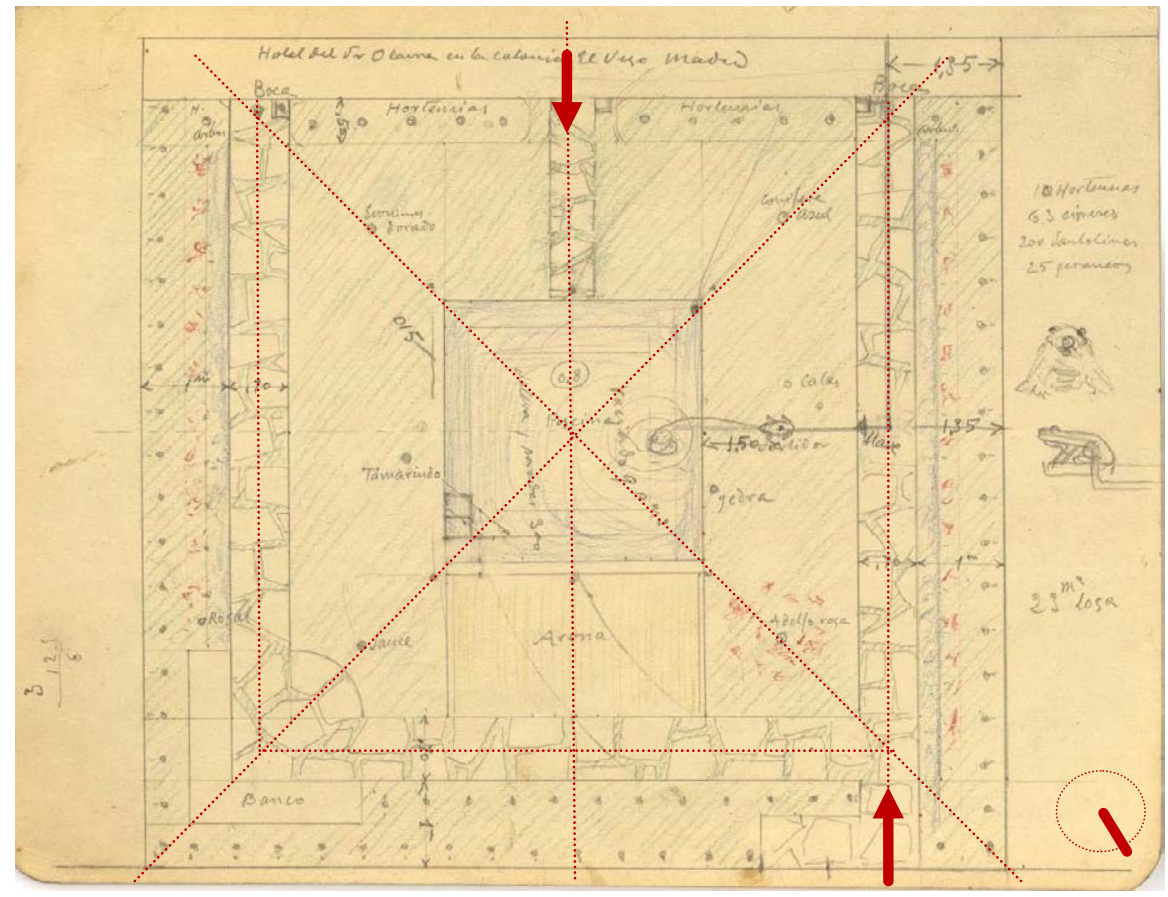

Se aprecia una riqueza en el jardín de acceso con los quiebros para formar los espacios. También en el trasero, con llamadas de atención en las diagonales frente al eje principal, que no se remata.

Similares características presenta el jardín que realiza Winthuysen para la vivienda del filósofo José Ortega y Gasset (1934), una de las primeras de esta colonia. El pequeño jardín de $420 \mathrm{~m}^{2}$ rodea a la vivienda en tres de sus lados libres ocupando una parcela en esquina. Cuenta con acceso peatonal en dos de los lados mientras que el tercero lo reserva para el acceso al garaje. Junto al acceso peatonal que da a la calle principal ubica el jardín representativo, de planta rectangular con dos cuadros simétricos que flanquean un pequeño estanque cuadrado con surtidor. Los cuadros -dos árboles en el centro y esquinas marcadas con laureles, evónimos, y arbustos de flor-eran similares a los de la casa Madariaga, pero más simplificados y muy parecidos a los de Forestier. Esta zona está delimitada por una alineación de chopos y un seto de ciprés perimetral que crea un 
fondo vegetal y le permite aislarse de la ciudad; éste continúa por el lateral estrechándose el espacio con un carácter de paso. Un ciprés marca el otro acceso peatonal y la entrada a la estancia posterior más íntima, constituida por un patio cuadrado de $13 \mathrm{~m}$ de lado. Protege el perímetro en tres de sus lados con una banda vegetal -laurel, rosales, evónimos y gran variedad de aromáticas- delimitada por un seto de boj y dos moreras en cada lado. La tapia se revestía de hiedra trepadora. Toda esta vegetación delimitaba el espacio y lo dotaba de intimidad y frescor. En la fachada del hotel sitúa una pérgola de madera con un banco ${ }^{45}$ del mismo material y en la diagonal opuesta una fuente rectangular esquinada de ladrillo y cerámica. Todas las fuentes tenían una triple función: control climático, ornamental y para riego.

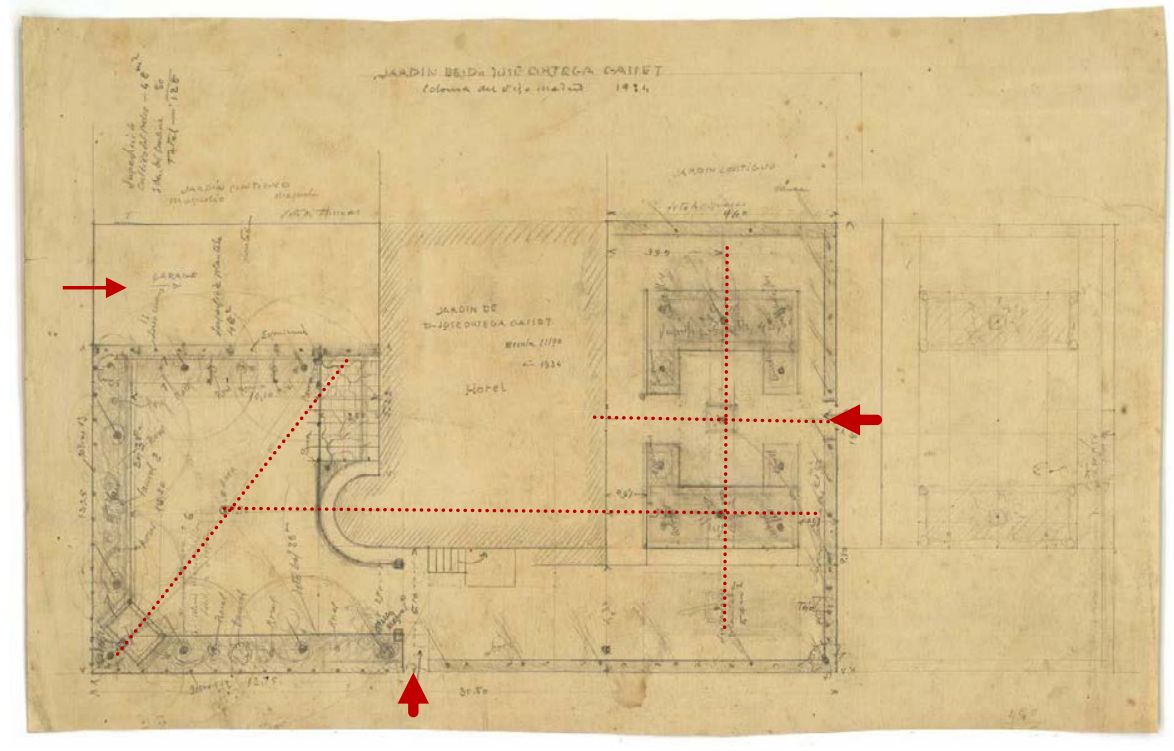

Se aprecia como Winthuysen relaciona el jardín con la casa, prolongando los ejes de ésta, como el eje que marca la rotonda de la vivienda que señala el centro del jardín íntimo y por el otro lado marca el centro de uno de los cuadros simétricos.

El arquitecto Luis Gutiérrez Soto construyó el hotel residencia del Sr. Moroder (1930-1934) en la calle Serrano para un matrimonio sin hijos; sigue la distribución general del resto de la colonia con un gran hall y un ventanal semicircular acompañado de una jardinera con la misma forma y un estudio en el piso superior abierto a la terraza sur con una pequeña jardinera en una esquina. El espacio libre se desarrolla en varios niveles: el patio de acceso con la entrada de coches desciende al patio de servicio para permitir llegar al garaje y el
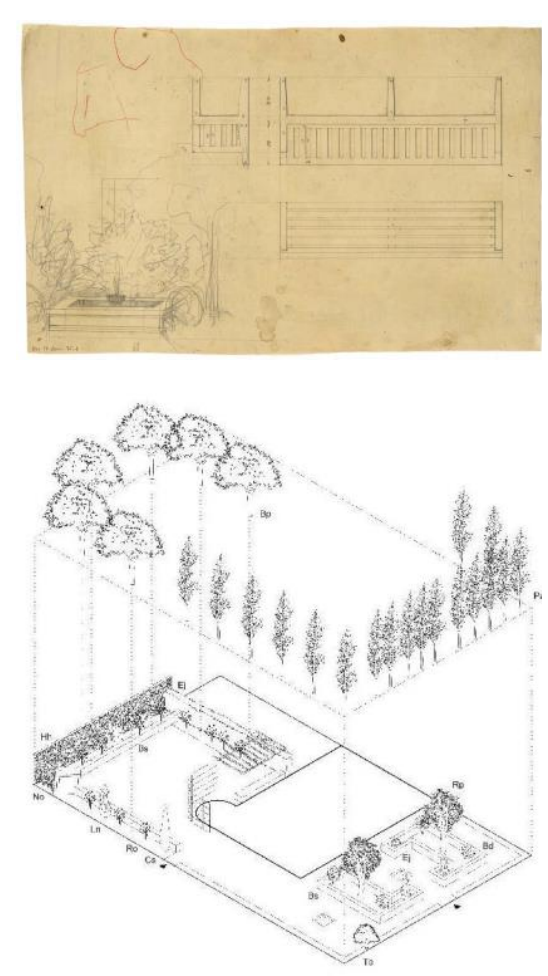

7.51 Jardín para la residencia del Sr. Ortega y Gasset. Winthuysen, 1934: detalle fuente y banco, axonometría y planta. APJM, lám. 35, 1-2. TUSET, 2013, p.82.

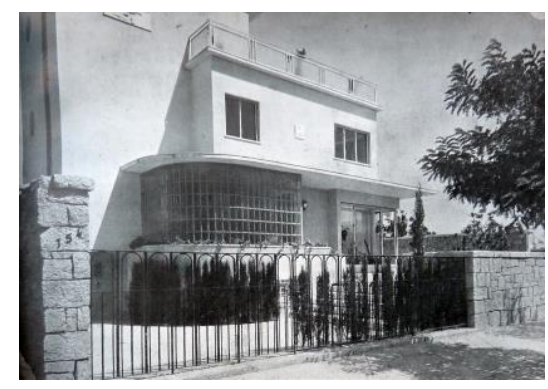

7.52 Residencia del Sr. Moroder. Gutiérrez Soto, 1930: entrada principal a la calle Serrano.

\footnotetext{
45 Juan Tuset indica que este banco se diseñó expresamente para favorecer la meditación del filósofo. TUSET, 2013, p.82.
} 
Posteriormente en estas colonias se fueron ocupando los solares vacios con proyectos que seguían el lenguaje del Movimiento Moderno, como es el caso de la vivienda realizada por Alejandro de la Sota (1955). Así describe este arquitecto las premisas del proyecto: "Vivir tranquilamente dentro de la casa, de espaldas al mundo; vivir buscando el sol, fuente de vida, y sin olvidar las ordenanzas municipales, que nos separan cinco metros de este linde y tres de este otro, fueron las premisas que influyeron en el proyecto de esta casa. /.../ Se buscó en esta casa el reposo y bienestar, huyendo de la calle y buscando el sol y las flores. Se ordenó el resultado arquitectónicamente ${ }^{\prime 46}$. La vivienda en esquina que da a la calle en dos de sus lados se distribuye en tres plantas como las del resto de la colonia; en la planta semisótano y en continuación con la jardinera curva del cuarto de estar aparece un cuarto para guardar los útiles del jardín sobre el cual se desarrolla la terraza de la planta alta a la que asoma el dormitorio principal.

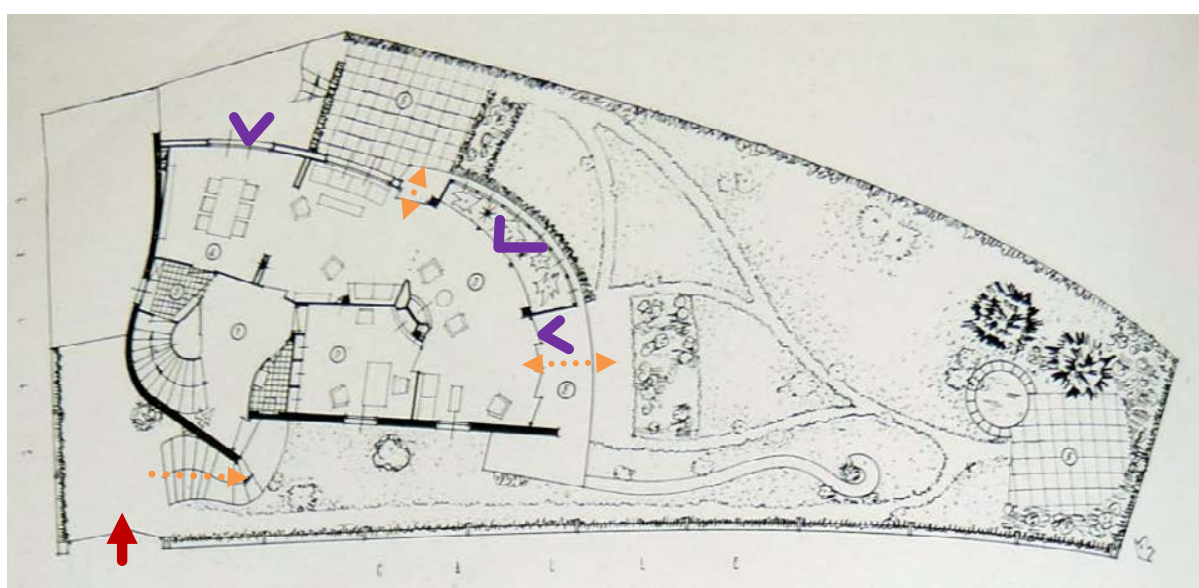

Cuenta con un único acceso por el norte para coches y peatones. El jardín se adapta a la topografía del terreno que desciende hacia el este de la parcela donde se dispone una terraza con un estanque circular bajo la sombra de dos cedros. Una serie de caminos sinuosos parten de la casa y conectan con esta zona. En general hay una pradera salpicada de algunos pequeños árboles salvo un talud vegetal y las jardineras que acompañan la terraza superior del estar. El muro perimetral aparece protegido por un seto que se hace más frondoso en la esquina este protegiendo y dando privacidad a la terraza inferior.

\footnotetext{
${ }^{46}$ SOTA, A. de la: Casa en el Viso. Revista Nacional de Arquitectura. Madrid: Consejo Superior de Colegios de Arquitectos de España. 1955, no 164 agosto, p. 28-29.
}
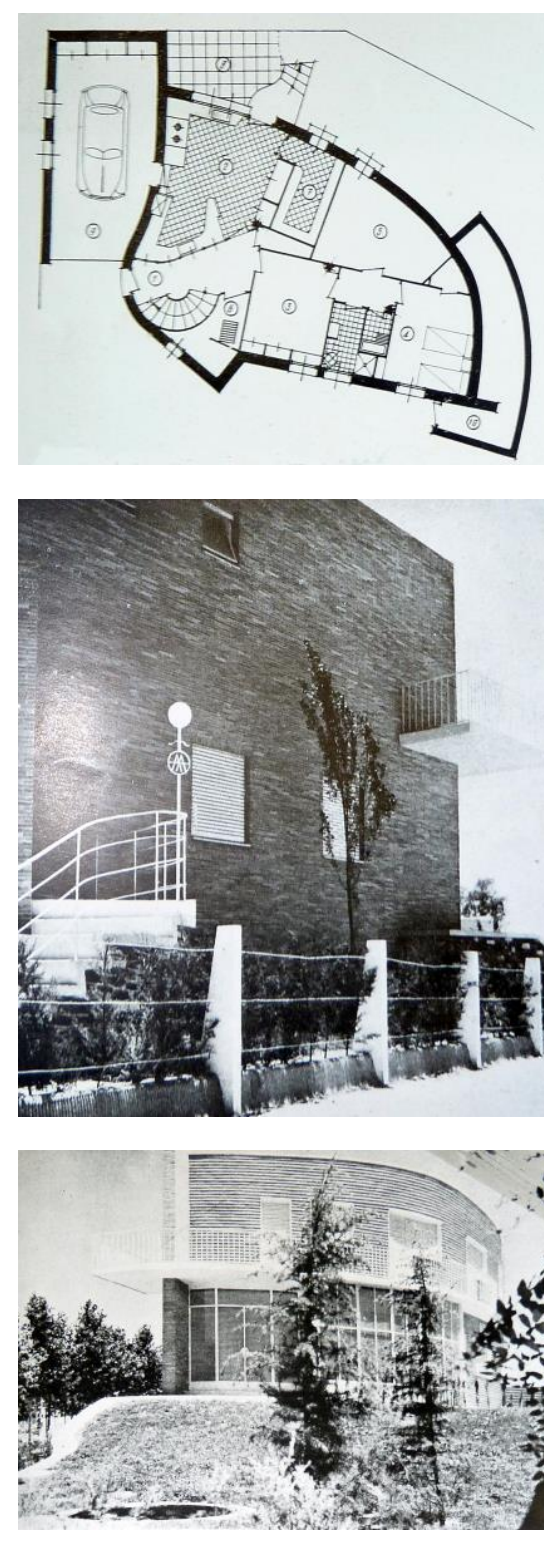

7.54 Jardín del Viso. Alejandro de la Sota, 1955: planta de semisótano, cerramiento perimetral, estanque inferior y planta baja. Revista Nacional de Arquitectura, 1955. no 164, p.30-31. 

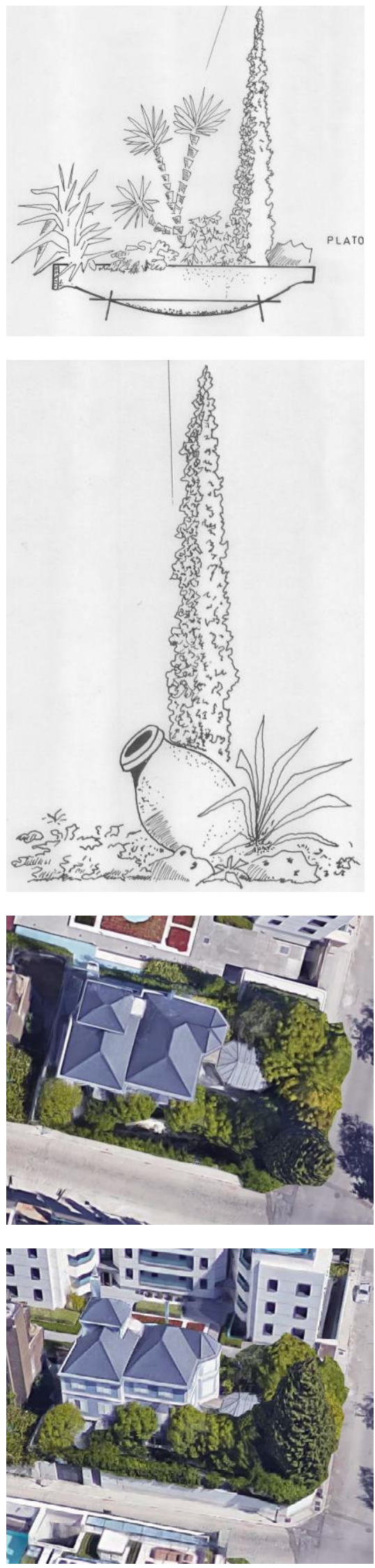

7.55 Jardín para el Sr. Fortes, Madrid. Gabriel Spalla, 1970: plato, tinaja y planta. Colección Javier Spalla. Vistas aéreas actuales. Googlemaps
La composición del jardín es muy diferente a las anteriores; el trazado es libre y orgánico, utilizando el mismo lenguaje que el edificio. La casa se abre al jardín mediante terrazas, porches, muros que se prolongan..., buscando una mayor relación interior-exterior.

Aunque cronológicamente algunos de estos proyectos pertenecen a periodos posteriores se han incluido aquí para ver cómo fueron evolucionando los jardines de estas colonias en manos de los arquitectos y también de otros profesionales, como el paisajista y viverista Gabriel Spalla ${ }^{47}$. Éste realiza el jardín para el Sr. Fortes (1970) en la calle Pisuerga no10 de El Viso, situado en una esquina de una parcela rectangular y con acceso peatonal lateral, independiente del rodado en la otra esquina. En la parte delantera se protege de las vistas con un muro de hiedra y un macizo de hortensias, acompañado de un grupo de chopos bolleana en la esquina junto al acceso peatonal y señalado también por un magnolio. El jardín posterior tiene una gran terraza como extensión de la vivienda -con los mismos retranqueos geométricos que ésta- y una superficie de césped, conectadas mediante un tramo de escaleras. La plantación se concentra en el límite de la terraza (coníferas, arbustos, plantas anuales de color) como separación y en el perímetro del jardín donde repite el muro de hiedra y coloca algunos ejemplares arbóreos de mayor porte (catalpa Bignonioides, prunus Pissardi, acer Variegata...) acompañados de arbustos y rocas. Incorpora detalles de tinajas de barro y platos con plantaciones -como el de la esquina de la terraza-, propios de las exposiciones florales y las ferias ${ }^{48}$.

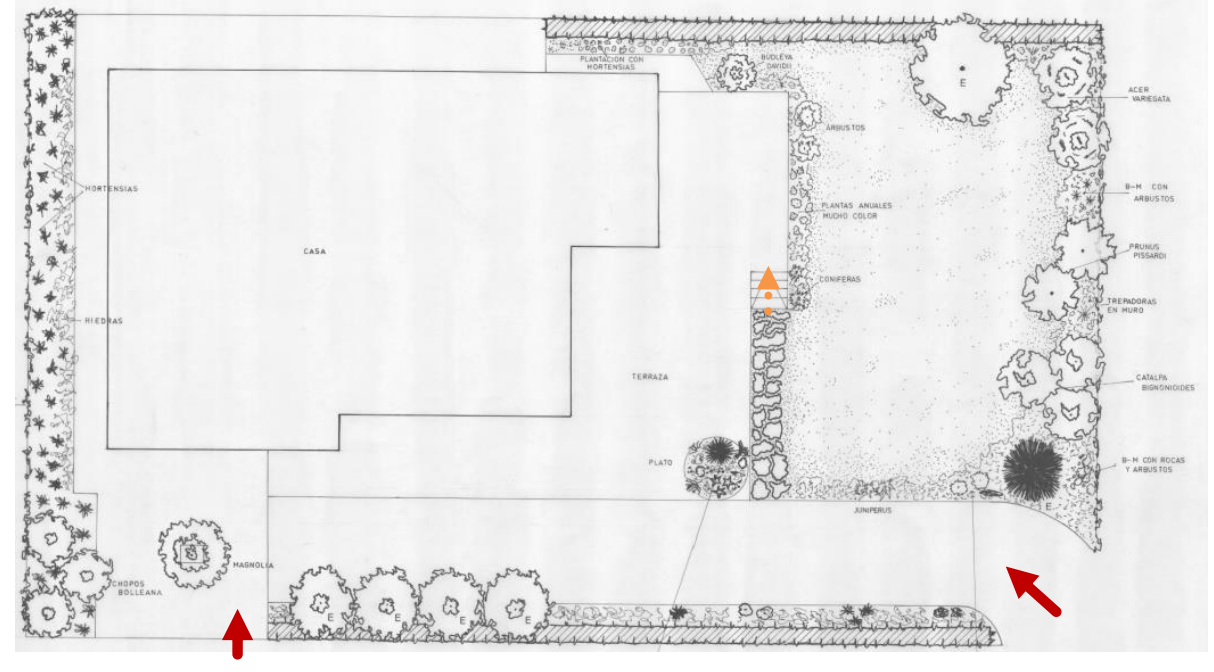

\footnotetext{
${ }^{47}$ Ver capítulo de Actuaciones urbanas, Exposiciones y viveristas.

${ }^{48}$ Actualmente está muy modificado ya que se ha cerrado el acceso rodado situándose uno nuevo junto al peatonal; se ha edificado una vivienda mucho mayor ocupando toda la antigua terraza, pero todavía se conservan los grandes árboles originales.
} 